Tese de doutorado

\title{
Identificação e anotação funcional de novos transcritos com expressão alterada no câncer pancreático
}

Omar Julio Sosa

Orientador: Prof. Dr. Eduardo Moraes Rego Reis

Co-orientador: Prof. Dr. João Carlos Setubal

Universidade de São Paulo 


\section{AGRADEGIMENTOS}

* A todos os membros do "Laboratório de Pesquisas Integradas em Câncer" (LAPIC, IQ-USP), e especialmente do "Laboratório de Genômica e Expressão Gênica em Câncer" do Prof. Eduardo Reis. Por ter me recebido e orientado durante esse importante período acadêmico.

* Aos membros do "Laboratório de Bioinformática" (LIB, IQ-USP) do Prof. João Carlos Setubal, por ter brindado o suporte computacional fundamental para o desenvolvimento do projeto.

* À Fundação de Amparo à Pesquisa do Estado de São Paulo (FAPESP), pelo apoio financeiro (processo no 2013/13350-0).

* À equipe do Hospital AC Camargo, por ter contribuído na preparação das amostras.

* A meus amigos, tanto da Argentina quanto do Brasil e outros países. Cada um contribuiu para que eu possa estar aqui hoje.

* À Nathalia, o amor da minha vida. Obrigado pelo companheirismo, pela amizade, por ter trazido cores na cidade cinza. Por ter me ajudado dando forças para conseguir terminar esta etapa da melhor forma, juntos!

* Gracias a mi familia, siempre juntos sin importar los kilómetros que nos puedan separar. A mis hermanos Riqui, Silvana y Laura, por ayudarme en cada momento, por enseñarme a compartir y a valorar las "pequeñas" grandes cosas de la vida. $A$ mis cuñados Gabriela, Daniel y Carlos, y a mis sobrinos Marcos, Martín, Pablo, Sebastián, Martina y Agustina, por ser la representación más pura de amor. A mis padres, por darme su apoyo incondicional, ser mi ejemplo de vida, mis maestros dentro y fuera de la escuela. Por mostrarme que cuando tenemos un sueño debemos transformarlo en un plan y luchar para conseguirlo. Gracias por darme las herramientas necesarias para conquistar este objetivo y tantos otros que vendrán!

Finalmente, dedico esse trabalho aos pacientes participaram no estudo e a suas famílias. A todas as pessoas que padecem ou padeceram algum tipo de câncer. A meus tios Omar e Daniel. 


\section{RESUMO}

O câncer de pâncreas é uma das neoplasias mais agressivas, com uma incidência próxima à mortalidade, e uma sobrevida de até 5 anos que permanece invariável nas últimas décadas. Os adenocarcinomas ductais pancreáticos (PDAC) que acometem a região exócrina do órgão correspondem a mais do $80 \%$ dos casos. Sua resistência a tratamentos quimioterápicos convencionais, dificuldades no detecção em estágios iniciais da doença e falta de marcadores precisos, indicam a necessidade de novos alvos moleculares para o desenvolvimento de estratégias diagnósticas e terapêuticas mais eficazes. A aplicação de tecnologias de sequenciamento de RNA (RNA-Seq) tem um enorme potencial para contribuir na identificação de variações transcricionais presentes em neoplasias humanas. A maioria dos trabalhos que aplicam essa técnica em PDAC foram realizados exclusivamente com tecido tumoral, e utilizaram bibliotecas enriquecidas em RNAs poliadenilados. Neste estudo foi implementado um pipeline bioinformático para processar e analisar dados de RNA-Seq total e fita-específico gerados em nosso laboratório a partir de amostras pareadas de tumor e tecido adjacente não tumoral de 14 pacientes com o objetivo de catalogar com alta-resolução a composição e alterações no transcritoma no PDAC incluindo genes codificadores e não codificadores de proteína. Além de 41.341 transcritos conhecidos que mapeiam em 17.834 genes do GENCODE, detectamos 6.710 transcritos novos, incluindo 6.187 variantes de splicing, 339 RNAs intergênicos e 184 RNAs antisensos. A análise dos novos transcritos ainda não anotados revelou que a maioria possui um baixo potencial codificador e apresenta marcas de regulação epigenética, sugerindo que são possíveis RNAs não codificadores longos (IncRNAs) expressos no tecido pancreático. Um subconjunto composto por 669 mRNAs codificantes de proteínas, 171 variantes de splicing não anotadas, 86 IncRNAs intergênicos (34 conhecidos e 52 novos) e 49 IncRNAs antisensos (14 conhecidos e 35 novos), apresentam expressão diferencial no PDAC. Também foi investigada a presença de RNAs circulares (circRNAs), que revelou a expressão no tecido pancreático de 6.285 circRNAs já anotados incluindo 23 circRNAs com expressão aberrante no PDAC, além de 1.174 possíveis novos circRNAs. Uma análise de enriquecimento de vias moleculares confirmou a desregulação nas amostras tumorais de genes envolvidos em processos celulares que favorecem o desenvolvimento do PDAC. A expressão aberrante de um subconjunto de IncRNAs foi validada experimentalmente a través de RT-qPCR em amostras de tumor/tecido não-tumoral de pacientes, linhagens celulares e xeno-tumores murinos derivados de pacientes. Considerando tudo, foi gerado um catálogo do transcritoma do PDAC que inclui alterações na expressão gênica em relação ao tecido pancreático não tumoral adjacente que pode contribuir com um maior entendimento do câncer pancreático e na descoberta de novos biomarcadores moleculares da doença. 


\section{ABSTRACT}

Pancreatic cancer is one of the more aggressive neoplasias, with an incidence close to mortality, and a survival rate of 5 years that remain constant in the last decades. Pancreatic ductal adenocarcinoma (PDAC) that affect the exocrine region of the organ correspond to more than $80 \%$ of the cases. Resistance to conventional chemotherapeutic treatments, difficulties for the early detection and lack of precise markers, highlights the necessity to find novel targets for the development of more effective therapeutic and diagnostic strategies. The application of RNA sequencing technologies (RNA-Seq) has a huge potential to contribute with the identification of transcriptional variations in human neoplasias. Most studies of the PDAC transcriptome were performed using RNA isolated exclusively from tumor tissue samples, with polyadenylated RNA enriched libraries. In the present work, we applied a bioinformatic pipeline to process and analyse data from total RNA-seq strand-oriented generated in our laboratory from matched samples of tumor and non-tumor adjacent pancreatic tissue from 14 patients with the goal of generate a high resolution catalog of the composition and the alterations in the transcriptome of PDAC, including protein coding and non coding genes. In addition to 41,341 known transcripts mapping to 17,834 GENCODE annotated genes, we detected 6,710 novel transcripts, including 6,187 splicing variants, 339 intergenic RNAs and 184 antisense RNAs. Analysis of the novel transcripts revealed that most of them have low coding potential and they present regulatory chromatin marks, suggesting that they could be novel long noncoding RNAs (IncRNAs) expressed in pancreatic tissues. A subset of 669 protein-coding mRNAs, 171 unannotated splicing isoforms, 86 intergenic IncRNAs (34 known and 52 novel) and 49 antisense IncRNAs (14 known and 35 novel) were aberrantly expressed in PDAC. We also investigate the presence of circular RNAs (circRNAs), that reveal the expression in pancreatic tissue of 6,285 annotated circRNAs including 23 circRNAs aberrantly expressed, besides 1,174 potentially novel circRNAs. An enrichment pathways analysis confirmed the presence of genes related to key cellular process that promote the tumorigenesis of PDAC. The dysregulated expression of a subset of IncRNAs was validated experimentally by RT-qPCR in samples of tumor/non-tumor tissues, cell lines and patient-derived tumor xenografts. Taken together, we have generated an original catalog of the PDAC transcriptome and identified gene expression changes in protein-coding and long noncoding RNAs relative to nontumor adjacent pancreatic tissue that may contribute with novel insights into the biology of pancreatic cancer and novel targets and biomarkers for the disease. 


\section{ÍNDICE}

$\begin{array}{ll}\text { 1. INTRODUÇÃO } & 7\end{array}$

I.1 Câncer de pâncreas $\quad 7$

I.1.a Fatores de risco $\quad 8$

I.1.b Lesões precursoras $\quad 8$

I.1.c Biomarcadores do PDAC 9

I.1.d Classificações moleculares a partir de perfis globais de expressão gênica $\quad 10$

$\begin{array}{ll}\text { I.2 Splicing alternativo } & 11\end{array}$

$\begin{array}{ll}\text { I.3 RNAs não codificadores longos (IncRNAs) } & 13\end{array}$

$\begin{array}{ll}\text { I.4 RNAs circulares (circRNAs) } & 15\end{array}$

$\begin{array}{ll}\text { I.5 Motivação } & 17\end{array}$

$\begin{array}{ll}\text { II. OBJETIVOS } & 18\end{array}$

$\begin{array}{ll}\text { II.1 Objetivos gerais } & 18\end{array}$

$\begin{array}{ll}\text { II.2 Objetivos específicos } & 18\end{array}$

$\begin{array}{ll}\text { III. MATERIAIS E MÉTODOS } & 19\end{array}$

III.1 Amostras de pacientes 19

$\begin{array}{ll}\text { III.2 Preparação das bibliotecas } & 20\end{array}$

III.3 Análises bioinformáticas $\quad 20$

III.3.1 Controle de qualidade das sequências $\quad 22$

III.3.2 Alinhamento das sequências $\quad 22$

III.3.3 Montagem do transcritoma $\quad 22$

III.3.4 Caracterização dos transcritos novos $\quad 24$

III.3.4.a Potencial codificador e conservação evolutiva 24

III.3.4.b Marcas epigenéticas $\quad 25$

III.3.4.c Variantes de splicing alternativo $\quad 25$

III.3.5 Quantificação e análise de expressão diferencial $\quad 26$

III.3.6 Identificação e quantificação de RNAs circulares $\quad 27$

III.3.7 Análise de vias moleculares alteradas no PDAC 27

III.4 Seleção de candidatos $\quad 27$

IV. RESULTADOS

IV.1 Análise da qualidade das sequências obtidas por RNA-seq 28

$\begin{array}{ll}\text { IV.2 Alinhamento genômico das sequências } & 29\end{array}$

IV.3 Montagem do transcritoma de tecido pancreático 30

IV.4 Anotação in silico dos novos transcritos $\quad 42$

IV.4.1 Potencial codificador e conservação evolutiva 42

IV.4.2 Marcas regulatórias da cromatina $\quad 45$ 
IV.4.3 Variantes de splicing alternativo $\quad 46$

IV.5 Quantificação da expressão gênica $\quad 50$

IV.5.1 Quantificação ao nível dos genes $\quad 50$

IV.5.2 Quantificação ao nível dos transcritos 53

IV.6 Análise de vias moleculares alteradas no PDAC $\quad 70$

IV.7 Identificação de RNAs circulares $\quad 73$

IV.8 Seleção de candidatos para validação 76

$\begin{array}{ll}\text { V. DISCUSSÃO } & \mathbf{7 8}\end{array}$

V.1 RNAs não codificadores longos $\quad 79$

V.2 Potencial codificador $\quad 80$

V.3 Marcas de regulação associadas a expressão de novos transcritos 80

V.4 Variantes de splicing $\quad 82$

V.5 RNAs circulares

V.6 Avaliação da metodologia para a quantificação da expressão gênica 84

V.7 Genes diferencialmente expressos no PDAC 85

V.8 Anotação em subtipos moleculares de PDAC $\quad 87$

V.9 Vias moleculares alteradas em PDAC $\quad 88$

V.10 Potencial prognóstico de transcritos diferencialmente expressos no PDAC 90

V.11 Seleção e validação de candidatos $\quad 94$

$\begin{array}{ll}\text { VI. CONCLUSÕES } & 96\end{array}$

$\begin{array}{lr}\text { REFERÊNCIAS } & 97\end{array}$

$\begin{array}{ll}\text { ANEXO 1. Scripts } & 115\end{array}$

Script "controle_de_qualidade": 115

Script "trimagem": 115

Script "mapeamento" 116

Script "montagem" 116

Script "melhora_montagem_1" 117

Script "melhora_montagem_2" 118

Script "melhora_montagem_3" 122

Script "anotação" 123

Script "remove_utrs" 123

Script "potencial_codificador" 124

Script "busca_de_orfs" 124

Script "marcas_de_regulação" 124

Script "sequências_aleatórias" 125

Script "porcentagem_sequências_aleatórias" 126

Script "splicing" 126 
$\begin{array}{ll}\text { Script "htseq" } & 126\end{array}$

Script "star_rsem" 127

Script "Salmon" $\quad 128$

Script "Kallisto" 128

Script "expressão_diferencial" 129

Script "circrna" 130

Script "anota_circrnas" 131

ANEXO 2. Certificado Comité de ética 133

ANEXO 3. Validações experimentais 135

$\begin{array}{lr}\text { ANEXO 4. Novas isoformas } & 138\end{array}$ 


\section{INTRODUÇÃO}

\section{l.1 Câncer de pâncreas}

O câncer de pâncreas é uma patologia altamente agressiva, sendo a sétima causa de morte relacionada a câncer no mundo, com um número de novos casos muito próximo ao número de óbitos pela doença (458.918 e 432.242 respectivamente) (F. Bray et al. 2018). No Brasil é responsável por aproximadamente $2 \%$ de todos os tipos de câncer diagnosticados e por 4\% das mortes por câncer ("INCA" 2018). O câncer pancreático pode ser dividido em dois grandes grupos: endócrinos e exócrinos. $O$ primeiro é menos comum e afeta as células produtoras de hormônios (Roldo et al. 2006). Os adenocarcinomas ductais que acometem a região exócrina do pâncreas (PDAC, "Pancreatic ductal adenocarcinoma") constituem o tipo mais frequente de neoplasia pancreática, representando mais de $80 \%$ dos casos (Anirban Maitra 2008). Uma das características histológicas mais importantes do PDAC é a presença de um denso estroma, que pode constituir aproximadamente o $90 \%$ do tumor e é caracterizado pela falta de vascularização, fibrose, infiltrados imunológicos, e hipóxia (Apte et al. 2004). Esse tecido fibroso está constituído por fibroblastos associados à câncer (CAFs: "cancer-associated fibroblasts"), que principalmente derivam de células estreladas pancreáticas (PSCs: "pancreatic stellate cells") (Pandol et al. 2009). A maioria dos infiltrados imunológicos são células mieloides, com granulocitos, monocitos MDSCs ("myeloid-derived suppressor cells") e macrófagos associados ao tumor (TAMs), que contribuem na imunossupressão (Dougan 2017). O componente não celular do estroma está representado pela matriz extracelular (ECM: "extracellular matrix") composta por colágeno, glicosaminoglicanos, proteoglicanos e fatores de crescimento (P. Lu, Weaver, and Werb 2012). Esse processo de acumulação de tecido conectivo é também conhecido como desmoplasia, e tem um papel muito importante no desenvolvimento do câncer de pâncreas (Veenstra et al. 2018). O denso estroma contribui na produção de fatores de crescimento, secreção de proteínas da matriz extracelular e ativação de fibroblastos que estimulam a proliferação e invasão das células cancerígenas (Qian et al. 2003).

O PDAC é um câncer altamente invasivo e $80 \%$ dos pacientes são diagnosticados num estado avançado da doença geralmente com metástase, com uma sobrevida de entre 2-4 meses (Q. Zhang et al. 2016). Está associado com um pobre prognóstico por vários motivos (Paul E. Oberstein 2013; Kamisawa et al. 2016): a) diagnóstico tardio (sintomas não específicos ou nulos), b) falta de marcadores moleculares sensíveis e específicos, c) dificuldades no diagnóstico por imagem dos 
tumores em estágios iniciais, d) resistência à quimioterapia e radioterapia. Somado a isso, somente $10-20 \%$ dos pacientes diagnosticados são operáveis, e deste grupo, somente $15-25 \%$ atingem conseguem viver até 5 anos (He et al. 2014). Com todas estas dificuldades, a taxa de sobrevivência permanece invariável já há duas décadas (Q. Zhang et al. 2016).

\section{I.1.a Fatores de risco}

Fatores genéticos e ambientais podem aumentar a probabilidade de desenvolver a doença, entre eles: ter um histórico familiar de câncer pancreático pode aumentar duas vezes o risco (Greer, Whitcomb, and Brand 2007); o hábito de fumar aumenta as probabilidades de contrair câncer pancreático num $75 \%$ comparado com não fumadores (lodice et al. 2008); indivíduos com diabetes mellitus possuem duas vezes mais risco (Maisonneuve and Lowenfels 2015; Batabyal et al. 2014); pancreatite crônica (1,34\% dos casos de câncer pancreático) ou hereditária (50-60 vezes mais risco do esperado) (Lowenfels, Maisonneuve, and Whitcomb 2000; Duell et al. 2012); e idade ( $80 \%$ dos casos de câncer pancreático acontecem entre os 60 e 80 anos) (Bosetti et al. 2012).

\section{I.1.b Lesões precursoras}

O desenvolvimento do PDAC é progressivo e existem três tipos de neoplasias precursoras que diferem biologicamente. A neoplasia mucinosa papilar intraductal (IPMN) é composta por células produtoras de mucina no ducto pancreático principal; o neoplasma cístico mucinoso ( $\mathrm{MCN}$ ) que não está conectado ao ducto primário e pode ser subclassificado em benigno, "borderline" e maligno; e a neoplasia intraepitelial pancreática (PanIN) que é o precursor mais frequente e pode ser dividido em quatro estágios (PanIN-1A, PanIN1-B, PanIN-2 e PanIN-3) de acordo com suas características histológicas (Q. Zhang et al. 2016). As PanIN-1 são formadas por células epiteliais colunares com núcleos basais e redondos; as PanIN-2 apresentam perda de polaridade nuclear, variações nos tamanhos dos núcleos (pleomorfismo) e hipercromasia nuclear; e as PanIN-3 que são alargadas, pleomórficas, com nucléolos proeminentes e mitoses anormais (Hruban et al. 2001). Já foram observadas alterações em oncogenes e genes supressores de tumores que ocorrem com frequência durante as etapas da progressão. Nas lesões PanIN-1, são observadas mutações ativadoras em KRAS e um encurtamento dos telômeros, seguido por inactivação de p16/CDKN2A (PanIN-2) e inactivação de TP53, SMAD4 e BRCA2 nas lesões PanIN-3 (figura 1) (Wilentz et al. 2000; Goggins, Hruban, and Kern 2000; Löhr et al. 2005; Rosty et al. 2003). 


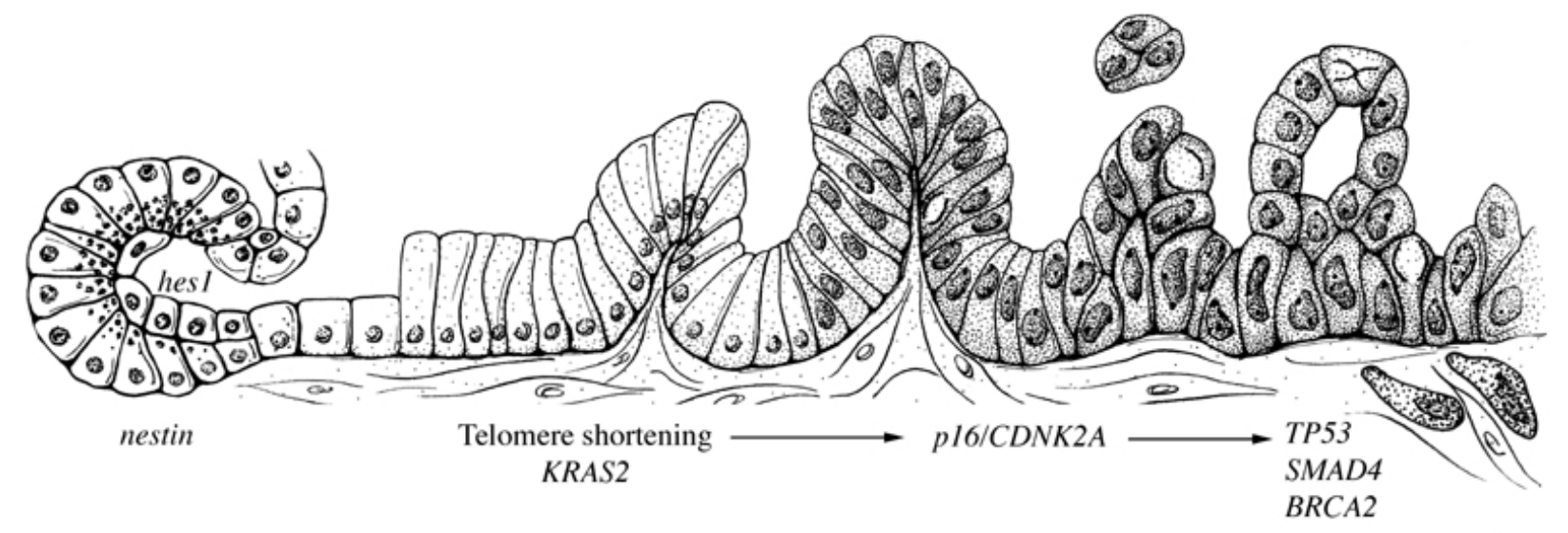

Figura 1. Alterações histológicas e genéticas no PDAC. Observa-se frequentemente a progressão desde células normais (esquerda), passando por lesões precursoras PanIN (centro) até o estágio de câncer pancreático invasivo (direita). (Imagem de Hruban et al. 2008)

\section{I.1.c Biomarcadores do PDAC}

Os biomarcadores utilizados correntemente para o diagnóstico do câncer pancreático como as proteínas CA19-9 ("carbohydrate antigen 19-9") e CEA ("carcinoembryonic antigen"), tem valor no direcionamento do tratamento do PDAC sendo utilizados como indicadores da progressão da doença durante a quimioterapia ou depois da cirurgia, mas não são efetivos na detecção de pequenos tumores e apresentam baixa sensibilidade e especificidade (Poruk et al. 2013; Locker et al. 2006). CA19-9 é um antígeno do grupo sanguíneo Lewis (Koprowski et al. 1981). Embora a maioria das pessoas sejam heterozigotas para esse gene, entre 6 e 22\% da população (nos Estados Unidos) são recessivos e não sintetizam o antígeno específico (Hamanaka, Hamanaka, and Suzuki 1996) de modo que CA19-9 é inefetivo nessa população, dando resultados falsos negativos. Outro problema deste marcador é que também pode estar elevado em condições benignas assim como em doenças extra-pancreáticas, diminuindo a especificidade e dificultando o diagnóstico adequado do PDAC (Poruk et al. 2013). O marcador CEA é uma glicoproteína que foi inicialmente encontrada em câncer de cólon (Phil Gold 1965), mas que também está elevada em câncer de pâncreas, mama, pulmão e tireoide (Meng et al. 2017). Particularmente em pâncreas, foram encontrados níveis aumentados no soro de $30 \%-60 \%$ dos pacientes (Nazli et al. 2000). Outra aplicação possível para CEA é como marcador prognóstico, Imaoka e colaboradores fizeram um estudo retrospectivo utilizando dados de 433 pacientes com metástase. Seus resultados indicaram que altos níveis de CEA estavam correlacionados com um comportamento mais agressivo, pior sobrevida e mais probabilidades de metástase no fígado (Imaoka et al. 2016). 
O entendimento das alterações genéticas em estágios iniciais da doença e a possibilidade de detectar DNA circulante (cfDNA: "circulating cell-free DNA") em plasma abre uma janela de oportunidades para possíveis testes diagnósticos. Embora a estratégia de detectar mutações em KRAS e TP53 seja em princípio promissora, os trabalhos que abordaram essa estratégia apresentaram até o momento resultados controversos, com uma grande variabilidade na sensibilidade e especificidade (Brychta, Krahn, and von Ahsen 2016; Maire et al. 2002; Marchese et al. 2006; Däbritz et al. 2009; H. Chen et al. 2010; Bettegowda et al. 2014). Recentemente Perets e colaboradores analisaram plasma de pacientes e encontraram mutações de KRAS somente em 5 de 17 amostras, e nos casos positivos a utilidade do ctDNA era semelhante a CA19-9 como marcador de resposta ao tratamento (Perets et al. 2018). Um outro estudo em 294 amostras de plasma de indivíduos com pancreatite crônica, detectaram mutações em KRAS em 64 casos e de $p 53$ em apenas 4, determinando a falta de eficácia dessa abordagem para monitorar o câncer pancreático (Rashid et al. 2018). Existe assim a necessidade de identificação de novos biomarcadores da presença do câncer de pâncreas que permitam a identificação da presença da doença de forma mais específica e sensível.

\section{l.1.d Classificações moleculares a partir de perfis globais de expressão} gênica

A partir de estudos globais do transcritoma e genoma de amostras clínicas foram propostas classificações moleculares do PDAC que apresentam associação com a sobrevida e têm possíveis implicações na conduta terapêutica dos pacientes. Em um estudo pioneiro, Collisson e colaboradores usaram dados de expressão de microarrays de 27 amostras de PDAC para definir três subtipos: "Classical", com genes epiteliais associados à adesão, uma maior sobrevida e terapia baseada em erlotinib; "Quasimesenchymal", apresenta genes associados à mesênquima, baixa sobrevida e sensível a gemcitabine; e "Exocrine-like": com genes enzimáticos digestivos e sobrevida intermediária (Collisson et al. 2011). Dados de expressão gênica de fragmentos de tumor refletem alterações na expressão dos diferentes componentes celulares que compõem a amostra de tecido. Moffitt et. al. separaram digitalmente o estroma do tumor chegando na identificação de dois tipos de amostras. Quanto ao tipo de estroma: "Normal" enriquecido em marcadores de células estreladas e associados com uma melhor sobrevida; e "Activated", enriquecido em genes associados com macrófagos e genes que promovem o tumor, e pior prognóstico. Também classificaram o tumor em "Classical", quando apresentavam alta expressão de genes de adesão, ribossômicos e GATA6, e sobrevida de 19 meses; e "Basal-like": com expressão de lamininas e queratinas, e sobrevida de 11 meses (Moffitt et al. 2015). Outra 
classificação foi proposta por Bailey e colaboradores, que propuseram quatro subtipos: "Squamous", apresenta mutações em TP53 e KDM6A, alta expressão de TP63, hipermetilação de genes determinantes endodérmicos pancreáticos e sobrevida de 13 meses; "Pancreatic progenitor", com genes envolvidos no desenvolvimento pancreático precoce (FOXA2/3, PDX1 e MNX1) e sobrevida de 23 meses; "Immunogenic": apresenta alta expressão de vias imunológicas e sobrevida de 30 meses; e "Aberrantly differentiated endocrine exocrine (ADEX)": com alta expressão de genes que regulam vias de ativação de KRAS, diferenciação exócrina (NRA2 e RBPJL) e endócrina (NEUROD1 e NKX2-2), com sobrevida de 25 meses (Bailey et al. 2016). Mais recentemente Raphael et al. realizaram uma análise com dados genômicos, transcriptômicos e proteômicos com 150 amostras, classificando dois subtipos de tumores: "basal-like/squamous" (enriquecido em mutações TP53) e "classical/pancreatic-progenitor" (com mutações em GNAS) (Aguirre A and TCGA 2017). Embora não exista um consenso perfeito, existe uma sobreposição entre algumas das classificações moleculares propostas. Todas as classificações identificam um subtipo clásico/canónico, caracterizado por genes epiteliais, e um subtipo mesenquimal de pior prognóstico com alta expressão de genes mesenquimais (Bijlsma et al. 2017). Também foram encontrados subtipos relacionados à funções exócrinas do pâncreas (Collisson "exocrine-like" e Bailey "ADEX") e imunogênicas (Bailey "immunogenic" e Moffitt "stroma normal/activated") (Veenstra et al. 2018). Resulta importante a contribuição desses estudos, mas ainda são necessários testes clínicos para verificar sua utilidade no direcionamento dos pacientes (Birnbaum et al. 2017).

\section{I.2 Splicing alternativo}

Um processo essencial das células eucariotas para regular a expressão dos genes e gerar mais variabilidade é o splicing. Na sua forma constitutiva, é o processo de remoção de íntron e ligação de éxon na ordem em que estão dispostos no gene. No splicing alternativo alguns éxons podem ser ignorados e íntrons podem ser mantidos resultando em formas distintas do mRNA maduro (Y. Wang et al. 2015). Na figura 2 é apresentada uma representação dos diferentes tipos de splicing. O mais frequente em vertebrados é o "exon skipping" onde um éxon é desconsiderado (E. Kim, Magen, and Ast 2007). As retenções de íntrons em transcritos humanos estão posicionados principalmente em regiões UTRs (Galante et al. 2004) e foram associadas com sítios de splicing fracos, tamanho de íntrons curtos e regulação de elementos regulatórios em cis (Noboru Jo Sakabe 2007). A seleção alternativa de sítios 3' ou 5' dentro de éxons podem levar a pequenas mudanças na sequência codificadora, e um outro caso que aumenta a complexidade é o de éxons alternativos mutuamente exclusivos (Y. Wang et al. 2015). 
Uma grande porcentagem das doenças genéticas em humanos estão relacionadas com mutações em sítios de splicing e elementos regulatórios resultando na formação alternativa de éxons (Matlin, Clark, and Smith 2005; Cáceres and Kornblihtt 2002; Cartegni, Chew, and Krainer 2002). Particularmente, variantes de splicing de genes relacionados a câncer poderiam afetar diversas funções tumorigênicas como controle do ciclo celular, apoptose, vias de sinalização, angiogênese, invasão e metástase (Skotheim and Nees 2007; Venables 2006a; Babita Singh 2017). A exclusão de um éxon no gene MST1R foi correlacionada com a aquisição de mobilidade celular e invasão em câncer de mama e cólon (Ghigna et al. 2005). Goldstein e colaboradores encontraram que alterações no splicing do gene NFE2L2 levam a uma perda da interação com seu regulador negativo KEAP1 ativando a via Nrf2 em vários cânceres humanos (Goldstein et al. 2016). Assim, a identificação e anotação de variantes de splicing com expressão alterada no tumor resulta de grande importância para entender a biologia do câncer, e podem ser utilizados como biomarcadores para diagnóstico, prognóstico e terapêuticos (Venables 2006b; Babita Singh 2017).

A

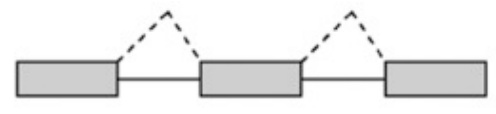

B
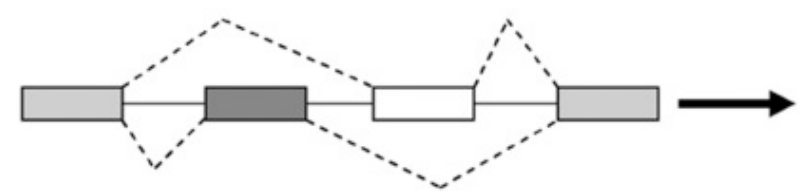

C

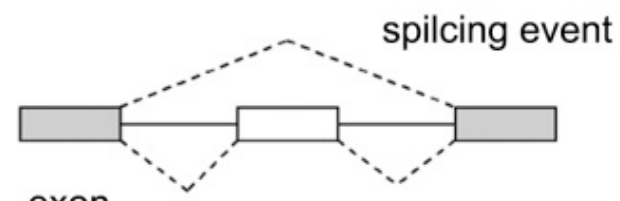

exon
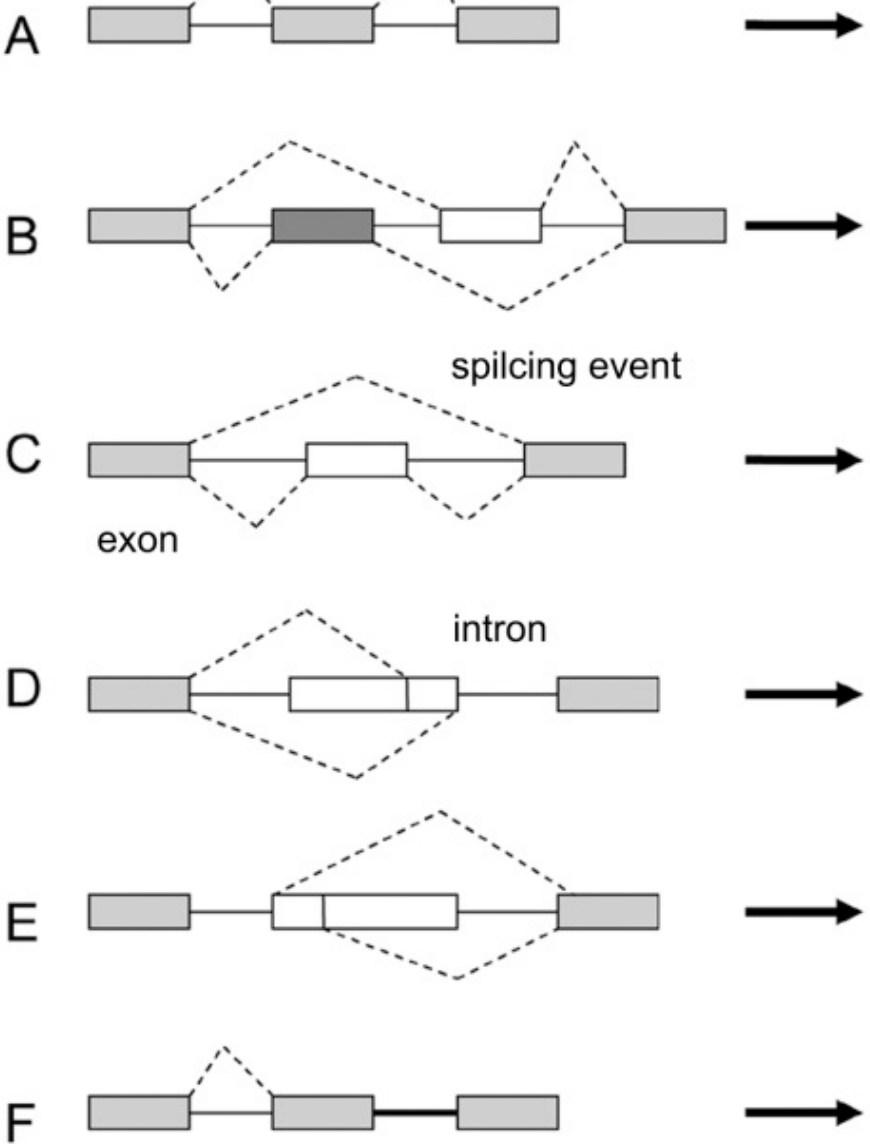
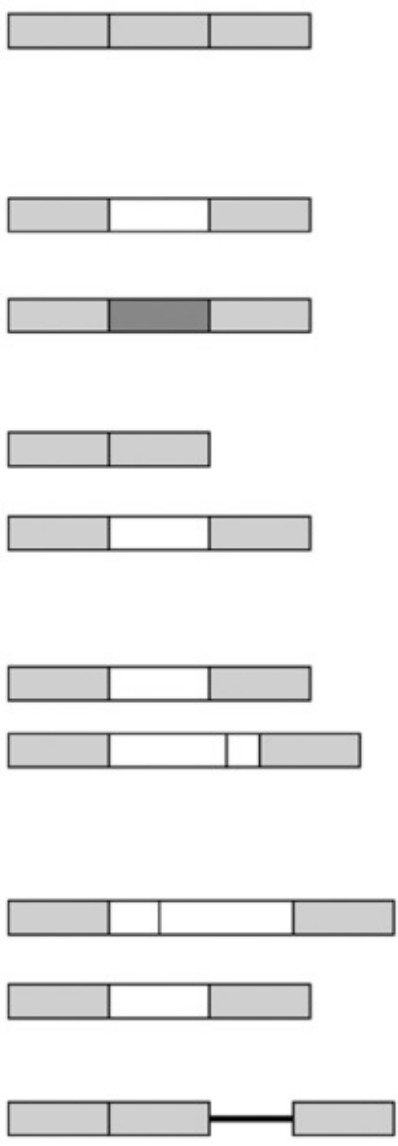
Figura 2. Esquema representativo dos tipos de splicing alternativos. Painéis (a) splicing constitutivo, (b) éxons mutuamente exclusivos, (c) "exon skipping", (d) sítio alternativo 3', (e) sítio alternativo 5' e (f) retenção de íntron. (Figura de Wang et al. 2014)

\section{I.3 RNAs não codificadores longos (IncRNAs)}

Os recentes avanços nas tecnologias de microarrays e sequenciamento de nova geração (NGS: "Next Generation Sequencing") revelaram que a maior parte do genoma humano $(\sim 75 \%)$ é transcrito em RNA, enquanto que somente cerca de $2 \%$ codifica proteínas (Djebali et al. 2012). Os RNAs não codificadores podem ser divididos em dois grandes grupos quanto a seu tamanho, se superam os 200 nt são designados como RNAs não-codificadores longos (IncRNAs: "long non-coding RNAs"), e os menores como RNAs pequenos (sRNAs: "small RNAs") (Huarte 2015). Os sRNAs são um grupo heterogêneo que inclui microRNAs (miRNAs), small nucleolar RNAs (snoRNAs) e piwiRNAs (piRNAs) (Ma, Bajic, and Zhang 2013). Dependendo de sua localização genômica os IncRNAs podem ser classificados em IncRNA intergênicos (lincRNA, quando é transcrito entre dois genes), IncRNA intrônico (transcrito completamente dentro de um íntron de outro gene), IncRNA senso (transcrito na mesma fita que o gene codificante e com sobreposição a éxons dele), ou IncRNA antisenso (transcrito na fita oposta do outro gene, com sobreposição parcial ou total) (Ma, Bajic, and Zhang 2013).

Os IncRNAs tem em geral expressão tecido específica, são menos abundantes e menos conservados evolutivamente que os genes codificadores (Derrien et al. 2012). Eles podem atuar em diversos processos, por exemplo: regulando a atividade transcricional em cis ou em trans, recrutando fatores de transcrição ou complexos modificadores de cromatina (Tsai et al. 2010); modulando o splicing alternativo (Gonzalez et al. 2015); regulando a tradução ou degradação de mRNAs (Yoon et al. 2012; Chenguang Gong 2011); ou ainda como esponjas de miRNAs que alvejam mRNAs (Z. Du et al. 2016). Uma classe especial de RNA não codificador recentemente descrita corresponde aos enhancers RNAs (eRNAs). Esses transcritos tem a capacidade de regular a expressão gênica através de sua ligação com fatores de transcrição (K. Lee et al. 2015) e formação de um loop que aproxima as regiões promotoras e enhancer (Schaukowitch et al. 2014; Y. Liu et al. 2018). eRNAs apresentam certas marcas epigenéticas caraterísticas, como modificações de histonas (H3K4me1, H3K27Ac), variantes de histonas (como H2AZ, H3.3) e estruturas de cromatina aberta (como hipersensibilidade a DNase I) que permitem sua interação com reguladores transcricionais (Ding et al. 2018) 


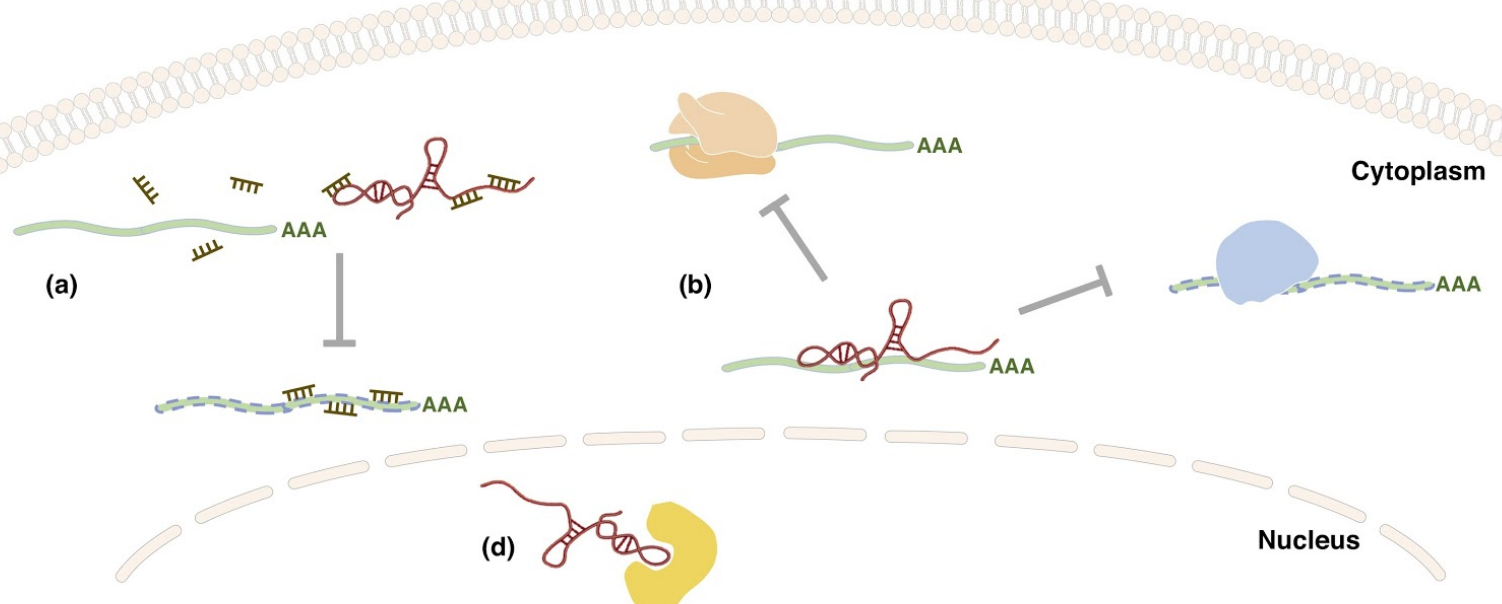

(a)

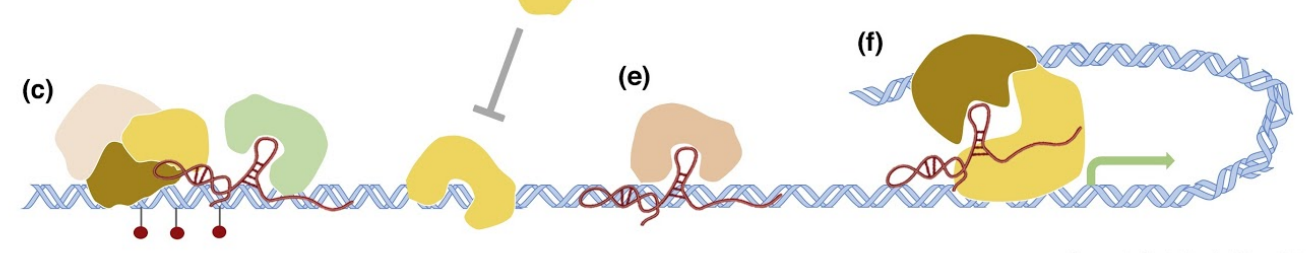

Current Opinion in Genetics \& Development

Figura 3. IncRNAs e seus mecanismos moleculares. Os IncRNAs podem atuar como RNAs competitivos endógenos (a); se-ligando a mRNAs e reprimindo sua tradução (b); como "scaffold" recrutando proteínas modificadoras da cromatina (c); como "decoy" inibindo a função de proteínas (d); guiando proteínas (e); ativando a transcrição (f). (Figura de Hu et al. 2018)

Os IncRNAs já foram envolvidos em vários processos que favorecem o desenvolvimento do câncer, como regulação do ciclo celular, sobrevivência, resposta imune e pluripotência (Huarte 2015). Por exemplo, PTENP1 actua como esponja, se-ligando a microRNAs que de outra forma inibiriam a expressão do mRNA PTEN, permitindo que cumpla sua função como supressor tumoral (Cesana et al. 2011). O IncRNA ANRIL atua silenciando os genes vizinhos CDKN2A e CDKN2B induzindo a proliferação celular (Kotake et al. 2011). HOTAIR tem um papel na repressão de genes distantes, como HOXD, mediante recrutamento de PRC2 e modificação da cromatina, promovendo a metástase em câncer de mama (Gupta et al. 2010).

Um importante estudo realizado para anotar novos IncRNAs no transcritoma humano foi desenvolvido por lyer e colaboradores (lyer et al. 2015). Nesse trabalho, designado como "MiTranscriptome", foram analisadas 7,256 bibliotecas de RNA-seq provenientes de dezenas de tumores (incluindo pâncreas, mama, ovário, próstata, pulmão e estômago) (lyer et al. 2015). O grupo conseguiu identificar 91,013 genes, dos quais 58.648 foram classificados como IncRNAs e um $79 \%$ deles eram desconhecidos até o momento (lyer et al. 2015).

No contexto do câncer pancreático, poucos estudos fizeram análises comparativas entre amostras tumorais $(T)$ e normais $(N)$ para identificação de IncRNAs 
associados a tumorigênese. Dois trabalhos utilizaram microarranjos de cDNA para analisar amostras T/N identificando perfis de expressão de IncRNAs associados com malignidade e metástase (Tahira et al. 2011; Fu et al. 2016). Recentemente, Song e colaboradores exploraram dados de expressão de 178 amostras de PDAC e apenas 4 de tecido não tumoral de pâncreas e encontraram 5 IncRNAs com potencial como marcador prognóstico (C9orf139, MIR600HG, RP5-965G21.4, RP11-436K8.1, e CTC-327F10.4) (Song et al. 2018). O grupo de Mao et al. foi o único que utilizou amostras pareadas de tecidos tumorais e normais adjacentes $(n=10)$ (Mao et al. 2017). Neste estudo, usaram RNA-seq enriquecido em mRNA para detectar 2.736 genes diferencialmente expressos, validando experimentalmente 5 RNAs codificadores de proteína (KRT16, HOXA10, CDX1, SI, e SERPINB5) por RT-PCR.

\section{I.4 RNAs circulares (circRNAs)}

Décadas atrás foi observada a presença de RNAs circulares (circRNAs) (Nigro et al. 1991; Cocquerelle et al. 1993), e por muito tempo foram esquecidos e considerados como produtos aberrantes do splicing. Recentemente, a aplicação de RNA-seq enriquecido com RNA total permitiu a identificação de circRNAs em humanos, macacos, camundongos, moscas, vermes, plantas, fungos e protistas (Salzman et al. 2012; Ivanov et al. 2015; S. P. Barrett, Wang, and Salzman 2015; Broadbent et al. 2015; T. Lu et al. 2015). Os circRNAs são conservados evolutivamente dentro dos mamíferos e possuem uma expressão tecido-específica (S. Barrett and Salzman 2016). Eles são sintetizados a partir do mRNA precursor (pre-mRNA) por um "back-splicing" de éxons nos quais o sítio de splicing (ss) 5' "downstream" é unido com um ss 3' "upstream", e o RNA circular resultante é ligado por uma união fosfodiéster 3'-5' no sítio da junção (X. $\mathrm{Li}$, Yang, and Chen 2018). 


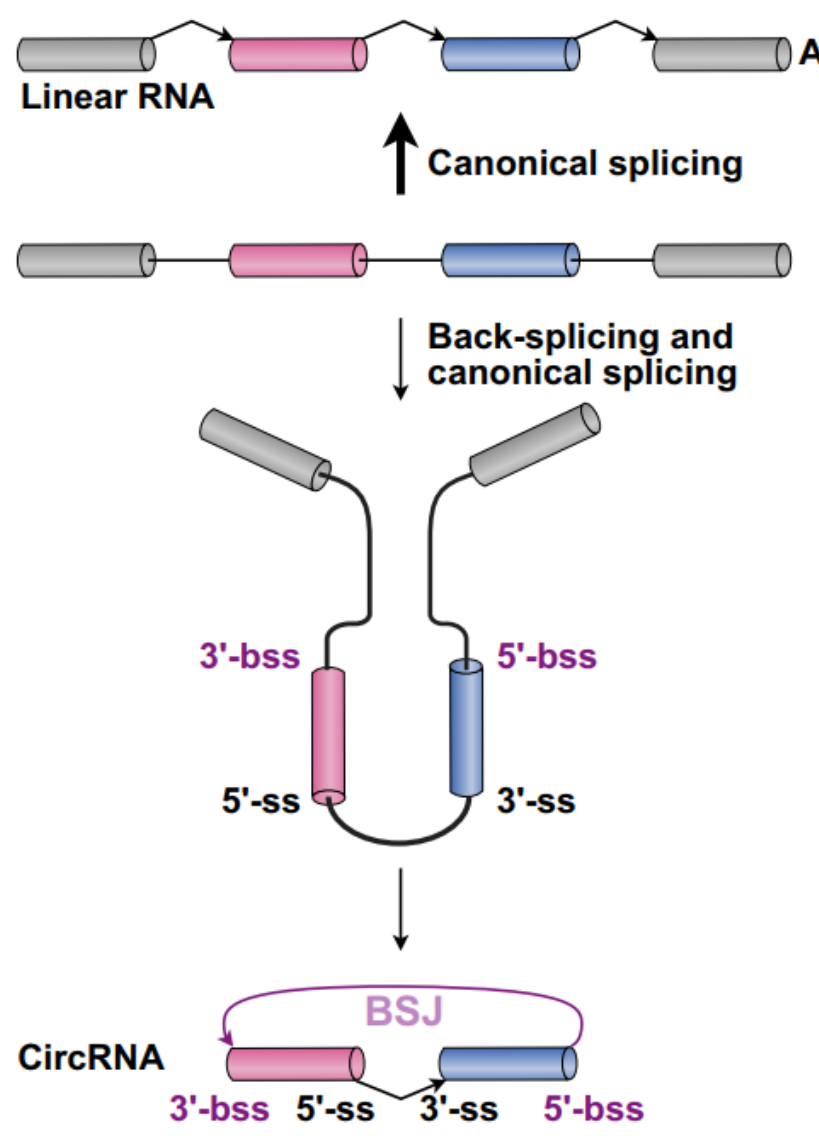

Figura 4. Biogênese dos circRNAs por "back-splicing". ss: "splice site", bss: "back splice site". (Figura de Li et al, 2018)

Embora a expressão dos circRNAs em geral seja baixa, diversos estudos sugerem que podem ter funções importantes em condições fisiológicas e patológicas, incluindo em câncer (X. Li, Yang, and Chen 2018). Panda e colaboradores demonstraram que a redução dos níveis do RNA circular circPVT1 em fibroblastos desencadeia a senescência (Panda et al. 2017), enquanto que Guarnerio et al. trabalhando com leucemia promielocítica aguda evidenciaram que a translocação PML/RARa induz a formação de circRNAs específicos que promovem a transformação maligna (Guarnerio et al. 2016). Em relação ao PDAC, recentemente foram publicados três trabalhos descrevendo a expressão de circRNAs. Li e colaboradores usaram microarrays para investigar o perfil de expressão de circRNAs em câncer pancreático (H. Li et al. 2016). Shao et al. identificaram dois circRNAs como possíveis alvos terapêuticos para pacientes que não respondem a gemcitabina (Shao et al. 2018). E outro estudo permitiu detectar uma expressão elevada do circ-IARS em tumores pancreáticos primários e em exossomas no plasma de pacientes com metástase (J. Li et al. 2018). As características mencionadas anteriormente, incluindo a estabilidade dos 
circRNAs dentro da célula, sangue, saliva e exossomas (Bahn et al. 2015; Y. Li et al. 2015) sugere que estas moléculas têm um alto potencial para serem utilizadas como biomarcadores para monitoramento da presença ou recorrência de tumores (X. Li, Yang, and Chen 2018).

\section{I.5 Motivação}

Embora muitos esforços estão sendo feitos, o câncer de pâncreas continua sendo um dos mais mortais e a sobrevida de 5 anos de $6 \%$ dos pacientes permanece invariável nas últimas quatro décadas (Paul E. Oberstein 2013). Sua agressividade, resistência a tratamentos quimioterápicos convencionais e falta de marcadores moleculares precisos, indicam que são necessários mais estudos para compreender melhor a biologia do tumor. Enquanto que a grande maioria dos trabalhos são concentrados na região codificadora de proteína, recentemente foi destacada a importância dos RNAs não codificadores em uma grande variedade de doenças, incluindo câncer. Apesar do grande número de IncRNAs no genoma humano, só uma minoria foram bem caracterizados, e mais estudos são necessários (X. Hu et al. 2018). Particularmente no câncer pancreático, poucos trabalhos em larga escala focaram na identificação de RNAs não codificadores com expressão desregulada no tumor em relação ao tecido pancreático não tumoral (Tahira et al. 2011; Song et al. 2018; Fu et al. 2016; Mao et al. 2017), sendo que nenhum deles aplicou uma abordagem experimental que investigasse a fração não-poliadenilada no transcritoma.

O presente trabalho pretendeu estabelecer uma rotina informática para a análise dos dados de sequenciamento com alta capacidade (RNA-seq) de bibliotecas geradas a partir de RNA poliadenilado e não poliadenilado, para a geração de um catálogo mais completo de genes expressos e desregulados no PDAC, incluindo novas variantes de splicing alternativo e IncRNAs conhecidos e transcritos ainda não anotados. Este catálogo permitirá aumentar nosso conhecimento sobre as bases moleculares da doença e será um recurso importante para guiar a seleção e priorização de transcritos com potencial biomarcador para serem validados experimentalmente. 


\section{OBJETIVOS}

\section{II.1 Objetivos gerais}

- Catalogar novos transcritos expressos e identificar alterações transcricionais através da análise computacional do transcritoma de amostras pareadas de adenocarcinoma e tecido pancreático não tumoral

\section{II.2 Objetivos específicos}

- Criar rotinas informáticas baseada em scripts customizados e programas pré-existentes para automatizar o processamento de dados de RNA-seq e a reconstrução do transcritoma de amostras de tumor e tecido não tumoral de 14 pacientes com PDAC;

- Comparar a sequência dos transcritos reconstruídos com anotações do transcritoma humano disponível em banco de dados públicos para identificar novos RNAs expressos no tecido pancreático;

- Catalogar potenciais novos IncRNAs (> 200 nt) intergênicos e antisensos;

- Identificar variantes de splicing expresso no PDAC e avaliar sua estrutura;

- Detectar a expressão de possíveis RNAs circulares (circRNAs) nas amostras tumorais e não-tumorais;

- Identificar genes codificadores e não codificadores diferencialmente expressos em amostras de PDAC, assim como vias moleculares enriquecidas entre os genes com expressão alterada nas células tumorais.

- Priorizar uma lista de transcritos para validação experimental através de qPCR e sequenciamento. 


\section{MATERIAIS E MÉTODOS}

\section{III.1 Amostras de pacientes}

Foram avaliadas amostras pareadas de tecido tumoral e não-tumoral adjacente de 14 indivíduos com uma média de 68 anos, sendo 8 homens e 6 mulheres (tabela 1). Um certificado do Comitê de ética para a participação de pacientes no estudo encontra-se no anexo 2.

Tabela 1. Informação clínico patológica dos pacientes avaliados por RNA-seq

\begin{tabular}{|c|c|c|c|c|c|}
\hline ID sample & $\begin{array}{l}\text { Survival } \\
\text { (days) }\end{array}$ & Status & Sex & Age & Anatomopathological classification (H\&E) \\
\hline 1 & 369 & Dead & M & 81 & $\begin{array}{l}\text { 95\% PDAC , 5\% inseparable intra-ductal } \\
\text { neoplasia. }\end{array}$ \\
\hline 2 & 3291 & Dead & M & 67 & $\begin{array}{l}80 \% \text { PDAC, non-neoplastic border removed } \\
\text { from the sample. }\end{array}$ \\
\hline 3 & 448 & Dead & $\mathrm{W}$ & 75 & $100 \%$ PDAC. \\
\hline 4 & 397 & Dead & M & 65 & $\begin{array}{l}80 \% \text { Adenosquamous carcinoma, } 20 \% \\
\text { borderline small intestine. }\end{array}$ \\
\hline 5 & 115 & Dead & M & 77 & 100\% PDAC. \\
\hline 6 & 80 & Alive & M & 77 & $\begin{array}{l}80 \% \text { PDAC, } 20 \% \text { inseparable endocrine } \\
\text { pancreatic tissue. }\end{array}$ \\
\hline 7 & 658 & Alive & M & 53 & $\begin{array}{l}80 \% \text { PDAC, } 20 \% \text { inseparable endocrine } \\
\text { pancreatic tissue. }\end{array}$ \\
\hline 8 & 1608 & Alive & $\mathrm{W}$ & 46 & $\begin{array}{l}70 \% \text { PDAC, } 30 \% \text { inseparable endocrine } \\
\text { pancreatic tissue. }\end{array}$ \\
\hline 9 & 1077 & Alive & M & 80 & $100 \%$ IPMN. \\
\hline 10 & 1170 & Alive & $\mathrm{W}$ & 67 & $100 \%$ PDAC. \\
\hline 11 & 405 & Alive & M & 62 & $\begin{array}{l}\text { 70\% PDAC, } 30 \% \text { IPMN low grade, } \\
\text { non-neoplastic border removed. }\end{array}$ \\
\hline 12 & 531 & Dead & $\mathrm{W}$ & 65 & $\begin{array}{l}90 \% \text { PDAC, } 10 \% \text { inseparable duodenum wall } \\
\text { border. }\end{array}$ \\
\hline 13 & 1287 & Alive & $\mathrm{W}$ & 75 & $\begin{array}{l}\text { 100\% Pancreatic intraepithelial neoplasia } \\
\text { (PanIN). }\end{array}$ \\
\hline 14 & 936 & Alive & $\mathrm{W}$ & 61 & $\begin{array}{l}\text { 90\% PDAC, } 5 \% \text { non-separable in situ lesion, } \\
\text { non-neoplastic border }\end{array}$ \\
\hline
\end{tabular}




\section{III.2 Preparação das bibliotecas}

As bibliotecas de RNA-seq de amostras pareadas de PDAC e tecido pancreático não tumoral de 14 pacientes com adenocarcinoma de pâncreas provenientes do banco de tumores do Hospital AC Camargo foram preparadas em nosso laboratório pelo aluno de doutorado Vinícius Ferreira da Paixão. As bibliotecas foram geradas a partir de RNA total depletado de RNA ribossomal citoplasmático e mitocondrial e mantém a informação de orientação genômica do transcrito (kit TruSeq Stranded Total RNA with RiboZero Gold, Illumina). O sequenciamento ("Paired-end") foi realizado utilizando kits de 150 ciclos ( 2 x 75 nt) na plataforma Illumina HiSeq 1500 do Instituto Butantan.

\section{III.3 Análises bioinformáticas}

O pipeline desenvolvido para realizar as análises bioinformáticas encontra-se representado na figura 5 . O processamento inicial dos dados envolveu a atribuição das sequências a cada biblioteca ("demultiplexing"), o controle de qualidade das sequências (reads) obtidas, a filtragem das regiões com baixa qualidade e por fim o mapeamento das sequências no genoma humano. A reconstrução do transcritoma incluiu a montagem incremental das sequências obtidas a partir das amostras tumorais e não-tumorais, uma série de filtragens para remover possíveis artefatos, e a comparação dos transcritos reconstruídos com catálogos de genes conhecidos (Gencode e MiTranscriptome). Os novos transcritos identificados foram avaliados em relação à presença de marcas de regulação epigenéticas, tipo de splicing alternativo, potencial codificador e conservação evolutiva. A análise de expressão gênica envolveu a identificação de genes/transcritos com expressão aumentada ou diminuída no PDAC em relação ao tecido não-tumoral e a avaliação das vias moleculares e funções biológicas preferencialmente perturbadas no PDAC. Também foi investigada a presença de potenciais RNAs circulares e sua expressão alterada nas amostras tumorais. Finalmente, foram selecionados um subconjunto de potenciais marcadores moleculares para validação experimental. 

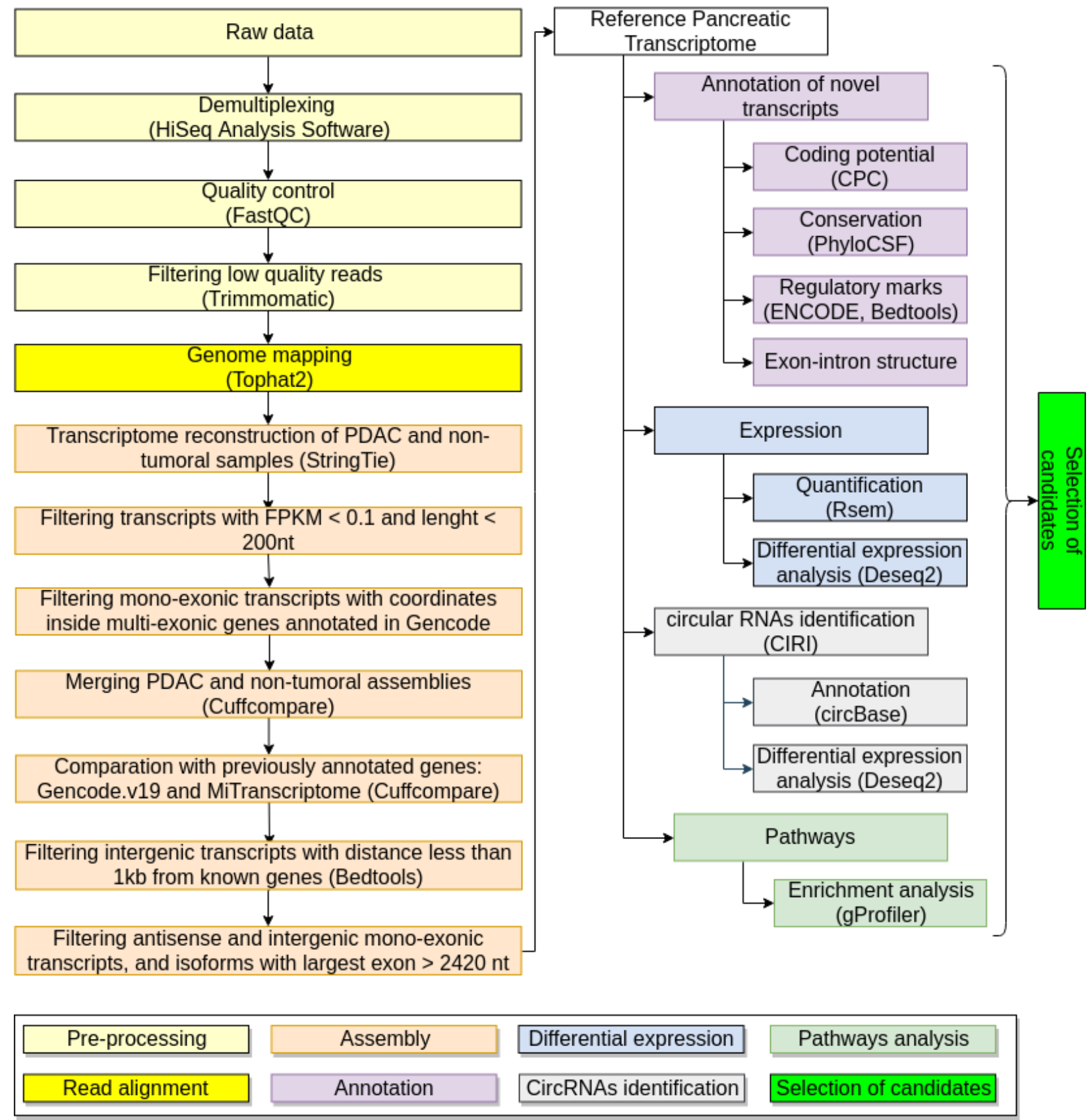

Figura 5. Fluxograma geral da rotina empregada na análise computacional dos dados de RNAseq de tumores de pâncreas. Scripts desenvolvidos em Bash, R e Python foram utilizados para integrar as entradas e saídas dos diferentes programas usados no pipeline. As diferentes etapas do pipeline informática estão representadas por cores.

Para realizar a análise computacional foram desenvolvidos scripts em Bash, Python e $\mathrm{R}$ que integram a execução de diferentes programas para cada etapa do pipeline, como detalhado nos itens abaixo. 


\section{III.3.1 Controle de qualidade das sequências}

O controle de qualidade dos reads foi feito com o programa FastQC v0.10.1 (Andrews 2010), esta é uma ferramenta que permite fazer uma série de análises modulares, entre elas a determinação da qualidade por base e conteúdo de bases indeterminadas $(\mathrm{N})$ e conteúdo $\mathrm{GC}$ da sequência. Os resultados de todas as amostras foram sumarizados utilizando o programa MultiQC (Ewels et al. 2016). Para a automatização do processamento das sequências ("reads") foi desenvolvido o script "controle_de_qualidade" (Anexo 1) em Bash. O mesmo recebe como entrada os arquivos com sequências em formato .fastq e para cada um deles executa o programa FastQC, salvando os resultados na pasta "fastqc_results".

A remoção dos adaptadores e filtragem dos reads com baixa qualidade foi feita com o programa Trimmomatic (Bolger, Lohse, and Usadel 2014). O script "trimagem" (Anexo 1) aceita os arquivos fastq originais e remove os adaptadores Illumina, assim como sequências com qualidade inferior que 15 e reads excessivamente pequenos (menores que 35 nucleotídeos).

\section{III.3.2 Alinhamento das sequências}

As sequências foram alinhadas e mapeadas contra o genoma humano de referência pré-indexado (HG 19) utilizando o programa TopHat v2.0.11 (D. Kim et al. 2013). Este programa utiliza as coordenadas genômicas para detectar junções de exons de genes previamente anotados assim como novas junções. Foi criado o script "mapeamento" (Anexo 1) para uma automatização desta etapa. O programa aceita como entrada os reads processados e tem como saída arquivos de formato bam (equivalente a "Sequence Alignment/Map") que armazenam informação do alinhamento.

\section{III.3.3 Montagem do transcritoma}

A reconstrução do transcritoma do pâncreas tumoral e não-tumoral foi feita separadamente e de forma hierárquica (figura 6) usando o programa StringTie (Pertea et al. 2015), ferramenta que permite uma rápida montagem dos reads. Para isso, os resultados dos alinhamentos (.bam) foram combinados em dois arquivos, um para as amostras tumorais e outro para as não-tumorais. Para cada montagem foi utilizado o arquivo de anotações "gencode.v19.annotation.gtf" como referência (script "montagem" no Anexo 1). 


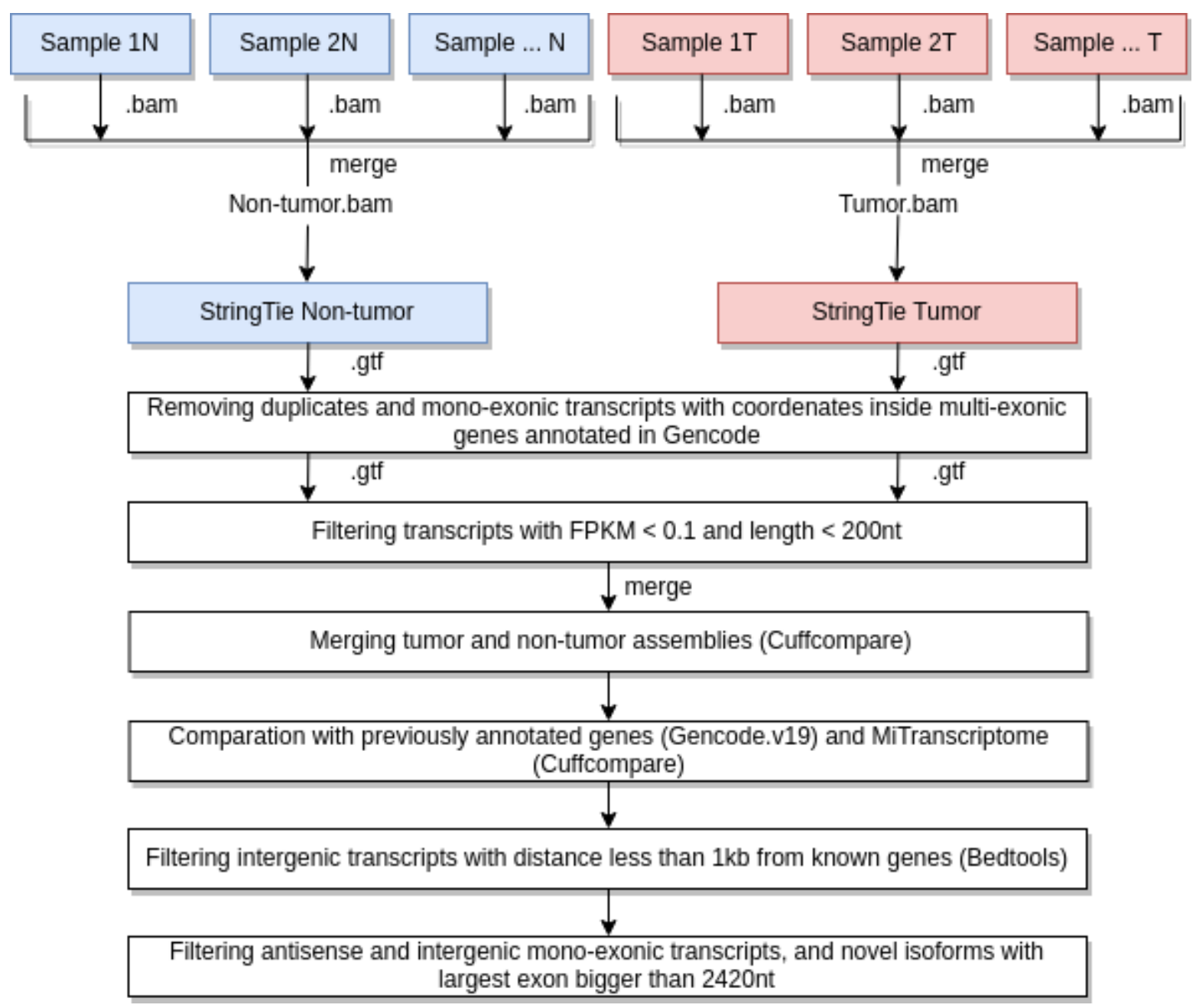

Figura 6. Reconstrução do transcritoma. Foi feita a montagem das amostras tumorais e não tumorais separadamente usando o programa StringTie (Pertea et al. 2015), e os transcritos foram filtrados por FPKM>0,1 e tamanho > 200nt. As duas montagens foram combinadas (Normal_filtrado.gtf e Tumor_filtrado.gtf) num só arquivo "Pâncreas.gtf", que foi comparado com a referência Gencode.v19 utilizando a ferramenta Cuffcompare (Trapnell, Roberts, et al. 2012).

Para melhorar a reconstrução do transcritoma removendo possíveis artefatos da reconstrução foram desenvolvidos scripts em Python. O código "melhora_montagem_1" (Anexo 1) remove transcritos que contém exatamente as mesmas coordenadas genômicas (duplicados), enquanto que "melhora_montagem_2" (Anexo 1) dispensa possíveis pre-RNAs mensageiros evidenciados como transcritos mono-exônicos que estão dentro de genes multi-exônicos anotados no Gencode.

Os transcritos com baixa expressão (FPKM menor que 0,1) e tamanho menor que 200nt também foram excluídos das análises posteriores. Para isso foi criado o script "melhora_montagem_3" (Anexo 1). 
Em seguida, o programa Cuffcompare (Trapnell, Roberts, et al. 2012) foi usado para combinar as montagens das amostras tumorais e não-tumorais, assim como para anotar os transcritos em função dos catálogos de referência GENCODE (versão 19) e MiTranscriptome (lyer et al. 2015) (script "anotação", Anexo 1).

Transcritos intergênicos com coordenadas genômicas menores que 1 kb de distância em comparação com genes conhecidos foram consideradas possíveis UTRs e não foram utilizados nas análises posteriores. Para realizar essa tarefa foi elaborado o script em Python "remove_utrs" (Anexo 1).

Também para restringir a possibilidade de artefatos resultantes da presença de pré-RNA imaturo não processado nas bibliotecas, optamos por não examinar novos transcritos mono-exônicos: foram considerados para análises mais detalhadas apenas novos transcritos intergênicos e antisensos com evidência de splicing (multi-exônicos). Baseado na observação de que $99 \%$ dos transcritos anotados no GENCODE tem exons com tamanho menor que $2420 \mathrm{nt}$, apenas foram analisadas novas isoformas que apresentassem exons menores que 2420 nt (ou maiores desde que confirmado de forma independente no catálogo MiTranscriptome).

\section{III.3.4 Caracterização dos transcritos novos}

Em relação aos transcritos reconstruídos que não estavam na referência (GENCODE.v19), foram analisadas certas características para identificar possíveis IncRNAs expressos em tecido pancreático, entre elas o potencial codificador, conservação evolutiva, presença de marcas regulatórias e tipos de splicing das novas isoformas.

As informações sobre os transcritos foram visualizadas no UCSC Genome Browser (James Kent et al. 2002). Para isso foram criados tracks customizados acessando ao site https://genome.ucsc.edu/. Os arquivos .bam foram previamente ordenados e indexados usando a ferramenta Samtools (Heng Li et al. 2009).

\section{III.3.4.a Potencial codificador e conservação evolutiva}

Considerando que um transcrito codificador provavelmente tem um Open Reading Frame (ORF) maior e de melhor qualidade que um RNA não codificador, o programa CPC (Heng Li et al. 2009; Kong et al. 2007) usa essa característica, em combinação com uma busca por similaridade de sequências (BLASTX) no banco de dados UniProt Reference Clusters (UniRef90), para estimar o potencial codificador do transcrito. Outro programa utilizado foi o PhyloCSF (Lin, Jungreis, and Kellis 2011), que aplica uma abordagem diferente examinando perfis evolutivos característicos a 
alinhamentos de regiões conservadas, tais como alta frequência de substituições de códons sinônimas e substituições de aminoácidos conservativas, e baixa frequência de outras substituições "missense" e "nonsense" (CSF = Codon Substitution Frequencies). Os transcritos foram classificados de acordo com seu score como "non-coding" (CPC score < - 1; ou PhyloCSF score $<=-5$ ), "non-coding weak" (CPC score $>=-1 \&<0$; ou PhyloCSF score $<0 \&>-5$ ), "coding weak" (CPC score $>=0 \&<1$; ou PhyloCSF score $>=0 \&<5$ ) e "coding" (CPC score $>=1$; or PhyloCSF score $>=5$ ).

Foi desenvolvido o script em Bash "potencial_codificador" (Anexo 1), que a partir das sequências em formato fasta executa os programas PhyloCSF e CPC, obtendo os escores dos diferentes tipos de transcritos.

Também foi realizada uma busca de ORFs (Open Reading Frames) utilizando o programa TransDecoder (Haas et al. 2013), considerando somente ORFs codificantes de sequências maiores que 100 aminoácidos. Foi avaliada a similaridade com o banco de dados Swissprot (baseado no threshold 1-e-5) utilizando BLASTP (Altschul SF n.d.) (script "busca_de_orfs", Anexo 1")

\section{III.3.4.b Marcas epigenéticas}

Regiões com hipersensibilidade DNase com atividade epigenética suportada por modificações nas histonas (H3K4me3 e H3K27ac) e dados de ligação com CTCF (cis-Regulatory Elements, ccRE) foram baixados do projeto ENCODE (http://screen.encodeproject.org). No script "marcas_de_regulação" (Anexo 1) foi usado o pacote BEDTools (Quinlan and Hall 2010) para estimar a distância entre as coordenadas genômicas dos ccREs e os sítios de início da transcrição (TSS) dos

transcritos novos (formas alternativas de splicing, RNAs intergênicos e RNAs antisensos) e dos já anotados no GENCODE que foram detectados em nosso trabalho (transcritos codificantes de proteínas, lincRNAs e antisensos). Para testar a significância estatística foi confeccionado o script em Bash "sequências_aleatórias" (Anexo 1), que cria 50 datasets de sequências aleatórias intergênicas, utilizando o programa "Bedtools shuffle" e considerando genes da referência Gencode. O script "porcentagem_sequências_aleatórias" foi elaborado para salvar as porcentagens de transcritos que possuem marcas de regulação próximas em cada intervalo. Finalmente, foi calculada a média dos 50 datasets aleatórios para cada distância (script em python "calcula_media_porcentagens", Anexo 1). Para comparar as distribuições e verificar a existência de diferenças estatisticamente significativas foi aplicado 0 teste Kolmogorov-Smirnov (KS).

\section{III.3.4.c Variantes de splicing alternativo}


As novas variantes de splicing alternativo foram anotadas utilizando o programa SUPPA (Alamancos et al. 2014) e classificadas em "retained intron", "skipped exon", "mutually exclusive exons", "alternative 5' splice-site", "alternative 3' splice-site", "alternative first exon" and "alternative last exon". O script em Bash "splicing" permitiu a execução do programa SUPPA para cada nova isoforma, a partir dos arquivos em formato gtf.

Para inferir a associação entre os genes contendo novas isoformas e câncer, os mesmos foram cruzados com a lista de genes do projeto "Cancer Gene Census" (Andrew Futreal et al. 2004) contido no banco de dados COSMIC (Forbes et al. 2017).

\section{III.3.5 Quantificação e análise de expressão diferencial}

Para a quantificação da expressão gênica a partir de dados de RNAseq, inicialmente foram criadas matrizes de contagem dos reads, considerando como referência o conjunto de transcritos reconstruídos na montagem inicial. Foram avaliadas diferentes abordagens para quantificar a expressão em nível de gene (considerando um valor único para o locus) ou a expressão em nível de transcrito (expressão individual das diferentes isoformas expressas no locus, considerando que um gene pode ter vários transcritos).

Para a quantificação ao nível de gene foram usados os programas HTSeq (Anders, Pyl, and Huber 2015) e RSEM (B. Li and Dewey 2011). O script "htseq" (Anexo 1) utiliza os arquivos de alinhamento (formato .bam) e a referência gerada na montagem (formato .gtf) para quantificar a expressão dos genes reconstruídos. Foi elaborado em Bash o código "star_rsem" (Anexo 1) para automatizar a execução dos programas STAR (Dobin et al. 2013) e RSEM. O primeiro é um alinhador que usa os arquivos das sequências (.fastq) e a montagem reconstruída como entrada, gerando arquivos de formato bam que são utilizados posteriormente pelo programa RSEM para quantificar em nível de gene e de isoforma.

Também foram comparadas diferentes abordagens para a quantificação relativa das diferentes isoformas de transcritos, incluindo Salmon (Patro et al. 2017), Kallisto (Nicolas L. Bray et al. 2016) e RSEM (B. Li and Dewey 2011). Tanto Salmon quanto Kallisto utilizam os arquivos de formato fastq como entrada, para estimar a expressão dos transcritos (scripts em Bash "salmon" e "kallisto", Anexo 1).

A elaboração do script em R "expressão_diferencial" (Anexo 1) possibilitou utilizar as contagens de reads geradas pelos diferentes programas como entrada para a identificação de genes/transcritos diferencialmente expressos no tumor utilizando a ferramenta DEseq2 (Love, Huber, and S 2014). O mesmo script inclui análises não supervisionadas baseadas em clusterização hierárquica, análise de componentes principais (PCA) e geração de figuras, com o pacote "ggplot2" (Wickham 2016). 


\section{III.3.6 Identificação e quantificação de RNAs circulares}

A identificação e quantificação de possíveis circRNAs expressos em tecido pancreático foi feita com o programa CIRI (Y. Gao, Wang, and Zhao 2015), que procura reads de junções com sinais característicos, incluindo sítios GT-AG ou AT-AC, informação do paired read, qualidade do mapeamento, e tamanho do alinhamento do read nas junções. Para isso, primeiramente foi necessário fazer um alinhamento dos reads com BWA (H. Li and Durbin 2009), programa que usa as sequências em formato fastq e gera arquivos sam que são utilizados por CIRI. Como referência foram usados o genoma humano hg19 e o arquivo de anotação gencode.v19. Todos os passos integrados no script "circrna" (Anexo 1).

Para a quantificação da expressão foram considerados somente os circRNAs com dois ou mais junction reads detectados em pelo menos 14 amostras. A análise de expressão diferencial foi feita com o programa Deseq2 (Love, Huber, and S 2014) (script "expressão_diferencial", Anexo 1).

Os circRNAs identificados foram anotados em relação ao banco de dados circBase (Glažar, Papavasileiou, and Rajewsky 2014) que contém informação de 92.368 circRNAs humanos. Para isso, foi desenvolvido o script em Python "anota_circrnas" (Anexo 1). O mesmo compara as coordenadas dos potenciais circRNAs de nosso trabalho com os da referência (circBase), classificando em "iguais" (símbolo "=") se tem coincidência perfeita, "contidos" (símbolo "c") se está dentro de um circRNA anotado, ou "novo" (símbolo "-") se não está na referência.

\section{III.3.7 Análise de vias moleculares alteradas no PDAC}

Para a análise de enriquecimento de vias entre os genes diferencialmente expressos foi usada a ferramenta gProfiler (Reimand et al. 2007), que utiliza informação do Gene Ontology (The Gene Ontology Consortium et al. 2000), KEGG (Minoru Kanehisa 2000) e Reactome (Fabregat et al. 2018).

\section{III.4 Seleção de candidatos}

Genes com expressão diferencial nas amostras tumorais, incluindo novas formas de splicing e novos transcritos intergênicos, foram selecionados para validação experimental mediante RT-qPCR utilizando um equipamento Applied Biosystems ${ }^{\circledR} 480$ 7500 Real-Time PCR System (Thermo Fisher) em colaboração com o aluno doutorando Vinicius Ferreira e os alunos de iniciação científica Victoria de Paiva e Ricardo Chiong. 


\section{RESULTADOS}

\section{IV.1 Análise da qualidade das sequências obtidas por RNA-seq}

A análise das sequências resultantes do sequenciamento das 14 amostras pareadas de indivíduos com tumores pancreáticos (Tumor/No-tumor) foi realizada utilizando o programa FastQC v0.10.1 (Andrews 2010). Na figura 7a é apresentada a qualidade (Phred Score) em função da posição da base na sequência para cada uma das amostras, enquanto que na figura $7 b$ é possível observar uma distribuição do número de reads considerando a qualidade média das sequências. Posteriormente foi utilizado o programa Trimmomatic (Bolger, Lohse, and Usadel 2014) para remover: 1) adaptadores Illumina; 2) bases iniciais e finais com qualidade inferior a 3 ou Ns; 3 ) regiões com qualidade inferior que 15 ; 4) reads com tamanho menor que 35 . Após essa série de filtragens restaram $92,3 \%$ dos reads que foram utilizados nas análises subsequentes.

A

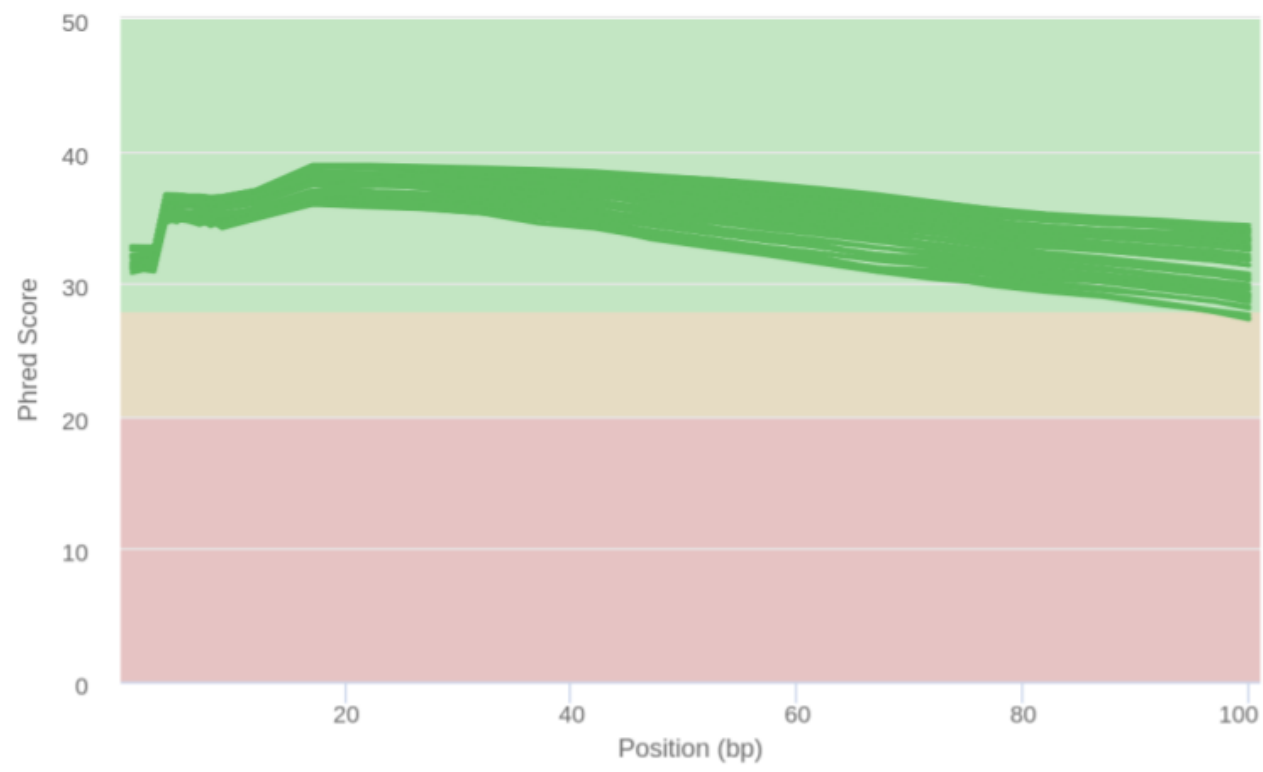


B

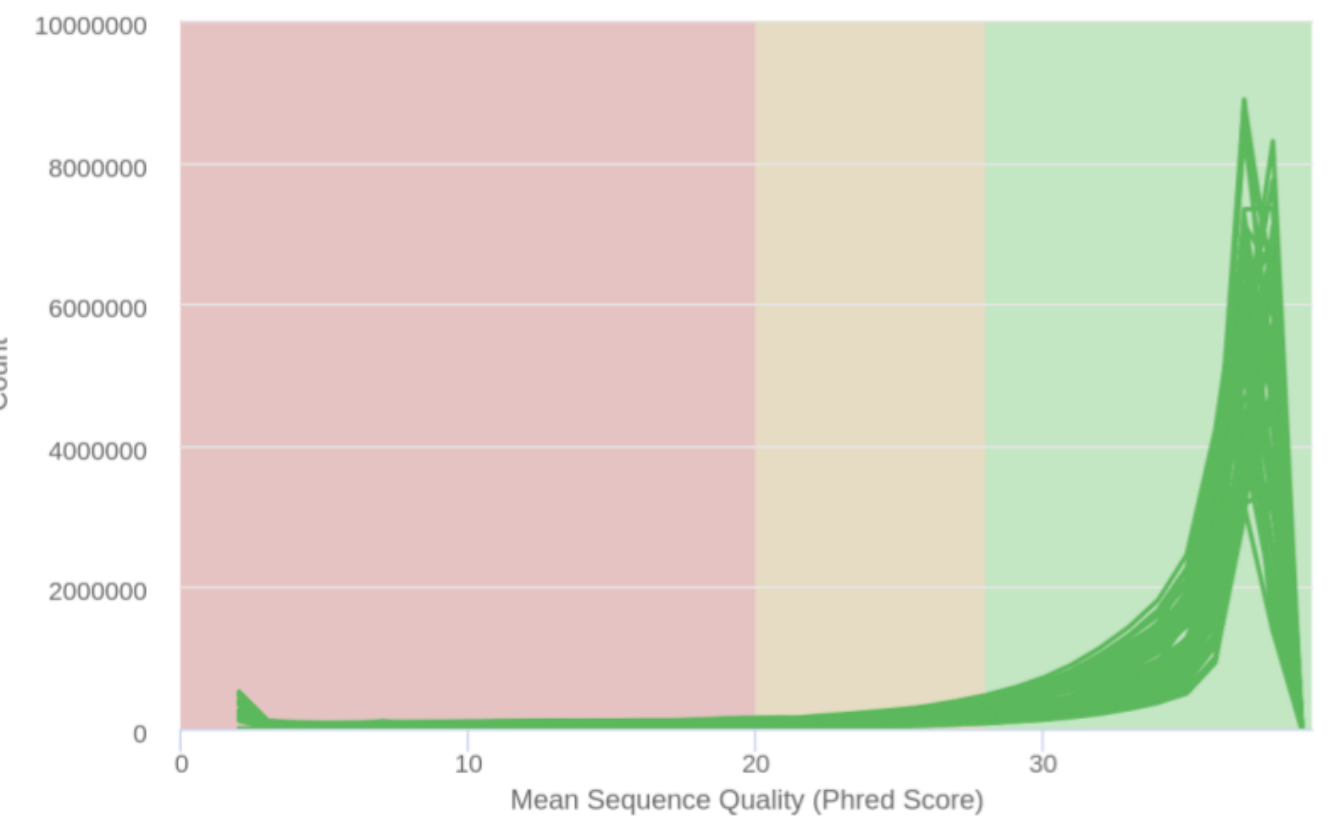

Figura 7. Controle de qualidade feito com FastQC (Andrews 2010). A qualidade média por base está representada no painel $A$, enquanto que os scores das qualidades por sequências estão no painel $B$. As figuras com todas as amostras foram geradas utilizando Multiqc (Ewels et al. 2016)

\section{IV.2 Alinhamento genômico das sequências}

Na tabela 2 é apresentado um resumo do resultado do alinhamento genômico das sequências usando o programa TopHat2 v2.0.11 (D. Kim et al. 2013). A porcentagem de mapeamento foi satisfatória, com uma média de $85 \%$. As sequências alinhadas no genoma foram utilizadas na etapa seguinte de montagem do transcritoma.

Tabela 2. Número de reads total e mapeados (N: não-tumor, T: tumor).

\begin{tabular}{|c|c|c|c|}
\hline Sample & \# total reads & \# mapped reads & \% mapped reads \\
\hline $1 \mathrm{~N}$ & $25,465,297$ & $22,383,996$ & 96 \\
\hline $1 \mathrm{~T}$ & $21,581,898$ & $20,783,368$ & 57 \\
\hline $2 \mathrm{~N}$ & $16,819,523$ & $9,553,489$ & 96 \\
\hline $2 \mathrm{~T}$ & $13,048,291$ & $12,539,408$ & 89 \\
\hline $3 \mathrm{~N}$ & $13,506,679$ & $12,074,971$ & 91 \\
\hline $3 T$ & $13,850,211$ & $12,645,243$ & 88 \\
\hline $4 \mathrm{~N}$ & $22,893,874$ & $20,077,927$ & 93 \\
\hline $4 T$ & $21,060,319$ & $19,670,338$ & 71 \\
\hline $5 \mathrm{~N}$ & $12,668,831$ & $9,032,877$ & \\
\hline
\end{tabular}




\begin{tabular}{|c|c|c|c|}
\hline $5 T$ & $14,164,307$ & $13,073,655$ & 92 \\
\hline $6 \mathrm{~N}$ & $13,639,049$ & $8,565,323$ & 63 \\
\hline $6 \mathrm{~T}$ & $12,944,700$ & $9,223,748$ & 89 \\
\hline $7 \mathrm{~N}$ & $11,636,296$ & $10,728,665$ & 92 \\
\hline $7 \mathrm{~T}$ & $14,659,909$ & $12,944,700$ & 88 \\
\hline $8 \mathrm{~N}$ & $17,334,453$ & $10,626,020$ & 61 \\
\hline $8 \mathrm{~T}$ & $18,715,428$ & $16,525,723$ & 88 \\
\hline $9 \mathrm{~N}$ & $11,485,387$ & $10,061,199$ & 88 \\
\hline $9 T$ & $14,639,918$ & $13,878,642$ & 95 \\
\hline $10 \mathrm{~N}$ & $21,180,027$ & $18,045,383$ & 85 \\
\hline $10 \mathrm{~T}$ & $12,782,377$ & $10,852,238$ & 85 \\
\hline $11 \mathrm{~N}$ & $21,739,600$ & $20,348,266$ & 94 \\
\hline $11 \mathrm{~T}$ & $20,274,193$ & $19,361,854$ & 44 \\
\hline $12 \mathrm{~N}$ & $17,555,622$ & $7,777,141$ & 94 \\
\hline $12 \mathrm{~T}$ & $22,347,733$ & $21,096,260$ & 85 \\
\hline $13 \mathrm{~N}$ & $15,073,484$ & $12,857,682$ & 89 \\
\hline $13 T$ & $19,683,721$ & $17,498,828$ & 85 \\
\hline $14 \mathrm{~N}$ & $20,070,073$ & $16,999,352$ & 98 \\
\hline $14 \mathrm{~T}$ & $24,023,625$ & $23,543,153$ & $\mathbf{8 5}$ \\
\hline Average & $\mathbf{1 7 , 1 8 2 , 9 9 5}$ & & \\
\hline & & & \\
\hline & & & \\
\hline
\end{tabular}

A cobertura média do transcriptoma obtido no sequenciamento das amostras de tecido pancreático na plataforma HiSeq foi de 3,4 Gb.

\section{IV.3 Montagem do transcritoma de tecido pancreático}

Como descrito em detalhe na seção Metodologia (figuras 5 e 6), e com o objetivo de tentar reconstruir transcritos raros expressos em tecido neoplásico e não tumoral, as montagens das amostras tumorais e não-tumorais foram feitas separadamente com o programa StringTie (Pertea et al. 2015), resultando na reconstrução de 79.498 genes (incluindo 189.837 transcritos) nas bibliotecas de tecido não tumoral e 104.452 genes (incluindo 242.093 transcritos) nas bibliotecas de tecido tumoral.

Aproximadamente $80 \%$ dos transcritos tiveram FPKM menor que 0,3 (figura 8), sendo a maior parte deles mono-exônicos (figuras 9 e 10). Para minimizar a presença de possíveis artefatos resultantes de pre-mRNAs nas bibliotecas de RNA total, foram excluídos os transcritos que apresentaram somente um éxon e estavam dentro de 
coordenadas de genes multi-exônicos do GENCODE considerando uma margem de +-500nt (down-stream e up-stream respectivamente). Esse filtro resultou em uma redução de $\sim 33 \%$ e $\sim 15 \%$ dos potenciais novos transcritos representados nas montagens de bibliotecas de amostras de tecido não tumoral (figura 9) e tumoral (figura 10) respectivamente.

a)

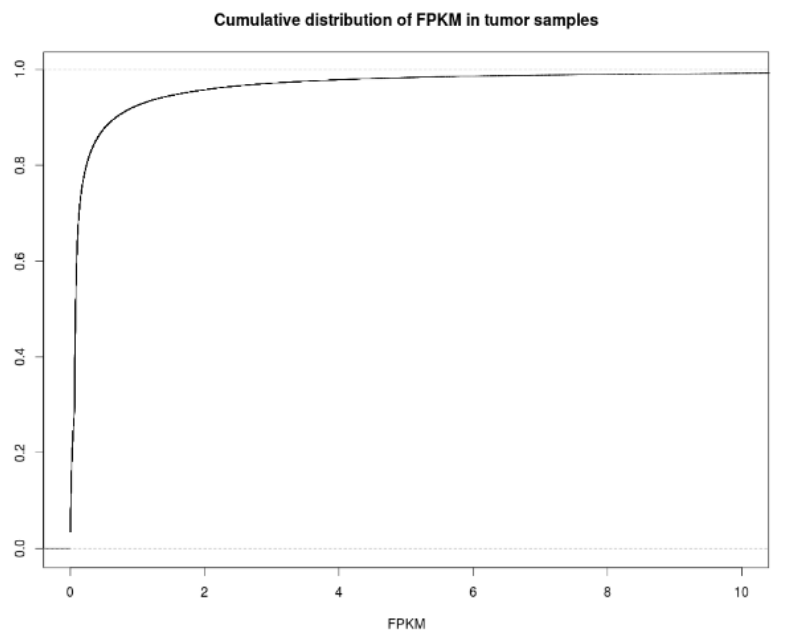

b)

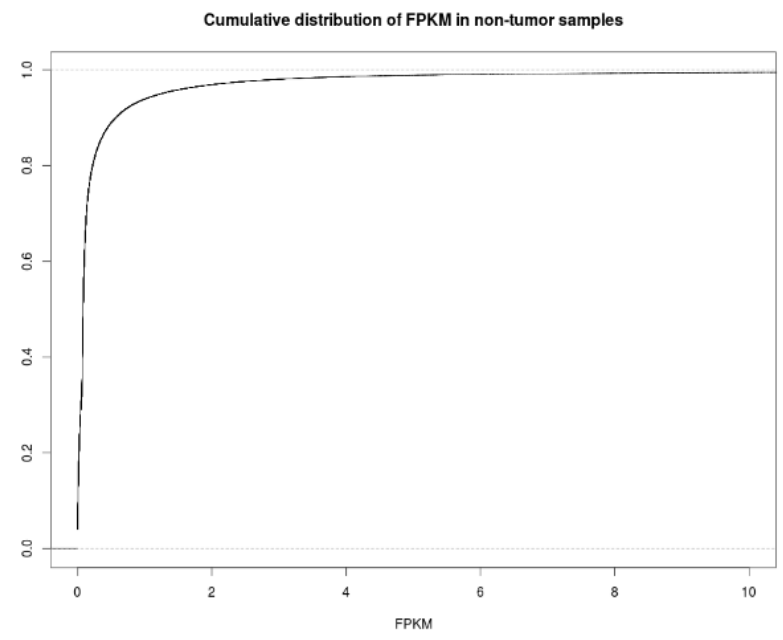

Figura 8. Distribuição cumulativa da abundância (em FPKM) de transcritos detectados em amostras tumorais (a) e não tumorais (b). FPKM em eixo "x" e proporção de transcritos no eixo "y". 


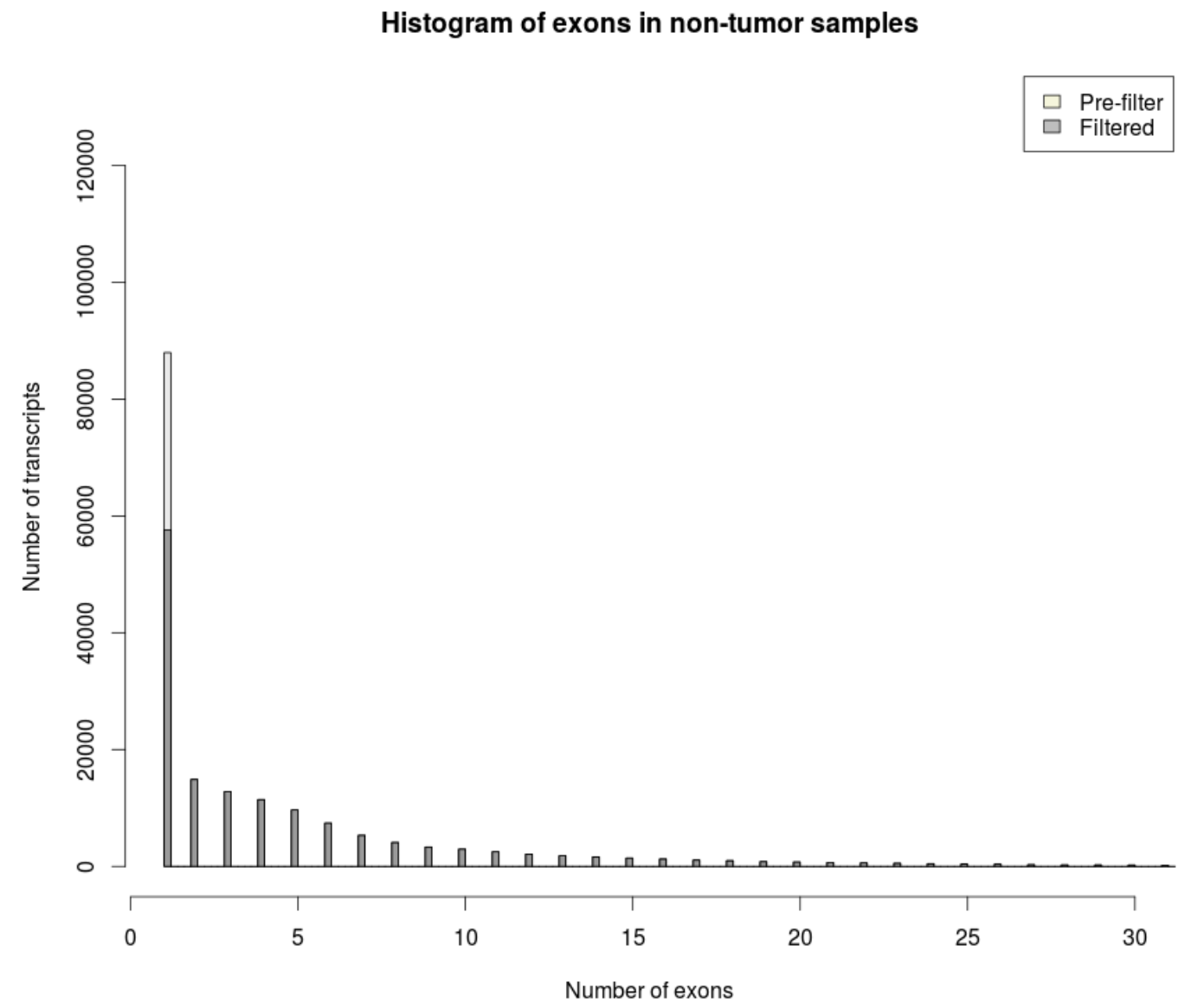

Figura 9. Histograma de número de éxons na montagem não-tumoral antes e depois da filtragem de transcritos mono-exónicos com coordenadas dentro de genes multi-exônicos anotados no GENCODE (considerando uma margem +-500nt, down-stream e up-stream respectivamente). 


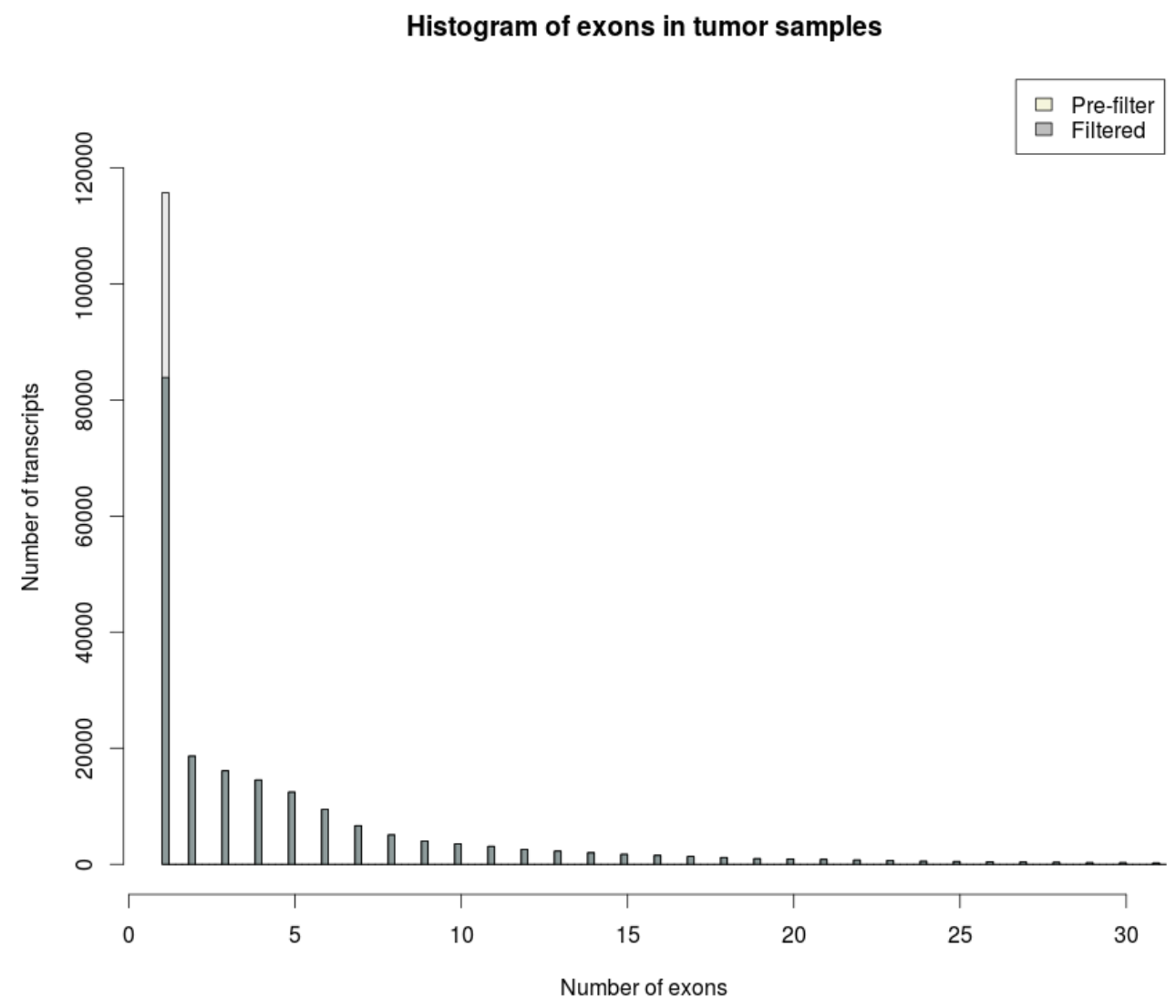

Figura 10. Histograma de número de éxons na montagem tumoral antes e depois da filtragem de transcritos mono-exônicos com coordenadas dentro de genes multi-exônicos anotados no GENCODE (versão 19) (considerando uma margem +-500nt, down-stream e up-stream respectivamente).

Considerando a grande porcentagem de transcritos com baixa expressão, foram feitas análises para estabelecer um valor de corte conservador a fim de restringir a presença de artefatos e priorizar um conjunto de transcritos mais confiável para seleção de candidatos para validação experimental, sem perder muita informação relevante.

As montagens de bibliotecas derivadas de amostras não-tumorais e tumorais foram comparadas com o catálogo de referência GENCODE (versão 19) usando o programa Cuffcompare (Trapnell, Roberts, et al. 2012), permitindo a identificação de três categorias de transcritos (classes "j", " $u$ " e " $x$ ") que poderiam conter novos IncRNAs. Essa nomenclatura é definida pelo programa Cuffcompare e utiliza as anotações do GENCODE. A categoria "j" compreende isoformas de genes conhecidos que compartilham pelo menos um sítio de splicing com o transcrito de referência (novel isoform). A categoria "u" corresponde a transcritos desconhecidos intergênicos (intergenic). Enquanto que a classe " $x$ " tem sobreposição com algum gene conhecido 
na fita oposta (antisense). Foram estabelecidos diferentes cutoffs de FPKM, e para cada um deles foi verificada a quantidade de transcritos de cada categoría (figura 11). Usando um FPKM > 0,1 o número de potenciais novas isoformas e antisensos permanece relativamente constante (em relação a cutoffs menores). Usando esse mesmo filtro, apenas $29 \%$ e $19 \%$ dos potenciais novos transcritos intergênicos reconstruídos a partir das bibliotecas de tecido não-tumoral e tumoral permaneceram na análise (figura 11).

a)

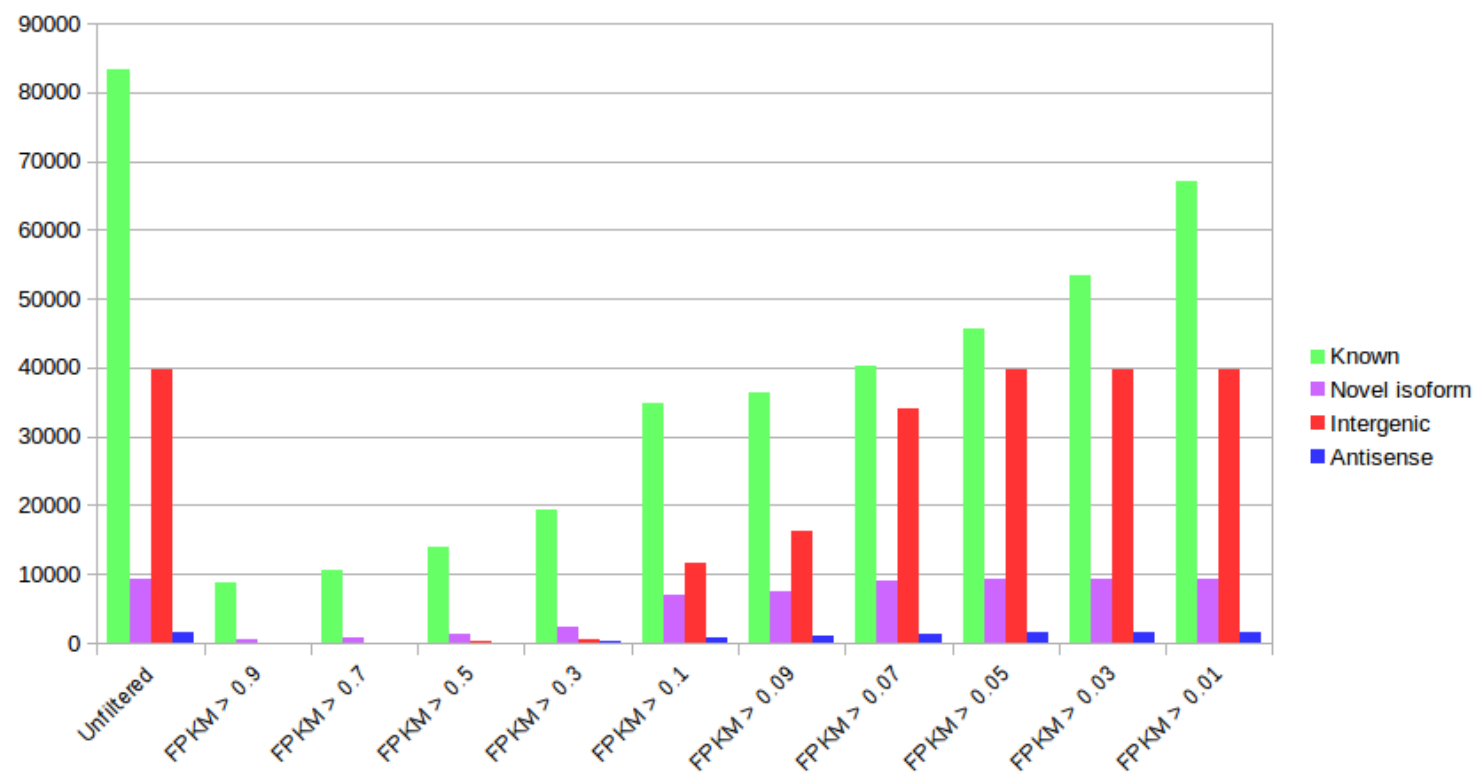

b)

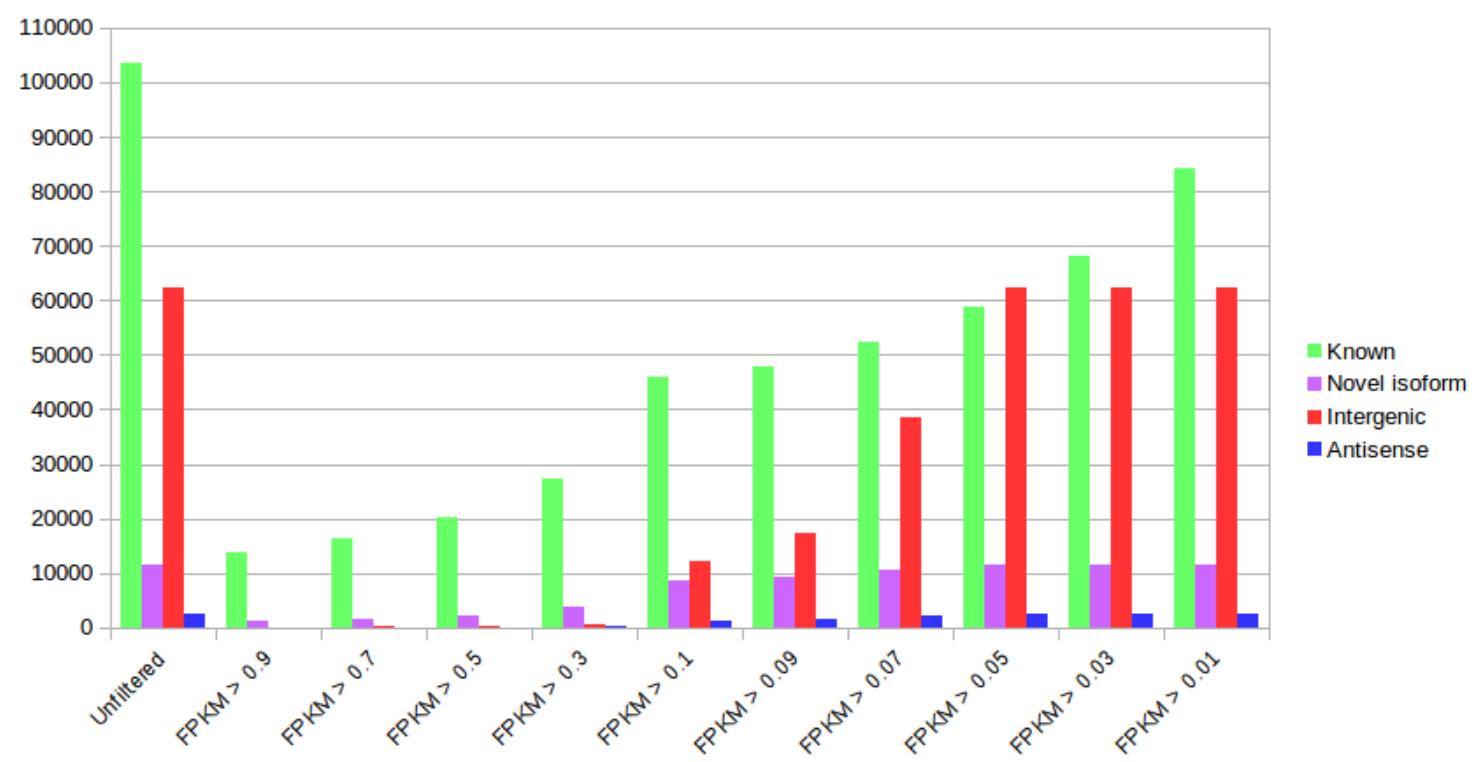


Figura 11. Seleção de cutoff por FPKM da montagem não-tumoral (a) e tumoral (b). Comparação dos transcritos com catálogo de referência GENCODE (versão 19) realizada usando o programa Cuffcompare (Trapnell et. al., 2012).

Também foi avaliado o efeito da abundância sobre a proporção de novos transcritos mono e multi-exônicos. A figura 12 apresenta o número de transcritos nas diferentes classes em função do FPKM, considerando somente aqueles com tamanho genômico maior que 200 nucleotídeos. Dados semelhantes foram observados para as bibliotecas de tumor (resultado não mostrado).

a)

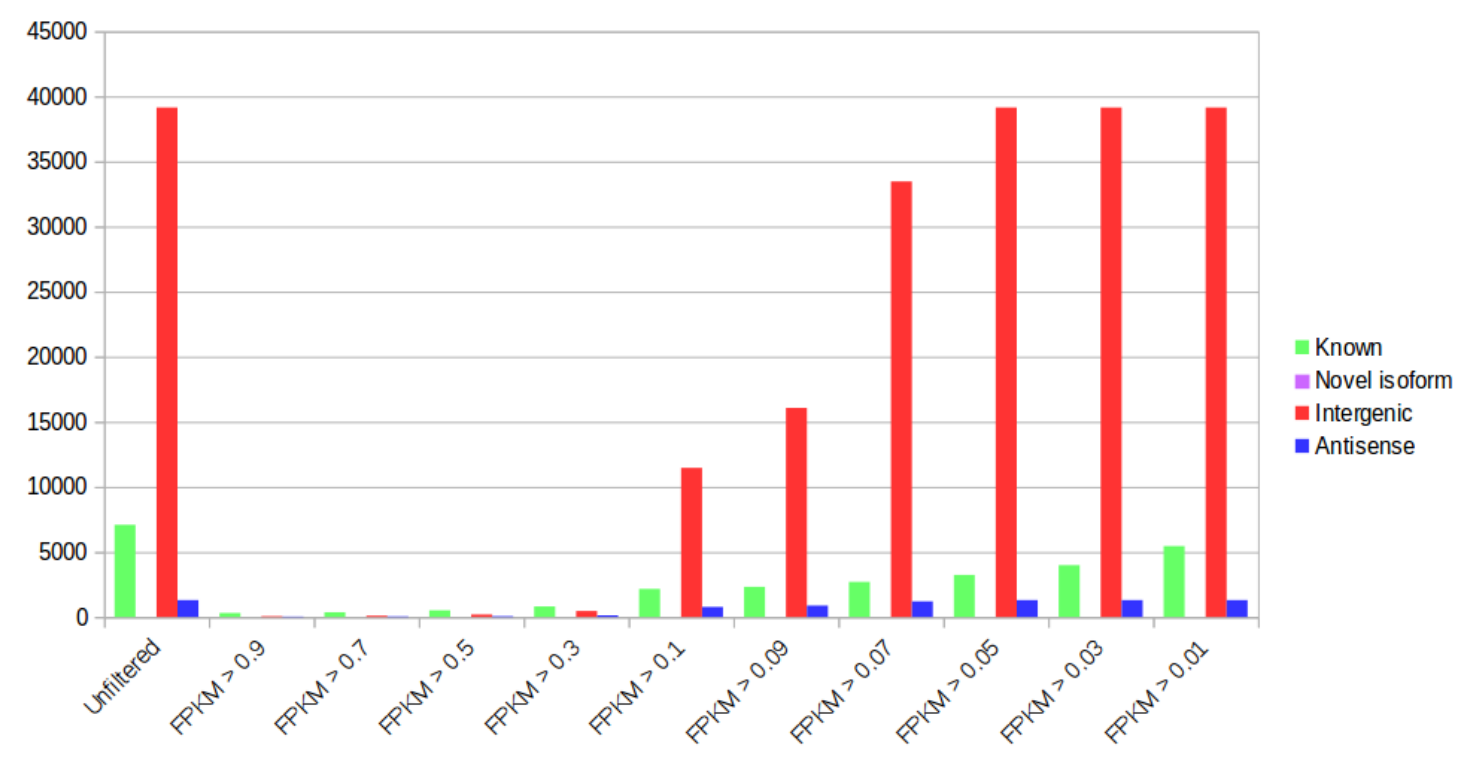

b) 


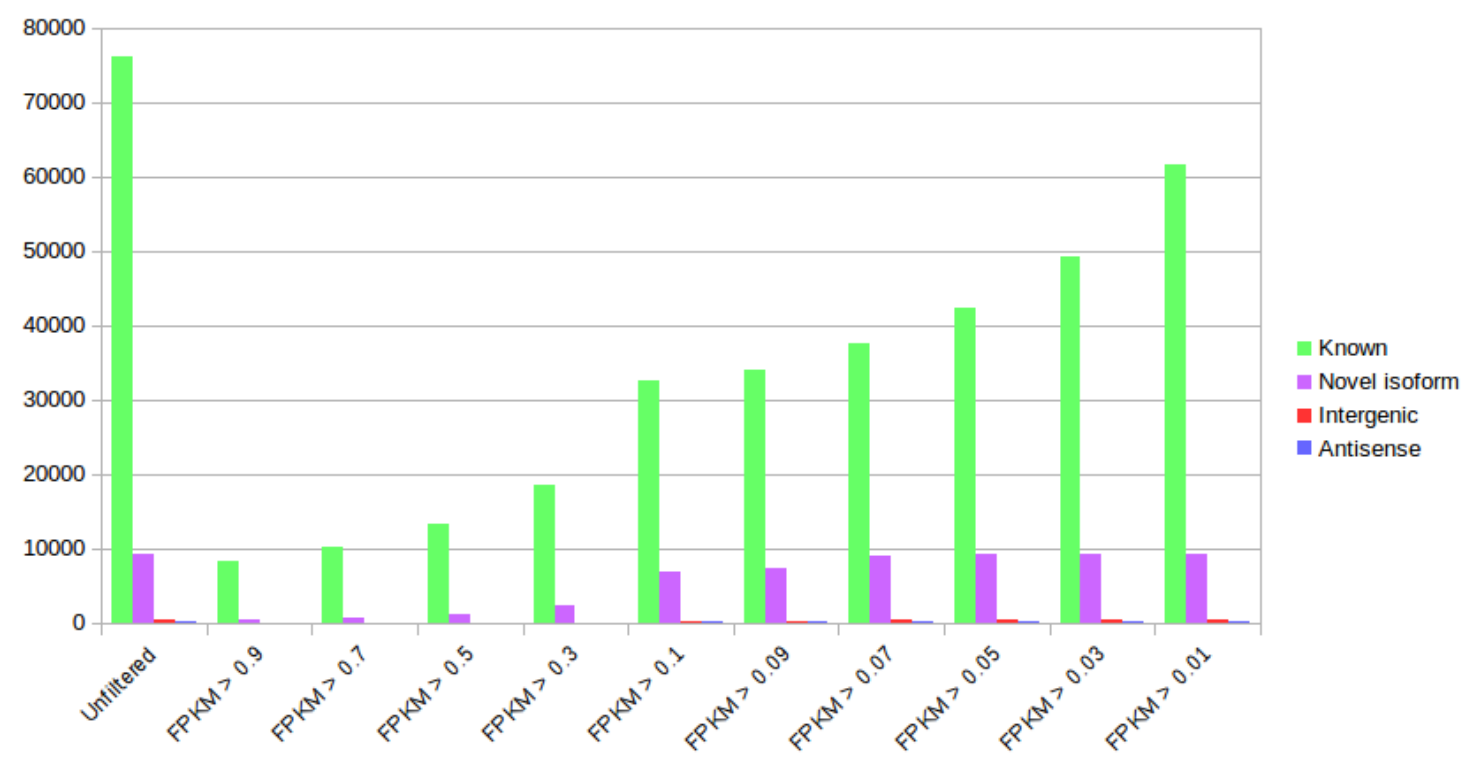

Figura 12. Número de transcritos mono-exônicos (a) e multi-exônicos (b) em função do FPKM na montagem de bibliotecas de tecido não-tumoral de pâncreas.

Como é possível observar na figura 12.a, a grande maioria dos novos transcritos mono-exônicos (82\%) são intergênicos. Fazendo um corte por FPKM > 0,3 restariam 816 transcritos já anotados no GENCODE (11\% do total detectado), 462 transcritos "Intergenic" (1\%) e 132 transcritos "Antisense" (10\%), entanto que com FPKM > 0,1 sobrariam 2158 transcritos já anotados no GENCODE (30\%), 11461 "Intergenic" (29\%) e 779 "Antisense" (59\%), enquanto que que não foram encontradas potenciais novas isoformas mono-exônicas. Optamos por usar um filtro de FPKM > 0,1 pois este valor de cutoff resultou em um número maior de novos transcritos e novas isoformas para seguir com as análises subsequentes.

Posteriormente foi utilizado o programa Cuffcompare (Trapnell, Roberts, et al. 2012) para unificar as duas montagens em um arquivo e fazer a anotação em relação ao GENCODE (versão 19) e MiTranscriptome (lyer et al. 2015), um catálogo com mais de 6.500 amostras e $\sim 91.000$ genes, sendo a maioria IncRNAs previamente não descritos.

É plausível que trechos correspondentes à regiões UTRs de genes sejam reconstruídas de forma fragmentada e incompleta, levando a sua anotação errônea como um transcrito intergênico. Para minimizar esse problema, foi aplicado o seguinte filtro considerando só os intergênicos. As coordenadas genômicas dos transcritos mono-exônicos classificados como "Intergenic" pelo programa Cuffcompare foram cruzadas com as coordenadas do conjunto de referência GENCODE usando a ferramenta Bedtools, e aqueles transcritos com uma distância em relação com genes conhecidos era menor que $1 \mathrm{~kb}$ foram excluídos. 
Após essa filtragem permaneceram na análise 90.522 transcritos referentes a 41.095 genes ("merged set", tabela 3), dos quais 58\% deles estão anotados no GENCODE, 16\% correspondem a "potential novel isoform", 21\% "Intergenic", 2\% "antisense" e $3 \%$ outras categorias. O tamanho médio dos transcritos reconstruídos em nossa montagem foi de $\sim 4.200$ nucleotídeos, enquanto as potenciais novas isoformas tem um tamanho maior (média 15.321nt). Acreditamos que o maior tamanho médio das novas isoformas de transcritos seja influenciado pela presença de pré-mRNA residual presente na fração de RNA total depletado de rRNA usada para a construção das bibliotecas de cDNA. Em relação ao número de éxons, mais do $90 \%$ dos intergênicos e antisensos detectados são mono-exônicos, enquanto que os conhecidos

e potenciais novas isoformas têm distribuições mais variáveis. A expressão média dos IncRNAs é notoriamente mais baixa que a de mRNAs codificadores de proteínas. Em função do grau de cobertura alcançado durante o sequenciamento das bibliotecas de RNAseq, que favorece a caracterização de RNAs mais abundantes, optamos por nos concentrar nas análises subsequentes em IncRNAs e isoformas de splicing multiexônicos. Nossa hipótese é que transcritos processados pela maquinaria celular tem maior possibilidade de serem biologicamente relevantes e portanto teriam prioridade para estudos funcionais. Os novos transcritos intergênicos mono-exônicos constituirão um recurso para exploração futura em combinação com novos dados gerados por outros grupos.

Para minimizar possíveis artefatos resultantes da presença de RNA imaturo nas bibliotecas de RNA-seq foram aplicados filtros baseados na distribuição de tamanho de éxons em genes conhecidos anotados no GENCODE (figura 13).

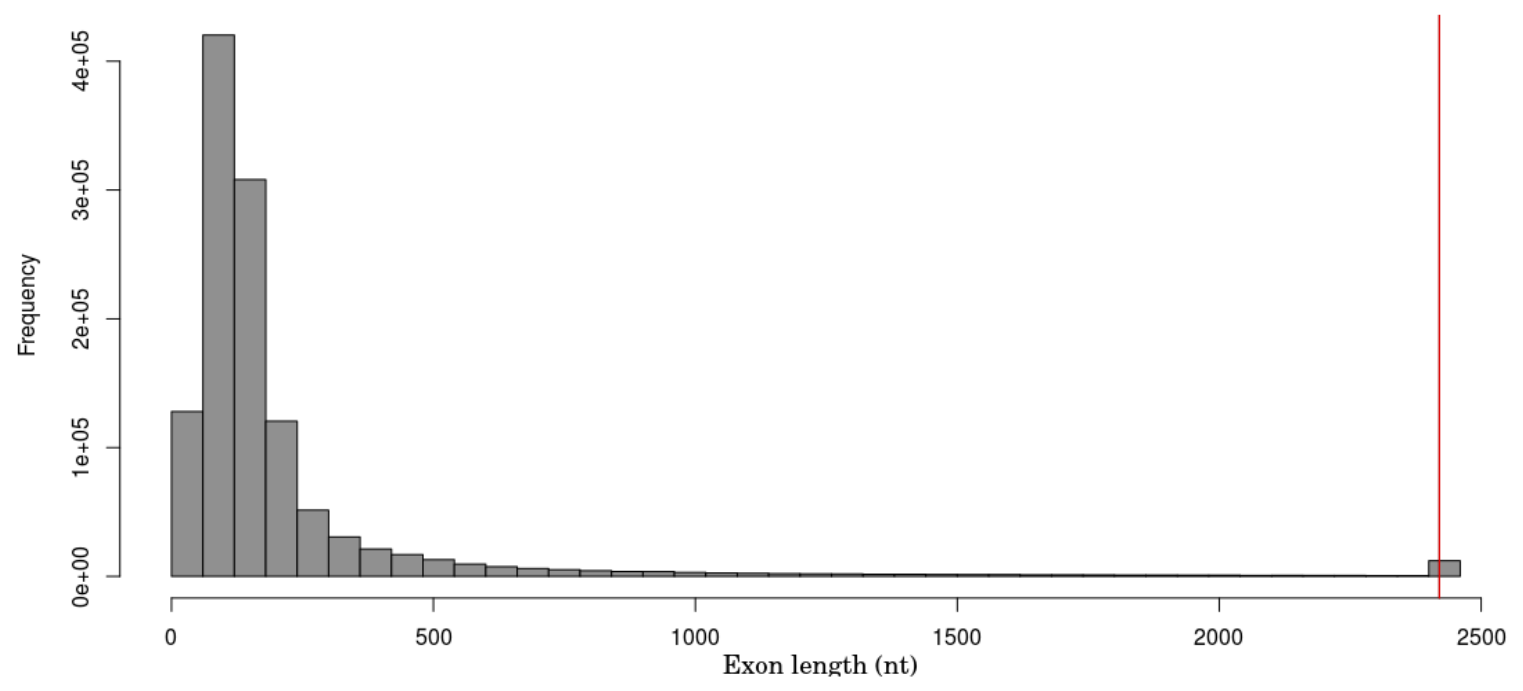

Figura 13. Histograma de tamanho dos éxons do catálogo GENCODE (v.19). Nota-se que $99 \%$ dos éxons possuem um tamanho menor que 2.420nt (linha vermelha). 
Considerando que o 99\% dos éxons neste catálogo têm tamanho menor que 2.420nt, foram filtradas as potenciais novas isoformas com éxons maiores que este valor que não foram confirmadas no catálogo MiTranscriptome (lyer et al. 2015). Para evitar outros possíveis artefatos só foram considerados os novos transcritos intergênicos ou antisensos que apresentem evidências de splicing (multi-exônicos). Após as filtragens, restou um conjunto com 41,341 transcritos anotados no GENCODE (inclui as categorias "protein-coding", "processed transcript", "pseudogene", "lincRNA" e "antisense"), 6.187 novas isoformas, 339 novos intergênicos e 184 novos antisensos ("filtered set b", tabela 3).

Tabela 3. Reconstrução do transcritoma pancreático. Número de loci e transcritos detectados nas diferentes etapas da montagem. Primeiro, os transcritos das amostras tumorais e não tumorais foram filtrados para remover RNAs curtos e de baixa expressão ("Filtered set a"). A continuação as montagens foram combinadas para gerar o transcritoma do pâncreas ("Merged set") que foi filtrado para remover novas isoformas com exons aberrantes ( $n=8.080)$ e outros possíveis artefatos (ver Metodologia para mais detalhes). Transcritos intergênicos e antisensos não anotados mono-exônicos ( $n=18,453$ and 1,515, respectively) não foram considerados para análises subsequentes. O conjunto final ("Filtered set b") contém 41.341 transcritos conhecidos do GENCODE correspondentes com 17.834 loci, assim como 6.710 transcritos não anotados ( $11,3 \%$ do total) de 4.359 loci (22,3\% do total). A maioria dos transcritos não anotados (>90\%) são variantes de splicing de genes conhecidos, uma proporção menor intergênicos (5\%) ou antisensos (3\%) em relação aos transcritos do GENCODE.

\begin{tabular}{|l|c|c|c|c|}
\hline & \multicolumn{2}{|c|}{ LOCI } & \multicolumn{2}{c|}{ TRANSCRIPTS } \\
\hline & Non-tumor & Tumor & Non-tumor & Tumor \\
\hline Total & 66,307 & 92,761 & 149,586 & 198,830 \\
\hline Filtered set (a) & 28,081 & 30,625 & 58,762 & 73,613 \\
\hline Merged set & 41,095 & 90,522 \\
\hline Filtered set (b) & 21,668 & 62,474 \\
\hline Annotated GENCODE & 17,834 & 41,341 \\
\hline Protein-coding & 13,560 & 30,771 & \\
\hline Processed transcript & 3,951 & 5,993 & 1,578 \\
\hline Pseudogene & 1,540 & \multicolumn{2}{|c|}{} \\
\hline
\end{tabular}




\begin{tabular}{|r|c|c|}
\hline lincRNA & 1,076 & 1,473 \\
\hline Antisense RNA & 1,196 & 1,526 \\
\hline Unannotated & 4,358 & 6,710 \\
\hline splicing variant & 3,935 & 6,187 \\
\hline intergenic RNA & 298 & 339 \\
\hline antisense RNA & 146 & 184 \\
\hline Other $^{\star}$ & 8,770 & 14,423 \\
\hline
\end{tabular}

* "Other" inclui: miscRNAs, 3 prime overlapping ncRNAs, IG genes, Mt rRNA, non stop decay, retained intron, nonsense mediated decay, sense overlapping, snoRNA, snRNA, TR genes, possible pre-mRNA fragments, intronic RNAs, possible polymerase run-on fragments.

As distribuições da contagem média de reads (base mean), tamanho e número de éxons de cada categoria estão representadas na figura 14. Percebem-se dois tipos de transcritos que apresentam distribuições semelhantes: novas isoformas detectadas em nosso trabalho e os genes codificadores anotados no GENCODE (roxo e preto na figura 14, respectivamente). Eles apresentam maior expressão (figura 12.a), maiores tamanhos (figura 14.b) e mais exons (figura 14.c), quando são comparados com os transcritos intergênicos (vermelho, laranja) e antisenso (azul escuro, azul claro), tanto novos quanto anotados no GENCODE. Essa observação coincide com dados da literatura onde RNAs não codificadores longos apresentam um número menor de exons e menor expressão que genes codificadores de proteína (Derrien et al. 2012; Igor Ulitsky 2013). 

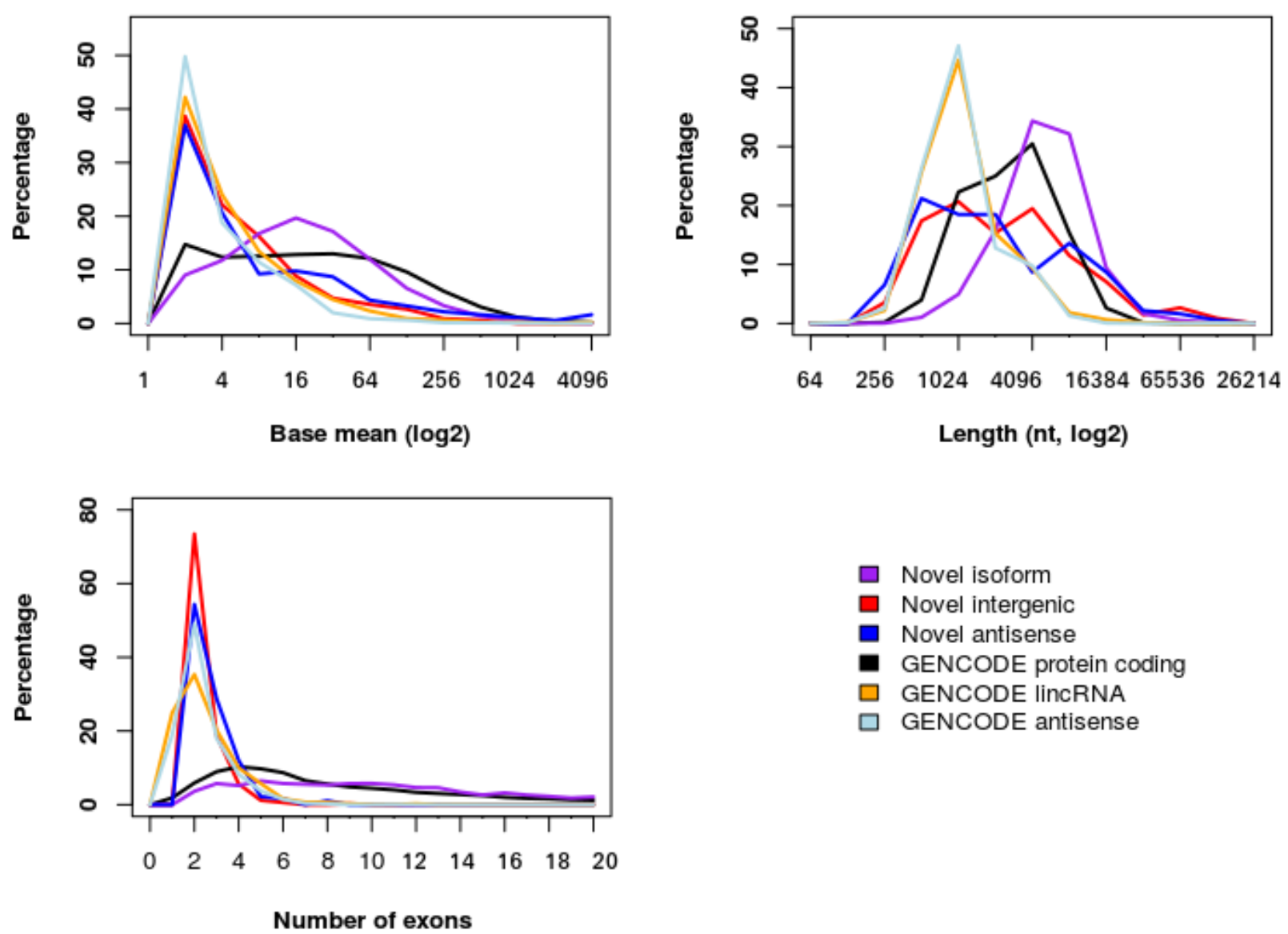

Figura 15. Distribuições de "base-mean", tamanho e número de éxons dos transcritos filtrados. Roxo: novas isoformas; Vermelho: novos intergênicos; Azul: novos antisensos; Preto: codificantes anotados no GENCODE; Laranja: lincRNAs anotados; Azul claro: antisensos anotados.

Para verificar a sobreposição do transcritoma detectado neste estudo com transcritos já detectados anteriormente na literatura foi feita a comparação com o catálogo MiTranscriptome (lyer et al. 2015), trabalho no qual foram analisadas 7.256 bibliotecas de tecidos tumorais, normais e linhagens celulares, chegando numa reconstrução com 91.013 genes (sendo 68\% deles IncRNAs). Aproximadamente 47\% das 6.187 potenciais novas isoformas de splicing foram também detectados no MiTranscriptome (MT), assim como 52\% dos 339 potenciais novos transcritos intergênicos e 43\% dos 184 novos antisensos (figura 16). 


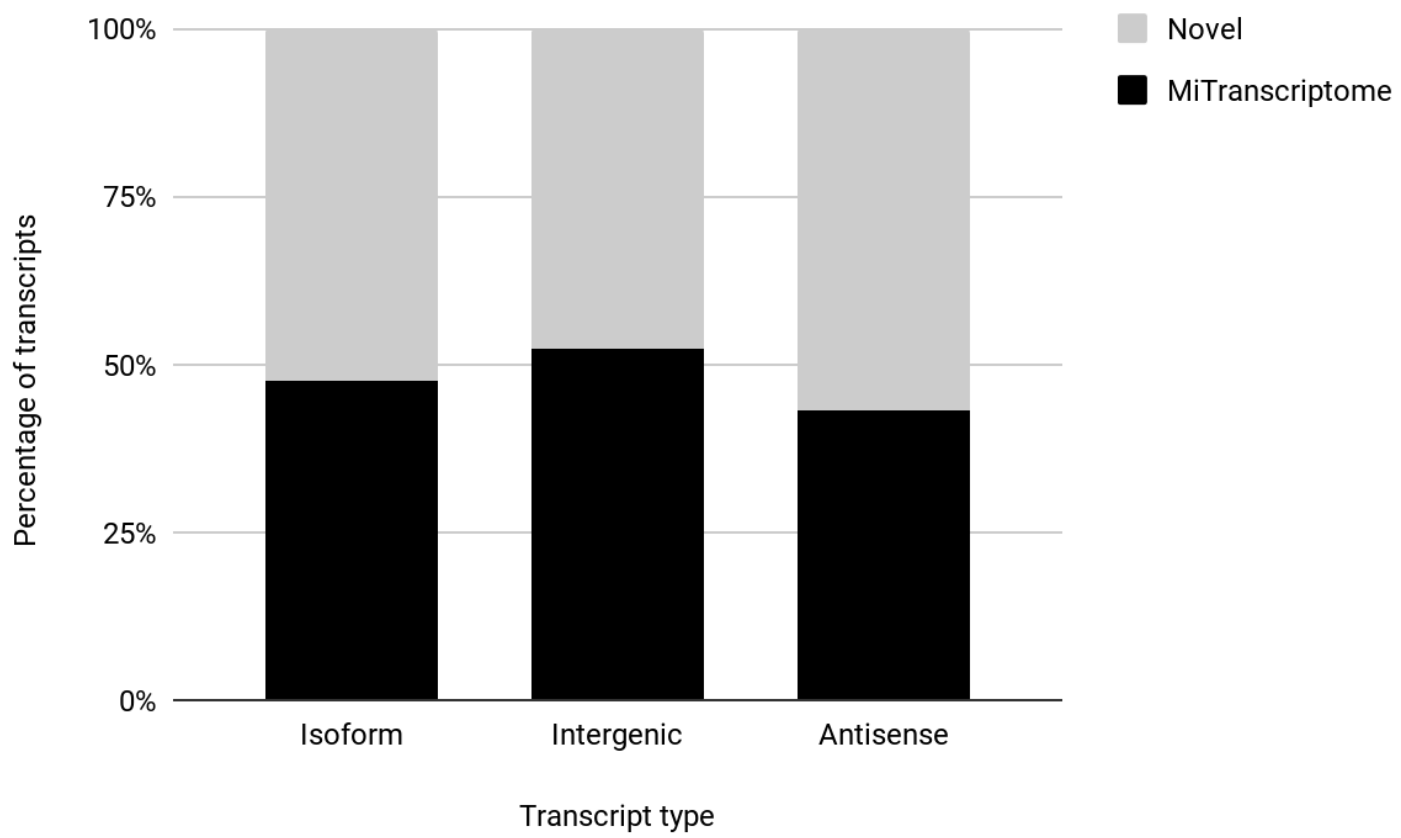

Figura 16. Comparação da montagem final dos dados de RNAseq de tecidos pancreáticos com o catálogo MiTranscriptome (MT).

Para facilitar a inspeção visual do transcritoma foram criados tracks customizados num servidor local:

http://genome.Ibi.iq.usp.br/cgi-bin/hgTracks?hgS_doOtherUser=submit\&hgS_otherUserName=j uliososa\&hgS_otherUserSessionName=paper_pdac

Os arquivos bam foram previamente ordenados e indexados usando a ferramenta Samtools (Heng Li et al. 2009), e convertidos ao formato BigWig. Na figura 17 é possível observar os genes do catálogo Ensembl (em vermelho), transcritos reconstruídos na presente montagem (em preto) e uma nova variante de splicing do gene reparador do DNA XRCC4 (em lilás) que foi detectada em nosso trabalho (TCONS_00069307). Na parte inferior encontram-se os "BigWig" contendo os reads mapeados correspondentes às amostras tumorais (azul) e não-tumorais (verde). 


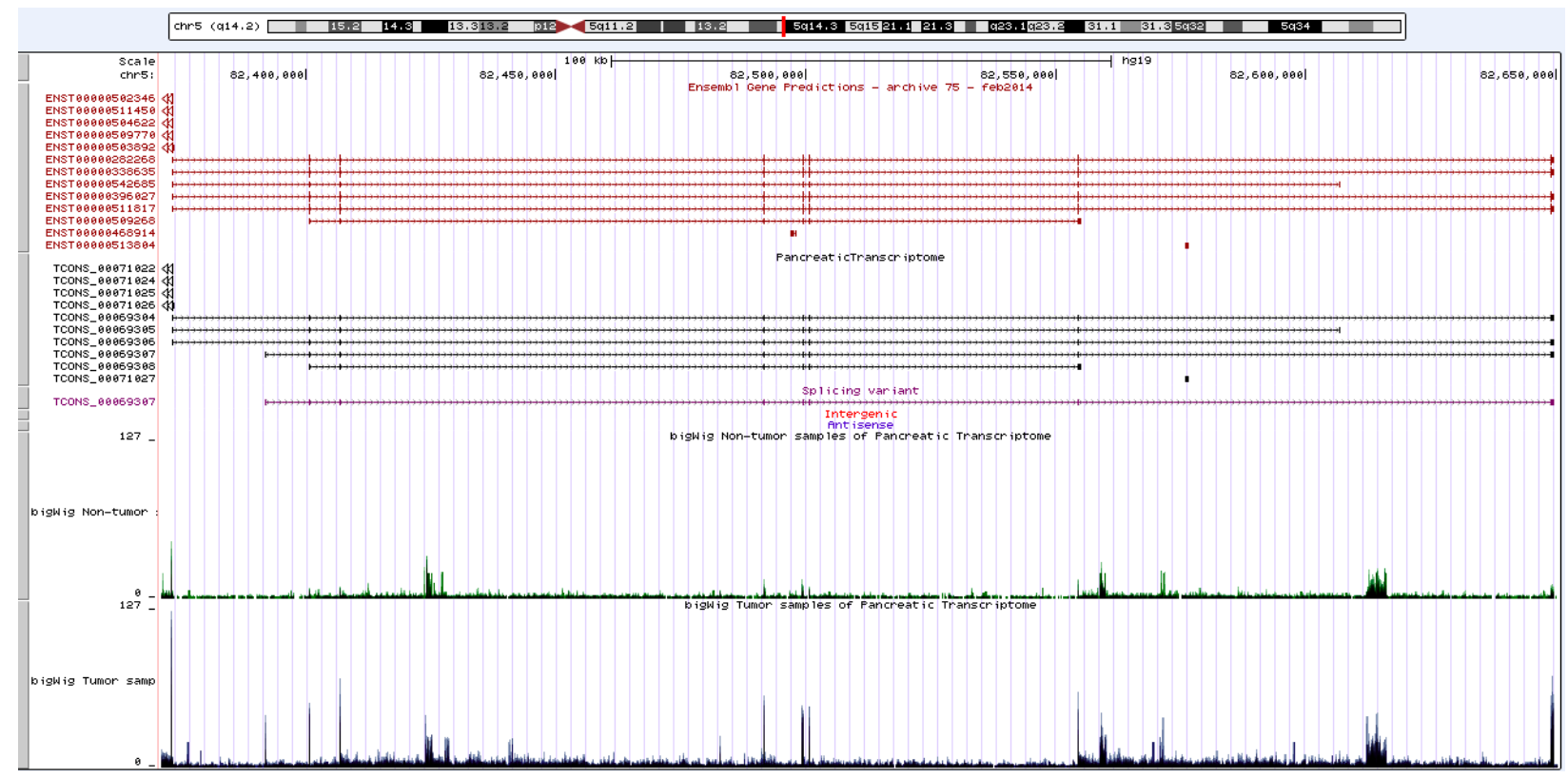

Figura 17. Visualização da reconstrução do transcritoma utilizando tracks customizados no UCSC Genome Browser. Em vermelho estão representados transcritos anotados no GENCODE, em preto transcritos reconstruídos do pâncreas e em lilás uma nova isoforma do gene XRCC4.

\section{IV.4 Anotação in silico dos novos transcritos}

Foram avaliadas diferentes características dos novos transcritos (6187 isoformas de splicing, 339 RNAs intergênicos e 184 RNAs antisensos), entre elas a presença de marcas regulatórias, tipos de splicing, potencial codificador e conservação evolutiva.

\section{IV.4.1 Potencial codificador e conservação evolutiva}

Foi estimado o grau de conservação evolutiva do conjunto de potenciais novos transcritos com o programa PhyloCSF (Lin, Jungreis, and Kellis 2011). O resultado é um "score" (em decibans) que expressa as probabilidades relativas da sequência de um dado transcrito estar sob um modelo que explica a evolução de códons em uma região codificadora versus um modelo de evolução de tripletes em regiões não codificadoras, baseado no alinhamento de sequências conservadas (Lin, Jungreis, and Kellis 2011). Por exemplo, um "score" de 10 decibans significa que o modelo codificador é 10:1 mais provável que o não codificador; 20 decibans, 100:1; 30 decibans, 1000:1; e assim sucessivamente. Um "score" de -20 indica que o modelo não codificador é 100:1 mais provável, e um valor de 0 significa que os dois modelos são igualmente prováveis.

$\mathrm{Na}$ figura 18 pode-se observar os histogramas dos "scores" separados por 
categorias dos transcritos. A grande maioria dos novos antisensos e intergênicos estão representados por sequências não codificadoras, enquanto que as novas isoformas contém um número semelhante de codificadores e não codificadores. Esses resultados confirmam o potencial para identificação de novos IncRNAs nos dados gerados no projeto.

\section{Isoform}

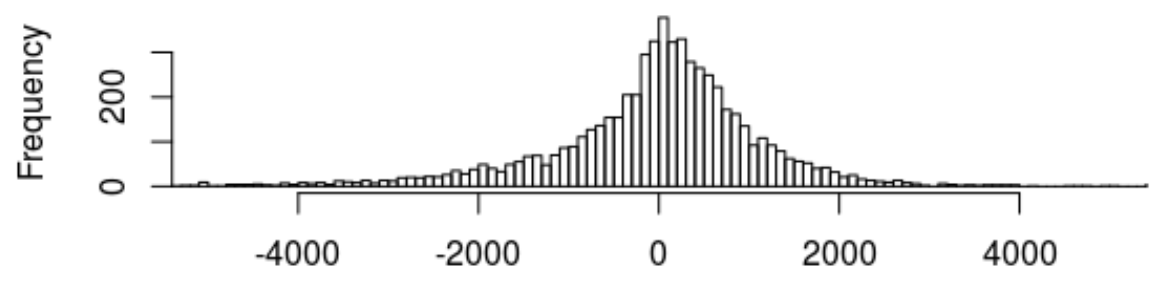

PhyloCSF score

\section{Intergenic}

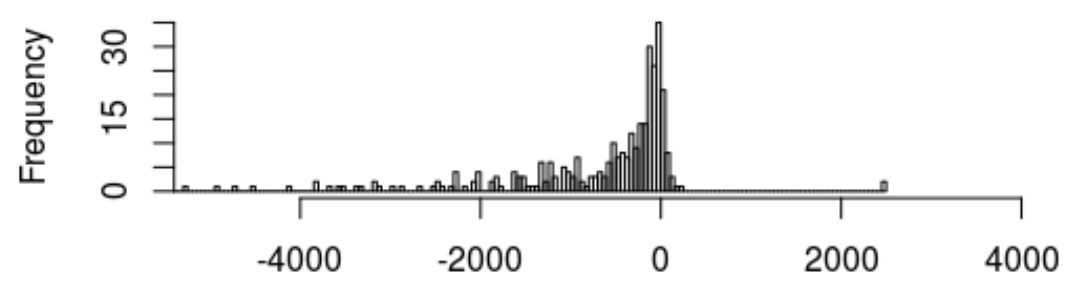

PhyloCSF score

\section{Antisense}

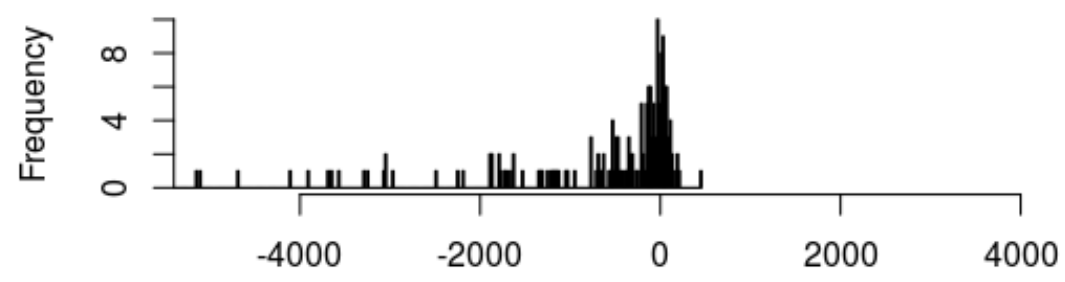

PhyloCSF score

Figura 18. Histogramas dos "score" (em decibans) gerados pelo programa PhyloCSF para as diferentes categorías de transcritos (novas isoformas de splicing, novos transcritos intergênicos e novos transcritos antisenso).

Para uma melhor interpretação dos resultados, os "scores" foram divididos na seguinte escala: Non-coding (PhyloCSF $<=-5$ ), Non-coding weak (PhyloCSF $<0 \&>$ 
-5), Coding weak (PhyloCSF $>=0 \&<5$ ) e Coding (PhyloCSF $>=5$ ). Os resultados, representados na figura 7 , indicam que $-75 \%$ dos novos transcritos antisenso e mais do que $85 \%$ dos novos transcritos intergênicos, correspondem a um modelo de RNA não codificador, enquanto que $\sim 52 \%$ das novas isoformas são possivelmente codificadoras.

Outra abordagem utilizada para estimar o potencial codificador foi o "CPC calculator" (Kong et al. 2007) (figura 19). Esse programa aplica um classificador de aprendizado de máquina SVM ("Support Vector Machine") incorporando características das ORFs ("Open Reading Frame") e do alinhamento com sequências de proteínas conhecidas, para estimar o potencial codificador do transcrito. Aqui valores menores que zero indicam um baixo potencial codificador, e os transcritos com valores entre -1 e 1 são considerados "weak non coding" ou "weak coding" respectivamente (Kong et al. 2007). Os resultados do programa CPC indicam que mais do $90 \%$ das novas isoformas são codificadoras, enquanto que $\sim 60 \%$ dos antisensos são não codificadores, assim como $\sim 52 \%$ dos intergênicos.
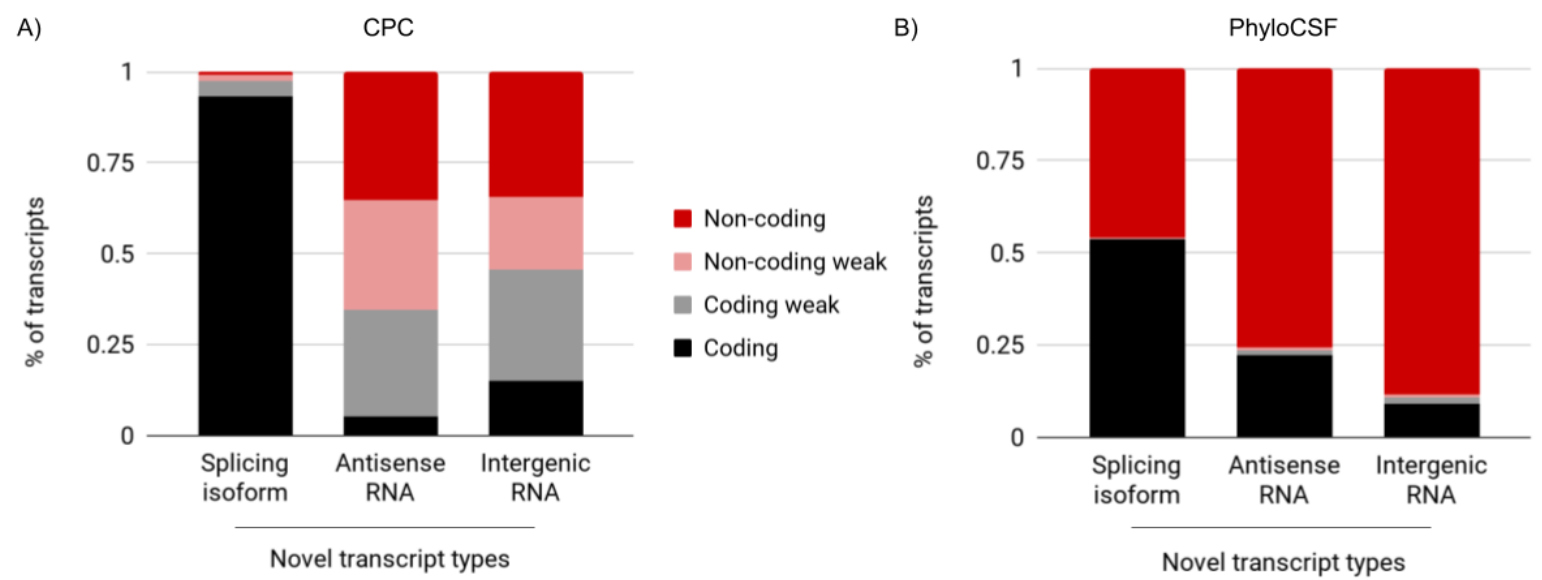

C)

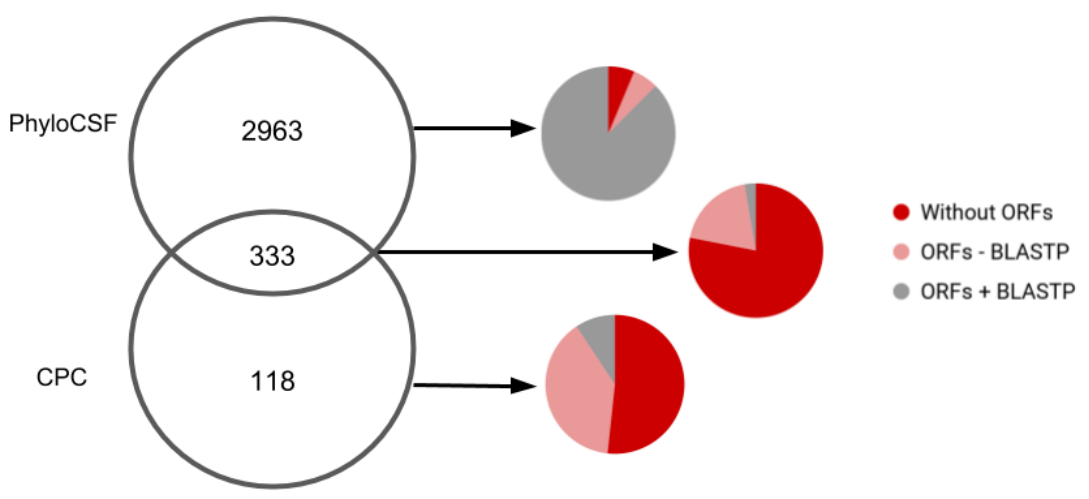

Figure 19. Potencial codificador dos novos transcritos (intergênicos, antisensos e variantes de splicing). O potencial codificador de proteína foi estimado utilizando CPC (Kong et al. 2007) (panel A) e PhyloCSF (Lin, Jungreis, and Kellis 2011) (panel B), e foi agrupado como 
"protein-coding", "coding/non-coding weak" e "non-coding" segundo os scores calculados com cada programa (ver Metodologia para mais detalhes). Panel C; diagrama com a intersecção entre os transcritos "non-coding" (score < 0) detectado pelos programas CPC e PhyloCSF. A análise das ORFs ("Open Reading Frame") foi feita com TransDecoder (https://transdecoder.github.io) e a similaridade com o banco de dados Swissprot foi avaliada usando BLASTP (Altschul et al. 1990).

Para avaliar a concordância entre os resultados gerados pelos programas PhyloCSF e CPC, foram cruzadas as listas de transcritos com valores menores que zero (potenciais não codificadores) (figura 19.c). Foram encontrados 333 transcritos com baixo potencial codificador comuns às duas análises, enquanto que 2963 foram determinados como não codificadores exclusivamente pelo programa PhyloCSF e 118 pelo CPC. A principal diferença entre os dois programas fica evidente na classificação das novas variantes de splicing, enquanto que CPC identifica a maioria deles como "coding" ou "coding-weak", PhyloCSF estima que aproximadamente a metade deles são "non-coding" a pesar de que a maioria possue ORFs maiores que 100 aminoácidos com similaridade significativa com proteínas conhecidas, como indicado na figura 17.c (direita).

\section{IV.4.2 Marcas regulatórias da cromatina}

Para documentar as características genômicas dos novos transcritos e obter evidências de que estes sejam gerados de forma regulada no tecido pancreático, foi feita uma análise procurando marcas epigenéticas que indiquem possíveis regiões regulatórias, usando dados de ChIP-Seq disponibilizados pelo projeto Encode (http://screen.encodeproject.org/). Os sítios de hipersensibilidade a DNase são classificados em três grupos: a) "Promoter-like signature": com alto enriquecimento de H3K4me3; b) "Enhancer-like signature": alto H3K27Ac; c) "CTCF-only": os restantes que somente possuem enriquecimento de sítios de ligação da proteína CTCF.

Como é possível observar na figura 20, uma fração significativa dos novos transcritos possui marcas relacionadas com regiões promotoras e enhancers a uma distância de até 1.000 nt desde o sítio de início da transcrição (TSS). Eles representam $17,1 \%$ / 58,7\% dos intergênicos, 46,2\% / 44,5\% dos antisenso e 60,6\% / 31,5\% das novas isoformas, considerando promotor e enhancer respectivamente. No caso do CTCF as marcas encontram-se espalhadas uniformemente nos diferentes tipos de transcritos, sendo discretamente mais concentradas perto do TSS em 10,8\% dos antisensos. 

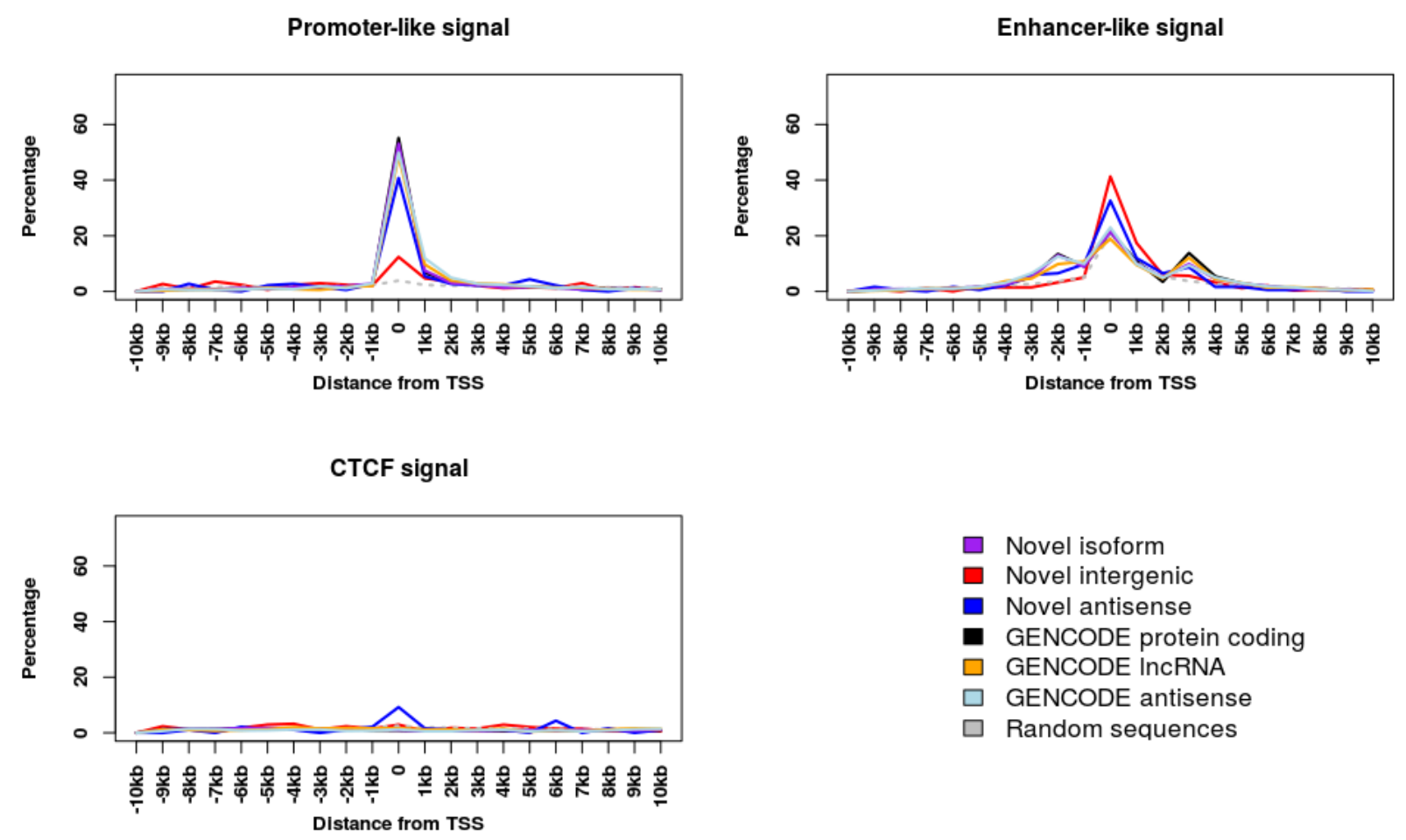

Figure 20. Identificação de elementos regulatórios. Distribuições das distâncias entre os TSSs (sítios de início da transcrição) e marcas associadas a regiões regulatórias promotoras, enhancers e insulator (CTCF).

\section{IV.4.3 Variantes de splicing alternativo}

Foram determinados os novos eventos de splicing das 6187 isoformas utilizando o programa SUPPA (Alamancos et al. 2014) (figura 19.a), encontrando-se 1.083 sítios alternativos 3' (A3 16.6\%), 1.006 sítios alternativos 5' (A5 15,4\%), 538 primeiro éxon alternativo ( $A F$ 8,3\%), 87 último éxon alternativo ( $A L$ 1,3\%), 62 éxons mutuamente excludentes (MX 1,0\%), 1.831 retenções de íntrons (RI 28,1\%) e 1.914 éxons ignorados (SE 29,4\%) (lista completa no Anexo 4, tabela 2). Na figura 21 observam-se alguns exemplos detectados de cada tipo de splicing alternativo. 


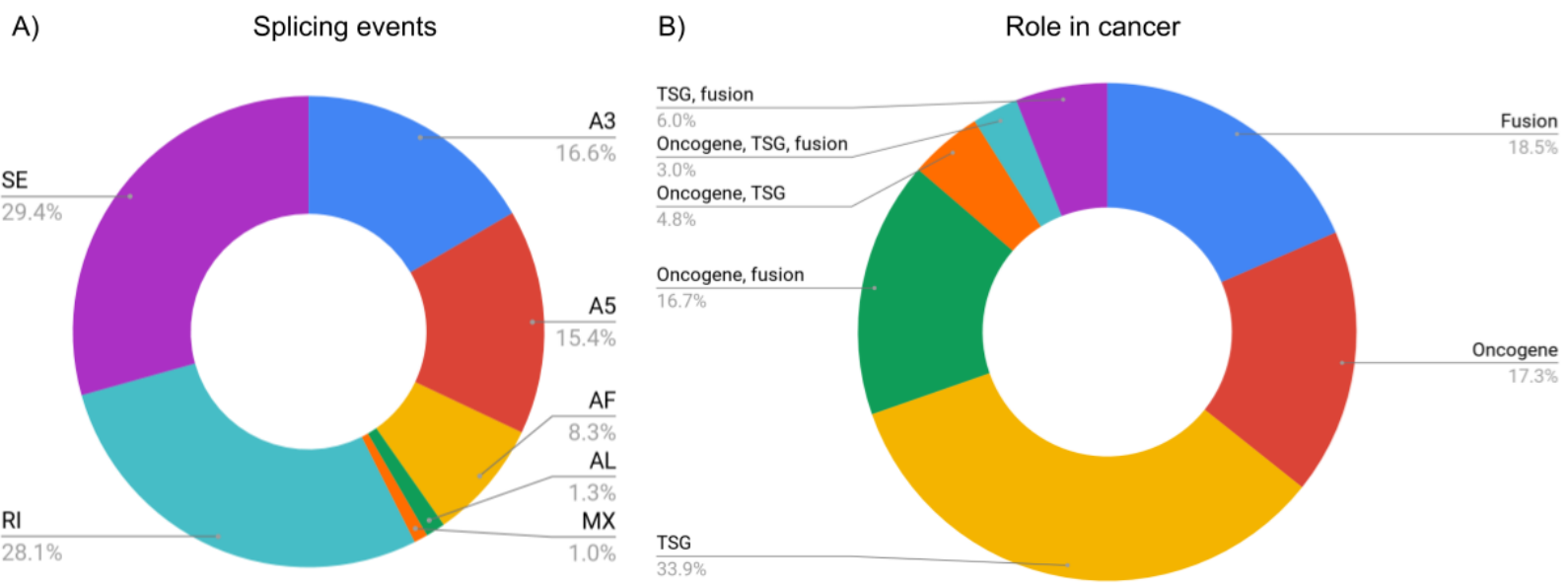

Figura 21. Tipos de splicing e participação dos genes em câncer considerando o banco de dados COSMIC. SE: éxons ignorados, RI: retenções de íntrons, A3: sítios alternativos 3', A5: sítios alternativos 5', AF: primeiro éxon alternativo, AL: último éxon alternativo, MX: éxons mutuamente excludentes, TSG: gene supressor tumoral.

Cabe mencionar que um transcrito pode ter mais de um tipo de evento de splicing, enquanto que outros (1.975) não foram anotados pelo programa devido a sua complexidade (exemplos na figura 22) e foram classificados como "Others".

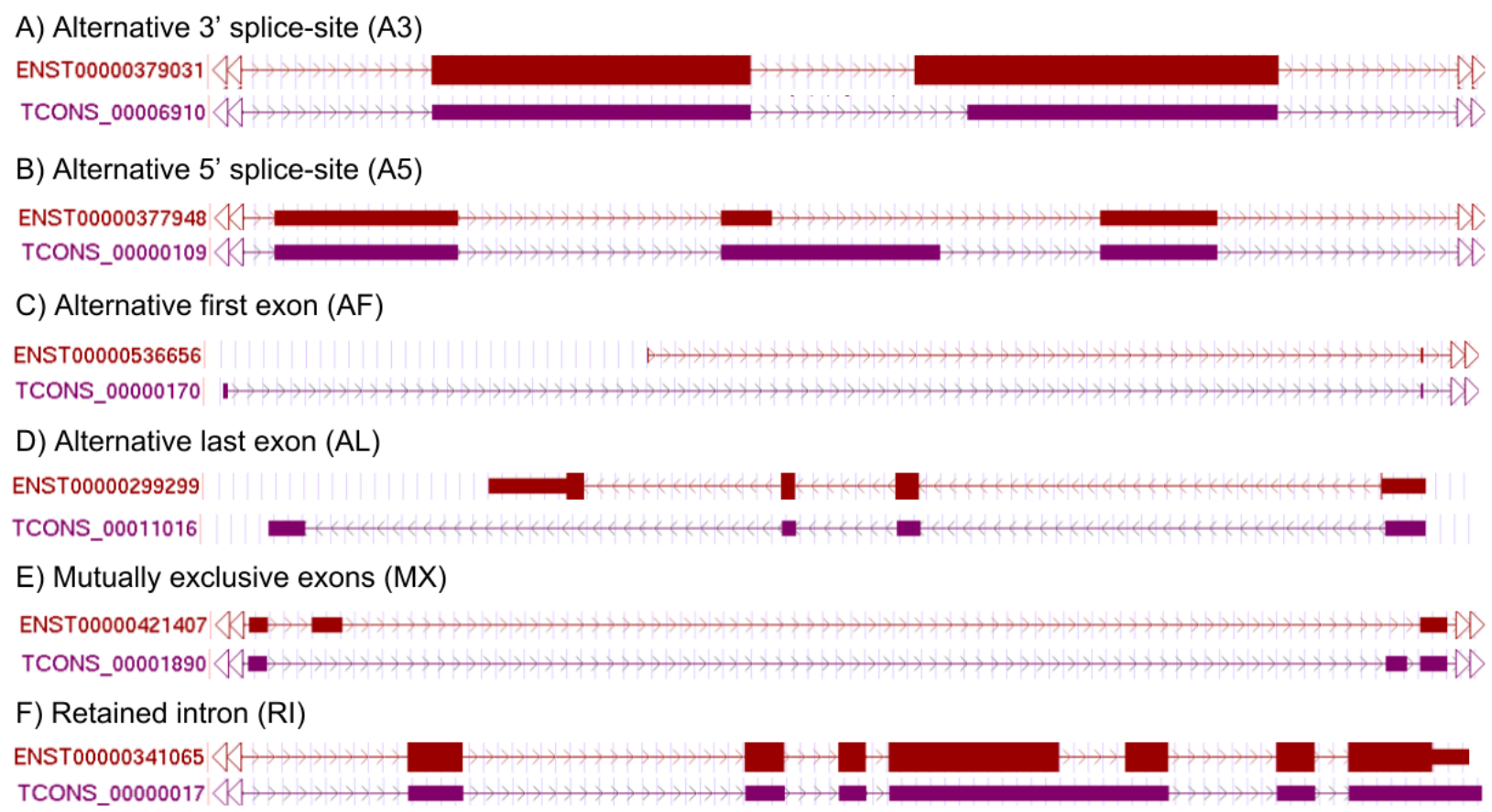


G) Skipping exon (SE)

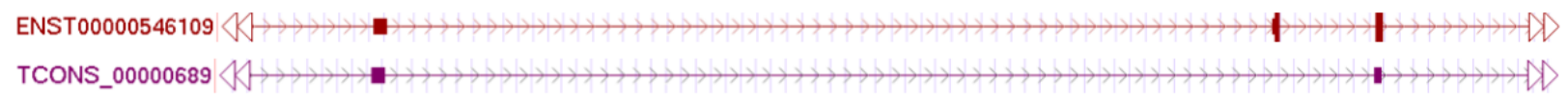

H) Others (O)

ENST00000434838

TCONS_00000405

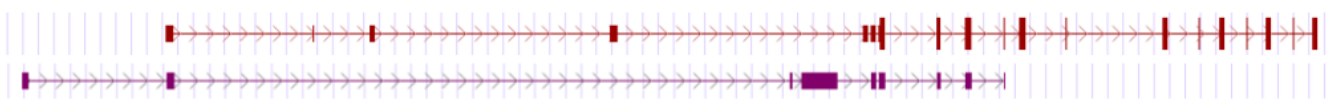

Figura 22. Eventos de splicing não detectados pelo programa SUPPA.

Os 4.001 genes correspondentes às 6.187 novas isoformas foram cruzados com um conjunto dados do projeto "Cancer Gene Census" (Andrew Futreal et al. 2004) contido no banco de dados COSMIC (Forbes et al. 2017). Esse catálogo contém 720 genes com mutações que foram implicadas no desenvolvimento de diferentes tipos de câncer. Entre eles encontram-se 172 que foram detectados em nosso trabalho, e que estão associados com funções tumorigênicas como oncogene, gene supressor tumoral (TSG) e fusões (figura 19.b, e tabela 1 do Anexo 4). Considerando o câncer de pâncreas em particular, encontramos 9 dos genes com variantes de splicing, entre eles FAT1 (TSG), GNAS (oncogene), HIF1A (oncogene), RNF43 (TSG), KRAS (oncogene), APC (TSG), ELF3 (TSG), FAT4 (TSG) e DAXX (TSG). Na figura 23 são apresentados alguns exemplos de isoformas relacionadas com câncer que foram detectadas neste estudo.

A) $A P C$

Scale

chr5:

ENST00000509732

ENST00000457016

ENST00000505350

ENST00000507379

ENST00000508624

ENST00000257430

ENST00000508376

ENST00000512211

ENST00000508108

ENST00000391068

ENST00000506342

ENST00000502371

ENST00000504915

ENST00000520401

ENST00000505084

ENST00000514164

TCONS_00072483

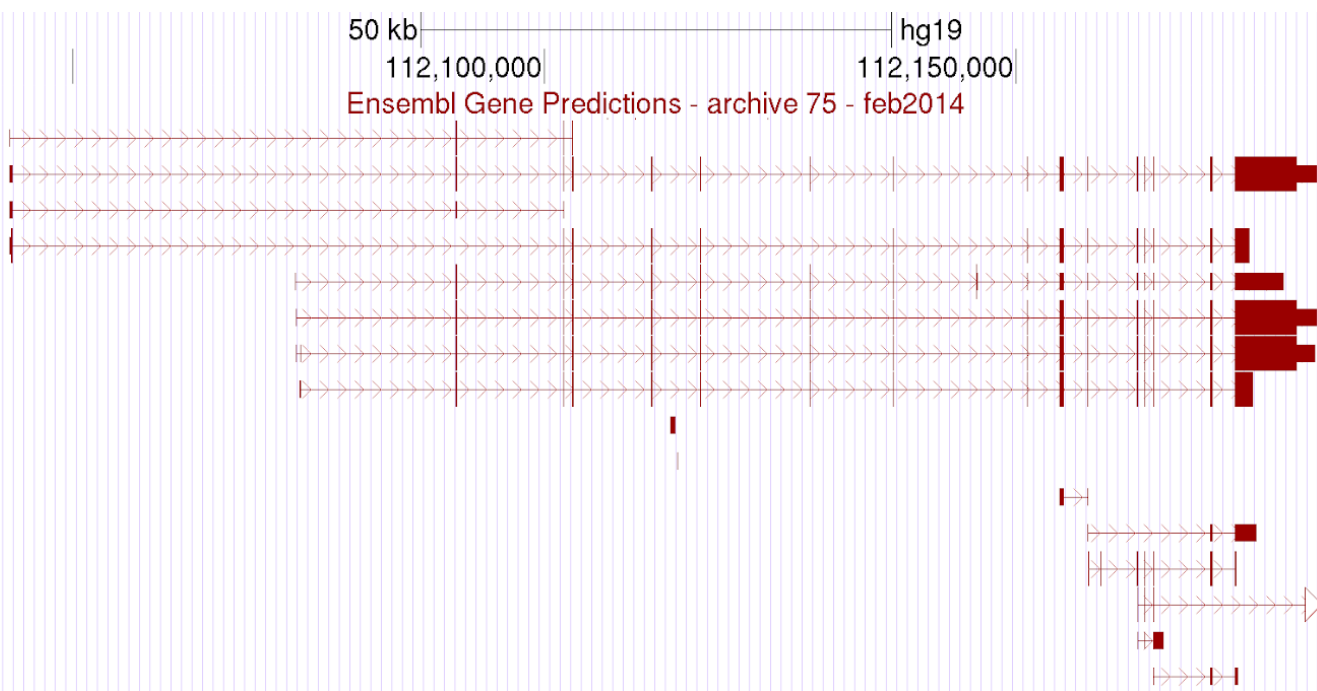

Splicing variant 


\section{B) $S M A D 2$}
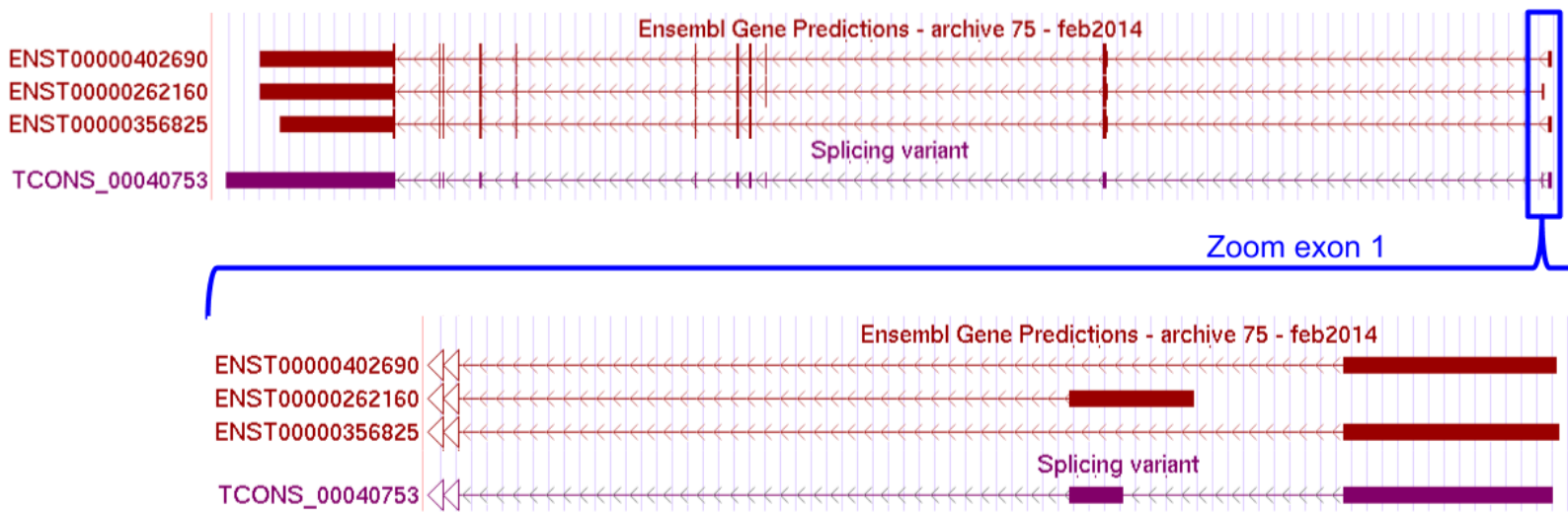

C) $M M P 14$

ENST00000311852 ENST00000547074 ENST00000548162 ENST00000547279 ENST00000548761 ENST00000547596

TCONS_00027381

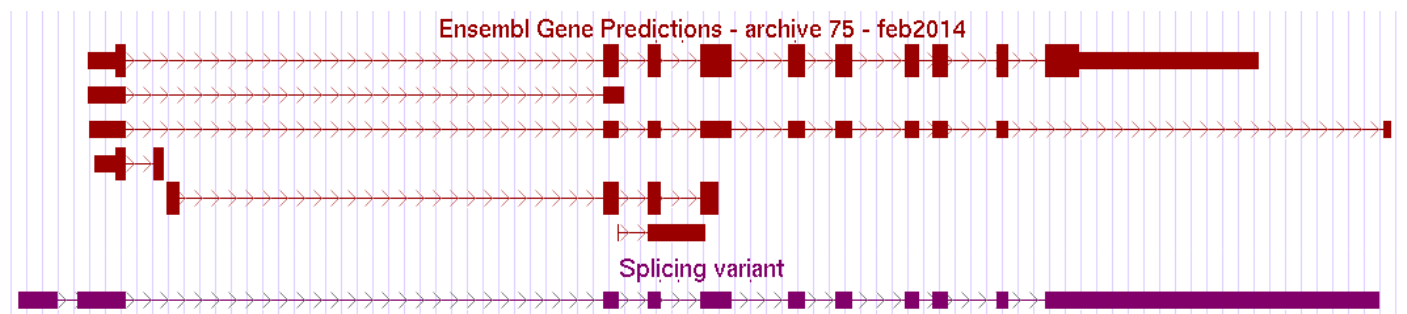

D) CAPN8

ENST00000484873 ENST 00000442247 ENST00000430824 ENST00000482401 ENST00000366872 ENST00000482183 TCONS_00006585

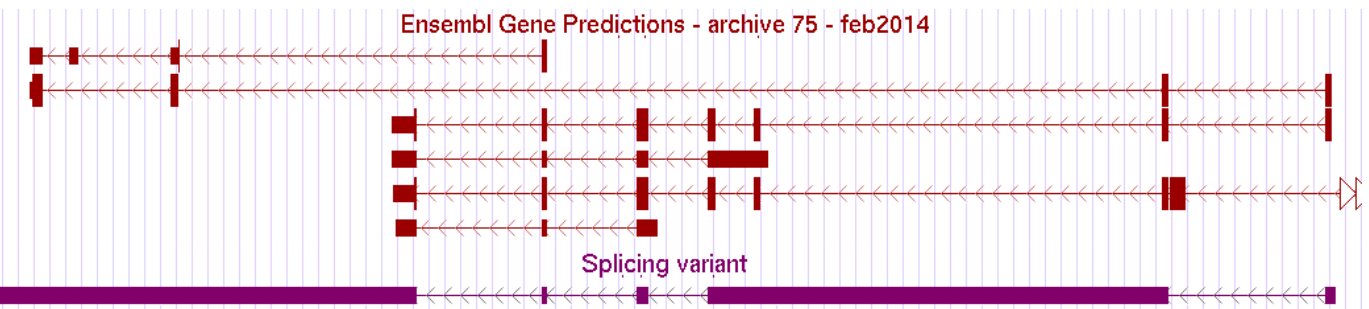

E) $L I F$
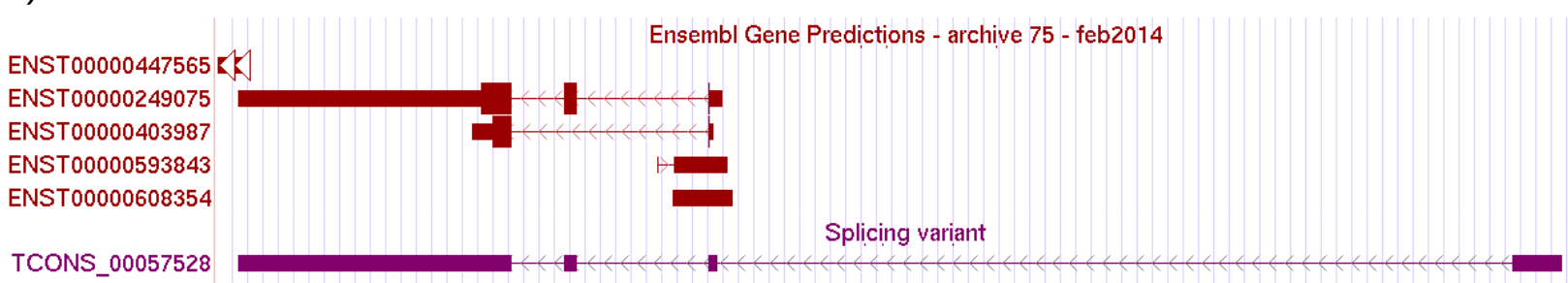

Figura 23. Novas variantes de splicing relacionadas com câncer. (a) APC e (b) SMAD2 integram o "Cancer Gene Census" no banco de dados COSMIC. Outras variantes também relacionadas com câncer incluem (c) MMP14, (d) CAPN8 e (e) LIF. 


\section{IV.5 Quantificação da expressão gênica}

Uma das aplicações mais importantes da técnica de RNA-seq é a estimação da expressão dos genes e transcritos. Foram testadas diferentes alternativas para fazer a análise em cada um desses níveis, e os resultados são descritos abaixo.

\section{IV.5.1 Quantificação ao nível dos genes}

Foram criadas matrizes de contagem dos reads usando o programa HTSeq (Anders, Pyl, and Huber 2015) implementado no ambiente R e considerando como referência o conjunto de genes reconstruídos na montagem.

Como é possível visualizar na figura 24, a análise de componentes principais (PCA) indica uma separação em dois grandes grupos correspondentes às bibliotecas não-tumorais (vermelho) e tumorais (azul).

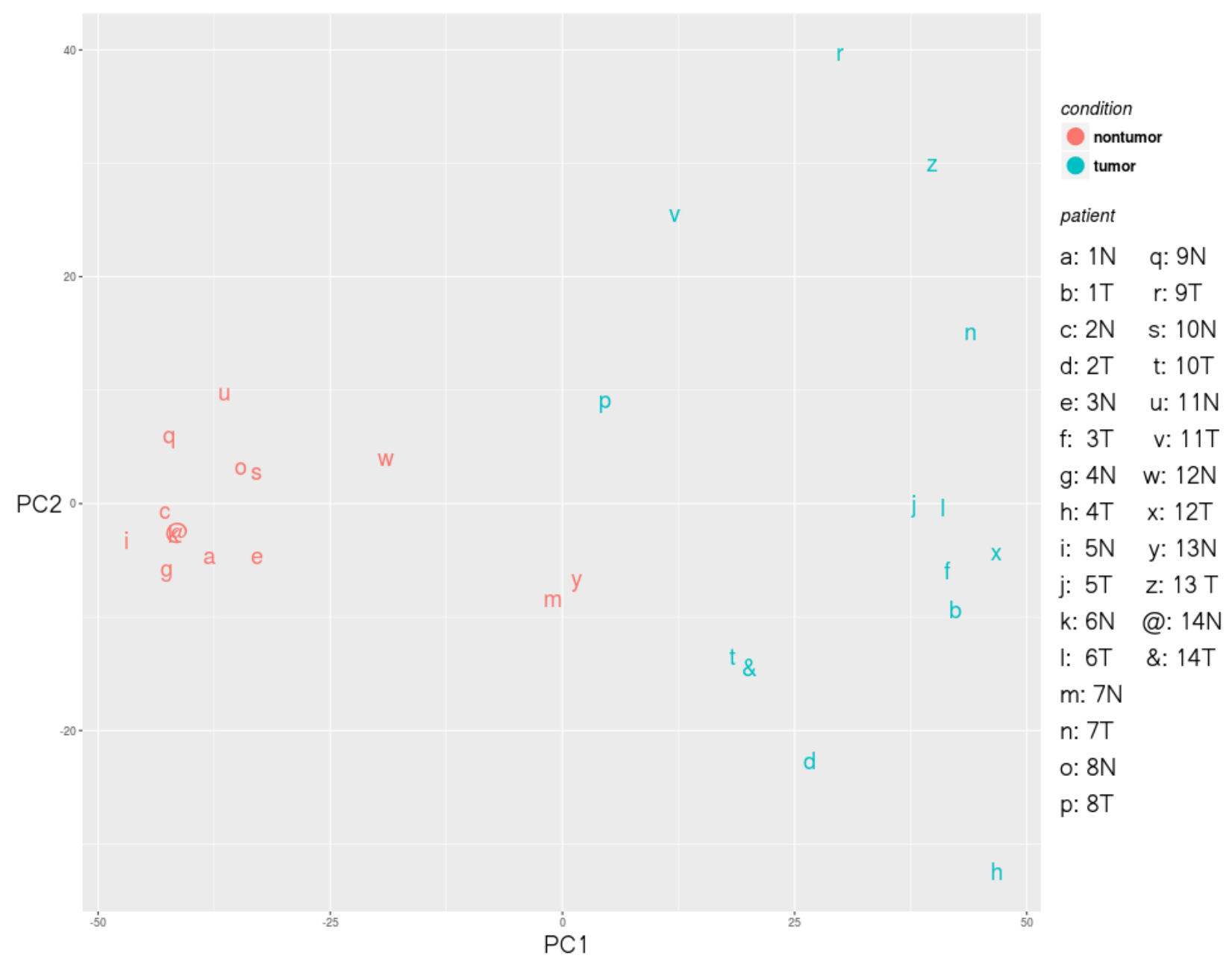


Figura 24. Análise de componentes principais (PCA) das amostras tumorais (azul) e não-tumorais (vermelho) utilizando os 500 genes mais variáveis.

De um total de 41,095 genes detectados em amostras pancreáticas, 11.942 apresentaram expressão diferencial estatisticamente significativa nas amostras tumorais (padj<0,1, usando Deseq2), e encontram-se representados como pontos vermelhos no plotMA da figura 25.

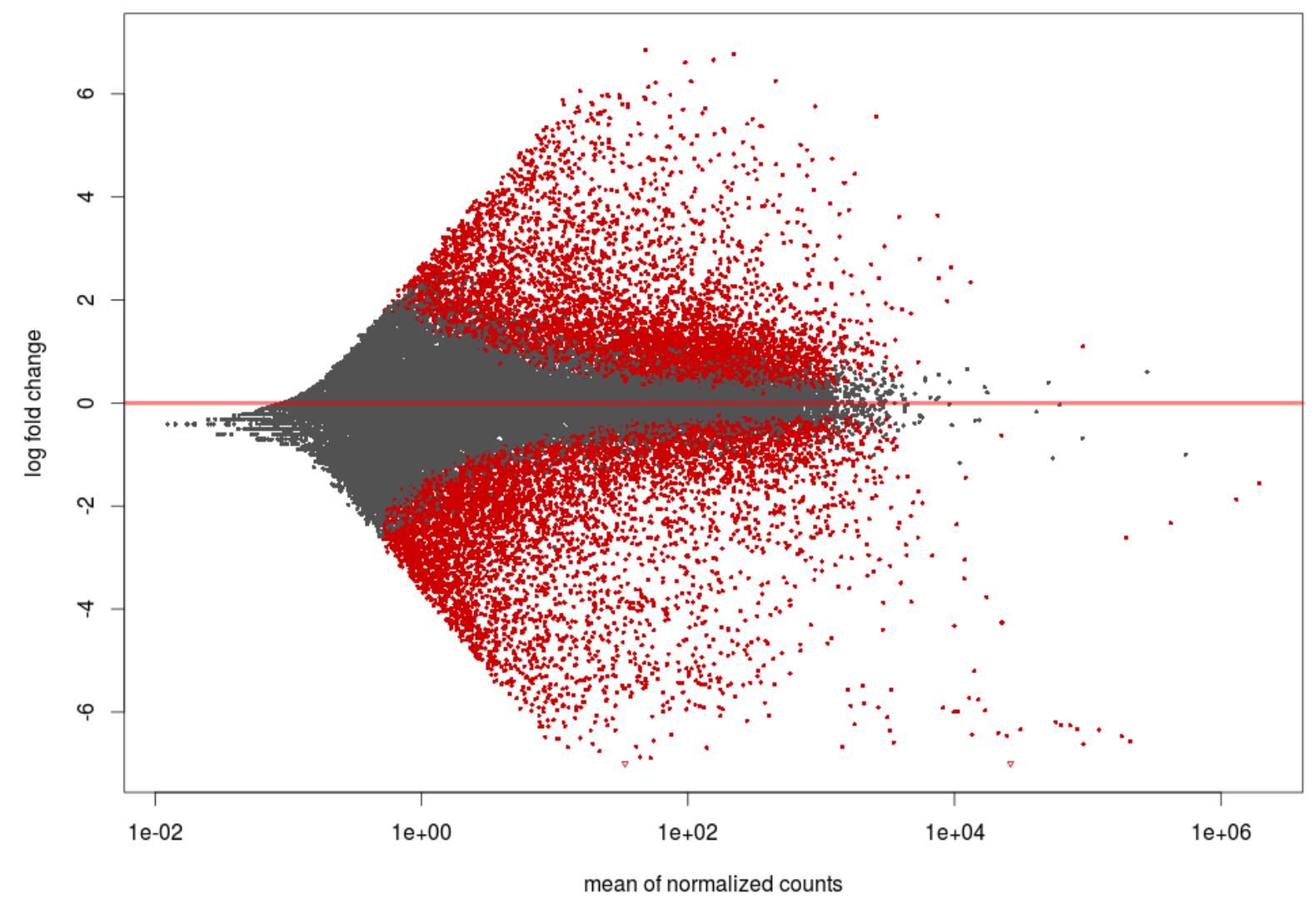

Figura 25. Plot MA com log fold change no eixo "y", e a contagem média normalizada no eixo " $x$ ". Pontos vermelhos representam genes com $p$ valor ajustado menor que 0,1.

Posteriormente, os genes foram filtrados considerando apenas os que tiveram um $\mathrm{p}$-adj<0.001 e Log2FoldChange $>$ |3.32|. Após esse critério de filtragem restaram 1617 genes (1085 down-regulated e 532 up-regulated). Os dados foram agrupados por clusterização hierárquica e foi gerado o heatmap da figura 26, no qual é possível perceber uma clara separação dos padrões de expressão entre amostras tumorais (marcadas com azul na coluna da direita) e não tumorais (cinza). 


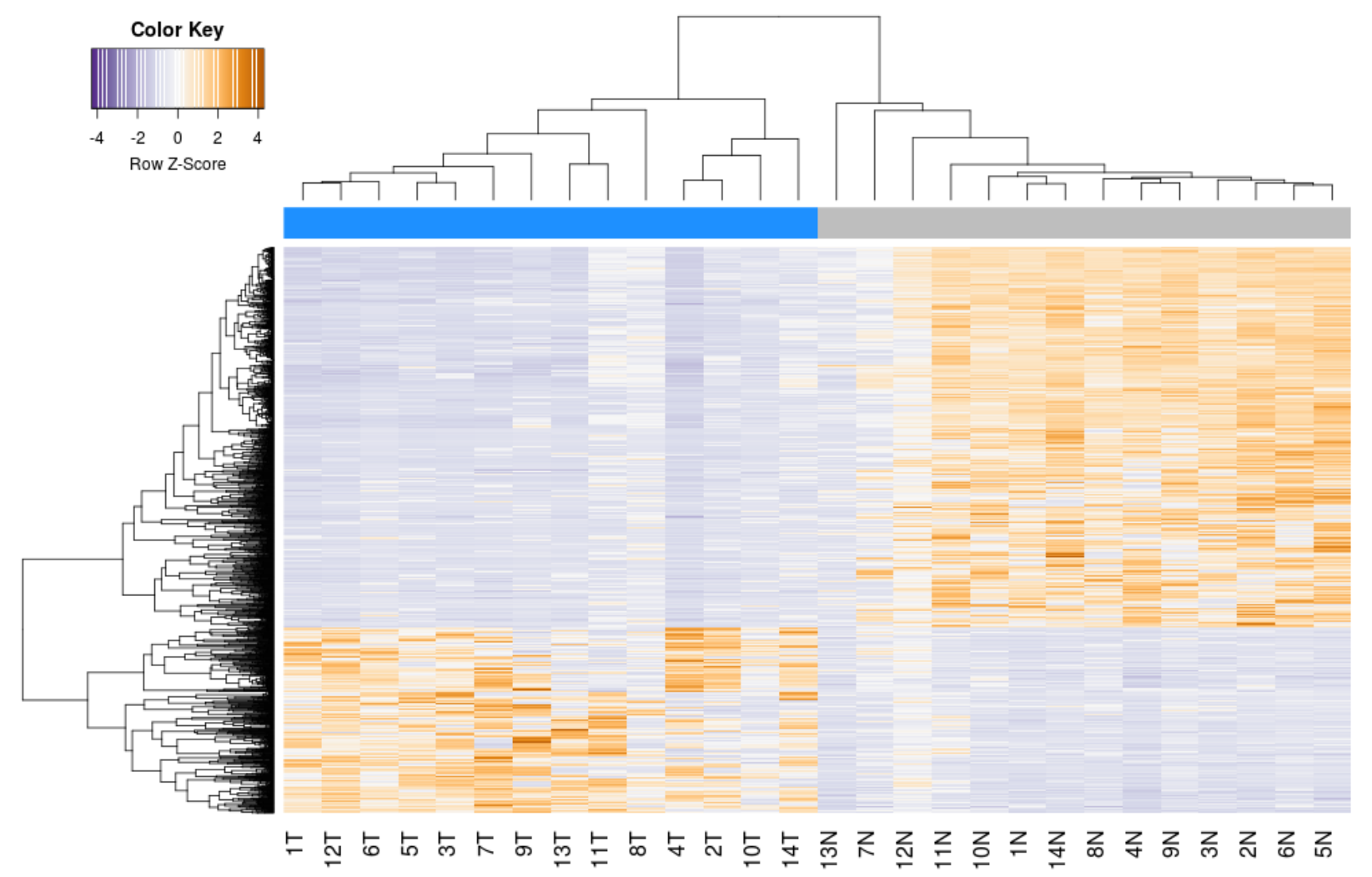

Figura 26. Agrupamento de genes com $p$-adj $<0,001$ e Ifc $>|3,32|$. Na primeira linha estão representadas com cor azul as amostras tumorais e cinza as amostras não tumorais.

Para testar a robustez dos resultados, a expressão gênica diferencial também foi avaliada com outros dois programas amplamente utilizados na literatura, EdgeR (Robinson, McCarthy, and Smyth 2010) e Cuffdiff2 (Trapnell, Hendrickson, et al. 2012), e os resultados encontram-se resumidos na tabela 4 e figura 27.

Tabela 4. Análise de expressão diferencial utilizando três metodologias: Deseq2, EdgeR e Cuffdiff2.

\begin{tabular}{|c|c|c|c|c|}
\hline Software & Filter & DEGs & Up-regulated & Down-regulated \\
\hline Deseq2 & Ifc $>=|3.32| \&$ padj $<0.001$ & 1617 & 532 & 1085 \\
\hline EdgeR & Ifc $>=|3.32|$ \& padj $<0.001$ & 1545 & 710 & 835 \\
\hline Cuffdiff2 & Ifc $>=|3.32| \&$ padj $<0.005$ & 295 & 146 & 149 \\
\hline
\end{tabular}




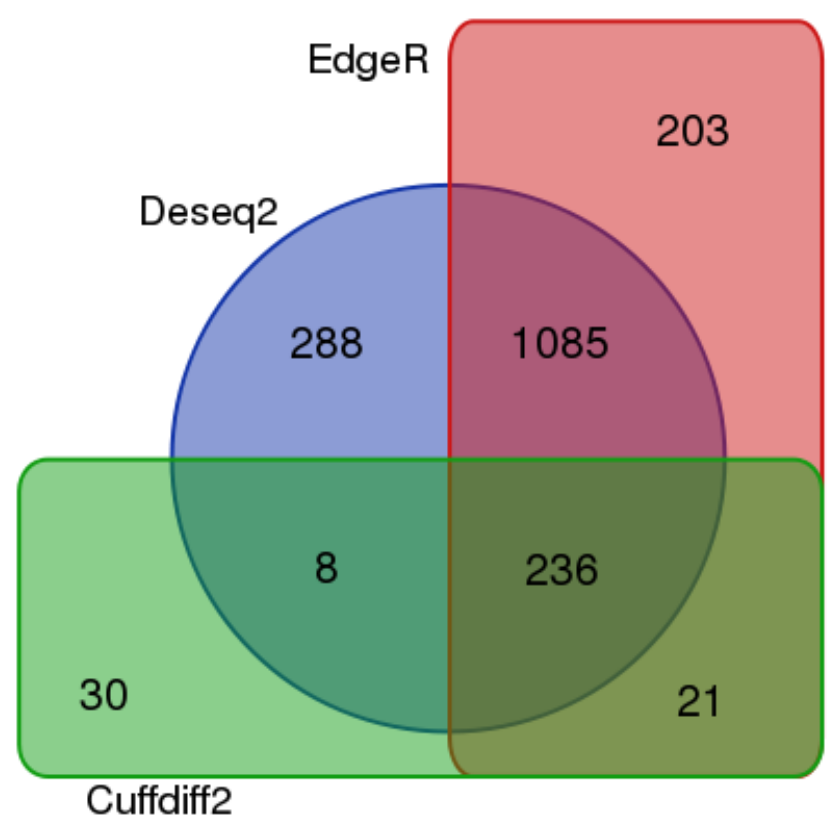

Figura 27. Sobreposição das análises de expressão diferencial utilizando Deseq2 (azul), EdgeR (vermelho) e Cuffdiff2 (verde).

A maior similaridade entre os resultados do Deseq2 e EdgeR pode ser explicada pela semelhança nos modelos estatísticos aplicados, entanto que Cuffdiff2 proporciona menos genes diferencialmente expressos, o $80 \%$ deles são compartilhados com os métodos anteriores. Em termos de tempo de processamento, Deseq2 e EdgeR são os mais velozes (na ordem de minutos), enquanto que Cuffdiff2 leva dias para concluir a análise usando 40 processadores. Esses resultados coincidem com estudos anteriores (Z. H. Zhang et al. 2014; Seyednasrollah, Laiho, and Elo 2015), e sugerem que a escolha do método depende principalmente das características dos dados e que quando o controle de falsos positivos é uma prioridade, a interseção dos resultados de vários métodos é uma boa opção.

\section{IV.5.2 Quantificação ao nível dos transcritos}

Para investigar a expressão diferencial ao nível de transcrito foram testadas diferentes ferramentas que geram contagens de reads, entre elas: HTSeq (Anders, Pyl, and Huber 2015), Salmon (Patro et al. 2017), Kallisto (N. L. Bray et al. 2016) e RSEM (B. Li and Dewey 2011).

Os resultados obtidos podem ser observados na figura 28 , onde foi considerado o número de isoformas anotadas para cada gene (eixo " $x$ "), com transcritos classificados como "detectados" se seu "base-mean" fosse maior ou igual que 1 (eixo "y"). Observa-se que o programa Salmon (verde) detectou um número maior de 
transcritos, independentemente do número de isoformas anotadas no locus. Seguem no ranqueamento o RSEM, Kallisto e por último HTSeq.

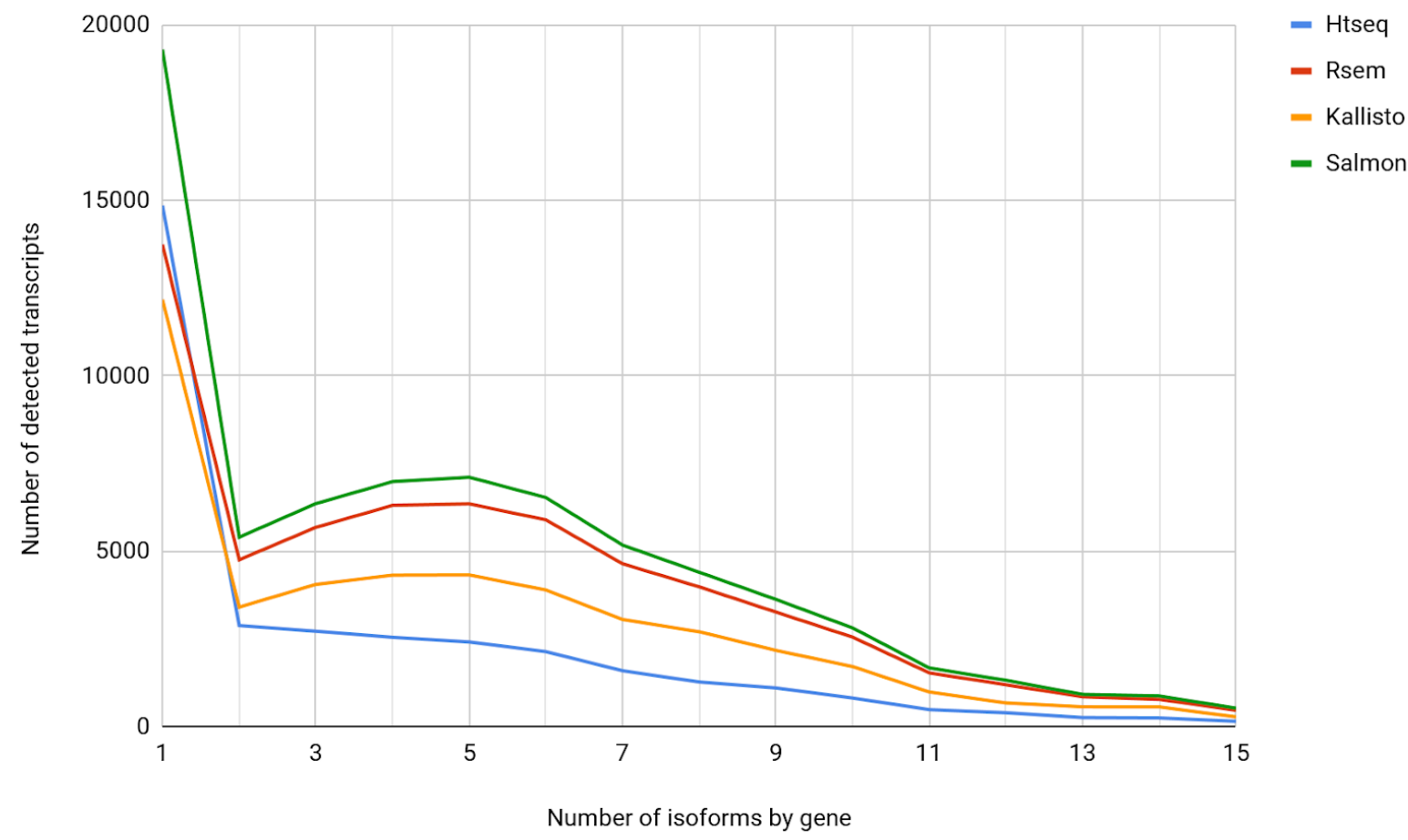

Figura 28. Comparação de ferramentas para quantificação da expressão em nível de transcrito, considerando o número de isoformas por gene. Um transcrito foi categorizado como detectado se tivesse um "base-mean" maior ou igual a 1. Azul: HTSeq (Anders, Pyl, and Huber 2015); Vermelho: RSEM (B. Li and Dewey 2011); Laranja: Kallisto (Nicolas L. Bray et al. 2016); Verde: Salmon (Patro et al. 2017).

Em seguida realizamos a inspeção visual de alguns genes de interesse para verificar a consistência entre os valores de quantificação ao nível de gene obtidos com HTSeq na secção anterior, e a expressão ao nível de transcrito realizada com os diferentes programas. Foram avaliados cinco genes que apresentavam um alto nível de expressão ("base-mean") ao nível de gene e ao menos 3 variantes de splicing anotadas: FN1, PRSS1, TSPAN1, KRAS e SLC4A4 (tabela 6).

Tabela 6. Genes com mais de 3 isoformas e elevado "base-mean" selecionados para teste de ferramentas que quantificam em nível de transcrito.

\begin{tabular}{|l|l|l|l|l|}
\hline Gene_ID & $\begin{array}{l}\text { GENCODE_Nam } \\
\text { e }\end{array}$ & BaseMean & log2FoldChange & padj \\
\hline
\end{tabular}




\begin{tabular}{|l|l|l|l|l|}
\hline XLOC_021770 & FN1 & 9403.0 & 2.6 & $3.0 \mathrm{e}-4$ \\
\hline XLOC_034688 & PRSS1 & 179777.1 & -6.5 & $2.8 \mathrm{e}-20$ \\
\hline XLOC_000565 & TSPAN1 & 348.8 & 5.4 & $1.9 \mathrm{e}-33$ \\
\hline XLOC_008982 & KRAS & 358.8 & 0.9 & $1.3 \mathrm{e}-3$ \\
\hline XLOC_027134 & SLC4A4 & 3992.5 & -3.5 & $8.7 \mathrm{e}-10$ \\
\hline
\end{tabular}

Para uma análise mais detalhada do desempenho dos programas de quantificação em nível de isoformas, foram testadas as ferramentas HTSeq, RSEM, Kallisto e Salmon, considerando 5 genes com as características acima descritas. $\mathrm{Na}$ tabela 7 e figura 29, encontram-se as contagens médias das isoformas correspondentes aos 5 genes, calculada com os diferentes programas (HTSeq, RSEM, Kallisto e Salmon).

Tabela 7. Contagens médias das isoformas dos genes FN1 (XLOC_021770), PRSS1 (XLOC_034688), TSPAN1 (XLOC_000565), KRAS (XLOC_008982) e SLC4A4 (XLOC_027134), utilizando os programas HTSeq, RSEM, Kallisto e Salmon. Uma isoforma foi considerada "detectada" se tivesse contagem média maior ou igual que 1.

\begin{tabular}{|l|l|c|c|c|c|}
\hline \multicolumn{1}{|c|}{ Gene_Id } & Transcript_Id & HTSeq & RSEM & Kallisto & Salmon \\
\hline XLOC_021770 & TCONS_00051219 & 0 & 2,6 & 2,0 & 2.0 \\
\hline XLOC_021770 & TCONS_00051220 & 0 & 229,7 & 297,5 & 169.1 \\
\hline XLOC_021770 & TCONS_00051221 & 0 & 3,8 & 4,9 & 2.8 \\
\hline XLOC_021770 & TCONS_00051222 & 0 & 181,5 & 111,3 & 46.6 \\
\hline XLOC_021770 & TCONS_00051223 & 0 & 10,0 & 12,2 & 59.8 \\
\hline XLOC_021770 & TCONS_00051224 & 0 & 4,3 & 81,3 & 155.8 \\
\hline XLOC_021770 & TCONS_00051225 & 0 & 424,0 & 214,7 & 99.2 \\
\hline XLOC_021770 & TCONS_00051226 & 0 & 1,1 & 137,8 & 60.9 \\
\hline XLOC_021770 & TCONS_00051227 & 0 & 12,6 & 230,2 & 271.8 \\
\hline XLOC_021770 & TCONS_00051228 & 0 & 4020,1 & 4907,7 & 4996.9 \\
\hline XLOC_021770 & TCONS_00051229 & 0 & 3936,7 & 4120,6 & 4494.2 \\
\hline XLOC_021770 & TCONS_00051230 & 0 & 4,4 & 1,0 & 3.1 \\
\hline XLOC_021770 & TCONS_00051231 & 0 & 2138,9 & 2724,9 & 2641.2 \\
\hline XLOC_021770 & TCONS_00051232 & 0 & 3493,1 & 3958,1 & 3968.0 \\
\hline XLOC_021770 & TCONS_00051233 & 0,9 & 26,9 & 13,7 & 13.9 \\
\hline XLOC_021770 & TCONS_00051234 & 7,1 & 158,0 & 239,2 & 234.3 \\
\hline
\end{tabular}




\begin{tabular}{|c|c|c|c|c|c|}
\hline XLOC_021770 & TCONS_00053339 & 66,5 & 624,5 & 698,9 & 626.4 \\
\hline \multicolumn{2}{|c|}{ Number of isoforms detected: } & 2 & 17 & 17 & 17 \\
\hline Gene_Id & Transcript_Id & HTSeq & RSEM & Kallisto & Salmon \\
\hline XLOC_034688 & TCONS_00080090 & 0 & 76,8 & 0,1 & 83.5 \\
\hline XLOC_034688 & TCONS_00080091 & 0 & 270,1 & 1,3 & 371.3 \\
\hline XLOC_034688 & TCONS_00080092 & 0 & 126743,2 & 344,1 & 131144.1 \\
\hline XLOC_034688 & TCONS_00080093 & 0 & 1465,2 & 1,0 & 270.6 \\
\hline XLOC_034688 & TCONS_00080094 & 0 & 70,5 & 38,7 & 78.1 \\
\hline XLOC_034688 & TCONS_00080095 & 0 & 3355,3 & 9,3 & 3102.5 \\
\hline \multicolumn{2}{|c|}{ Number of isoforms detected: } & 0 & 6 & 5 & 6 \\
\hline Gene_Id & Transcript_Id & HTSeq & RSEM & Kallisto & Salmon \\
\hline XLOC_000565 & TCONS_00001059 & 0 & 0 & 0 & 0.6 \\
\hline XLOC_000565 & TCONS_00001060 & 0 & 0,2 & 0 & 0.1 \\
\hline XLOC_000565 & TCONS_00001061 & 0 & 0,2 & 0 & 0.3 \\
\hline XLOC_000565 & TCONS_00001062 & 0 & 432,0 & 0,5 & 503.6 \\
\hline XLOC_000565 & TCONS_00001063 & 0,5 & 5,6 & 0,2 & 8.6 \\
\hline XLOC_000565 & TCONS_00001064 & 0 & 0,7 & 0,1 & 1.0 \\
\hline XLOC_000565 & TCONS_00001065 & 0,7 & 0,2 & 0,2 & 3.9 \\
\hline XLOC_000565 & TCONS_00001066 & 0 & 7,9 & 0,4 & 7.3 \\
\hline XLOC_000565 & TCONS_00007215 & 0 & 76,5 & 0,8 & 81.7 \\
\hline \multicolumn{2}{|c|}{ Number of isoforms detected: } & 0 & 4 & 0 & 6 \\
\hline Gene_Id & Transcript_Id & HTSeq & RSEM & Kallisto & Salmon \\
\hline XLOC_008982 & TCONS_00020360 & 0 & 138,0 & 208,5 & 310.7 \\
\hline XLOC_008982 & TCONS_00020361 & 0 & 240,7 & 251,8 & 176.3 \\
\hline XLOC_008982 & TCONS_00020362 & 0 & 4,7 & 4,2 & 4.3 \\
\hline XLOC_008982 & TCONS_00020363 & 2,8 & 17,5 & 30,3 & 28.6 \\
\hline \multicolumn{2}{|c|}{ Number of isoforms detected: } & 1 & 4 & 4 & 4 \\
\hline Gene_Id & Transcript_ld & HTSeq & RSEM & Kallisto & Salmon \\
\hline XLOC_027134 & TCONS_00064861 & 0 & 11,7 & 2,0 & 29.0 \\
\hline XLOC_027134 & TCONS_00064862 & 0 & 1078,7 & 8,6 & 1454.9 \\
\hline XLOC_027134 & TCONS_00064863 & 0 & 39,9 & 2,6 & 75.6 \\
\hline XLOC_027134 & TCONS_00067432 & 0 & 56,2 & 0,5 & 53.1 \\
\hline XLOC_027134 & TCONS_00067433 & 0,6 & 3,9 & 0,2 & 21.6 \\
\hline XLOC_027134 & TCONS_00067434 & 0 & 1697,2 & 3,2 & 1776.6 \\
\hline
\end{tabular}


a)

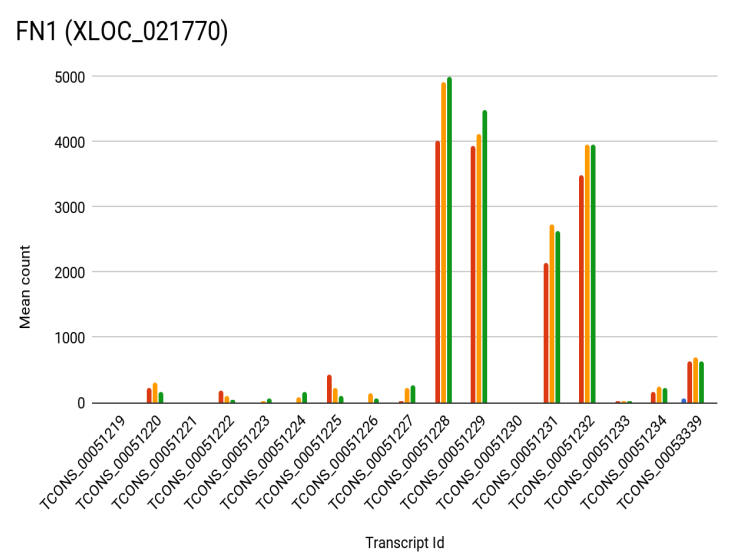

c)

TSPAN1 (XLOC_000565)

600

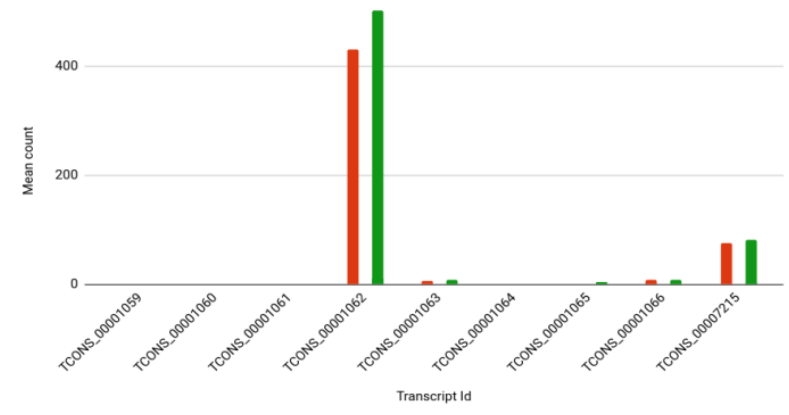

e)

SLC4A4 (XLOC_027134)

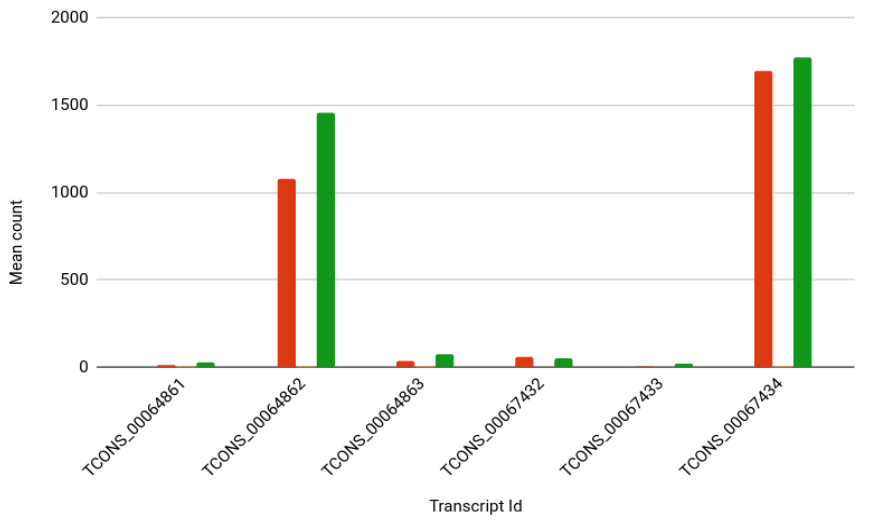

b) PRSS1 (XLOC_034688)

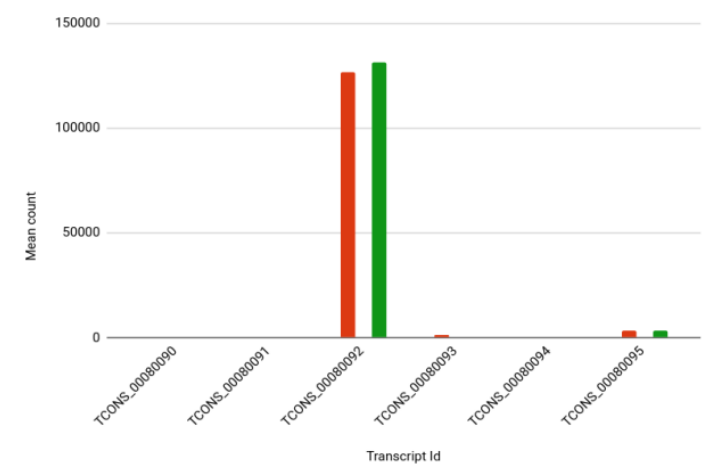

d)

$$
\text { KRAS (XLOC_008982) }
$$

400

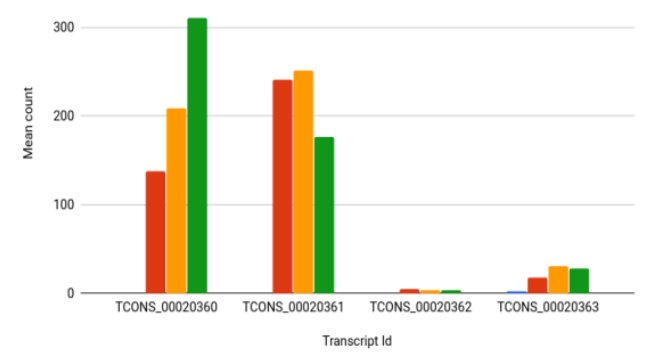

Htseq

Rsem

Kallisto

- Salmon 
Figura 29. Contagem média das isoformas dos genes (a) FN1, (b) PRSS1, (c) TSPAN1, (d) KRAS e (e) SLC4A4 utilizando os programas HTSeq (azul), RSEM (vermelho), Kallisto (laranja) e Salmon (verde).

É possível observar que Salmon e RSEM são os programas que apresentam contagens mais altas para os loci avaliados, seguido por Kallisto. Chama a atenção o fraco desempenho do programa HTSeq em detectar a presença e abundância das diferentes isoformas dos genes avaliados quando comparado às demais abordagens, em especial Salmon e RSEM (Tabela 7 e Figura 29); nos exemplos analisados o HTSeq detectou apenas 3 de 42 isoformas anotadas (<10\%).

Para avaliar a estratégia mais eficiente para quantificação e expressão diferencial de transcritos foi feito uma comparação utilizando as seguintes estratégias:

a) Tophat2 - HTSeq - Deseq2

b) Star - RSEM - Deseq2

c) Kallisto - Deseq2

d) Salmon - Deseq2

e) Tophat2 - Cuffdiff2

f) Tophat2 - HTSeq - EdgeR

Os resultados para os 5 genes estão representados na figura 30, onde é plotado o Ifc (log2 fold change) e p-adj (sendo: * padj $<0.5$, ${ }^{\star \star}$ padj $<0.1$, ${ }^{\star \star *}$ padj $<0.01$ ), calculado com as 6 estratégias.

a)

FN1 (XLOC_021770)

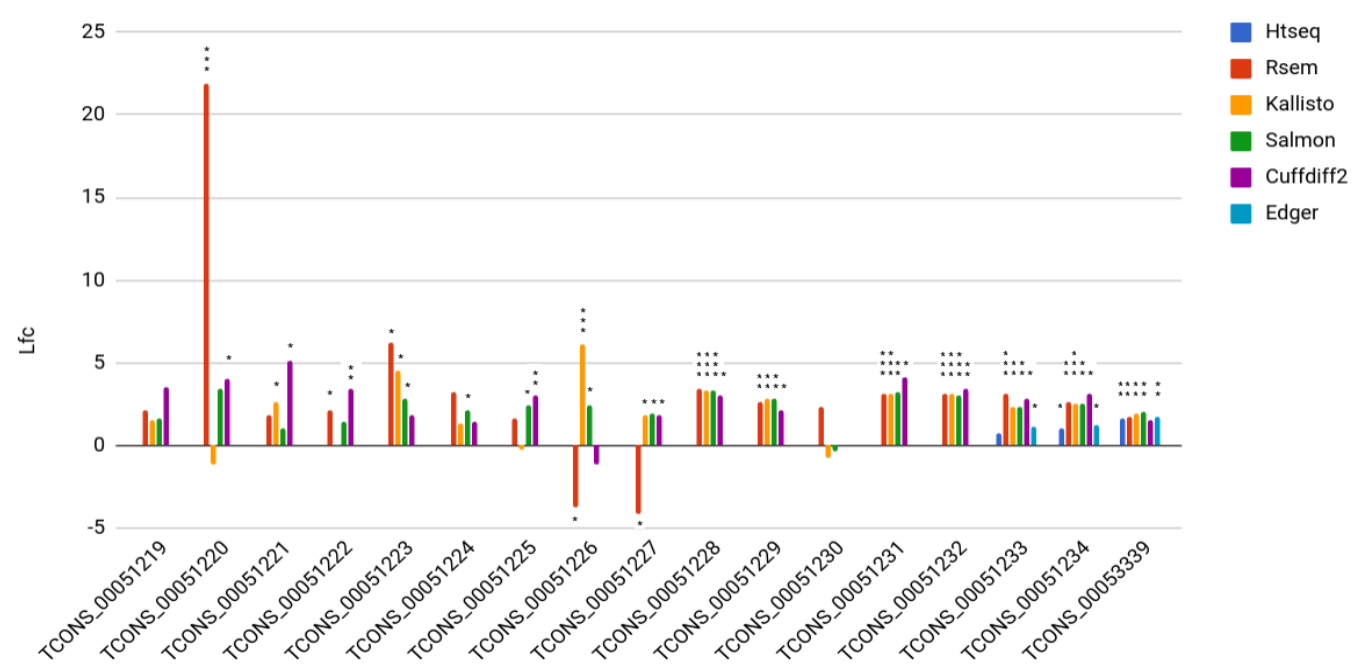

b) 


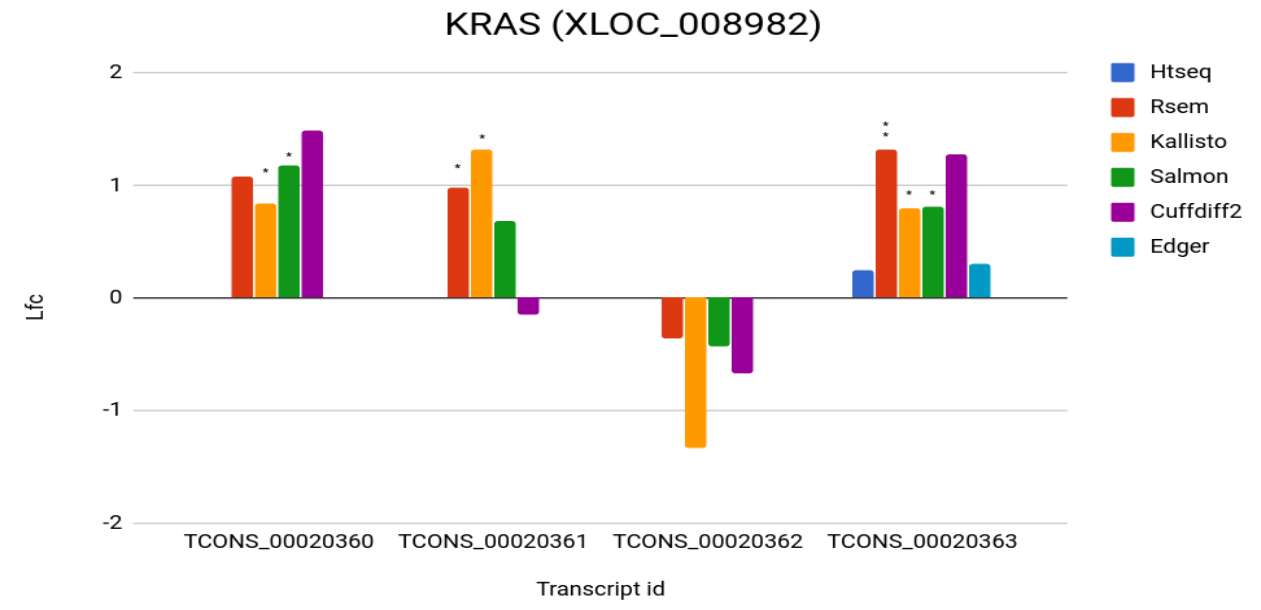

c)

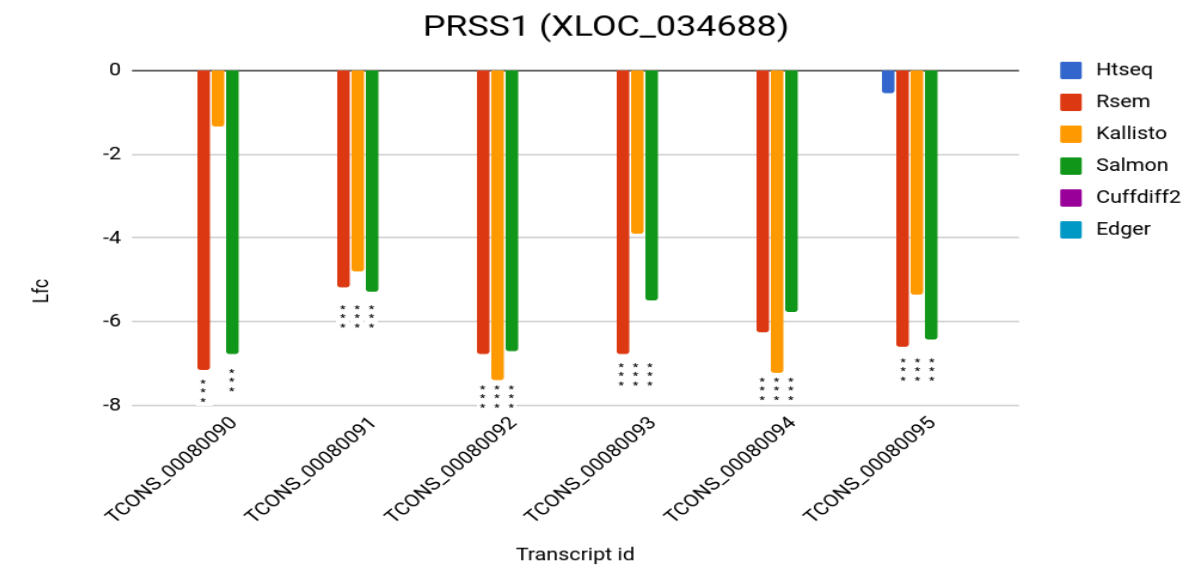

d)

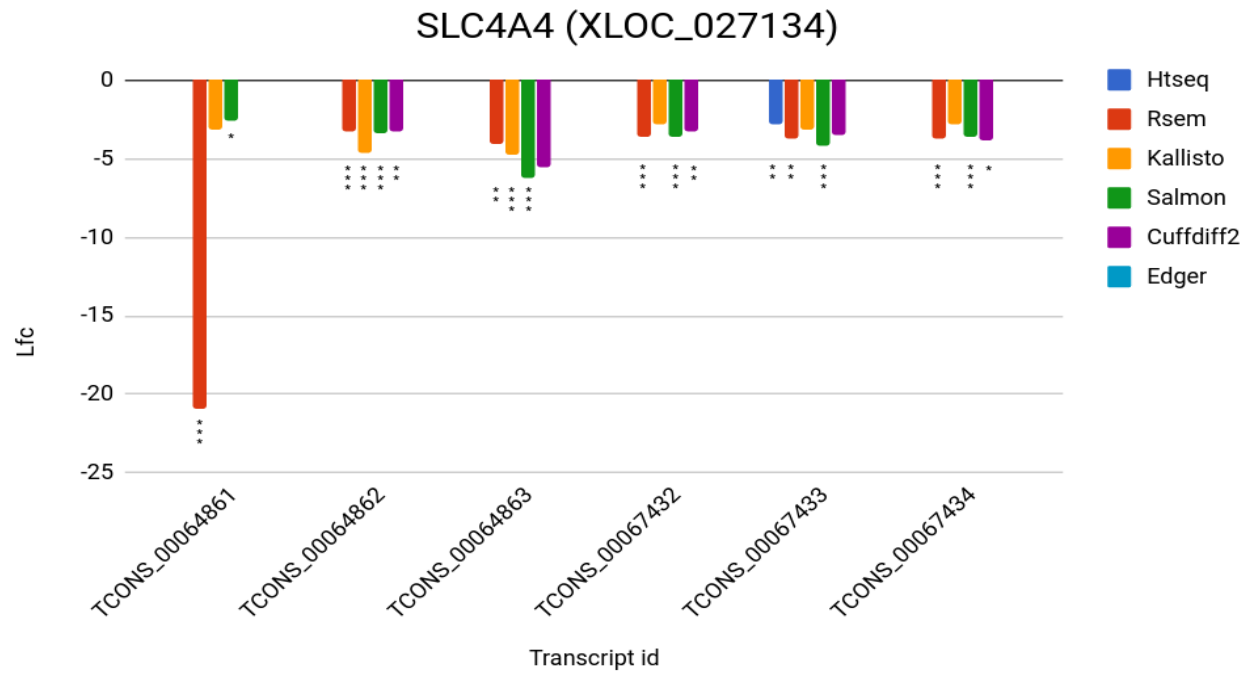

e) 
TSPAN1 (XLOC_000565)

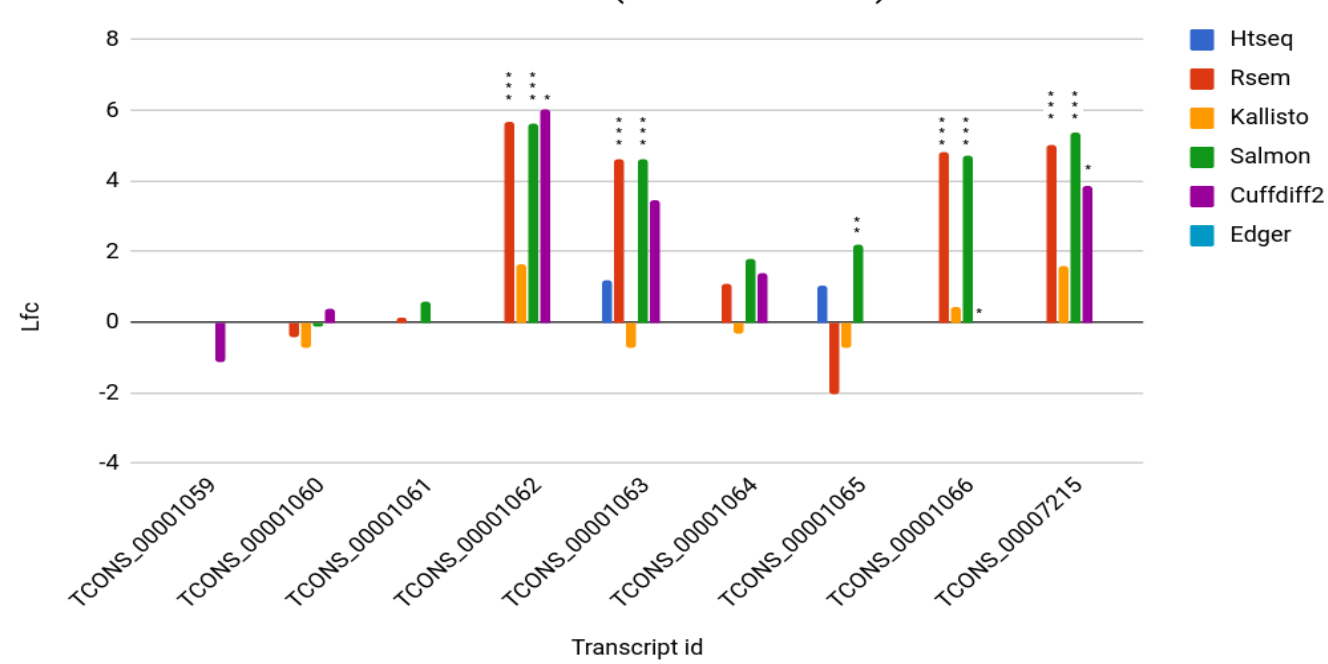

Figura 30. Análise de expressão diferencial para os genes FN1 (a), KRAS (b), PRSS1 (c), SLC4A4 (d) e TSPAN1 (e) utilizando os pipelines: Tophat2-HTSeq-Deseq2 (azul), Star-RSEM-Deseq2 (vermelho), Kallisto-Deseq2 (laranja), Salmon-Deseq2 (verde), Tophat2-Cuffdiff2 (lilás) e Tophat2-HTSeq-EdgeR (azul claro). * padj $<0.5,{ }^{\star \star}$ padj $<0.1$, ${ }^{\star \star \star}$ padj $<0.01$

Baseado na análise destes 5 genes, os pipelines que utilizam quantificação das isoformas dos genes usando RSEM, Kallisto e Salmon apresentam alta concordância nos resultados de detecção de transcritos diferencialmente expressos (em média 62\% das isoformas anotadas no locus são detectadas), e permitem uma boa diferenciação das isoformas dos genes estudados. Quando é usado o estimador de abundância HTSeq percebe-se uma baixa sensibilidade para detecção de isoformas diferencialmente expressas (7\%) em relação às outras abordagens.

Os resultados das análises, considerando todos os transcritos diferencialmente expressos com um $\mathrm{Ifc}>|3,32|$ e padj $<0,001$, encontram-se resumidos na tabela 7 . Observa-se um maior número de transcritos detectados com RSEM-Deseq2, seguido por HTSeq-EdgeR e Salmon-Deseq2. Curiosamente, as análises com HTSeq-EdgeR não tiveram um bom desempenho na detecção de isoformas dos genes previamente descritos (figura 30), mas ainda assim identifica um número elevado de transcritos diferencialmente expressos (tabela 8).

Tabela 8. Análise de expressão diferencial, apresentando número de transcritos com Ifc $>=|3,32|$ e padj $<0,001$

\begin{tabular}{|c|c|c|}
\hline Softwares & Genes & Transcripts \\
\hline Tophat2 / Cuffdiff2 * & 295 & $311(0.3 \%)$ \\
\hline Star / RSEM / Deseq2 & 1767 & $2341(2.6 \%)$ \\
\hline
\end{tabular}




\begin{tabular}{|c|c|c|}
\hline HTSeq / Edger & 1545 & $1917(2.1 \%)$ \\
\hline HTSeq / Deseq2 & 1617 & $1610(1.8 \%)$ \\
\hline Kallisto / Deseq2 & 801 & $1075(1.2 \%)$ \\
\hline Salmon / Deseq2 & 1331 & $1825(2.0 \%)$ \\
\hline
\end{tabular}

* Tophat2 / Cuffdiff2: foi usado um cutoff de Ifc $>|3.32|$ e padj $<0.005$ para genes, e Ifc $>|3.32|$ e padj<0.05 para transcritos

Os transcritos detectados como diferencialmente expressos por cada pipeline foram cruzados (figura 31), encontrando em ordem decrescente de sobreposição de transcritos em comum: 1395 entre HTSeq e RSEM, 1391 entre RSEM e Salmon, 903 entre HTSeq e Salmon, 823 entre Kallisto e Salmon, 808 entre RSEM e Kallisto, e 502 entre HTSeq e Kallisto. A maior similaridade foi observada entre os programas que aplicam uma etapa inicial de mapeamento (HTSeq e RSEM), embora isso pode estar relacionado ao fato que esses são também os protocolos que detectaram o maior número de DEGs.

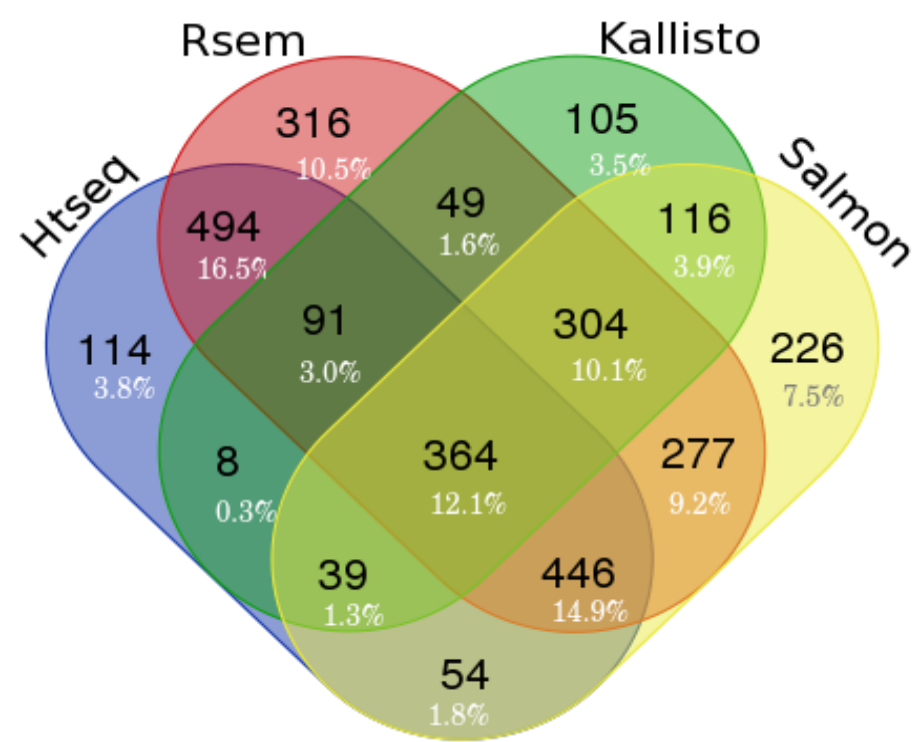

Figura 31. Intersecção dos transcritos diferencialmente expressos (Ifc $>|3,32|$ e padj<0,001) utilizando os pipelines: HTSeq (HTSeq-Deseq2), RSEM (Star-RSEM-Deseq2), Kallisto (Kallisto-Deseq2) e Salmon (Salmon-Deseq2).

As abordagens de quantificação utilizando Salmon, RSEM e Kallisto foram ainda avaliadas quanto a capacidade de recuperar os mesmos genes diferencialmente expressos identificados na seção anterior utilizando o pipeline HTSeq-DESeq2. Destas, apenas RSEM permite a quantificação ao nível de gene. Para Kallisto e Salmon, a análise de contagem e expressão diferencial foram realizadas ao nível de transcrito e 
os loci gênicos correspondentes usados na comparação. A identificação de genes diferencialmente expressos foi feita usando DESeq2 e os mesmos critérios de corte (Ifc $>|3,32|$ e p-adj<0.001). O cruzamento par-a-par da lista de DEGs resultou na sobreposição de $81 \%$ dos DEGs entre HTSeq e RSEM, 46\% entre HTSeq e Salmon e $27 \%$ entre HTSeq e Kallisto. A comparação entre todos as 4 abordagens está representada na figura 32.

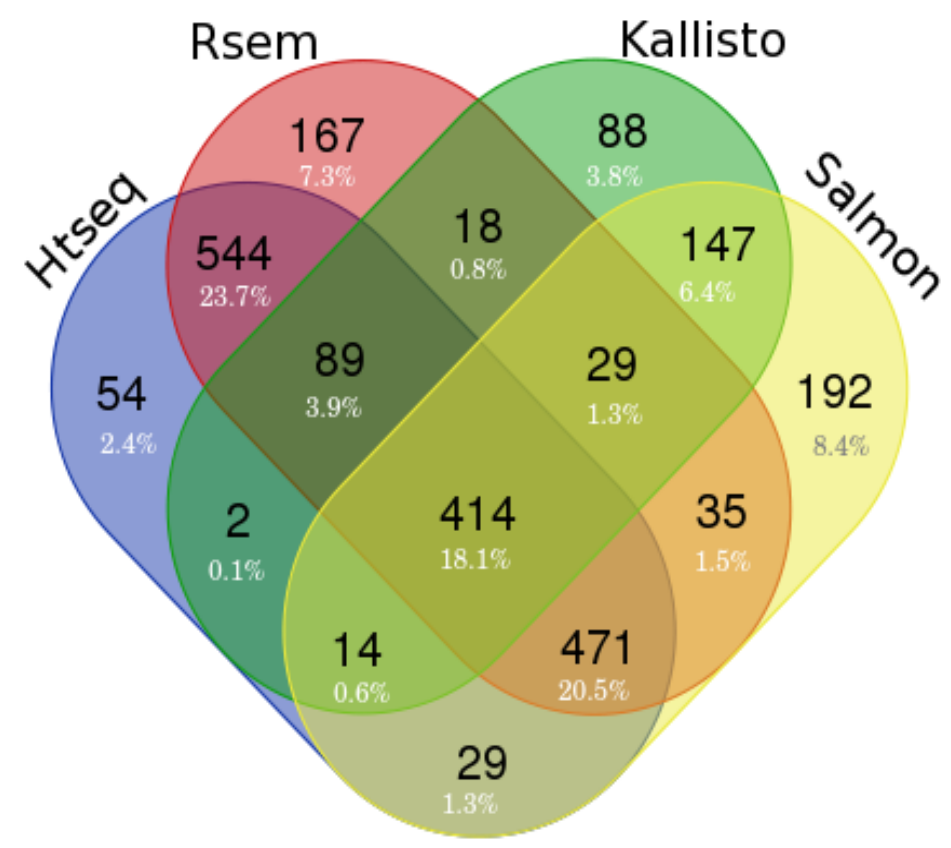

Figura 32. Sobreposição de genes diferencialmente expressos ( $|\mathrm{fc}>| 3,32 \mid$ e $\mathrm{p}$-adj $<0,001$ ) utilizando as abordagens HTSeq-Deseq2, RSEM-Deseq2, Kallisto-Deseq2 e Salmon-Deseq2

Considerando as diversas análises abordadas percebe-se que a quantificação da expressão em nível de gene e de transcrito não é uma tarefa trivial, e de fato, não existe um consenso geral na comunidade científica na determinação de qual é a melhor ferramenta disponível (Kanitz et al. 2015; C. Zhang et al. 2017). Para a quantificação ao nível do locus gênico, tanto a abordagem com HTSeq quanto por RSEM geram alta concordância, e são recomendados. Quando o objetivo é quantificar individualmente as diferentes isoformas produzidas em um mesmo locus gênico, os programas que apresentaram melhor desempenho foram Salmon, RSEM e Kallisto.

Considerando o bom desempenho e a flexibilidade de uso tanto em nível de gene quanto para transcrito, decidimos utilizar a ferramenta RSEM nas etapas subsequentes deste trabalho. Com esta ferramenta junto com Deseq2, e aplicando um filtro de fold change $>|10|$ e $p$-adj $\leq 0.001$, foram detectados 669 transcritos codificantes de proteínas, 171 novas formas de splicing, 49 RNAs antisensos (14 
conhecidos e 35 novos) e 86 RNAs intergênicos (34 conhecidos e 52 novos) (figura 33 e tabela 9).

a)

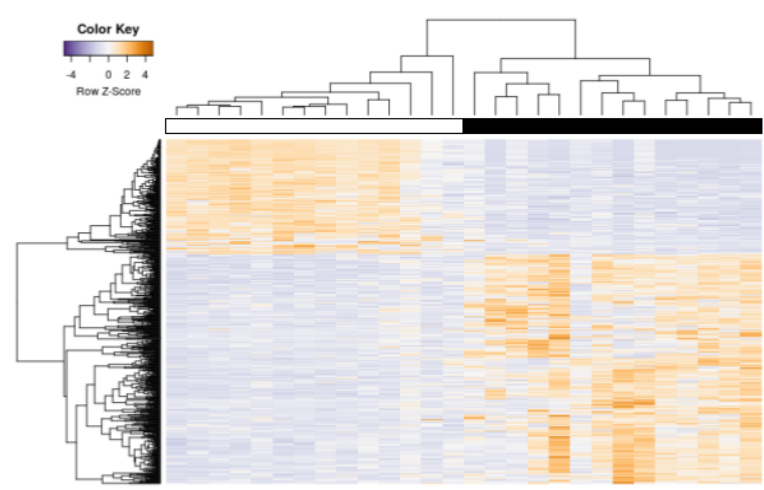

c)

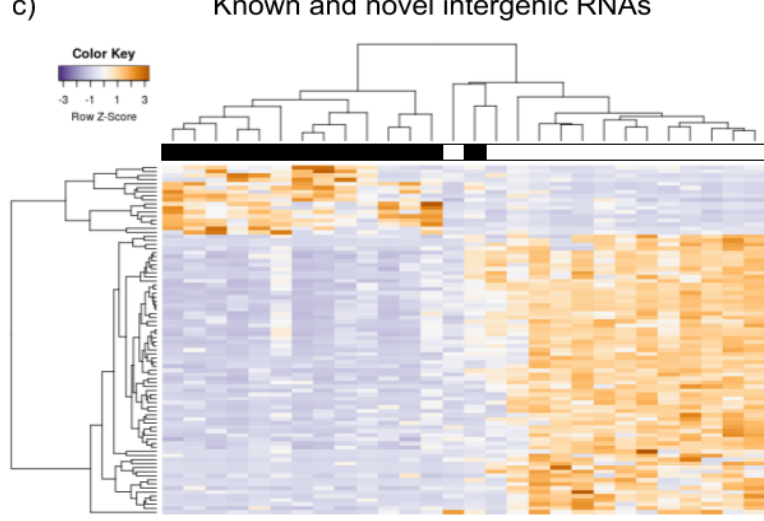

b)

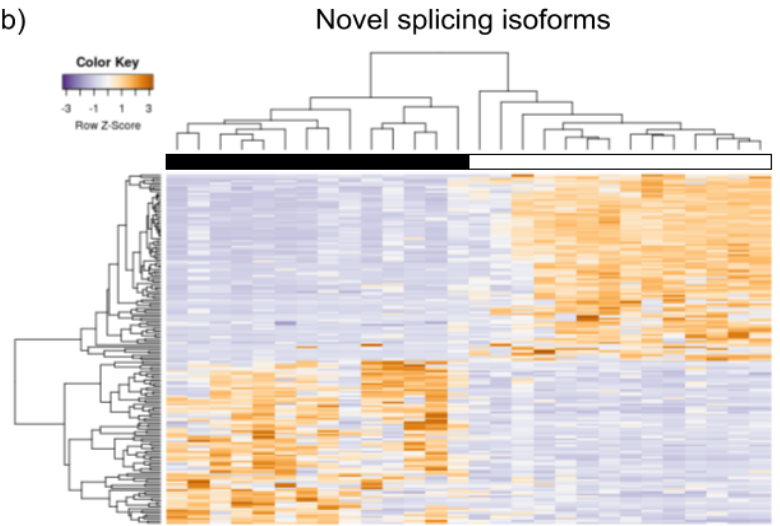

d)

Known and novel antisense RNAs

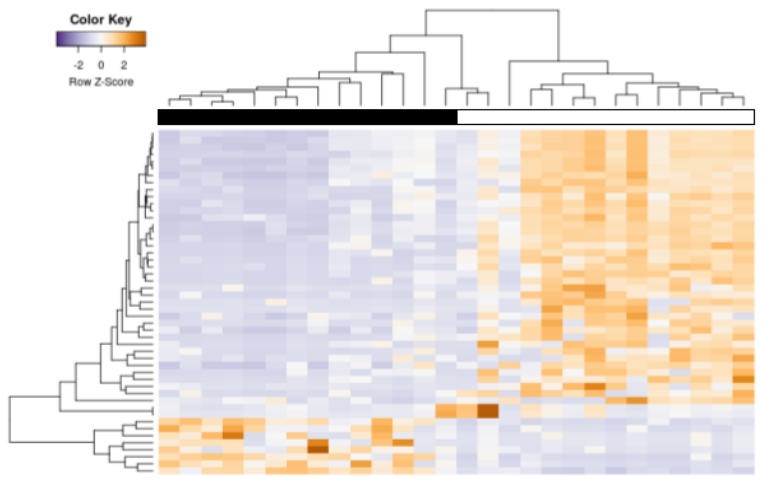

Figura 33. Transcritos novos e anotados no GENCODE diferencialmente expressos em PDAC. Painéis: a) codificadores de proteína ( $n=669) ; b)$ novas variantes de splicing $(n=171) ; c)$ RNAs intergênicos ( $n=86$; 34 conhecidos, 52 novos); e d) RNAs antisensos ( $n=49 ; 14$ conhecidos, 35 novos). Barras brancas: amostras não tumorais; barras pretas: amostras tumorais.

$\mathrm{Na}$ figura 34 estão representados os valores de expressão (log2 da razão Tumor/Não-tumor) desses 975 transcritos, junto com informação da classificação das amostras tumorais (colaboração do aluno Diogo Pessoa) nos subtipos descritos por Collison (Collisson et al. 2011) ("classical", "exocrine", "quase-mesenchymal") e Moffit (Moffitt et al. 2015) ("normal stroma", "activated stroma", "classical tumor" and "basal tumor"). A maioria das amostras foram classificadas como "activated stroma Moffit", "classical Moffit" (menos amostras s2, s4, s12 e s14), "exocrine Collison" (exceto s2, s4, s8, s10 e s14), enquanto que três amostras não foram enriquecidas nos subtipos Moffit tumor (amostras s3 e s10) nem Moffit stroma (s9). 

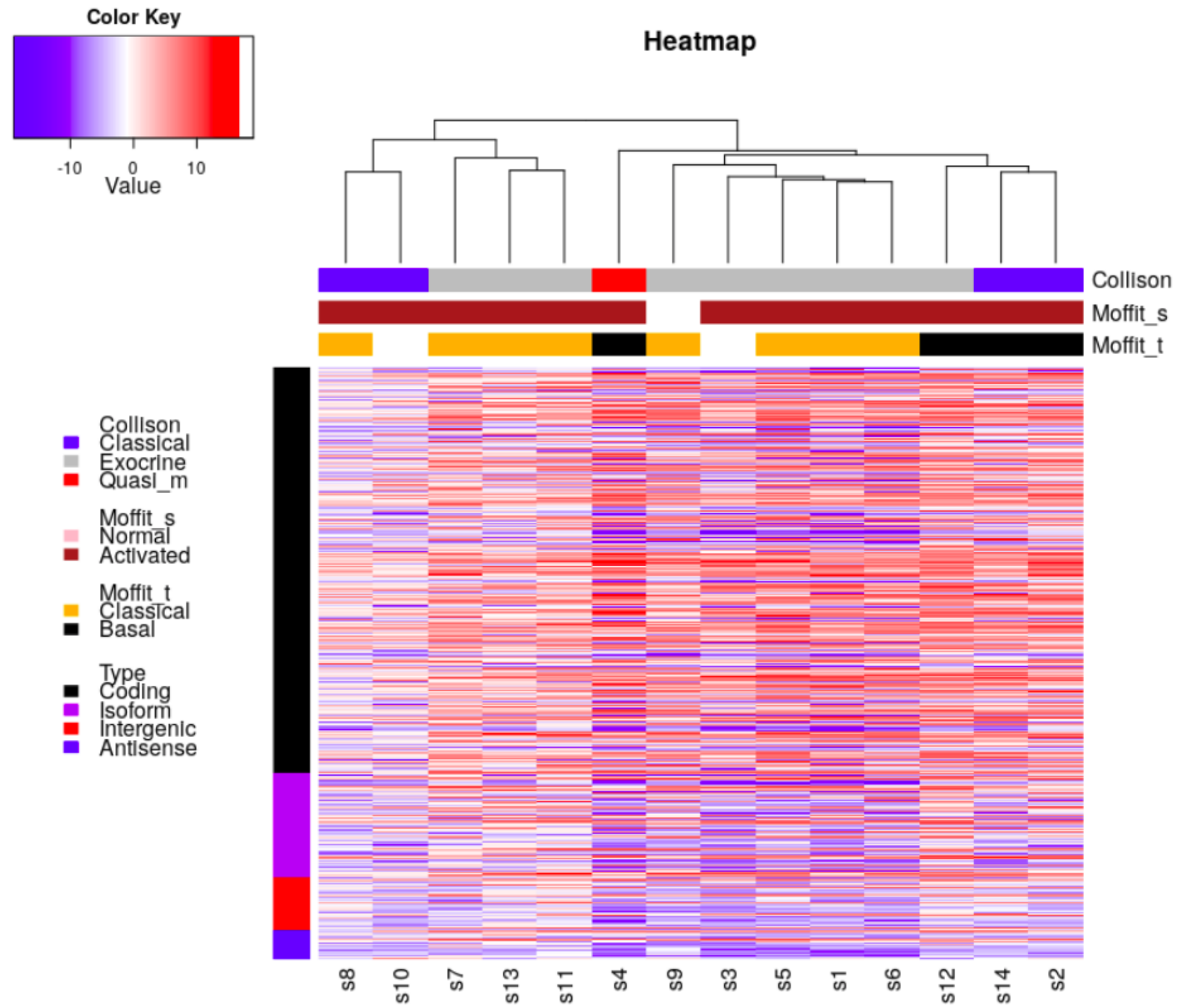

Figura 34. Heatmap representado os valores de expressão (log2 da razão Tumor/Não-tumor) dos 975 transcritos diferencialmente expressos (RSEM-Deseq2) separados por categorias e classificados nos subtipos tumorais descritos por Collison (Collisson et al. 2011) (classical, exocrine, quase-mesenchymal) e Moffit (Moffitt et al. 2015) (normal stroma, activated stroma, classical tumor and basal tumor).

Tabela 9. Top 10 genes de cada categoría identificados como diferencialmente expressos com um filtro de fold change $>|10|$ e $p$-adj $\leq 0.001$ (quantificação com RSEM e Deseq2).

\begin{tabular}{|c|c|c|c|}
\hline \multicolumn{4}{|c|}{ Annotated in GENCODE (protein coding) } \\
\hline \multicolumn{4}{|c|}{ Up-regulated } \\
\hline Transcript Id & Lfc & Padj & Gene name \\
\hline TCONS_00010277 & 23.2 & $5.5 \mathrm{e}-13$ & DMBT1 \\
\hline
\end{tabular}




\begin{tabular}{|c|c|c|c|}
\hline TCONS_00086165 & 23.1 & $7.3 e-13$ & PLEC \\
\hline TCONS_00051220 & 21.9 & $1.4 \mathrm{e}-11$ & FN1 \\
\hline TCONS_00079546 & 9.8 & $6.7 e-06$ & MUC17 \\
\hline TCONS_00048662 & 9.1 & $1.0 \mathrm{e}-16$ & UGT1A10 \\
\hline \multicolumn{4}{|c|}{ Down-regulated } \\
\hline TCONS_00082445 & -23.7 & $1.8 e-13$ & CUX1 \\
\hline TCONS_00064861 & -20.8 & $1.7 e-10$ & SLC4A4 \\
\hline TCONS_00064878 & -10.4 & 0.0001 & $A L B$ \\
\hline TCONS_00022133 & -9.5 & $1.6 e-20$ & C12orf39 \\
\hline TCONS_00008861 & -8.6 & $1.2 \mathrm{e}-12$ & PM20D1 \\
\hline \multicolumn{4}{|c|}{ Annotated in GENCODE (lincRNA) } \\
\hline \multicolumn{4}{|c|}{ Up-regulated } \\
\hline TCONS_00079631 & 5.4 & $4.3 e-06$ & $R P 5-884 M 6.1$ \\
\hline TCONS_00037260 & 5.2 & 0.0002 & LINC00675 \\
\hline TCONS_00002346 & 5.1 & $5.9 e-09$ & $R P 11-48020.4$ \\
\hline TCONS_00085965 & 4.9 & $1.2 \mathrm{e}-07$ & CCAT1 \\
\hline TCONS_00000395 & 4.9 & 0.0003 & $R P 3-340 N 1.2$ \\
\hline \multicolumn{4}{|c|}{ Down-regulated } \\
\hline TCONS_00008912 & -5.9 & $1.2 \mathrm{e}-08$ & $R P 11-392017.1$ \\
\hline TCONS_00067877 & -5.8 & $2.8 e-12$ & $R P 11-502 M 1.2$ \\
\hline TCONS_00021964 & -5.7 & $1.7 e-14$ & RP11-320N7.2 \\
\hline TCONS_00077139 & -5.5 & $1.2 \mathrm{e}-09$ & $R P 11-354 K 4.2$ \\
\hline TCONS_00052408 & -5.5 & $2.9 e-06$ & AC011298.2 \\
\hline \multicolumn{4}{|c|}{ Annotated in GENCODE (Antisense) } \\
\hline \multicolumn{4}{|c|}{ Up-regulated } \\
\hline TCONS_00078564 & 5.0 & 0.0007 & AC005550.3 \\
\hline
\end{tabular}




\begin{tabular}{|c|c|c|c|}
\hline TCONS_00005824 & 4.9 & $8.9 e-09$ & RP11-284F21.10 \\
\hline TCONS_00074870 & 4.5 & $8.2 \mathrm{e}-07$ & $R P 11-350 J 20.12$ \\
\hline TCONS_00011020 & 4.2 & 0.0002 & UNC5B-AS1 \\
\hline TCONS_00081467 & 4.2 & 4.0e-05 & $R P 11-395 B 7.4$ \\
\hline \multicolumn{4}{|c|}{ Down-regulated } \\
\hline TCONS_00086777 & -7.1 & $1.0 e-18$ & AF131216.5 \\
\hline TCONS_00057992 & -5.2 & 0.0004 & DGCR5 \\
\hline TCONS_00050250 & -5.1 & $1.2 \mathrm{e}-08$ & AC066593.1 \\
\hline TCONS_00027110 & -4.7 & $2.4 \mathrm{e}-08$ & $R P 11-404 P 21.3$ \\
\hline TCONS_00052435 & -4.5 & $5.8 e-06$ & AC131097.3 \\
\hline \multicolumn{4}{|c|}{ Novel isoform } \\
\hline \multicolumn{4}{|c|}{ Up-regulated } \\
\hline TCONS_00073520 & 21.1 & 7.7e-11 & CD83 \\
\hline TCONS_00084483 & 8.5 & $1.4 \mathrm{e}-06$ & FER1L6 \\
\hline TCONS_00062418 & 8.2 & $2.8 e-12$ & PLD1 \\
\hline TCONS_00042620 & 7.9 & $3.1 \mathrm{e}-10$ & $M I A-R A B 4 B$ \\
\hline TCONS_00038567 & 7.7 & $2.1 e-05$ & $A C O X 1$ \\
\hline \multicolumn{4}{|c|}{ Down-regulated } \\
\hline TCONS_00063350 & -9.0 & $4.6 e-21$ & CPB1 \\
\hline TCONS_00041017 & -8.4 & $5.3 e-21$ & ANKRD62 \\
\hline TCONS_00045939 & -7.8 & $1.8 e-17$ & ATP4A \\
\hline TCONS_00001645 & -7.7 & $3.4 e-16$ & $A M Y 1 A$ \\
\hline TCONS_00077036 & -7.5 & 4.0e-10 & CLPSL1 \\
\hline \multicolumn{4}{|c|}{ Novel intergenic } \\
\hline \multicolumn{4}{|c|}{ Up-regulated } \\
\hline TCONS_00009076 & 6.8 & $2.1 \mathrm{e}-06$ & - \\
\hline
\end{tabular}




\begin{tabular}{|c|c|c|c|}
\hline TCONS_00085964 & 6.3 & $1.2 \mathrm{e}-10$ & - \\
\hline TCONS_00021240 & 5.7 & $1.3 e-09$ & - \\
\hline TCONS_00036574 & 5.7 & $5.8 e-06$ & - \\
\hline TCONS_00060634 & 5.6 & 0.0003 & - \\
\hline \multicolumn{4}{|c|}{ Down-regulated } \\
\hline TCONS_00093593 & -6.8 & $4.5 e-17$ & - \\
\hline TCONS_00053018 & -6.3 & $5.0 e-14$ & - \\
\hline TCONS_00067632 & -6.0 & $1.0 \mathrm{e}-07$ & - \\
\hline TCONS_00028038 & -6.0 & 1.0e-09 & - \\
\hline TCONS_00055269 & -5.9 & $4.7 e-07$ & - \\
\hline \multicolumn{4}{|c|}{ Novel antisense } \\
\hline \multicolumn{4}{|c|}{ Up-regulated } \\
\hline TCONS_00014424 & 6.0 & 8.3e-11 & MMP12 \\
\hline TCONS_00089029 & 5.9 & $1.8 e-22$ & RP11-460N11.2 \\
\hline TCONS_00016117 & 5.1 & 0.0003 & ACER3 \\
\hline \multicolumn{4}{|c|}{ Down-regulated } \\
\hline TCONS_00067826 & -7.0 & $2.7 e-17$ & $R P 11-6 C 14.1$ \\
\hline TCONS_00082593 & -6.9 & $2.3 e-08$ & TRBV5-4 \\
\hline TCONS_00083248 & -6.0 & $3.9 e-14$ & TRBV5-1 \\
\hline TCONS_00067825 & -5.9 & $1.5 e-16$ & RP11-6C14.1 \\
\hline TCONS_00086443 & -5.7 & $1.0 \mathrm{e}-10$ & RNF5P1 \\
\hline TCONS_00017328 & -5.6 & $1.0 \mathrm{e}-07$ & OR6M1 \\
\hline TCONS_00012834 & -5.3 & $7.8 e-11$ & PNLIPRP1 \\
\hline
\end{tabular}

Entre os antisensos, 13 apresentam expressão diretamente correlacionada com seu par (senso), enquanto que 2 estão inversamente correlacionados (Lfc <> 0 e Padj < 
$0,5)$ (tabela 10). A lista completa de genes diferencialmente expressos foi inspecionada com o catálogo "Cancer Gene Census", encontrando 29 DEGs codificadores de proteína implicados em câncer com funções como oncogene e gene supressor tumoral (tabela 11).

Tabela 10. Correlação entre genes antisensos e seus respectivos sensos. Foram considerados significativos os pares com Lfc $<>0$ e Padj $<0,5$.

\begin{tabular}{|c|c|c|c|c|c|c|}
\hline Transcript Id & $\begin{array}{l}\text { Antisense } \\
\text { gene }\end{array}$ & Lfc & Padj & Sense gene & $\begin{array}{l}\text { Lfc sense } \\
\text { gene }\end{array}$ & $\begin{array}{l}\text { Padj sense } \\
\text { gene }\end{array}$ \\
\hline TCONS_00011020 & UNC5B-AS1 & 4.26 & 0.0002 & UNC5B & 1.55 & 0.0002 \\
\hline TCONS_00081467 & $\begin{array}{l}\text { RP11-395B7. } \\
4\end{array}$ & 4.24 & $4.06 e-05$ & MUC12 & 3.36 & 0.0002 \\
\hline TCONS_00014917 & AP006621.8 & -4.50 & $2.92 \mathrm{e}-06$ & EFCAB4A & -2.02 & 0.0002 \\
\hline TCONS_00052435 & AC131097.3 & -4.59 & $5.80 e-06$ & AC131097.4 & -4.72 & $2.11 \mathrm{e}-08$ \\
\hline TCONS_00050250 & AC066593.1 & -5.15 & $1.26 \mathrm{e}-08$ & DPP10 & -4.41 & 7.38e-09 \\
\hline TCONS_00063750 & FLNB-AS1 & -4.53 & $9.22 \mathrm{e}-05$ & FLNB & 0.81 & 0.0018 \\
\hline TCONS_00086777 & AF131216.5 & -7.19 & $1.05 e-18$ & TDH & -6.59 & $4.45 e-17$ \\
\hline TCONS_00012834 & - & -5.35 & $7.82 \mathrm{e}-11$ & PNLIPRP1 & -6.39 & $8.71 \mathrm{e}-17$ \\
\hline TCONS_00014424 & - & 6.00 & $8.36 e-11$ & MMP12 & 3.53 & 0.0066 \\
\hline TCONS_00016117 & - & 5.16 & 0.0003 & ACER3 & 0.90 & 0.0012 \\
\hline TCONS_00045274 & - & -4.20 & $6.36 \mathrm{e}-09$ & $\begin{array}{l}\text { RP11-678G14 } \\
.3\end{array}$ & -4.64 & $2.57 \mathrm{e}-10$ \\
\hline TCONS_00063392 & - & -3.96 & 0.0001 & SERPINI2 & -7.10 & $1.25 e-21$ \\
\hline TCONS_00077037 & - & -4.47 & 0.0002 & CLPS & -7.46 & $2.05 e-24$ \\
\hline TCONS_00083282 & - & -4.63 & $4.33 e-06$ & PRSS3P2 & -4.78 & 8.97e-08 \\
\hline TCONS_00090957 & - & -4.63 & 0.0005 & LRRC8A & 1.32 & 0.0003 \\
\hline
\end{tabular}

Tabela 11. Genes diferencialmente expressos (DEGs) encontrados no catálogo "Cancer Gene Census".

\begin{tabular}{|l|l|l|l|}
\hline Gene & Ensembl Id & Role in cancer & Cancer type \\
\hline BCL11B & ENSG00000127152 & $\begin{array}{l}\text { oncogene, TSG, } \\
\text { fusion }\end{array}$ & T-ALL \\
BUB1B & ENSG00000156970 & TSG & rhabdomyosarcoma \\
CASC5 & ENSG00000137812 & TSG, fusion & AML
\end{tabular}




\begin{tabular}{|c|c|c|c|}
\hline CDH11 & ENSG00000140937 & TSG, fusion & aneurysmal bone cyst \\
\hline COL1A1 & ENSG00000108821 & fusion & DFSP, aneurysmal bone cyst \\
\hline CSMD3 & ENSG00000164796 & TSG & ovarian cancer, oral SCC, lung cancer \\
\hline CTNNA2 & ENSG00000066032 & oncogene & gastric cancer \\
\hline CTNND2 & ENSG00000169862 & oncogene & prostae adenocarcinoma, GIST \\
\hline CUX1 & ENSG00000257923 & oncogene, TSG & $\begin{array}{l}\text { endometrial, melanoma, colorectal, AML, MDS, other } \\
\text { tumour types }\end{array}$ \\
\hline ELF4 & ENSG00000102034 & $\begin{array}{l}\text { oncogene, TSG, } \\
\text { fusion }\end{array}$ & AML \\
\hline FOXA1 & ENSG00000129514 & oncogene & breast, prostate \\
\hline HIST1H3B & ENSG00000124693 & oncogene & glioma \\
\hline HMGA2 & ENSG00000149948 & oncogene, fusion & $\begin{array}{l}\text { lipoma, leiomyoma, pleomorphic salivary gland } \\
\text { adenoma }\end{array}$ \\
\hline HOXA13 & ENSG00000106031 & oncogene, fusion & AML \\
\hline KCNJ5 & ENSG00000120457 & oncogene & adrenal adenoma \\
\hline LEF1 & ENSG00000138795 & oncogene, TSG & $\begin{array}{l}\text { B-ALL, T-ALL, eyelid sebaceous carcinoma, AML, } \\
\text { lymphomas }\end{array}$ \\
\hline MUC4 & ENSG00000145113 & oncogene & HNSCC \\
\hline MYB & ENSG00000118513 & oncogene, fusion & adenoid cystic carcinoma \\
\hline MYCL & ENSG00000116990 & oncogene & small cell lung carcinoma \\
\hline PALB2 & ENSG00000083093 & TSG & Wilms tumour, medulloblastoma, AML ,breast \\
\hline PTK6 & ENSG00000101213 & oncogene, TSG & renal, gastric, head and neck, ovarian, others \\
\hline $\mathrm{RHOH}$ & ENSG00000168421 & TSG, fusion & $\mathrm{NHL}$ \\
\hline RUNX1 & ENSG00000159216 & $\begin{array}{l}\text { oncogene, TSG, } \\
\text { fusion }\end{array}$ & AML, pre B-ALL, T-ALL \\
\hline SIX1 & ENSG00000126778 & oncogene & Wilms tumour \\
\hline SLC45A3 & ENSG00000158715 & fusion & prostate \\
\hline sox21 & ENSG00000125285 & TSG & multiple myeloma \\
\hline TP63 & ENSG00000073282 & oncogene, TSG & HNSCC, DLBCL, NSCLC \\
\hline TPM3 & ENSG00000143549 & TSG, fusion & papillary thyroid, ALCL, NSCLC, Spitzoid tumour \\
\hline WNK2 & ENSG00000165238 & TSG & gastric cancer \\
\hline
\end{tabular}




\section{IV.6 Análise de vias moleculares alteradas no PDAC}

Considerando os genes codificadores de proteínas que foram encontrados na seção anterior com uma expressão diferencial significativa, foi realizado uma análise de categorias funcionais e vias moleculares enriquecidas com o programa gProfiler (Reimand et al. 2007). Esta ferramenta utiliza informação de "Gene Ontology" (The Gene Ontology Consortium et al. 2000), KEGG (Minoru Kanehisa 2000) e "Reactome" (Fabregat et al. 2018) para gerar uma lista das vias afetadas (tabela 12). Entre os processos biológicos "up-regulated" observamos alterações que promovem o desenvolvimento tumoral como proliferação celular, divisão nuclear e regulação negativa de processos biológicos. Também encontramos vias relacionadas com o microambiente tumoral como degradação da matriz extracelular, ativação de metaloproteinases e formação de colágeno. Adicionalmente, vias envolvidas na regulação epigenética como metilação do DNA, histonas acetilases HATs e histonas metilases PRC2 são essenciais na tumorigênese (Biswas and Rao 2017), e o complexo repressivo Polycomb (PRC2) tem recebido a atenção da comunidade científica por seu envolvimento com diferentes tipos de tumores e a possibilidade de terapia com inibidores (Comet et al. 2016). Entre as vias "down-regulated" podemos observar uma alteração no funcionamento normal do pâncreas incluindo processos metabólicos, digestão, absorção, secreção e inclusive problemas na regulação de expressão gênica de células pancreáticas precursoras.

Tabela 12. Análise de enriquecimento gênico. Os genes codificantes de proteínas com expressão diferencial significativa (tumor vs não-tumor) foram considerados para realizar uma análise de vias utilizando o programa gProfiler (Reimand et al. 2007).

\begin{tabular}{|l|r|r|r|}
\hline \multicolumn{3}{|c|}{ UP-REGULATED } \\
\hline Term name & $\begin{array}{l}\text { N. of term } \\
\text { genes }\end{array}$ & $\begin{array}{l}\text { Corrected } \\
\text { p-value }\end{array}$ & $\begin{array}{l}\text { N. of query } \\
\text { genes }\end{array}$ \\
\hline Gene Ontology (Biological process) & 2121 & $1.64 \mathrm{E}-05$ & 78 \\
\hline cell proliferation & 1708 & $1.27 \mathrm{E}-02$ & 59 \\
\hline regulation of cell proliferation & 263 & $3.48 \mathrm{E}-02$ & 17 \\
\hline negative regulation of peptidase activity & 3044 & $4.33 \mathrm{E}-04$ & 96 \\
\hline immune system process & 35 & $1.03 \mathrm{E}-02$ & 7 \\
\hline anaphase-promoting complex-dependent catabolic process & 444 & $1.49 \mathrm{E}-08$ & 34 \\
\hline organelle fission & 401 & $8.44 \mathrm{E}-10$ & 34 \\
\hline nuclear division & 15950 & $4.81 \mathrm{E}-02$ & 331 \\
\hline cellular process & 591 & $2.57 \mathrm{E}-16$ & 51 \\
\hline cell division & & & \\
\hline
\end{tabular}




\begin{tabular}{|c|c|c|c|}
\hline cell cycle & 1766 & 3.27E-05 & 68 \\
\hline cellular developmental process & 4270 & 3.36E-02 & 116 \\
\hline epithelial cell differentiation & 759 & $4.26 \mathrm{E}-07$ & 43 \\
\hline cell cycle checkpoint & 213 & 4.15E-02 & 15 \\
\hline negative regulation of biological process & 5209 & 3.11E-02 & 136 \\
\hline cellular component organization & 6120 & $2.74 \mathrm{E}-02$ & 155 \\
\hline extracellular matrix organization & 332 & $6.85 \mathrm{E}-05$ & 24 \\
\hline chromosome organization & 1167 & 2.89E-06 & 54 \\
\hline chromatin assembly or disassembly & 187 & 1.69E-03 & 16 \\
\hline nucleosome organization & 174 & $3.46 \mathrm{E}-03$ & 15 \\
\hline response to stress & 3862 & 4.80E-05 & 118 \\
\hline hemidesmosome assembly & 11 & 5.53E-05 & 6 \\
\hline cell adhesion & 1343 & 4.45E-03 & 51 \\
\hline keratinocyte proliferation & 40 & 1.35E-04 & 9 \\
\hline collagen metabolic process & 100 & 8.89E-03 & 11 \\
\hline \multicolumn{4}{|l|}{ Gene Ontology (Molecular function) } \\
\hline laminin binding & 28 & $3.44 \mathrm{E}-02$ & 6 \\
\hline cell adhesion molecule binding & 470 & $1.11 \mathrm{E}-02$ & 25 \\
\hline calcium ion binding & 707 & 5.59E-03 & 33 \\
\hline \multicolumn{4}{|l|}{ Biological pathways (KEGG) } \\
\hline ECM-receptor interaction & 82 & 8.80E-03 & 9 \\
\hline Alcoholism & 180 & $2.08 \mathrm{E}-02$ & 13 \\
\hline Cell cycle & 124 & $6.85 \mathrm{E}-05$ & 14 \\
\hline \multicolumn{4}{|l|}{ Biological pathways (Reactome) } \\
\hline Signaling by Rho GTPases & 427 & $1.30 \mathrm{E}-05$ & 30 \\
\hline RHO GTPases Activate Formins & 121 & $1.45 \mathrm{E}-03$ & 13 \\
\hline RHO GTPases activate PKNs & 94 & 3.68E-03 & 11 \\
\hline Polo-like kinase mediated events & 16 & 3.70E-04 & 6 \\
\hline Cyclin A/B1/B2 associated events during G2/M transition & 25 & 4.18E-04 & 7 \\
\hline Signaling by Nuclear Receptors & 199 & $4.91 \mathrm{E}-03$ & 16 \\
\hline Cell Cycle & 628 & 1.89E-08 & 43 \\
\hline Type I hemidesmosome assembly & 9 & $4.26 \mathrm{E}-08$ & 7 \\
\hline HATs acetylate histones & 143 & $9.14 \mathrm{E}-03$ & 13 \\
\hline PRC2 methylates histones and DNA & 73 & $1.62 \mathrm{E}-02$ & 9 \\
\hline
\end{tabular}




\begin{tabular}{|c|c|c|c|}
\hline Phosphorylation of Emi1 & 6 & $1.64 \mathrm{E}-03$ & 4 \\
\hline HDACs deacetylate histones & 94 & $7.66 \mathrm{E}-05$ & 13 \\
\hline RMTs methylate histone arginines & 79 & 3.06E-02 & 9 \\
\hline TP53 Regulates Transcription of Cell Cycle Genes & 49 & 4.70E-02 & 7 \\
\hline Nucleosome assembly & 73 & $1.62 \mathrm{E}-02$ & 9 \\
\hline Extracellular matrix organization & 296 & 9.88E-09 & 29 \\
\hline Degradation of the extracellular matrix & 111 & 8.28E-05 & 14 \\
\hline Activation of Matrix Metalloproteinases & 33 & 3.70E-02 & 6 \\
\hline Collagen formation & 90 & $3.46 \mathrm{E}-04$ & 12 \\
\hline DNA methylation & 65 & $6.26 \mathrm{E}-03$ & 9 \\
\hline Activation of NIMA Kinases NEK9, NEK6, NEK7 & 7 & 3.76E-03 & 4 \\
\hline MET promotes cell motility & 29 & $1.71 \mathrm{E}-02$ & 6 \\
\hline MET activates PTK2 signaling & 18 & 1.70E-02 & 5 \\
\hline \multicolumn{4}{|c|}{ DOWN-REGULATED } \\
\hline Term name & \begin{tabular}{|l} 
N. of term \\
genes
\end{tabular} & $\begin{array}{l}\text { Corrected } \\
\text { p-value }\end{array}$ & $\begin{array}{l}\text { N. of query } \\
\text { genes }\end{array}$ \\
\hline \multicolumn{4}{|l|}{ Gene Ontology (Biological process) } \\
\hline vitamin metabolic process & 126 & $1.46 \mathrm{E}-04$ & 10 \\
\hline cofactor metabolic process & 533 & 1.18E-02 & 16 \\
\hline drug metabolic process & 757 & 5.08E-03 & 20 \\
\hline \multicolumn{4}{|l|}{ Gene Ontology (Molecular function) } \\
\hline serine hydrolase activity & 281 & 5.77E-03 & 12 \\
\hline peptidase activity & 721 & 9.70E-03 & 19 \\
\hline \multicolumn{4}{|l|}{ Biological pathways (KEGG) } \\
\hline Protein digestion and absorption & 90 & 4.23E-07 & 11 \\
\hline Pancreatic secretion & 96 & 6.34E-13 & 16 \\
\hline Fat digestion and absorption & 41 & 8.12E-03 & 5 \\
\hline Glycine, serine and threonine metabolism & 40 & $1.08 \mathrm{E}-06$ & 8 \\
\hline \multicolumn{4}{|l|}{ Biological pathways (Reactome) } \\
\hline Digestion & 22 & 4.42E-04 & 5 \\
\hline Metabolism of amino acids and derivatives & 369 & $1.88 \mathrm{E}-03$ & 14 \\
\hline Metabolism of vitamins and cofactors & 189 & 2.67E-03 & 10 \\
\hline Regulation of gene expression in early pancreatic precursor cells & 8 & $1.34 \mathrm{E}-02$ & 3 \\
\hline
\end{tabular}




\section{IV.7 Identificação de RNAs circulares}

Os RNAs circulares (circRNAs) são um tipo de moléculas que possuem as extremidades 5' e 3' ligadas covalentemente resultante de processamento pós-transcricional (Salzman et al. 2012). Sua detecção em amostras de RNA-seq é feita procurando especificamente reads "quiméricos", ou seja, reads em que a sequência 5' no read é "downstream" da sequência 3' com respeito à transcrição (S. Barrett and Salzman 2016). No presente trabalho foi aplicado o programa CIRI (Y. Gao, Wang, and Zhao 2015), resultando na identificação de 3.731 possíveis circRNAs nas amostras não-tumorais, e 6.115 nas amostras tumorais. As coordenadas dos possíveis circRNAs das duas condições foram cruzadas, chegando na identificação de 2.387 circRNAs comuns, 1.344 exclusivos não-tumorais e 3728 exclusivos tumorais (figura 35a). Os mesmos foram classificados como exônicos (3.464 não-tumorais e 5.518 tumorais), intrônicos (129 não-tumorais e 315 tumorais) ou intergênicos (138 não-tumorais e 282 tumorais) (figura 35b). Os potenciais circRNAs foram anotados considerando o banco de dados circBase (Glažar, Papavasileiou, and Rajewsky 2014), chegando na identificação de 6.285 RNAs com coordenadas dentro de circRNAs conhecidos $(84,3 \%)$ e 1.174 novos $(15,7 \%)$. 


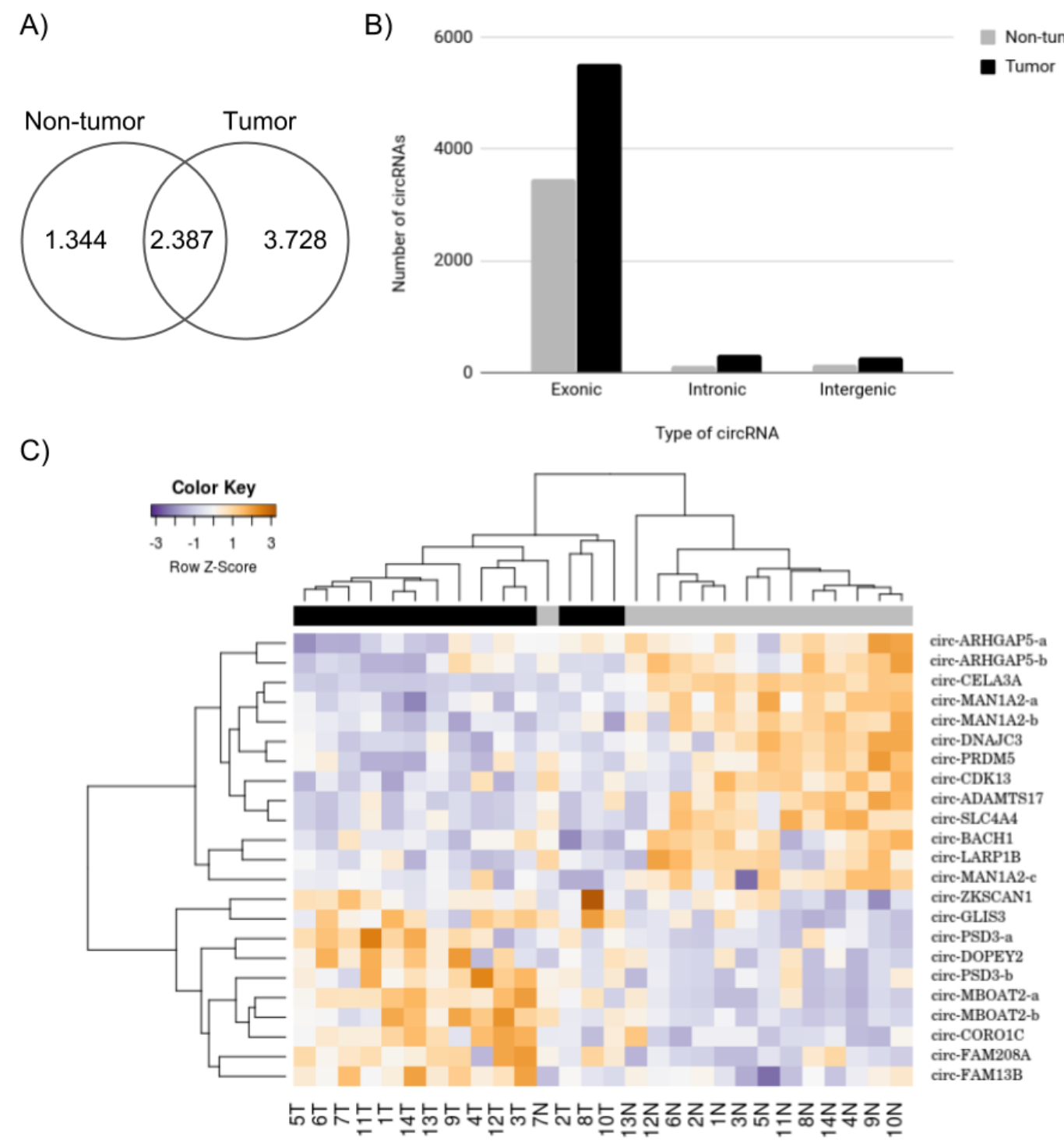

Figura 35. Identificação de circRNAs no pâncreas. A) Número de possíveis circRNAs nas amostras tumorais e não-tumorais. B) Diferentes tipos de circRNAs (exônicos, intrônicos e intergênicos) detectados nas duas condições. C) Análise de expressão diferencial dos circRNAs detectados (Ifc $<>0$ \& padj < 0.05).

Como seguinte passo, consideramos somente os potenciais circRNAs que foram detectados em pelo menos a metade das amostras, restando 340 transcritos que foram utilizados para fazer uma análise de expressão diferencial (figura 35c) resultando em 10 circRNAs "up-regulated" e 13 "down-regulated", considerando um log2FC <> 0 e p-adj < 0,05 (tabela 13). 
Tabela 13. circRNAs diferencialmente expressos no PDAC (padj < $0.05 \&$ Ifc $<>0$ )

\begin{tabular}{|c|c|c|c|c|c|c|c|c|}
\hline Chr & Coo1 & Coo2 & Strand & IfC & padj & Class & Locus_id & Gene_name \\
\hline chr12 & 109046048 & 109048186 & - & 1.5 & 3.00E-02 & C & XLOC_009555 & CORO1C \\
\hline chr21 & 37619815 & 37620866 & + & 2.1 & 0.0357 & c & XLOC_022904 & DOPEY2 \\
\hline chr2 & 9048751 & 9098771 & - & 2.6 & 0.0012 & c & XLOC_020158 & MBOAT2 (a) \\
\hline chr2 & 9083316 & 9098771 & - & 2.6 & 0.0076 & C & XLOC_020158 & MBOAT2 (b) \\
\hline chr3 & 56661065 & 56662642 & - & 2 & 0.0324 & c & XLOC_025893 & FAM208A \\
\hline chr5 & 137320946 & 137324004 & - & 0.8 & $4.32 \mathrm{E}-02$ & c & XLOC_030790 & FAM13B \\
\hline chr7 & 99621042 & 99621930 & + & 1.1 & 4.63E-02 & c & XLOC_034337 & ZKSCAN1 \\
\hline chr8 & 18622959 & 18662408 & - & 2.4 & 0.0072 & C & XLOC_037008 & PSD3 (b) \\
\hline chr8 & 18656805 & 18662408 & - & 2.1 & 0.0069 & c & XLOC_037008 & PSD3 (a) \\
\hline chr9 & 4286038 & 4286523 & - & 1.7 & 0.0377 & c & XLOC_038679 & GLIS3 \\
\hline chr1 & 117944808 & 117957453 & + & -1.9 & 5.31E-06 & c & XLOC_001008 & MAN1A2 (b) \\
\hline chr1 & 117944808 & 117963271 & + & -1.5 & 2.06E-05 & C & XLOC_001008 & MAN1A2 (a) \\
\hline chr1 & 117944808 & 117984947 & + & -1.1 & 0.0432 & c & XLOC_001008 & MAN1A2 (c) \\
\hline chr1 & 22307531 & 22332037 & + & -7.4 & 8.79E-09 & - & XLOC_000238 & CELA3A / CELA3B \\
\hline chr13 & 96409898 & 96416207 & + & -2.5 & 1.87E-05 & C & XLOC_010033 & DNAJC3 \\
\hline chr14 & 32559708 & 32563592 & + & -1.6 & 0.0069 & C & XLOC_010745 & ARHGAP5 (a) \\
\hline chr14 & 32559708 & 32586493 & + & -2.6 & 0.0006 & C & XLOC_010745 & ARHGAP5 (b) \\
\hline chr15 & 100871094 & 100874385 & - & -3.1 & 0.0004 & - & XLOC_013225 & ADAMTS17 \\
\hline chr21 & 30693542 & 30702014 & + & -1.4 & 0.0307 & C & XLOC_022873 & $B A C H 1$ \\
\hline chr4 & 121675708 & 121732604 & - & -2.1 & 0.0069 & c & XLOC_028497 & PRDM5 \\
\hline chr4 & 128995615 & 129003460 & + & -2.2 & 0.0099 & C & XLOC_027386 & $L A R P 1 B$ \\
\hline chr4 & 72102293 & 72121116 & + & -3.3 & 0.0001 & C & XLOC_027134 & SLC4A4 \\
\hline chr7 & 40027198 & 40041630 & + & -2 & 0.0049 & c & XLOC_034006 & CDK13 \\
\hline
\end{tabular}

Foi observada uma alta correlação entre o log2-fold-change dos circRNAs e dos genes parentais (correlação Pearson $=0.8$ ), como pode ser observado no scatter plot da figura 36. 


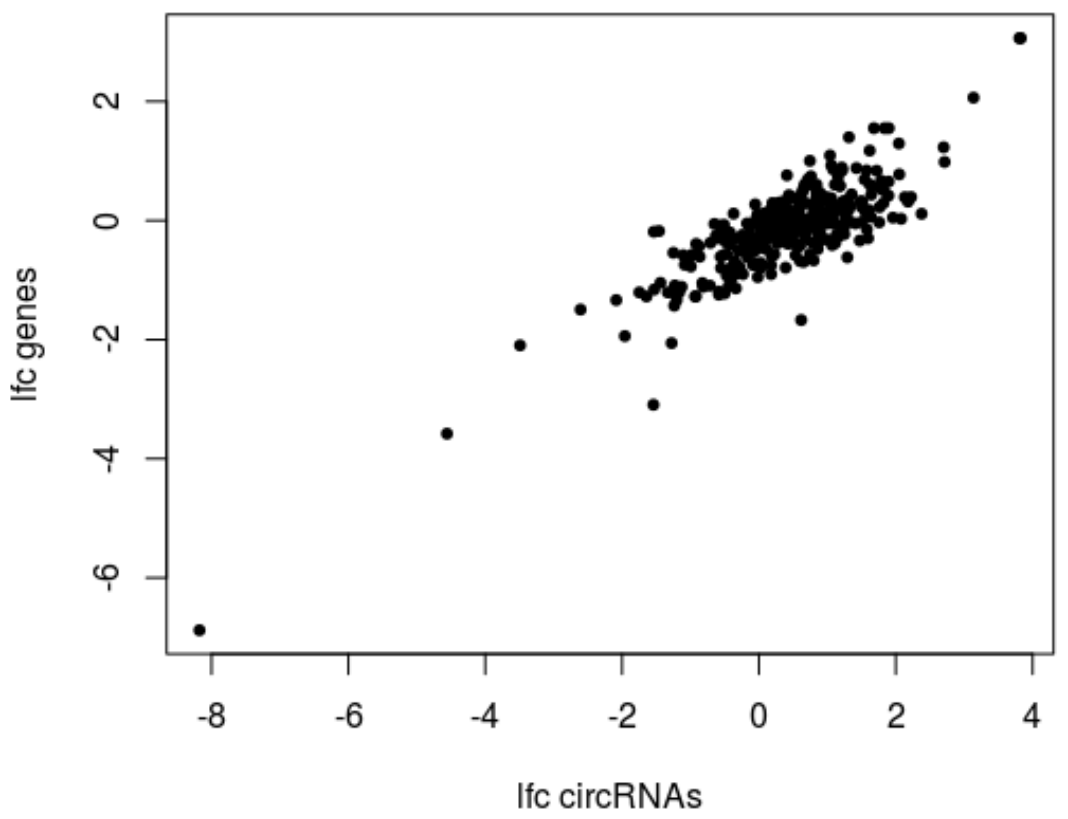

Figura 36. Scatter plot da correlação de Ifc (log2 fold change) dos circRNAs com os genes parentais (Pearson $=0,8$ ).

\section{IV.8 Seleção de candidatos para validação}

Foram selecionados genes diferencialmente expressos detectados com pelo menos três programas diferentes (secção IV.2.5.1). As validações experimentais por RT-PCR, foram realizadas pelos alunos Vinicius Ferreira, Victoria de Paiva e Ricardo Chiong como parte do seus projetos de doutorado e iniciação científica respectivamente.

Inicialmente foram escolhidos 6 RNAs não-codificadores longos (IncRNAs) já anotados no catálogo GENCODE que não tinham sido descritos anteriormente em PDAC (LINC01559, LINC01614, LINC01133, LINC00920, RP-5884M61, e DRAIC), assim como um (CCAT1) que já foi relacionado com câncer pancreático (Yu et al. 2016). Os resultados das validações encontram-se na figura 1 do Anexo 3.

Considerando os transcritos novos, foram selecionados e validados experimentalmente dois RNAs intergênicos (TCONS_00085964 e TCONS_00009076) com o maior fold change nas análises de RNA-seq (resultados da validação na figura 2 do Anexo 3). Um resumo de suas características é apresentado na tabela 14. 
Tabela 14. Transcritos novos intergênicos selecionados para validação experimental. Marcas regulatórias foram consideradas presentes se estavam a menos de $5 \mathrm{~kb}$ do TSS.

\begin{tabular}{|l|l|l|l|l|l|l|l|}
\hline Transcript Id & Lfc & P-adj & Cpc & Phylocsf & Promoter & Enhancer & CTCF \\
\hline TCONS_00085964 & 6.3 & $1.2 \mathrm{e}-10$ & 0.37 & -6944.9 & - & yes & yes \\
\hline TCONS_00009076 & 6.8 & $2.1 \mathrm{e}-06$ & 0.45 & -6956.6 & - & yes & - \\
\hline
\end{tabular}

Em relação às novas formas de splicing, foram selecionados para validação três genes (MMP14, CAPN8 e LIF) relacionados com diversos tipos de câncer, incluindo PDAC (Ota et al. 2009; W. Jiang et al. 2015; D.-T. Chen et al. 2015; Bressy et al. 2018; Ma et al. 2016), e que tem expressão desregulada em nossas amostras. Na figura 23 (painéis C, D e E) foi apresentada uma visualização dos transcritos no genome browser, e na figura 3 do Anexo 3 os resultados das validações experimentais. 


\section{DISCUSSÃO}

A agressividade do câncer de pâncreas, junto com as dificuldades diagnósticas e resistência aos tratamentos convencionais, o projetam como a segunda causa de morte relacionada à neoplasias para o ano 2030 (Rahib et al. 2014). Sendo assim, resulta fundamental aumentar nosso conhecimento da biologia molecular do tumor para tentar achar novos alvos diagnósticos e terapêuticos.

Em nosso trabalho, aplicamos a técnica de sequenciamento massivo de RNA (RNA-Seq) para caracterizar o transcritoma do tecido pancreático tumoral e tecido adjacente histologicamente normal, incluindo o componente que não codifica proteínas que até o momento foi pouco estudado. A boa qualidade dos reads e a alta porcentagem de mapeamento (média 85\%), assim como uma série de etapas de filtragem no processo de montagem para remover possíveis artefatos, baseadas em informação da literatura e na observação dos nosso dados, permitiu a identificação de um conjunto de 41.341 transcritos já anotados em Gencode e 6.710 transcritos ainda não anotados neste catálogo, muitos deles com um baixo potencial codificador.

Esses resultados foram obtidos utilizando uma cobertura média do transcritoma de 3,4Gb, e é plausível que o sequenciamento das bibliotecas com maior profundidade permita a detecção de transcritos raros não amostrados nessa análise. Para estimar se a profundidade é suficiente para detectar transcritos e formas alternativas de splicing menos abundantes, foram geradas curvas de rarefação utilizando a ferramenta RSeQC (L. Wang, Wang, and Li 2012) (colaboração Eduardo Reis). Este programa utiliza como referência as junções de splicing já anotadas no transcritoma e verifica a saturação com que estas junções são detectadas nas bibliotecas sequenciadas fazendo amostragens de $5 \%, 10 \%, 15 \%, \ldots$,até $95 \%$ do total de alinhamentos partindo do arquivo BAM (Figura 37). 
Top $10 \%$ most abundant genes

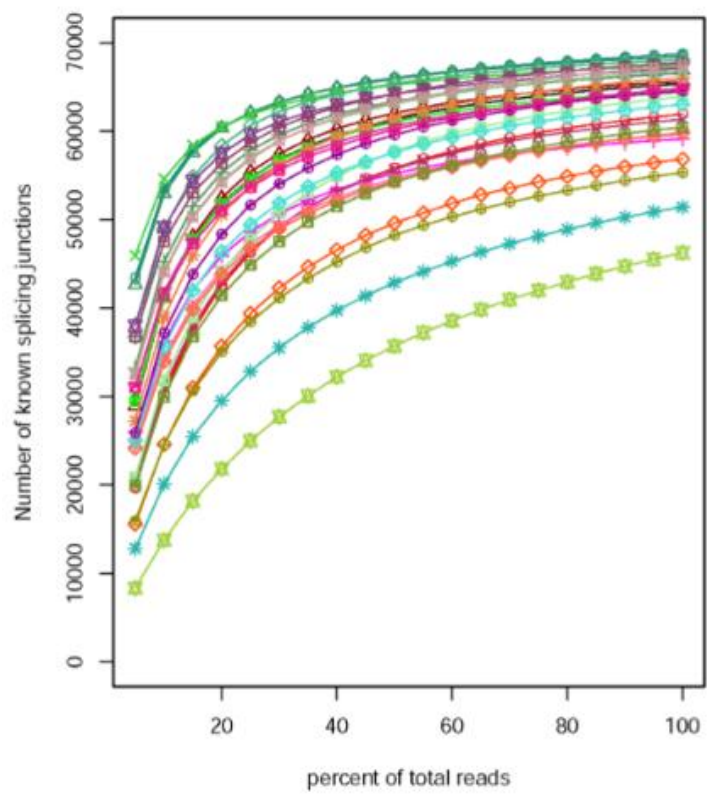

40 to $50 \%$ most abundant genes

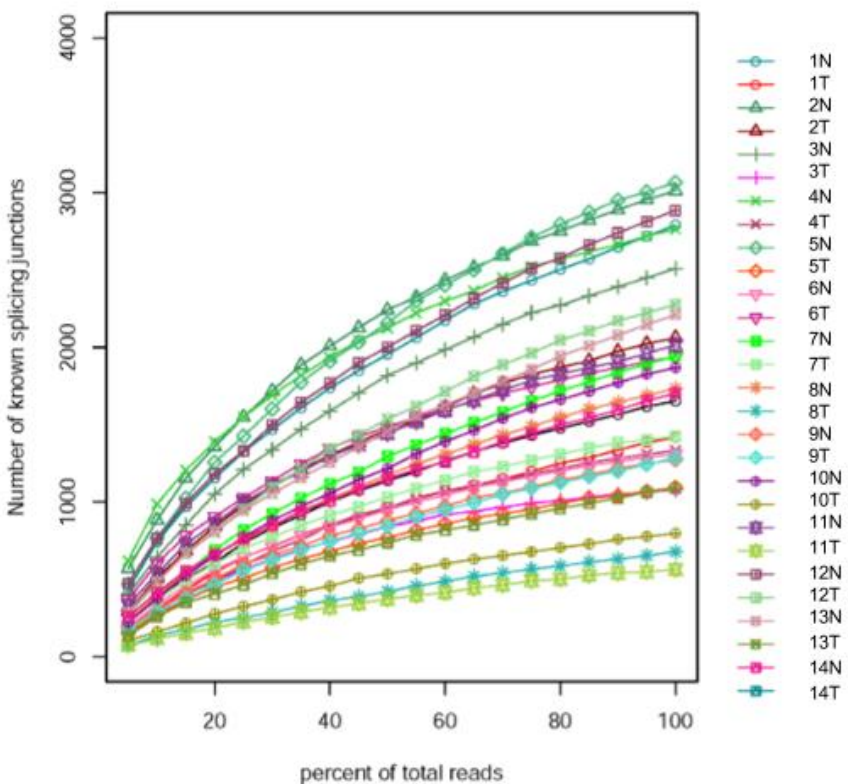

Figura 37. Curvas de rarefação da detecção de junções de splicing anotadas em genes com diferentes faixas de expressão (RSeQC). Créditos Eduardo Reis.

Nota-se que para os genes mais abundantes a profundidade de sequenciamento é adequada, pois o número de junções conhecidas vai chegando a um plateau. Por outro lado, observa-se que para os genes ranqueados entre os $40-50 \%$ mais abundantes a curva de rarefação não atinge um plateau, sendo necessário mais sequenciamento para que todas as junções de splicing anotadas sejam detectadas. Este resultado indica que para detectar a totalidade de transcritos expressos nesses tecidos, incluindo novos transcritos e novas formas de splicing, seria necessário produzir mais sequências das bibliotecas.

\section{V.1 RNAs não codificadores longos}

Os IncRNAs são um grupo RNAs não codificadores frequentemente reportados como envolvidos na regulação da expressão gênica e que já foram vinculados com diversas funções que favorecem ou inibem o desenvolvimento tumoral, tendo sido propostos como possíveis biomarcadores para diagnóstico, prognóstico e terapia (C. Huang et al. 2015; X. Q. Zhang et al. 2013; M. Zhou et al. 2015; Gibb, Brown, and Lam 2011; X. Hu et al. 2018; Evans, Feng, and Chinnaiyan 2016). Em relação ao câncer pancreático a maioria dos estudos de expressão gênica global focaram no componente codificador de proteínas. Nosso trabalho resultou na descoberta de milhares de novos transcritos que foram comparados com catálogos de referências, incluindo Gencode e MiTranscriptome. Coincidindo com a literatura, encontramos que os RNAs intergênicos 
e antisenso possuem baixa expressão, menor número de éxons e menor tamanho quando são comparados com genes codificantes (Derrien et al. 2012; Igor Ulitsky 2013). Também observamos que um $52 \%$ dos transcritos intergênicos e um $43 \%$ dos antisensos foram confirmados no catálogo MiTranscriptome, enquanto que os restantes (48\% e 57\% respectivamente) são possíveis novos IncRNAs detectados em nosso trabalho.

\section{V.2 Potencial codificador}

Para a determinação do potencial codificador, utilizamos diferentes abordagens: CPC que aplica aprendizado de máquina e calcula um score considerando características das ORFs ("Open reading frame") e de alinhamentos das sequências (Kong et al. 2007); e PhyloCSF que analisa a conservação evolutiva, sendo que as regiões mais conservadas têm maiores probabilidades de serem codificantes (Lin, Jungreis, and Kellis 2011). Além dessas duas ferramentas, procuramos a maior ORF de cada transcrito e comparamos a possível sequência de aminoácidos com o banco de dados de proteínas Swissprot, obtendo resultados mais semelhantes aos do CPC (a maioria dos que foram classificados como não-codificantes pelo CPC não possuem ORFs maiores que 100 aminoácidos, ou se têm não são semelhantes a proteínas conhecidas). O programa PhyloCSF por outra parte, classificou quase a metade das novas isoformas como não-codificadoras embora a maioria delas tem ORFs maiores que 100 com similaridade significativa no Swissprot.

Embora os IncRNAs em geral possuam um baixo potencial codificador, foi observado que uma fração deles possui a capacidade de gerar pequenos peptídeos. Por exemplo, o gene SRA foi inicialmente descrito como não codificador, mas Leygue e colaboradores encontraram que também pode ser traduzido em proteína (Leygue 2007). Num trabalho mais recente, Ruiz-Orera e colaboradores identificaram que uma importante proporção de IncRNAs expressos em células de 6 espécies diferentes estão associados com ribosomas (Ruiz-Orera et al. 2014). Em nosso trabalho, encontramos que entre um 48 e um 10\% das novas variantes de splicing possuem baixo potencial codificador (considerando PhyloCSF e CPC respectivamente), assim como mais de um $75 \%$ dos novos RNAs intergênicos e antisensos, sendo possíveis IncRNAs.

\section{V.3 Marcas de regulação associadas a expressão de novos transcritos}

Foi observado que unidades transcricionais possuem marcas de regulação epigenéticas caraterísticas que tem a capacidade de influenciar a arquitetura da cromatina, desde um estado condensado e inativo até um nível laxo e ativo que possibilita o acesso de fatores de transcrição e da RNA polimerase (Ernst et al. 2011; 
Barski A 2007). No presente trabalho cruzamos as coordenadas genômicas dos novos transcritos com dados de elementos regulatórios candidatos do projeto "SCREEN" que incluem sítios de hipersensibilidade à DNase com atividade epigenética suportada por modificações de histonas (H3K4me3 e H3K27ac) ou ligação com CTCF. Considerando a primeira base 5' do transcrito como TSS ("Transcription start site") calculamos as distâncias com a marca promotora, enhancer e CTCF mais próxima. Encontramos que uma fração expressiva das novas formas de splicing e dos novos RNAs antisensos e intergênicos possuem marcas de promotor e enhancer perto do seu TSS (Transcription Start Site), enquanto que as sinais de ligação com CTCF (CCCTC-binding factor) encontram-se uniformemente distribuídas entre os diferentes tipos de transcritos. No genoma humano foram encontrados sítios de ligação CTCF nos limites de domínios da cromatina, em enhancers, promotores e dentro do gene (Holwerda and de Laat 2013). Entre as diversas funções que foram atribuídas a essa proteína, temos as de ativador transcricional, repressor, insulator (bloqueando a comunicação entre promotores e enhancers), e organizador da estrutura terciária da cromatina (S. Kim, Yu, and Kaang 2015). Recentemente foi descrito que certos enhancers são ativos transcricionalmente gerando uma nova classe de IncRNA: os enhancers RNAs (eRNAs) (T.-K. Kim et al. 2010). Tendo em vista o grande número de RNAs novos com marcas de enhancer descobertos em nosso trabalho, é possível que alguns deles possam ser incluídos nesta categoria. Existem indícios de que a síntese dos eRNAs é de forma regulada e não apenas ruído transcricional, assim por exemplo no trabalho de Kim et. al., depois de estimulação neuronal somente alguns enhancers produziram eRNAs, e se localizaram perto dos mRNAs que são induzidos (T.-K. Kim et al. 2010). Sua função na regulação da expressão gênica foi evidenciada em diversos tecidos, sendo que knockdown de vários eRNAs causaram uma diminuição da expressão de genes alvos vizinhos (Lam et al. 2013; W. Li et al. 2013; Melo et al. 2013). Resulta importante também o papel dos eRNAs no desenvolvimento do câncer, e já foi descrita sua participação em mama (W. Li et al. 2013), próstata (Zhao et al. 2016), câncer colorretal (McCleland et al. 2016) e carcinoma celular basal (Bal et al. 2017). Um exemplo interessante é o trabalho de McCleland et. al. onde utilizaram CRISPR para identificar reguladores epigenéticos em câncer de cólon. Eles observaram que a proteína BRD4 é fundamental para proliferação celular e sua inibição com JQ1 (um inibidor da família proteica BET que inclui BRD4) reduz o crescimento in vivo. Encontraram um enhancer que regula a transcrição de $C M Y C$ e curiosamente o IncRNA CCAT1 é transcrito desde essa região e é sensível a inibição de BET (McCleland et al. 2016). Esses resultados sugerem que CCAT1 ("up-regulated" e validado experimentalmente em nossas amostras) é um possível biomarcador para identificar pacientes que poderiam se beneficiar com tratamentos inibidores de BET. O trabalho de Rahnamoun et. al. demonstra que interações BRD4-eRNAs aumentam a ligação de BRD4 com histonas 
acetiladas, e a estabilização do complexo incrementa a expressão de genes próximos que promovem a tumorigênese (Rahnamoun et al. 2018). Particularmente em câncer de pâncreas, Mazur et. al. testaram em camundongos uma terapia combinada com JQ1 e SAHA (um inibidor desacetilase de histonas HDAC), resultando num aumento da morte celular e suprimindo o avanço do PDAC (Mazur et al. 2015). Também foi demonstrado que o inibidor JQ1 diminui o estroma e suprime o crescimento de tumores derivados de pacientes (PDX) de PDAC, atuando nos fibroblastos associados a câncer (CAFs) (Yamamoto et al. 2016). Huang et. al. apresentam evidência que a inibição de BET resulta numa diminuição de "sonic hedgehog" SHH ("up-regulated" em nosso trabalho), um mediador chave no microambiente tumoral (Y. Huang et al. 2016). A sinalização "hedgehog" em câncer pancreático é controversa, embora um aumento da expressão de $S H H$ favorece a proliferação celular e conduce a formação de estroma desmoplásico rico em fibroblastos, a deleção de $\mathrm{SHH}$ em modelo murino reduziu o conteúdo estromal mas os tumores foram mais agressivos e indiferenciados histologicamente (Rhim et al. 2014). Outro trabalho recente usa um novo inibidor de $\mathrm{BET}$, BAY 1238097, em modelos de PDAC com mutações de RAS in vivo e in vitro, resultando numa redução tumoral independente da regulação por MYC (Jauset et al. 2018).

\section{V.4 Variantes de splicing}

Encontramos 6.187 potenciais novas isoformas de genes conhecidos, sendo que uma fração compreende genes previamente relacionados com câncer (entre eles $A P C$, SMAD2, MMP14, CAPN8 e LIF). O gene APC (Adenomatous Polyposis Coli) é um supressor tumoral que atua como antagonista na via Wnt, e foi encontrado com mutações em câncer pancreático (Horii et al. 1992; Shamai et al. 2015). O gene SMAD2 pertence a uma família de moléculas citoplasmáticas envolvidas na via TGF- $\beta$, frequentemente alterada no PDAC e que resulta no aumento da migração celular, invasão e metástase (Ungefroren et al. 2011). MMP14 é uma metalloproteinase (MMP) responsável pelo remodelamento da matriz extracelular. As MMPs foram propostas como possíveis alvos terapêuticos, e foi relatado que podem influenciar o microambiente tumoral levando a um maior crescimento, angiogênese e metástase (Cathcart, Pulkoski-Gross, and Cao 2015). CAPN (Calpains) é uma família de proteases dependentes de cálcio que regula vários processos celulares clivando sustratos (Hata et al. 2016), e já foi correlacionada a expressão de CAPN8 com pior prognóstico em PDAC (D.-T. Chen et al. 2015). Recentemente Bressy e colaboradores encontraram uma sobre-expressão de LIF em tecidos de câncer pancreático, e detectaram sua presença em soro de pacientes e de camundongos com a doença mas não nos indivíduos saudáveis, indicando que poderia servir como biomarcador (Bressy 
et al. 2018). Curiosamente, também encontramos uma variante do gene KRAS. Após uma análise mais detalhada observamos que a diferença com os transcritos de referência estava numa pequena região da extremidade 5' UTR, motivo pelo qual não foi considerada para validação experimental subsequente.

\section{V.5 RNAs circulares}

RNAs circulares constituem uma classe de RNA não codificador descrita recentemente e ainda pouco estudada. Centenas de circRNAs são sintetizados e regulados durante a transição epitélio-mesênquima (EMT), indicando que podem ter implicâncias em migração, invasão e metástase, favorecendo o desenvolvimento do câncer (Conn et al. 2015). Aplicando a ferramenta CIRI (Y. Gao, Wang, and Zhao 2015) conseguimos identificar 3.731 possíveis circRNAs nas amostras não-tumorais, e 6.115 nas amostras tumorais. Embora os resultados são promissores, estudos comparativos de programas bioinformáticos evidenciaram uma alta proporção de falsos positivos (Hansen et al. 2016). Existem vários desafios para sua correta identificação, os circRNAs representam uma pequena porcentagem dos reads, aproximadamente 1-3\% do nível dos mRNAs, e em geral são expressos em baixos níveis (Szabo et al. 2015; Memczak et al. 2013; J. U. Guo et al. 2014). Alterações nos motivos de regiões exônicas por erros de sequenciamento podem levar a alinhamentos falso-positivos (Linda Szabo 2016). Estruturas circulares como lariats (productos do splicing linear) também podem ser detectados pelos algoritmos, embora foi observado que eles representam menos do $2 \%$ dos casos (Hansen et al. 2016). Para continuar trabalhando com um conjunto mais confiável consideramos somente os circRNAs que foram detectados em pelo menos a metade das amostras, restando 340 transcritos. Após uma análise de expressão diferencial encontramos 10 circRNAs "up-regulated" e 13 "down-regulated". Entre os genes parentais desregulados temos vários que foram descritos em diferentes processos tumorigênicos como: ASPH, MAN1A2, PSD3, CELA3B, ADAMTS17, PRDM5, SLC4A4, RhoBTB3 e CDK13 (Su et al. 2016; Sturla et al. 2016; J.-H. Lee et al. 2016; Kumar, Rao, and Ge 2012; Deng and Huang 2004; Parks and Pouyssegur n.d.; Albert Lu 2013; Pils et al. 2005; Even et al. 2016). A maioria deles tem uma correlação positiva com o fold change do circRNA correspondente, com excepção dos pares: circ-PSD3 (up) com PSD3 (down), e circ-CDK13 (down) com CDK13 (up). Enquanto que os genes parentais FAM208A, FAM13B, ZKSCAN1, GLIS3, DNAJC3 e ARHGAP5 não estão diferencialmente expressos em nossas amostras. Embora pouco se saiba sobre os mecanismos pelos quais os circRNAs atuam e se regulam a expressão gênica em células distantes de onde foram produzidos, a existência de circRNAs circulantes abre uma nova janela 
para sua aplicação como biomarcadores diagnósticos e terapêuticos (X. Li, Yang, and Chen 2018).

\section{V.6 Avaliação da metodologia para a quantificação da expressão gênica}

Um aspecto importante de nosso trabalho foi a utilização de amostras pareadas de 14 pacientes (colaboração com o Hospital AC Camargo, São Paulo) que permitiu a comparação da expressão gênica entre tecidos tumorais e não-tumorais. Foram feitas análises em nível de gene e de transcrito, sendo que a quantificação neste último nível apresentou uma maior complexidade resultante da alta sobreposição de éxons. Aplicamos várias ferramentas para determinar a melhor forma de tratar esse problema. Enquanto que RSEM, Salmon e Kallisto conseguiram detectar um maior número de isoformas e tiveram um bom desempenho geral, os piores resultados foram com HTSeq quem detectou apenas um $10 \%$ das isoformas consideradas. Isto está possivelmente relacionado a fato deste programa não lidar adequadamente com reads que alinham em regiões onde existe sobreposição de mais de um transcrito, sendo descartados da análise e assim subestimando a abundância da isoforma, ou mesmo não detectando a sua expressão. As novas ferramentas utilizadas para quantificação da expressão (Salmon, Kalisto e RSEM) possuem abordagens particulares para tratar esses casos, conseguindo detectar um número maior de isoformas (92\% Salmon, 71\% Kallisto, 88\% RSEM). Salmon consiste basicamente em três componentes: um modelo de mapeamento "light-weight" onde os reads são mapeados em posições do transcrito que são computadas sem realizar um alinhamento base por base, uma "fase online" que faz uma estimação inicial dos níveis de expressão e dos parâmetros do modelo, e uma "fase offline" que melhora as estimações de expressão (Patro et al. 2017). Outra particularidade desse programa é que consegue corrigir bias por conteúdo GC, melhorando as estimações de abundância e a sensibilidade da subsequente análise de expressão diferencial (Patro et al. 2017). Kallisto também compartilha o conceito de que não é importante saber exatamente onde alinha o read no transcrito, mas sim saber quais transcritos poderiam ter originado esse read. A estratégia deste programa é dividir os reads em pequenos "k-mers" e aplicar um "de Bruijn graph" para estimar qual é a isoforma que está sendo expressa (Nicolas L. Bray et al. 2016). RSEM por sua parte utiliza um modelo onde os parâmetros correspondem a níveis de expressão, distribuições dos reads nos transcritos e erros de sequenciamento (B. Li et al. 2010). Outra característica importante a considerar é o tempo de execução. Enquanto que para rodar HTSeq e RSEM é necessário um passo prévio de mapeamento no genoma (foram utilizados os alinhadores Tophat2 e Star, respectivamente), os programas Salmon e Kallisto usam diretamente os arquivos fastq como entrada e aplicam uma estratégia de "pseudo-alinhamento", sendo muito mais velozes (minutos vs. horas). 
Nossos resultados coincidem com outros trabalhos que avaliaram a capacidade de diferentes ferramentas para quantificar a expressão, sendo destacados RSEM, Kalisto e Salmon, e sem grandes diferenças na sensibilidade e especificidade entre eles (C. Zhang et al. 2017; Kanitz et al. 2015). No trabalho de Teng et. al. foi feita uma comparação de 7 pipelines (eXpress, FluxCapacitor, RSEM, Cufflinks, Sailfish, Salmon e Kallisto) utilizando dois conjuntos de dados (real e simulado), e encontraram que os rendimentos mais baixos foram os de express e Flux Capacitor, enquanto que os outros tiveram um desempenho semelhante com uma leve adventagem de RSEM (Teng et al. 2016). Considerando o bom rendimento de RSEM em nossas amostras e na literatura, assim como sua capacidade para funcionar tanto em nível de gene quanto de transcrito, decidimos continuar trabalhando com essa ferramenta nas análises subsequentes.

\section{V.7 Genes diferencialmente expressos no PDAC}

Entre os genes já anotados que tem uma expressão aumentada foram achados: SERPINB5, também conhecido como Maspin, foi proposto como possível biomarcador por sua detecção em tecidos tumorais pancreáticos e falta de expressão em tecidos pancreáticos normais (Maass et al. 2001), estando correlacionado o incremento na expressão de SERPINB5 com uma maior probabilidade de metástase (Wolf A. Mardin et al. 2010). Mais recentemente, foi observado que a desmetilação do seu promotor conseguiu diferenciar pancreatite de PDAC com uma sensibilidade de $57 \%$ e especificidade de 95\%, podendo ser utilizado como marcador na detecção de PDAC (W. A. Mardin et al. 2016). IncRNA LINC00941: foi encontrado com expressão aumentada em câncer gástrico, associando-se com invasão e metástase linfática, sendo sugerido como um novo potencial biomarcador diagnóstico ou terapêutico (Luo et al. 2018). COL17A1: codifica a cadeia alfa da proteína transmembrana colágeno XVII. No microambiente tumoral, níveis alterados de proteínas de matriz extracelular (como colágeno) podem facilitar os primeiros passos da invasão celular (metástase) em outros tecidos e sangue (Thangavelu et al. 2016). Particularmente, metilações no promotor de COL17A1 foram associadas com pior prognóstico no câncer epitelial (Thangavelu et al. 2016). IncRNA LINC00675: Li et. al. estimaram que sua expressão estava centos de vezes aumentada em comparação com amostras de pancreatite crônica, assim como também em relação a tecido normal. Sua expressão foi correlacionada positivamente com metástase linfática, invasão perineural e baixa sobrevida em PDAC (D.-D. Li et al. 2015). IncRNA PVT1: Huang e colaboradores observaram que o aumento de expressão deste gene está associado a uma menor sobrevida em pacientes com câncer pancreático (C. Huang et al. 2015), enquanto que Conte et. al. indicaram que este IncRNA estaria atuando como esponja de microRNAs 
da família miR-200 em tecido mamário (Conte et al. 2017). IncRNA UCA1: foi observado com expressão aumentada em diversos tipos de tumores, incluindo câncer pancreático favorecendo a proliferação celular, migração e invasão (P. Chen et al. 2016; X. Zhang et al. 2017; Y. Zhou et al. 2018; M. Zhang et al. 2018). Zhang et. al. sugere que UCA1 participa na via de sinalização Hippo interatuando com MOB1, Lats1 e YAP promovendo a migração celular (M. Zhang et al. 2018). Zhou et. al. fizeram análises de microarray em 36 tecidos tumorais e 16 normais, determinando que UCA1 atua regulando negativamente miR-96 e positivamente FOXO3 (Y. Zhou et al. 2018); enquanto que Zhang et. al. sugerem que UCA1 é um oncogene com função de esponja do microRNA miR-135a, regulando o crescimento e metástase do câncer pancreático (X. Zhang et al. 2017). A sobre-expressão de UCA1 também foi correlacionada com resistência a quimioterápicos como gemcitabina, cisplatina, tamoxifen, 5-FU, imatinib e EGFR-TKIs, enquanto que a inativação de UCA1 restabelece a sensibilidade às drogas $(\mathrm{H}$. Wang et al. 2017). Todos esses trabalhos destacam a importância de UCA1 como biomarcador diagnóstico e prognóstico, assim como também como possível alvo terapêutico em câncer pancreático (H. Wang et al. 2017). S100P: estudos recentes mostraram que a proteína S100P favorece a progressão do câncer participando na proliferação celular, angiogênese e metástase (Jiang et al. 2012), indicando que poderia ser um candidato terapéutico em PDAC. Além disso, a super-expressão de S100P em diferentes tipos de câncer, incluindo mama (Guerreiro Da Silva et al. 2000), cólon (Bertram et al. 1998), próstata (Averboukh et al. 1996), pulmão (Beer et al. 2002), gástrico (Shyu, Huang, and Jiang 2003) e colangiocarcinoma (Hamada et al. 2011), está correlacionada com pobre prognóstico nos pacientes com câncer quando é comparada com tecido normal. Hu et. al. (H. Hu et al. 2014) testaram o valor diagnóstico de S100P no câncer pancreático, achando uma grande sensibilidade $(0,87)$ e especificidade $(0,88)$, sugerindo seu possível uso como biomarcador. Mesothelin: é uma proteína localizada na membrana celular, e possível alvo terapêutico baseado em anticorpos, com alta expressão em vários tipos de câncer incluindo pancreático, mesotelioma, câncer de ovário e adenocarcinoma de pulmão (Hassan et al. 2016). Tang et. al. encontraram que MSLN e MUC1 (também "up-regulated" em nosso trabalho) são preditores de mortalidade em câncer pancreático (Tang, Qian, and Ho 2013) embora os mecanismos e funções na célula tumoral permaneçam desconhecidos (White et al. 2018). Também dentro dos genes "up-regulated" em nossas amostras tumorais, temos que os IncRNAs AC093850.2 e RP5-884M6.1 foram encontrados com expressão aumentada em câncer esofágico e nasofaríngeo respectivamente (G.-W. Huang et al. 2018; Wen et al. 2016), mas nunca em pâncreas. O IncRNA DLEU1 (aumentado em nossas amostras tumorais) foi recentemente encontrado "up-regulated" em PDAC e experimentos "knockdown" inibiram proliferação, migração e invasão in vitro e reduziram o tumor in vivo (S. Gao et al. 2018). Enquanto 
que entre os genes com expressão diminuída destacam-se: SERPINI2: membro da superfamília serpin, inibe elastase e quimiotripsina pancreática, protegendo as células do pâncreas de zimógenos ativados prematuramente (Higgins et al. 2017). CPA2: A Carboxipeptidase A2 é uma proteína monomérica secretada que atua nos resíduos aromáticos C-terminal, também foi descrita com expressão diminuída em pacientes com Adenocarcinoma Pancreático Ductal (PDAC) em diversos estudos (Grützmann et al. 2004; Tian et al. 2008). IncRNA LINC00339: encontrado "down-regulated" em PDAC e associado sua baixa expressão com pior sobrevida ( $F u$ et al. 2016), mas curiosamente estava "up-regulated" em glioma e em câncer de pulmão de células não pequenas, onde foi associado com os microRNAs miR-539-5p e miR-145 respectivamente (Yuan et al. 2018; J. Guo et al. 2018). CTRC: codifica um membro da família peptidase S1. Mutações nesse gene pode incrementar o risco de pancreatite, mas sua relação com câncer pancreático não está bem definida (Chu, Kohlmann, and Adler 2010). CELA2A: enzima secretada no pâncreas que degrada elastina, também foi achada com expressão diminuída em pacientes com PDAC (Gutiérrez et al. 2015).

\section{V.8 Anotação em subtipos moleculares de PDAC}

Nos últimos anos surgiram propostas para classificar o PDAC em subtipos moleculares a partir de assinaturas gênicas predominantes. Assim Collison et. al. identificou os grupos "classical", "quasi-mesenchymal" e "exocrine-like"; enquanto que Moffitt et. al. encontrou os subtipos de tumor "classical" e " "basal-like" e de estroma "normal" e "activated". Embora o subtipo "classical Moffitt" teria uma sobreposição com "classical Collison" (Torres and Grippo 2018), ambos com bom prognóstico, em nosso trabalho somente uma amostra (s8) coincidiu nos dois subtipos, sendo que é o segundo paciente com melhor sobrevida (4,5 anos). Os outros três pacientes "classical Collison" (s2, s10 e s14) também estiveram dentro dos seis com melhor sobrevida (9 anos, 3,2 anos e 2,6 anos respectivamente). Como descrito por Collisson et. al., pacientes com o padrão de expressão desse grupo seriam mais sensíveis a quimioterapia com Erlotinib, em contraposição aos subtipos "Collison quasimesenchymal" que seriam beneficiados com gemcitabina, caso do paciente s4 que teve a segunda pior sobrevida (1,1 anos) e corresponde a uma pessoa falecida de 65 anos com carcinoma adenoescamoso. Considerando o perfil de expressão dos genes "up" e "down-regulated", essa amostra foi agrupada separadamente das outras que tinham um maior componente PDAC. Apesar dos importantes esforços para classificar molecularmente o PDAC, falta um consenso entre os diferentes subtipos descritos (Torres and Grippo 2018), que possivelmente também sofrem a influência dos diferentes métodos de preparação das amostras, processamento dos dados e 
tecnologias utilizadas (Y. Du et al. 2017). Os resultados de classificação das 14 amostras analisadas neste trabalho corrobora a heterogeneidade descrita na literatura.

\section{V.9 Vias moleculares alteradas em PDAC}

Como resultado das análises de expressão diferencial, foram geradas listas com centenas de genes. Para reduzir a complexidade e aumentar o entendimento de como estes genes estão relacionados funcionalmente, foi empregada uma análise de enriquecimento de vias. Encontramos que genes "up-regulated" estão enriquecidos em funções chave na tumorigênese como proliferação celular, degradação da matriz extracelular, "checkpoint" do ciclo celular e adesão. O PDAC é caracterizado por um estroma prominente com implicações na progressão da doença (Hwang et al. 2008; E. et al. 2012), assim como também em possíveis terapias (Neesse et al. 2015). A matriz extracelular é o principal componente do estroma e a formação de colágeno promove a invasão e migração das células tumorais (Levental et al. 2009). Outra via importante é a sinalização por Rho GTPases, um regulador da polimerização do citoesqueleto de actina que já foi inibido sinteticamente com 8-hydroxydeoxyguanosine e teve efeito antimetastático em células cancerosas pancreáticas abrindo as possibilidades para novos tratamentos (Park et al. 2017).

Em relação aos IncRNAs, há evidências de que alguns deles possuem um papel regulatório na expressão gênica, e que essas associações podem ser investigadas através de redes de co-expressão. Em uma rede dessa natureza, os genes formam nós em um grafo não orientado em que as ligações são determinadas por uma medida de correlação de seus níveis de expressão. É de se esperar em sistemas biológicos que alguns genes estejam muito mais ligados que outros, adquirindo um comportamento de centralidade (hub), e quando esse gene é um IncRNA pode-se supor que este gene esteja agindo como um regulador daqueles com os quais ele esteja ligado (Liao et al. 2011). Como parte do projeto de doutorado do aluno Diogo Pellegrina (Programa de pós-graduação em Bioinformática da USP), a reconstrução do transcritoma e quantificações geradas nesse trabalho foram utilizadas em uma análise de redes de co-expressão com a ferramenta WGCNA (Langfelder and Horvath 2008), identificando-se clusters de genes altamente correlacionados que incluem novos transcritos e possibilita associar essa semelhança de expressão com possíveis funções. Para cada cluster gerado foi feita uma análise de enriquecimento gênico com gPofiler (Reimand et al. 2007). Para cada módulo foram selecionados os IncRNAs (conhecidos e novos) e foram comparadas suas distâncias na rede com outros membros do cluster. Na figura 38 é possível observar heatmaps de algumas vias importantes em câncer onde os IncRNAs estão representados nas colunas e os outros genes relacionados com a via estão representados nas linhas. 
A)

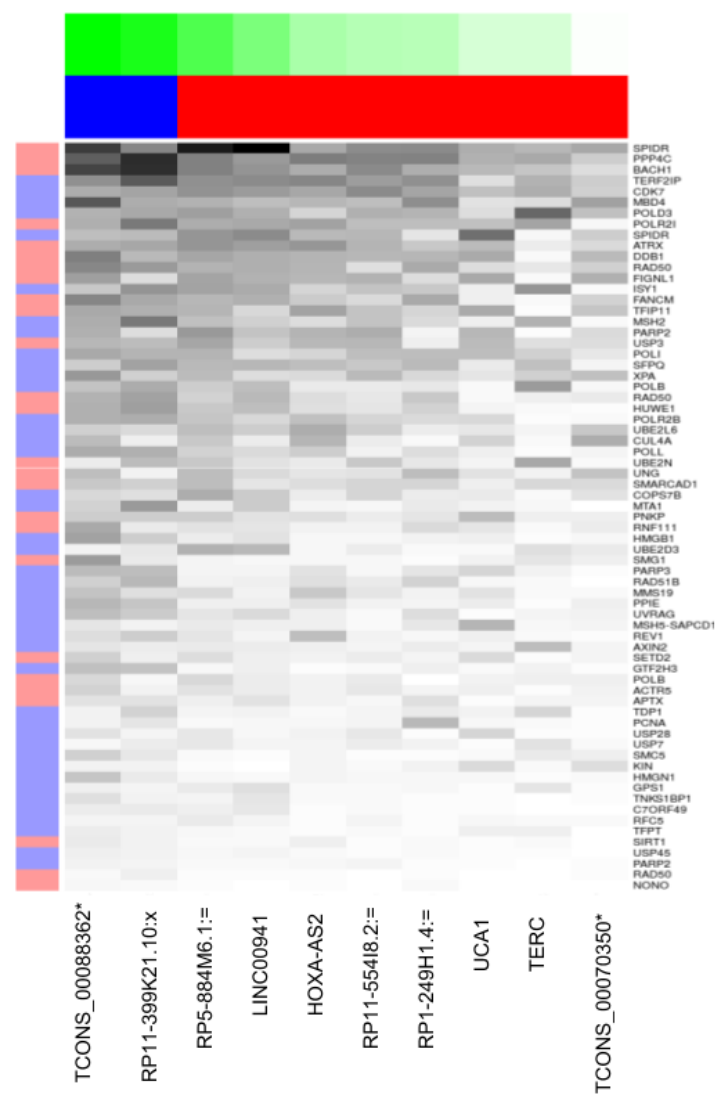

B) O-linked glycosylation of mucins

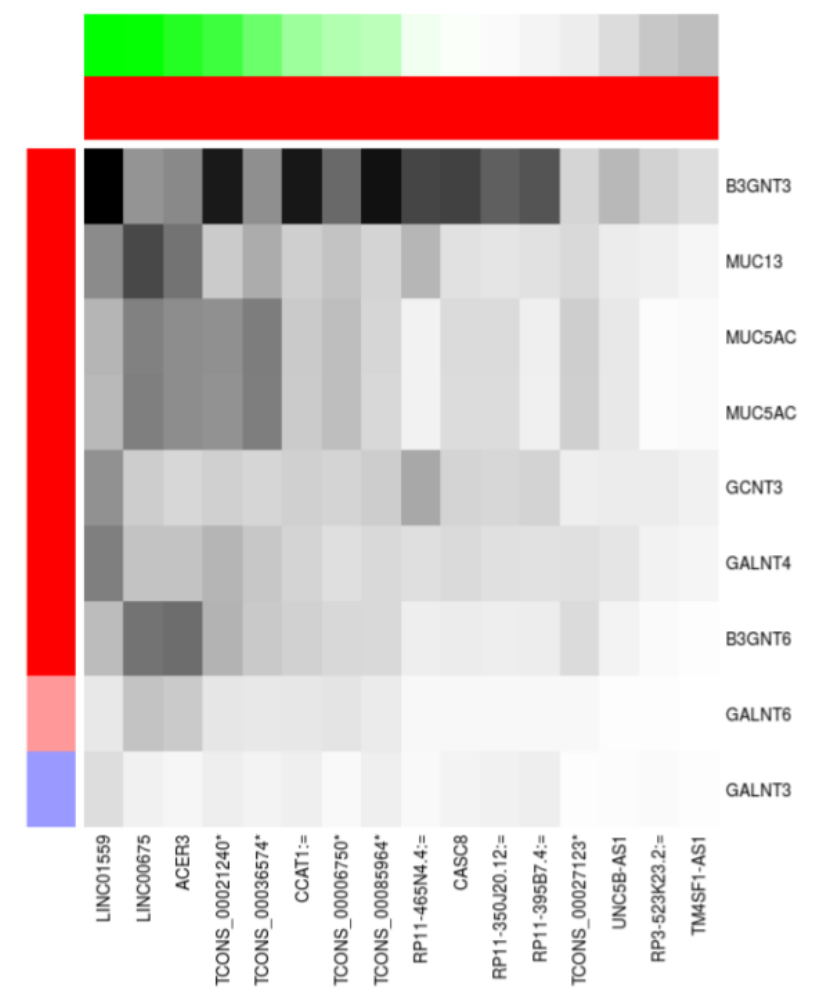

Figura 38. Heatmaps com a correlação entre os genes de diferentes vias (linhas) e os IncRNAs (colunas) detectados em nosso trabalho. Para cada gene conhecidamente de uma via, foi calculada a correlação média com os outros do cluster assim como a mediana. Os IncRNAs com uma média da correlação com os genes dessa via maior à mediana foram marcados com uma linha verde, os que tiveram igual à mediana com branco e menor com cinza. Em vermelho: genes up-regulated e em azul: down-regulated (Créditos: Diogo Pellegrina, tese de doutorado).

Entre os transcritos intergênicos novos detectados na análise de co-expressão encontramos vários com possíveis funções relacionadas a processos tumorigênicos. Os TCONS_00019150, TCONS_00020533, TCONS_00070643, TCONS_00074748 e TCONS_00087289 foram associados com adesão celular e atividade receptor, e todos eles estão com expressão aumentada no tumor. Assim mesmo, os transcritos intergênicos TCONS_00088362 e TCONS_00070350 (down e up-regulated respectivamente) encontram-se correlacionados com genes da via de reparo de DNA (figura 36), junto com os IncRNAs UCA1, RP5-884M6.1 (validado experimentalmente em nosso trabalho), e TERC (relacionado com senescência, estudos em camundongos 
sugeriram que também participa em reparo cromosômico ("TERC Telomerase RNA Component" n.d.)). Os IncRNAs validados experimentalmente CCAT1, LINC01559 e TCONS_00085964 encontram-se relacionados com "O-linked glycosylation of mucins" (figura 36), assim como também os TCONS_00021240 e TCONS_00036574 (todos up-regulated). Vale destacar que as mucinas são proteínas de membranas que estão sendo investigadas como potenciais target para terapia e diagnóstico do câncer pancreático (Suh, Pillai, and Morris 2017). A participação de glicanos em câncer está atraindo atenção porque alterações na glicosilação regulam o desenvolvimento e progressão de câncer, servindo como biomarcadores e possíveis alvos para terapia (Pinho and Reis 2015). Outro transcrito validado em nosso trabalho é o TCONS_00009076 que foi associado com "processos metabólicos de drogas e lipídios". A grande maioria dos IncRNAs aqui mencionados nunca antes foram relacionados a funções nem mecanismos de atuação.

\section{PDAC}

\section{V.10 Potencial prognóstico de transcritos diferencialmente expressos no}

Para a integração de dados públicos com os dados gerados em nosso laboratório, a aluna Ester Bertoldi desenvolveu um banco de dados local como parte do seu trabalho de mestrado (Programa de pós-graduação em Bioinformática, USP). Para determinar se existe uma associação com sobrevida dos transcritos diferencialmente expressos que foram reconstruídos em nosso trabalho, foram baixados dados clínicos e de alinhamentos do International Cancer Genome Consortium (https://icgc.org/) de 76 pacientes com PDAC do projeto PACA-AU e 137 do PAAD-US. As curvas de sobrevida Kaplan-Meier foram geradas com o pacote do R "Survival" (Therneau T. 2000). Dos 975 transcritos diferencialmente expressos (secção IV.6.2), 622 foram detectados no ICGC $(63,8 \%)$ e 78 com significância no KM, enquanto que no TCGA foram encontrados 642 $(65,8 \%)$ transcritos sendo que 74 deles são significativos na análise KM (tabela 15).

Tabela 15. Valor prognóstico dos transcritos diferencialmente expressos em amostras públicas. Os dados de RNA-seq e clínicos foram baixados do ICGC e TCGA. Créditos: Ester Bertoldi

\begin{tabular}{|c|c|c|c|c|c|}
\hline & & \multicolumn{2}{|c|}{ ICGC (PACA-AU; $\mathrm{n}=76)$} & \multicolumn{2}{c|}{ TCGA (PAAD-US; $\mathrm{n=137)}$} \\
\hline Gene Type & $\begin{array}{c}\text { \# transcripts (genes) } \\
\text { differentially expressed } \\
\text { in PDAC }\end{array}$ & $\begin{array}{c}\# \\
\text { detected }\end{array}$ & $\begin{array}{c}\text { \# significant in KM } \\
\text { analysis }(p<0.05)\end{array}$ & \# detected & $\begin{array}{c}\text { \# significant in } \\
\text { KM analysis }(p< \\
0.05)\end{array}$ \\
\hline Protein coding & $669(537)$ & 484 & 55 & 490 & 57 \\
\hline Novel splicing isoforms & $171(132)$ & 97 & 17 & 109 & 18 \\
\hline Intergenic RNA & $86(32)$ & 27 & 3 & 30 & 4 \\
\hline
\end{tabular}


Entre os novos transcritos com associação significativa (pvalue < 0,05 ) temos:

a) Novas formas de splicing: TCONS_00000294 (CELA2B), TCONS_00006993 (CELA2A), TCONS_0006994 (CELA2A), TCONS_00007028 (CELA3B), TCONS_0007373 (RNPC3), TCONS_00007980 (TMEM52), TCONS_00011665 (CUZD1), TCONS_00022296 (SLC39A5), TCONS_00034685 (DPEP1), TCONS_00045348 (KIRREL2), TCONS_00052405 (AC011298.2), TCONS_00052445 (FAM150B), TCONS_00055170 (RBPJL), TCONS_00067940(F11), TCONS_00067967 (TMED11P), TCONS_00077827 (CLPS), TCONS_00080096 (PRSS3P1), TCONS_00093899 (TEX11), TCONS_00000814 (SH3D21), TCONS_00005092 (EPS8L3), TCONS_00005094 (EPS8L3), TCONS_00005430 (MTMR11), TCONS_00005778 (ARHGEF2), TCONS_00006585 (CAPN8), TCONS_000028413 (CKMT1B), TCONS_00033418 (ERN2), TCONS_00033420 (ERN2), TCONS_00048744 (GPR35), TCONS_00054615 (FER1L4), TCONS_00054617 (FER1L4), TCONS_00054987 (PTK6), TCONS_00061202 (MST1R), TCONS_00062627 (TNK2), TCONS_00075403 (TRIM31) e TCONS_00084485 (FER1L6). b) RNAs intergénicos: TCONS_00000419 (LINC00339), TCONS_00014884 (MIR210HG), TCONS_00037260 (LINC00675), TCONS_00077086 (RP1-302G2.5), TCONS_00000395 (RP3-340N1.2) e TCONS_00079631 (RP5-884M6.1). c) RNAs antisensos: TCONS_00093419 (AS-GAPDHP1), TCONS_00014424 (AS-MMP12), TCONS_00014917 (AP006621.8) e TCONS_00090957 (AS-LRRC8A).

Encontramos que o aumento nos níveis do gene codificador da proteína CapG está associado com uma menor sobrevida dos pacientes. Thompson e colaboradores demonstraram que a inibição de CapG utilizando RNA de interferência em linhagens de células de câncer pancreático foi acompanhada por uma diminuição da mobilidade celular (Thompson et al. 2007). A alta expressão de CapG já foi reportada principalmente em câncer de mama, onde está sendo estudada como possível biomarcador e alvo para terapia. Van Impe et. al. desenvolveram "nanobodies" contra CapG que bloqueiam sua interação com os filamentos de actina, conseguindo diminuir a migração celular e invasão em células de câncer de pulmão (Van Impe et al. 2013). Recentemente Westbrook et. al. demonstram que a alta expressão em tumores de mama primários de CapG e GIPC1 (também aumentado em nosso trabalho) está associada com maior probabilidade de ter metástase em osso, e esses pacientes seriam beneficiados com uma terapia baseada no adjuvante bisfosfonato (Westbrook et al. 2016). Em nosso trabalho, encontramos que a elevada expressão da nova isoforma do IncRNA FER1L4 se corresponde com uma melhor sobrevida, coincidindo com outros estudos em câncer gástrico e de cólon (Z. Liu et al. 2014; Yue et al. 2015). Xia et. al. propuseram que FER1L4 supreme o crescimento de células cancerosas atuando 
como competidor endógeno RNA (ceRNA) ligando-se ao miR-106a-5p e regulando a expressão de PTEN em câncer gástrico (Xia et al. 2015). A nova isoforma do gene CELA2A (TCONS_00006993) e o codificador SERPINI2 (TCONS_00064081), genes que normalmente estão expressos no pâncreas (Gutiérrez et al. 2015) mas que nas células tumorais apresentam uma menor expressão ("down-regulated" em nosso estudo), foram associados com melhor prognóstico. Encontramos que a baixa expressão do IncRNA LINC00339 (TCONS_00000419, Ifc $=-5$ ) está correlacionada com menor sobrevida, coincidindo com o trabalho de Fu e colaboradores (Fu et al. 2016). O IncRNA RP5-884M6.1 (validado experimentalmente), identificado no cluster "DNA repair" na nossa análise de correlação, também foi encontrado com um valor prognóstico significativo sendo melhor quanto mais expresso (figura 39).

A)
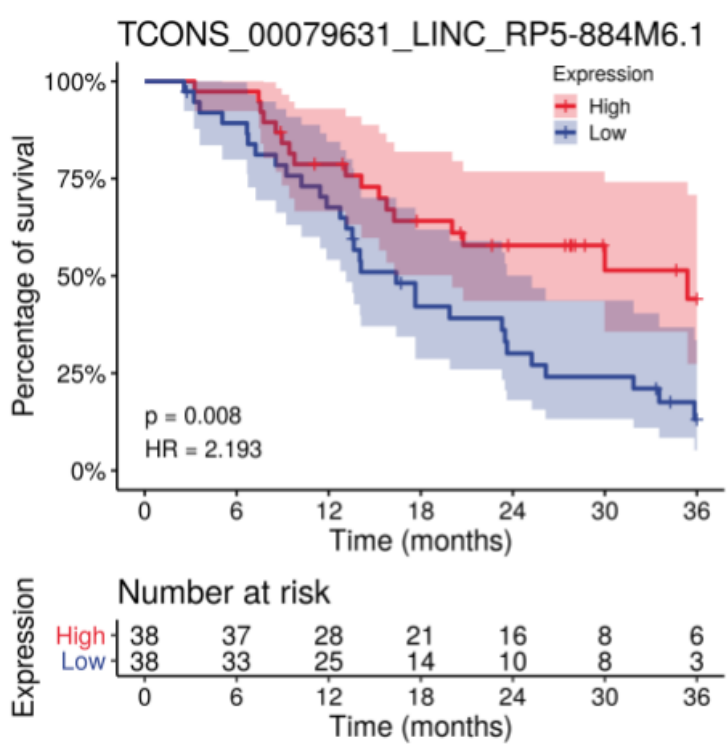

B)
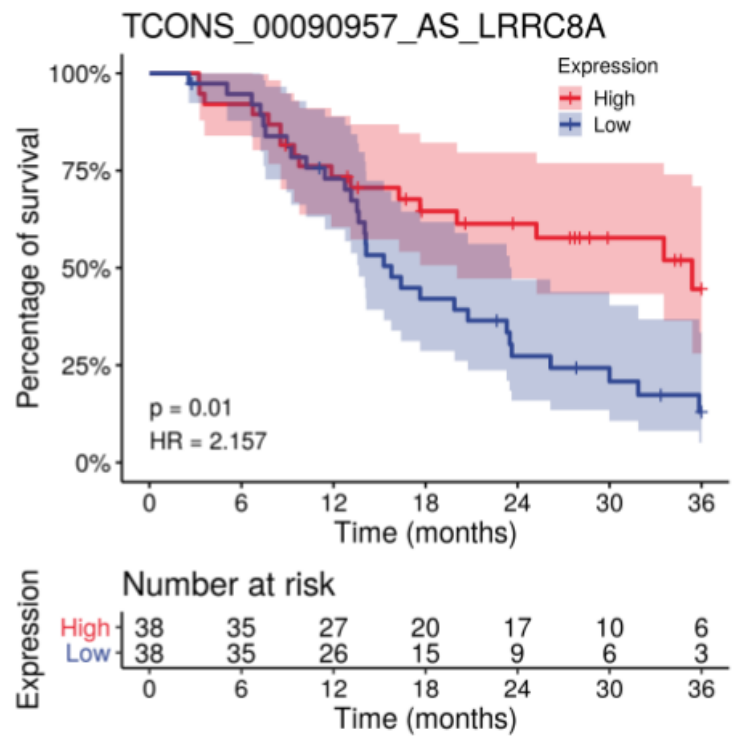

Figura 39. Curvas de sobrevida Kaplan-Meier. A) IncRNA RP5-884M6.1. B) Novo RNA antisenso do gene LRRC8A (TCONS_00090957) (Crédito Ester Bertoldi).

Finalmente, observamos que uma menor expressão do novo transcrito antisenso do gene LRRC8A (TCONS_00090957: AS-LRRC8A) está associada com um pior prognóstico. LRRC8A é uma proteína transmembrana que foi proposta como componente importante do canal aniônico regulado por volume (VRAC: volume-regulated anion channel) (Qiu et al. 2014; Voss et al. 2014). A regulação do volume celular tem um papel fundamental em muitas funções celulares, como metabolismo, transporte, liberação hormonal, migração, proliferação e morte celular (Pedersen, Hoffmann, and Novak 2013). Em doenças como câncer, frequentemente existe uma desregulação do volume celular e do transporte iónico, o balanço 
sobrevivência/morte celular está alterado, e novas interações com o estroma acontecem (Pedersen, Hoffmann, and Novak 2013). Uma das características morfológicas mais importantes da apoptose, depois de uma exposição a drogas quimioterápicas como cisplatina, é uma importante redução do volume celular. A magnitude dessa redução reflete o balanço entre as atividades pro-apoptóticas e anti-apoptóticas dos transportadores de iones e osmolitos orgánicos (Else K. Hoffmann 2014). O processo apoptótico, por ativação de caspases e quebra de DNA por nucleases, depende de uma diminuição da concentração celular de $\mathrm{K}+$, desregulação dos canais sensíveis a volume e baixa eficiência dos transportadores Na+/K+ ATPase (Lang and Hoffmann 2012). Sorensen et. al. demonstraram que a resistência à cisplatina em células de câncer de ovário está correlacionada com uma expressão diminuída de $L R R C 8 A$, indicando que $L R R C 8 A$ seria um bom biomarcador para resistência à cisplatina (Sørensen et al. 2016). Considerando que em nosso trabalho $L R R C 8 A$ está "up-regulated" e que $A S-L R R C 8 A$ está "down-regulated" no tumor, é possível que na célula normal o novo antisenso $A S-L R R C 8 A$ esteja regulando negativamente a expressão de $L R R C 8 A$. Para testar se existe uma relação entre os dois, utilizamos a ferramenta RegRNA2.0 (Chang et al. 2013) para buscar sítios de ligação de fatores de transcrição (TFs) e de microRNAs em ambas sequências. Encontramos que o antisenso AS-LRRC8A contém sítios de ligação de TFs relacionados com câncer muito importantes, como GATA-1, NF-kappaB, NFAT1 e TFCP2. A via NF-kB já foi relacionada com um aumento da proliferação celular, mobilidade, sinais anti-apoptóticas e inflamatórias que favorecem a metástase e progressão do PDAC (Prabhu et al. 2014). Também foi observado que sua activação favorece a quimio-resistência, por lo tanto o desenvolvimento de inibidores de NF-KB em combinação com drogas citotóxicas abre um caminho para melhorar a sensibilidade à quimioterapia no câncer pancreático (Q. Li et al. 2018). A família de fatores de transcrição NFAT também foi associada com vários passos da carcinogénese e quimio-resistência em PDAC, e pode interagir junto com NF-KB (Arlt, Schäfer, and Kalthoff 2012). Interessantemente encontramos que tanto $L R R C 8 A$ quanto $A S-L R R C 8 A$ compartilham motivos relacionados à subfamília de fatores de transcrição TFCP2 (sinônimos: CP2, LSF, LBP-1c). TFCP2 é um fator pro-oncogênico em câncer pancreático, câncer de mama e carcinoma hepatocelular, e foi observado que ativa genes relacionados com proliferação, invasão, angiogênese e metástase como OPN e MMP9 (ambos "up-regulated" em nosso trabalho), genes envolvidos no ciclo celular e quimiorresistência, como TS ("up-regulated" em nosso estudo), e também ativa a FN1 ("up-regulated" em nosso trabalho) que está envolvido na transição epitélio-mesênquima (EMT) (Kotarba et al. 2018). Outra característica importante que encontramos na sequência do $A S-L R R C 8 A$, é a presença de sítios de ligação aos microRNAs hsa-miR-4259, hsa-miR-4692, hsa-miR-5001-5p e hsa-miR-5589-5p. 
Considerando todo o exposto, é possível que na célula normal TFCP2 se ligue a $A S-L R R C 8 A$ (que tem expressão aumentada), evitando sua união com $L R R C 8 A$ e impedindo a propagação de sinais cancerígenas. Na célula tumoral, AS-LRRC8A está com expressão diminuída (possivelmente inibido por microRNAs), então TFCP2 ativa a $\angle R R C 8 A$ junto com os genes OPN, MMP-9, TS e $F N 1$, favorecendo a proliferação, invasão, angiogênese, metástase e transição epitélio-mesênquima. $O$ aumento da expressão de $L R R C 8 A$, gera um desbalanço eletrolítico e escape da morte celular, levando a um pior prognóstico para o paciente, que se beneficiaria com terapia baseada em cisplatina.

\section{V.11 Seleção e validação de candidatos}

Foram selecionados e validados experimentalmente por RT-qPCR (realizada pelos alunos Vinicius Ferreira, Victoria Oliveira e Ricardo Chiong) diferentes tipos de transcritos que apresentaram uma expressão diferencial significativa em nosso trabalho, incluindo IncRNAs conhecidos no Gencode (LINC01559, LINC01614, LINC01133, LINC00920, RP5-884M6.1, CCAT1 e DRAIC), novos transcritos intergênicos (TCONS_00085964 e TCONS_00009076) e novas variantes de splicing de genes codificadores de proteínas (MMP14, CAPN8 e LIF). Os resultados dos experimentos, apresentados no Anexo 3, confirmam nossas análises por RNA-seq em diversas linhagens celulares (Capan1, AsPc1, MiaPaca2, Panc1 e BxPc3) e em xenografts tumorais derivados do paciente (os PDXs foram gerados pelo aluno doutorando em Bioquímica Bruno Moraes).

Validações funcionais dos IncRNAs LINC01559 e LINC01133 estão em andamento (realizadas pelos alunos Vinicius Ferreira da Paixão e Thalita Bueno, doutorandos em Bioquímica).

Considerando as análises relatadas no presente trabalho, são propostos como candidatos para validações experimentais futuras os transcritos apresentados na tabela 16

Tabela 16. Transcritos candidatos para futura validação experimental. Marcas regulatórias foram consideradas presentes com distâncias até $5 \mathrm{~kb}$ do TSS.

\begin{tabular}{|l|l|l|l|l|l|}
\hline \multicolumn{7}{|c|}{ Novel intergenic } \\
\hline Id & LfC & $\begin{array}{l}\text { Coding } \\
\text { potential }\end{array}$ & $\begin{array}{l}\text { Regulatory } \\
\text { marks }\end{array}$ & WGCNA & Survival \\
\hline TCONS_00019150 & Up & Low & E & Cellular adhesion & - \\
\hline TCONS_00020533 & Up & Medium & E / P & Cellular adhesion & - \\
\hline
\end{tabular}




\begin{tabular}{|c|c|c|c|c|c|}
\hline TCONS_00021240 & Up & Low & $\mathrm{E}$ & $\begin{array}{l}\text { glycosylation of } \\
\text { mucins }\end{array}$ & - \\
\hline \multicolumn{6}{|c|}{ Novel antisense } \\
\hline TCONS_00090957 & Down & Low & $P$ & - & Yes \\
\hline \multicolumn{6}{|c|}{ Novel isoform } \\
\hline TCONS_00006993 & Down & High & $P / E$ & - & Yes \\
\hline TCONS_00054615 & Up & High & $P / E$ & - & Yes \\
\hline \multicolumn{6}{|c|}{ Gencode IncRNA } \\
\hline UCA1 & Up & - & - & DNA repair & - \\
\hline LINC00339 & Down & - & - & - & Yes \\
\hline LINC00941 & Up & - & - & - & - \\
\hline LINC00675 & Up & - & - & - & - \\
\hline \multicolumn{6}{|c|}{ Gencode antisense } \\
\hline AP006621.8 & Down & - & - & - & Yes \\
\hline \multicolumn{6}{|c|}{ Gencode protein coding } \\
\hline CAPG & Up & - & - & - & Yes \\
\hline
\end{tabular}




\section{GONCLUSÕES}

No presente trabalho foi desenvolvido um pipeline bioinformático que possibilitou identificar um conjunto de alterações transcricionais no tecido pancreático tumoral, incluindo genes codificadores e não codificadores de proteína.

Foram detectados 339 novos transcritos intergênicos, 184 antisensos, 340 circRNAs, e 6.187 potenciais novas variantes de splicing. A maioria deles possuem um baixo potencial codificador, e apresentam marcas de regulação epigenética sugerindo que são unidades transcricionais independentes e possíveis IncRNAs.

As análises de expressão diferencial permitiram encontrar 669 transcritos codificantes de proteínas, 171 novas formas de splicing, 86 RNAs intergênicos e 49 RNAs antisensos com expressão alterada no tumor.

Análises de enriquecimento de vias vislumbraram a presença de genes envolvidos em processos celulares que favorecem o desenvolvimento e metástase tumoral.

Um conjunto de 12 transcritos foram validados experimentalmente por RT-PCR, confirmando os resultados do RNA-Seq. 


\section{REFERÊNGIAS}

Aguirre A, Raphael B., and TCGA. 2017. "Integrated Genomic Characterization of Pancreatic Ductal Adenocarcinoma.” Cancer Cell 32 (2): 185.

Alamancos, Gael P., Amadís Pagès, Juan L. Trincado, Nicolás Bellora, and Eduardo Eyras. 2014. "SUPPA: A Super-Fast Pipeline for Alternative Splicing Analysis from RNA-Seq.” bioRxiv. https://doi.org/10.1101/008763.

Albert Lu, Suzanne R. Pfeffer. 2013. “Golgi-Associated RhoBTB3 Targets Cyclin E for Ubiquitylation and Promotes Cell Cycle Progression.” The Journal of Cell Biology 203 (2): 233.

Altschul SF, Et al. n.d. “Basic Local Alignment Search Tool. - PubMed - NCBI.” Accessed October 1, 2018. https://www.ncbi.nlm.nih.gov/pubmed/2231712?dopt=Citation.

Altschul, S. F., W. Gish, W. Miller, E. W. Myers, and D. J. Lipman. 1990. "Basic Local Alignment Search Tool.” J Mol Biol 215 (3): 403-10.

Anders, Simon, Paul Theodor Pyl, and Wolfgang Huber. 2015. "HTSeq-a Python Framework to Work with High-Throughput Sequencing Data.” Bioinformatics 31 (2): 166.

Andrew Futreal, P., Lachlan Coin, Mhairi Marshall, Thomas Down, Timothy Hubbard, Richard Wooster, Nazneen Rahman, and Michael R. Stratton. 2004. “A Census of Human Cancer Genes.” Nature Reviews. Cancer 4 (3): 177.

Andrews, S. 2010. "FastQC: A Quality Control Tool for High Throughput Sequence Data.” http://www.bioinformatics.babraham.ac.uk/projects/fastqc.

Anirban Maitra, Ralph H. Hruban. 2008. "Pancreatic Cancer.” Annual Review of Pathology 3: 157.

Apte, M. V., S. Park, P. A. Phillips, N. Santucci, D. Goldstein, R. K. Kumar, G. A. Ramm, et al. 2004. "Desmoplastic Reaction in Pancreatic Cancer: Role of Pancreatic Stellate Cells." Pancreas 29 (3): 179-87.

Arlt, A., H. Schäfer, and H. Kalthoff. 2012. “The 'N-Factors' in Pancreatic Cancer: Functional Relevance of NF-kB, NFAT and Nrf2 in Pancreatic Cancer.” Oncogenesis 1 (11): e35.

Averboukh, L., P. Liang, P. W. Kantoff, and Pardee Ab. 1996. "Regulation of S100P Expression by Androgen.” Prostate 29 (6): 350-55.

Babita Singh, Eduardo Eyras. 2017. “The Role of Alternative Splicing in Cancer.” Transcription 8 (2): 91.

Bahn, Jae Hoon, Qing Zhang, Feng Li, Tak-Ming Chan, Xianzhi Lin, Yong Kim, David T. W. Wong, and Xinshu Xiao. 2015. "The Landscape of MicroRNA, Piwi-Interacting RNA, and Circular RNA in Human Saliva.” Clinical Chemistry 61 (1): 221-30.

Bailey, Peter, David K. Chang, Katia Nones, Amber L. Johns, Ann-Marie Patch, Marie-Claude Gingras, David K. Miller, et al. 2016. “Genomic Analyses Identify Molecular Subtypes of Pancreatic Cancer.” Nature 531 (7592): 47-52.

Bal, Elodie, Hyun-Sook Park, Zakia Belaid-Choucair, Hülya Kayserili, Magali Naville, Marine Madrange, Elena Chiticariu, et al. 2017. "Mutations in ACTRT1 and Its Enhancer RNA Elements Lead to Aberrant Activation of Hedgehog Signaling in Inherited and Sporadic Basal Cell Carcinomas.” Nature Medicine 23 (10): 1226.

Barrett, S., and J. Salzman. 2016. “Circular RNAs: Analysis, Expression and Potential 
Functions.” Development 143 (11): 1838.

Barrett, Steven P., Peter L. Wang, and Julia Salzman. 2015. "Circular RNA Biogenesis Can Proceed through an Exon-Containing Lariat Precursor.” eLife 4. https://doi.org/10.7554/eLife.07540.

Barski A, Et al. 2007. "High-Resolution Profiling of Histone Methylations in the Human Genome.” Cell 129 (4): 823-37.

Batabyal, Pikli, Stephen Vander Hoorn, Christopher Christophi, and Mehrdad Nikfarjam. 2014.

"Association of Diabetes Mellitus and Pancreatic Adenocarcinoma: A Meta-Analysis of 88 Studies.” Annals of Surgical Oncology 21 (7): 2453-62.

Beer, David G., Sharon L. R. Kardia, Chiang-Ching Huang, Thomas J. Giordano, Albert M. Levin, David E. Misek, Lin Lin, et al. 2002. "Gene-Expression Profiles Predict Survival of Patients with Lung Adenocarcinoma.” Nature Medicine 8 (8): 816.

Bertram, J., K. Palfner, W. Hiddemann, and Kneba M. 1998. "Elevated Expression of S100P, CAPL and MAGE 3 in Doxorubicin-Resistant Cell Lines: Comparison of mRNA Differential Display Reverse Transcription-Polymerase Chain Reaction and Subtractive Suppressive Hybridization for the Analysis of Differential Gene Expression.” Anticancer Drugs 9 (4): 311-17.

Bettegowda, Chetan, Mark Sausen, Rebecca J. Leary, Isaac Kinde, Yuxuan Wang, Nishant Agrawal, Bjarne R. Bartlett, et al. 2014. "Detection of Circulating Tumor DNA in Earlyand Late-Stage Human Malignancies.” Science Translational Medicine 6 (224): 224ra24.

Bijlsma, Maarten F., Anguraj Sadanandam, Patrick Tan, and Louis Vermeulen. 2017. "Molecular Subtypes in Cancers of the Gastrointestinal Tract.” Nature Reviews. Gastroenterology \& Hepatology 14 (6): 333.

Birnbaum, David J., Pascal Finetti, Daniel Birnbaum, Emilie Mamessier, and François Bertucci. 2017. "Validation and Comparison of the Molecular Classifications of Pancreatic Carcinomas.” Molecular Cancer 16. https://doi.org/10.1186/s12943-017-0739-z.

Biswas, S., and C. Rao. 2017. "Epigenetics in Cancer: Fundamentals and Beyond.” Pharmacol Ther. https://doi.org/10.1016/j.pharmthera.2017.02.011.

Bolger, Anthony M., Marc Lohse, and Bjoern Usadel. 2014. "Trimmomatic: A Flexible Trimmer for Illumina Sequence Data.” Bioinformatics 30 (15): 2114-20.

Bosetti, C., P. Bertuccio, E. Negri, C. La Vecchia, M. P. Zeegers, and P. Boffetta. 2012. "Pancreatic Cancer: Overview of Descriptive Epidemiology.” Mol Carcinog 51 (1): 3-13.

Bray, F., J. Ferlay, I. Soerjomataram, R. L. Siegel, L. A. Torre, and A. Jemal. 2018. “Global Cancer Statistics 2018: GLOBOCAN Estimates of Incidence and Mortality Worldwide for 36 Cancers in 185 Countries.” CA Cancer J Clin. https://doi.org/10.3322/caac.21492.

Bray, Nicolas L., Harold Pimentel, Páll Melsted, and Lior Pachter. 2016. "Near-Optimal Probabilistic RNA-Seq Quantification.” Nature Biotechnology 34 (5): 525.

Bray, N. L., H. Pimentel, P. Melsted, and L. Pachter. 2016. "Near-Optimal Probabilistic RNA-Seq Quantification.” Nat Biotechnol 34 (5): 525-27.

Bressy, Christian, Sophie Lac, Jérémy Nigri, Julie Leca, Julie Roques, Marie-Nöelle Lavaut, Véronique Secq, et al. 2018. "LIF Drives Neural Remodeling in Pancreatic Cancer and Offers a New Candidate Biomarker.” Cancer Research 78 (4): 909-21.

Broadbent, Kate M., Jill C. Broadbent, Ulf Ribacke, Dyann Wirth, John L. Rinn, and Pardis C. Sabeti. 2015. "Strand-Specific RNA Sequencing in Plasmodium Falciparum Malaria Identifies Developmentally Regulated Long Non-Coding RNA and Circular RNA.” BMC 
Genomics 16 (1): 454.

Brychta, Nora, Thomas Krahn, and Oliver von Ahsen. 2016. "Detection of KRAS Mutations in Circulating Tumor DNA by Digital PCR in Early Stages of Pancreatic Cancer.” Clinical Chemistry 62 (11): 1482-91.

Cáceres, J. F., and A. R. Kornblihtt. 2002. “Alternative Splicing: Multiple Control Mechanisms and Involvement in Human Disease.” Trends Genet 18 (4): 186-93.

Cartegni, Luca, Shern L. Chew, and Adrian R. Krainer. 2002. "Listening to Silence and Understanding Nonsense: Exonic Mutations That Affect Splicing.” Nature Reviews. Genetics 3 (4): 285.

Cathcart, Jillian, Ashleigh Pulkoski-Gross, and Jian Cao. 2015. “Targeting Matrix Metalloproteinases in Cancer: Bringing New Life to Old Ideas.” Genes \& Diseases 2 (1): 26.

Cesana, Marcella, Davide Cacchiarelli, Ivano Legnini, Tiziana Santini, Olga Sthandier, Mauro Chinappi, Anna Tramontano, and Irene Bozzoni. 2011. “A Long Noncoding RNA Controls Muscle Differentiation by Functioning as a Competing Endogenous RNA.” Cell 147 (2): 358.

Chang, Tzu-Hao, Hsi-Yuan Huang, Justin Bo-Kai Hsu, Shun-Long Weng, Jorng-Tzong Horng, and Hsien-Da Huang. 2013. "An Enhanced Computational Platform for Investigating the Roles of Regulatory RNA and for Identifying Functional RNA Motifs.” BMC Bioinformatics 14 (Suppl 2): S4.

Chen, Dung-Tsa, Ashley H. Davis-Yadley, Po-Yu Huang, Kazim Husain, Barbara A. Centeno, Jennifer Permuth-Wey, Jose M. Pimiento, and Mokenge Malafa. 2015. "Prognostic Fifteen-Gene Signature for Early Stage Pancreatic Ductal Adenocarcinoma.” PloS One 10 (8): e0133562.

Chenguang Gong, Lynne E. Maquat. 2011. "IncRNAs Transactivate Staufen1-Mediated mRNA Decay by Duplexing with 3’UTRs via Alu Elements.” Nature 470 (7333): 284.

Chen, H., H. Tu, Z. Q. Meng, Z. Chen, P. Wang, and L. M. Liu. 2010. "K-Ras Mutational Status Predicts Poor Prognosis in Unresectable Pancreatic Cancer.” Eur J Surg Oncol 36 (7): 657-62.

Chen, P., D. Wan, D. Zheng, Q. Zheng, F. Wu, and Q. Zhi. 2016. “Long Non-Coding RNA UCA1 Promotes the Tumorigenesis in Pancreatic Cancer.” Biomed Pharmacother 83: 1220-26.

Chu, David, Wendy Kohlmann, and Douglas G. Adler. 2010. "Identification and Screening of Individuals at Increased Risk for Pancreatic Cancer with Emphasis on Known Environmental and Genetic Factors and Hereditary Syndromes.” JOP: Journal of the Pancreas 11 (3): 203-12.

Cocquerelle, C., B. Mascrez, D. Hétuin, and Bailleul B. 1993. "Mis-Splicing Yields Circular RNA Molecules.” FASEB J 7 (1): 155-60.

Collisson, Eric A., Anguraj Sadanandam, Peter Olson, William J. Gibb, Morgan Truitt, Shenda Gu, Janine Cooc, et al. 2011. "Subtypes of Pancreatic Ductal Adenocarcinoma and Their Differing Responses to Therapy.” Nature Medicine 17 (4): 500.

Comet, I., E. M. Riising, B. Leblanc, and K. Helin. 2016. "Maintaining Cell Identity: PRC2-Mediated Regulation of Transcription and Cancer.” Nat Rev Cancer 16 (12): 803-10.

Conn, S. J., K. A. Pillman, J. Toubia, V. M. Conn, M. Salmanidis, C. A. Phillips, S. Roslan, A. W. Schreiber, P. A. Gregory, and G. J. Goodall. 2015. “The RNA Binding Protein Quaking 
Regulates Formation of circRNAs.” Cell 160 (6): 1125-34.

Conte, Federica, Giulia Fiscon, Matteo Chiara, Teresa Colombo, Lorenzo Farina, and Paola Paci. 2017. "Role of the Long Non-Coding RNA PVT1 in the Dysregulation of the ceRNA-ceRNA Network in Human Breast Cancer.” PloS One 12 (2): e0171661.

Däbritz, Jan, Roman Preston, Joachim Hänfler, and Helmut Oettle. 2009. "Follow-up Study of K-: Correlation With Clinical Features and Carbohydrate Antigen 19-9ras: Correlation With Clinical Features and Carbohydrate Antigen 19-9 Mutations in the Plasma of Patients With Pancreatic Cancer: Correlation With Clinical Features and Carbohydrate Antigen 19-9.” Pancreas 38 (5): 534-41.

Deng, Qingdong, and Shi Huang. 2004. "PRDM5 Is Silenced in Human Cancers and Has Growth Suppressive Activities.” Oncogene 23 (28): 4903.

Derrien, Thomas, Rory Johnson, Giovanni Bussotti, Andrea Tanzer, Sarah Djebali, Hagen Tilgner, Gregory Guernec, et al. 2012. “The GENCODE v7 Catalog of Human Long Noncoding RNAs: Analysis of Their Gene Structure, Evolution, and Expression.” Genome Research 22 (9): 1775.

Ding, Mengting, Yuhan Liu, Xinhui Liao, Hengji Zhan, Yuchen Liu, and Weiren Huang. 2018. "Enhancer RNAs (eRNAs): New Insights into Gene Transcription and Disease Treatment." Journal of Cancer 9 (13): 2334.

Djebali, Sarah, Carrie A. Davis, Angelika Merkel, Alex Dobin, Timo Lassmann, Ali M. Mortazavi, Andrea Tanzer, et al. 2012. "Landscape of Transcription in Human Cells.” Nature 489 (7414): 101.

Dobin, Alexander, Carrie A. Davis, Felix Schlesinger, Jorg Drenkow, Chris Zaleski, Sonali Jha, Philippe Batut, Mark Chaisson, and Thomas R. Gingeras. 2013. "STAR: Ultrafast Universal RNA-Seq Aligner.” Bioinformatics 29 (1): 15.

Dougan, S. K. 2017. “The Pancreatic Cancer Microenvironment.” Cancer J 23 (6): 321-25.

Duell, E. J., E. Lucenteforte, S. H. Olson, P. M. Bracci, D. Li, H. A. Risch, D. T. Silverman, et al. 2012. "Pancreatitis and Pancreatic Cancer Risk: A Pooled Analysis in the International Pancreatic Cancer Case-Control Consortium (PanC4).” Ann Oncol 23 (11): 2964-70.

Du, Yongxing, Bangbo Zhao, Ziwen Liu, Xiaoxia Ren, Wenjing Zhao, Zongze Li, Lei You, and Yupei Zhao. 2017. "Molecular Subtyping of Pancreatic Cancer: Translating Genomics and Transcriptomics into the Clinic.” Journal of Cancer 8 (4): 513.

Du, Zhou, Tong Sun, Ezgi Hacisuleyman, Teng Fei, Xiaodong Wang, Myles Brown, John L. Rinn, et al. 2016. "Integrative Analyses Reveal a Long Noncoding RNA-Mediated Sponge Regulatory Network in Prostate Cancer.” Nature Communications 7. https://doi.org/10.1038/ncomms10982.

E., Lonardo, Frias-Aldeguer J., P. C. Hermann, and Heeschen C. 2012. "Pancreatic Stellate Cells Form a Niche for Cancer Stem Cells and Promote Their Self-Renewal and Invasiveness.” Cell Cycle 11 (7): 1282-90.

Else K. Hoffmann, Ian H. Lambert. 2014. "Ion Channels and Transporters in the Development of Drug Resistance in Cancer Cells.” Philosophical Transactions of the Royal Society of London. Series B, Biological Sciences 369 (1638). https://doi.org/10.1098/rstb.2013.0109. Ernst, Jason, Pouya Kheradpour, Tarjei S. Mikkelsen, Noam Shoresh, Lucas D. Ward, Charles B. Epstein, Xiaolan Zhang, et al. 2011. "Mapping and Analysis of Chromatin State Dynamics in Nine Human Cell Types.” Nature 473 (7345): 43.

Evans, Joseph R., Felix Y. Feng, and Arul M. Chinnaiyan. 2016. “The Bright Side of Dark 
Matter: lncRNAs in Cancer.” The Journal of Clinical Investigation 126 (8): 2775.

Even, Yasmine, Marie-Line Escande, Claire Fayet, and Anne-Marie Genevière. 2016. "CDK13, a Kinase Involved in Pre-mRNA Splicing, Is a Component of the Perinucleolar Compartment.” PloS One 11 (2): e0149184.

Ewels, Philip, Måns Magnusson, Sverker Lundin, and Max Käller. 2016. "MultiQC: Summarize Analysis Results for Multiple Tools and Samples in a Single Report.” Bioinformatics 32 (19): 3047.

Fabregat, Antonio, Steven Jupe, Lisa Matthews, Konstantinos Sidiropoulos, Marc Gillespie, Phani Garapati, Robin Haw, et al. 2018. “The Reactome Pathway Knowledgebase.” Nucleic Acids Research 46 (Database issue): D649.

Forbes, Simon A., David Beare, Harry Boutselakis, Sally Bamford, Nidhi Bindal, John Tate, Charlotte G. Cole, et al. 2017. "COSMIC: Somatic Cancer Genetics at High-Resolution.” Nucleic Acids Research 45 (D1): D777-83.

Fu, Xue-Liang, De-Jun Liu, Ting-Ting Yan, Jian-Yu Yang, Min-Wei Yang, Jiao Li, Yan-Miao Huo, et al. 2016. "Analysis of Long Non-Coding RNA Expression Profiles in Pancreatic Ductal Adenocarcinoma.” Scientific Reports 6. https://doi.org/10.1038/srep33535.

Galante, Pedro Alexandre Favoretto, Noboru J. O. Sakabe, Natanja Kirschbaum-Slager, and Sandro José de Souza. 2004. "Detection and Evaluation of Intron Retention Events in the Human Transcriptome.” RNA 10 (5): 757.

Gao, S., Y. Cai, H. Zhang, F. Hu, L. Hou, and Q. Xu. 2018. “Long Noncoding RNA DLEU1 Aggravates Pancreatic Ductal Adenocarcinoma Carcinogenesis via the miR-381/CXCR4 Axis.” J Cell Physiol. https://doi.org/10.1002/jcp.27421.

Gao, Yuan, Jinfeng Wang, and Fangqing Zhao. 2015. "CIRI: An Efficient and Unbiased Algorithm for de Novo Circular RNA Identification.” Genome Biology 16 (1): 4.

Ghigna, C., S. Giordano, H. Shen, F. Benvenuto, F. Castiglioni, P. M. Comoglio, M. R. Green, S. Riva, and G. Biamonti. 2005. "Cell Motility Is Controlled by SF2/ASF through Alternative Splicing of the Ron Protooncogene.” Mol Cell 20 (6): 881-90.

Gibb, Ewan A., Carolyn J. Brown, and Wan L. Lam. 2011. "The Functional Role of Long Non-Coding RNA in Human Carcinomas.” Molecular Cancer 10: 38.

Glažar, Petar, Panagiotis Papavasileiou, and Nikolaus Rajewsky. 2014. "circBase: A Database for Circular RNAs.” RNA, September. https://doi.org/10.1261/rna.043687.113.

Goggins, Michael, Ralph H. Hruban, and Scott E. Kern. 2000. "BRCA2 Is Inactivated Late in the Development of Pancreatic Intraepithelial Neoplasia : Evidence and Implications.” The American Journal of Pathology 156 (5): 1767.

Goldstein, Leonard D., James Lee, Florian Gnad, Christiaan Klijn, Annalisa Schaub, Jens Reeder, Anneleen Daemen, et al. 2016. "Recurrent Loss of NFE2L2 Exon 2 Is a Mechanism for Nrf2 Pathway Activation in Human Cancers.” Cell Reports 16 (10): 2605-17.

Gonzalez, Inma, Roberto Munita, Eneritz Agirre, Travis A. Dittmer, Katia Gysling, Tom Misteli, and Reini F. Luco. 2015. "A lncRNA Regulates Alternative Splicing via Establishment of a Splicing-Specific Chromatin Signature.” Nature Structural \& Molecular Biology 22 (5): 370.

Greer, Julia B., David C. Whitcomb, and Randall E. Brand. 2007. “Genetic Predisposition to Pancreatic Cancer: A Brief Review.” The American Journal of Gastroenterology 102 (11): 2564.

Grützmann, Robert, Christian Pilarsky, Ole Ammerpohl, Jutta Lüttges, Armin Böhme, Bence 
Sipos, Melanie Foerder, et al. 2004. "Gene Expression Profiling of Microdissected Pancreatic Ductal Carcinomas Using High-Density DNA Microarrays.” Neoplasia 6 (5): 611.

Guarnerio, J., M. Bezzi, J. C. Jeong, S. V. Paffenholz, K. Berry, M. M. Naldini, F. Lo-Coco, Y. Tay, A. H. Beck, and P. P. Pandolfi. 2016. "Oncogenic Role of Fusion-circRNAs Derived from Cancer-Associated Chromosomal Translocations.” Cell 166 (4): 1055-56.

Guerreiro Da Silva, I. D., Y. F. Hu, I. H. Russo, X. Ao, A. M. Salicioni, X. Yang, and J. Russo. 2000. "S100P Calcium-Binding Protein Overexpression Is Associated with Immortalization of Human Breast Epithelial Cells in Vitro and Early Stages of Breast Cancer Development in Vivo.” International Journal of Oncology 16 (2): 231-71.

Guo, Junjie U., Vikram Agarwal, Huili Guo, and David P. Bartel. 2014. "Expanded Identification and Characterization of Mammalian Circular RNAs.” Genome Biology 15 (7). https://doi.org/10.1186/s13059-014-0409-z.

Guo, Junqing, Heng Cai, Xiaobai Liu, Jian Zheng, Yunhui Liu, Wei Gong, Jiajia Chen, Zhuo Xi, and Yixue Xue. 2018. “Long Non-Coding RNA LINC00339 Stimulates Glioma Vasculogenic Mimicry Formation by Regulating the miR-539-5p/TWIST1/MMPs Axis.” Molecular Therapy. Nucleic Acids 10 (March): 170.

Gupta, Rajnish A., Nilay Shah, Kevin C. Wang, Jeewon Kim, Hugo M. Horlings, David J. Wong, Miao-Chih Tsai, et al. 2010. "Long Non-Coding RNA HOTAIR Reprograms Chromatin State to Promote Cancer Metastasis.” Nature 464 (7291): 1071.

Gutiérrez, María Laura, Luis Corchete, Cristina Teodosio, María Eugenia Sarasquete, María del Mar Abad, Manuel Iglesias, Carmen Esteban, José María Sayagues, Alberto Orfao, and Luis Muñoz-Bellvis. 2015. "Identification and Characterization of the Gene Expression Profiles for Protein Coding and Non-Coding RNAs of Pancreatic Ductal Adenocarcinomas.” Oncotarget 6 (22): 19070.

Haas, Brian J., Alexie Papanicolaou, Moran Yassour, Manfred Grabherr, Philip D. Blood, Joshua Bowden, Matthew Brian Couger, et al. 2013. "De Novo Transcript Sequence Reconstruction from RNA-Seq: Reference Generation and Analysis with Trinity.” Nature Protocols 8 (8). https://doi.org/10.1038/nprot.2013.084.

Hamada, S., K. Satoh, M. Hirota, A. Kanno, K. Ishida, J. Umino, H. Ito, et al. 2011. "Calcium-binding Protein S100P Is a Novel Diagnostic Marker of Cholangiocarcinoma." Cancer Sci 102 (1): 150-56.

Hamanaka, Y., S. Hamanaka, and M. Suzuki. 1996. "Sialyl Lewis(a) Ganglioside in Pancreatic Cancer Tissue Correlates with the Serum CA 19-9 Level.” Pancreas 13 (2): 160-65.

Hansen, Thomas B., Morten T. Venø, Christian K. Damgaard, and Jørgen Kjems. 2016. “Comparison of Circular RNA Prediction Tools.” Nucleic Acids Research 44 (6): e58.

Hassan, Raffit, Anish Thomas, Christine Alewine, Dung T. Le, Elizabeth M. Jaffee, and Ira Pastan. 2016. “Mesothelin Immunotherapy for Cancer: Ready for Prime Time?” Journal of Clinical Oncology: Official Journal of the American Society of Clinical Oncology 34 (34): 4171.

Hata, Shoji, Fujiko Kitamura, Midori Yamaguchi, Hiroshi Shitara, Makoto Murakami, and Hiroyuki Sorimachi. 2016. “A Gastrointestinal Calpain Complex, G-Calpain, Is a Heterodimer of CAPN8 and CAPN9 Calpain Isoforms, Which Play Catalytic and Regulatory Roles, Respectively.” The Journal of Biological Chemistry 291 (53): 27313-22. He, Jin, Nita Ahuja, Martin A. Makary, John L. Cameron, Frederic E. Eckhauser, Michael A. 
Choti, Ralph H. Hruban, Timothy M. Pawlik, and Christopher L. Wolfgang. 2014. “2564 Resected Periampullary Adenocarcinomas at a Single Institution: Trends over Three Decades.” HPB: The Official Journal of the International Hepato Pancreato Biliary Association 16 (1): 83.

Higgins, W. J., G. T. Grehan, K. J. Wynne, and D. M. Worrall. 2017. "SerpinI2 (pancpin) Is an Inhibitory Serpin Targeting Pancreatic Elastase and Chymotrypsin.” Biochim Biophys Acta Proteins Proteom 1865 (2): 195-200.

Holwerda, S., and Wouter de Laat. 2013. "CTCF: The Protein, the Binding Partners, the Binding Sites and Their Chromatin Loops." Philosophical Transactions of the Royal Society of London. Series B, Biological Sciences 368 (1620). https://doi.org/10.1098/rstb.2012.0369.

Horii, A., S. Nakatsuru, Y. Miyoshi, S. Ichii, H. Nagase, H. Ando, A. Yanagisawa, E. Tsuchiya, Y. Kato, and Y. Nakamura. 1992. "Frequent Somatic Mutations of the APC Gene in Human Pancreatic Cancer." Cancer Res 52 (23): 6696-98.

Hruban, Ralph H., N. Volkan Adsay, Jorge Albores-saavedra, Carolyn Compton, Elizabeth S. Garrett, Steven N. Goodman, Scott E. Kern, et al. 2001. "Pancreatic Intraepithelial Neoplasia: A New Nomenclature and Classification System for Pancreatic Duct Lesions.” The American Journal of Surgical Pathology 25 (5): 579-86.

Huang, C., W. Yu, Q. Wang, H. Cui, Y. Wang, L. Zhang, F. Han, and T. Huang. 2015. "Increased Expression of the lncRNA PVT1 Is Associated with Poor Prognosis in Pancreatic Cancer Patients.” Minerva Med 106 (3): 143-49.

Huang, Guo-Wei, Yu-Jie Xue, Zhi-Yong Wu, Xiu-E Xu, Jian-Yi Wu, Hui-Hui Cao, Ying Zhu, et al. 2018. "A Three-lncRNA Signature Predicts Overall Survival and Disease-Free Survival in Patients with Esophageal Squamous Cell Carcinoma.” BMC Cancer 18. https://doi.org/10.1186/s12885-018-4058-6.

Huang, Yinshi, Sabikun Nahar, Akifumi Nakagawa, Maite G. Fernandez de Barrena, Jennifer A. Mertz, Barbara M. Bryant, Curtis E. Adams, et al. 2016. "Regulation of GLI Underlies a Role for BET Bromodomains in Pancreatic Cancer Growth and the Tumor Microenvironment.” Clinical Cancer Research: An Official Journal of the American Association for Cancer Research 22 (16): 4259.

Huarte, Maite. 2015. “The Emerging Role of lncRNAs in Cancer.” Nature Medicine 21 (11): 1253.

Hu, Haolin, Qi Zhang, Chenfei Huang, Yi Shen, Xundi Chen, Xin Shi, and Wenhao Tang. 2014. "Diagnostic Value of S100P for Pancreatic Cancer: A Meta-Analysis.” Tumor Biology 35 (10): 9479-85.

Hu, X., A. K. Sood, C. V. Dang, and L. Zhang. 2018. "The Role of Long Noncoding RNAs in Cancer: The Dark Matter Matters.” Curr Opin Genet Dev. https://doi.org/10.1016/j.gde.2017.10.004.

Hwang, Rosa F., Todd Moore, Thiruvengadam Arumugam, Vijaya Ramachandran, Keith D. Amos, Armando Rivera, Baoan Ji, Douglas B. Evans, and Craig D. Logsdon. 2008. "Cancer-Associated Stromal Fibroblasts Promote Pancreatic Tumor Progression." Cancer Research 68 (3): 918.

Igor Ulitsky, David P. Bartel. 2013. "lincRNAs: Genomics, Evolution, and Mechanisms.” Cell 154 (1): 26.

Imaoka, Hiroshi, Nobumasa Mizuno, Kazuo Hara, Susumu Hijioka, Masahiro Tajika, Tsutomu Tanaka, Makoto Ishihara, et al. 2016. "Prognostic Impact of Carcinoembryonic Antigen 
(CEA) on Patients with Metastatic Pancreatic Cancer: A Retrospective Cohort Study.” Pancreatology: Official Journal of the International Association of Pancreatology ... [et Al.] 16 (5): 859-64.

“INCA.” 2018. Instituto Nacional de Câncer. 2018. http://www2.inca.gov.br/wps/wcm/connect/inca/portal/home.

Iodice, S., S. Gandini, P. Maisonneuve, and A. B. Lowenfels. 2008. "Tobacco and the Risk of Pancreatic Cancer: A Review and Meta-Analysis.” Langenbecks Arch Surg 393 (4): 535-45.

Ivanov, A., S. Memczak, E. Wyler, F. Torti, H. T. Porath, M. R. Orejuela, M. Piechotta, et al. 2015. "Analysis of Intron Sequences Reveals Hallmarks of Circular RNA Biogenesis in Animals.” Cell Rep 10 (2): 170-77.

Iyer, M. K., Y. S. Niknafs, R. Malik, U. Singhal, A. Sahu, Y. Hosono, T. R. Barrette, et al. 2015. "The Landscape of Long Noncoding RNAs in the Human Transcriptome." Nature Genetics 47 (3): 199.

James Kent, W., Charles W. Sugnet, Terrence S. Furey, Krishna M. Roskin, Tom H. Pringle, Alan M. Zahler, and And David Haussler. 2002. "The Human Genome Browser at UCSC." Genome Research 12 (6): 996-1006.

Jauset, Toni, Daniel Massó-Vallés, Sandra Martínez-Martín, Marie-Eve Beaulieu, Laia Foradada, Francesco Paolo Fiorentino, Jun Yokota, et al. 2018. "BET Inhibition Is an Effective Approach against KRAS-Driven PDAC and NSCLC.” Oncotarget 9 (27): 18734.

Jiang, Hongfei, Hang Hu, Xiaomei Tong, Qiuhong Jiang, Haiyan Zhu, and Songying Zhang. 2012. "Calcium-Binding Protein S100P and Cancer: Mechanisms and Clinical Relevance." Journal of Cancer Research and Clinical Oncology 138 (1): 1-9.

Kamisawa, T., L. D. Wood, T. Itoi, and K. Takaori. 2016. "Pancreatic Cancer.” Lancet 388 (10039): 73-85.

Kanitz, Alexander, Foivos Gypas, Andreas J. Gruber, Andreas R. Gruber, Georges Martin, and Mihaela Zavolan. 2015. "Comparative Assessment of Methods for the Computational Inference of Transcript Isoform Abundance from RNA-Seq Data.” Genome Biology 16 (1). https://doi.org/10.1186/s13059-015-0702-5.

Kim, Daehwan, Geo Pertea, Cole Trapnell, Harold Pimentel, Ryan Kelley, and Steven L. Salzberg. 2013. "TopHat2: Accurate Alignment of Transcriptomes in the Presence of Insertions, Deletions and Gene Fusions.” Genome Biology 14 (4): R36.

Kim, Eddo, Alon Magen, and Gil Ast. 2007. "Different Levels of Alternative Splicing among Eukaryotes.” Nucleic Acids Research 35 (1): 125.

Kim, S., N. Yu, and B. Kaang. 2015. "CTCF as a Multifunctional Protein in Genome Regulation and Gene Expression.” Experimental \& Molecular Medicine 47 (6): e166.

Kim, Tae-Kyung, Martin Hemberg, Jesse M. Gray, Allen M. Costa, Daniel M. Bear, Jing Wu, David A. Harmin, et al. 2010. "Widespread Transcription at Neuronal Activity-Regulated Enhancers.” Nature 465 (7295): 182.

Kong, Lei, Yong Zhang, Zhi-Qiang Ye, Xiao-Qiao Liu, Shu-Qi Zhao, Liping Wei, and Ge Gao. 2007. "CPC: Assess the Protein-Coding Potential of Transcripts Using Sequence Features and Support Vector Machine.” Nucleic Acids Research 35 (Web Server issue): W345.

Koprowski, H., M. Herlyn, Z. Steplewski, and H. F. Sears. 1981. "Specific Antigen in Serum of Patients with Colon Carcinoma.” Science 212 (4490): 53-55.

Kotake, Y., T. Nakagawa, K. Kitagawa, S. Suzuki, N. Liu, M. Kitagawa, and Y. Xiong. 2011. "Long Non-Coding RNA ANRIL Is Required for the PRC2 Recruitment to and Silencing of 
p15INK4B Tumor Suppressor Gene.” Oncogene 30 (16): 1956.

Kotarba, Grzegorz, Ewa Krzywinska, Anna I. Grabowska, Agnieszka Taracha, and Tomasz Wilanowski. 2018. “TFCP2/TFCP2L1/UBP1 Transcription Factors in Cancer.” Cancer Letters 420 (April): 72-79.

Kumar, Saran, Nithya Rao, and Ruowen Ge. 2012. "Emerging Roles of ADAMTSs in Angiogenesis and Cancer.” Cancers 4 (4): 1252.

Lam, Michael T. Y., Han Cho, Hanna P. Lesch, David Gosselin, Sven Heinz, Yumiko Tanaka-Oishi, Christopher Benner, et al. 2013. "Rev-Erbs Repress Macrophage Gene Expression by Inhibiting Enhancer-Directed Transcription.” Nature 498 (7455): 511.

Langfelder, Peter, and Steve Horvath. 2008. "WGCNA: An R Package for Weighted Correlation Network Analysis.” BMC Bioinformatics 9 (1): 559.

Lang, F., and E. K. Hoffmann. 2012. "Role of Ion Transport in Control of Apoptotic Cell Death." Compr Physiol 2 (3): 2037-61.

Lee, Ji-Hyun, Xing-Ming Zhao, Ina Yoon, Jin Young Lee, Nam Hoon Kwon, Yin-Ying Wang, Kyung-Min Lee, et al. 2016. "Integrative Analysis of Mutational and Transcriptional Profiles Reveals Driver Mutations of Metastatic Breast Cancers.” Cell Discovery 2 (August): 16025.

Lee, Kiwon, Chris C. -S. Hsiung, Peng Huang, Arjun Raj, and Gerd A. Blobel. 2015. "Dynamic Enhancer-gene Body Contacts during Transcription Elongation." Genes \& Development 29 (19): 1992.

Levental, Kandice R., Hongmei Yu, Laura Kass, Johnathon N. Lakins, Mikala Egeblad, Janine T. Erler, Sheri F. T. Fong, et al. 2009. "Matrix Crosslinking Forces Tumor Progression by Enhancing Integrin Signaling.” Cell 139 (5): 891.

Leygue, Etienne. 2007. "Steroid Receptor RNA Activator (SRA1): Unusual Bifaceted Gene Products with Suspected Relevance to Breast Cancer.” Nuclear Receptor Signaling 5. https://doi.org/10.1621/nrs.05006.

Liao, Qi, Changning Liu, Xiongying Yuan, Shuli Kang, Ruoyu Miao, Hui Xiao, Guoguang Zhao, et al. 2011. "Large-Scale Prediction of Long Non-Coding RNA Functions in a Coding-non-Coding Gene Co-Expression Network.” Nucleic Acids Research 39 (9): 3864.

Li, Bo, and Colin N. Dewey. 2011. "RSEM: Accurate Transcript Quantification from RNA-Seq Data with or without a Reference Genome.” BMC Bioinformatics 12 (1): 323.

Li, Bo, Victor Ruotti, Ron M. Stewart, James A. Thomson, and Colin N. Dewey. 2010. "RNA-Seq Gene Expression Estimation with Read Mapping Uncertainty." Bioinformatics 26 (4): 493.

Li, Dou-Dou, Zhi-Qiang Fu, Qing Lin, Yu Zhou, Quan-Bo Zhou, Zhi-Hua Li, Lang-Ping Tan, Ru-Fu Chen, and Yi-Min Liu. 2015. "Linc00675 Is a Novel Marker of Short Survival and Recurrence in Patients with Pancreatic Ductal Adenocarcinoma.” World Journal of Gastroenterology: WJG 21 (31): 9348.

Li, H., and R. Durbin. 2009. "Fast and Accurate Short Read Alignment with Burrows-Wheeler Transform.” Bioinformatics 25 (14): 1754-60.

Li, Heng, Bob Handsaker, Alec Wysoker, Tim Fennell, Jue Ruan, Nils Homer, Gabor Marth, Goncalo Abecasis, Richard Durbin, and 1000 Genome Project Data Processing Subgroup. 2009. "The Sequence Alignment/Map Format and SAMtools.” Bioinformatics 25 (16): 2078.

Li, H., X. Hao, H. Wang, Z. Liu, Y. He, M. Pu, H. Zhang, H. Yu, J. Duan, and S. Qu. 2016. 
"Circular RNA Expression Profile of Pancreatic Ductal Adenocarcinoma Revealed by Microarray.” Cell Physiol Biochem 40 (6): 1334-44.

Li, Jie, Zhonghu Li, Peng Jiang, Minjie Peng, Xi Zhang, Kai Chen, Hui Liu, Huaqiang Bi, Xiangde Liu, and Xiaowu Li. 2018. “Circular RNA IARS (circ-IARS) Secreted by Pancreatic Cancer Cells and Located within Exosomes Regulates Endothelial Monolayer Permeability to Promote Tumor Metastasis.” Journal of Experimental \& Clinical Cancer Research: CR 37. https://doi.org/10.1186/s13046-018-0822-3.

Linda Szabo, Julia Salzman. 2016. "Detecting Circular RNAs: Bioinformatic and Experimental Challenges.” Nature Reviews. Genetics 17 (11): 679.

Lin, Michael F., Irwin Jungreis, and Manolis Kellis. 2011. "PhyloCSF: A Comparative Genomics Method to Distinguish Protein Coding and Non-Coding Regions.” Bioinformatics 27 (13): i275-82.

Li, Q., G. Yang, M. Feng, S. Zheng, Z. Cao, J. Qiu, L. You, et al. 2018. “NF-кB in Pancreatic Cancer: Its Key Role in Chemoresistance.” Cancer Lett 421: 127-34.

Liu, Yuhan, Mengting Ding, Qunjun Gao, Anbang He, Yuchen Liu, and Hongbing Mei. 2018. "Current Advances on the Important Roles of Enhancer RNAs in Gene Regulation and Cancer.” BioMed Research International 2018. https://doi.org/10.1155/2018/2405351.

Liu, Zhong, Yongfu Shao, Lin Tan, Huajun Shi, Shengcan Chen, and Junming Guo. 2014. "Clinical Significance of the Low Expression of FER1L4 in Gastric Cancer Patients." Tumor Biology 35 (10): 9613-17.

Li, Wenbo, Dimple Notani, Qi Ma, Bogdan Tanasa, Esperanza Nunez, Aaron Yun Chen, Daria Merkurjev, et al. 2013. "Functional Importance of eRNAs for Estrogen-Dependent Transcriptional Activation Events.” Nature 498 (7455): 516.

Li, Xiang, Li Yang, and Ling-Ling Chen. 2018. "The Biogenesis, Functions, and Challenges of Circular RNAs.” Molecular Cell 71 (3): 428-42.

Li, Yan, Qiupeng Zheng, Chunyang Bao, Shuyi Li, Weijie Guo, Jiang Zhao, Di Chen, Jianren Gu, Xianghuo He, and Shenglin Huang. 2015. "Circular RNA Is Enriched and Stable in Exosomes: A Promising Biomarker for Cancer Diagnosis.” Cell Research 25 (8): 981-84.

Locker, G. Y., S. Hamilton, J. Harris, J. M. Jessup, N. Kemeny, J. S. Macdonald, M. R. Somerfield, D. F. Hayes, and R. C. Bast. 2006. "ASCO 2006 Update of Recommendations for the Use of Tumor Markers in Gastrointestinal Cancer.” J Clin Oncol 24 (33): 5313-27.

Löhr, Matthias, Günter Klöppel, Patrick Maisonneuve, Albert B. Lowenfels, and Jutta Lüttges. 2005. "Frequency of K-Ras Mutations in Pancreatic Intraductal Neoplasias Associated with Pancreatic Ductal Adenocarcinoma and Chronic Pancreatitis: A Meta-Analysis.” Neoplasia 7 (1): 17.

Love, M. I., W. Huber, and Anders S. 2014. "Moderated Estimation of Fold Change and Dispersion for RNA-Seq Data with DESeq2. - PubMed - NCBI.” Genome Biol 15 (12): 550.

Lowenfels, A. B., P. Maisonneuve, and D. C. Whitcomb. 2000. "Risk Factors for Cancer in Hereditary Pancreatitis. International Hereditary Pancreatitis Study Group.” Med Clin North Am 84 (3): 565-73.

Luo, C., Y. Tao, Y. Zhang, Y. Zhu, D. N. Minyao, M. Haleem, C. Dong, et al. 2018. "Regulatory Network Analysis of High Expressed Long Non-Coding RNA LINC00941 in Gastric Cancer." Gene 662: 103-9.

Lu, Pengfei, Valerie M. Weaver, and Zena Werb. 2012. “The Extracellular Matrix: A Dynamic 
Niche in Cancer Progression.” The Journal of Cell Biology 196 (4): 395.

Lu, Tingting, Lingling Cui, Yan Zhou, Chuanrang Zhu, Danlin Fan, Hao Gong, Qiang Zhao, et al. 2015. “Transcriptome-Wide Investigation of Circular RNAs in Rice.” RNA 21 (12): 2076-87.

Maass, Nicolai, Takashi Hojo, Michael Ueding, Jutta Lüttges, Günter Klöppel, Walter Jonat, and Koichi Nagasaki. 2001. "Expression of the Tumor Suppressor Gene Maspin in Human Pancreatic Cancers.” Clinical Cancer Research: An Official Journal of the American Association for Cancer Research 7 (4): 812-17.

Maire, F., S. Micard, P. Hammel, H. Voitot, P. Lévy, P-H Cugnenc, P. Ruszniewski, and P. Laurent Puig. 2002. "Differential Diagnosis between Chronic Pancreatitis and Pancreatic Cancer: Value of the Detection of KRAS2 Mutations in Circulating DNA.” British Journal of Cancer 87 (5): 551.

Maisonneuve, P., and A. B. Lowenfels. 2015. "Risk Factors for Pancreatic Cancer: A Summary Review of Meta-Analytical Studies.” Int J Epidemiol 44 (1): 186-98.

Ma, Lina, Vladimir B. Bajic, and Zhang Zhang. 2013. “On the Classification of Long Non-Coding RNAs.” RNA Biology 10 (6): 924.

Mao, Yixiang, Jianjun Shen, Yue Lu, Kevin Lin, Huamin Wang, Yanan Li, Ping Chang, Mary G. Walker, and Donghui Li. 2017. "RNA Sequencing Analyses Reveal Novel Differentially Expressed Genes and Pathways in Pancreatic Cancer.” Oncotarget 8 (26): 42537.

Marchese, Rodolfo, Alessandra Muleti, Patrizio Pasqualetti, Barbara Bucci, Antonio Stigliano, Ercole Brunetti, Monica De Angelis, Gianluca Mazzoni, Adriano Tocchi, and Stefania Brozzetti. 2006. "Low Correspondence Between K-Ras Mutations in Pancreatic Cancer Tissue and Detection of K-Ras Mutations in Circulating DNA.” Pancreas 32 (2): 171.

Mardin, W. A., D. Ntalos, S. T. Mees, T. Spieker, N. Senninger, J. Haier, and S. A. Dhayat. 2016. "SERPINB5 Promoter Hypomethylation Differentiates Pancreatic Ductal Adenocarcinoma From Pancreatitis.” Pancreas 45 (5): 743-47.

Mardin, Wolf A., Kostadin O. Petrov, Andreas Enns, Norbert Senninger, Joerg Haier, and Soeren T. Mees. 2010. "SERPINB5 and AKAP12 -- Expression and Promoter Methylation of Metastasis Suppressor Genes in Pancreatic Ductal Adenocarcinoma.” BMC Cancer 10 (1): 549.

Matlin, Arianne J., Francis Clark, and Christopher W. J. Smith. 2005. "Understanding Alternative Splicing: Towards a Cellular Code.” Nature Reviews. Molecular Cell Biology 6 (5): 386.

Mazur, Pawel K., Alexander Herner, Stephano S. Mello, Matthias Wirth, Simone Hausmann, Francisco J. Sánchez-Rivera, Shane M. Lofgren, et al. 2015. “Combined Inhibition of BET Family Proteins and Histone Deacetylases as a Potential Epigenetics-Based Therapy for Pancreatic Ductal Adenocarcinoma.” Nature Medicine 21 (10): 1163.

McCleland, Mark L., Kathryn Mesh, Edward Lorenzana, Vivek S. Chopra, Ehud Segal, Colin Watanabe, Benjamin Haley, et al. 2016. “CCAT1 Is an Enhancer-Templated RNA That Predicts BET Sensitivity in Colorectal Cancer.” The Journal of Clinical Investigation 126 (2): 639.

Melo, C. A., J. Drost, P. J. Wijchers, H. van de Werken, E. de Wit, Oude Vrielink Ja, R. Elkon, et al. 2013. "eRNAs Are Required for p53-Dependent Enhancer Activity and Gene Transcription.” Mol Cell 49 (3): 524-35.

Memczak, S., M. Jens, A. Elefsinioti, F. Torti, J. Krueger, A. Rybak, L. Maier, et al. 2013. 
"Circular RNAs Are a Large Class of Animal RNAs with Regulatory Potency.” Nature 495 (7441): 333-38.

Meng, Qingcai, Si Shi, Chen Liang, Dingkong Liang, Wenyan Xu, Shunrong Ji, Bo Zhang, Quanxing Ni, Jin Xu, and Xianjun Yu. 2017. "Diagnostic and Prognostic Value of Carcinoembryonic Antigen in Pancreatic Cancer: A Systematic Review and Meta-Analysis." OncoTargets and Therapy 10: 4591-98.

Minoru Kanehisa, Susumu Goto. 2000. "KEGG: Kyoto Encyclopedia of Genes and Genomes.” Nucleic Acids Research 28 (1): 27.

Moffitt, Richard A., Raoud Marayati, Elizabeth L. Flate, Keith E. Volmar, S. Gabriela Herrera Loeza, Katherine A. Hoadley, Naim U. Rashid, et al. 2015. "Virtual Microdissection Identifies Distinct Tumor- and Stroma-Specific Subtypes of Pancreatic Ductal Adenocarcinoma." Nature Genetics 47 (10): 1168.

Nazli, O., A. D. Bozdag, T. Tansug, R. Kir, and E. Kaymak. 2000. "The Diagnostic Importance of CEA and CA 19-9 for the Early Diagnosis of Pancreatic Carcinoma." Hepato-Gastroenterology 47 (36): 1750-52.

Neesse, Albrecht, Hana Algül, David A. Tuveson, and Thomas M. Gress. 2015. "Stromal Biology and Therapy in Pancreatic Cancer: A Changing Paradigm.” Gut 64 (9): 1476-84.

Nigro, J. M., K. R. Cho, E. R. Fearon, S. E. Kern, J. M. Ruppert, J. D. Oliner, K. W. Kinzler, and B. Vogelstein. 1991. "Scrambled Exons.” Cell 64 (3): 607-13.

Noboru Jo Sakabe, Sandro José de Souza. 2007. "Sequence Features Responsible for Intron Retention in Human.” BMC Genomics 8: 59.

Panda, Amaresh C., Ioannis Grammatikakis, Kyoung Mi Kim, Supriyo De, Jennifer L. Martindale, Rachel Munk, Xiaoling Yang, Kotb Abdelmohsen, and Myriam Gorospe. 2017. "Identification of Senescence-Associated Circular RNAs (SAC-RNAs) Reveals Senescence Suppressor CircPVT1.” Nucleic Acids Research 45 (7): 4021-35.

Pandol, Stephen, Mouad Edderkaoui, Ilya Gukovsky, Aurelia Lugea, and Anna Gukovskaya. 2009. "Desmoplasia of Pancreatic Ductal Adenocarcinoma.” Clinical Gastroenterology and Hepatology: The Official Clinical Practice Journal of the American Gastroenterological Association 7 (11 0): S44.

Park, J. M., Y. M. Han, M. Jeong, M. Chung, C. I. Kwon, K. H. Ko, and K. B. Hahm. 2017. "Synthetic 8-Hydroxydeoxyguanosine Inhibited Metastasis of Pancreatic Cancer through Concerted Inhibitions of ERM and Rho-GTPase.” Free Radic Biol Med 110: 151-61.

Parks, S. K., and J. Pouyssegur. n.d. "The Na(+)/HCO3(-) Co-Transporter SLC4A4 Plays a Role in Growth and Migration of Colon and Breast Cancer Cells. - PubMed - NCBI.” Accessed November 6, 2018. https://www.ncbi.nlm.nih.gov/pubmed/25612232.

Patro, Rob, Geet Duggal, Michael I. Love, Rafael A. Irizarry, and Carl Kingsford. 2017. "Salmon: Fast and Bias-Aware Quantification of Transcript Expression Using Dual-Phase Inference.” Nature Methods 14 (4): 417.

Paul E. Oberstein, Kenneth P. Olive. 2013. "Pancreatic Cancer: Why Is It so Hard to Treat?" Therapeutic Advances in Gastroenterology 6 (4): 321.

Pedersen, Stine F., Else K. Hoffmann, and Ivana Novak. 2013. "Cell Volume Regulation in Epithelial Physiology and Cancer.” Frontiers in Physiology 4. https://doi.org/10.3389/fphys.2013.00233.

Perets, R., O. Greenberg, T. Shentzer, V. Semenisty, R. Epelbaum, T. Bick, S. Sarji, O. Ben-Izhak, E. Sabo, and D. Hershkovitz. 2018. "Mutant KRAS Circulating Tumor DNA Is 
an Accurate Tool for Pancreatic Cancer Monitoring.” Oncologist 23 (5): 566-72.

Pertea, Mihaela, Geo M. Pertea, Corina M. Antonescu, Tsung-Cheng Chang, Joshua T. Mendell, and Steven L. Salzberg. 2015. "StringTie Enables Improved Reconstruction of a Transcriptome from RNA-Seq Reads.” Nature Biotechnology 33 (3): 290.

Phil Gold, Samuel O. Freedman. 1965. "SPECIFIC CARCINOEMBRYONIC ANTIGENS OF THE HUMAN DIGESTIVE SYSTEM.” The Journal of Experimental Medicine 122 (3): 467.

Pils, D., P. Horak, A. Gleiss, C. Sax, G. Fabjani, V. J. Moebus, C. Zielinski, A. Reinthaller, R. Zeillinger, and M. Krainer. 2005. "Five Genes from Chromosomal Band 8p22 Are Significantly down-Regulated in Ovarian Carcinoma: N33 and EFA6R Have a Potential Impact on Overall Survival.” Cancer 104 (11): 2417-29.

Pinho, Salomé S., and Celso A. Reis. 2015. "Glycosylation in Cancer: Mechanisms and Clinical Implications.” Nature Reviews. Cancer 15 (9): 540.

Poruk, Katherine E., David Z. Gay, Kurt Brown, Jeffrey D. Mulvihill, Kenneth M. Boucher, Courtney L. Scaife, Matthew A. Firpo, and Sean J. Mulvihill. 2013. "The Clinical Utility of CA 19-9 in Pancreatic Adenocarcinoma: Diagnostic and Prognostic Updates.” Current Molecular Medicine 13 (3): 340.

Prabhu, Lakshmi, Rasika Mundade, Murray Korc, Patrick J. Loehrer, and Tao Lu. 2014. “Critical Role of NF-kB in Pancreatic Cancer.” Oncotarget 5 (22): 10969.

Qian, Li-Wu, Kazuhiro Mizumoto, Naoki Maehara, Kenoki Ohuchida, Naoki Inadome, Michiyo Saimura, Eishi Nagai, Kunio Matsumoto, Toshikazu Nakamura, and Masao Tanaka. 2003. "Co-Cultivation of Pancreatic Cancer Cells with Orthotopic Tumor-Derived Fibroblasts: Fibroblasts Stimulate Tumor Cell Invasion via HGF Secretion Whereas Cancer Cells Exert a Minor Regulative Effect on Fibroblasts HGF Production.” Cancer Letters 190 (1): 105-12.

Qiu, Zhaozhu, Adrienne E. Dubin, Jayanti Mathur, Buu Tu, Kritika Reddy, Loren J. Miraglia, Jürgen Reinhardt, Anthony P. Orth, and Ardem Patapoutian. 2014. "SWELL1, a Plasma Membrane Protein, Is an Essential Component of Volume-Regulated Anion Channel.” Cell 157 (2): 447.

Quinlan, A. R., and I. M. Hall. 2010. "BEDTools: A Flexible Suite of Utilities for Comparing Genomic Features. - PubMed - NCBI.” 2010. https://www.ncbi.nlm.nih.gov/pubmed/20110278.

Rahib, Lola, Benjamin D. Smith, Rhonda Aizenberg, Allison B. Rosenzweig, Julie M. Fleshman, and Lynn M. Matrisian. 2014. "Projecting Cancer Incidence and Deaths to 2030: The Unexpected Burden of Thyroid, Liver, and Pancreas Cancers in the United States.” Cancer Research 74 (11): 2913-21.

Rahnamoun, Homa, Jihoon Lee, Zhengxi Sun, Hanbin Lu, Kristen M. Ramsey, Elizabeth A. Komives, and Shannon M. Lauberth. 2018. "RNAs Interact with BRD4 to Promote Enhanced Chromatin Engagement and Transcription Activation.” Nature Structural \& Molecular Biology 25 (8): 687.

Rashid, S., N. Singh, S. Gupta, S. Rashid, N. Nalika, V. Sachdev, C. S. Bal, Datta Gupta S, S. S. Chauhan, and A. Saraya. 2018. "Progression of Chronic Pancreatitis to Pancreatic Cancer: Is There a Role of Gene Mutations as a Screening Tool?” Pancreas 47 (2): 227-32.

Reimand, Jüri, Meelis Kull, Hedi Peterson, Jaanus Hansen, and Jaak Vilo. 2007. "g:Profiler—a Web-Based Toolset for Functional Profiling of Gene Lists from Large-Scale Experiments.” 
Nucleic Acids Research 35 (Web Server issue): W193.

Rhim, Andrew D., Paul E. Oberstein, Dafydd H. Thomas, Emily T. Mirek, Carmine F. Palermo, Steve A. Sastra, Erin N. Dekleva, et al. 2014. "Stromal Elements Act to Restrain, rather than Support, Pancreatic Ductal Adenocarcinoma." Cancer Cell 25 (6): 735.

Robinson, Mark D., Davis J. McCarthy, and Gordon K. Smyth. 2010. "edgeR: A Bioconductor Package for Differential Expression Analysis of Digital Gene Expression Data.” Bioinformatics 26 (1): 139.

Roldo, C., E. Missiaglia, J. P. Hagan, M. Falconi, P. Capelli, S. Bersani, G. A. Calin, et al. 2006. "MicroRNA Expression Abnormalities in Pancreatic Endocrine and Acinar Tumors Are Associated with Distinctive Pathologic Features and Clinical Behavior.” J Clin Oncol 24 (29): 4677-84.

Rosty, C., J. Geradts, N. Sato, R. E. Wilentz, H. Roberts, T. Sohn, J. L. Cameron, C. J. Yeo, R. H. Hruban, and M. Goggins. 2003. "p16 Inactivation in Pancreatic Intraepithelial Neoplasias (PanINs) Arising in Patients with Chronic Pancreatitis.” Am J Surg Pathol 27 (12): $1495-1501$.

Ruiz-Orera, Jorge, Xavier Messeguer, Juan Antonio Subirana, and M. Mar Alba. 2014. "Long Non-Coding RNAs as a Source of New Peptides.” eLife 3. https://doi.org/10.7554/eLife.03523.

Salzman, Julia, Charles Gawad, Peter Lincoln Wang, Norman Lacayo, and Patrick O. Brown. 2012. "Circular RNAs Are the Predominant Transcript Isoform from Hundreds of Human Genes in Diverse Cell Types.” PloS One 7 (2). https://doi.org/10.1371/journal.pone.0030733.

Schaukowitch, Katie, Jae-Yeol Joo, Xihui Liu, Jonathan K. Watts, Carlos Martinez, and Tae-Kyung Kim. 2014. "Enhancer RNA Facilitates NELF Release from Immediate Early Genes.” Molecular Cell 56 (1): 29.

Seyednasrollah, Fatemeh, Asta Laiho, and Laura L. Elo. 2015. "Comparison of Software Packages for Detecting Differential Expression in RNA-Seq Studies.” Briefings in Bioinformatics 16 (1): 59.

Shamai, Sivan, Ilana Nabiochtchikov, Sarah Kraus, Sally Zigdon, Dina Kazanov, Michal Itzhak-Klutch, Carmit Eizner, Nadir Arber, and Ravit Geva. 2015. "CD24 and APC Genetic Polymorphisms in Pancreatic Cancers as Potential Biomarkers for Clinical Outcome.” PloS One 10 (9): e0134469.

Shao, Feng, Mei Huang, Futao Meng, and Qiang Huang. 2018. "Circular RNA Signature Predicts Gemcitabine Resistance of Pancreatic Ductal Adenocarcinoma.” Frontiers in Pharmacology 9. https://doi.org/10.3389/fphar.2018.00584.

Shyu, R. Y., S. L. Huang, and S. Y. Jiang. 2003. "Retinoic Acid Increases Expression of the Calcium-Binding Protein S100P in Human Gastric Cancer Cells.” J Biomed 10 (3): 313-19.

Skotheim, R. I., and M. Nees. 2007. "Alternative Splicing in Cancer: Noise, Functional, or Systematic?” Int J Biochem Cell Biol 39 (7-8): 1432-49.

Song, Jukun, Qiuyan Xu, Haodeng Zhang, Xinhai Yin, Chen Zhu, Ke Zhao, and Jianguo Zhu. 2018. "Five Key lncRNAs Considered as Prognostic Targets for Predicting Pancreatic Ductal Adenocarcinoma.” Journal of Cellular Biochemistry 119 (6): 4559.

Sørensen, B. H., C. S. Dam, S. Stürup, and I. H. Lambert. 2016. "Dual Role of LRRC8A-Containing Transporters on Cisplatin Resistance in Human Ovarian Cancer Cells.” J Inorg Biochem 160: 287-95. 
Sturla, Lisa-Marie, Ming Tong, Nick Hebda, Jinsong Gao, John-Michael Thomas, Mark Olsen, and Suzanne M. de la Monte. 2016. “Aspartate- $\beta$-Hydroxylase (ASPH): A Potential Therapeutic Target in Human Malignant Gliomas.” Heliyon 2 (12). https://doi.org/10.1016/j.heliyon.2016.e00203.

Suh, Hyerim, Krishna Pillai, and David Lawson Morris. 2017. "Mucins in Pancreatic Cancer: Biological Role, Implications in Carcinogenesis and Applications in Diagnosis and Therapy.” American Journal of Cancer Research 7 (6): 1372.

Su, Huafang, Fuqiang Lin, Xia Deng, Lanxiao Shen, Ya Fang, Zhenghua Fei, Lihao Zhao, et al. 2016. "Profiling and Bioinformatics Analyses Reveal Differential Circular RNA Expression in Radioresistant Esophageal Cancer Cells.” Journal of Translational Medicine 14 (1): 225.

Szabo, Linda, Robert Morey, Nathan J. Palpant, Peter L. Wang, Nastaran Afari, Chuan Jiang, Mana M. Parast, Charles E. Murry, Louise C. Laurent, and Julia Salzman. 2015. "Statistically Based Splicing Detection Reveals Neural Enrichment and Tissue-Specific Induction of Circular RNA during Human Fetal Development.” Genome Biology 16 (1). https://doi.org/10.1186/s13059-015-0690-5.

Tahira, Ana C., Márcia S. Kubrusly, Michele F. Faria, Bianca Dazzani, Rogério S. Fonseca, Vinicius Maracaja-Coutinho, Sergio Verjovski-Almeida, Marcel C. C. Machado, and Eduardo M. Reis. 2011. "Long Noncoding Intronic RNAs Are Differentially Expressed in Primary and Metastatic Pancreatic Cancer.” Molecular Cancer 10 (1): 141.

Tang, Zhewei, Min Qian, and Mitchell Ho. 2013. "The Role of Mesothelin in Tumor Progression and Targeted Therapy.” Anti-Cancer Agents in Medicinal Chemistry 13 (2): 276.

Teng, Mingxiang, Michael I. Love, Carrie A. Davis, Sarah Djebali, Alexander Dobin, Brenton R. Graveley, Sheng Li, et al. 2016. “A Benchmark for RNA-Seq Quantification Pipelines.” Genome Biology 17 (1): 74.

“TERC Telomerase RNA Component.” n.d. NCBI. Accessed November 5, 2018. https://www.ncbi.nlm.nih.gov/gene?Db=gene\&Cmd=ShowDetailView\&TermToSearch=70 12.

Thangavelu, Pulari U., Tibor Krenács, Eloise Dray, and Pascal H. G. Duijf. 2016. “In Epithelial Cancers, Aberrant COL17A1 Promoter Methylation Predicts Its Misexpression and Increased Invasion.” Clinical Epigenetics 8 (1): 120.

The Gene Ontology Consortium, Michael Ashburner, Catherine A. Ball, Judith A. Blake, David Botstein, Heather Butler, J. Michael Cherry, et al. 2000. "Gene Ontology: Tool for the Unification of Biology.” Nature Genetics 25 (1): 25.

Therneau T., Grambsch P. 2000. Modeling Survival Data: Extending the Cox Model. Springer.

Thompson, C. C., F. J. Ashcroft, S. Patel, G. Saraga, D. Vimalachandran, W. Prime, F. Campbell, et al. 2007. "Pancreatic Cancer Cells Overexpress Gelsolin Family-capping Proteins, Which Contribute to Their Cell Motility.” Gut 56 (1): 95.

Tian, Mei, Ya-Zhou Cui, Guan-Hua Song, Mei-Juan Zong, Xiao-Yan Zhou, Yu Chen, and Jin-Xiang Han. 2008. "Proteomic Analysis Identifies MMP-9, DJ-1 and A1BG as Overexpressed Proteins in Pancreatic Juice from Pancreatic Ductal Adenocarcinoma Patients.” BMC Cancer 8: 241.

Torres, C., and P. J. Grippo. 2018. "Pancreatic Cancer Subtypes: A Roadmap for Precision Medicine.” Ann Med 50 (4): 277-87.

Trapnell, Cole, David G. Hendrickson, Martin Sauvageau, Loyal Goff, John L. Rinn, and Lior Pachter. 2012. "Differential Analysis of Gene Regulation at Transcript Resolution with 
RNA-Seq.” Nature Biotechnology 31 (1): 46.

Trapnell, Cole, Adam Roberts, Loyal Goff, Geo Pertea, Daehwan Kim, David R. Kelley, Harold Pimentel, Steven L. Salzberg, John L. Rinn, and Lior Pachter. 2012. "Differential Gene and Transcript Expression Analysis of RNA-Seq Experiments with TopHat and Cufflinks." Nature Protocols 7 (3): 562.

Tsai, Miao-Chih, Ohad Manor, Yue Wan, Nima Mosammaparast, Jordon K. Wang, Fei Lan, Yang Shi, Eran Segal, and Howard Y. Chang. 2010. "Long Noncoding RNA as Modular Scaffold of Histone Modification Complexes.” Science 329 (5992): 689.

Ungefroren, Hendrik, Stephanie Groth, Susanne Sebens, Hendrik Lehnert, Frank Gieseler, and Fred Fändrich. 2011. "Differential Roles of Smad2 and Smad3 in the Regulation of TGF- $31-M e d i a t e d$ Growth Inhibition and Cell Migration in Pancreatic Ductal Adenocarcinoma Cells: Control by Rac1.” Molecular Cancer 10 (1): 67.

Van Impe, Katrien, Jonas Bethuyne, Steven Cool, Francis Impens, David Ruano-Gallego, Olivier De Wever, Berlinda Vanloo, et al. 2013. "A Nanobody Targeting the F-Actin Capping Protein CapG Restrains Breast Cancer Metastasis.” Breast Cancer Research: BCR 15 (6): R116.

Veenstra, Veronique L., Andrea Garcia-Garijo, Hanneke W. van Laarhoven, and Maarten F. Bijlsma. 2018. "Extracellular Influences: Molecular Subclasses and the Microenvironment in Pancreatic Cancer." Cancers 10 (2). https://doi.org/10.3390/cancers10020034.

Venables, J. P. 2006a. "Unbalanced Alternative Splicing and Its Significance in Cancer." Bioessays 28 (4): 378-86.

—. 2006b. "Unbalanced Alternative Splicing and Its Significance in Cancer.” Bioessays 28 (4): 378-86.

Voss, Felizia K., Florian Ullrich, Jonas Münch, Katina Lazarow, Darius Lutter, Nancy Mah, Miguel A. Andrade-Navarro, Jens P. von Kries, Tobias Stauber, and Thomas J. Jentsch. 2014. "Identification of LRRC8 Heteromers as an Essential Component of the Volume-Regulated Anion Channel VRAC.” Science 344 (6184): 634-38.

Wang, Haohao, Zhonghai Guan, Kuifeng He, Jiong Qian, Jiang Cao, and Lisong Teng. 2017. "LncRNA UCA1 in Anti-Cancer Drug Resistance.” Oncotarget 8 (38): 64638.

Wang, Liguo, Shengqin Wang, and Wei Li. 2012. "RSeQC: Quality Control of RNA-Seq Experiments.” Bioinformatics 28 (16): 2184-85.

Wang, Yan, Jing Liu, B. O. Huang, Yan-Mei Xu, Jing Li, Lin-Feng Huang, Jin Lin, et al. 2015. "Mechanism of Alternative Splicing and Its Regulation.” Biomedical Reports 3 (2): 152.

Wen, Xin, Xinran Tang, Yingqin Li, Xianyue Ren, Qingmei He, Xiaojing Yang, Jian Zhang, Yaqin Wang, Jun Ma, and Na Liu. 2016. "Microarray Expression Profiling of Long Non-Coding RNAs Involved in Nasopharyngeal Carcinoma Metastasis.” International Journal of Molecular Sciences 17 (11). https://doi.org/10.3390/ijms17111956.

Westbrook, Jules A., David A. Cairns, Jianhe Peng, Valerie Speirs, Andrew M. Hanby, Ingunn Holen, Steven L. Wood, et al. 2016. "CAPG and GIPC1: Breast Cancer Biomarkers for Bone Metastasis Development and Treatment.” Journal of the National Cancer Institute 108 (4). https://doi.org/10.1093/jnci/djv360.

White, Michael, Andrew Freistaedter, Gwendolyn J. B. Jones, Emmanuel Zervos, and Rachel L. Roper. 2018. "Development of Improved Therapeutic Mesothelin-Based Vaccines for Pancreatic Cancer.” PloS One 13 (2). https://doi.org/10.1371/journal.pone.0193131.

Wickham, H. 2016. ggplot2: Elegant Graphics for Data Analysis. New York: Springer-Verlag. 
Wilentz, Robb E., Christine A. Iacobuzio-Donahue, Pedram Argani, Denis M. McCarthy, Jennifer L. Parsons, Charles J. Yeo, Scott E. Kern, and Ralph H. Hruban. 2000. "Loss of Expression of Dpc4 in Pancreatic Intraepithelial Neoplasia: Evidence That DPC4 Inactivation Occurs Late in Neoplastic Progression.” Cancer Research 60 (7): 2002-6.

Xia, Tian, Shengcan Chen, Zhen Jiang, Yongfu Shao, Xiaoming Jiang, Peifei Li, Bingxiu Xiao, and Junming Guo. 2015. "Long Noncoding RNA FER1L4 Suppresses Cancer Cell Growth by Acting as a Competing Endogenous RNA and Regulating PTEN Expression.” Scientific Reports 5 (August): 13445.

Yamamoto, Keisuke, Keisuke Tateishi, Yotaro Kudo, Mayumi Hoshikawa, Mariko Tanaka, Takuma Nakatsuka, Hiroaki Fujiwara, et al. 2016. "Stromal Remodeling by the BET Bromodomain Inhibitor JQ1 Suppresses the Progression of Human Pancreatic Cancer.” Oncotarget 7 (38): 61469.

Yoon, Je-Hyun, Kotb Abdelmohsen, Subramanya Srikantan, Xiaoling Yang, Jennifer L. Martindale, Supriyo De, Maite Huarte, Ming Zhan, Kevin G. Becker, and Myriam Gorospe. 2012. “LincRNA-p21 Suppresses Target mRNA Translation.” Molecular Cell 47 (4): 648.

Yuan, Y., G. Haiying, L. Zhuo, L. Ying, and H. Xin. 2018. "Long Non-Coding RNA LINC00339 Facilitates the Tumorigenesis of Non-Small Cell Lung Cancer by Sponging miR-145 through Targeting FOXM1.” Biomed Pharmacother 105: 707-13.

Yue, Ben, Bo Sun, Chenchen Liu, Senlin Zhao, Dongyuan Zhang, Fudong Yu, and Dongwang Yan. 2015. "Long Non-Coding RNA Fer-1-like Protein 4 Suppresses Oncogenesis and Exhibits Prognostic Value by Associating with miR-106a-5p in Colon Cancer.” Cancer Science 106 (10): 1323.

Yu, Qiuyun, Xinfeng Zhou, Qing Xia, Jia Shen, Jia Yan, Jiuting Zhu, Xiang Li, and Ming Shu. 2016. "Long Non-Coding RNA CCAT1 That Can Be Activated by c-Myc Promotes Pancreatic Cancer Cell Proliferation and Migration.” American Journal of Translational Research 8 (12): 5444.

Zhang, Chi, Baohong Zhang, Lih-Ling Lin, and Shanrong Zhao. 2017. "Evaluation and Comparison of Computational Tools for RNA-Seq Isoform Quantification.” BMC Genomics 18 (1): 583.

Zhang, M., Y. Zhao, Y. Zhang, D. Wang, S. Gu, W. Feng, W. Peng, A. Gong, and M. Xu. 2018. "LncRNA UCA1 Promotes Migration and Invasion in Pancreatic Cancer Cells via the Hippo Pathway.” Biochim Biophys Acta Mol Basis Dis 1864: 1770-82.

Zhang, Qiubo, Linjuan Zeng, Yinting Chen, Guoda Lian, Chenchen Qian, Shaojie Chen, Jiajia Li, and Kaihong Huang. 2016. "Pancreatic Cancer Epidemiology, Detection, and Management.” Gastroenterology Research and Practice 2016. https://doi.org/10.1155/2016/8962321.

Zhang, X., F. Gao, L. Zhou, H. Wang, G. Shi, and X. Tan. 2017. "UCA1 Regulates the Growth and Metastasis of Pancreatic Cancer by Sponging miR-135a.” Oncol Res 25 (9): 1529-41.

Zhang, X. Q., S. Sun, K. F. Lam, K. M. Kiang, J. K. Pu, A. S. Ho, W. M. Lui, C. F. Fung, T. S. Wong, and G. K. Leung. 2013. “A Long Non-Coding RNA Signature in Glioblastoma Multiforme Predicts Survival.” Neurobiol Dis 58: 123-31.

Zhang, Zong Hong, Dhanisha J. Jhaveri, Vikki M. Marshall, Denis C. Bauer, Janette Edson, Ramesh K. Narayanan, Gregory J. Robinson, et al. 2014. “A Comparative Study of Techniques for Differential Expression Analysis on RNA-Seq Data.” PloS One 9 (8). https://doi.org/10.1371/journal.pone.0103207. 
Zhao, Yu, Liguo Wang, Shancheng Ren, Lan Wang, Patrick R. Blackburn, Melissa S. McNulty, Xu Gao, et al. 2016. "Activation of P-TEFb by Androgen Receptor-Regulated Enhancer RNAs in Castration-Resistant Prostate Cancer.” Cell Reports 15 (3): 599.

Zhou, Meng, Hengqiang Zhao, Zhenzhen Wang, Liang Cheng, Lei Yang, Hongbo Shi, Haixiu Yang, and Jie Sun. 2015. "Identification and Validation of Potential Prognostic lncRNA Biomarkers for Predicting Survival in Patients with Multiple Myeloma." Journal of Experimental \& Clinical Cancer Research: CR 34 (1): 102.

Zhou, Y., Y. Chen, W. Ding, Z. Hua, L. Wang, Y. Zhu, H. Qian, and T. Dai. 2018. “LncRNA UCA1 Impacts Cell Proliferation, Invasion, and Migration of Pancreatic Cancer through Regulating miR-96/FOXO3.” IUBMB Life 70 (4): 276-90. 


\section{ANEXO 1. Scripts}

\section{Script "controle_de_qualidade":}

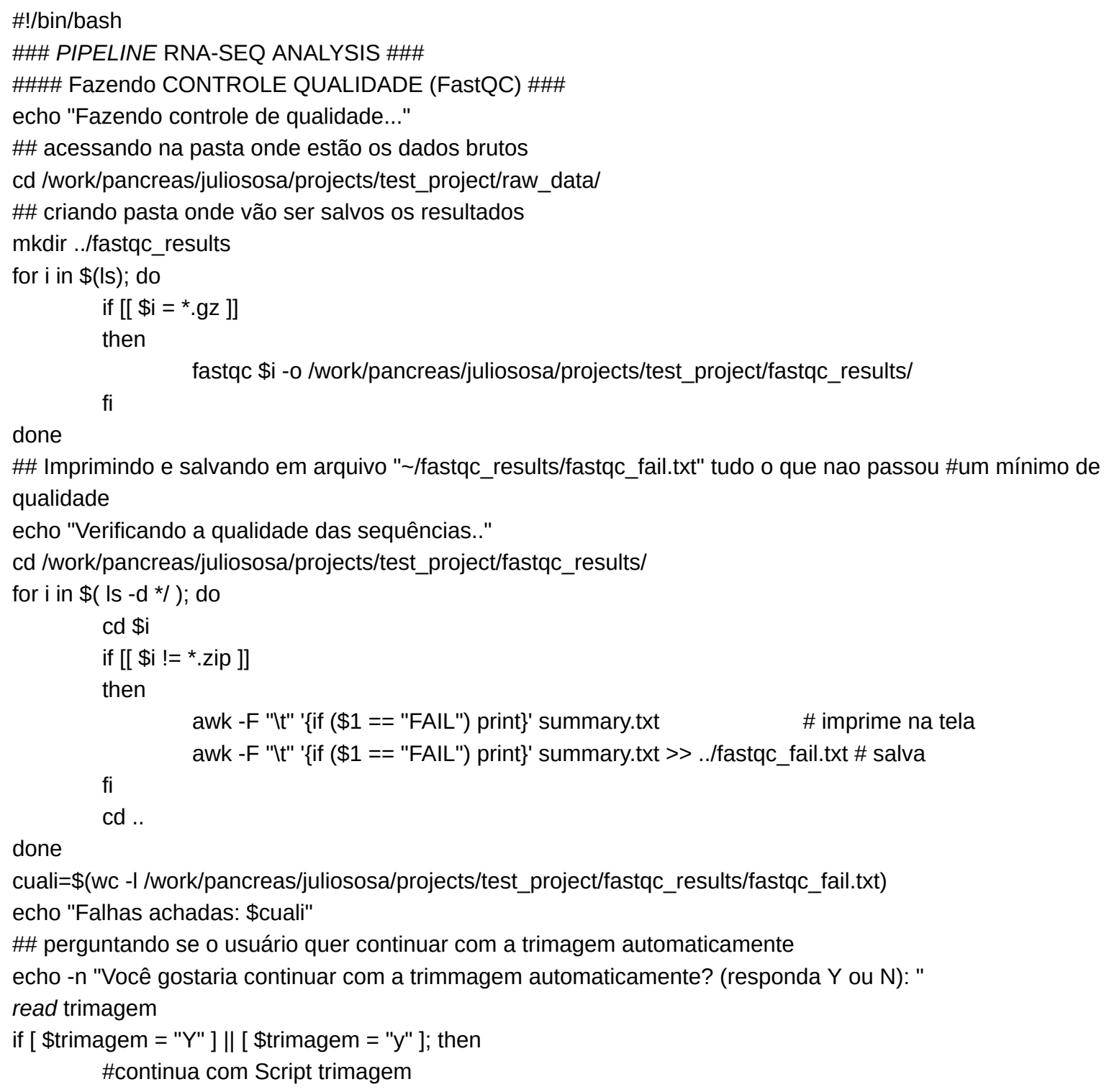

\section{Script "trimagem":}

\#!/bin/bash

echo "Fazendo trimagen..."

cd/work/pancreas/juliososa/projects/test_project/raw_data/

temp $=$ "'" 
for $\mathrm{k}$ in $\$(\mathrm{ls})$; do

\# pegando somente a primeira parte do arquivo para usa-lo como saída de trimmomatic (separado por

\#12N_S7_L001_R1_001.fastq.gz) e depois ligando com /)

temp2=\$(echo "\$k" | cut $-d$ " - - $f$ 1)

if [[ \$temp2 = \$temp ]]; then \# se tem o mesmo nome (sao R1 e R2) vai rodar o trimmomatic

java -jar/work/pancreas/data/bin/Trimmomatic-0.32/trimmomatic-0.32.jar PE -threads 10 \$nome1

\$k \$temp2\_output_paired.R1.fq.gz \$temp2\_output_unpaired.R1.fq.gz \$temp2\_output_paired.R2.fq.gz

\$temp2I_output_unpaired.R2.fq.gz ILLUMINACLIP:/work/pancreas/data/bin/Trimmomatic-0.32ln

/adapters/TruSeq3-PE-2.fa:2:30:10 LEADING:3 TRAILING:3 SLIDINGWINDOW:4:15 MINLEN:35

else

temp $=\$($ echo "\$k" | cut $-\mathrm{d} "$ " " -f 1) \# temp = 12N = temp2

nome1 $=\$ \mathrm{k}$

fi

done

cd /work/pancreas/juliososa/projects/test_project/

mkdir trimmomatic_results

mkdir trimmomatic_results/paired/

mv raw_data/*_output* trimmomatic_results/

mv trimmomatic_results/*_paired* trimmomatic_results/paired/

\#\# resultados em $\sim /$ trimmomatic_results/paired/

\section{Script "mapeamento"}

\#!/bin/bash

echo "Iniciando mapeamento..."

mkdir /work/pancreas/juliososa/projects/test_project/tophat2_results/

$\mathrm{cd} /$ work/pancreas/juliososa/projects/test_project/trimmomatic_results/paired/

nome1="a"

nome_old="b"

for $\mathrm{i}$ in $\$(\mathrm{Is})$; do

nome1=\$(echo "\$i" | cut $-d$ " $"$ " - 1 )

if [ "\$nome1" == "\$nome_old" ]

then

tophat2 -o /work/pancreas/juliososa/projects/test_project/tophat2_results/\$nome1\_out -p 20

--library-type=fr-firststrand

--transcriptome-index=/work/pancreas/data/databases/Homo_sapiens_UCSC_hg19/gencode.v19/gencode.v19.annot

ation/work/pancreas/data/databases/Homo_sapiens_UCSC_hg19/UCSC/hg19/Sequence/Bowtie2Index/genome

\$arquivo_old \$i 2>> \$nome1!_fusion.out

fi

nome_old=\$nome1

arquivo_old $=\$$ i

done

\section{Script "montagem"}

\#!/bin/bash

echo "Iniciando montagem (Stringtie)..." 
stringtie Normal_merged.bam -o stringtie_Normal_hg19_result.gtf -p 15 -G

/work/pancreas/data/databases/gencode.v19/gencode.v19.annotation.gtf

stringtie Tumor_merged.bam -o stringtie_Tumor_hg19_result.gtf -p 15 -G

/work/pancreas/data/databases/gencode.v19/gencode.v19.annotation.gtf

\section{Script "melhora_montagem_1"}

\#!/usr/bin/python

\# Remove transcritos repetidos

repetido = "false"

infile=open('./stringtie_Normal_hg19_result.gtf','r')

for line in infile:

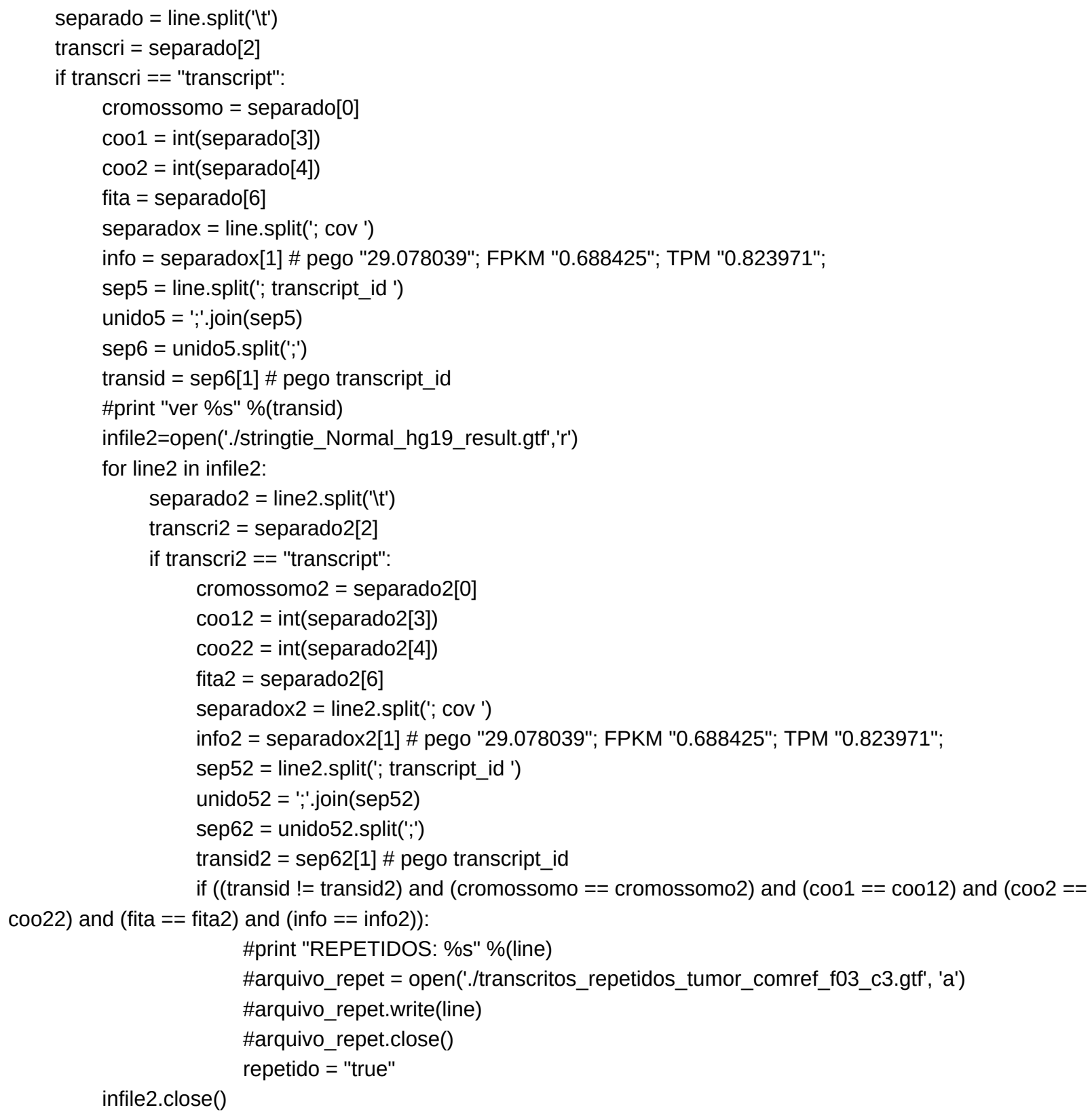


if repetido == "true": \# tem mais que um igual

arquivo_repet $=$ open('./transcritos_repetidos_normal_comref.gtf', 'a')

arquivo_repet.write(line)

arquivo_repet.close()

else: \# nao e repetido

arquivo = open('./transcritos_unicos_normal_comref.gtf', 'a') \# depois pegar somente o transcript id e

por em outro arquivo txt

arquivo.write(line)

arquivo.close()

repetido $=$ "false"

infile.close()

\section{Script "melhora_montagem_2"}

\#!/usr/bin/python

\# melhorando montagem, removendo os monoexonicos que estão dentro de coordenadas de genes do gencode \# 1) Separar monoexonicos: pego coord, chr e fita de "transcript" e de "exon", se são iguais salvo como monoexonico

\# 2) Olhar se esses monoexonicos estão dentro de coordenadas de genes do gencode.19, com um margem -+500 nt, salvar somente os transcript_ids em .txt

\# 3) Criar um gtf sem os monoexonicos que cumpliram condicao anterior

\# fazendo para Normal

infile=open('./stringtie_Normal_hg19_result_semrepetidos.gtf','r')

for line in infile:

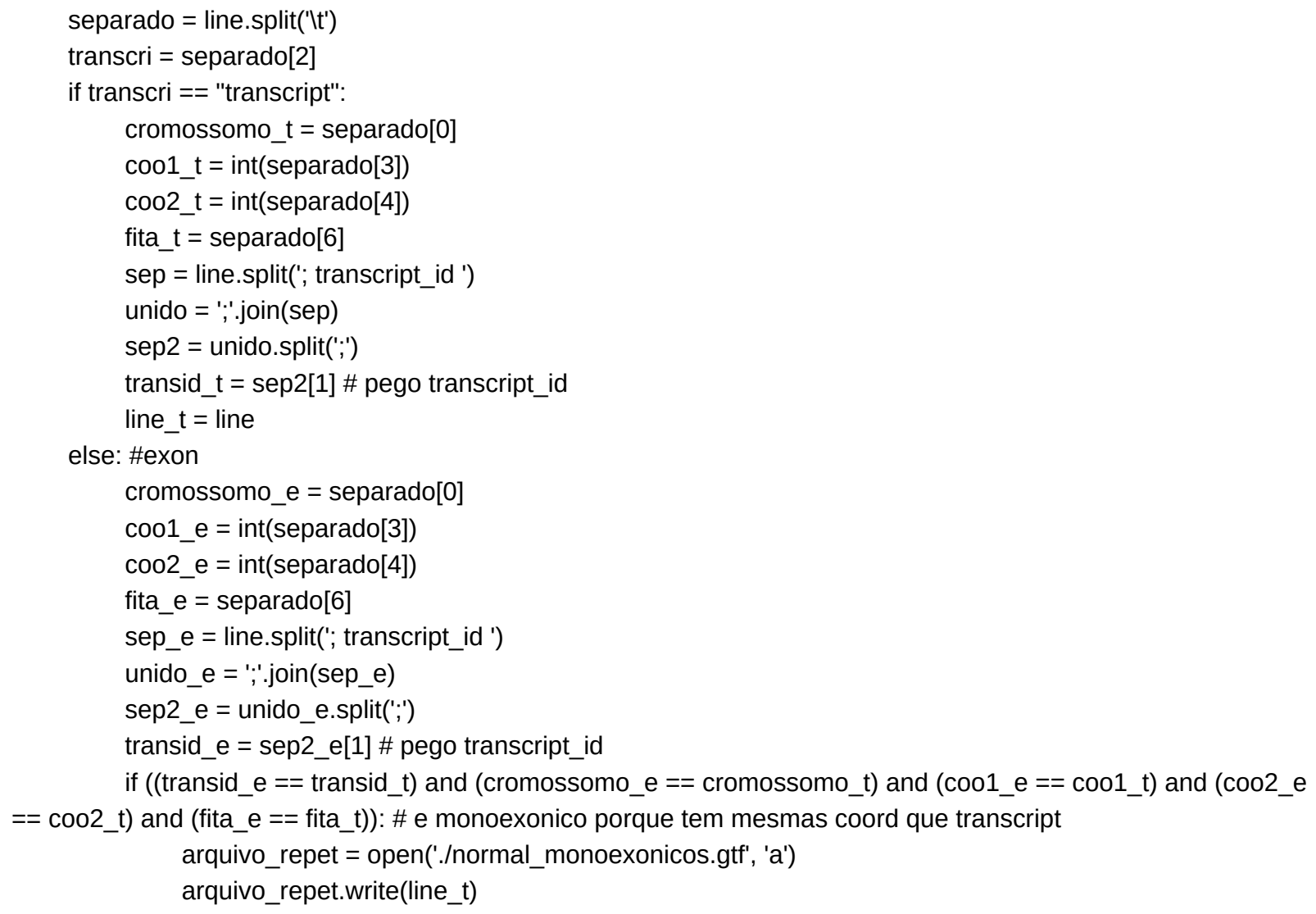




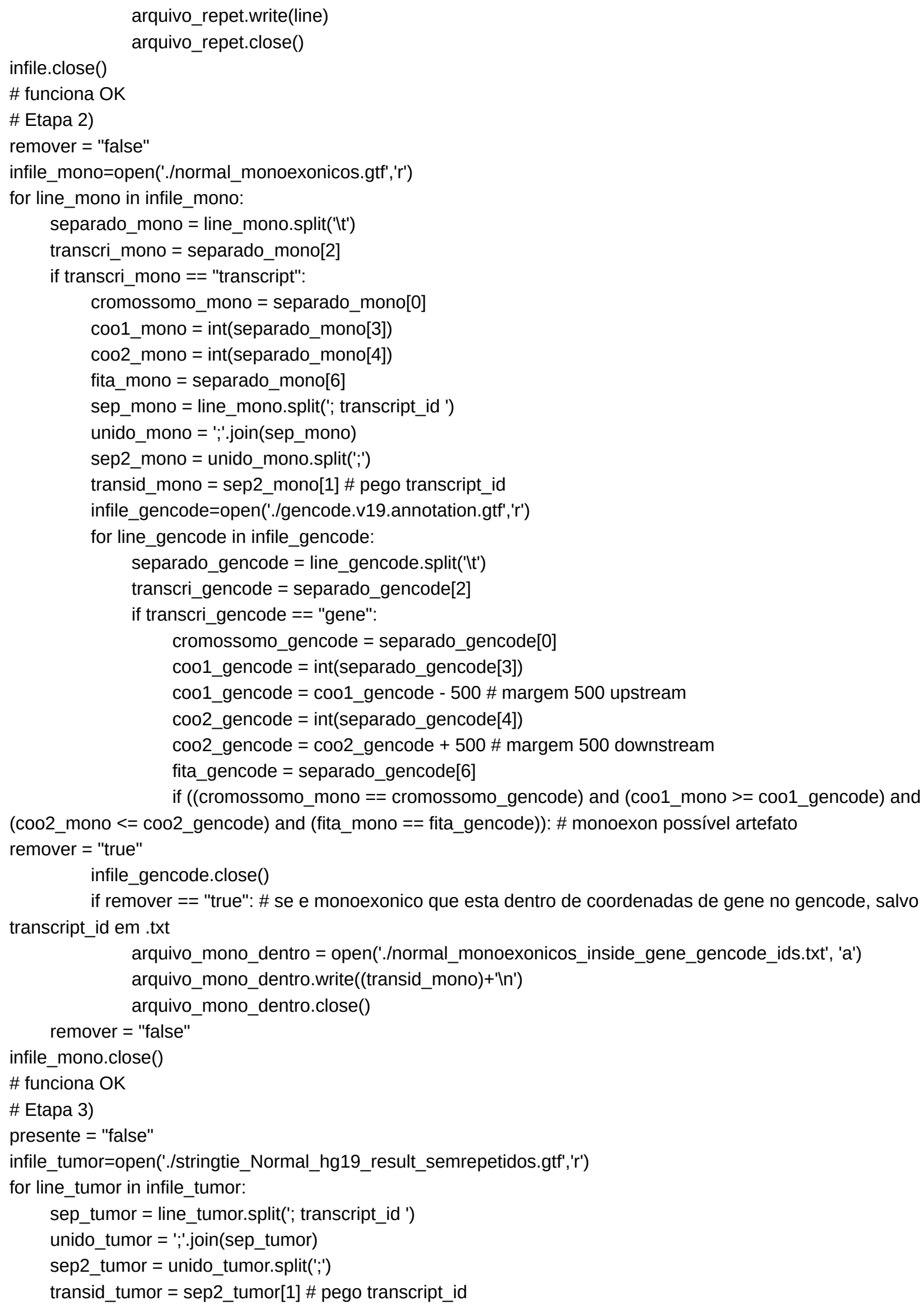


infile_ids = open('./normal_monoexonicos_inside_gene_gencode_ids.txt','r')

for line_ids in infile_ids:

if line_ids[-1] == 'In':

line_ids = line_ids[:-1] \#tiro enter da linha

if transid_tumor $==$ line_ids:

presente = "true"

infile_ids.close()

if presente != "true": \# se nao esta dentro da lista dos monoexonicos possíveis artefatos, salvo em gtf final" arquivo_sem_mono_dentro=open('./stringtie_Normal_hg19_result_final', 'a')

arquivo_sem_mono_dentro.write(line_tumor)

arquivo_sem_mono_dentro.close()

presente $=$ "false"

infile_tumor.close()

\# funciona OK

\#!/usr/bin/python

\#coding: utf-8

\# 1) Separa monoexonicos do gencode e salva em outro arquivo gtf: pego coord, chr e fita de "transcript" e de "exon", se são iguais salvo como monoexonico

\# 2) Olha se os monoexonicos da reconstrução ( $\mathrm{N}$ e T) estão dentro de coordenadas de genes monoexonicos do gencode.19, com um margem -+500 nt, salvar em outro gtf (depois adicionar no gtf final)

\# 1) separando monoexonicos do gencode

infile=open('./gencode.v19.annotation.gtf','r')

for line in infile:

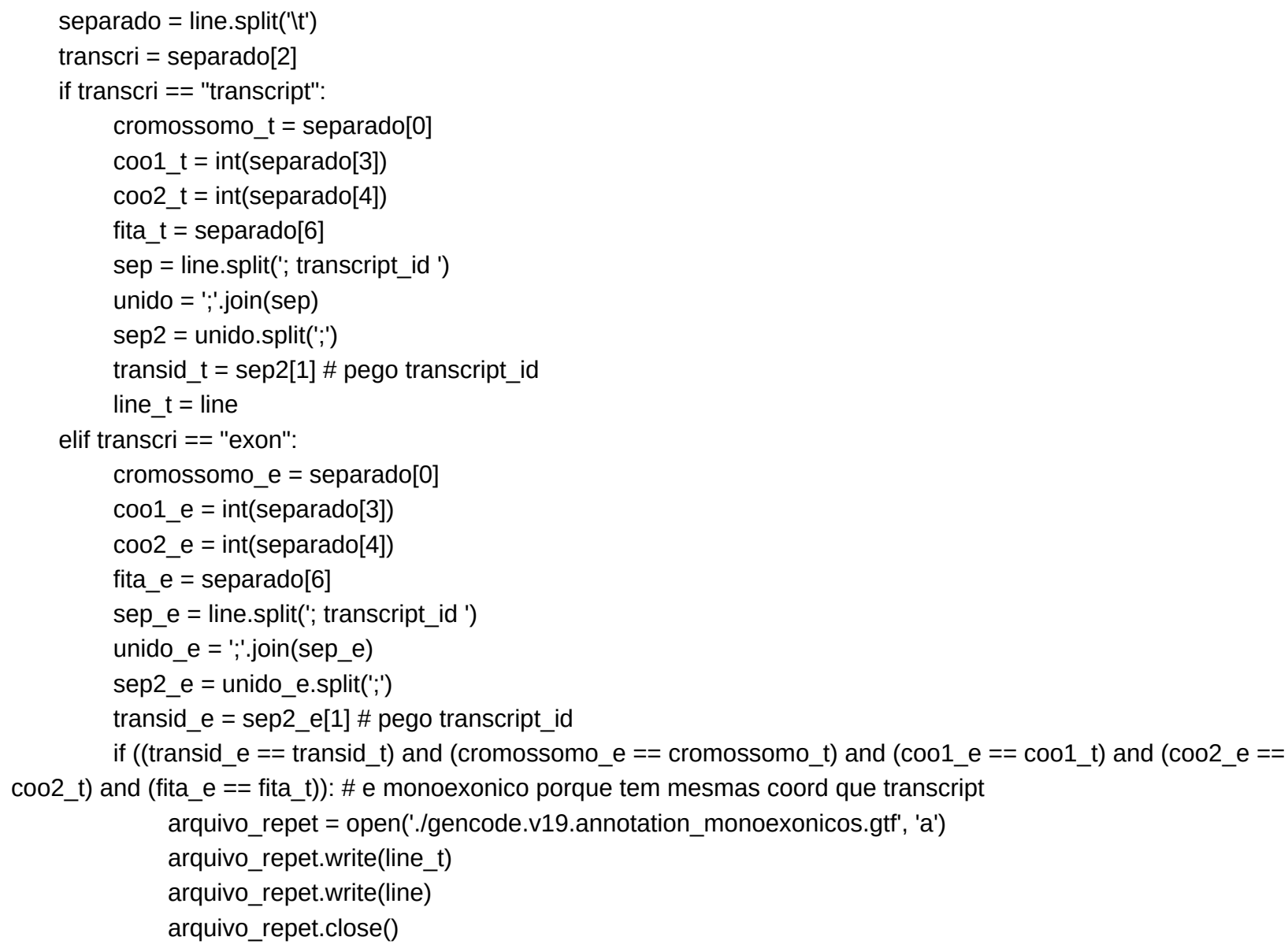




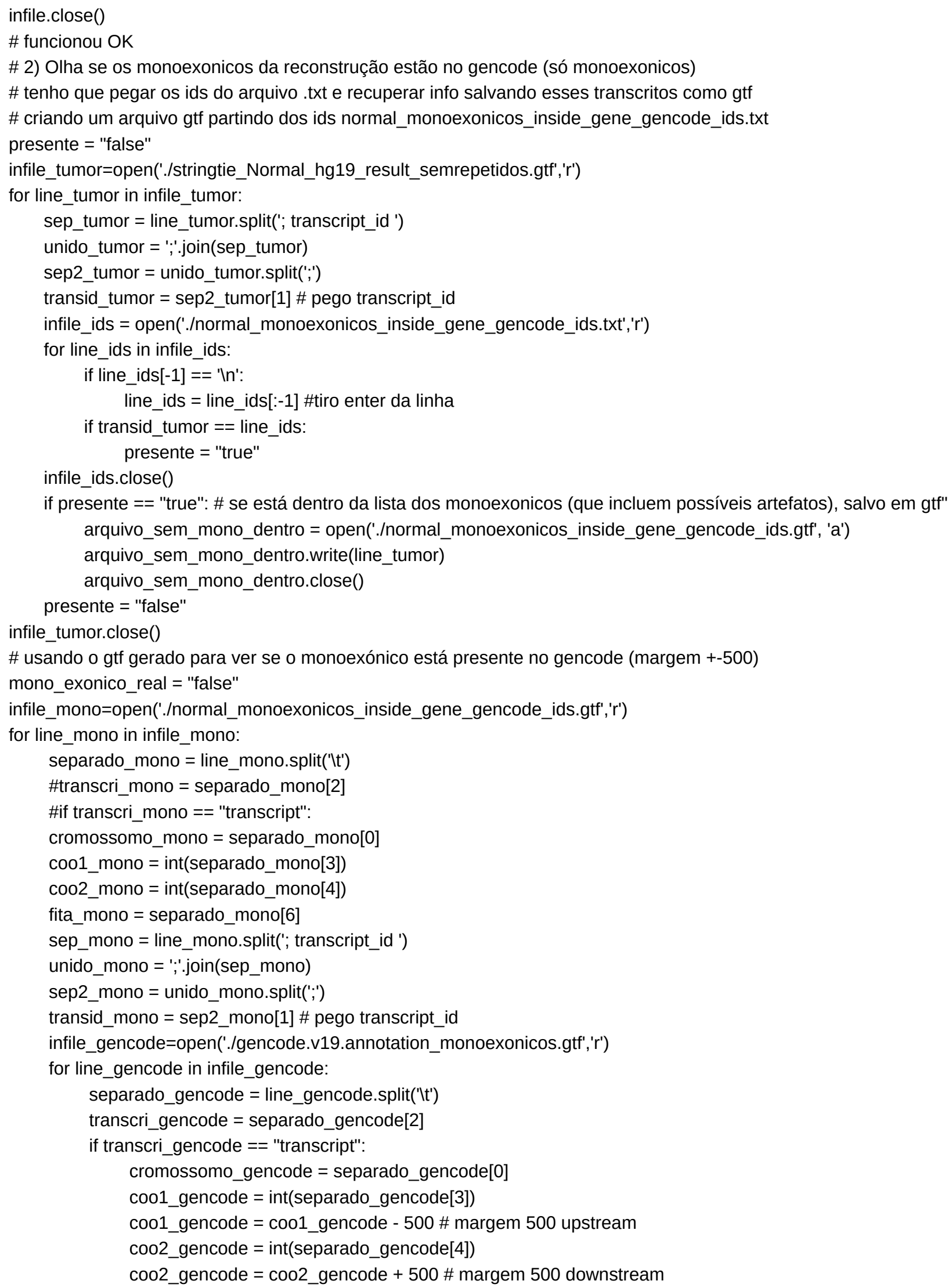




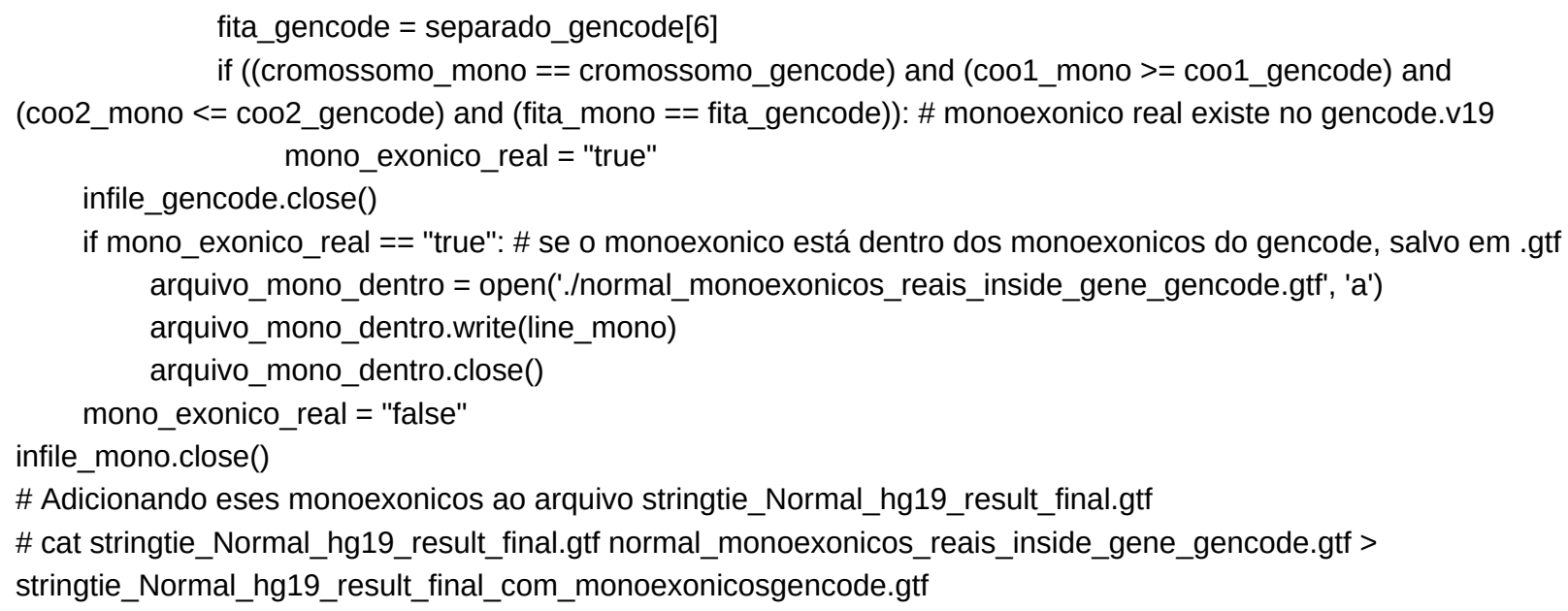

\section{Script "melhora_montagem_3"}

\#!/usr/bin/python

infile=open('./stringtie_Tumor_hg19_result_final_com_monoexonicosgencode.gtf','r')

for line in infile:

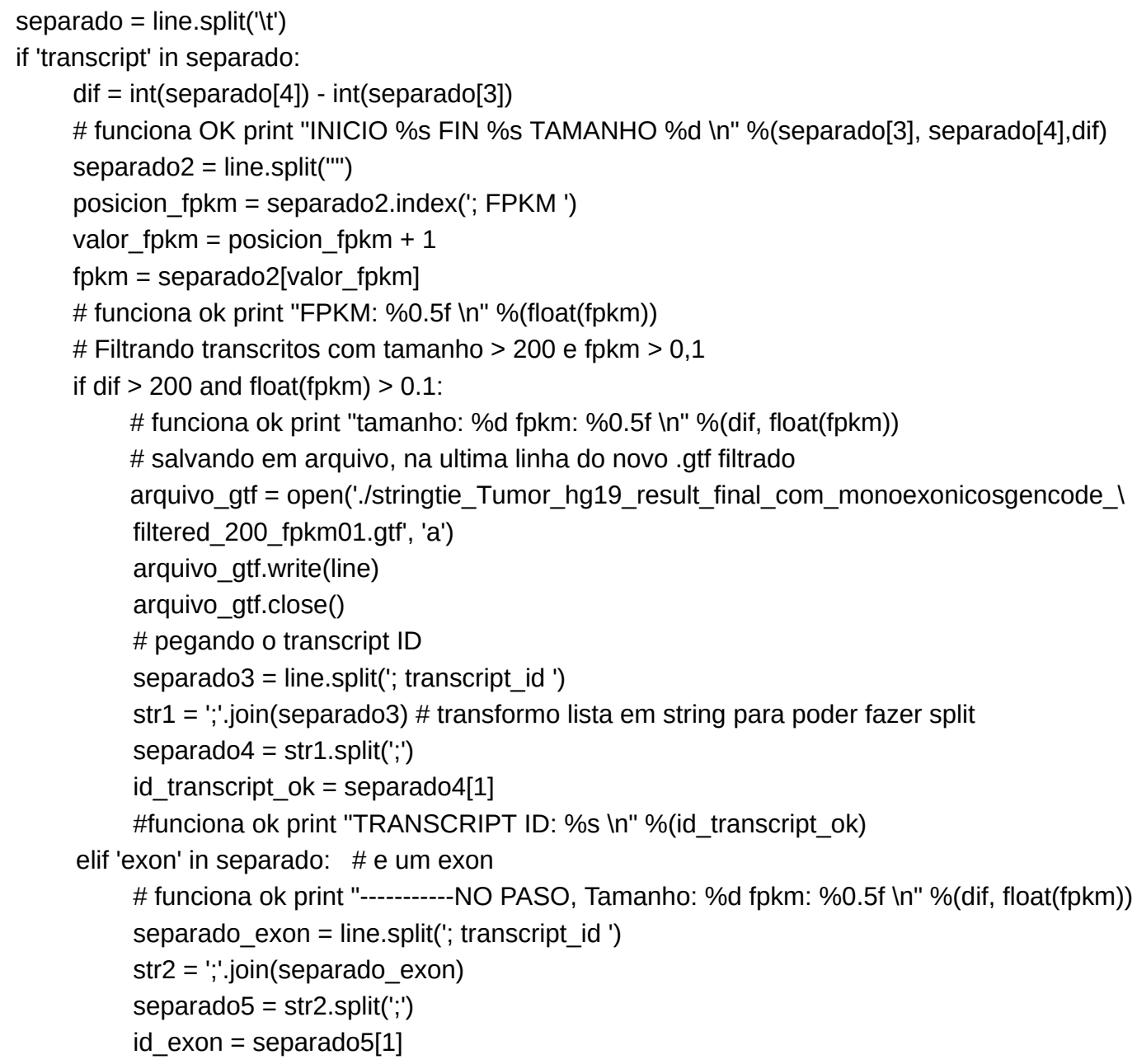


if id_exon == id_transcript_ok:

arquivo_gtf = open('./stringtie_Tumor_hg19_result_final_com_monoexonicosgencode_।

filtered_200_fpkm01.gtf', 'a')

arquivo_gtf.write(line)

arquivo_gtf.close()

infile.close()

\section{Script "anotação"}

\#!/bin/bash

echo "Juntando montagens tumorais e não-tumorais..."

cuffcompare stringtie_Tumor_hg19_result_final_com_monoexonicosgencode_filtered_200_fpkm01.gtf

stringtie_Normal_hg19_result_final_com_monoexonicosgencode_filtered_200_fpkm01.gtf -0

./cuffcompare/filtered/tumor_e_normal/result_cuffcompare_Tumor_e_Normal_filtered_fpkm01_t200

echo "Fazendo comparação NT vs Gencode.v19..."

cuffcompare ./cuffcompare/filtered/tumor_e_normal/result_cuffcompare_Tumor_e_Normal_filtered_l

fpkm01_t200.combined.gtf -r gencode.v19.annotation.gtf -o

./cuffcompare/filtered/tumor_e_normal/result_cuffcompare-merge_NT_filtered_200_fpkm01_vs_gencode19

echo "Fazendo comparação NT vs mitranscriptome"

cuffcompare ../result_cuffcompare_Tumor_e_Normal_filtered_fpkm01_t200.combined.gtf -r

/work/pancreas/juliososa/projects/camargo/hiseq/hg19_analysis/paper2016/mitranscriptome.v2.gtf -o

./result_cuffcompare-merge_NT_filtered_200_fpkm01_vs_mitranscriptome

\section{Script "remove_utrs"}

\#!/usr/bin/python

\# salvo todas as linhas do arquivo result_cuffcompare_Tumor_e_Normal_filtered_fpkm01_t2001

\#.combined.gtf que não tem o mesmo transcript_id que os intergênicos com distância menor $1 \mathrm{~kb}$

bandeira = "falso"

infile=open('./result_cuffcompare_Tumor_e_Normal_filtered_fpkm01_t200.combined.gff','r')

for line in infile:

separado_exon = line.split('; transcript_id ')

str2 = ',','join(separado_exon)

separado5 = str2.split(';')

id = separado5[1]

file_id_u=open('./intergenics_com_distancias_menorigual1kb_ids.txt','r')

for line_u in file_id_u:

if line_u[-1] == 'In':

line_u $=$ line_u[:-1] \#tiro enter da linha

line_u = "l"\%s|"'" \%(line_u) \# adiciono "'" nos ids

if id == line_u:

bandeira = "menor"

file_id_u.close()

if bandeira == "falso":

arq_1k=open('./result_cuffcompare_Tumor_e_Normal_filtered_fpkm01_t200_1kb.combined.gtf','a')

arq_1k.write(str(line))

arq_1k.close 
bandeira = "falso"

infile.close()

\section{Script "potencial_codificador"}

\#!/bin/bash

files $=\$($ ls *.fa $\mid$ sort $-n)$

for $i$ in $\$$ files;

do

/usr/bin/PhyloCSF -p 30 29mammals \$i --frames=3 >> phylocsf_intergenic_results.txt

echo Finished analysing fasta \$i

done

/usr/bin/run_predict intergenics_fpkm01_t200_1kb.fa result_table_intergenics ./cpc/results/intergenic2/

result_evidence_intergenics

/usr/bin/run_predict antisenses_fpkm01_t200_1kb.fa result_table_antisenses./cpc/results/

result_evidence_antisenses

/usr/bin/run_predict novel_isoform_fpkm01_t200_1kb.fa result_table_novel_isoform ./cpc/results/novel_isoform/ result_evidence_novel_isoform

\section{Script "busca_de_orfs"}

\#!/bin/bash

\# Step 1: extract the long open reading frames

TransDecoder.LongOrfs -t intergenics_filtradosmultiexonicoslargestexon.fa

TransDecoder.LongOrfs -t antisenses_filtradosmultiexonicoslargestexon.fa

TransDecoder.LongOrfs -t novel_isoform_filtradosmultiexonicoslargestexon.fa

\# Step 2: identify ORFs with homology to known proteins via blast searches

blastp -query intergenics_filtradosmultiexonicoslargestexon.fa.transdecoder_dir/longest_orfs.pep I

-db /work/databases/blast/swissprot/swissprot -max_target_seqs 11

-outfmt 6 -evalue 1e-5 -num_threads 5 > blastp.outfmt 6

blastp -query antisenses_filtradosmultiexonicoslargestexon.fa.transdecoder_dir/longest_orfs.pep ।

-db/work/databases/blast/swissprot/swissprot -max_target_seqs 11

-outfmt 6 -evalue 1e-5 -num_threads 5 > antisenses_blastp.outfmt6

blastp -query novel_isoform_filtradosmultiexonicoslargestexon.fa.transdecoder_dir/longest_orfs.pep I

-db/work/databases/blast/swissprot/swissprot -max_target_seqs 11

-outfmt 6 -evalue 1e-5 -num_threads 5 > isoforms_blastp.outfmt 6

\section{Script "marcas_de_regulação"}

\#!/bin/bash

\# promoter-like signatures (ccRE-PLS)

bedtools closest - $a$ j_sorted.bed -b ccRE-PLS.bed -D ref > j_com_distancias_tss_encode_ccRE-PLS.bed bedtools closest - $a$ u_sorted.bed -b ccRE-PLS.bed -D ref $>$ u_com_distancias_tss_encode_ccRE-PLS.bed bedtools closest $-a$ x_sorted.bed $-b$ ccRE-PLS.bed $-D$ ref $>$ x_com_distancias_tss_encode_ccRE-PLS.bed bedtools closest -a knonw_proteincoding_sorted.bed -b ccRE-PLS.bed -D ref > 
knownprotein_com_distancias_tss_encode_ccRE-PLS.bed

bedtools closest -a knonw_antisense_sorted.bed -b ccRE-PLS.bed -D ref >

known_antisense_com_distancias_tss_encode_ccRE-PLS.bed

bedtools closest -a knonw_lincRNA_sorted.bed -b ccRE-PLS.bed -D ref >

known_lincrna_com_distancias_tss_encode_ccRE-PLS.bed

\# enhancer-like signatures (ccRE-ELS)

bedtools closest -a j_sorted.bed -b ccRE-ELS.bed -D ref $>$ j_com_distancias_tss_encode_ccRE-ELS.bed

bedtools closest - $a$ u_sorted.bed -b ccRE-ELS.bed -D ref $>$ u_com_distancias_tss_encode_ccRE-ELS.bed bedtools closest -a x_sorted.bed -b ccRE-ELS.bed -D ref $>$ x_com_distancias_tss_encode_ccRE-ELS.bed bedtools closest -a knonw_proteincoding_sorted.bed -b ccRE-ELS.bed -D ref >

knownprotein_com_distancias_tss_encode_ccRE-ELS.bed

bedtools closest -a knonw_antisense_sorted.bed -b ccRE-ELS.bed -D ref >

known_antisense_com_distancias_tss_encode_ccRE-ELS.bed

bedtools closest -a knonw_lincRNA_sorted.bed -b ccRE-ELS.bed -D ref >

known_lincrna_com_distancias_tss_encode_ccRE-ELS.bed

\# CTCF-only

bedtools closest -a j_sorted.bed -b CTCF-only.bed -D ref $>$ j_com_distancias_tss_encode_CTCF-only.bed bedtools closest -a u_sorted.bed -b CTCF-only.bed -D ref $>$ u_com_distancias_tss_encode_CTCF-only.bed bedtools closest -a x_sorted.bed -b CTCF-only.bed -D ref $>$ x_com_distancias_tss_encode_CTCF-only.bed bedtools closest -a knonw_proteincoding_sorted.bed -b CTCF-only.bed -D ref $>$ knownprotein_com_distancias_tss_encode_CTCF-only.bed bedtools closest -a knonw_antisense_sorted.bed -b CTCF-only.bed -D ref > known_antisense_com_distancias_tss_encode_CTCF-only.bed bedtools closest -a knonw_lincRNA_sorted.bed -b CTCF-only.bed -D ref > known_lincrna_com_distancias_tss_encode_CTCF-only.bed

\section{Script "sequências_aleatórias"}

\# peguei o tamanho médio (2010 nt) dos intergênicos e salvei em arquivo u_size_average.bed \# shuffle vai gerar uma linha com coordenadas do mesmo tamanho e excluindo as sequências gênicas for i in `seq 150 '; do \# faz 50 vezes o cálculo de distância com arquivo random de 5 mil linhas, e calcule a distância \#média para cada posição

for i in `seq 1 2500`; do \#2500 para gerar de 5mil linhas

bedtools shuffle -i u_size_average.bed -g hg19.genome -excl gencode.v19.annotation_genes_sorted.bed

>> random_shuffle_intergenics.bed

done

\# gera um arquivo com 5 mil linhas (50\% fita +)

awk -F "It" '\{print \$1 "It" \$2 "lt" \$2 "It" \$4\}' random_shuffle_intergenics.bed >

random_shuffle_intergenics_coo1.bed

sort -k1,1-k2,2n random_shuffle_intergenics_coo1.bed > random_shuffle_intergenics_sorted.bed

\# Calculando distâncias bedtools -closest

bedtools closest -a random_shuffle_intergenics_sorted.bed -b ENCFF788SJC_col-1-2-3.bed -D ref > random_com_distancias_tss_encode_5g.bed

bedtools closest -a random_shuffle_intergenics_sorted.bed -b ccRE-PLS.bed -D ref > random_com_distancias_tss_encode_ccRE-PLS.bed

bedtools closest -a random_shuffle_intergenics_sorted.bed -b ccRE-ELS.bed -D ref > random_com_distancias_tss_encode_ccRE-ELS.bed

bedtools closest -a random_shuffle_intergenics_sorted.bed -b CTCF-only.bed -D ref > random_com_distancias_tss_encode_CTCF-only.bed 
Rscript script_plot_random.r \# Script "porcentagem_sequências_aleatórias"

rm -f random_com_distancias_* \# se não apago simplesmente vai sobrescrever

rm -f random_shuffle_intergenics.bed random_shuffle_intergenics_coo1.bed

random_shuffle_intergenics_sorted.bed

done

./calcula_media_porcentagens.py

\section{Script "porcentagem_sequências_aleatórias"}

\# script para salvar as porcentagens de transcritos random para cada distância, e fazer a média para figura $x<-$ seq $(-10000,10000,1000)$

\# Promoter-like

read.delim("./random_com_distancias_tss_encode_ccRE-PLS.bed", header=F)-> plan

hist(plan\$V8, breaks $=\mathrm{c}\left(-10^{\wedge} 8, \mathrm{x}, 10^{\wedge} 8\right)$, plot $\left.=\mathrm{F}\right)->\mathrm{d}$

$c(0, d \$$ counts[2:21])->yP

yP/sum(d\$counts)*100-> yP

write.table(yP,"./random_porcentagens_PLS.txt", sep = "It", col.names = F, append = T)

\# Enhancer-like

read.delim("./random_com_distancias_tss_encode_ccRE-ELS.bed", header=F)-> plan

hist(plan\$V8, breaks $=\mathrm{c}\left(-10^{\wedge} 8, \mathrm{x}, 10^{\wedge} 8\right)$, plot $\left.=\mathrm{F}\right)->\mathrm{d}$

$c(0, d \$$ counts[2:21])->yE

yE/sum(d\$counts)*100-> yE

write.table(yE,"./random_porcentagens_ELS.txt", sep = "It", col.names = F, append = T)

\# CTCF

read.delim("./random_com_distancias_tss_encode_CTCF-only.bed", header=F)-> plan

hist $\left(\right.$ plan $\$ \vee 8$, breaks $=\mathrm{c}\left(-10^{\wedge} 8, \mathrm{x}, 10^{\wedge} 8\right)$, plot $\left.=\mathrm{F}\right)->\mathrm{d}$

$\mathrm{c}(0, \mathrm{~d} \$$ counts[2:21])->yC

$\mathrm{yC} /$ sum(d\$counts)*100-> yc

write.table(yC,"./random_porcentagens_CTCF.txt", sep = "It", col.names = F, append = T)

\section{Script "splicing"}

\#!/bin/bash

cd./gtf_files

for $\mathrm{j}$ in $\$(\mathrm{ls} *$.gtf); do

nome $=\$($ echo "\$j" | cut $-d$ "." -f 1)

\#echo "Nome \$nome J \$j Nome_output \$nomel_suppa_output"

suppa generateEvents -i \$j -o /suppa/output_suppa/\$nomel_suppa -f ioe -e SE SS MX RI FL done

\section{Script "htseq"}

\#!/bin/bash

cd/work/pancreas/juliososa/projects/camargo/hiseq/results/tophat2

for I in $\$($ Is $-d * /)$; do 
$\mathrm{cd} \$$

nome $=\$($ echo "\$l" | cut $-d$ "_" -f 1)

samtools view accepted_hits.sorted.name.bam | HTSeq-count --strand=reverse --idattr transcript_id -q -

/work/pancreas/juliososa/projects/camargo/hiseq/hg19_analysis/paper2016/distance_intergenics/result_cuffcompare_ Tumor_e_Normal_filtered_fpkm01_t200_1kb.combined.gtf >

/work/pancreas/juliososa/projects/camargo/hiseq/hg19_analysis/paper2016/HTSeq/results_transcript/\$nomel_HTSeq

_filtered_t200_fpkm01_1kb_transcript.out

$\mathrm{cd} .$.

done

\section{Script "star_rsem"}

\#!/bin/bash

\# 1) Preparando a referencia

\# \$ STAR --runThreadN 10 --limitGenomeGenerateRAM 124544990592 --runMode genomeGenerate --genomeDir

GENOME_data/star --genomeFastaFiles GENOME_data/genome.fa --sjdbGTFfile

GENOME_data/result_cuffcompare_Tumor_e_Normal_filtered_fpkm01_t200_1kb.combined.gtf

\# 2) Alinhando com Star

cd fastq_concatenados

for I in $\$$ (ls *.fastq.gz); do

nome $=\$($ echo "\$l" | cut - $d$ "_" -f 1)

read=\$(echo "\$l" | cut -d "_" -f 2)

if [ "\$read" == "R1"]; then

$\mathrm{r} 1=\$ 1$

nomer1=\$nome

\#echo "R1 " \$nomer1

else

nomer2=\$nome

$\mathrm{r} 2=\$ 1$

\#echo "R2 " \$nomer2

fi

\#Options para RSEM-prepare-reference

\#--bam Input file is in BAM format.

\#--no-bam-output Do not output any BAM file.

\#-p Number of threads to use.

\#--paired-end Input reads are paired-end reads.

\#--forward-prob Probability of generating a read from the forward strand of a transcript. 1: strand-specific protocol where all (upstream) reads are derived from the forward strand; 0: strand-specific protocol where all (upstream) read are derived from the reverse strand; 0.5: non-strand-specific protocol.

\#RSEM generates 2 result files:

\#1. RSEM.genes.results

\#2. RSEM.isoforms.results.

\# Agora criando index

\#\$ nohup RSEM-prepare-reference --gtf

GENOME_data/result_cuffcompare_Tumor_e_Normal_filtered_fpkm01_t200_1kb.combined.gtf

GENOME_data/genome.fa GENOME_data/RSEM/hg_montagem \&

\#\#\# rodando rsem para todas as amostras \#\#\#

cd result_star 
for I in $\$$ (Is *toTranscriptome.out.bam); do

nome $=\$($ echo "\$l" | cut - d "_" -f 1)

RSEM-calculate-expression --bam --no-bam-output -p 40 --paired-end --forward-prob 0 \$I

/work/pancreas/juliososa/projects/camargo/hiseq/hg19_analysis/paper2016/RSEM/GENOME_data/RSEM/hg_monta gem

/work/pancreas/juliososa/projects/camargo/hiseq/hg19_analysis/paper2016/RSEM/result_RSEM/\$nomel_RSEM.txt done

\section{Script "Salmon"}

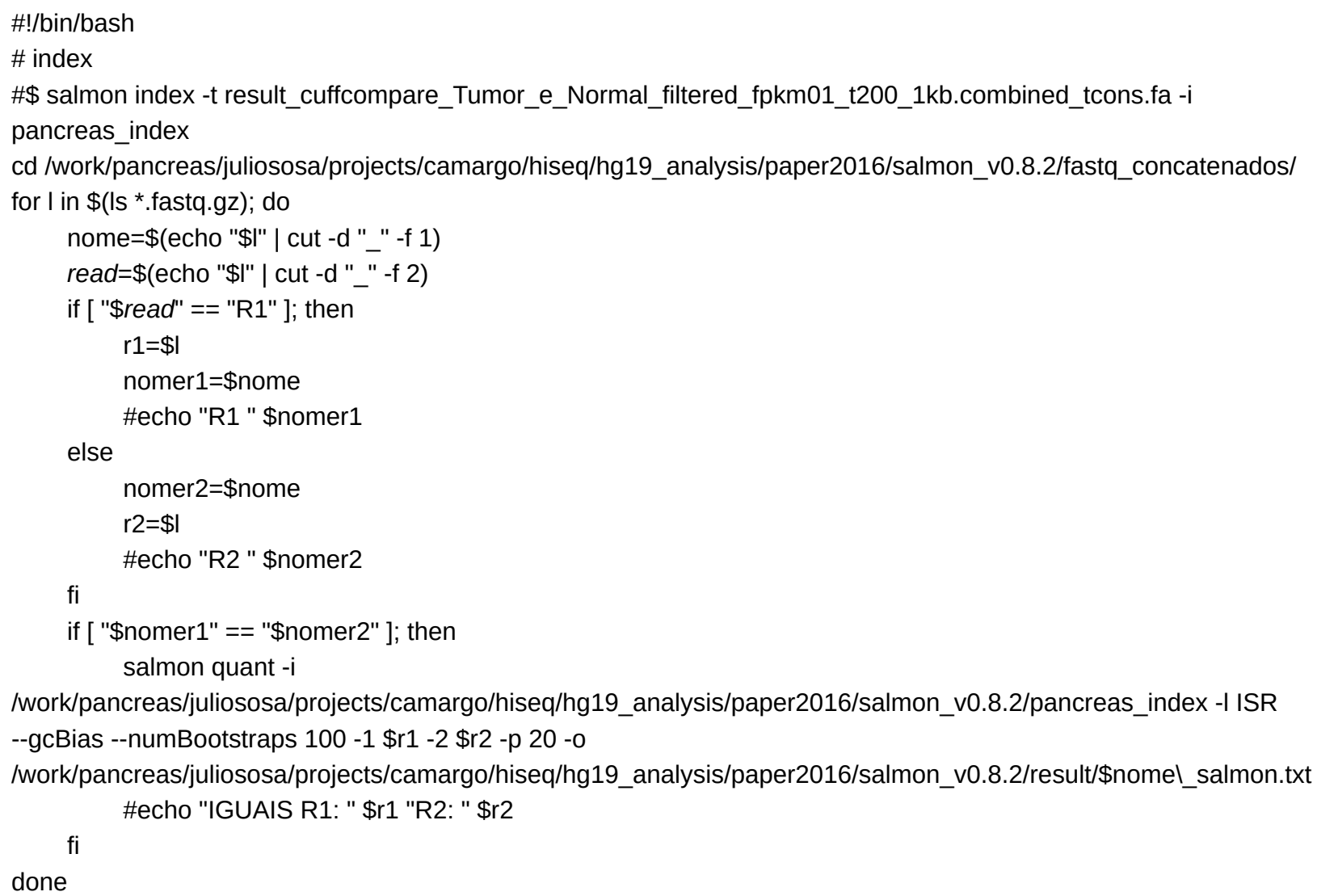

\section{Script "Kallisto"}

\# convertindo gtf to fasta (minha referencia)

\#\$ nohup gtf_to_fasta result_cuffcompare_Tumor_e_Normal_filtered_fpkm01_t200_1kb.combined.gtf genome.fa result_cuffcompare_Tumor_e_Normal_filtered_fpkm01_t200_1kb.combined.fa \& \# Gera id numerico e não TCONS, entao tenho que trocar cabeçalho do fasta para que o id seja TCONS:

\#\$ cp result_cuffcompare_Tumor_e_Normal_filtered_fpkm01_t200_1kb.combined.fa result_cuffcompare_Tumor_e_Normal_filtered_fpkm01_t200_1kb.combined_tcons.fa \#\$ vi result_cuffcompare_Tumor_e_Normal_filtered_fpkm01_t200_1kb.combined_tcons.fa \# \%s/>[0-9]/>/ \# fiz varias vezez ate todos ficarem > TCONS... 


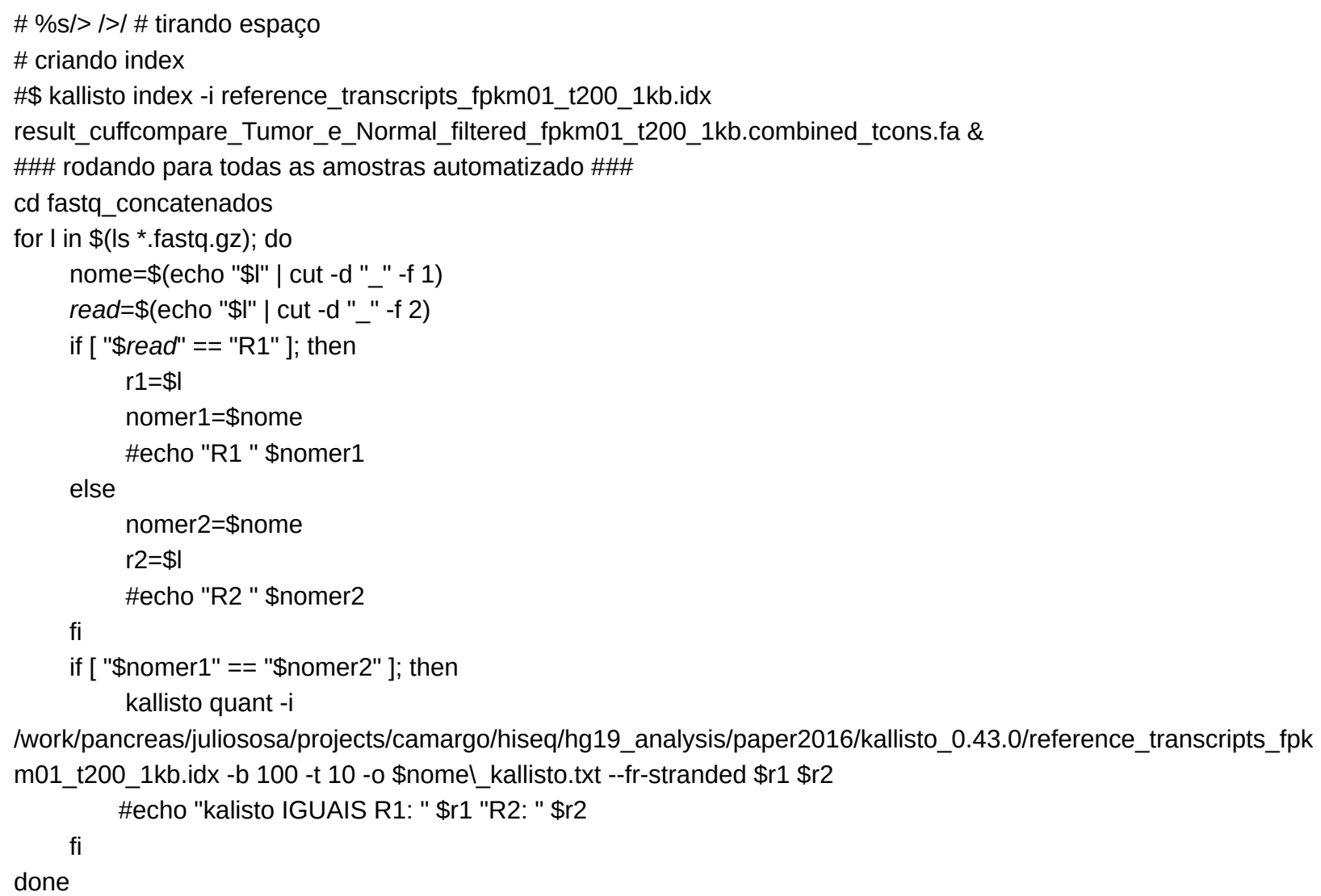

\section{Script "expressão_diferencial"}

\# carregando livraria

library("DESeq2")

\# carregando tabela de contagem countdata e informação coldata

coldata <- read.table("coldata.txt", header = TRUE) \# colClasses = c("NULL", NA, NA))

countdata <-read.table("countdata_transcript.txt", header = TRUE)

countdata<-countdata[-((nrow(countdata)-4):nrow(countdata)),] \# apagando as últimas 5 linhas (informação de alinhamento)

dds <- DESeqDataSetFromMatrix (countData = countdata, colData $=$ coldata, design $=\sim$ condition $)$

rld $<-$ rlog(dds)

dds <- estimateSizeFactors(dds)

sampleDists <- dist( t( assay(rld) ) )

library("gplots")

library("RColorBrewer")

sampleDistMatrix <- as.matrix ( sampleDists )

rownames(sampleDistMatrix) <- paste( rld\$sample )

colors <- colorRampPalette( rev(brewer.pal(9, "Blues")) )(255)

hc $<-$ hclust(sampleDists)

\#jpeg("figura1.jpg") \#salvando figura

heatmap.2( sampleDistMatrix, symm=TRUE, trace="none", col=colors, margins=c $(2,10)$, labCol=FALSE, Colv=TRUE ) 


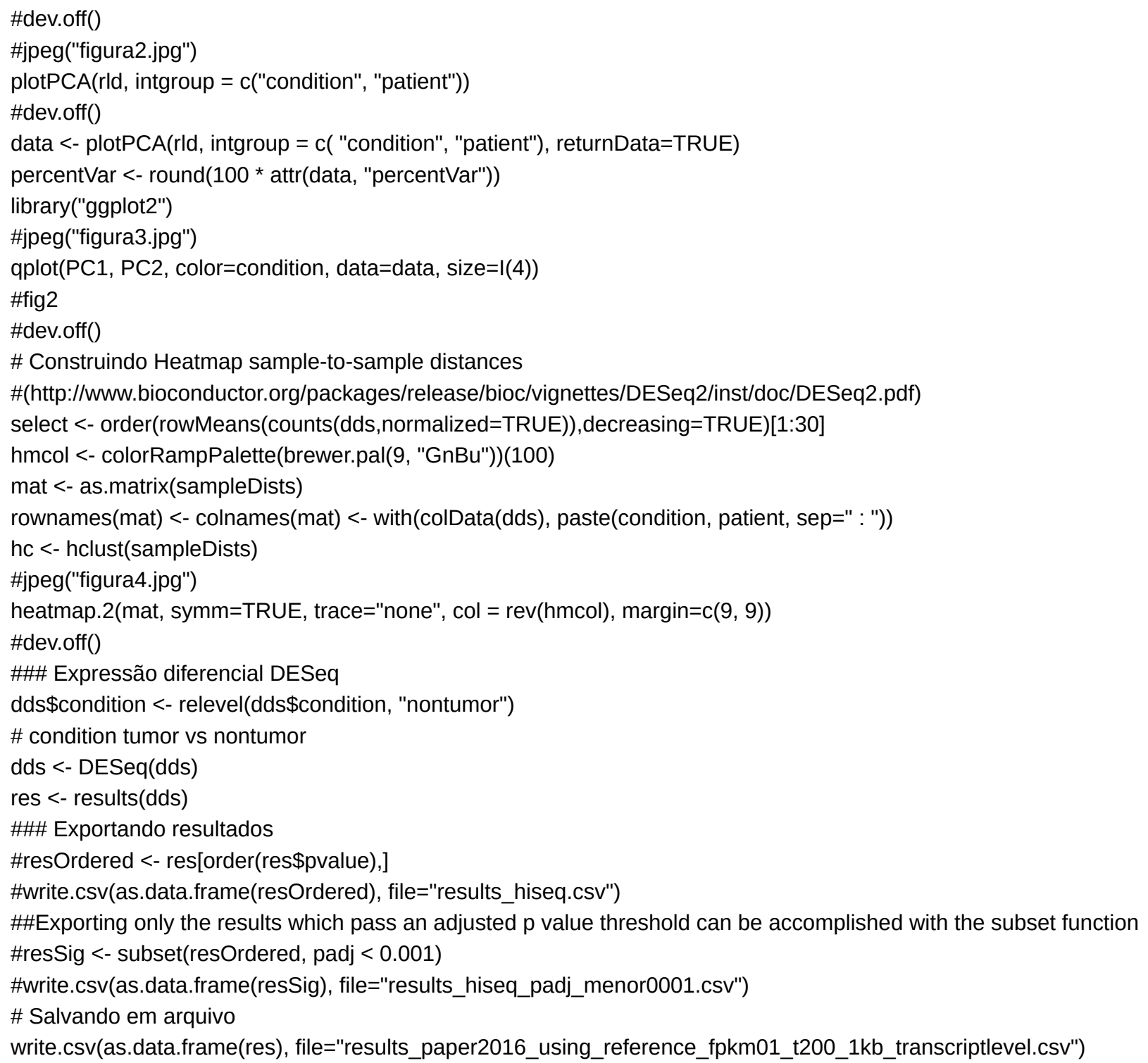

\section{Script "circrna"}

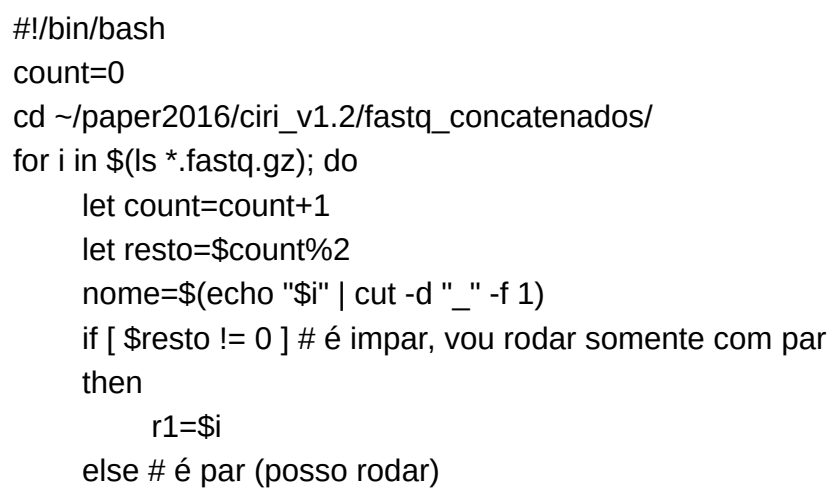


\#echo bwa mem -t 40 -T 19 genome.fa \$r1 \$i /work/pancreas/\$nomel_bwa.sam

bwa mem -t 40 -T 19

/work/pancreas/juliososa/projects/camargo/hiseq/hg19_analysis/paper2016/ciri_v1.2/genome.fa \$r1 \$i >

/work/pancreas/juliososa/projects/camargo/hiseq/hg19_analysis/paper2016/ciri_v1.2/bwa_output/\$nomel_bwa.sam $\mathrm{fi}$

done

cd /work/pancreas/juliososa/projects/camargo/hiseq/hg19_analysis/paper2016/ciri_v1.2/bwa_output/

for $\mathrm{i}$ in $\$($ ls *.sam); do

nome $=\$($ echo "\$i" | cut $-d "$ " - f 1$)$

perl /usr/bin/CIRI2 -I \$i -O

/work/pancreas/juliososa/projects/camargo/hiseq/hg19_analysis/paper2016/ciri_v1.2/ciri_output/\$i_ciri_out -F /work/pancreas/juliososa/projects/camargo/hiseq/hg19_analysis/paper2016/ciri_v1.2/genome.fa -P -A

/work/pancreas/juliososa/projects/camargo/hiseq/hg19_analysis/paper2016/ciri_v1.2/GENCODE.v19.annotation.gtf done

\section{Script "anota_circrnas"}

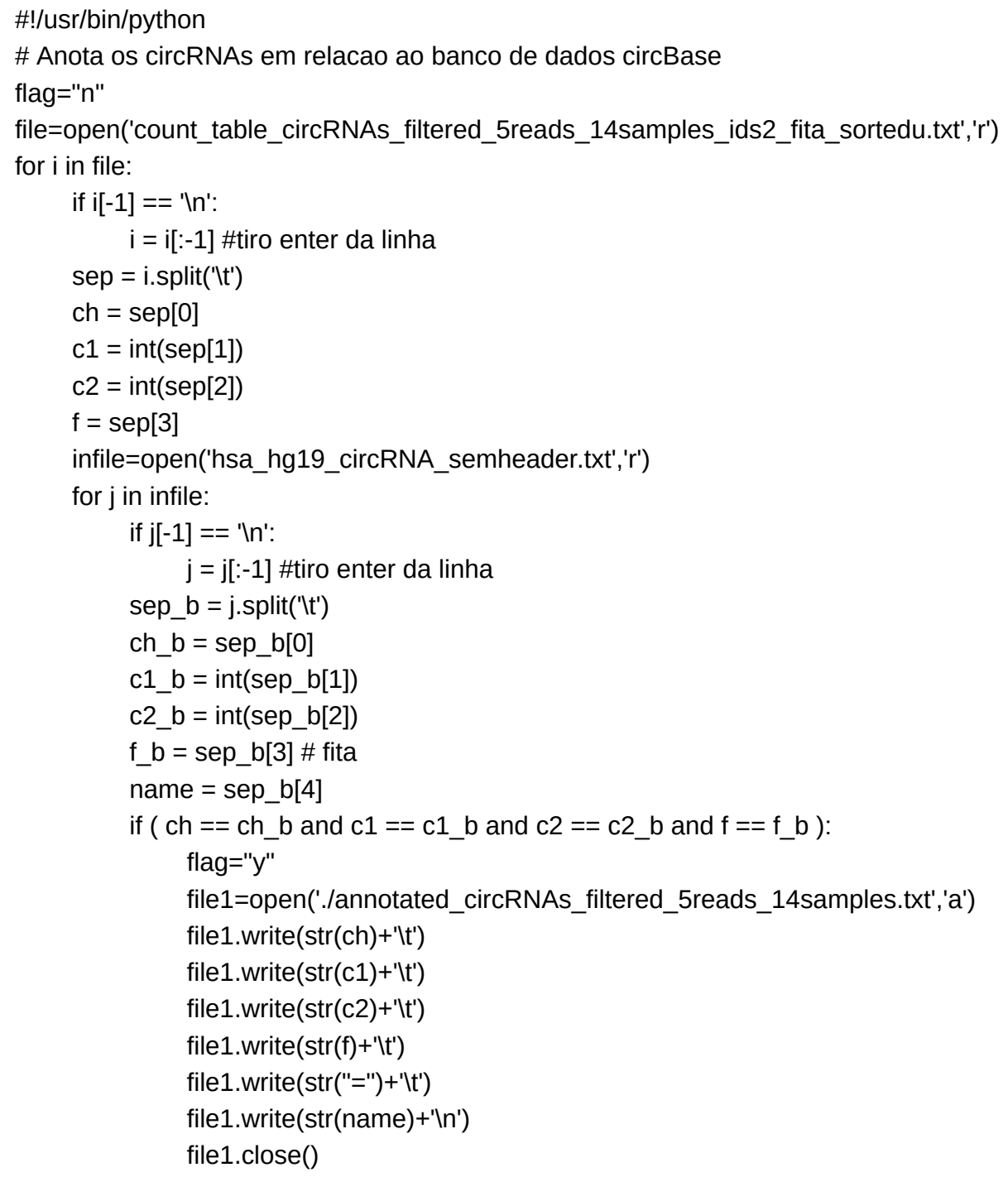




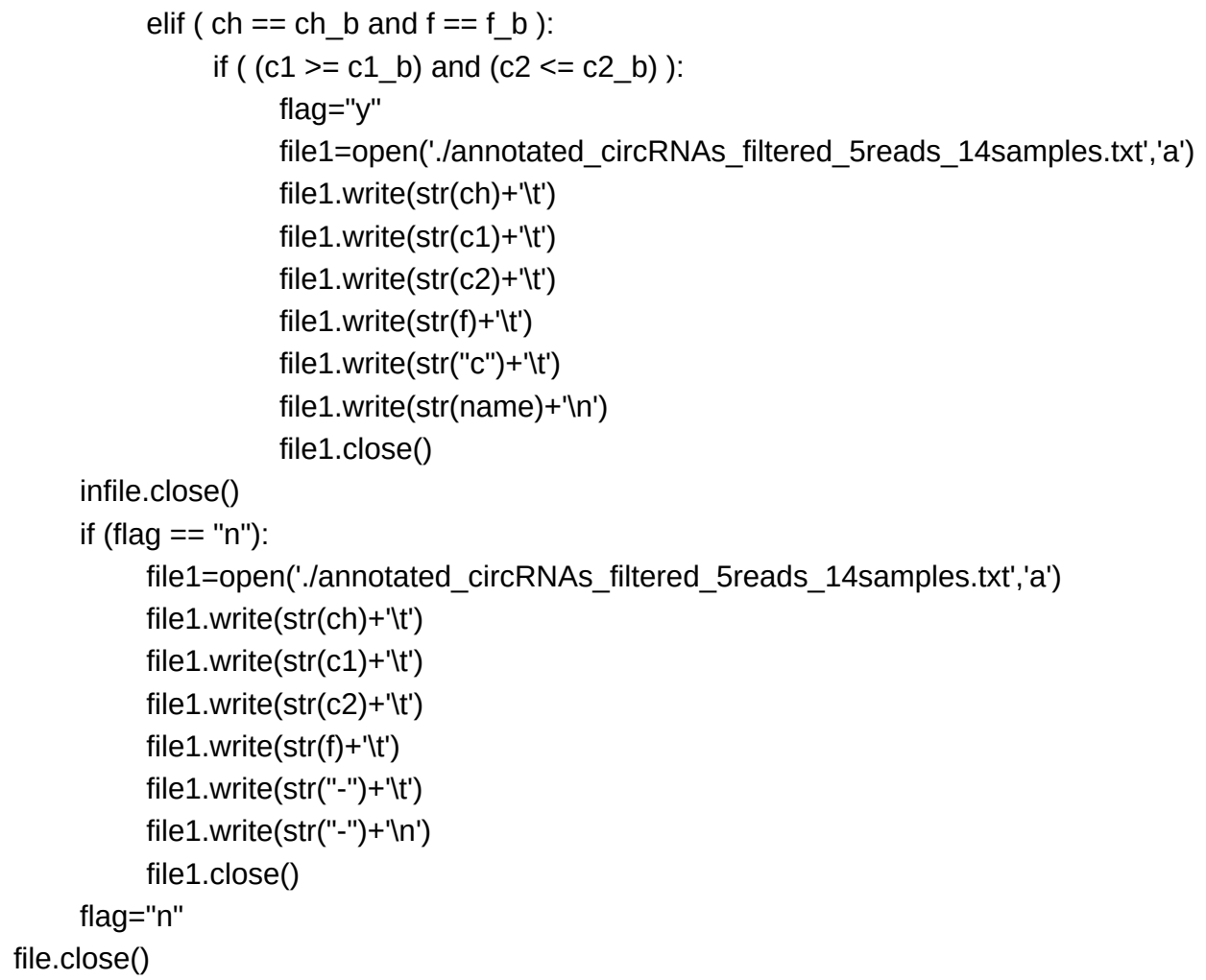




\section{ANEXO 2. Certificado Comité de ética}

\section{A.C.Camargo
Cancer Center
$\begin{aligned} & \text { FUNDAÇÃO ANTÔNIO } \\ & \text { CÂNCER A C CAMARGO }\end{aligned}$}

\section{PARECER CONSUBSTANCIADO DO CEP}

\section{DADOS DO PROJETO DE PESQUISA}

Título da Pesquisa: Identificação de Biomarcadores para Diagnóstico Molecular do Adenocarcinoma Ductal do Pâncreas

Pesquisador: Eduardo Moraes Rego Reis

Área Temática:

Versão: 1

CAAE: 15059213.0 .0000 .5432

Instituição Proponente:

Patrocinador Principal: Financiamento Próprio

DADOS DO PARECER

Número do Parecer: 457.476

Data da Relatoria: 05/11/2013

\section{Apresentação do Projeto:}

Adequada.

\section{Objetivo da Pesquisa:}

Os pesquisadores pretendem estabelecer uma plataforma analítica para identificar alterações no perfil de expressão de RNAs (transcritoma) e na sequência de DNA (exoma) através do sequenciamento de alta capacidade de RNAIDNA proveniente de amostras clínicas de tumores pancreáticos. Um aspecto original da proposta será a análise de RNAs não codificadores longos poliadenilados e não poliadenilados expressos em amostras de PDAC e tecido pancreático não tumoral. Outro aspecto inovador será a utilização de biópsias de tumores de pâncreas obtidas através de ecoendoscopia aspirativa por agulha fina (EUS-FNA). Os pesquisadores também se propõe a investigar o potencial diagnóstico de RNAs isolados de amostras do plasma e de líquido cístico de pacientes com tumores císticos de pâncreas. Com a análise integrada dos dados eles pretendem identificar genes, vias moleculares e módulos funcionais preferencialmente afetados por alterações somáticas ou transcricionais durante a transformação maligna e progressão de tumores de pâncreas. RNAs diferencialmente expressos e mutações somáticas com potencial relevância diagnóstica/clínica serão selecionados para avaliação em um painel independente de 


\section{FUNDAÇÃO ANTÔNIO PRUDENTE-HOSPITAL DO CÂNCER A C CAMARGO}

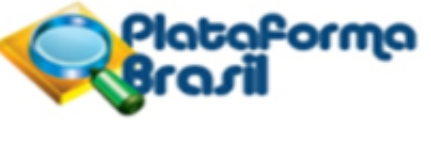

Continuação do Parecer: 457.476

amostras de pacientes.

Avaliação dos Riscos e Benefícios:

Não se aplica.

Comentários e Considerações sobre a Pesquisa:

Estudo relevante com metodologia consistente. Não há comprometimento do ponto de vista ético.

Considerações sobre os Termos de apresentação obrigatória:

Adequados.

Recomendações:

Conclusões ou Pendências e Lista de Inadequações:

Não se aplica. Projeto sem pendências e/ou solicitações de esclarecimentos ao pesquisador.

Situação do Parecer:

Aprovado

Necessita A preciação da CONEP:

Não

Considerações Finais a critério do CEP:

Análise da Comissão de Pesquisa (COPE): Aprovado.

SAO PAULO, 14 de Novembro de 2013

Assinador por:

Luiz Paulo Kowalski

(Coordenador) 


\section{ANEXO 3. Validações experimentais}

A

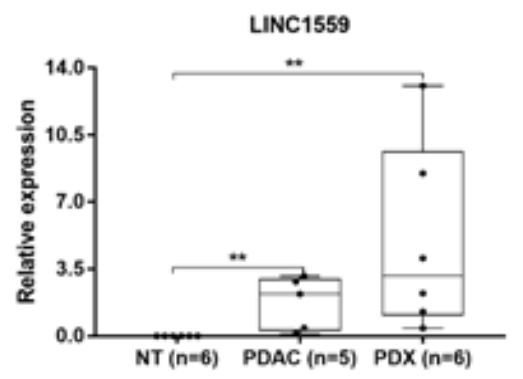

D

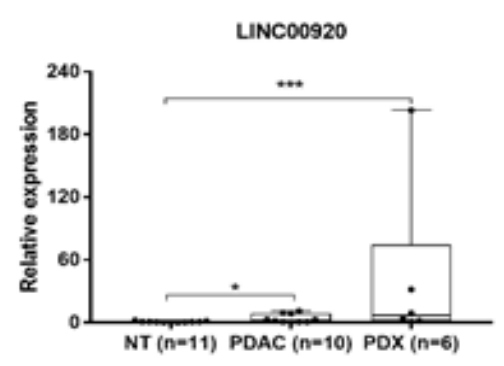

$\mathrm{F}$

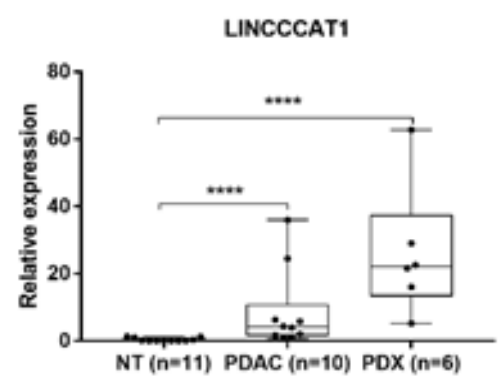

B

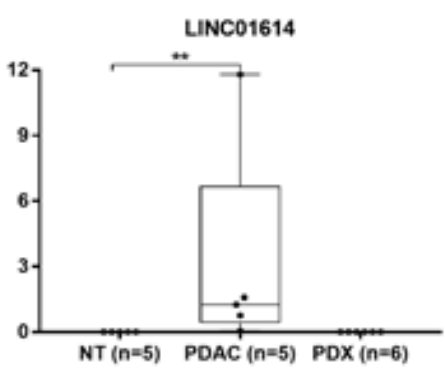

E

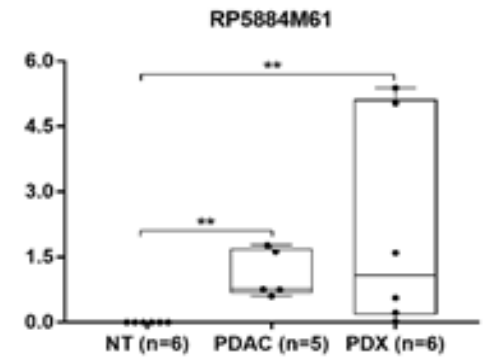

G

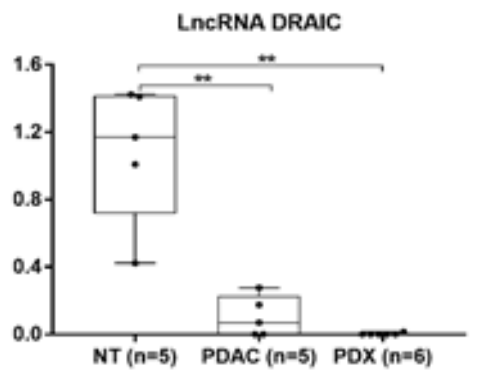

C

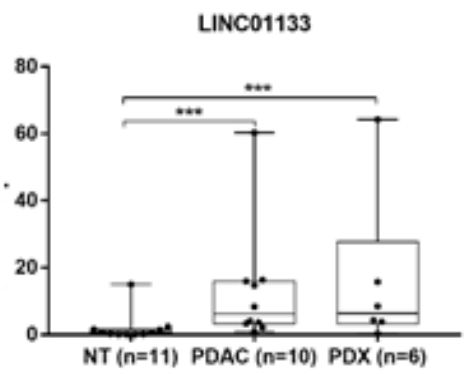

NT $(n=11)$ PDAC $(n=10)$ PDX $(n=6)$

Figura 1. Validação de IncRNAs candidatos em linhagens celulares e PDXs. A expressão aberrante de IncRNAs anotados no Gencode foi confirmada por RT-qPCR em amostras de PDAC, tecido adjacente não-tumoral (NT) e xenografts tumorais derivados do paciente (PDXs). Para cada transcrito, a expressão relativa refere à expressão média nas amostras não-tumorais (designadas como 1) seguidas de normalização com o gene referência. Painéis (A) LINC01559, (B) LINC01614, (C) LINC01133, (D) LINC00920, (E) RP5-884M6.1, (F) CCAT1, (G) DRAIC. 
A

TCONS_00085964

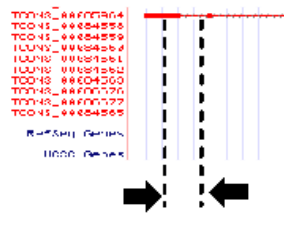

C

TCONS_00009076
B

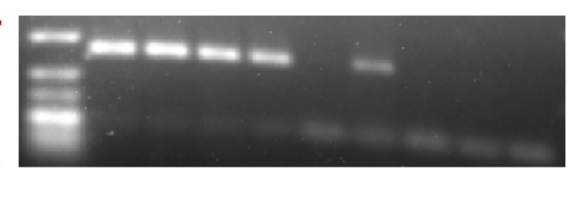

D

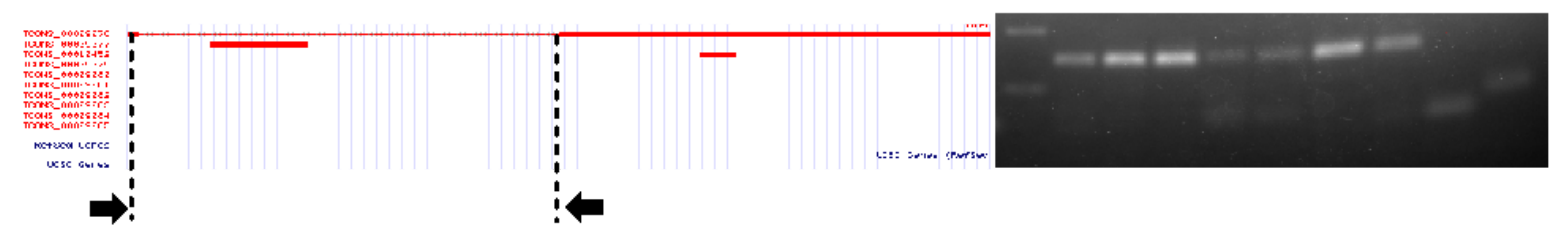

$\mathbf{E}$

$\mathbf{F}$
TCONS_00009076
TCONS_00085964

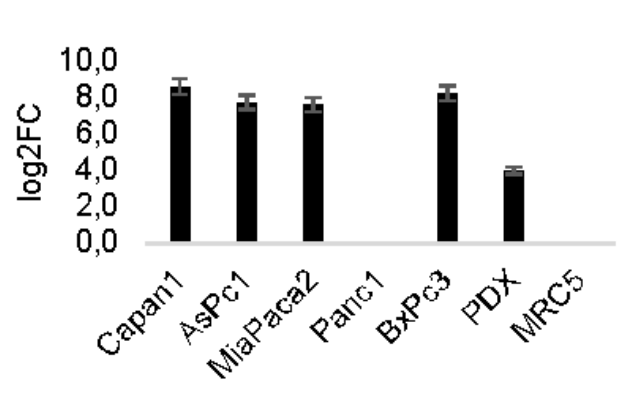

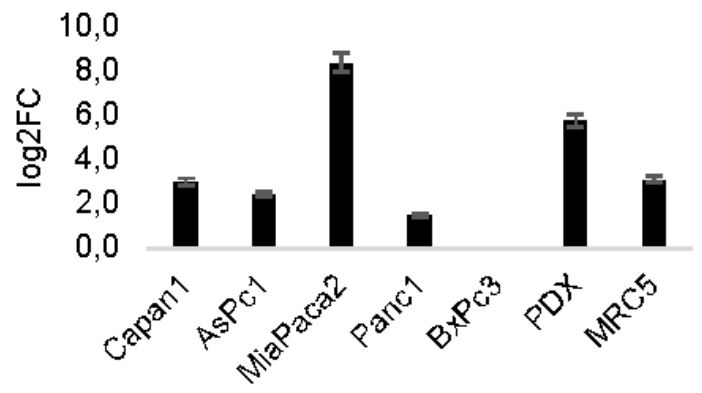

Figura 2. Validação de novos transcritos intergênicos. (Painéis A e C) Tracks gerados no Genome Browser para visualização dos novos transcritos em nossa montagem. As setas representam as regiões das bordas flanqueadas por primers para validação por PCR. (Painéis B e D) Gel de eletroforese agarose 2\%. Lane 1: Gene Ruler; lane 2: template, Capan-1 cDNA; lane 3: template, AsPC-1 cDNA; lane 4: template, MiaPaCa-2 cDNA; lane 5: template, Panc-1 cDNA; lane 6: template, BxPC-3 cDNA; lane 7: template, PDX cDNA; lane 8: template, MRC-5; lane 9: template, gDNA from HeLa; lane 10: NTC. O amplicon esperado resultado da PCR foi de 132 pb e 145 pb, respectivamente. (Painéis E e F) Expressão relativa dos novos intergênicos em linhagens celulares de PDAC e fibroblasto de pulmão MRC-5. 
A

MMP14 novel AS

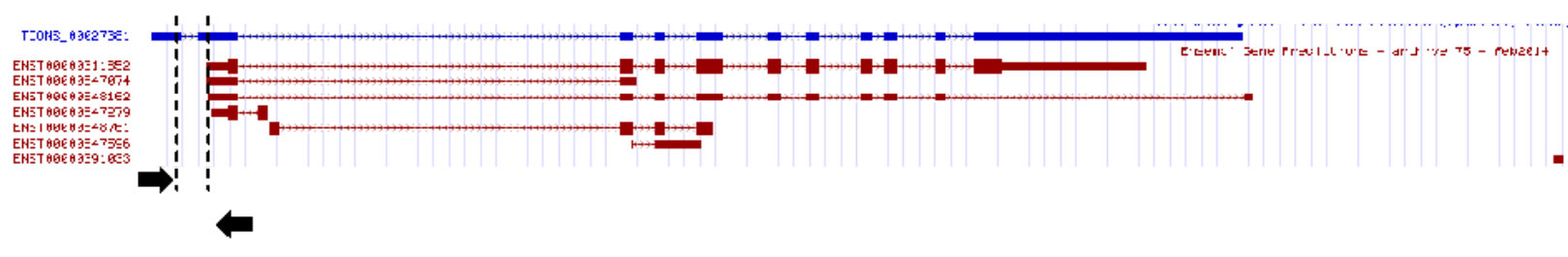

B

CAPN8 novel AS

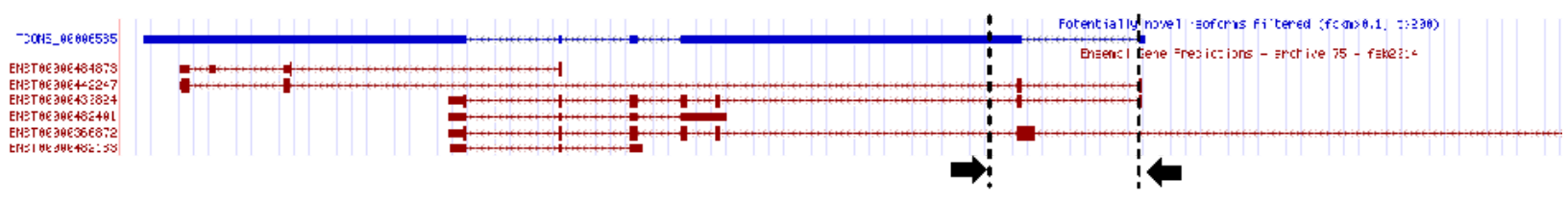

C

LIF novel AS

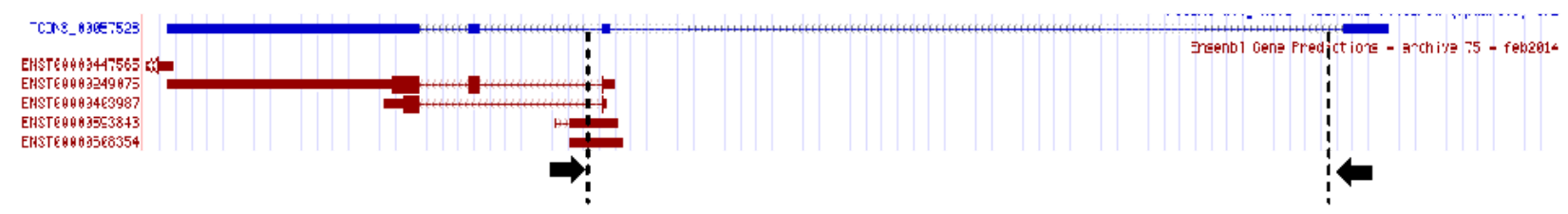

D

MMP14

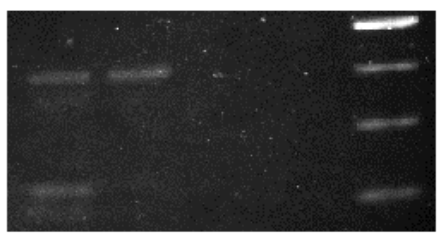

E

CAPN8

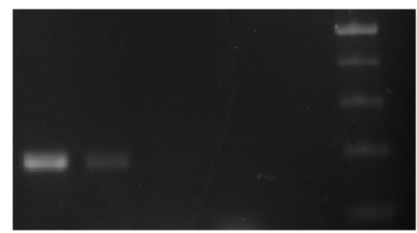

F

LIF

Figura 3. Validação de novas formas de splicing. (Painéis A-C) Tracks gerados no Genome Browser para visualização de três novas formas de splicing. As setas representam as regiões das bordas flanqueadas por primers para validação por PCR. (Painéis D-E) Eletroforese em gel de agarose 2\%. Lane 1: template, Capan-1 cDNA; lane 2 template, Panc-1 cDNA; lane 3: template genomic DNA from HeLa; lane 4: template RNA from Capan-1; lane 5: nom template control (NTC). O amplicon esperado resultado da PCR foi de 414 pb e 180 pb, referentes a MMP14 e CAPN8 respectivamente. (Panel F) Curva melting da RT-qPCR usando linhagens celulares de PDAC, referente à isoforma LIF. 


\section{ANEXO 4. Novas isoformas}

Tabela 1. Genes com novas variantes de splicing encontrados no catálogo "Cancer Gene Census" (CGC) (Andrew Futreal et al. 2004) do banco de dados COSMIC (Forbes et al. 2017). Das 6.187 novas isoformas detectadas em nosso trabalho, 172 genes estão contidos no catálogo CGC, e foram associados com funções tumorigênicas como oncogene, gene supressor tumoral (TSG) e fusões.

\begin{tabular}{|c|c|c|c|}
\hline Gene name & Gene ensembl Id & $\begin{array}{l}\text { Role in } \\
\text { cancer }\end{array}$ & Cancer type \\
\hline LASP1 & ENSG00000002834 & fusion & AML \\
\hline CCL26 & ENSG00000006606 & TSG & $\begin{array}{l}\text { pheochromocytoma, endometrioid carcinoma, colon } \\
\text { carcinoma }\end{array}$ \\
\hline WAS & ENSG00000015285 & oncogene & \\
\hline BCLAF1 & ENSG00000029363 & & melanoma, SCC \\
\hline RABEP1 & ENSG00000029725 & fusion & CMML \\
\hline $\mathrm{ZCCHC8}$ & ENSG00000033030 & fusion & Spitzoid tumour \\
\hline TNC & ENSG00000041982 & oncogene & SCC, melanoma \\
\hline TPR & ENSG00000047410 & fusion & papillary thyroid, NSCLC \\
\hline ELN & ENSG00000049540 & fusion & B-ALL \\
\hline KMT2C & ENSG00000055609 & TSG & medulloblastoma \\
\hline POLD1 & ENSG00000062822 & TSG & CRC \\
\hline CASP8 & ENSG00000064012 & TSG & hepatocellular, oral squamous cell, breast \\
\hline ERBB3 & ENSG00000065361 & oncogene & colon, gastric, head and neck, bladder, skin \\
\hline SPEN & ENSG00000065526 & TSG & SMZL, adenoid cystic carcinoma, DLBCL \\
\hline SMARCD1 & ENSG00000066117 & TSG & breast \\
\hline FGFR2 & ENSG00000066468 & $\begin{array}{l}\text { oncogene, } \\
\text { fusion }\end{array}$ & gastric, NSCLC, endometrial \\
\hline FGFR3 & ENSG00000068078 & $\begin{array}{l}\text { oncogene, } \\
\text { fusion }\end{array}$ & bladder, MM, T-cell lymphoma \\
\hline BCL3 & ENSG00000069399 & $\begin{array}{l}\text { oncogene, } \\
\text { fusion }\end{array}$ & CLL \\
\hline PABPC1 & ENSG00000070756 & $\begin{array}{l}\text { oncogene, } \\
\text { TSG }\end{array}$ & HNSCC, biliary tract carcinoma \\
\hline
\end{tabular}




\begin{tabular}{|c|c|c|c|}
\hline TCF3 & ENSG00000071564 & $\begin{array}{l}\text { oncogene, } \\
\text { TSG, fusion }\end{array}$ & pre B-ALL \\
\hline AFF4 & ENSG00000072364 & $\begin{array}{l}\text { oncogene, } \\
\text { fusion }\end{array}$ & ALL \\
\hline NFKB2 & ENSG00000077150 & $\begin{array}{l}\text { oncogene, } \\
\text { TSG, fusion }\end{array}$ & B-NHL \\
\hline FGFR1 & ENSG00000077782 & $\begin{array}{l}\text { oncogene, } \\
\text { fusion }\end{array}$ & MPN, NHL, salivary adenoma \\
\hline ARAF & ENSG00000078061 & oncogene & $\begin{array}{l}\text { cholangiocarcinoma, lung adenocarcinoma, Langerhans } \\
\text { cell histiocytosis }\end{array}$ \\
\hline N4BP2 & ENSG00000078177 & TSG & lung cancer \\
\hline MLLT10 & ENSG00000078403 & $\begin{array}{l}\text { oncogene, } \\
\text { fusion }\end{array}$ & $A L$ \\
\hline PCM1 & ENSG00000078674 & fusion & papillary thyroid, CML, MPN \\
\hline DNM2 & ENSG00000079805 & TSG & T-ALL \\
\hline XPO1 & ENSG00000082898 & oncogene & CLL \\
\hline PALB2 & ENSG00000083093 & TSG & \\
\hline CYLD & ENSG00000083799 & TSG & cylindroma \\
\hline FAT1 & ENSG00000083857 & TSG & $\begin{array}{l}\text { oral squamous cell, chemorefractory CLL, head and neck, } \\
\text { pancreatic acinar cell carcinoma }\end{array}$ \\
\hline NCOA1 & ENSG00000084676 & fusion & alveolar rhabdomyosarcoma \\
\hline GNAS & ENSG00000087460 & oncogene & $\begin{array}{l}\text { pituitary adenoma, pancreatic intraductal papillary } \\
\text { mucinous neoplasm, fibrous dysplasia }\end{array}$ \\
\hline CD209 & ENSG00000090659 & & prostate carcinoma \\
\hline LZTR1 & ENSG00000099949 & TSG & glioblastoma \\
\hline HIF1A & ENSG00000100644 & oncogene & $\begin{array}{l}\text { endometrioid carcinoma, glioblastoma, colorectal, renal, } \\
\text { lung, pancreatic }\end{array}$ \\
\hline SALL4 & ENSG00000101115 & oncogene & $\begin{array}{l}\text { colorectal cancer, breast cancer, prostate cancer, } \\
\text { glioblastoma, melanoma }\end{array}$ \\
\hline PTK6 & ENSG00000101213 & $\begin{array}{l}\text { oncogene, } \\
\text { TSG }\end{array}$ & renal, gastric, head and neck, ovarian, others \\
\hline CTCF & ENSG00000102974 & TSG & endometrial, breast, head and neck cancer \\
\hline TSC2 & ENSG00000103197 & TSG & $\begin{array}{l}\text { pulmonary lymphangioleiomyomatosis (LAM), renal } \\
\text { angiomyolipoma, HNSCC }\end{array}$ \\
\hline NBN & ENSG00000104320 & TSG & \\
\hline UBR5 & ENSG00000104517 & TSG & mantle cell lymphoma, gastric, colorectal \\
\hline
\end{tabular}




\begin{tabular}{|c|c|c|c|}
\hline ARHGEF10 & ENSG00000104728 & TSG & colon cancer \\
\hline TFPT & ENSG00000105619 & fusion & pre-B ALL \\
\hline JAK3 & ENSG00000105639 & oncogene & acute megakaryocytic leukaemia, ETP ALL \\
\hline ELL & ENSG00000105656 & TSG, fusion & $\mathrm{AL}$ \\
\hline CPEB3 & ENSG00000107864 & TSG & lung cancer \\
\hline LARP4B & ENSG00000107929 & TSG & CRC, glioma \\
\hline RNF43 & ENSG00000108375 & TSG & cholangiocarcinoma, ovary, pancreas \\
\hline DDX5 & ENSG00000108654 & $\begin{array}{l}\text { oncogene, } \\
\text { fusion }\end{array}$ & prostate \\
\hline WHSC1 & ENSG00000109685 & $\begin{array}{l}\text { oncogene, } \\
\text { fusion }\end{array}$ & MM \\
\hline DDX6 & ENSG00000110367 & $\begin{array}{l}\text { oncogene, } \\
\text { fusion }\end{array}$ & B-NHL \\
\hline CARS & ENSG00000110619 & TSG, fusion & ALCL \\
\hline PPFIBP1 & ENSG00000110841 & fusion & Spitzoid tumour, inflammatory myofibroblastic tumour \\
\hline $\mathrm{CHD} 4$ & ENSG00000111642 & oncogene & uterine serous carcinoma \\
\hline DROSHA & ENSG00000113360 & TSG & Wilms tumour, NSCLC, bladder carcinoma \\
\hline SF3B1 & ENSG00000115524 & oncogene & myelodysplastic syndrome \\
\hline BIRC6 & ENSG00000115760 & $\begin{array}{l}\text { oncogene, } \\
\text { fusion }\end{array}$ & melanoma, gastric adenocarcinoma, lung adenocarcinoma \\
\hline STRN & ENSG00000115808 & fusion & anaplastic thyroid, papillary thyroid, lung \\
\hline PRRX1 & ENSG00000116132 & fusion & AML \\
\hline SFPQ & ENSG00000116560 & TSG, fusion & papillary renal \\
\hline KMT2A & ENSG00000118058 & $\begin{array}{l}\text { oncogene, } \\
\text { fusion }\end{array}$ & AML, ALL \\
\hline CREB1 & ENSG00000118260 & $\begin{array}{l}\text { oncogene, } \\
\text { fusion }\end{array}$ & clear cell sarcoma, angiomatoid fibrous histiocytoma \\
\hline TNFAIP3 & ENSG00000118503 & TSG & $\begin{array}{l}\text { marginal zone B-cell lymphomas, Hodgkin lymphoma, } \\
\text { PMBL }\end{array}$ \\
\hline SGK1 & ENSG00000118515 & oncogene & Nodular lymphocyte predominant Hodgkin lymphoma \\
\hline SET & ENSG00000119335 & $\begin{array}{l}\text { oncogene, } \\
\text { fusion }\end{array}$ & T-ALL \\
\hline CNTRL & ENSG00000119397 & fusion & MPN, NHL \\
\hline
\end{tabular}




\begin{tabular}{|c|c|c|c|}
\hline CSF3R & ENSG00000119535 & oncogene & $\begin{array}{l}\text { aCML, CNL, leukaemia lymphoma and MDS associated } \\
\text { with severe congenital neutropenia, CMML, de novo AML, } \\
\text { MDS }\end{array}$ \\
\hline DNMT3A & ENSG00000119772 & TSG & AML \\
\hline SPOP & ENSG00000121067 & TSG & prostate, endometrial \\
\hline ZMYM2 & ENSG00000121741 & fusion & MPN, NHL \\
\hline PMS2 & ENSG00000122512 & TSG & \\
\hline PLCG1 & ENSG00000124181 & $\begin{array}{l}\text { oncogene, } \\
\text { fusion }\end{array}$ & angiosarcoma \\
\hline ZNF384 & ENSG00000126746 & fusion & ALL \\
\hline KTN1 & ENSG00000126777 & fusion & papillary thyroid \\
\hline NUP214 & ENSG00000126883 & fusion & AML, T-ALL \\
\hline SMARCA4 & ENSG00000127616 & TSG & NSCLC, SCCOHT \\
\hline AKAP9 & ENSG00000127914 & fusion & papillary thyroid \\
\hline SPECC1 & ENSG00000128487 & fusion & JMML \\
\hline РOT1 & ENSG00000128513 & TSG & CLL \\
\hline MLLT4 & ENSG00000130396 & $\begin{array}{l}\text { oncogene, } \\
\text { fusion }\end{array}$ & $\mathrm{AL}$ \\
\hline CLIP1 & ENSG00000130779 & fusion & Spitzoid tumour \\
\hline DNAJB1 & ENSG00000132002 & fusion & fibrolamellar hepatocellular carcinoma \\
\hline RAF1 & ENSG00000132155 & $\begin{array}{l}\text { oncogene, } \\
\text { fusion }\end{array}$ & pilocytic astrocytoma, prostate \\
\hline KRAS & ENSG00000133703 & oncogene & $\begin{array}{l}\text { pancreatic, colorectal, lung, thyroid, AML, other tumour } \\
\text { types }\end{array}$ \\
\hline DDB2 & ENSG00000134574 & $\begin{array}{l}\text { oncogene, } \\
\text { TSG }\end{array}$ & \\
\hline APC & ENSG00000134982 & TSG & $\begin{array}{l}\text { colorectal, pancreatic, desmoid, hepatoblastoma, glioma, } \\
\text { other CNS }\end{array}$ \\
\hline LMO2 & ENSG00000135363 & $\begin{array}{l}\text { oncogene, } \\
\text { fusion }\end{array}$ & T-ALL \\
\hline MDM2 & ENSG00000135679 & oncogene & sarcoma, glioma, colorectal, other tumour types \\
\hline LCP1 & ENSG00000136167 & fusion & $\mathrm{NHL}$ \\
\hline $\mathrm{ABI} 1$ & ENSG00000136754 & TSG, fusion & AML \\
\hline KLF4 & ENSG00000136826 & $\begin{array}{l}\text { oncogene, } \\
\text { TSG }\end{array}$ & meningioma \\
\hline
\end{tabular}




\begin{tabular}{|c|c|c|c|}
\hline XPA & ENSG00000136936 & TSG & \\
\hline USP8 & ENSG00000138592 & oncogene & corticotroph adenoma \\
\hline NCOA2 & ENSG00000140396 & $\begin{array}{l}\text { oncogene, } \\
\text { fusion }\end{array}$ & AML, chondrosarcoma, rhabdomyosarcoma \\
\hline POLG & ENSG00000140521 & TSG & CRC \\
\hline $\mathrm{CDH} 11$ & ENSG00000140937 & TSG, fusion & aneurysmal bone cyst \\
\hline NCOR1 & ENSG00000141027 & TSG & breast \\
\hline CLTC & ENSG00000141367 & TSG, fusion & ALCL, renal \\
\hline BRD4 & ENSG00000141867 & $\begin{array}{l}\text { oncogene, } \\
\text { fusion }\end{array}$ & lethal midline carcinoma of young people \\
\hline AKT1 & ENSG00000142208 & oncogene & breast, colorectal, ovarian, NSCLC \\
\hline ARNT & ENSG00000143437 & $\begin{array}{l}\text { oncogene, } \\
\text { TSG, fusion }\end{array}$ & AML \\
\hline ACKR3 & ENSG00000144476 & $\begin{array}{l}\text { oncogene, } \\
\text { fusion }\end{array}$ & lipoma \\
\hline FANCD2 & ENSG00000144554 & TSG & \\
\hline LPP & ENSG00000145012 & $\begin{array}{l}\text { oncogene, } \\
\text { fusion }\end{array}$ & lipoma, leukaemia \\
\hline MUC4 & ENSG00000145113 & oncogene & HNSCC \\
\hline FIP1L1 & ENSG00000145216 & fusion & idiopathic hypereosinophilic syndrome \\
\hline KDM6A & ENSG00000147050 & $\begin{array}{l}\text { oncogene, } \\
\text { TSG }\end{array}$ & $\begin{array}{l}\text { renal cell carcinoma, bladder carcinoma, oesophageal } \\
\text { SCC, MM, medulloblastoma, T-ALL, other tumour types }\end{array}$ \\
\hline ZMYM3 & ENSG00000147130 & TSG & CRC, breast cancer \\
\hline NONO & ENSG00000147140 & fusion & papillary renal \\
\hline RPL10 & ENSG00000147403 & TSG & T-ALL \\
\hline ZEB1 & ENSG00000148516 & oncogene & CCRCC, melanoma \\
\hline TCF7L2 & ENSG00000148737 & $\begin{array}{l}\text { oncogene, } \\
\text { fusion }\end{array}$ & colorectal \\
\hline ATM & ENSG00000149311 & TSG & T-PLL \\
\hline RAD17 & ENSG00000152942 & TSG & lymphoma, colon cancer \\
\hline RGPD3 & ENSG00000153165 & & endometrioid adenocarcinoma \\
\hline RANBP2 & ENSG00000153201 & TSG, fusion & inflammatory myofibroblastic tumour \\
\hline FLCN & ENSG00000154803 & TSG & \\
\hline
\end{tabular}




\begin{tabular}{|c|c|c|c|}
\hline EIF4A2 & ENSG00000156976 & fusion & NHL \\
\hline CACNA1D & ENSG00000157388 & oncogene & adrenal aldosterone producing adenoma \\
\hline TNFRSF14 & ENSG00000157873 & TSG & follicular lymphoma \\
\hline RUNX1 & ENSG00000159216 & $\begin{array}{l}\text { oncogene, } \\
\text { TSG, fusion }\end{array}$ & AML, pre B-ALL, T-ALL \\
\hline FGFR4 & ENSG00000160867 & oncogene & rhabdomyosarcoma \\
\hline FUBP1 & ENSG00000162613 & oncogene & oligodendroglioma \\
\hline RBM15 & ENSG00000162775 & fusion & acute megakaryocytic leukaemia \\
\hline ERCC3 & ENSG00000163161 & TSG & \\
\hline ATP1A1 & ENSG00000163399 & $\begin{array}{l}\text { oncogene, } \\
\text { TSG }\end{array}$ & adrenal aldosterone producing adenoma \\
\hline ELF3 & ENSG00000163435 & TSG & pancreatic cancer \\
\hline FBLN2 & ENSG00000163520 & TSG & breast cancer, colorectal adenocarcinoma \\
\hline PTPN13 & ENSG00000163629 & TSG & lung, NSCLC, gastric, peritoneal carcinomatosis \\
\hline BAP1 & ENSG00000163930 & TSG & uveal melanoma, breast, NSCLC, RCC \\
\hline PBRM1 & ENSG00000163939 & TSG & clear cell renal carcinoma, breast \\
\hline PSIP1 & ENSG00000164985 & $\begin{array}{l}\text { oncogene, } \\
\text { fusion }\end{array}$ & AML \\
\hline SYK & ENSG00000165025 & $\begin{array}{l}\text { oncogene, } \\
\text { fusion }\end{array}$ & MDS, peripheral T-cell lymphoma \\
\hline WNK2 & ENSG00000165238 & TSG & gastric cancer \\
\hline FAT3 & ENSG00000165323 & & SCC, colon adenocarcinoma, gastric adenocarcinoma \\
\hline NSD1 & ENSG00000165671 & fusion & AML \\
\hline KMT2D & ENSG00000167548 & $\begin{array}{l}\text { oncogene, } \\
\text { TSG }\end{array}$ & medulloblastoma, renal \\
\hline AXIN2 & ENSG00000168646 & TSG & $\begin{array}{l}\text { colorectal carcinoma, stomach carcinoma, hepatocellular } \\
\text { carcinoma }\end{array}$ \\
\hline GPHN & ENSG00000171723 & fusion & $\mathrm{AL}$ \\
\hline TAF15 & ENSG00000172660 & $\begin{array}{l}\text { oncogene, } \\
\text { fusion }\end{array}$ & extraskeletal myxoid chondrosarcoma, ALL \\
\hline MYD88 & ENSG00000172936 & oncogene & ABC-DLBCL \\
\hline $\mathrm{CHD} 2$ & ENSG00000173575 & TSG & $\begin{array}{l}\text { melanoma, large intestine, CLL, monoclonal B } \\
\text { lymphocytosis }\end{array}$ \\
\hline RNF213 & ENSG00000173821 & fusion & ALCL \\
\hline
\end{tabular}




\begin{tabular}{|c|c|c|c|}
\hline HRAS & ENSG00000174775 & oncogene & infrequent sarcomas, rare other tumour types \\
\hline SMAD2 & ENSG00000175387 & TSG & colorectal carcinoma, hepatocellular carcinoma \\
\hline POLE & ENSG00000177084 & TSG & $\begin{array}{l}\text { colorectal carcinoma, endometrioid carcinoma, stomach } \\
\text { carcinoma, skin cancer }\end{array}$ \\
\hline TBL1XR1 & ENSG00000177565 & $\begin{array}{l}\text { oncogene, } \\
\text { TSG, fusion }\end{array}$ & $\begin{array}{l}\text { splenic marginal zone lymphoma, primary central nervous } \\
\text { system lymphoma, colorectal carcinoma, gallbladder } \\
\text { carcinoma }\end{array}$ \\
\hline CALR & ENSG00000179218 & oncogene & MPN, MDS \\
\hline GATA2 & ENSG00000179348 & oncogene & AML (CML blast transformation) \\
\hline CIITA & ENSG00000179583 & TSG, fusion & PMBL, Hodgkin lymphoma \\
\hline EXT1 & ENSG00000182197 & TSG, fusion & \\
\hline LCK & ENSG00000182866 & $\begin{array}{l}\text { oncogene, } \\
\text { fusion }\end{array}$ & T-ALL \\
\hline RBM10 & ENSG00000182872 & TSG & lung adenocarcinoma \\
\hline EWSR1 & ENSG00000182944 & $\begin{array}{l}\text { oncogene, } \\
\text { fusion }\end{array}$ & $\begin{array}{l}\text { Ewing sarcoma, desmoplastic small round cell tumour, } \\
\text { ALL, clear cell sarcoma, sarcoma, myoepithelioma, } \\
\text { mesothelioma }\end{array}$ \\
\hline MED12 & ENSG00000184634 & TSG & uterine leiomyoma, fibroadenoma, phyllodes tumour \\
\hline AMER1 & ENSG00000184675 & TSG & Wilms tumour \\
\hline SEPT5 & ENSG00000184702 & fusion & AML \\
\hline FANCA & ENSG00000187741 & TSG & \\
\hline FAT4 & ENSG00000196159 & TSG & $\begin{array}{l}\text { lymphoma, pancreatic, head and neck, melanoma, } \\
\text { hepatocellular carcinoma }\end{array}$ \\
\hline TRRAP & ENSG00000196367 & oncogene & melanoma \\
\hline NCOR2 & ENSG00000196498 & TSG & prostate \\
\hline ARHGEF12 & ENSG00000196914 & TSG, fusion & AML \\
\hline SRC & ENSG00000197122 & oncogene & colorectal cancer, endometrial carcinoma \\
\hline SIRPA & ENSG00000198053 & TSG & HNSCC, colorectal cancer, Lung SCC \\
\hline MTOR & ENSG00000198793 & oncogene & $\begin{array}{l}\text { endometrial carcinoma, head and neck, clear cell renal cell } \\
\text { carcinoma, anaplastic thyroid cancer, urothelial cell } \\
\text { carcinoma, central nervous system tumours, testicular } \\
\text { germ cell tumours and other tumour types }\end{array}$ \\
\hline DAXX & ENSG00000204209 & $\begin{array}{l}\text { oncogene, } \\
\text { TSG }\end{array}$ & pancreatic neuroendocrine tumour, paediatric glioblastoma \\
\hline HLA-A & ENSG00000206503 & fusion & Spitzoid tumour \\
\hline
\end{tabular}




\begin{tabular}{|llll} 
MTCP1 & ENSG00000214827 & $\begin{array}{l}\text { oncogene, } \\
\text { fusion }\end{array}$ & T cell prolymphocytic leukaemia \\
FANCG & ENSG00000221829 & TSG & \\
LSM14A & ENSG00000257103 & fusion & Spitzoid tumour
\end{tabular}


Tabela 2. Tipos de splicing alternativo. Foi utilizado o programa SUPPA (Alamancos et al. 2014) para determinar o tipo de splicing das 6.187 novas isoformas. SE: éxons ignorados, RI: retenções de íntrons, A3: sítios alternativos 3', A5: sítios alternativos 5', AF: primeiro éxon alternativo, AL: último éxon alternativo, MX: éxons mutuamente excludentes, O: outros.

\begin{tabular}{|c|c|c|c|c|c|c|c|c|}
\hline $\begin{array}{l}\text { Transcript } \\
\text { Id }\end{array}$ & $\begin{array}{l}\text { Gene } \\
\text { name }\end{array}$ & $\begin{array}{l}\text { Splici } \\
\text { ng }\end{array}$ & $\begin{array}{l}\text { Transcript } \\
\text { Id }\end{array}$ & $\begin{array}{l}\text { Gene } \\
\text { name }\end{array}$ & Splicing & $\begin{array}{l}\text { Transcript } \\
\text { Id }\end{array}$ & $\begin{array}{l}\text { Gene } \\
\text { name }\end{array}$ & Splicing \\
\hline TCONS_000 & & $\mathrm{A} 5, \mathrm{AF}$ & TCONS_000 & CTA-217 & & TCONS_000 & & \\
\hline 00017 & SAMD11 & ,RI & 57880 & C2.1 & $\mathrm{O}$ & 27299 & IGHA1 & $\mathrm{O}$ \\
\hline TCONS_000 & & & TCONS_000 & CTA-941 & & TCONS_000 & & \\
\hline 06902 & AGRN & $\mathrm{O}$ & $57891-$ & F9.9 & A3 & 27300 & IGHA1 & $\mathrm{O}$ \\
\hline TCONS_000 & & & TCONS_000 & CTA-941 & & TCONS_000 & & \\
\hline $06910^{-}$ & PUSL1 & A3 & 57892 & F9.9 & $\mathrm{O}$ & 27301 & IGHA1 & $\mathrm{O}$ \\
\hline TCONS_000 & & & TCONS_000 & & & TCONS_000 & & \\
\hline 00033 & PUSL1 & $\mathrm{O}$ & 57905 & CELSR1 & A3 & 27304 & IGHG1 & $\mathrm{O}$ \\
\hline TCONS_000 & & & TCONS_000 & & & TCONS_000 & & \\
\hline 00034 & PUSL1 & A3 & 57912 & BRD1 & A3 & 27305 & IGHG1 & $\mathrm{O}$ \\
\hline TCONS_000 & & & TCONS_000 & & & TCONS_000 & & \\
\hline 00046 & VWA1 & $\mathrm{O}$ & 57910 & BRD1 & $\mathrm{O}$ & 27308 & IGHG3 & $\mathrm{O}$ \\
\hline TCONS_000 & & & TCONS_000 & TUBGC & & TCONS_000 & & \\
\hline 06914 & ATAD3B & $A 3, R I$ & 58396 & P6 & $\mathrm{RI}$ & 27309 & IGHM & $\mathrm{O}$ \\
\hline TCONS_000 & & & TCONS_000 & TUBGC & & TCONS_000 & & \\
\hline 06916 & ATAD3B & SE & 57929 & P6 & $\mathrm{RI}$ & 27310 & IGHM & $\mathrm{O}$ \\
\hline TCONS_000 & & & TCONS_000 & TUBGC & & TCONS_000 & & \\
\hline 00072 & RER1 & $\mathrm{O}$ & 57930 & P6 & $\mathrm{RI}$ & 27311 & IGHM & $\mathrm{O}$ \\
\hline TCONS_000 & TNFRSF & & TCONS_000 & TUBGC & & TCONS_000 & IGHV4-2 & \\
\hline 00078 & 14 & $A 3, R I$ & 57931 & P6 & $\mathrm{RI}$ & 27331 & 8 & $\mathrm{O}$ \\
\hline TCONS_000 & TNFRSF & & TCONS_000 & TUBGC & & TCONS_000 & IGHV4-6 & \\
\hline 06926 & 14 & A3 & 57932 & P6 & $A 3, R I$ & 27333 & 1 & $\mathrm{O}$ \\
\hline TCONS_000 & RP3-395 & & TCONS_000 & TUBGC & & TCONS_000 & IGHV4-3 & \\
\hline 00085 & M20.9 & $\mathrm{O}$ & 58397 & P6 & $A 3, R I$ & 27336 & 4 & $\mathrm{O}$ \\
\hline TCONS_000 & ARHGE & & TCONS_000 & & & TCONS_000 & IGHV1-6 & \\
\hline 00090 & F16 & A5 & 57934 & MAPK12 & $A 3, R I$ & 27349 & 9 & $\mathrm{O}$ \\
\hline TCONS_000 & ARHGE & & TCONS_000 & & & TCONS_000 & RP11-60 & \\
\hline 06928 & F16 & $A 5, R I$ & 57935 & MAPK12 & A3 & $28145^{-}$ & 3B24.1 & $\mathrm{O}$ \\
\hline TCONS_000 & & & TCONS_000 & & & TCONS_000 & TUBGC & \\
\hline 00098 & SMIM1 & $\mathrm{O}$ & 57936 & MAPK11 & RI & 28149 & P5 & $\mathrm{RI}$ \\
\hline TCONS_000 & & & TCONS_000 & & & TCONS_000 & TUBGC & \\
\hline 00109 & RNF207 & A5,RI & 57937 & MAPK11 & RI & 28150 & P5 & A3,SE \\
\hline
\end{tabular}




\begin{tabular}{|c|c|c|c|c|c|c|c|c|}
\hline $\begin{array}{l}\text { TCONS_000 } \\
00110\end{array}$ & RNF207 & RI & $\begin{array}{l}\text { TCONS_000 } \\
58399\end{array}$ & MAPK11 & RI & $\begin{array}{l}\text { TCONS_000 } \\
28157\end{array}$ & CYFIP1 & $\mathrm{RI}, \mathrm{SE}$ \\
\hline $\begin{array}{l}\text { TCONS_000 } \\
\text { o0111 }\end{array}$ & RNF207 & $A 3, R I$ & $\begin{array}{l}\text { TCONS_000 } \\
58400\end{array}$ & PLXNB2 & SE & $\begin{array}{l}\text { TCONS_000 } \\
30555\end{array}$ & SNHG14 & SE \\
\hline $\begin{array}{l}\text { TCONS_000 } \\
00112\end{array}$ & RNF207 & A5 & $\begin{array}{l}\text { TCONS_000 } \\
57947\end{array}$ & SBF1 & RI & $\begin{array}{l}\text { TCONS_000 } \\
30560\end{array}$ & $\begin{array}{l}\text { HERC2 } \\
\text { P9 }\end{array}$ & SE \\
\hline $\begin{array}{l}\text { TCONS_000 } \\
06932\end{array}$ & RNF207 & $\mathrm{O}$ & $\begin{array}{l}\text { TCONS_000 } \\
58403\end{array}$ & SBF1 & RI & $\begin{array}{l}\text { TCONS_000 } \\
30561\end{array}$ & $\begin{array}{l}\text { HERC2 } \\
\text { P9 }\end{array}$ & A5,SE \\
\hline TCONS_000 & 7RTR18 & & TCONS_000 & & & TCONS_000 & HERC2 & $05 c 5$ \\
\hline 00116 & СВIB48 & A5 & 58404 & SBF1 & RI & 28180 & P9 & $A b, S E$ \\
\hline $\begin{array}{l}\text { TCONS_000 } \\
06937\end{array}$ & PER3 & A5 & $\begin{array}{l}\text { TCONS_000 } \\
58405\end{array}$ & SBF1 & RI & $\begin{array}{l}\text { TCONS_000 } \\
28182\end{array}$ & $\begin{array}{l}\text { WHAMM } \\
\text { P2 }\end{array}$ & A5,SE \\
\hline $\begin{array}{l}\text { TCONS_000 } \\
00137\end{array}$ & PER3 & $\mathrm{RI}$ & $\begin{array}{l}\text { TCONS_000 } \\
58407\end{array}$ & TYMP & 0 & $\begin{array}{l}\text { TCONS_000 } \\
28185\end{array}$ & $\begin{array}{l}\text { RP11-57 } \\
\text { 8F21.12 }\end{array}$ & A3,A5 \\
\hline $\begin{array}{l}\text { TCONS_000 } \\
00138\end{array}$ & PER3 & A3,A5 & $\begin{array}{l}\text { TCONS_000 } \\
58408\end{array}$ & TYMP & $\mathrm{O}$ & $\begin{array}{l}\text { TCONS_000 } \\
30571\end{array}$ & $\begin{array}{l}\text { GOLGA } \\
8 Q\end{array}$ & $\mathrm{O}$ \\
\hline $\begin{array}{l}\text { TCONS_000 } \\
00139\end{array}$ & PER3 & RI & $\begin{array}{l}\text { TCONS_000 } \\
57956\end{array}$ & TYMP & $\mathrm{O}$ & $\begin{array}{l}\text { TCONS_000 } \\
30572\end{array}$ & $\begin{array}{l}\text { CTD-30 } \\
\text { 92A11.1 }\end{array}$ & $\mathrm{O}$ \\
\hline $\begin{array}{l}\text { TCONS_000 } \\
00158\end{array}$ & H6PD & A3 & $\begin{array}{l}\text { TCONS_000 } \\
57957\end{array}$ & TYMP & A3 & $\begin{array}{l}\text { TCONS_000 } \\
30574\end{array}$ & $\begin{array}{l}\text { CTD-30 } \\
\text { 92A11.1 }\end{array}$ & SE \\
\hline $\begin{array}{l}\text { TCONS_000 } \\
\text { 00159 }\end{array}$ & H6PD & $\mathrm{O}$ & $\begin{array}{l}\text { TCONS_000 } \\
57958\end{array}$ & TYMP & $\mathrm{A} 3, \mathrm{RI}$ & $\begin{array}{l}\text { TCONS_000 } \\
28198\end{array}$ & $\begin{array}{l}\text { GOLGA } \\
8 Q\end{array}$ & $\mathrm{O}$ \\
\hline $\begin{array}{l}\text { TCONS_000 } \\
\text { 00170 }\end{array}$ & PIK3CD & A3,AF & $\begin{array}{l}\text { TCONS_000 } \\
58409\end{array}$ & $\begin{array}{l}\text { CHKB-C } \\
\text { PT1B }\end{array}$ & $\begin{array}{l}\text { A3,A5,RI, } \\
\text { SE }\end{array}$ & $\begin{array}{l}\text { TCONS_000 } \\
28199\end{array}$ & $\begin{array}{l}\text { GOLGA } \\
8 Q\end{array}$ & $\mathrm{O}$ \\
\hline $\begin{array}{l}\text { TCONS_000 } \\
00171\end{array}$ & PIK3CD & $A 3, R I$ & $\begin{array}{l}\text { TCONS_000 } \\
58410\end{array}$ & $\begin{array}{l}\text { CHKB-C } \\
\text { PT1B }\end{array}$ & $\mathrm{A} 3, \mathrm{RI}$ & $\begin{array}{l}\text { TCONS_000 } \\
30577\end{array}$ & $\begin{array}{l}\text { GOLGA } \\
8 \mathrm{H}\end{array}$ & $\mathrm{O}$ \\
\hline $\begin{array}{l}\text { TCONS_000 } \\
00182\end{array}$ & KIF1B & AF,SE & $\begin{array}{l}\text { TCONS_000 } \\
57965\end{array}$ & $\begin{array}{l}\text { CHKB-C } \\
\text { PT1B }\end{array}$ & RI & $\begin{array}{l}\text { TCONS_000 } \\
28220\end{array}$ & $\begin{array}{l}\text { GOLGA } \\
8 \mathrm{~N}\end{array}$ & 0 \\
\hline $\begin{array}{l}\text { TCONS_000 } \\
00201\end{array}$ & TARDBP & $\mathrm{O}$ & $\begin{array}{l}\text { TCONS_000 } \\
58413\end{array}$ & RABL2B & RI & $\begin{array}{l}\text { TCONS_000 } \\
30613\end{array}$ & EIF2AK4 & $\mathrm{O}$ \\
\hline $\begin{array}{l}\text { TCONS_000 } \\
00202\end{array}$ & TARDBP & $\mathrm{O}$ & $\begin{array}{l}\text { TCONS_000 } \\
57976\end{array}$ & RABL2B & RI & $\begin{array}{l}\text { TCONS_000 } \\
30620\end{array}$ & BAHD1 & A3,AF \\
\hline $\begin{array}{l}\text { TCONS_000 } \\
00203\end{array}$ & TARDBP & $\mathrm{O}$ & $\begin{array}{l}\text { TCONS_000 } \\
57977\end{array}$ & RABL2B & $\mathrm{O}$ & $\begin{array}{l}\text { TCONS_000 } \\
28292\end{array}$ & BAHD1 & A3 \\
\hline $\begin{array}{l}\text { TCONS_000 } \\
06962\end{array}$ & FBXO44 & SE & $\begin{array}{l}\text { TCONS_000 } \\
57978\end{array}$ & RABL2B & $\mathrm{O}$ & $\begin{array}{l}\text { TCONS_000 } \\
28296\end{array}$ & RAD51 & A5 \\
\hline $\begin{array}{l}\text { TCONS_000 } \\
06963\end{array}$ & FBXO44 & $\mathrm{RI}$ & $\begin{array}{l}\text { TCONS_000 } \\
58416\end{array}$ & CHL1 & AF,SE & $\begin{array}{l}\text { TCONS_000 } \\
28307\end{array}$ & $\begin{array}{l}\text { ZFYVE1 } \\
9\end{array}$ & 0 \\
\hline $\begin{array}{l}\text { TCONS_000 } \\
00216\end{array}$ & FBXO44 & $\mathrm{O}$ & $\begin{array}{l}\text { TCONS_000 } \\
62740\end{array}$ & CNTN4 & SE & $\begin{array}{l}\text { TCONS_000 } \\
30623\end{array}$ & $\begin{array}{l}\text { ZFYVE1 } \\
9\end{array}$ & 0 \\
\hline
\end{tabular}




\begin{tabular}{|c|c|c|c|c|c|c|c|c|}
\hline $\begin{array}{l}\text { TCONS_000 } \\
00217\end{array}$ & FBXO44 & SE & $\begin{array}{l}\text { TCONS_000 } \\
58421\end{array}$ & CNTN4 & A3 & $\begin{array}{l}\text { TCONS_000 } \\
28312\end{array}$ & SPINT1 & A5 \\
\hline $\begin{array}{l}\text { TCONS_000 } \\
\text { 06965 }\end{array}$ & FBXO6 & AF & $\begin{array}{l}\text { TCONS_000 } \\
62744\end{array}$ & ITPR1 & SE & $\begin{array}{l}\text { TCONS_000 } \\
28336\end{array}$ & NUSAP1 & A3 \\
\hline $\begin{array}{l}\text { TCONS_000 } \\
06967\end{array}$ & MFN2 & A3 & $\begin{array}{l}\text { TCONS_000 } \\
58436\end{array}$ & ITPR1 & RI,SE & $\begin{array}{l}\text { TCONS_000 } \\
28350\end{array}$ & MGA & $\mathrm{A} 3, \mathrm{RI}$ \\
\hline TCONS_000 & & & TCONS_000 & BHLHE4 & & TCONS_000 & PLA2G4 & \\
\hline 00237 & MFN2 & A3,SE & 58441 & 0 & RI & 30636 & B & $\mathrm{O}$ \\
\hline TCONS_000 & & & TCONS_000 & & & TCONS_000 & RP11-16 & \\
\hline 00241 & MIIP & $\mathrm{O}$ & 62746 & EDEM1 & $\mathrm{O}$ & 30642 & 4J13.1 & 0 \\
\hline $\begin{array}{l}\text { TCONS_000 } \\
06993\end{array}$ & CELA2A & $\mathrm{O}$ & $\begin{array}{l}\text { TCONS_000 } \\
62762\end{array}$ & OGG1 & $\mathrm{O}$ & $\begin{array}{l}\text { TCONS_000 } \\
28400\end{array}$ & $\begin{array}{l}\text { CCNDB } \\
\text { P1 }\end{array}$ & SE \\
\hline $\begin{array}{l}\text { TCONS_000 } \\
06994\end{array}$ & CELA2A & $\mathrm{O}$ & $\begin{array}{l}\text { TCONS_000 } \\
58539\end{array}$ & IL17RC & A5,SE & $\begin{array}{l}\text { TCONS_000 } \\
30653\end{array}$ & $\begin{array}{l}\text { TUBGC } \\
\text { P4 }\end{array}$ & SE \\
\hline $\begin{array}{l}\text { TCONS_000 } \\
\text { 00294 }\end{array}$ & CELA2B & SE & $\begin{array}{l}\text { TCONS_000 } \\
58540\end{array}$ & IL17RC & A5,SE & $\begin{array}{l}\text { TCONS_000 } \\
28410\end{array}$ & $\begin{array}{l}\text { CKMT1 } \\
\text { B }\end{array}$ & A3 \\
\hline $\begin{array}{l}\text { TCONS_000 } \\
07005\end{array}$ & $\begin{array}{l}\text { PLEKH } \\
\text { M2 }\end{array}$ & A3,RI & $\begin{array}{l}\text { TCONS_000 } \\
\text { 62766 }\end{array}$ & IL17RC & A5 & $\begin{array}{l}\text { TCONS_000 } \\
28411\end{array}$ & $\begin{array}{l}\text { CKMT1 } \\
\text { B }\end{array}$ & $\mathrm{O}$ \\
\hline TCONS_000 & PLEKH & & TCONS_000 & & & TCONS_000 & CKMT1 & \\
\hline $00307^{-}$ & M2 & $\mathrm{RI}$ & $62767^{-}$ & IL17RC & A5,RI,SE & 28412 & & A3 \\
\hline TCONS_000 & PLEKH & A3,A5, & TCONS_000 & & & TCONS_000 & CKMT1 & \\
\hline 00308 & M2 & SE & 62768 & IL17RC & SE & 28413 & & $A 3, R I$ \\
\hline TCONS_000 & PLEKH & & TCONS_000 & PRRT3- & & TCONS_000 & CKMT1 & \\
\hline 00309 & M2 & $\mathrm{A} 3, \mathrm{RI}$ & 62770 & AS1 & A5 & 28416 & A & A3 \\
\hline $\begin{array}{l}\text { TCONS_000 } \\
00312\end{array}$ & FBLIM1 & A3,A5 & $\begin{array}{l}\text { TCONS_000 } \\
58545\end{array}$ & FANCD2 & AF,SE & $\begin{array}{l}\text { TCONS_000 } \\
28439\end{array}$ & CASC4 & $\mathrm{O}$ \\
\hline $\begin{array}{l}\text { TCONS_000 } \\
00313\end{array}$ & FBLIM1 & $\mathrm{O}$ & $\begin{array}{l}\text { TCONS_000 } \\
58589\end{array}$ & TSEN2 & $A F, R I$ & $\begin{array}{l}\text { TCONS_000 } \\
28440\end{array}$ & CASC4 & SE \\
\hline TCONS 000 & & & TCONS 000 & & & TCONS 000 & DUOXA & \\
\hline 00314 & FBLIM1 & A3 & $58591-$ & TSEN2 & RI & $28474^{-}$ & 2 & $\mathrm{O}$ \\
\hline $\begin{array}{l}\text { TCONS_000 } \\
\text { 00315 }\end{array}$ & FBLIM1 & A5 & $\begin{array}{l}\text { TCONS_000 } \\
58594\end{array}$ & HDAC11 & SE & $\begin{array}{l}\text { TCONS_000 } \\
28481\end{array}$ & $\begin{array}{l}\text { SPATA5 } \\
\text { L1 }\end{array}$ & SE \\
\hline $\begin{array}{l}\text { TCONS_000 } \\
07007\end{array}$ & FBLIM1 & A5 & $\begin{array}{l}\text { TCONS_000 } \\
58599\end{array}$ & FBLN2 & $\mathrm{O}$ & $\begin{array}{l}\text { TCONS_000 } \\
28521\end{array}$ & GALK2 & AF,SE \\
\hline TCONS_000 & & & TCONS_000 & TMEM4 & & TCONS_000 & & AF,MX,S \\
\hline 07010 & SPEN & A5 & 62781 & 3 & RI & 30671 & GALK2 & E \\
\hline TCONS 000 & & & TCONS 000 & CCDC17 & & TCONS 000 & & \\
\hline $07016^{-}$ & SZRD1 & SE & $58609^{-}$ & 4 & RI & $28539^{-}$ & USP8 & A5 \\
\hline $\begin{array}{l}\text { TCONS_000 } \\
\text { 00333 }\end{array}$ & SZRD1 & SE & $\begin{array}{l}\text { TCONS_000 } \\
58615\end{array}$ & FGD5 & $\mathrm{O}$ & $\begin{array}{l}\text { TCONS_000 } \\
28540\end{array}$ & USP8 & SE \\
\hline
\end{tabular}




\begin{tabular}{|c|c|c|c|c|c|c|c|c|}
\hline \multicolumn{3}{|l|}{ TCONS_000 } & \multicolumn{3}{|l|}{ TCONS 000} & \multicolumn{3}{|l|}{ TCONS 000} \\
\hline 00334 & SZRD1 & A3,SE & 58653 & PLCL2 & 0 & 28542 & USP8 & A3 \\
\hline TCONS_000 & & & TCONS_000 & GOLGA & & TCONS_000 & & \\
\hline 07018 & MST1P2 & $\mathrm{A} 3, \mathrm{SE}$ & 58818 & 4 & SE & 30676 & USP8 & SE \\
\hline TCONS_000 & & & TCONS_000 & GOLGA & & TCONS_000 & & \\
\hline 00350 & CROCC & A5,RI & 58817 & & SE & 30677 & USP8 & SE \\
\hline TCONS_000 & & & TCONS_000 & GOLGA & & TCONS_000 & & \\
\hline 00353 & PADI1 & RI & 62997 & 4 & SE & 28545 & USP8 & $\mathrm{O}$ \\
\hline TCONS_000 & & & TCONS_000 & & & TCONS_000 & RP11-12 & \\
\hline 00354 & PADI1 & RI,SE & 63001 & CTDSPL & $\mathrm{O}$ & 28547 & OK9.2 & $\mathrm{O}$ \\
\hline TCONS_000 & & & TCONS_000 & MYD88 & $\Delta 5$ & TCONS_000 & PIGR & 15 \\
\hline TCONS 000 & & & TCONS 000 & & & TCONS 000 & & \\
\hline 00369 & PQLC2 & $\mathrm{O}$ & $63012^{-}$ & ACVR2B & A5 & 28593 & PIGB & A5,RI \\
\hline TCONS_000 & & & TCONS_000 & & & TCONS_000 & & \\
\hline 00403 & PINK1 & $\mathrm{O}$ & 63023 & TRAK1 & A5 & 28655 & FAM81A & $\mathrm{O}$ \\
\hline $\begin{array}{l}\text { TCONS_000 } \\
00405\end{array}$ & NBPF3 & 0 & $\begin{array}{l}\text { TCONS_000 } \\
58922\end{array}$ & TRAK1 & A5 & TCONS_000 & $\mathrm{GCNT3}$ & $\Delta l$ \\
\hline TCONS 000 & & & TCONS & & & TCONS 000 & & \\
\hline 07028 & CELA3B & $\mathrm{O}$ & $\begin{array}{l}\text { TCONS_000 } \\
58927\end{array}$ & TRAK1 & A5 & $\begin{array}{l}\text { TCONS_000 } \\
28661\end{array}$ & GCNT3 & $\mathrm{AL}$ \\
\hline TCONS_000 & LINC003 & & TCONS_000 & & & TCONS_000 & & \\
\hline 00421 & 39 & SE & 58932 & SS18L2 & A3 & 30774 & TLN2 & AF,SE \\
\hline $\begin{array}{l}\text { TCONS_000 } \\
07038\end{array}$ & ZBTB40 & RI,SE & $\begin{array}{l}\text { TCONS_000 } \\
63026\end{array}$ & NKTR & RI,SE & $\begin{array}{l}\text { TCONS_000 } \\
28671\end{array}$ & TLN2 & $\mathrm{O}$ \\
\hline TCONS_000 & & & TCONS_000 & & & TCONS_000 & RP11-32 & \\
\hline 00442 & C1QC & A5 & 58935 & NKTR & $A 3, R I$ & 30779 & 1G12.1 & A3 \\
\hline $\begin{array}{l}\text { TCONS_000 } \\
00454\end{array}$ & KDM1A & SE & $\begin{array}{l}\text { TCONS_000 } \\
58936\end{array}$ & NKTR & A3 RISE & $\begin{array}{l}\text { TCONS_000 } \\
28712\end{array}$ & USP3 & SF \\
\hline TCONS_000 & & & TCONS_000 & & & TCONS_000 & & \\
\hline 00455 & KDM1A & SE & 58979 & ZNF502 & A5 & 30783 & USP3 & SE \\
\hline $\begin{array}{l}\text { TCONS_000 } \\
00461\end{array}$ & RPL11 & A5 & $\begin{array}{l}\text { TCONS_000 } \\
59016\end{array}$ & NBEAL2 & RI,SE & $\begin{array}{l}\text { TCONS_000 } \\
28727\end{array}$ & ZNF609 & $\mathrm{O}$ \\
\hline $\begin{array}{l}\text { TCONS_000 } \\
00495\end{array}$ & RCAN3 & $\mathrm{AF}$ & $\begin{array}{l}\text { TCONS_000 } \\
59017\end{array}$ & NBEAL2 & RI,SE & $\begin{array}{l}\text { TCONS_000 } \\
30796\end{array}$ & DIS3L & A5 \\
\hline $\begin{array}{l}\text { TCONS_000 } \\
07049\end{array}$ & RCAN3 & A5 & $\begin{array}{l}\text { TCONS_000 } \\
59018\end{array}$ & NBEAL2 & A3,RI,SE & $\begin{array}{l}\text { TCONS_000 } \\
30797\end{array}$ & DIS3L & AF \\
\hline $\begin{array}{l}\text { TCONS_000 } \\
00542\end{array}$ & MTFR1L & $A F, R I$ & $\begin{array}{l}\text { TCONS_000 } \\
63043\end{array}$ & NBEAL2 & A3,RI & $\begin{array}{l}\text { TCONS_000 } \\
28795\end{array}$ & $\mathrm{IQCH}$ & $\mathrm{O}$ \\
\hline $\begin{array}{l}\text { TCONS_000 } \\
00555\end{array}$ & CEP85 & $\mathrm{O}$ & $\begin{array}{l}\text { TCONS_000 } \\
63045\end{array}$ & NBEAL2 & RI & $\begin{array}{l}\text { TCONS_000 } \\
28796\end{array}$ & IQCH & SE \\
\hline
\end{tabular}




\begin{tabular}{|c|c|c|c|c|c|c|c|c|}
\hline $\begin{array}{l}\text { TCONS_000 } \\
00556\end{array}$ & CEP85 & $\mathrm{O}$ & $\begin{array}{l}\text { TCONS_000 } \\
59026\end{array}$ & PTPN23 & $A 3, R I$ & $\begin{array}{l}\text { TCONS_000 } \\
30814\end{array}$ & GLCE & AL \\
\hline $\begin{array}{l}\text { TCONS_000 } \\
00610\end{array}$ & WDTC1 & RI & $\begin{array}{l}\text { TCONS_000 } \\
59027\end{array}$ & PTPN23 & RI & $\begin{array}{l}\text { TCONS_000 } \\
28817\end{array}$ & KIF23 & SE \\
\hline $\begin{array}{l}\text { TCONS_000 } \\
00618\end{array}$ & SYTL1 & A3 & $\begin{array}{l}\text { TCONS_000 } \\
59030\end{array}$ & DHX30 & A3,SE & $\begin{array}{l}\text { TCONS_000 } \\
30832\end{array}$ & NEO1 & $\begin{array}{l}A 3, A 5, S \\
E\end{array}$ \\
\hline $\begin{array}{l}\text { TCONS_000 } \\
07085\end{array}$ & SYTL1 & $A 3, R I$ & $\begin{array}{l}\text { TCONS_000 } \\
63051\end{array}$ & TMA7 & A3 & $\begin{array}{l}\text { TCONS_000 } \\
30833\end{array}$ & NEO1 & A3,SE \\
\hline $\begin{array}{l}\text { TCONS_000 } \\
07086\end{array}$ & SYTL1 & $\begin{array}{l}\text { A3,A5, } \\
\text { RI }\end{array}$ & $\begin{array}{l}\text { TCONS_000 } \\
59043\end{array}$ & ATRIP & A5,SE & $\begin{array}{l}\text { TCONS_000 } \\
28876\end{array}$ & $\begin{array}{l}\text { UBL7-A } \\
\text { S1 }\end{array}$ & SE \\
\hline $\begin{array}{l}\text { TCONS_000 } \\
00619\end{array}$ & SYTL1 & $\mathrm{O}$ & $\begin{array}{l}\text { TCONS_000 } \\
63053\end{array}$ & ARIH2 & A5,SE & $\begin{array}{l}\text { TCONS_000 } \\
30840\end{array}$ & $\begin{array}{l}\text { UBL7-A } \\
\text { S1 }\end{array}$ & A5,SE \\
\hline $\begin{array}{l}\text { TCONS_000 } \\
07098\end{array}$ & RCC1 & A5,SE & $\begin{array}{l}\text { TCONS_000 } \\
63057\end{array}$ & P4HTM & 0 & $\begin{array}{l}\text { TCONS_000 } \\
28893\end{array}$ & $\begin{array}{l}\text { SCAMP } \\
5\end{array}$ & SE \\
\hline TCONS_000 & & & TCONS_000 & KLHDC8 & & TCONS_000 & SCAMP & \\
\hline 00661 & RCC1 & A5 & 63062 & B & $\mathrm{O}$ & 28894 & 5 & SE \\
\hline $\begin{array}{l}\text { TCONS_000 } \\
\text { 00679 }\end{array}$ & EPB41 & A3 & $\begin{array}{l}\text { TCONS_000 } \\
59065\end{array}$ & $\begin{array}{l}\text { KLHDC8 } \\
\text { B }\end{array}$ & RI & $\begin{array}{l}\text { TCONS_000 } \\
28913\end{array}$ & NEIL1 & A3 \\
\hline $\begin{array}{l}\text { TCONS_000 } \\
00680\end{array}$ & EPB41 & A3,SE & $\begin{array}{l}\text { TCONS_000 } \\
63063\end{array}$ & APEH & RI,SE & $\begin{array}{l}\text { TCONS_000 } \\
30853\end{array}$ & NEIL1 & SE \\
\hline $\begin{array}{l}\text { TCONS_000 } \\
07103\end{array}$ & EPB41 & A3 & $\begin{array}{l}\text { TCONS_000 } \\
59101\end{array}$ & SEMA3F & A5,SE & $\begin{array}{l}\text { TCONS_000 } \\
28952\end{array}$ & DNAJA4 & SE \\
\hline TCONS_000 & $\mathrm{ZCCHC}$ & & TCONS_000 & SLC38A & & TCONS_000 & & \\
\hline 00689 & 17 & A5,SE & 63071 & 3 & A5 & 28954 & DNAJA4 & $\mathrm{O}$ \\
\hline $\begin{array}{l}\text { TCONS_000 } \\
00718\end{array}$ & IQCC & A5,RI & $\begin{array}{l}\text { TCONS_000 } \\
63072\end{array}$ & $\begin{array}{l}\text { SLC38A } \\
3\end{array}$ & A5,RI & $\begin{array}{l}\text { TCONS_000 } \\
30865\end{array}$ & IREB2 & A5 \\
\hline $\begin{array}{l}\text { TCONS_000 } \\
00720\end{array}$ & EIF3I & $\mathrm{O}$ & $\begin{array}{l}\text { TCONS_000 } \\
59114\end{array}$ & $\begin{array}{l}\text { SEMA3 } \\
\text { B }\end{array}$ & $A 3, R I$ & $\begin{array}{l}\text { TCONS_000 } \\
28982\end{array}$ & $\begin{array}{l}\text { CHRNA } \\
5\end{array}$ & A5 \\
\hline TCONS_000 & & $A 3, A F$ & TCONS_000 & SEMA3 & & TCONS_000 & CHRNA & \\
\hline 00727 & LCK & ,RI & 59115 & B & A3,RI & 28983 & 5 & A5 \\
\hline $\begin{array}{l}\text { TCONS_000 } \\
00729\end{array}$ & LCK & A3 & $\begin{array}{l}\text { TCONS_000 } \\
59134\end{array}$ & $\begin{array}{l}\text { MAPKA } \\
\text { PK3 }\end{array}$ & A5 & $\begin{array}{l}\text { TCONS_000 } \\
28984\end{array}$ & $\begin{array}{l}\text { CHRNA } \\
5\end{array}$ & A5 \\
\hline $\begin{array}{l}\text { TCONS_000 } \\
07116\end{array}$ & HDAC1 & $\mathrm{RI}$ & $\begin{array}{l}\text { TCONS_000 } \\
59135\end{array}$ & $\begin{array}{l}\text { MAPKA } \\
\text { PK3 }\end{array}$ & A5,SE & $\begin{array}{l}\text { TCONS_000 } \\
28986\end{array}$ & $\begin{array}{l}\text { CHRNA } \\
5\end{array}$ & $\mathrm{O}$ \\
\hline $\begin{array}{l}\text { TCONS_000 } \\
07126\end{array}$ & ZNF362 & A3 & $\begin{array}{l}\text { TCONS_000 } \\
63083\end{array}$ & PARP3 & 0 & $\begin{array}{l}\text { TCONS_000 } \\
29044\end{array}$ & $\begin{array}{l}\text { RP11-76 } \\
114.3\end{array}$ & $\mathrm{O}$ \\
\hline $\begin{array}{l}\text { TCONS_000 } \\
07127\end{array}$ & $\begin{array}{l}\text { ZSCAN2 } \\
0\end{array}$ & A5 & $\begin{array}{l}\text { TCONS_000 } \\
59152\end{array}$ & PARP3 & RI & $\begin{array}{l}\text { TCONS_000 } \\
29051\end{array}$ & $\begin{array}{l}\text { UBE2Q2 } \\
\text { P2 }\end{array}$ & $\begin{array}{l}A 3, A F, S \\
E\end{array}$ \\
\hline $\begin{array}{l}\text { TCONS_000 } \\
00765\end{array}$ & GJB4 & A5 & $\begin{array}{l}\text { TCONS_000 } \\
59156\end{array}$ & $\begin{array}{l}\text { ABHD14 } \\
\text { A-ACY1 }\end{array}$ & $A F$ & $\begin{array}{l}\text { TCONS_000 } \\
30888\end{array}$ & $\begin{array}{l}\text { RP11-15 } \\
\text { 2F13.7 }\end{array}$ & 0 \\
\hline
\end{tabular}




\begin{tabular}{|c|c|c|c|c|c|c|c|c|}
\hline $\begin{array}{l}\text { TCONS_000 } \\
00766\end{array}$ & GJB4 & SE & $\begin{array}{l}\text { TCONS_000 } \\
59166\end{array}$ & PPM1M & $\mathrm{O}$ & $\begin{array}{l}\text { TCONS_000 } \\
29059\end{array}$ & $\begin{array}{l}\text { RP11-15 } \\
\text { 2F13.7 }\end{array}$ & $\mathrm{A} 3, \mathrm{~A} 5$ \\
\hline TCONS_000 & & & TCONS_000 & & & TCONS_000 & RP11-18 & \\
\hline 00778 & ZMYM4 & SE & 59169 & DNAH1 & A3,SE & 30893 & 2J1.16 & $\mathrm{O}$ \\
\hline $\begin{array}{l}\text { TCONS_000 } \\
00788\end{array}$ & AGO4 & AF & $\begin{array}{l}\text { TCONS_000 } \\
63088\end{array}$ & DNAH1 & RI & $\begin{array}{l}\text { TCONS_000 } \\
29114\end{array}$ & AKAP13 & SE \\
\hline $\begin{array}{l}\text { TCONS_000 } \\
\text { 00814 }\end{array}$ & SH3D21 & 0 & $\begin{array}{l}\text { TCONS_000 } \\
63089\end{array}$ & DNAH1 & RI & $\begin{array}{l}\text { TCONS_000 } \\
29115\end{array}$ & AKAP13 & A3,SE \\
\hline $\begin{array}{l}\text { TCONS_000 } \\
00815\end{array}$ & SH3D21 & $\mathrm{RI}, \mathrm{SE}$ & $\begin{array}{l}\text { TCONS_000 } \\
59172\end{array}$ & PHF7 & A5 & $\begin{array}{l}\text { TCONS_000 } \\
29119\end{array}$ & AKAP13 & $\mathrm{O}$ \\
\hline $\begin{array}{l}\text { TCONS_000 } \\
00831\end{array}$ & UTP11L & $\mathrm{O}$ & $\begin{array}{l}\text { TCONS_000 } \\
59173\end{array}$ & PHF7 & $\mathrm{O}$ & $\begin{array}{l}\text { TCONS_000 } \\
29146\end{array}$ & FANCI & A5 \\
\hline TCONS_000 & & & TCONS_000 & & & TCONS_000 & & \\
\hline 07161 & PPIE & A5 & 59181 & STAB1 & RI & 29147 & FANCI & A5 \\
\hline TCONS_000 & MFSD2 & & TCONS_000 & & & TCONS_000 & & \\
\hline 00871 & A & A3,A5 & 63093 & STAB1 & RI & $29149^{-}$ & FANCI & $\mathrm{AF}, \mathrm{RI}$ \\
\hline $\begin{array}{l}\text { TCONS_000 } \\
\text { o0899 }\end{array}$ & ZFP69 & $\mathrm{O}$ & $\begin{array}{l}\text { TCONS_000 } \\
63094\end{array}$ & GNL3 & A5,RI & $\begin{array}{l}\text { TCONS_000 } \\
29150\end{array}$ & FANCI & AF \\
\hline $\begin{array}{l}\text { TCONS_000 } \\
07184\end{array}$ & ERMAP & A5 & $\begin{array}{l}\text { TCONS_000 } \\
63095\end{array}$ & GNL3 & 0 & $\begin{array}{l}\text { TCONS_000 } \\
30931\end{array}$ & ZNF710 & $A F$ \\
\hline $\begin{array}{l}\text { TCONS_000 } \\
07189\end{array}$ & SZT2 & SE & $\begin{array}{l}\text { TCONS_000 } \\
59195\end{array}$ & ITIH3 & O & $\begin{array}{l}\text { TCONS_000 } \\
30932\end{array}$ & ZNF710 & $A F$ \\
\hline $\begin{array}{l}\text { TCONS_000 } \\
\text { 07190 }\end{array}$ & SZT2 & RI,SE & $\begin{array}{l}\text { TCONS_000 } \\
63099\end{array}$ & $\begin{array}{l}\text { CACNA } \\
1 \mathrm{D}\end{array}$ & SE & $\begin{array}{l}\text { TCONS_000 } \\
29155\end{array}$ & ZNF710 & $\mathrm{O}$ \\
\hline $\begin{array}{l}\text { TCONS_000 } \\
\text { o0964 }\end{array}$ & SZT2 & RI,SE & $\begin{array}{l}\text { TCONS_000 } \\
59212\end{array}$ & APPL1 & 0 & $\begin{array}{l}\text { TCONS_000 } \\
30935\end{array}$ & $\begin{array}{l}\text { SEMA4 } \\
\text { B }\end{array}$ & 0 \\
\hline TCONS_000 & & & TCONS_000 & & & TCONS_000 & SEMA4 & \\
\hline 00965 & SZT2 & RI,SE & 59225 & SLMAP & $\mathrm{MX}, \mathrm{SE}$ & 30937 & B & $\mathrm{O}$ \\
\hline $\begin{array}{l}\text { TCONS_000 } \\
00967\end{array}$ & SZT2 & RI & $\begin{array}{l}\text { TCONS_000 } \\
59226\end{array}$ & SLMAP & SE & $\begin{array}{l}\text { TCONS_000 } \\
29199\end{array}$ & FURIN & A5 \\
\hline $\begin{array}{l}\text { TCONS_000 } \\
\text { C0989 }\end{array}$ & DPH2 & 0 & $\begin{array}{l}\text { TCONS_000 } \\
59227\end{array}$ & SLMAP & SE & $\begin{array}{l}\text { TCONS_000 } \\
30959\end{array}$ & FURIN & $A F$ \\
\hline $\begin{array}{l}\text { TCONS_000 } \\
\text { 07204 }\end{array}$ & CCDC24 & $\mathrm{A} 3, \mathrm{AF}$ & $\begin{array}{l}\text { TCONS_000 } \\
59228\end{array}$ & SLMAP & 0 & $\begin{array}{l}\text { TCONS_000 } \\
30960\end{array}$ & FURIN & $A F$ \\
\hline $\begin{array}{l}\text { TCONS_000 } \\
07205\end{array}$ & DMAP1 & A3,RI & $\begin{array}{l}\text { TCONS_000 } \\
63108\end{array}$ & SLMAP & SE & $\begin{array}{l}\text { TCONS_000 } \\
29201\end{array}$ & MAN2A2 & $\mathrm{O}$ \\
\hline $\begin{array}{l}\text { TCONS_000 } \\
\text { 07206 }\end{array}$ & RNF220 & 0 & $\begin{array}{l}\text { TCONS_000 } \\
63109\end{array}$ & SLMAP & SE & $\begin{array}{l}\text { TCONS_000 } \\
30962\end{array}$ & MAN2A2 & A3 \\
\hline $\begin{array}{l}\text { TCONS_000 } \\
01020\end{array}$ & PLK3 & RI & $\begin{array}{l}\text { TCONS_000 } \\
59244\end{array}$ & FLNB & SE & $\begin{array}{l}\text { TCONS_000 } \\
30963\end{array}$ & MAN2A2 & RI \\
\hline
\end{tabular}




\begin{tabular}{|c|c|c|c|c|c|c|c|c|}
\hline $\begin{array}{l}\text { TCONS_000 } \\
01021\end{array}$ & PLK3 & RI & $\begin{array}{l}\text { TCONS_000 } \\
59263\end{array}$ & PXK & SE & $\begin{array}{l}\text { TCONS_000 } \\
30967\end{array}$ & UNC45A & RI \\
\hline TCONS_000 & & & TCONS_000 & & & TCONS_000 & & \\
\hline 07210 & AKR1A1 & RI & 63119 & PXK & SE & 29207 & UNC45A & RI \\
\hline $\begin{array}{l}\text { TCONS_000 } \\
07211\end{array}$ & AKR1A1 & $\mathrm{RI}, \mathrm{SE}$ & $\begin{array}{l}\text { TCONS_000 } \\
59291\end{array}$ & ATXN7 & AF,SE & $\begin{array}{l}\text { TCONS_000 } \\
30968\end{array}$ & UNC45A & RI \\
\hline TCONS_000 & & & TCONS_000 & ADAMT & & TCONS_000 & SLCO3A & \\
\hline 01037 & AKR1A1 & SE & 63131 & S9-AS2 & 0 & 29216 & 1 & AL \\
\hline $\begin{array}{l}\text { TCONS_000 } \\
01038\end{array}$ & AKR1A1 & SE & $\begin{array}{l}\text { TCONS_000 } \\
63143\end{array}$ & $\begin{array}{l}\text { RP11-81 } \\
\text { N13.1 }\end{array}$ & $\mathrm{O}$ & $\begin{array}{l}\text { TCONS_000 } \\
30989\end{array}$ & CHD2 & SE \\
\hline TCONS_000 & TSPAN11 & $\mathrm{s}^{-}$ & TCONS_000 & RP11-15 & & TCONS_000 & MCTP? & 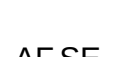 \\
\hline TCONS 000 & & & TCONS 000 & CRYBG & & TCONS_000 & CTD-21 & \\
\hline 01062 & TSPAN1 & AF & 63163 & 3 & 0 & 29257 & $47 F 2.1$ & $\mathrm{O}$ \\
\hline TCONS_000 & & & TCONS_000 & TBC1D2 & & TCONS_000 & & \\
\hline 01070 & RAD54L & $\mathrm{O}$ & 59433 & 3 & 0 & 29260 & IGF1R & $\mathrm{O}$ \\
\hline TCONS_000 & & & TCONS_000 & TMEM4 & & TCONS_000 & & \\
\hline 01082 & FAAH & A3,RI & 63173 & $5 \mathrm{~A}$ & SE & 29261 & IGF1R & $\mathrm{O}$ \\
\hline $\begin{array}{l}\text { TCONS_000 } \\
01083\end{array}$ & FAAH & RI & $\begin{array}{l}\text { TCONS_000 } \\
59450\end{array}$ & GPR128 & SE & $\begin{array}{l}\text { TCONS_000 } \\
29263\end{array}$ & IGF1R & A3,A5 \\
\hline $\begin{array}{l}\text { TCONS_000 } \\
01118\end{array}$ & OSBPL9 & SE & $\begin{array}{l}\text { TCONS_000 } \\
59498\end{array}$ & ZPLD1 & 0 & $\begin{array}{l}\text { TCONS_000 } \\
29294\end{array}$ & $\begin{array}{l}\text { WASH3 } \\
\text { P }\end{array}$ & A5 \\
\hline TCONS_000 & PRPF38 & & TCONS_000 & & & TCONS_000 & WASH3 & \\
\hline 01143 & A & $\mathrm{O}$ & 59520 & HHLA2 & A3 & 29296 & $\mathrm{P}$ & A5,RI \\
\hline $\begin{array}{l}\text { TCONS_000 } \\
01163\end{array}$ & LRRC42 & MX & $\begin{array}{l}\text { TCONS_000 } \\
59522\end{array}$ & DZIP3 & A5 & $\begin{array}{l}\text { TCONS_000 } \\
29297\end{array}$ & $\begin{array}{l}\text { WASH3 } \\
\text { P }\end{array}$ & $A 3, A 5, R I$ \\
\hline TCONS_000 & & & TCONS_000 & & & TCONS_000 & WASH3 & גוס \\
\hline 01171 & ACOT11 & AF & 59602 & PHLDB2 & RI,SE & 31019 & P & A5,RI \\
\hline TCONS_000 & $\mathrm{MROH} 7-$ & & TCONS_000 & & & TCONS_000 & WASH3 & \\
\hline 01172 & TTC4 & $\mathrm{O}$ & 59613 & C3orf52 & 0 & 29299 & $\mathrm{P}$ & 0 \\
\hline TCONS_000 & TMEM6 & & TCONS_000 & & & TCONS_000 & HERC2 & \\
\hline 01179 & 1 & AF & 63198 & C3orf52 & $\mathrm{O}$ & 29305 & P3 & RI \\
\hline $\begin{array}{l}\text { TCONS_000 } \\
07240\end{array}$ & FGGY & $\mathrm{O}$ & $\begin{array}{l}\text { TCONS_000 } \\
63199\end{array}$ & C3orf52 & $\mathrm{O}$ & $\begin{array}{l}\text { TCONS_000 } \\
31026\end{array}$ & NIPA2 & A5,SE \\
\hline $\begin{array}{l}\text { TCONS_000 } \\
07243\end{array}$ & INADL & SE & $\begin{array}{l}\text { TCONS_000 } \\
59637\end{array}$ & $\mathrm{BOC}$ & A5 & $\begin{array}{l}\text { TCONS_000 } \\
29315\end{array}$ & NIPA2 & SE \\
\hline $\begin{array}{l}\text { TCONS_000 } \\
07265\end{array}$ & RAVER2 & $\mathrm{O}$ & $\begin{array}{l}\text { TCONS_000 } \\
59638\end{array}$ & $\mathrm{BOC}$ & A3,A5 & $\begin{array}{l}\text { TCONS_000 } \\
29316\end{array}$ & NIPA2 & 0 \\
\hline $\begin{array}{l}\text { TCONS_000 } \\
07267\end{array}$ & LEPR & $\mathrm{AL}$ & $\begin{array}{l}\text { TCONS_000 } \\
59655\end{array}$ & $\begin{array}{l}\text { ZDHHC } \\
23\end{array}$ & 0 & $\begin{array}{l}\text { TCONS_000 } \\
29317\end{array}$ & NIPA2 & A5 \\
\hline
\end{tabular}




\begin{tabular}{|c|c|c|c|c|c|c|c|c|}
\hline $\begin{array}{l}\text { TCONS_000 } \\
01368\end{array}$ & FAM73A & A3 & $\begin{array}{l}\text { TCONS_000 } \\
59656\end{array}$ & $\begin{array}{l}\text { ZDHHC } \\
23\end{array}$ & A3 & $\begin{array}{l}\text { TCONS_000 } \\
31028\end{array}$ & $\begin{array}{l}\text { WHAMM } \\
\text { P3 }\end{array}$ & SE \\
\hline TCONS_000 & & & TCONS_000 & ZDHHC & & TCONS_000 & HERC2 & \\
\hline 01392 & IFI44L & SE & 63212 & 23 & A3 & 29330 & P2 & RI,SE \\
\hline $\begin{array}{l}\text { TCONS_000 } \\
01394\end{array}$ & IFI44L & $\mathrm{O}$ & $\begin{array}{l}\text { TCONS_000 } \\
59675\end{array}$ & $\begin{array}{l}\text { LSAMP- } \\
\text { AS1 }\end{array}$ & $\mathrm{O}$ & $\begin{array}{l}\text { TCONS_000 } \\
29333\end{array}$ & $\begin{array}{l}\text { HERC2 } \\
\text { P2 }\end{array}$ & A3,RI \\
\hline $\begin{array}{l}\text { TCONS_000 } \\
01400\end{array}$ & LPHN2 & SE & $\begin{array}{l}\text { TCONS_000 } \\
63220\end{array}$ & ADPRH & A3 & $\begin{array}{l}\text { TCONS_000 } \\
29331\end{array}$ & $\begin{array}{l}\text { HERC2 } \\
\text { P2 }\end{array}$ & RI.SE \\
\hline TCONS_000 & & $M X, S$ & TCONS_000 & & & TCONS_000 & & \\
\hline 07308 & LPHN2 & E & 59694 & PLA1A & SE & 31038 & HERC2 & $\mathrm{O}$ \\
\hline TCONS_000 & & & TCONS_000 & RP11-29 & & TCONS_000 & & \\
\hline 07309 & LPHN2 & SE & 59728 & $9 J 3.8$ & $\mathrm{O}$ & 29355 & HERC2 & $\mathrm{RI}$ \\
\hline TCONS_000 & SAMO13 & $c 5$ & TCONS_000 & KAIRN & A3,A5,AF, & TCONS_000 & $\mathrm{HERC} ?$ & וס \\
\hline 01415 & SAIVID & SE & $59 / 53$ & KALRN & RI,SE & 29356 & HERCL & $\mathrm{RI}$ \\
\hline $\begin{array}{l}\text { TCONS_000 } \\
01430\end{array}$ & CYR61 & O & $\begin{array}{l}\text { TCONS_000 } \\
63243\end{array}$ & KALRN & $A 3, A 5, A F$ & $\begin{array}{l}\text { TCONS_000 } \\
31039\end{array}$ & $\begin{array}{l}\text { RP11-57 } \\
8 F 21.2\end{array}$ & $\mathrm{O}$ \\
\hline TCONS_000 & & & TCONS_000 & ENPP7P & & TCONS_000 & GOLGA & \\
\hline 01462 & GBP1P1 & $\mathrm{O}$ & 59780 & 4 & RI & $31047^{-}$ & $8 \mathrm{R}$ & RI \\
\hline $\begin{array}{l}\text { TCONS_000 } \\
01463\end{array}$ & LRRC8B & O & $\begin{array}{l}\text { TCONS_000 } \\
59785\end{array}$ & PLXNA1 & 0 & $\begin{array}{l}\text { TCONS_000 } \\
29371\end{array}$ & $\begin{array}{l}\text { GOLGA } \\
8 R\end{array}$ & $A F$ \\
\hline TCONS_000 & KIAA110 & & TCONS_000 & & & TCONS_000 & GOLGA & \\
\hline 01484 & 7 & $\mathrm{O}$ & 63252 & PLXNA1 & $\mathrm{O}$ & 29384 & & $\mathrm{O}$ \\
\hline TCONS_000 & SLC44A & & TCONS_000 & & & TCONS_000 & GOLGA & \\
\hline 07340 & 3 & A3,A5 & 59787 & PLXNA1 & RI & 29385 & & $\mathrm{AF}$ \\
\hline TCONS_000 & SLC44A & & TCONS_000 & & & TCONS_000 & RP11-63 & \\
\hline 01529 & 3 & A3 & 59792 & PODXL2 & $\mathrm{O}$ & 29386 & 2K20.2 & $\mathrm{A} 5, \mathrm{MX}$ \\
\hline TCONS_000 & RP11-57 & & TCONS_000 & KBTBD1 & & TCONS_000 & RP11-63 & \\
\hline 07341 & H12.6 & $\mathrm{AF}$ & 59801 & 2 & RI & 31057 & 2K20.2 & A5,MX \\
\hline TCONS_000 & RP11-57 & & TCONS_000 & SEC61A & & TCONS_000 & RP11-63 & \\
\hline 07342 & H12.6 & $\mathrm{O}$ & 63254 & 1 & A5 & 31058 & 2K20.7 & A5 \\
\hline TCONS_000 & & & TCONS_000 & SEC61A & 0 & TCONS_000 & RP11-63 & \\
\hline & RVVDD3 & AS & 59802 & 1 & 0 & 29392 & $2 K 20.1$ & AS,SE \\
\hline $\begin{array}{l}\text { TCONS_000 } \\
01541\end{array}$ & RWDD3 & $\mathrm{O}$ & $\begin{array}{l}\text { TCONS_000 } \\
59803\end{array}$ & $\begin{array}{l}\text { SEC61A } \\
1\end{array}$ & $\mathrm{RI}$ & $\begin{array}{l}\text { TCONS_000 } \\
31060\end{array}$ & $\begin{array}{l}\text { RP11-63 } \\
2 \mathrm{~K} 20.7\end{array}$ & A5 \\
\hline $\begin{array}{l}\text { TCONS_000 } \\
07345\end{array}$ & RWDD3 & A5 & $\begin{array}{l}\text { TCONS_000 } \\
63268\end{array}$ & ACAD9 & $\mathrm{O}$ & $\begin{array}{l}\text { TCONS_000 } \\
29398\end{array}$ & FMN1 & $\mathrm{O}$ \\
\hline $\begin{array}{l}\text { TCONS_000 } \\
01591\end{array}$ & SNX7 & SE & $\begin{array}{l}\text { TCONS_000 } \\
59837\end{array}$ & ACAD9 & O & $\begin{array}{l}\text { TCONS_000 } \\
29425\end{array}$ & LPCAT4 & $\mathrm{O}$ \\
\hline $\begin{array}{l}\text { TCONS_000 } \\
01592\end{array}$ & SNX7 & SE & $\begin{array}{l}\text { TCONS_000 } \\
59838\end{array}$ & ACAD9 & $\mathrm{O}$ & $\begin{array}{l}\text { TCONS_000 } \\
29426\end{array}$ & LPCAT4 & RI \\
\hline
\end{tabular}




\begin{tabular}{|c|c|c|c|c|c|c|c|c|}
\hline $\begin{array}{l}\text { TCONS_000 } \\
01605\end{array}$ & HIAT1 & $\mathrm{O}$ & $\begin{array}{l}\text { TCONS_000 } \\
63275\end{array}$ & IFT122 & A3,RI,SE & $\begin{array}{l}\text { TCONS_000 } \\
29429\end{array}$ & $\begin{array}{l}\text { GOLGA } \\
8 \mathrm{~B}\end{array}$ & $\mathrm{O}$ \\
\hline TCONS_000 & & & TCONS_000 & NUDT16 & & TCONS_000 & & \\
\hline 01609 & TRMT13 & A3 & 59884 & $\mathrm{P}$ & RI & 31068 & GJD2 & A5 \\
\hline TCONS_000 & & & TCONS_000 & DNAJC1 & & TCONS_000 & & \\
\hline 01610 & TRMT13 & RI,SE & 63280 & 3 & RI & 29451 & MEIS2 & SE \\
\hline $\begin{array}{l}\text { TCONS_000 } \\
07360\end{array}$ & TRMT13 & A3 SE & TCONS_000 & IRA5 & 0 & $\begin{array}{l}\text { TCONS_000 } \\
\end{array}$ & MFIS? & $\mathrm{Rl}$ \\
\hline $\begin{array}{l}\text { TCONS_000 } \\
07361\end{array}$ & TRMT13 & $\mathrm{O}$ & $\begin{array}{l}\text { TCONS_000 } \\
59959\end{array}$ & MRAS & A5 & $\begin{array}{l}\text { TCONS_000 } \\
29480\end{array}$ & BMF & A3 \\
\hline $\begin{array}{l}\text { TCONS_000 } \\
07363\end{array}$ & RTCA & RI & $\begin{array}{l}\text { TCONS_000 } \\
60047\end{array}$ & $\begin{array}{l}\text { U2SUR } \\
\mathrm{P}\end{array}$ & A5,SE & $\begin{array}{l}\text { TCONS_000 } \\
29481\end{array}$ & BMF & 0 \\
\hline TCONS_000 & RP11-42 & & TCONS_000 & & & TCONS_000 & & \\
\hline 01629 & 1L21.3 & $\mathrm{O}$ & 63349 & CPB1 & $\mathrm{O}$ & 29487 & PLCB2 & $\mathrm{RI}$ \\
\hline $\begin{array}{l}\text { TCONS_000 } \\
07373\end{array}$ & RNPC3 & A3 & $\begin{array}{l}\text { TCONS_000 } \\
63350\end{array}$ & CPB1 & $\mathrm{O}$ & $\begin{array}{l}\text { TCONS_000 } \\
31116\end{array}$ & RMDN3 & A5,RI \\
\hline TCONS_000 & & & TCONS_000 & & & TCONS_000 & PPP1R1 & \\
\hline 01636 & RNPC3 & $\mathrm{O}$ & 60085 & HPS3 & A3 & 29505 & $4 D$ & SE \\
\hline TCONS_000 & & & TCONS_000 & RP11-16 & & TCONS_000 & RP11-53 & \\
\hline 01639 & RNPC3 & A3 & 60099 & 7H9.4 & $\mathrm{O}$ & 29509 & 2F12.5 & $\mathrm{A} 3, \mathrm{SE}$ \\
\hline $\begin{array}{l}\text { TCONS_000 } \\
01640\end{array}$ & RNPC3 & $\mathrm{O}$ & $\begin{array}{l}\text { TCONS_000 } \\
60116\end{array}$ & $\begin{array}{l}\text { RP11-64 } \\
\text { D22.2 }\end{array}$ & SE & $\begin{array}{l}\text { TCONS_000 } \\
31120\end{array}$ & RHOV & $\mathrm{O}$ \\
\hline TCONS_000 & & & TCONS_000 & RP11-64 & & TCONS_000 & NDUFA & \\
\hline 07378 & AMY2A & $\mathrm{O}$ & 60117 & D22.2 & $\mathrm{O}$ & 29518 & F1 & A3,A5 \\
\hline TCONS_000 & & & TCONS_000 & RP11-64 & & TCONS_000 & NDUFA & \\
\hline 07379 & AMY2A & SE & 60118 & D22.2 & 0 & 29519 & F1 & A5,SE \\
\hline TCONS_000 & & & TCONS_000 & RP11-64 & & TCONS_000 & TMEM8 & \\
\hline 07380 & AMY2A & $\mathrm{O}$ & 60119 & D22.2 & SE & 31124 & & $\mathrm{O}$ \\
\hline TCONS_000 & & & TCONS_000 & RP11-64 & & TCONS_000 & TMEM8 & \\
\hline 01645 & AMY1A & $\mathrm{O}$ & 60121 & D22.2 & RI,SE & 29534 & $7 A$ & $\mathrm{MX}$ \\
\hline $\begin{array}{l}\text { TCONS_000 } \\
01646\end{array}$ & AMY1A & $\mathrm{O}$ & $\begin{array}{l}\text { TCONS_000 } \\
60126\end{array}$ & AADAC & 0 & $\begin{array}{l}\text { TCONS_000 } \\
29537\end{array}$ & ZNF106 & $\mathrm{O}$ \\
\hline TCONS_000 & PRPF38 & & TCONS_000 & & & TCONS_000 & ZSCAN2 & \\
\hline $01660^{-}$ & B & A5,SE & $60127^{-}$ & AADAC & $\mathrm{O}$ & $29557-$ & 9 & $\mathrm{O}$ \\
\hline TCONS_000 & KIAA132 & & TCONS_000 & & & TCONS_000 & PPIP5K & \\
\hline 01677 & 4 & $\mathrm{O}$ & 60158 & MME & $A F$ & 29564 & 1 & $A 3, R I$ \\
\hline TCONS_000 & & & TCONS_000 & IQCJ-SC & & TCONS_000 & PPIP5K & $A 3, R I, S$ \\
\hline 01699 & AMPD2 & RI,SE & 60211 & HIP1 & $\mathrm{O}$ & 29565 & 1 & $\mathrm{E}$ \\
\hline $\begin{array}{l}\text { TCONS_000 } \\
01700\end{array}$ & AMPD2 & RI & $\begin{array}{l}\text { TCONS_000 } \\
60212\end{array}$ & $\begin{array}{l}\text { IQCJ-SC } \\
\text { HIP1 }\end{array}$ & $\mathrm{O}$ & $\begin{array}{l}\text { TCONS_000 } \\
29593\end{array}$ & DUOX2 & $\mathrm{O}$ \\
\hline
\end{tabular}




\begin{tabular}{|c|c|c|c|c|c|c|c|c|}
\hline $\begin{array}{l}\text { TCONS_000 } \\
01702\end{array}$ & AMPD2 & $\mathrm{O}$ & $\begin{array}{l}\text { TCONS_000 } \\
60223\end{array}$ & SMC4 & RI,SE & $\begin{array}{l}\text { TCONS_000 } \\
31144\end{array}$ & DUOX2 & RI \\
\hline TCONS_000 & & & TCONS_000 & & & TCONS_000 & DUOXA & \\
\hline 07396 & RBM15 & SE & 63383 & SMC4 & RI & 29597 & 1 & $\mathrm{O}$ \\
\hline TCONS_000 & & & TCONS_000 & & & TCONS_000 & DUOXA & \\
\hline $01 / 31$ & CYMP & SE & 63384 & SMC4 & A3 & 29598 & 1 & A5 \\
\hline $\begin{array}{l}\text { TCONS_000 } \\
01732\end{array}$ & CYMP & 0 & $\begin{array}{l}\text { TCONS_000 } \\
60256\end{array}$ & MYNN & SE & $\begin{array}{l}\text { TCONS_000 } \\
29599\end{array}$ & $\begin{array}{l}\text { DUOXA } \\
1\end{array}$ & A3,A5 \\
\hline $\begin{array}{l}\text { TCONS_000 } \\
01733\end{array}$ & CD53 & $\mathrm{O}$ & $\begin{array}{l}\text { TCONS_000 } \\
\text { 60265 }\end{array}$ & GPR160 & A5,SE & $\begin{array}{l}\text { TCONS_000 } \\
31167\end{array}$ & $\begin{array}{l}\text { RP11-51 } \\
9 \text { G16.5 }\end{array}$ & $\mathrm{O}$ \\
\hline $\begin{array}{l}\text { TCONS_000 } \\
01774\end{array}$ & LRIG2 & $\mathrm{O}$ & $\begin{array}{l}\text { TCONS_000 } \\
60273\end{array}$ & SKIL & A5,RI & $\begin{array}{l}\text { TCONS_000 } \\
29645\end{array}$ & HDC & $\mathrm{O}$ \\
\hline TCONS_000 & & & TCONS_000 & & & TCONS_000 & & \\
\hline 01803 & ATP1A1 & $\mathrm{A} 5, \mathrm{AF}$ & 60348 & TTC14 & $\mathrm{AL}$ & 29647 & HDC & $\mathrm{O}$ \\
\hline TCONS_000 & ATP1A1 & $\mathrm{AF}$ & TCONS_000 & TTC14 & $\Delta l$ & TCONS_000 & GABPB1 & SF \\
\hline TCONS_000 & & & TCONS_000 & & & TCONS_000 & & \\
\hline 07419 & ATP1A1 & $\mathrm{AF}$ & 60385 & EIF2B5 & RI & 31188 & SPPL2A & A5 \\
\hline TCONS_000 & & & TCONS_000 & & & TCONS_000 & & \\
\hline 01818 & WDR3 & A5 & 60386 & EIF2B5 & RI & 31189 & SPPL2A & RI \\
\hline TCONS_000 & SRGAP & & TCONS_000 & & & TCONS_000 & & \\
\hline 07468 & $2 \mathrm{C}$ & $\mathrm{O}$ & 63436 & EIF2B5 & A5 & 29660 & SPPL2A & SE \\
\hline $\begin{array}{l}\text { TCONS_000 } \\
01881\end{array}$ & NBPF8 & $\mathrm{O}$ & $\begin{array}{l}\text { TCONS_000 } \\
63440\end{array}$ & PSMD2 & AF & $\begin{array}{l}\text { TCONS_000 } \\
29671\end{array}$ & DMXL2 & SE \\
\hline $\begin{array}{l}\text { TCONS_000 } \\
07481\end{array}$ & NBPF8 & RI & $\begin{array}{l}\text { TCONS_000 } \\
\text { 60396 }\end{array}$ & EPHB3 & $\mathrm{O}$ & $\begin{array}{l}\text { TCONS_000 } \\
29670\end{array}$ & DMXL2 & A3,SE \\
\hline TCONS_000 & & & TCONS_000 & & & TCONS_000 & FAM214 & \\
\hline 01884 & NBPF8 & $\mathrm{O}$ & 60401 & VPS8 & A3,RI,SE & 31201 & A & A5 \\
\hline TCONS_000 & RP11-64 & $M X, S$ & TCONS_000 & & & TCONS_000 & & \\
\hline 01889 & OM9.2 & E & 63445 & VPS8 & RI,SE & 29744 & RFX7 & $\mathrm{O}$ \\
\hline TCONS_000 & RP11-64 & $M X, S$ & TCONS_000 & & & TCONS_000 & & \\
\hline 01890 & 0M9.2 & $\mathrm{E}$ & 63447 & VPS8 & RI,SE & 29769 & SLTM & A3,SE \\
\hline $\begin{array}{l}\text { TCONS_000 } \\
07484\end{array}$ & NBPF9 & RI & $\begin{array}{l}\text { TCONS_000 } \\
63451\end{array}$ & VPS8 & RI,SE & $\begin{array}{l}\text { TCONS_000 } \\
29771\end{array}$ & SLTM & A3 \\
\hline $\begin{array}{l}\text { TCONS_000 } \\
07485\end{array}$ & NBPF9 & $\mathrm{O}$ & $\begin{array}{l}\text { TCONS_000 } \\
60434\end{array}$ & EIF4A2 & RI,SE & $\begin{array}{l}\text { TCONS_000 } \\
31218\end{array}$ & SLTM & RI \\
\hline $\begin{array}{l}\text { TCONS_000 } \\
07494\end{array}$ & RBM8A & 0 & $\begin{array}{l}\text { TCONS_000 } \\
60469\end{array}$ & LPP & AF,SE & $\begin{array}{l}\text { TCONS_000 } \\
31219\end{array}$ & SLTM & A3,AF \\
\hline $\begin{array}{l}\text { TCONS_000 } \\
\text { 01936 }\end{array}$ & ITGA10 & RI & $\begin{array}{l}\text { TCONS_000 } \\
60474\end{array}$ & LPP & $A F$ & $\begin{array}{l}\text { TCONS_000 } \\
29800\end{array}$ & ANXA2 & 0 \\
\hline
\end{tabular}




\begin{tabular}{|c|c|c|c|c|c|c|c|c|}
\hline $\begin{array}{l}\text { TCONS_000 } \\
01937\end{array}$ & PIAS3 & AF & $\begin{array}{l}\text { TCONS_000 } \\
\text { 60495 }\end{array}$ & CLDN16 & $\mathrm{O}$ & $\begin{array}{l}\text { TCONS_000 } \\
31238\end{array}$ & HERC1 & RI \\
\hline TCONS_000 & & & TCONS_000 & TMEM4 & & TCONS_000 & & \\
\hline 01938 & PIAS3 & A5,AF & 60525 & 4-AS1 & SE & 31240 & HERC1 & $A 3, A 5, R I$ \\
\hline $\begin{array}{l}\text { TCONS_000 } \\
01939\end{array}$ & PIAS3 & $A F, R I$ & $\begin{array}{l}\text { TCONS_000 } \\
\text { 60535 }\end{array}$ & SDHAP2 & SE & $\begin{array}{l}\text { TCONS_000 } \\
31241\end{array}$ & HERC1 & $\mathrm{A} 3, \mathrm{~A} 5$ \\
\hline TCONS_000 & & & TCONS_000 & & & TCONS_000 & & \\
\hline 01940 & PIAS3 & $\mathrm{AF}$ & 60543 & PIGX & SE & 29851 & HERC1 & A3 \\
\hline $\begin{array}{l}\text { TCONS_000 } \\
07503\end{array}$ & GPR89B & RI & $\begin{array}{l}\text { TCONS_000 } \\
60549\end{array}$ & PIGX & SE & $\begin{array}{l}\text { TCONS_000 } \\
29856\end{array}$ & HERC1 & A5 \\
\hline $\begin{array}{l}\text { TCONS_000 } \\
07504\end{array}$ & GPR89B & $\mathrm{O}$ & $\begin{array}{l}\text { TCONS_000 } \\
63471\end{array}$ & PIGX & SE & $\begin{array}{l}\text { TCONS_000 } \\
29857\end{array}$ & HERC1 & A5,RI \\
\hline TCONS_000 & & & TCONS_000 & NCBP2- & & TCONS_000 & & \\
\hline 01963 & GPR89B & $\mathrm{O}$ & 60560 & AS1 & 0 & 31246 & HERC1 & RI \\
\hline TCONS_000 & RP11-49 & & TCONS_000 & DLG1-A & & TCONS_000 & & \\
\hline 07505 & 5P10.1 & $\mathrm{O}$ & 60566 & S1 & A5 & 31249 & SPG21 & SE \\
\hline TCONS_000 & NRPE15 & $\hat{n}^{2}$ & TCONS_000 & תחקח & $c 5$ & TCONS_000 & $\checkmark M / \Delta O$ & 0 \\
\hline TCONS 000 & & & TCONS 000 & FAM157 & & TCONS 000 & & \\
\hline 07507 & NBPF15 & $A 3, R I$ & 60601 & A & 0 & 31254 & VWA9 & $\mathrm{O}$ \\
\hline TCONS_000 & FCGR1 & & TCONS 000 & FAM157 & & TCONS_000 & DENND & $\mathrm{A} 3, \mathrm{AF}, \mathrm{S}$ \\
\hline 01999 & C & A3 & 60603 & A & $\mathrm{O}$ & 31261 & $4 \mathrm{~A}$ & $\mathrm{E}$ \\
\hline TCONS 000 & HIST2H & & TCONS 000 & AC0262 & & TCONS 000 & RP11-79 & \\
\hline 02009 & $4 \mathrm{~A}$ & A5 & 63503 & 02.3 & $\mathrm{O}$ & 31266 & $8 \mathrm{~K} 3.2$ & A3 \\
\hline TCONS_000 & PLEKH & & TCONS_000 & LMCD1- & & TCONS_000 & IQCH-A & \\
\hline 07519 & $\mathrm{O} 1$ & O & 60639 & AS1 & 0 & 29951 & S1 & 0 \\
\hline TCONS_000 & & & TCONS_000 & RPUSD & & TCONS_000 & & \\
\hline 02025 & CA14 & $\mathrm{O}$ & 63514 & 3 & RI & 29955 & CLN6 & $\mathrm{O}$ \\
\hline TCONS_000 & & & TCONS_000 & & & TCONS_000 & RP11-25 & \\
\hline 02027 & C1orf54 & $\mathrm{O}$ & 63518 & CIDEC & $A F$ & 31275 & 3M7.1 & $\mathrm{O}$ \\
\hline $\begin{array}{l}\text { TCONS_000 } \\
\text { 02036 }\end{array}$ & PRPF3 & SE & $\begin{array}{l}\text { TCONS_000 } \\
\text { 60676 }\end{array}$ & $\begin{array}{l}\text { FANCD2 } \\
\text { OS }\end{array}$ & 0 & $\begin{array}{l}\text { TCONS_000 } \\
30006\end{array}$ & PKM & $M X$ \\
\hline $\begin{array}{l}\text { TCONS_000 } \\
02037\end{array}$ & PRPF3 & $\begin{array}{l}\text { A3,RI, } \\
\text { SE }\end{array}$ & $\begin{array}{l}\text { TCONS_000 } \\
60708\end{array}$ & RAF1 & SE & $\begin{array}{l}\text { TCONS_000 } \\
30021\end{array}$ & PARP6 & $\begin{array}{l}\text { A3,A5,RI } \\
\text {,SE }\end{array}$ \\
\hline $\begin{array}{l}\text { TCONS_000 } \\
07521\end{array}$ & PRPF3 & SE & $\begin{array}{l}\text { TCONS_000 } \\
60725\end{array}$ & IQSEC1 & A3 & $\begin{array}{l}\text { TCONS_000 } \\
30022\end{array}$ & PARP6 & $\begin{array}{l}A 5, R I, S \\
E\end{array}$ \\
\hline $\begin{array}{l}\text { TCONS_000 } \\
07522\end{array}$ & PRPF3 & A3,A5 & $\begin{array}{l}\text { TCONS_000 } \\
63530\end{array}$ & IQSEC1 & $\mathrm{O}$ & $\begin{array}{l}\text { TCONS_000 } \\
30023\end{array}$ & PARP6 & $\begin{array}{l}\mathrm{A} 5, \mathrm{RI}, \mathrm{S} \\
\mathrm{E}\end{array}$ \\
\hline $\begin{array}{l}\text { TCONS_000 } \\
\text { 02049 }\end{array}$ & ECM1 & $\mathrm{O}$ & $\begin{array}{l}\text { TCONS_000 } \\
60770\end{array}$ & $\begin{array}{l}\text { FGD5-A } \\
\text { S1 }\end{array}$ & A5 & $\begin{array}{l}\text { TCONS_000 } \\
30024\end{array}$ & PARP6 & $\begin{array}{l}\text { A3,A5,RI } \\
\text {,SE }\end{array}$ \\
\hline
\end{tabular}




\begin{tabular}{|c|c|c|c|c|c|c|c|c|}
\hline $\begin{array}{l}\text { TCONS_000 } \\
02058\end{array}$ & $\begin{array}{l}\text { ADAMT } \\
\text { SL4 }\end{array}$ & RI & $\begin{array}{l}\text { TCONS_000 } \\
60775\end{array}$ & MRPS25 & O & $\begin{array}{l}\text { TCONS_000 } \\
30040\end{array}$ & ADPGK & $A 3, A 5, R I$ \\
\hline $\begin{array}{l}\text { TCONS_000 } \\
02071\end{array}$ & SETDB1 & A3 & $\begin{array}{l}\text { TCONS_000 } \\
63545\end{array}$ & HACL1 & SE & $\begin{array}{l}\text { TCONS_000 } \\
31294\end{array}$ & UBL7 & SE \\
\hline TCONS_000 & & & TCONS_000 & ANKRD & & TCONS_000 & & \\
\hline 02072 & SETDB1 & $A 3, R I$ & 63547 & 28 & AF & 30079 & ULK3 & A5,RI \\
\hline TCONS_000 & & & TCONS_000 & & & TCONS_000 & MAN2C & \\
\hline 07533 & SETDB1 & A3,RI & 63569 & THRB & A3,A5 & 30103 & 1 & A3,RI \\
\hline $\begin{array}{l}\text { TCONS_000 } \\
02078\end{array}$ & ANXA9 & RI & $\begin{array}{l}\text { TCONS_000 } \\
60840\end{array}$ & THRB & A5 & $\begin{array}{l}\text { TCONS_000 } \\
30104\end{array}$ & $\begin{array}{l}\text { MAN2C } \\
1\end{array}$ & RI \\
\hline TCONS_000 & & & TCONS_000 & & & TCONS_000 & MAN2C & \\
\hline 07535 & ANXA9 & $\mathrm{O}$ & 60841 & THRB & $\mathrm{O}$ & 30105 & 1 & $\mathrm{~A} 3, \mathrm{SE}$ \\
\hline TCONS_000 & & & TCONS_000 & & & TCONS_000 & MAN2C & \\
\hline 07537 & PRUNE & $\mathrm{A} 3, \mathrm{SE}$ & 60900 & CLASP2 & SE & 30106 & 1 & A5,RI \\
\hline TCONS_000 & & & TCONS_000 & & & TCONS_000 & MAN2C & \\
\hline 07538 & PRUNE & SE & 60908 & TRANK1 & SE & 31299 & 1 & RI \\
\hline $\begin{array}{l}\text { TCONS_000 } \\
\text { 02112 }\end{array}$ & CGN & RI & $\begin{array}{l}\text { TCONS_000 } \\
\text { 60910 }\end{array}$ & TRANK1 & SE & $\begin{array}{l}\text { TCONS_000 } \\
31300\end{array}$ & $\begin{array}{l}\text { MAN2C } \\
1\end{array}$ & A3 \\
\hline TCONS_000 & & & TCONS_000 & GORAS & & TCONS_000 & & \\
\hline 07548 & CGN & RI & 63608 & P1 & RI & 30120 & SNUPN & $\mathrm{O}$ \\
\hline $\begin{array}{l}\text { TCONS_000 } \\
02128\end{array}$ & OAZ3 & AF & $\begin{array}{l}\text { TCONS_000 } \\
60983\end{array}$ & ZNF445 & RI & $\begin{array}{l}\text { TCONS_000 } \\
31308\end{array}$ & NRG4 & SE \\
\hline TCONS_000 & AL4509 & & TCONS_000 & ZDHHC & & TCONS_000 & & \\
\hline 02131 & 92.2 & $\mathrm{O}$ & 63636 & 3 & SE & 30166 & PEAK1 & $\mathrm{O}$ \\
\hline TCONS_000 & & & TCONS_000 & & & TCONS_000 & & \\
\hline 02134 & SPRR1A & A3 & 63641 & LTF & O & 30167 & PEAK1 & $\mathrm{O}$ \\
\hline TCONS_000 & BX4701 & & TCONS_000 & & & TCONS_000 & & \\
\hline 02139 & 02.3 & $\mathrm{O}$ & 61029 & CCDC12 & $\mathrm{O}$ & 30168 & PEAK1 & MX \\
\hline $\begin{array}{l}\text { TCONS_000 } \\
02156\end{array}$ & NPR1 & RI $>$ & TCONS_000 & CCDC12 & & TCONS_000 & PFAK1 & O \\
\hline TCONS_000 & SLC27A & & TCONS_000 & & & TCONS_000 & & \\
\hline $075566^{-}$ & 3 & RI & $61043^{-}$ & SCAP & A3 & $31320^{-}$ & PEAK1 & $\mathrm{O}$ \\
\hline $\begin{array}{l}\text { TCONS_000 } \\
07558\end{array}$ & UBAP2L & RI & $\begin{array}{l}\text { TCONS_000 } \\
61056\end{array}$ & MAP4 & A3,SE & $\begin{array}{l}\text { TCONS_000 } \\
31321\end{array}$ & PEAK1 & $\mathrm{O}$ \\
\hline TCONS_000 & ||RAP2| & $\Delta 5$ Sᄃ & TCONS_000 & $M \triangle \mathrm{PA}$ & $\mathrm{A}^{2} \mathrm{SF}$ & TCONS_000 & CHRNA & 0 \\
\hline TCONS_000 & & & TCONS_000 & & & TCONS_000 & AC1039 & \\
\hline 02190 & ATP8B2 & $\mathrm{AF}$ & 61058 & MAP4 & $\mathrm{A} 3, \mathrm{~A} 5, \mathrm{SE}$ & 30261 & 65.1 & SE \\
\hline $\begin{array}{l}\text { TCONS_000 } \\
02204\end{array}$ & FLAD1 & RI,SE & $\begin{array}{l}\text { TCONS_000 } \\
61065\end{array}$ & CDC25A & $\mathrm{O}$ & $\begin{array}{l}\text { TCONS_000 } \\
30267\end{array}$ & $\begin{array}{l}\text { UBE2Q2 } \\
\text { P1 }\end{array}$ & $\begin{array}{l}\text { A5,MX,R } \\
\text { I,SE }\end{array}$ \\
\hline
\end{tabular}




\begin{tabular}{|c|c|c|c|c|c|c|c|c|}
\hline $\begin{array}{l}\text { TCONS_000 } \\
02205\end{array}$ & FLAD1 & RI & $\begin{array}{l}\text { TCONS_000 } \\
61091\end{array}$ & SHISA5 & A3 & $\begin{array}{l}\text { TCONS_000 } \\
30268\end{array}$ & $\begin{array}{l}\text { UBE2Q2 } \\
\text { P1 }\end{array}$ & $\begin{array}{l}\text { A5,RI,S } \\
\text { E }\end{array}$ \\
\hline TCONS_000 & SLC50A & & TCONS_000 & & & TCONS_000 & UBE2Q2 & A5,RI,S \\
\hline 02221 & 1 & $\mathrm{O}$ & 61104 & COL7A1 & RI & 30269 & P1 & \\
\hline $\begin{array}{l}\text { TCONS_000 } \\
02231\end{array}$ & MTX1P1 & $\mathrm{O}$ & $\begin{array}{l}\text { TCONS_000 } \\
61105\end{array}$ & COL7A1 & $\mathrm{O}$ & $\begin{array}{l}\text { TCONS_000 } \\
30282\end{array}$ & NMB & A3 \\
\hline TCONS_000 & & & TCONS_000 & UQCRC & & TCONS_000 & RP11-56 & \\
\hline $02232^{-}$ & HCN3 & RI & $63662-$ & 1 & A5 & $31356-$ & $1 C 5.4$ & A3,SE \\
\hline TCONS_000 & & & TCONS_000 & SLC26A & & TCONS_000 & & \\
\hline 07575 & FDPS & $\mathrm{O}$ & 61110 & 6 & $\mathrm{O}$ & 31361 & DET1 & RI \\
\hline $\begin{array}{l}\text { TCONS_000 } \\
02234\end{array}$ & RUSC1 & A3 & $\begin{array}{l}\text { TCONS_000 } \\
61111\end{array}$ & $\begin{array}{l}\text { SLC26A } \\
6\end{array}$ & A3 & $\begin{array}{l}\text { TCONS_000 } \\
30316\end{array}$ & POLG & 0 \\
\hline TCONS_000 & & & TCONS_000 & SLC26A & & TCONS_000 & & \\
\hline 02235 & RUSC1 & SE & 61112 & 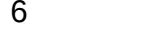 & A3,RI & 30317 & POLG & RI,SE \\
\hline TCONS_000 & & & TCONS_000 & SLC26A & & TCONS_000 & & \\
\hline 02236 & RUSC1 & SE & 63663 & 6 & RI & 31369 & PLIN1 & $\mathrm{O}$ \\
\hline $\begin{array}{l}\text { TCONS_000 } \\
02247\end{array}$ & MSTO1 & RI & $\begin{array}{l}\text { TCONS_000 } \\
61121\end{array}$ & IP6K2 & A3,A5,RI & $\begin{array}{l}\text { TCONS_000 } \\
31370\end{array}$ & PLIN1 & 0 \\
\hline TCONS 000 & & & TCONS 000 & SLC25A & & TCONS 000 & & \\
\hline 02248 & MSTO1 & A5 & 61133 & 20 & RI,SE & 31371 & PLIN1 & $\mathrm{O}$ \\
\hline TCONS_000 & & & TCONS_000 & SLC25A & & TCONS_000 & & \\
\hline 07581 & MSTO1 & $\mathrm{O}$ & 63668 & 20 & SE & 31372 & PLIN1 & $\mathrm{O}$ \\
\hline $\begin{array}{l}\text { TCONS_000 } \\
07585\end{array}$ & TSACC & A5 & $\begin{array}{l}\text { TCONS_000 } \\
63670\end{array}$ & DALRD3 & $A 3, R I$ & $\begin{array}{l}\text { TCONS_000 } \\
30325\end{array}$ & ANPEP & $\mathrm{O}$ \\
\hline $\begin{array}{l}\text { TCONS_000 } \\
02285\end{array}$ & TSACC & A3 & $\begin{array}{l}\text { TCONS_000 } \\
61139\end{array}$ & DALRD3 & RI & $\begin{array}{l}\text { TCONS_000 } \\
30327\end{array}$ & ANPEP & AF \\
\hline TCONS_000 & RRNAD & & TCONS_000 & & & TCONS_000 & & \\
\hline 02295 & 1 & A5,RI & 61140 & DALRD3 & A3 & 31378 & CIB1 & RI \\
\hline TCONS_000 & & & TCONS_000 & & & TCONS_000 & RP11-38 & \\
\hline 07589 & PEAR1 & $\mathrm{O}$ & 61146 & QRICH1 & RI & 30346 & 7D10.2 & 0 \\
\hline TCONS_000 & & & TCONS_000 & & & TCONS_000 & & \\
\hline 07590 & CD1D & $\mathrm{O}$ & 63675 & QRICH1 & RI,SE & 30351 & PRC1 & 0 \\
\hline $\begin{array}{l}\text { TCONS_000 } \\
02306\end{array}$ & CD1D & A5 & $\begin{array}{l}\text { TCONS_000 } \\
61155\end{array}$ & QARS & $\mathrm{O}$ & $\begin{array}{l}\text { TCONS_000 } \\
30352\end{array}$ & PRC1 & SE \\
\hline $\begin{array}{l}\text { TCONS_000 } \\
02307\end{array}$ & CD1D & RI & $\begin{array}{l}\text { TCONS_000 } \\
63679\end{array}$ & LAMB2 & RI & $\begin{array}{l}\text { TCONS_000 } \\
30356\end{array}$ & VPS33B & $A 3, R I$ \\
\hline $\begin{array}{l}\text { TCONS_000 } \\
02308\end{array}$ & CD1D & SE & $\begin{array}{l}\text { TCONS_000 } \\
63680\end{array}$ & LAMB2 & RI & $\begin{array}{l}\text { TCONS_000 } \\
31382\end{array}$ & VPS33B & A5 \\
\hline $\begin{array}{l}\text { TCONS_000 } \\
02310\end{array}$ & CD1C & O & $\begin{array}{l}\text { TCONS_000 } \\
63681\end{array}$ & LAMB2 & RI & $\begin{array}{l}\text { TCONS_000 } \\
30374\end{array}$ & $\begin{array}{l}\text { CTD-25 } \\
3611.1\end{array}$ & 0 \\
\hline
\end{tabular}




\begin{tabular}{|c|c|c|c|c|c|c|c|c|}
\hline $\begin{array}{l}\text { TCONS_000 } \\
\text { O2318 }\end{array}$ & IFI16 & SE & $\begin{array}{l}\text { TCONS_000 } \\
61164\end{array}$ & USP4 & SE & $\begin{array}{l}\text { TCONS_000 } \\
30375\end{array}$ & $\begin{array}{l}\text { CTD-25 } \\
3611.1\end{array}$ & $A L$ \\
\hline TCONS_000 & & & TCONS_000 & & & TCONS_000 & & \\
\hline 07591 & IFI16 & SE & 61165 & USP4 & 0 & 30399 & LYSMD4 & SE \\
\hline $\begin{array}{l}\text { TCONS_000 } \\
02340\end{array}$ & SLAMF8 & $\mathrm{O}$ & $\begin{array}{l}\text { TCONS_000 } \\
61178\end{array}$ & AMT & RI & $\begin{array}{l}\text { TCONS_000 } \\
30400\end{array}$ & LYSMD4 & SE \\
\hline TCONS_000 & RP11-52 & & TCONS_000 & & & TCONS_000 & & \\
\hline $07593^{-}$ & $8 G 1.2$ & SE & $63692^{-}$ & AMT & 0 & $31410^{-}$ & TARSL2 & SE \\
\hline $\begin{array}{l}\text { TCONS_000 } \\
07595\end{array}$ & KLHDC9 & $\mathrm{O}$ & $\begin{array}{l}\text { TCONS_000 } \\
\text { 61185 }\end{array}$ & NICN1 & $\mathrm{O}$ & $\begin{array}{l}\text { TCONS_000 } \\
31426\end{array}$ & ITFG3 & A3 \\
\hline TCONS_000 & & & TCONS_000 & & & TCONS_000 & & \\
\hline & UFCI & 0 & 61196 & UBA? & $\mathrm{RI}$ & 34204 & PDIA2 & A3 \\
\hline TCONS_000 & & & TCONS_000 & & & TCONS_000 & & \\
\hline 02378 & UFC1 & $\mathrm{O}$ & 61197 & UBA7 & RI & 31434 & DECR2 & 0 \\
\hline $\begin{array}{l}\text { TCONS_000 } \\
02379\end{array}$ & UFC1 & 0 & $\begin{array}{l}\text { TCONS_000 } \\
61198\end{array}$ & UBA7 & RISE & $\begin{array}{l}\text { TCONS_000 } \\
31439\end{array}$ & NMF4 & $\mathrm{AF}$ \\
\hline TCONS 000 & & & TCONS 000 & & & TCONS 000 & & \\
\hline 02380 & UFC1 & A5 & 63696 & UBA7 & RI & 31440 & DECR2 & 0 \\
\hline $\begin{array}{l}\text { TCONS_000 } \\
02384\end{array}$ & USP21 & $\mathrm{RI}, \mathrm{SE}$ & $\begin{array}{l}\text { TCONS_000 } \\
61202\end{array}$ & MST1R & 0 & $\begin{array}{l}\text { TCONS_000 } \\
31447\end{array}$ & CAPN15 & $\mathrm{AF}, \mathrm{SE}$ \\
\hline TCONS_000 & ISP21 & $\mathrm{A} 3 \mathrm{RI}$ & TCONS_000 & MST1R & RI SF & TCONS_000 & CAPN15 & $A F_{1}$ \\
\hline $\begin{array}{l}\text { TCONS_000 } \\
07597\end{array}$ & USP21 & 0 & $\begin{array}{l}\text { TCONS_000 } \\
61206\end{array}$ & MST1R & A3.RI & $\begin{array}{l}\text { TCONS_000 } \\
34222\end{array}$ & RAB40C & A5 \\
\hline $\begin{array}{l}\text { TCONS_000 } \\
02386\end{array}$ & PPOX & A3,RI & $\begin{array}{l}\text { TCONS_000 } \\
63698\end{array}$ & MON1A & 0 & $\begin{array}{l}\text { TCONS_000 } \\
31459\end{array}$ & WDR90 & A5, RI \\
\hline TCONS_000 & & & TCONS_000 & & & TCONS_000 & & \\
\hline 07598 & PPOX & RI,SE & 63699 & IFRD2 & $\mathrm{O}$ & 31460 & WDR90 & A5 \\
\hline TCONS_000 & TOMM4 & & TCONS_000 & & & TCONS_000 & & \\
\hline 07602 & $\mathrm{OL}$ & $\mathrm{O}$ & 63710 & PCBP4 & $A 3, M X$ & $34229^{-}$ & RHOT2 & A3 \\
\hline $\begin{array}{l}\text { TCONS_000 } \\
07605\end{array}$ & DUSP12 & A3 & $\begin{array}{l}\text { TCONS_000 } \\
61265\end{array}$ & DUSP7 & 0 & $\begin{array}{l}\text { TCONS_000 } \\
34230\end{array}$ & RHOT2 & $\mathrm{RI}$ \\
\hline $\begin{array}{l}\text { TCONS_000 } \\
02432\end{array}$ & $\begin{array}{l}\text { NOS1A } \\
\text { P }\end{array}$ & SE & $\begin{array}{l}\text { TCONS_000 } \\
61277\end{array}$ & BAP1 & RI & $\begin{array}{l}\text { TCONS_000 } \\
31468\end{array}$ & STUB1 & A3 \\
\hline TCONS_000 & HSD17B & & TCONS_000 & & & TCONS_000 & & \\
\hline 07612 & 7 & A3 & 63713 & BAP1 & $\mathrm{A} 3, \mathrm{RI}$ & 31472 & METRN & A3 \\
\hline TCONS_000 & HSD17B & & TCONS_000 & & & TCONS_000 & FAM173 & \\
\hline 02447 & 7 & A3 & 61290 & PBRM1 & 0 & 31477 & A & $\mathrm{O}$ \\
\hline $\begin{array}{l}\text { TCONS_000 } \\
02533\end{array}$ & GORAB & A5 & $\begin{array}{l}\text { TCONS_000 } \\
63715\end{array}$ & PBRM1 & SE & $\begin{array}{l}\text { TCONS_000 } \\
31481\end{array}$ & HAGHL & $\mathrm{O}$ \\
\hline
\end{tabular}




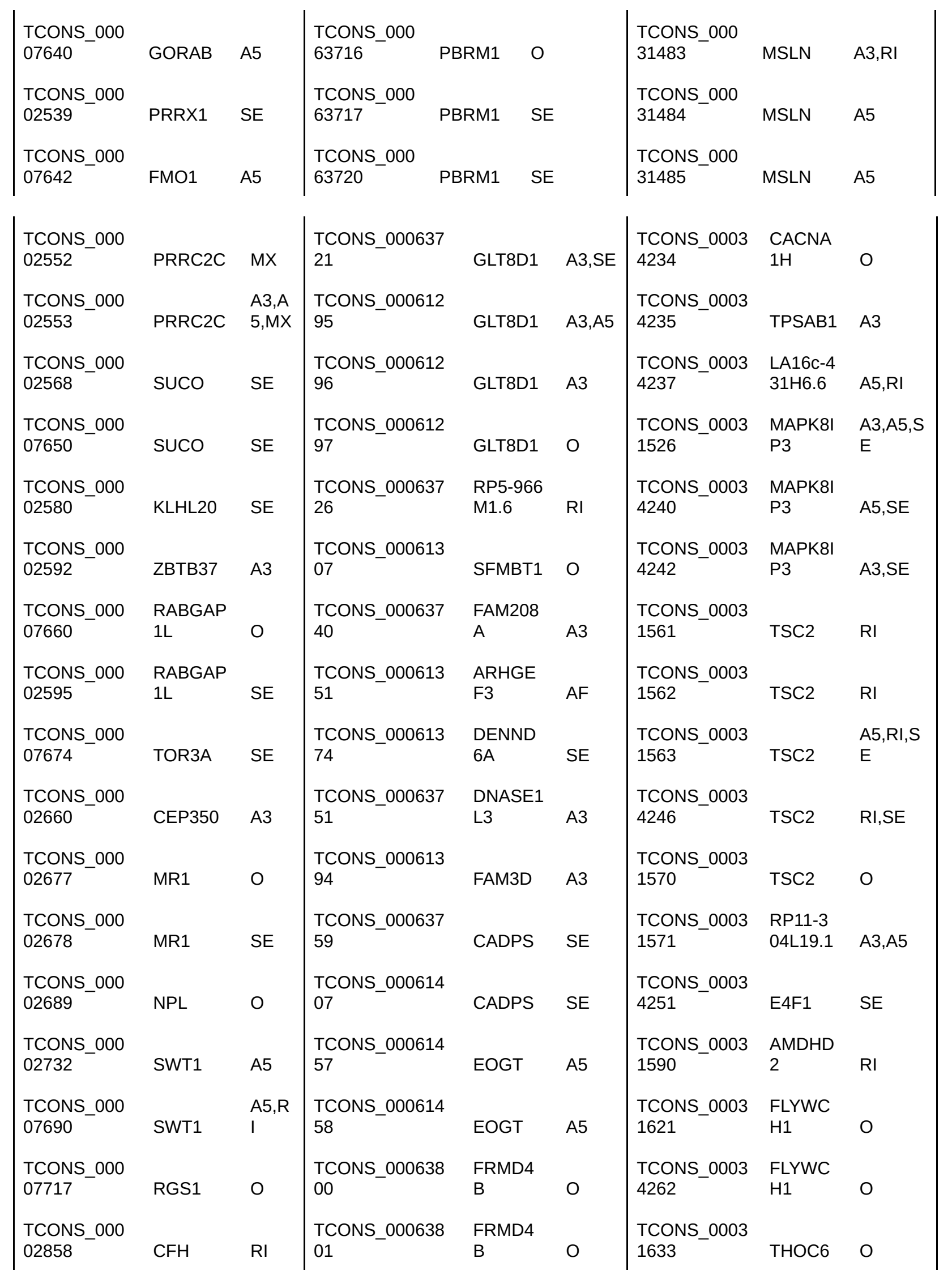




\begin{tabular}{|c|c|c|c|c|c|c|c|c|}
\hline TCONS_000 & RPS10P & & TCONS_000638 & & & TCONS_0003 & & \\
\hline 07746 & 7 & $\mathrm{O}$ & $12-$ & CNTN3 & RI & 1634 & THOC6 & A3 \\
\hline TCONS_000 & & & TCONS_000638 & & & TCONS_0003 & RP11-4 & \\
\hline 02902 & NAV1 & SE & 47 & STX19 & SE & 4265 & 73M20.5 & RI \\
\hline TCONS_0000 & & & TCONS_00061 & TOMM7 & & TCONS_000 & & \\
\hline 2917 & ELF3 & $\mathrm{O}$ & 589 & $\mathrm{OA}$ & $\mathrm{O}$ & 31638 & IL32 & AL,SE \\
\hline TCONS_0000 & & & TCONS_00063 & & & TCONS_000 & & \\
\hline 7751 & ELF3 & $\mathrm{O}$ & 854 & ABI3BP & $\mathrm{O}$ & 31639 & IL32 & AL \\
\hline TCONS_0000 & & & TCONS_00063 & & & TCONS_000 & & \\
\hline 1102 & CLFJ & 0 & 856 & ADIODF & SE & 31600 & $\angle I N T \angle U 5$ & 0 \\
\hline TCONS_0000 & PPP1R1 & & TCONS_00061 & & & TCONS_000 & & \\
\hline 2929 & $2 \mathrm{~B}$ & $\mathrm{O}$ & 703 & ATG3 & $\mathrm{O}$ & 31666 & ZNF263 & $\mathrm{O}$ \\
\hline TCONS_0000 & PPP1R1 & & TCONS_00063 & & & TCONS_000 & & \\
\hline 2934 & 2B & $\mathrm{O}$ & 883 & C3orf17 & $\mathrm{RI}$ & 34266 & ZNF263 & $\mathrm{O}$ \\
\hline TCONS_0000 & ZC3H11 & $\mathrm{RI}, \mathrm{S}$ & TCONS_00063 & & & TCONS_000 & & \\
\hline 2956 & A & $\mathrm{E}$ & 885 & WDR52 & A5 & 34267 & ZNF263 & $\mathrm{O}$ \\
\hline TCONS_0000 & ZC3H11 & & TCONS_00063 & & & TCONS_000 & & \\
\hline 2958 & A & $\mathrm{RI}$ & 886 & WDR52 & $\mathrm{O}$ & 31672 & ZNF75A & SE \\
\hline TCONS_0000 & & & TCONS_00063 & KIAA140 & & TCONS_000 & & \\
\hline 2981 & NFASC & $M X$ & 893 & 7 & RI,SE & 31673 & ZNF75A & A3 \\
\hline $\begin{array}{l}\text { TCONS_0000 } \\
3024\end{array}$ & IKBKE & $\mathrm{O}$ & $\begin{array}{l}\text { TCONS_00061 } \\
744\end{array}$ & ZBTB20 & SE & $\begin{array}{l}\text { TCONS_000 } \\
31678\end{array}$ & DNASE1 & RI,SE \\
\hline TCONS_0000 & & & TCONS_00061 & B4GALT & $c 5$ & TCONS_000 & & A5,RI,S \\
\hline 3025 & IKBKE & $\mathrm{RI}$ & $7 / 6$ & 4 & SE & 31680 & DNASE1 & \\
\hline $\begin{array}{l}\text { TCONS_0000 } \\
3026\end{array}$ & IKBKE & RI & $\begin{array}{l}\text { TCONS_00061 } \\
828\end{array}$ & HCLS1 & RI & $\begin{array}{l}\text { TCONS_000 } \\
31683\end{array}$ & GLIS2 & $\mathrm{O}$ \\
\hline TCONS_0000 & & & TCONS_00063 & GOLGB & & TCONS_000 & & \\
\hline 3046 & C4BPB & A3 & 921 & 1 & SE & 31690 & MGRN1 & A3,SE \\
\hline TCONS_0000 & & $A 3, A$ & TCONS_00061 & GOLGB & & TCONS_000 & & \\
\hline 3048 & C4BPB & 5 & 832 & 1 & A5,SE & 31699 & SMIM22 & A5 \\
\hline $\begin{array}{l}\text { TCONS_0000 } \\
3053\end{array}$ & C4BPA & A3 & $\begin{array}{l}\text { TCONS_00061 } \\
835\end{array}$ & $\begin{array}{l}\text { GOLGB } \\
1\end{array}$ & A5 & $\begin{array}{l}\text { TCONS_000 } \\
31700\end{array}$ & SMIM22 & $\mathrm{O}$ \\
\hline TCONS_0000 & & & TCONS_00063 & & & TCONS_000 & & \\
\hline 3073 & CR1 & $\mathrm{O}$ & 930 & CCDC58 & A5 & 31701 & UBN1 & A5 \\
\hline $\begin{array}{l}\text { TCONS_0000 } \\
7798\end{array}$ & CDA6 & O & TCONS_00061 & קסקטמי & $\mathrm{C}_{\mathrm{s}}$ & TCONS_000 & METTL2 & Pl \\
\hline TCONS_0000 & & & TCONS_00061 & & & TCONS_000 & & \\
\hline 7801 & DIEXF & RI & & PARP9 & A5,AF & 31718 & PMM2 & $\mathrm{O}$ \\
\hline TCONS_0000 & SPATA1 & & TCONS_00063 & & & TCONS_000 & C16orf7 & \\
\hline 3189 & 7 & A3 & 936 & MYLK & SE & 31725 & 2 & $\mathrm{O}$ \\
\hline
\end{tabular}




\begin{tabular}{|c|c|c|c|c|c|c|c|c|}
\hline TCONS_0000 & RP11-40 & & TCONS_00063 & & & TCONS_000 & & \\
\hline 3238 & 0N13.2 & $\mathrm{O}$ & 938 & MYLK & SE & 34303 & ATF7IP2 & $\mathrm{O}$ \\
\hline TCONS_0000 & & & TCONS_00061 & & & TCONS_000 & & \\
\hline 3251 & BROX & SE & 893 & ITGB5 & $A F$ & 31746 & NUBP1 & 0 \\
\hline TCONS_0000 & RROX & 0 & TCONS_00061 & ITGR5 & O & TCONS_000 & CITA & $\hat{n}^{2}$ \\
\hline & Eren & & & (1) & r & G1rus & & מu \\
\hline TCONS_0000 & & & TCONS_00061 & & & TCONS_000 & CLEC16 & \\
\hline 3250 & BROX & A5 & $899-$ & HEG1 & SE & 31754 & A & SE \\
\hline TCONS_0000 & & & TCONS_00061 & & & TCONS_000 & RP11-95 & \\
\hline 3276 & CAPN2 & $\mathrm{RI}$ & $941-$ & ZXDC & $\mathrm{O}$ & 34326 & 8N24.1 & $\mathrm{RI}$ \\
\hline TCONS_0000 & RP11-50 & & TCONS_00061 & & & TCONS_000 & RP11-95 & \\
\hline $7853^{-}$ & 4P24.4 & $\mathrm{O}$ & $953-$ & MGLL & SE & $31790^{-}$ & 8N24.1 & RI \\
\hline $\begin{array}{l}\text { TCONS_0000 } \\
3310\end{array}$ & EPHX1 & AF & $\begin{array}{l}\text { TCONS_00063 } \\
966\end{array}$ & GATA2 & AF & $\begin{array}{l}\text { TCONS_000 } \\
31810\end{array}$ & NDE1 & $\mathrm{A} 5, \mathrm{AL}$ \\
\hline TCONS_0000 & & & TCONS_00062 & EFCAB1 & & TCONS_000 & & \\
\hline 7868 & C1orf95 & SE & 004 & 2 & $\mathrm{O}$ & 31813 & NDE1 & AL \\
\hline TCONS_0000 & & $A F, S$ & TCONS_00062 & EFCAB1 & & TCONS_000 & & \\
\hline 3319 & PSEN2 & $\mathrm{E}$ & 005 & 2 & $\mathrm{O}$ & 31814 & NDE1 & AL \\
\hline TCONS_0000 & & & TCONS_00063 & & & TCONS_000 & & \\
\hline 3323 & ADCK3 & $\mathrm{RI}$ & $976-$ & MBD4 & A3 & 31823 & NOMO3 & A3 \\
\hline TCONS_0000 & & & TCONS_00063 & & & TCONS_000 & & A5,RI,S \\
\hline 7871 & SNAP47 & AL & 977 & MBD4 & A3 & 34337 & PKD1P1 & $\mathrm{E}$ \\
\hline $\begin{array}{l}\text { TCONS_0000 } \\
7884\end{array}$ & GNPAT & $\mathrm{RI}$ & $\begin{array}{l}\text { TCONS_00063 } \\
981\end{array}$ & PLXND1 & A5,RI & $\begin{array}{l}\text { TCONS_000 } \\
31827\end{array}$ & PKD1P1 & $\begin{array}{l}\text { A5,RI,S } \\
E\end{array}$ \\
\hline TCONS_0000 & SLC35F & & TCONS_00063 & & & TCONS_000 & & $A 5, R I, S$ \\
\hline 3448 & 3 & 0 & 982 & TMCC1 & 0 & 31828 & PKD1P1 & $\mathrm{E}$ \\
\hline TCONS_0000 & & & TCONS_00062 & & & TCONS_000 & $\mathrm{ABCC} 6 \mathrm{P}$ & \\
\hline 3465 & TBCE & SE & $014-$ & TMCC1 & $\mathrm{O}$ & 34341 & 1 & SE \\
\hline TCONS_0000 & & $A 3, R$ & TCONS_00062 & RP11-93 & & TCONS_000 & & \\
\hline 7896 & TBCE & 1 & 019 & $\mathrm{~K} 22.13$ & SE & 34344 & ССР110 & $\mathrm{O}$ \\
\hline TCONS_0000 & & & TCONS_00062 & & & TCONS_000 & & \\
\hline 7910 & RYR2 & SE & 025 & ASTE1 & A5,SE & 31869 & IQCK & A3 \\
\hline $\begin{array}{l}\text { TCONS_0000 } \\
3497\end{array}$ & CHRM3 & AL & $\begin{array}{l}\text { TCONS_00063 } \\
988\end{array}$ & NPHP3 & RI,SE & $\begin{array}{l}\text { TCONS_000 } \\
34347\end{array}$ & IQCK & $\mathrm{O}$ \\
\hline TCONS_0000 & & & TCONS_00062 & & $A 3, R I, S$ & TCONS_000 & CTD-254 & \\
\hline 3500 & EXO1 & A3 & 037 & NPHP3 & $\mathrm{E}$ & 31903 & 7E10.3 & $\mathrm{O}$ \\
\hline TCONS_0000 & & & TCONS_00062 & & & TCONS_000 & SNX29P & \\
\hline 3507 & ZBTB18 & AF & & TOPBP1 & A3 & 31905 & 1 & $\mathrm{O}$ \\
\hline $\begin{array}{l}\text { TCONS_0000 } \\
3512\end{array}$ & COX20 & SE & $\begin{array}{l}\text { TCONS_00063 } \\
995\end{array}$ & TOPBP1 & A3 & $\begin{array}{l}\text { TCONS_000 } \\
31907\end{array}$ & METTL9 & $\mathrm{O}$ \\
\hline
\end{tabular}




\begin{tabular}{|c|c|c|c|c|c|c|c|c|}
\hline \multicolumn{3}{|l|}{ TCONS_000 } & TCONS_0006 & \multicolumn{2}{|l|}{ TOPBP } & \multicolumn{3}{|l|}{ TCONS_0003 } \\
\hline 07916 & $\operatorname{cox} 20$ & $\mathrm{O}$ & 3996 & 1 & A3 & 1908 & METTL9 & A3 \\
\hline TCONS_000 & EFCAB & & TCONS_0006 & TOPBP & & TCONS_0003 & & \\
\hline 07917 & 2 & $\mathrm{O}$ & 2049 & 1 & $\mathrm{RI}$ & 1922 & EEF2K & 0 \\
\hline TCONS_000 & & & TCONS_0006 & & & TCONS_0003 & & \\
\hline 07931 & NLRP3 & A3 & 2055 & RYK & A3,SE & 1970 & RBBP6 & $\mathrm{O}$ \\
\hline TCONS_000 & WASH7 & & TCONS_0006 & & & TCONS_0003 & & \\
\hline 03549 & $\mathrm{P}$ & A3,A5 & 2087 & A4GNT & AL & 1973 & RBBP6 & $\mathrm{O}$ \\
\hline TCONS_000 & WASH7 & & TCONS_0006 & & & TCONS_0003 & TNRC6 & \\
\hline 03550 & $\mathrm{P}$ & A5,RI & 2145 & PLOD2 & $\mathrm{O}$ & 1976 & A & SE \\
\hline TCONS_000 & WASH7 & & TCONS_0006 & & & TCONS_0003 & & \\
\hline 07935 & $\mathrm{P}$ & A5,RI & 4032 & PLOD2 & SE & 4380 & LCMT1 & $\mathrm{O}$ \\
\hline TCONS_000 & WASH7 & A3,A5, & TCONS_0006 & & & TCONS_0003 & & \\
\hline 07936 & $\mathrm{P}$ & RI & 4033 & PLOD2 & 0 & 4382 & AQP8 & $\mathrm{O}$ \\
\hline TCONS_000 & RP11-3 & & TCONS_0006 & & & TCONS_0003 & KIAA05 & \\
\hline 03558 & 4P13.13 & $\mathrm{O}$ & 4034 & PLOD2 & SE & 2003 & 56 & SE \\
\hline TCONS_000 & RP11-3 & & TCONS_0006 & & & TCONS_0003 & NFATC2 & \\
\hline 07938 & 4P13.13 & $\mathrm{RI}$ & 2183 & $\mathrm{CP}$ & $\mathrm{O}$ & 2031 & IP & $\mathrm{RI}$ \\
\hline TCONS_000 & RP11-3 & & TCONS_0006 & TM4SF1 & & TCONS_0003 & RP11-2 & \\
\hline 07939 & 4P13.13 & A5 & 2189 & 8 & $\mathrm{O}$ & 2036 & 64B17.3 & 0 \\
\hline TCONS_000 & RP11-2 & & TCONS_0006 & & & TCONS_0003 & СТВ-13 & \\
\hline 07944 & 06L10.2 & $\mathrm{O}$ & 4050 & IGSF10 & $\mathrm{O}$ & 2037 & $4 \mathrm{H} 23.2$ & 0 \\
\hline TCONS_000 & RP11-2 & & TCONS_0006 & & & TCONS_0003 & CTB-13 & \\
\hline 07945 & 06L10.2 & A5 & 2310 & CCNL1 & SE & 2038 & $4 \mathrm{H} 23.2$ & 0 \\
\hline TCONS_000 & RP11-2 & & TCONS_0006 & & & TCONS_0003 & RRN3P & \\
\hline 07946 & 06L10.2 & $\mathrm{O}$ & 4068 & CCNL1 & $\mathrm{O}$ & 2039 & 2 & $\mathrm{~A} 3, \mathrm{SE}$ \\
\hline TCONS_000 & RP11-2 & & TCONS_0006 & & & TCONS_0003 & & \\
\hline 07947 & 06L10.2 & $\mathrm{O}$ & 2340 & IFT80 & SE & 4408 & KIF22 & $\mathrm{RI}$ \\
\hline TCONS_000 & & & TCONS_0006 & & & TCONS_0003 & & \\
\hline 07948 & NOC2L & A5,SE & 2341 & IFT80 & RI,SE & 4410 & MAZ & SE \\
\hline TCONS_000 & & & TCONS_0006 & & & TCONS_0003 & & \\
\hline 03571 & HES4 & $\mathrm{RI}$ & 4076 & IFT80 & $\mathrm{RI}$ & 4411 & MAZ & $\mathrm{O}$ \\
\hline TCONS_000 & & & TCONS_0006 & & & TCONS_0003 & & \\
\hline 03601 & CPSF3L & RI & 4079 & KPNA4 & $\mathrm{RI}$ & 2054 & MAZ & SE \\
\hline TCONS_000 & & & TCONS_0006 & & & TCONS_0003 & & \\
\hline 07959 & CPSF3L & RI & 2418 & PLD1 & A5,SE & 4413 & MVP & A5 \\
\hline
\end{tabular}




\begin{tabular}{|c|c|c|c|c|c|c|c|c|}
\hline \multicolumn{3}{|l|}{ TCONS_000 } & TCONS_0006 & \multicolumn{2}{|l|}{ TBL1XR } & TCONS_0003 & \multicolumn{2}{|l|}{ ASPHD } \\
\hline 03605 & DVL1 & $A 5, R I$ & 2438 & 1 & $\mathrm{O}$ & 2062 & 1 & $\mathrm{O}$ \\
\hline TCONS_000 & & & TCONS_0006 & TBL1XR & & TCONS_0003 & & \\
\hline 03606 & DVL1 & $\mathrm{RI}$ & 2439 & 1 & $\mathrm{O}$ & 4418 & TAOK2 & $\mathrm{RI}$ \\
\hline TCONS_000 & & & TCONS_0006 & & & TCONS_0003 & & \\
\hline $03620^{-}$ & CCNL2 & $\mathrm{O}$ & $4111-$ & ZMAT3 & SE & 4421 & INO80E & A3 \\
\hline TCONS_000 & & & TCONS_0006 & & & TCONS_0003 & & A3,A5,RI \\
\hline $07969^{-}$ & CDK11B & A3 & 2504 & ABCC5 & $\mathrm{O}$ & 2072 & INO80E & ,SE \\
\hline TCONS_000 & & & TCONS_0006 & & & TCONS_0003 & & \\
\hline 03644 & CDK11B & A3 & 4134 & ALG3 & A5 & 2073 & INO80E & $A 3, R I$ \\
\hline TCONS_000 & RP1-28 & & TCONS_0006 & TBCCD & & TCONS_0003 & & \\
\hline 07972 & $3 \mathrm{E} 3.8$ & $\mathrm{O}$ & 2551 & 1 & $\mathrm{AF}$ & 4424 & ALDOA & RI,SE \\
\hline TCONS_000 & & & TCONS_0006 & LEPREL & & TCONS_0003 & & \\
\hline 07976 & NADK & $\mathrm{AF}$ & 2573 & 1 & $\mathrm{O}$ & 2078 & ALDOA & A5,SE \\
\hline TCONS_000 & TMEM5 & & TCONS_0006 & ATP13A & & TCONS_0003 & & \\
\hline 07980 & 2 & $\mathrm{O}$ & 2596 & 3 & SE & 2079 & ALDOA & A5,RI,SE \\
\hline TCONS_000 & & & TCONS_0006 & & & TCONS_0003 & & \\
\hline 07986 & PANK4 & $\mathrm{A} 3$ & 2605 & LSG1 & $\mathrm{RI}$ & 2090 & PPP4C & A5 \\
\hline TCONS_000 & RP3-39 & & TCONS_0006 & & & TCONS_0003 & SULT1A & \\
\hline 03676 & $5 \mathrm{M} 20.8$ & $\mathrm{O}$ & 2622 & MUC4 & SE & 4428 & 3 & SE \\
\hline TCONS_000 & TP73-A & & TCONS_0006 & & & TCONS_0003 & & \\
\hline $03686^{-}$ & S1 & $\mathrm{O}$ & 2627 & TNK2 & A3 & 2108 & PRR14 & AF \\
\hline TCONS_000 & TP73-A & & TCONS_0006 & & & TCONS_0003 & & \\
\hline $07993^{-}$ & S1 & SE & 2628 & TNK2 & $\mathrm{AF}$ & 4433 & PRR14 & $\mathrm{O}$ \\
\hline TCONS_000 & TP73-A & & TCONS_0006 & & & TCONS_0003 & & \\
\hline $07994^{-}$ & S1 & A3 & 4168 & TNK2 & $\mathrm{A} 3, \mathrm{~A} 5$ & 4438 & SRCAP & AF,SE \\
\hline TCONS_000 & & & TCONS_0006 & SDHAP & & TCONS_0003 & & \\
\hline $03706^{-}$ & GPR153 & $\mathrm{O}$ & 4174 & 1 & $\mathrm{O}$ & 2121 & RNF40 & $\mathrm{O}$ \\
\hline TCONS_000 & TNFRS & & TCONS_0006 & SDHAP & & TCONS_0003 & & \\
\hline $03710^{-}$ & F25 & $\mathrm{O}$ & 4176 & 1 & SE & 2125 & FBXL19 & $\mathrm{O}$ \\
\hline TCONS_000 & PLEKH & & TCONS_0006 & TM4SF1 & & TCONS_0003 & & \\
\hline $03711^{-}$ & G5 & $\mathrm{O}$ & 2653 & 9 & A5 & 2126 & FBXL19 & $\mathrm{O}$ \\
\hline TCONS_000 & PLEKH & & TCONS_0006 & & & TCONS_0003 & & \\
\hline $03712^{-}$ & G5 & $\mathrm{RI}$ & 2664 & WDR53 & $\mathrm{O}$ & 4446 & SETD1A & $\mathrm{AF}$ \\
\hline TCONS_000 & & & TCONS_0006 & & & TCONS_0003 & & \\
\hline $08004^{-}$ & KLHL21 & 0 & 2665 & WDR53 & A5 & 4447 & HSD3B7 & A3,SE \\
\hline
\end{tabular}




\begin{tabular}{|c|c|c|c|c|c|c|c|c|}
\hline \multirow{2}{*}{$\begin{array}{l}\text { TCONS_000 } \\
03751\end{array}$} & \multicolumn{2}{|l|}{ RP11-5 } & \multicolumn{3}{|l|}{ TCONS_0006 } & \multicolumn{3}{|l|}{ TCONS_0003 } \\
\hline & 58F24.4 & $\mathrm{O}$ & 2666 & WDR53 & $A 5, A F$ & 4448 & STX4 & A3,A5 \\
\hline TCONS_000 & & & TCONS_0006 & & & TCONS_0003 & & \\
\hline 03752 & CLSTN1 & SE & 4190 & DLG1 & AF,SE & 2135 & ZNF646 & 0 \\
\hline TCONS_000 & EXOSC & & TCONS_0006 & & $\mathrm{A} 5, \mathrm{MX}$ & TCONS_0003 & & \\
\hline 03768 & 10 & $\mathrm{O}$ & 4191 & DLG1 & SE & 4455 & ITGAX & $\mathrm{O}$ \\
\hline TCONS_000 & & & TCONS_0006 & KIAA02 & & TCONS_0003 & & \\
\hline 08020 & MTOR & SE & 4194 & 26 & SE & 4463 & GPT2 & $\mathrm{O}$ \\
\hline TCONS_000 & & & TCONS_0006 & & & TCONS_0003 & & \\
\hline 03785 & DHRS3 & $\mathrm{O}$ & 4233 & MYL5 & A3 & 2202 & GPT2 & $\mathrm{O}$ \\
\hline TCONS_000 & TMEM5 & & TCONS_0006 & & & TCONS_0003 & & \\
\hline 03789 & 1-AS1 & $\mathrm{O}$ & 4236 & PCGF3 & $\mathrm{A} 3, \mathrm{RI}$ & 2206 & PHKB & $\mathrm{A} 3, \mathrm{MX}$ \\
\hline TCONS_000 & & & TCONS_0006 & & & TCONS_0003 & & \\
\hline 03793 & AGMAT & $\mathrm{O}$ & 4237 & PCGF3 & $\mathrm{RI}$ & 2230 & ADCY7 & $\mathrm{AF}$ \\
\hline TCONS_000 & & & TCONS_0006 & & & TCONS_0003 & & \\
\hline 03799 & ZBTB17 & $A 3, R I$ & 7199 & PCGF3 & $\mathrm{RI}$ & 2233 & ADCY7 & $\mathrm{RI}$ \\
\hline TCONS_000 & ARHGE & & TCONS_0006 & & & TCONS_0003 & & \\
\hline 08038 & F19 & $\mathrm{O}$ & 7200 & PCGF3 & $\mathrm{RI}, \mathrm{SE}$ & 2241 & NOD2 & $\mathrm{AF}$ \\
\hline TCONS_000 & CROCC & & TCONS_0006 & & & TCONS_0003 & & \\
\hline 08042 & P3 & SE & 4247 & IDUA & RI & 4480 & CYLD & AF,SE \\
\hline TCONS_000 & & & TCONS_0006 & & & TCONS_0003 & RP11-2 & \\
\hline 03824 & NBPF1 & A3 & 7206 & FGFRL1 & SE & 2252 & 97L17.2 & $\mathrm{AF}$ \\
\hline TCONS_000 & & & TCONS_0006 & & & TCONS_0003 & & \\
\hline 08043 & NBPF1 & $A 3, R I$ & 4248 & FGFRL1 & $\mathrm{O}$ & 2254 & CHD9 & A5 \\
\hline TCONS_000 & & & TCONS_0006 & & & TCONS_0003 & & \\
\hline 08044 & NBPF1 & $A 3, R I$ & 7221 & FGFR3 & $\mathrm{RI}$ & 2255 & CHD9 & A3,A5 \\
\hline TCONS_000 & & & TCONS_0006 & & & TCONS_0003 & & \\
\hline 08045 & NBPF1 & $A 3, R I$ & 7222 & FGFR3 & $\mathrm{RI}, \mathrm{SE}$ & 4486 & RBL2 & A5,RI \\
\hline TCONS_000 & & & TCONS_0006 & & & TCONS_0003 & & \\
\hline 08046 & NBPF1 & $A 3, R I$ & 4267 & FGFR3 & $\mathrm{O}$ & 2279 & LPCAT2 & $\mathrm{O}$ \\
\hline TCONS_000 & CROCC & & TCONS_0006 & & & TCONS_0003 & & \\
\hline 03827 & P2 & $\mathrm{O}$ & 4269 & FGFR3 & A3 & 2308 & NUP93 & RI,SE \\
\hline TCONS_000 & CROCC & & TCONS_0006 & & & TCONS_0003 & & \\
\hline 08047 & P2 & $\mathrm{O}$ & 4270 & FGFR3 & A3 & 2327 & NLRC5 & A3,A5 \\
\hline TCONS_000 & & & TCONS_0006 & & & TCONS_0003 & & \\
\hline 03836 & MFAP2 & AF & 7223 & FGFR3 & A5 & 2342 & ARL2BP & $\mathrm{O}$ \\
\hline
\end{tabular}




\begin{tabular}{|c|c|c|c|c|c|c|c|c|}
\hline TCONS_000 & ATP13A & & TCONS_0006 & & & TCONS_0003 & & \\
\hline 03842 & 2 & A3,A5 & 7226 & WHSC1 & SE & 2361 & GPR56 & 0 \\
\hline TCONS_000 & & & TCONS_0006 & & & TCONS_0003 & & \\
\hline 08070 & TMCO4 & $\mathrm{O}$ & 4310 & RGS12 & $\mathrm{AF}$ & 2362 & GPR56 & RI \\
\hline TCONS_000 & PLA2G2 & & TCONS_0006 & KIAA02 & & TCONS_0003 & & \\
\hline 03879 & A & 0 & 4349 & 32 & SE & 4507 & GPR56 & $\mathrm{O}$ \\
\hline TCONS_000 & CAMK2 & & TCONS_0006 & & & TCONS_0003 & & \\
\hline 03886 & $\mathrm{~N} 1$ & $\mathrm{O}$ & 4363 & SH3TC1 & $\mathrm{A} 3, \mathrm{RI}$ & 4508 & GPR56 & $A F, R I$ \\
\hline TCONS_000 & CAMK2 & & TCONS_0006 & CC2D2 & & TCONS_0003 & CTD-26 & \\
\hline 03887 & N1 & $\mathrm{O}$ & 4507 & A & SE & 4512 & 0009.1 & AL \\
\hline TCONS_000 & & & TCONS_0006 & & & TCONS_0003 & & \\
\hline 03890 & DDOST & $\mathrm{O}$ & 4540 & SLIT2 & SE & 4517 & SETD6 & $\mathrm{O}$ \\
\hline TCONS_000 & & & TCONS_0006 & PACRG & & TCONS_0003 & & \\
\hline 03897 & HP1BP3 & $\mathrm{AF}$ & 7314 & L & $A 3, A F$ & 4518 & SETD6 & $\mathrm{RI}$ \\
\hline TCONS_000 & & & TCONS_0006 & & & TCONS_0003 & & \\
\hline 03898 & HP1BP3 & $\mathrm{O}$ & 7320 & SOD3 & $\mathrm{O}$ & 2387 & SETD6 & $\mathrm{O}$ \\
\hline TCONS_000 & & & TCONS_0006 & ANAPC & & TCONS_0003 & & \\
\hline 03896 & HP1BP3 & A5 & 4558 & 4 & $\mathrm{RI}$ & 2388 & SETD6 & $\mathrm{RI}$ \\
\hline TCONS_000 & NBPF2 & & TCONS_0006 & ANAPC & & TCONS_0003 & & \\
\hline 03914 & $\mathrm{P}$ & $\mathrm{O}$ & 7326 & 4 & RI & 2392 & BEAN1 & 0 \\
\hline TCONS_000 & NBPF2 & & TCONS_0006 & FAM114 & & TCONS_0003 & & \\
\hline 08080 & $\mathrm{P}$ & $\mathrm{O}$ & 4624 & A1 & SE & 2396 & СMTM1 & 0 \\
\hline TCONS_000 & RAP1G & & TCONS_0006 & & & TCONS_0003 & & \\
\hline 08084 & AP & SE & 4640 & WDR19 & $\mathrm{RI}, \mathrm{SE}$ & 2401 & СMTM3 & A5 \\
\hline TCONS_000 & RAP1G & $A 3, R I$, & TCONS_0006 & & & TCONS_0003 & & \\
\hline 03915 & $\mathrm{AP}$ & SE & 4641 & WDR19 & $\mathrm{RI}$ & 2402 & СмTMЗ & A5 \\
\hline TCONS_000 & & & TCONS_0006 & & & TCONS_0003 & & \\
\hline 03919 & USP48 & $\mathrm{RI}$ & 4646 & LIAS & SE & 2404 & СMTM3 & A5 \\
\hline TCONS_000 & & & TCONS_0006 & & & TCONS_0003 & C16orf7 & \\
\hline 08087 & HSPG2 & $\mathrm{O}$ & 4647 & LIAS & SE & 2429 & 0 & A5 \\
\hline TCONS_000 & & & TCONS_0006 & UGDH- & & TCONS_0003 & C16orf7 & \\
\hline 08088 & HSPG2 & SE & 7356 & AS1 & $\mathrm{O}$ & 2430 & 0 & A3 \\
\hline TCONS_000 & & & TCONS_0006 & & & TCONS_0003 & & \\
\hline 03930 & LUZP1 & $\mathrm{AF}$ & 7359 & N4BP2 & SE & 4525 & HSF4 & $A 3, R I$ \\
\hline TCONS_000 & & & TCONS_0006 & & & TCONS_0003 & & \\
\hline 03946 & ZNF436 & SE & 7367 & LIMCH1 & SE & 4526 & HSF4 & $A 3, R I$ \\
\hline
\end{tabular}




\begin{tabular}{|c|c|c|c|c|c|c|c|c|}
\hline \multicolumn{3}{|l|}{ TCONS_000 } & \multicolumn{3}{|l|}{ TCONS_0006 } & \multicolumn{3}{|l|}{ TCONS_0003 } \\
\hline 03950 & TCEA3 & SE & 4702 & GUF1 & SE & 4527 & HSF4 & $A 3, R I$ \\
\hline TCONS_000 & & & TCONS_0006 & & & TCONS_0003 & & \\
\hline 08099 & ASAP3 & $A 5, R I$ & 4703 & GUF1 & $\mathrm{O}$ & 2444 & ELMO3 & $\mathrm{O}$ \\
\hline TCONS_000 & RP5-88 & & TCONS_0006 & & & TCONS_0003 & & \\
\hline 08100 & $6 K 2.3$ & A5 & 7374 & GUF1 & $\mathrm{O}$ & 4531 & ELMO3 & A5,RI \\
\hline TCONS_000 & & & TCONS_0006 & & & TCONS_0003 & HSD11B & \\
\hline 03962 & GALE & SE & 7375 & GUF1 & SE & 2451 & 2 & $\mathrm{AF}$ \\
\hline TCONS_000 & & & TCONS_0006 & & & TCONS_0003 & & \\
\hline 08101 & GALE & A3 & 7376 & GUF1 & A5 & 4539 & CTCF & A3 \\
\hline TCONS_000 & & & TCONS_0006 & & & TCONS_0003 & & \\
\hline 04017 & PAQR7 & $\mathrm{O}$ & 7377 & GUF1 & SE & 4550 & SLC7A6 & A5,SE \\
\hline TCONS_000 & & & TCONS_0006 & & & TCONS_0003 & & \\
\hline 08109 & PAFAH2 & A5 & 7378 & GUF1 & A3 & 4552 & PRMT7 & $\mathrm{O}$ \\
\hline TCONS_000 & & & TCONS_0006 & & & TCONS_0003 & & \\
\hline 04024 & PAFAH2 & SE & 4757 & FIP1L1 & SE & 2493 & PRMT7 & AF \\
\hline TCONS_000 & & & TCONS_0006 & & & TCONS_0003 & & \\
\hline 04028 & AIM1L & $\mathrm{O}$ & 4782 & EXOC1 & SE & 2494 & PRMT7 & SE \\
\hline TCONS_000 & & & TCONS_0006 & & & TCONS_0003 & & \\
\hline $04029^{-}$ & AIM1L & $\mathrm{O}$ & 4787 & CEP135 & $\mathrm{RI}$ & 2495 & PRMT7 & AF \\
\hline TCONS_000 & GPATC & & TCONS_0006 & KIAA12 & & TCONS_0003 & & \\
\hline 08119 & $\mathrm{H} 3$ & $\mathrm{O}$ & 4791 & 11 & AF,SE & 2497 & ZFP90 & A3 \\
\hline TCONS_000 & & & TCONS_0006 & KIAA12 & & TCONS_0003 & & \\
\hline 08121 & SLC9A1 & 0 & 4796 & 11 & 0 & 4563 & WWP2 & SE \\
\hline TCONS_000 & MAP3K & & TCONS_0006 & & & TCONS_0003 & & \\
\hline 04056 & 6 & $\mathrm{RI}$ & 4812 & REST & A5 & 2556 & WWP2 & 0 \\
\hline TCONS_000 & & & TCONS_0006 & & & TCONS_0003 & & \\
\hline 04064 & FGR & $\mathrm{RI}$ & 4823 & LPHN3 & SE & 2560 & PDPR & SE \\
\hline TCONS_000 & & & TCONS_0006 & & & TCONS_0003 & & \\
\hline 04065 & FGR & $A 3, R I$ & 7413 & LPHN3 & SE & 4570 & DDX19B & $\mathrm{O}$ \\
\hline TCONS_000 & RP11-4 & & TCONS_0006 & & & TCONS_0003 & & \\
\hline 08126 & 60113.2 & $\mathrm{O}$ & 7414 & LPHN3 & SE & 2608 & DHX38 & $\mathrm{O}$ \\
\hline TCONS_000 & DNAJC & & TCONS_0006 & & & TCONS_0003 & & \\
\hline 04088 & 8 & SE & 7415 & LPHN3 & SE & 4581 & DHX38 & $\mathrm{RI}$ \\
\hline TCONS_000 & & & TCONS_0006 & & & TCONS_0003 & & \\
\hline 04118 & PUM1 & A5 & 4838 & ODAM & $\mathrm{O}$ & 2609 & DHX38 & RI \\
\hline
\end{tabular}




\begin{tabular}{|c|c|c|c|c|c|c|c|c|}
\hline \multicolumn{3}{|l|}{ TCONS_000 } & \multicolumn{3}{|l|}{ TCONS_0006 } & TCONS_0003 & \multicolumn{2}{|l|}{ NPIPB1 } \\
\hline 04119 & PUM1 & A3,SE & 4839 & ODAM & SE & 4582 & 5 & $\mathrm{O}$ \\
\hline TCONS_000 & COL16A & & TCONS_0006 & & & TCONS_0003 & & \\
\hline 04144 & 1 & A5 & 4899 & AREG & $\mathrm{O}$ & 2686 & KLHL36 & A5 \\
\hline TCONS_000 & COL16A & & TCONS_0006 & & & TCONS_0003 & MAP1L & \\
\hline 04145 & 1 & 0 & 4903 & AREGB & 0 & 2784 & C3B & A5,SE \\
\hline TCONS_000 & COL16A & & TCONS_0006 & & & TCONS_0003 & MAP1L & \\
\hline 04146 & 1 & A5,SE & 7474 & AREGB & $\mathrm{O}$ & 2785 & C3B & A5,SE \\
\hline TCONS_000 & COL16A & & TCONS_0006 & SHROO & & TCONS_0003 & & $A 3, A F, S$ \\
\hline 04147 & 1 & MX,SE & 4923 & M3 & $\mathrm{O}$ & 2789 & BANP & E \\
\hline TCONS_000 & COL16A & & TCONS_0006 & SHROO & & TCONS_0003 & & \\
\hline 04148 & 1 & $\mathrm{MX}$ & 7480 & M3 & $\mathrm{O}$ & 4667 & ZFPM1 & $\mathrm{O}$ \\
\hline TCONS_000 & COL16A & & TCONS_0006 & & & TCONS_0003 & TRAPP & \\
\hline 04149 & 1 & $\mathrm{~A} 5, \mathrm{MX}$ & 4930 & SEPT11 & $\mathrm{O}$ & 2804 & $\mathrm{C} 2 \mathrm{~L}$ & $\mathrm{~A} 3, \mathrm{~A} 5$ \\
\hline TCONS_000 & COL16A & & TCONS_0006 & & & TCONS_0003 & & \\
\hline 08143 & 1 & A5 & 7482 & CCNG2 & A5 & 4671 & ACSF3 & A5 \\
\hline TCONS_000 & COL16A & & TCONS_0006 & & & TCONS_0003 & & \\
\hline 08148 & 1 & SE & 7488 & ANXA3 & $\mathrm{RI}, \mathrm{SE}$ & 2844 & CPNE7 & $\mathrm{A} 3, \mathrm{SE}$ \\
\hline TCONS_000 & TMEM2 & & TCONS_0006 & & & TCONS_0003 & & \\
\hline 04166 & 34 & A3 & 7494 & THAP9 & SE & 4685 & DPEP1 & AF \\
\hline TCONS_000 & TMEM2 & & TCONS_0006 & & & TCONS_0003 & & \\
\hline 04167 & 34 & RI,SE & 7515 & PTPN13 & RI,SE & 2856 & CDK10 & A5 \\
\hline TCONS_000 & TMEM2 & & TCONS_0006 & & & TCONS_0003 & & \\
\hline 08151 & 34 & RI,SE & 5004 & PTPN13 & A5,SE & 4689 & CDK10 & A5,RI \\
\hline TCONS_000 & TMEM2 & & TCONS_0006 & & & TCONS_0003 & & \\
\hline 08152 & 34 & SE & 5100 & NFKB1 & A5 & 2855 & CDK10 & A5 \\
\hline TCONS_000 & TMEM2 & & TCONS_0006 & ARHGE & & TCONS_0003 & & \\
\hline 08153 & 34 & $\mathrm{O}$ & 5121 & F38 & $\mathrm{O}$ & 2857 & CDK10 & A5,RI \\
\hline TCONS_000 & MTMR9 & & TCONS_0006 & & & TCONS_0003 & VPS9D1 & \\
\hline 04175 & LP & SE & 5135 & SGMS2 & A5 & 2863 & -AS1 & 0 \\
\hline TCONS_000 & MTMR9 & & TCONS_0006 & & & TCONS_0003 & & \\
\hline 04176 & LP & SE & 5138 & SGMS2 & $\mathrm{O}$ & 2880 & DEF8 & $\mathrm{O}$ \\
\hline TCONS_000 & & & TCONS_0006 & & & TCONS_0003 & & \\
\hline 04181 & BSDC1 & SE & 5181 & AP1AR & A5 & 2881 & DEF8 & A3,RI,SE \\
\hline TCONS_000 & & & TCONS_0006 & & & TCONS_0003 & & \\
\hline 08156 & SYNC & 0 & 7554 & LARP7 & A3,A5 & 4701 & GAS8 & $\mathrm{O}$ \\
\hline
\end{tabular}




\begin{tabular}{|c|c|c|c|c|c|c|c|c|}
\hline \multicolumn{3}{|l|}{ TCONS_000 } & \multicolumn{3}{|l|}{ TCONS_0006 } & \multicolumn{3}{|l|}{ TCONS_0003 } \\
\hline 04246 & SFPQ & $\mathrm{O}$ & 7555 & LARP7 & A3 & 2886 & GAS8 & $\mathrm{O}$ \\
\hline TCONS_000 & & & TCONS_0006 & & & TCONS_0003 & WASH4 & \\
\hline 04247 & SFPQ & $\mathrm{O}$ & 7556 & ANK2 & SE & 4707 & $\mathrm{P}$ & $\mathrm{O}$ \\
\hline TCONS_000 & & & TCONS_0006 & & & TCONS_0003 & WASH4 & \\
\hline 04248 & SFPQ & $\mathrm{O}$ & 5196 & ANK2 & SE & 4708 & $\mathrm{P}$ & $\mathrm{A} 3, \mathrm{~A} 5$ \\
\hline TCONS_000 & & & TCONS_0006 & & & TCONS_0003 & WASH4 & \\
\hline 08167 & SFPQ & $\mathrm{O}$ & 7557 & ANK2 & SE & 4709 & $\mathrm{P}$ & $A 3, A 5$ \\
\hline TCONS_000 & & & TCONS_0006 & & & TCONS_0003 & RHBDF & \\
\hline 08168 & SFPQ & $\mathrm{O}$ & 7558 & ANK2 & SE & 2894 & 1 & $\mathrm{O}$ \\
\hline TCONS_000 & & & TCONS_0006 & & & TCONS_0003 & RHBDF & \\
\hline 04261 & COL8A2 & $\mathrm{AF}$ & 5211 & SNHG8 & A3 & 4712 & 1 & $\mathrm{~A} 5, \mathrm{RI}$ \\
\hline TCONS_000 & & & TCONS_0006 & CEP170 & & TCONS_0003 & & \\
\hline 04272 & EVA1B & $\mathrm{O}$ & 5215 & $\mathrm{P} 1$ & $\mathrm{O}$ & 2899 & NPRL3 & $\mathrm{O}$ \\
\hline TCONS_000 & & & TCONS_0006 & & & TCONS_0003 & & \\
\hline 04290 & CSF3R & A3 & 5231 & USP53 & SE & 2904 & LUC7L & $\mathrm{RI}, \mathrm{SE}$ \\
\hline TCONS_000 & & & TCONS_0006 & & & TCONS_0003 & & \\
\hline 04300 & SNIP1 & $\mathrm{O}$ & 7574 & USP53 & SE & 2905 & LUC7L & $\mathrm{A} 5, \mathrm{SE}$ \\
\hline TCONS_000 & C1orf10 & & TCONS_0006 & RP11-3 & & TCONS_0003 & & \\
\hline 04304 & 9 & $\mathrm{~A} 3, \mathrm{~A} 5$ & 7580 & 3B1.1 & $\mathrm{O}$ & 4717 & LUC7L & $\mathrm{O}$ \\
\hline TCONS_000 & C1orf10 & & TCONS_0006 & RP11-3 & & TCONS_0003 & & \\
\hline 04305 & 9 & $A 3, A 5$ & 5243 & 3B1.1 & SE & 4718 & LUC7L & RI,SE \\
\hline TCONS_000 & & & TCONS_0006 & KIAA11 & & TCONS_0003 & & \\
\hline 08181 & INPP5B & A3 & 5256 & 09 & A5,SE & 4719 & LUC7L & $\mathrm{O}$ \\
\hline TCONS_000 & & & TCONS_0006 & KIAA11 & & TCONS_0003 & & \\
\hline 08184 & SF3A3 & $\mathrm{O}$ & 7584 & 09 & A5,SE & 4724 & JMJD8 & $\mathrm{RI}$ \\
\hline TCONS_000 & PABPC & & TCONS_0006 & KIAA11 & & TCONS_0003 & & \\
\hline 04336 & 4 & O & 7585 & 09 & A5,SE & 4725 & JMJD8 & $\mathrm{RI}$ \\
\hline TCONS_000 & РABPC & & TCONS_0006 & & & TCONS_0003 & & \\
\hline 08191 & 4 & $\mathrm{O}$ & 5267 & SPRY1 & A5 & 2940 & WDR24 & $\mathrm{O}$ \\
\hline TCONS_000 & & & TCONS_000 & & & TCONS_000 & & \\
\hline 04349 & TRIT1 & A5 & 65268 & SPRY1 & A5 & 32942 & FBXL16 & $\mathrm{O}$ \\
\hline TCONS_000 & & & TCONS_000 & & & TCONS_000 & & \\
\hline 08205 & COL9A2 & $\mathrm{RI}$ & 65276 & FAT4 & A3 & 32948 & RPUSD1 & $\mathrm{O}$ \\
\hline TCONS_000 & ZMYND & 0 & TCONS_000 & C4orf29 & $\mathrm{MX}$ & TCONS_000 & TPSB2 & 0 \\
\hline
\end{tabular}




\begin{tabular}{|c|c|c|c|c|c|c|c|c|}
\hline 04388 & 12 & & 65285 & & & 32955 & & \\
\hline TCONS 000 & & & TCONS 000 & & & TCONS 000 & RP11-61 & \\
\hline 04428 & $\mathrm{HYI}$ & A5 & 67623 & PHF17 & A5 & 32958 & $6 \mathrm{M} 22.7$ & $\mathrm{O}$ \\
\hline TCONS_000 & & & TCONS_000 & & & TCONS_000 & & \\
\hline 04429 & $\mathrm{HYI}$ & A5,RI & 67628 & PHF17 & $\mathrm{AF}$ & 32968 & CLCN7 & $A F, R I$ \\
\hline TCONS_000 & & & TCONS_000 & & & TCONS_000 & & \\
\hline 04443 & ERI3 & 0 & 65316 & RAB33B & $\mathrm{O}$ & 34735 & CLCN7 & RI \\
\hline TCONS_000 & HECTD & & TCONS_000 & & & TCONS_000 & & \\
\hline 08215 & 3 & RI & 67671 & ZNF330 & RI & 34736 & IFT140 & $\mathrm{O}$ \\
\hline TCONS_000 & GPBP1 & & TCONS_000 & & A3,A5, & TCONS_000 & & \\
\hline 04468 & L1 & $\mathrm{O}$ & 65381 & IL15 & SE & 34737 & NME3 & A5 \\
\hline TCONS_000 & GPBP1 & & TCONS_000 & & & TCONS_000 & & \\
\hline 04469 & L1 & AF & 67698 & IL15 & SE & 34740 & IGFALS & AF \\
\hline TCONS_000 & GPBP1 & & TCONS_000 & & & TCONS_000 & & \\
\hline 04471 & L1 & $\mathrm{O}$ & 65400 & HHIP & $\mathrm{O}$ & 34742 & HAGH & SE \\
\hline TCONS_000 & & & TCONS_000 & & & TCONS_000 & & \\
\hline 08221 & MKNK1 & SE & 65403 & SMAD1 & $\mathrm{AF}$ & 33020 & BRICD5 & RI \\
\hline TCONS_000 & EFCAB & & TCONS_000 & & & TCONS_000 & & \\
\hline 04503 & 14 & SE & 65404 & SMAD1 & AF & 34752 & ABCA3 & AF \\
\hline TCONS_000 & EFCAB & & TCONS_000 & ARHGA & & TCONS_000 & ERVK13- & \\
\hline 04504 & 14 & $\mathrm{O}$ & 65431 & P10 & SE & 33045 & 1 & $\mathrm{O}$ \\
\hline TCONS_000 & $\mathrm{ZCCHC}$ & & TCONS_000 & FAM160 & & TCONS_000 & & \\
\hline 04577 & 11 & A3 & 65451 & A1 & SE & 33058 & PRSS22 & $\mathrm{O}$ \\
\hline TCONS_000 & ECHDC & & TCONS_000 & FAM160 & & TCONS_000 & LA16c-32 & \\
\hline 08243 & 2 & $\mathrm{O}$ & 65452 & A1 & SE & 33066 & 1D4.2 & SE \\
\hline TCONS_000 & ECHDC & & TCONS_000 & TMEM1 & & TCONS_000 & CCDC64 & \\
\hline 04586 & 2 & $\mathrm{RI}$ & 65543 & 44 & $\mathrm{O}$ & 34760 & B & $A 3, R I$ \\
\hline TCONS_000 & & & TCONS_000 & & & TCONS_000 & CCDC64 & \\
\hline 04603 & LRP8 & $\mathrm{MX}, \mathrm{SE}$ & 67814 & ETFDH & A3 & 34761 & B & $A 3, R I$ \\
\hline TCONS_000 & & & TCONS_000 & & & TCONS_000 & CCDC64 & \\
\hline 04614 & HSPB11 & $A F$ & 65554 & FNIP2 & SE & 33073 & B & A3 \\
\hline TCONS_000 & & & TCONS_000 & RAPGE & & TCONS_000 & CCDC64 & \\
\hline 04645 & USP24 & A3 & 65559 & F2 & SE & 33074 & B & $A 3, R I$ \\
\hline TCONS_000 & RP4-79 & & TCONS_000 & RAPGE & & TCONS_000 & & \\
\hline 08274 & $4 \mathrm{H} 19.1$ & $\mathrm{AF}$ & 67820 & F2 & SE & 33082 & ZNF200 & $\mathrm{O}$ \\
\hline
\end{tabular}




\begin{tabular}{|c|c|c|c|c|c|c|c|c|}
\hline \multicolumn{3}{|l|}{ TCONS_000 } & TCONS_000 & \multicolumn{2}{|l|}{ RAPGE } & \multicolumn{3}{|l|}{ TCONS_000 } \\
\hline 04711 & DOCK7 & SE & 65558 & $\mathrm{~F} 2$ & SE & 33083 & ZNF200 & A3,A5 \\
\hline TCONS_000 & & & TCONS_000 & & & TCONS_000 & ZSCAN3 & \\
\hline 04734 & WDR78 & SE & 67888 & ANXA10 & $\mathrm{O}$ & 33091 & 2 & $\mathrm{RI}, \mathrm{SE}$ \\
\hline TCONS_000 & SERBP & & TCONS_000 & & & TCONS_000 & & \\
\hline 04747 & 1 & A3 & 65609 & CLCN3 & SE & 34771 & TRAP1 & $\mathrm{O}$ \\
\hline TCONS_000 & & & TCONS_000 & RP11-78 & & TCONS_000 & & \\
\hline 04754 & GNG12 & AF & 65611 & $9 \mathrm{C} 1.1$ & AF & 33112 & ADCY9 & AL \\
\hline TCONS_000 & ZRANB & & TCONS_000 & & & TCONS_000 & & \\
\hline 04773 & 2 & $\mathrm{RI}$ & 67898 & CEP44 & O & 34775 & ADCY9 & A5 \\
\hline TCONS_000 & ZRANB & & TCONS_000 & & & TCONS_000 & & \\
\hline 08298 & 2 & $\mathrm{RI}$ & 65646 & TENM3 & $\mathrm{O}$ & 34782 & CDIP1 & $A F, R I$ \\
\hline TCONS_000 & ZRANB & & TCONS_000 & SLC25A & & TCONS_000 & & \\
\hline 08299 & 2 & $\mathrm{RI}, \mathrm{SE}$ & 67923 & 4 & $\mathrm{RI}$ & 33134 & CDIP1 & $\mathrm{AF}$ \\
\hline TCONS_000 & & & TCONS_000 & ANKRD & & TCONS_000 & & \\
\hline 08306 & USP33 & $\mathrm{RI}, \mathrm{SE}$ & 67926 & 37 & $\mathrm{RI}$ & 34786 & ROGDI & $\mathrm{O}$ \\
\hline TCONS_000 & & & TCONS_000 & & & TCONS_000 & & \\
\hline 04813 & USP33 & $\mathrm{A} 3, \mathrm{RI}$ & 65695 & KLKB1 & $\mathrm{O}$ & 33143 & ROGDI & $\mathrm{O}$ \\
\hline TCONS_000 & & & TCONS_000 & & & TCONS_000 & & \\
\hline 04819 & FUBP1 & A3 & 67938 & F11 & A3 & 34788 & GLYR1 & SE \\
\hline TCONS_000 & & & TCONS_000 & & $\mathrm{MX}, \mathrm{RI}$ & TCONS_000 & & \\
\hline 04820 & FUBP1 & A3,RI & 67940 & F11 & SE & 34789 & GLYR1 & $\mathrm{A} 3, \mathrm{SE}$ \\
\hline TCONS_000 & RP11-4 & & TCONS_000 & & & TCONS_000 & & \\
\hline 08389 & 7506.1 & $\mathrm{O}$ & 65721 & FRG1 & $\mathrm{O}$ & 34790 & GLYR1 & AF,RI,SE \\
\hline TCONS_000 & & & TCONS_000 & & & TCONS_000 & & \\
\hline 08399 & SSX2IP & A5,SE & 65744 & MFSD7 & $\mathrm{RI}$ & 33145 & GLYR1 & SE \\
\hline TCONS_000 & & & TCONS_000 & & A3,A5, & TCONS_000 & & \\
\hline 08400 & LPAR3 & AF & 67953 & GAK & RI & 33146 & GLYR1 & SE \\
\hline TCONS_000 & COL24A & & TCONS_000 & & & TCONS_000 & & \\
\hline 04880 & 1 & 0 & 67960 & RNF212 & $\mathrm{O}$ & 33159 & FAM86A & SE \\
\hline TCONS_000 & & & TCONS_000 & TMED11 & & TCONS_000 & & \\
\hline 08413 & ODF2L & A3,SE & 67967 & $\mathrm{P}$ & $\mathrm{O}$ & 33180 & TVP23A & $\mathrm{O}$ \\
\hline TCONS_000 & & & TCONS_000 & TMED11 & & TCONS_000 & & \\
\hline 08441 & HFM1 & SE & 67968 & $\mathrm{P}$ & $\mathrm{O}$ & 34807 & LITAF & SE \\
\hline TCONS_000 & & & TCONS_000 & & & TCONS_000 & & \\
\hline 08442 & HFM1 & $\mathrm{O}$ & 65767 & CTBP1 & $\mathrm{A} 3, \mathrm{AF}$ & 33210 & ZC $3 \mathrm{H} 7 \mathrm{~A}$ & SE \\
\hline
\end{tabular}




\begin{tabular}{|c|c|c|c|c|c|c|c|c|}
\hline \multicolumn{3}{|l|}{ TCONS_000 } & \multicolumn{3}{|l|}{ TCONS_000 } & TCONS_000 & \multicolumn{2}{|l|}{ RP11-16 } \\
\hline 04980 & EVI5 & $\mathrm{AF}$ & 65768 & СТВP1 & $\mathrm{A} 3, \mathrm{AF}$ & 33231 & 6B2.1 & $\mathrm{O}$ \\
\hline TCONS_000 & & & TCONS_000 & & & TCONS_000 & & \\
\hline 04979 & EVI5 & $\mathrm{AF}$ & 65790 & POLN & O & 34813 & PKD1P6 & $\mathrm{O}$ \\
\hline TCONS_000 & & & TCONS_000 & & & TCONS_000 & & \\
\hline $08457^{-}$ & F3 & A5 & $65805^{-}$ & MFSD10 & $\mathrm{O}$ & 33264 & NPIPA5 & $\mathrm{O}$ \\
\hline TCONS_000 & LINC01 & & TCONS_000 & & & TCONS_000 & & \\
\hline $08461^{-}$ & 057 & O & $65806^{-}$ & MFSD10 & $A 3, R I$ & 33265 & NPIPA5 & RI \\
\hline TCONS_000 & & & TCONS_000 & & & TCONS_000 & & \\
\hline $05041^{-}$ & FRRS1 & $\mathrm{AF}$ & 65835 & CYTL1 & A3 & 33266 & NPIPA5 & $\mathrm{O}$ \\
\hline TCONS_000 & RP11-3 & & TCONS_000 & & & TCONS_000 & & \\
\hline 08464 & 05E17.6 & $\mathrm{O}$ & 65954 & LDB2 & A3 & 33296 & ABCC6 & RI \\
\hline TCONS_000 & & & TCONS_000 & & & TCONS_000 & RP11-12 & \\
\hline 05081 & SORT1 & A3 & 68075 & DCAF16 & SE & 33299 & $12 \mathrm{~A} 22.1$ & RI,SE \\
\hline TCONS_000 & & & TCONS_000 & & & TCONS_000 & & \\
\hline 05092 & EPS8L3 & $A 3, R I$ & 65996 & DHX15 & RI & 33301 & PKD1P5 & $\mathrm{O}$ \\
\hline TCONS_000 & & & TCONS_000 & SEPSE & & TCONS_000 & & \\
\hline 05093 & EPS8L3 & $A 3, R I$ & 66006 & CS & $\mathrm{O}$ & 34832 & SMG1 & SE \\
\hline TCONS_000 & & & TCONS_000 & & & TCONS_000 & & \\
\hline 05094 & EPS8L3 & $A 3, R I$ & 66029 & ARAP2 & SE & 33362 & NPIPB3 & $\mathrm{O}$ \\
\hline TCONS_000 & & & TCONS_000 & & & TCONS_000 & & \\
\hline 05120 & DRAM2 & $\mathrm{O}$ & 66030 & ARAP2 & A3 & 33363 & NPIPB3 & RI \\
\hline TCONS_000 & & & TCONS_000 & RP11-61 & & TCONS_000 & & \\
\hline 05121 & DRAM2 & $\mathrm{O}$ & 68099 & 7D20.1 & $A F$ & 33381 & RRN3P1 & RI,SE \\
\hline TCONS_000 & & & TCONS_000 & & & TCONS_000 & & \\
\hline 08481 & DRAM2 & $\mathrm{O}$ & 66051 & RPL9 & A3 & 34849 & RRN3P1 & $\mathrm{O}$ \\
\hline TCONS_000 & & & TCONS_000 & & & TCONS_000 & RP11-64 & \\
\hline 08482 & DRAM2 & A5 & 66076 & RBM47 & SE & 34860 & $5 C 24.2$ & RI,SE \\
\hline TCONS_000 & ADORA & & TCONS_000 & & & TCONS_000 & & \\
\hline $05137^{-}$ & 3 & $\mathrm{O}$ & $66105^{-}$ & ATP8A1 & SE & 33396 & CDR2 & SE \\
\hline TCONS_000 & & & TCONS_000 & & & TCONS_000 & & \\
\hline 05141 & KCND3 & $\mathrm{AF}$ & 66121 & CNGA1 & SE & 34877 & PALB2 & SE \\
\hline TCONS_000 & & & TCONS_000 & & & TCONS_000 & & \\
\hline 05145 & ST7L & SE & 68122 & CNGA1 & $\mathrm{O}$ & 33418 & ERN2 & RI \\
\hline TCONS_000 & RP11-4 & & TCONS_000 & & & TCONS_000 & & \\
\hline 08495 & 26L16.1 & $\mathrm{O}$ & 66127 & FRYL & SE & 33420 & ERN2 & RI \\
\hline
\end{tabular}




\begin{tabular}{|c|c|c|c|c|c|c|c|c|}
\hline & 0 & & & & & & & \\
\hline TCONS_000 & & & TCONS_000 & RP11-24 & & TCONS_000 & ARHGAP & \\
\hline 08502 & PTPN22 & $\mathrm{O}$ & 66146 & 1F15.1 & $\mathrm{AF}$ & 33422 & 17 & SE \\
\hline TCONS_000 & & & TCONS_000 & & & TCONS_000 & & \\
\hline 05180 & PTPN22 & $\mathrm{O}$ & 68133 & LNX1 & $\mathrm{O}$ & 33437 & GTF3C1 & $\mathrm{RI}$ \\
\hline TCONS_000 & DENND & & TCONS_000 & RP11-12 & & TCONS_000 & & \\
\hline 05200 & $2 \mathrm{C}$ & $\mathrm{O}$ & 66229 & $67 \mathrm{H} 10.4$ & $\mathrm{O}$ & 33456 & RABEP2 & $\mathrm{O}$ \\
\hline TCONS_000 & & & TCONS_000 & & & TCONS_000 & & \\
\hline 05202 & CSDE1 & SE & 66295 & CXCL2 & $\mathrm{O}$ & 33457 & RABEP2 & $\mathrm{O}$ \\
\hline TCONS_000 & & & TCONS_000 & RP11-44 & & TCONS_000 & & \\
\hline 05224 & CASQ2 & $\mathrm{O}$ & 66302 & F21.5 & $\mathrm{O}$ & 34888 & RABEP2 & $\mathrm{O}$ \\
\hline TCONS_000 & & & TCONS_000 & & & TCONS_000 & & \\
\hline 05263 & ZNF697 & $\mathrm{AF}$ & 66314 & G3BP2 & AF,SE & 33463 & NPIPB11 & $\mathrm{O}$ \\
\hline TCONS_000 & RP11-4 & & TCONS_000 & HNRNP & & TCONS_000 & & \\
\hline 08553 & 39A17.7 & $\mathrm{O}$ & 66397 & $\mathrm{DL}$ & $\mathrm{O}$ & 34889 & NPIPB11 & $\mathrm{O}$ \\
\hline TCONS_000 & RP11-4 & & TCONS_000 & & & TCONS_000 & RP11-23 & \\
\hline 08562 & $35 \mathrm{~B} 5.4$ & AF & 66442 & HELQ & A5 & 33469 & $1 C 14.4$ & $\mathrm{O}$ \\
\hline TCONS_000 & LINCOO & A5,AF, & TCONS_000 & & & TCONS_000 & RP11-23 & \\
\hline 08563 & 623 & $\mathrm{MX}$ & 66443 & HELQ & A5,RI & 33470 & 1C14.4 & SE \\
\hline TCONS_000 & RP11-6 & & TCONS_000 & & & TCONS_000 & RP11-34 & \\
\hline 08564 & 40M9.1 & SE & 66457 & WDFY3 & SE & 33471 & $5 J 4.8$ & $\mathrm{O}$ \\
\hline TCONS_000 & LINCOO & & TCONS_000 & & & TCONS_000 & AC00913 & \\
\hline 05324 & 623 & $\mathrm{O}$ & 68201 & WDFY3 & A3,SE & 33487 & 3.20 & A5 \\
\hline TCONS_000 & WI2-189 & & TCONS_000 & & & TCONS_000 & & \\
\hline 05337 & 6014.1 & RI & 68204 & MAPK10 & A5 & 33496 & SEZ6L2 & A3 \\
\hline TCONS_000 & GNRHR & & TCONS_000 & & & TCONS_000 & & \\
\hline 08575 & 2 & A3 & 66465 & MAPK10 & SE & 34896 & SEZ6L2 & $\mathrm{A} 3, \mathrm{SE}$ \\
\hline TCONS_000 & GPR89 & & TCONS_000 & & & TCONS_000 & & \\
\hline 05361 & A & A3,SE & 66495 & PYURF & $\mathrm{O}$ & 33503 & DOC2A & $\mathrm{O}$ \\
\hline TCONS_000 & GPR89 & & TCONS_000 & & & TCONS_000 & & \\
\hline 05362 & A & $\mathrm{RI}, \mathrm{SE}$ & 66514 & UNC5C & SE & 33514 & GDPD3 & $\mathrm{O}$ \\
\hline TCONS_000 & & & TCONS_000 & & & TCONS_000 & TBC1D10 & \\
\hline 08581 & NBPF11 & SE & 66550 & ADH1C & SE & 33534 & B & $\mathrm{RI}$ \\
\hline TCONS_000 & & & TCONS_000 & & & TCONS_000 & RP11-19 & \\
\hline 08582 & NBPF11 & O & 68276 & C4orf21 & SE & 33574 & 6G11.1 & O \\
\hline
\end{tabular}




\begin{tabular}{|c|c|c|c|c|c|c|c|c|}
\hline TCONS_000 & WI2-365 & & TCONS_000 & & & TCONS_000 & & \\
\hline 05368 & 8N16.1 & $\mathrm{O}$ & 66702 & ARSJ & $\mathrm{O}$ & 33589 & C16orf58 & $\mathrm{RI}$ \\
\hline TCONS_000 & & & TCONS_000 & & & TCONS_000 & & \\
\hline 05367 & NBPF11 & $\mathrm{O}$ & 68316 & BBS7 & $\mathrm{O}$ & 34914 & C16orf58 & $\mathrm{O}$ \\
\hline TCONS_000 & & & TCONS_000 & & & TCONS_000 & & \\
\hline 05393 & NBPF20 & $\mathrm{O}$ & 68339 & MFSD8 & 0 & 34928 & AKTIP & A3 \\
\hline TCONS_000 & & & TCONS_000 & RP11-74 & & TCONS_000 & & \\
\hline 05394 & NBPF20 & $\mathrm{O}$ & 68354 & 5L13.2 & $\mathrm{O}$ & 34929 & AKTIP & $\mathrm{O}$ \\
\hline TCONS_000 & & & TCONS_000 & RP11-83 & & TCONS_000 & & \\
\hline 05397 & NBPF20 & O & 68361 & A24. 2 & O & 33647 & AKTIP & A3 \\
\hline TCONS_000 & & & TCONS_000 & & & TCONS_000 & & \\
\hline 05398 & NBPF20 & $\mathrm{O}$ & 68367 & INPP4B & SE & 33649 & AKTIP & $\mathrm{O}$ \\
\hline TCONS_000 & & & TCONS_000 & & & TCONS_000 & & \\
\hline 05399 & NBPF20 & $\mathrm{O}$ & 66866 & GYPE & AF & 33655 & IRX3 & $\mathrm{O}$ \\
\hline TCONS_000 & & & TCONS_000 & & & TCONS_000 & & \\
\hline 08594 & NBPF20 & $\mathrm{O}$ & 66903 & SH3D19 & $\mathrm{A} 3, \mathrm{SE}$ & 34931 & CES1 & A3 \\
\hline TCONS_000 & & & TCONS_000 & & A3,AF, & TCONS_000 & & \\
\hline 08595 & NBPF20 & $\mathrm{O}$ & 66905 & SH3D19 & SE & 33697 & CIAPIN1 & A3 \\
\hline TCONS_000 & & & TCONS_000 & & & TCONS_000 & & \\
\hline 08596 & NBPF20 & SE & 68410 & MAP9 & A3 & 33705 & DOK4 & A5 \\
\hline TCONS_000 & MTMR1 & & TCONS_000 & & & TCONS_000 & & \\
\hline 05427 & 1 & $\mathrm{RI}$ & 66943 & MAP9 & A3,A5 & 34941 & KIFC3 & $\mathrm{O}$ \\
\hline TCONS_000 & MTMR1 & & TCONS_000 & & & TCONS_000 & & \\
\hline 05429 & 1 & A3 & 68425 & NPY1R & AF & 34950 & ZNF319 & $\mathrm{O}$ \\
\hline TCONS_000 & MTMR1 & & TCONS_000 & & & TCONS_000 & & \\
\hline 05430 & 1 & A3 & 67000 & TRIM61 & $\mathrm{O}$ & 33718 & ZNF319 & $\mathrm{O}$ \\
\hline TCONS_000 & MTMR1 & & TCONS_000 & & & TCONS_000 & CSNK2A & \\
\hline 05431 & 1 & $\mathrm{RI}$ & 67017 & DDX60L & A3 & 33724 & 2 & $\mathrm{O}$ \\
\hline TCONS_000 & & & TCONS_000 & & & TCONS_000 & & \\
\hline 05449 & $\mathrm{APH} 1 \mathrm{~A}$ & $\mathrm{O}$ & 67038 & NEK1 & SE & 33736 & GOT2 & SE \\
\hline TCONS_000 & & & TCONS_000 & & & TCONS_000 & & \\
\hline 08608 & $\mathrm{APH} 1 \mathrm{~A}$ & A3 & 67049 & AADAT & $\mathrm{RI}$ & 33772 & CDH11 & $\mathrm{AF}, \mathrm{SE}$ \\
\hline TCONS_000 & & & TCONS_000 & RP11-10 & & TCONS_000 & DYNC1LI & \\
\hline 05502 & ARNT & A3,SE & 67050 & K16.1 & RI & 33798 & 2 & $\mathrm{RI}$ \\
\hline TCONS_000 & & & TCONS_000 & & & TCONS_000 & KIAA089 & \\
\hline 05506 & CERS2 & A3 & 67125 & MLF1IP & A5 & 34981 & $5 \mathrm{~L}$ & A5 \\
\hline
\end{tabular}




\begin{tabular}{|c|c|c|c|c|c|c|c|c|}
\hline TCONS_000 & FAM63 & & TCONS_000 & SORBS & & TCONS_000 & KIAA089 & \\
\hline 05509 & A & $\mathrm{O}$ & 67156 & 2 & SE & 34982 & $5 \mathrm{~L}$ & A5,RI \\
\hline TCONS_000 & FAM63 & & TCONS_000 & & & TCONS_000 & KIAA089 & \\
\hline 05510 & A & A3 & 67171 & FAT1 & AF & 33816 & $5 \mathrm{~L}$ & A5,RI \\
\hline TCONS_000 & FAM63 & & TCONS_000 & & & TCONS_000 & KIAA089 & \\
\hline 08616 & A & $\mathrm{O}$ & 67172 & FAT1 & AF,SE & 33817 & $5 \mathrm{~L}$ & $\mathrm{RI}$ \\
\hline TCONS_000 & SEMA6 & & TCONS_000 & & & TCONS_000 & & \\
\hline 05520 & C & A5 & 68544 & EXOC3 & $\mathrm{O}$ & 33819 & FHOD1 & A3,RI,SE \\
\hline TCONS_000 & & & TCONS_000 & & & TCONS_000 & & \\
\hline 05529 & PI4KB & SE & 72133 & EXOC3 & $\mathrm{O}$ & 33828 & ZDHHC1 & A3 \\
\hline TCONS_000 & & & TCONS_000 & & & TCONS_000 & & \\
\hline 08626 & PI4KB & $\mathrm{O}$ & 68546 & EXOC3 & AF & 33835 & AGRP & $\mathrm{O}$ \\
\hline TCONS_000 & & & TCONS_000 & CTD-22 & & TCONS_000 & CTD-201 & \\
\hline 05536 & RFX5 & $\mathrm{A} 5, \mathrm{AF}$ & 68548 & $28 \mathrm{~K} 2.7$ & A3 & 33836 & 2K14.2 & $\mathrm{O}$ \\
\hline TCONS_000 & & & TCONS_000 & CTD-22 & & TCONS_000 & & \\
\hline 05553 & CELF3 & A3,SE & 68549 & $28 \mathrm{~K} 2.7$ & A3 & 34986 & ENKD1 & $\mathrm{O}$ \\
\hline TCONS_000 & S100A1 & & TCONS_000 & & & TCONS_000 & & \\
\hline 05605 & 4 & $\mathrm{RI}$ & 68551 & CEP72 & A5 & 34987 & ENKD1 & $\mathrm{RI}, \mathrm{SE}$ \\
\hline TCONS_000 & RP1-17 & & TCONS_000 & & & TCONS_000 & & \\
\hline 05610 & 8F15.5 & $\mathrm{A} 3, \mathrm{SE}$ & 68552 & CEP72 & $\mathrm{O}$ & 33843 & GFOD2 & $\mathrm{O}$ \\
\hline TCONS_000 & RP1-17 & & TCONS_000 & MIR445 & & TCONS_000 & & \\
\hline 05611 & $8 F 15.5$ & A3 & 68588 & $8 \mathrm{HG}$ & $\mathrm{O}$ & 34990 & CENPT & $\mathrm{RI}$ \\
\hline TCONS_000 & RP1-17 & & TCONS_000 & MARCH & & TCONS_000 & & \\
\hline 05612 & 8F15.5 & $\mathrm{A} 3, \mathrm{RI}$ & 68598 & 6 & $\mathrm{O}$ & 33850 & CENPT & $\mathrm{RI}$ \\
\hline TCONS_000 & RP1-17 & & TCONS_000 & & & TCONS_000 & & \\
\hline 05613 & 8F15.5 & A3 & 68705 & SLC1A3 & $\mathrm{O}$ & 33851 & CENPT & $\mathrm{RI}$ \\
\hline TCONS_000 & RP1-17 & A3,RI, & TCONS_000 & & & TCONS_000 & & \\
\hline 05614 & 8F15.5 & SE & 68706 & SLC1A3 & SE & 33852 & CENPT & $\mathrm{RI}$ \\
\hline TCONS_000 & RP1-17 & A3,RI, & TCONS_000 & & & TCONS_000 & & \\
\hline 05615 & 8F15.5 & SE & 68726 & OSMR & A5 & 34991 & CENPT & $\mathrm{O}$ \\
\hline TCONS_000 & RP1-17 & & TCONS_000 & & & TCONS_000 & & \\
\hline 08641 & 8F15.5 & $\mathrm{A} 3, \mathrm{SE}$ & 68749 & FBXO4 & O & 34992 & CENPT & $\mathrm{RI}$ \\
\hline TCONS_000 & RP1-17 & & TCONS_000 & & & TCONS_000 & & \\
\hline 08643 & 8F15.5 & $\mathrm{O}$ & 72208 & FBXO4 & A5 & 33862 & SLC12A4 & $\mathrm{RI}$ \\
\hline TCONS_000 & DENND & AF, RI, & TCONS_000 & CCDC15 & & TCONS_000 & & \\
\hline 08646 & 4B & SE & 72209 & 2 & $\mathrm{RI}$ & 33863 & SLC12A4 & $\mathrm{O}$ \\
\hline
\end{tabular}




\begin{tabular}{|c|c|c|c|c|c|c|c|c|}
\hline \multirow{2}{*}{$\begin{array}{l}\text { TCONS_000 } \\
05628\end{array}$} & \multicolumn{2}{|l|}{ DENND } & \multicolumn{3}{|l|}{ TCONS_000 } & \multicolumn{3}{|l|}{ TCONS_000 } \\
\hline & $4 \mathrm{~B}$ & A5 & 68778 & ZNF131 & RI & 34998 & SLC12A4 & 0 \\
\hline TCONS_000 & & & TCONS_000 & & & TCONS_000 & & \\
\hline 08655 & C1orf43 & 0 & 68815 & PELO & 0 & 33867 & DPEP2 & A3 \\
\hline TCONS_000 & & & TCONS_000 & & & TCONS_000 & & \\
\hline 08656 & C1orf43 & A5 & 68816 & ITGA1 & O & 35001 & ESRP2 & 0 \\
\hline TCONS_000 & & & TCONS_000 & & & TCONS_000 & & \\
\hline 08661 & SHC1 & 0 & 68826 & FST & $A 3, R I$ & 33881 & CHTF8 & AF \\
\hline & RP11-3 & & & & & & & \\
\hline TCONS_000 & 07C12.1 & & TCONS_000 & & & TCONS_000 & & \\
\hline 05697 & 1 & $\mathrm{O}$ & 68838 & SNX18 & A5 & 35005 & CHTF8 & A3,SE \\
\hline TCONS_000 & & & TCONS_000 & & & TCONS_000 & & \\
\hline 08666 & THBS3 & A3 & 68891 & KIF2A & A5,SE & 35006 & CHTF8 & $\mathrm{O}$ \\
\hline TCONS_000 & FAM189 & & TCONS_000 & & & TCONS_000 & & \\
\hline 05733 & B & $\mathrm{RI}$ & 72271 & PPWD1 & RI,SE & 33895 & NQO1 & $\mathrm{O}$ \\
\hline TCONS_000 & & & TCONS_000 & & & TCONS_000 & RP11-29 & \\
\hline 08669 & CLK2 & $\mathrm{O}$ & 72273 & NLN & A5 & 35026 & 6110.6 & A5 \\
\hline TCONS_000 & & & TCONS_000 & ERBB2I & & TCONS_000 & & \\
\hline 08670 & CLK2 & RI & 68925 & $\mathrm{P}$ & SE & 33923 & MTSS1L & A3,SE \\
\hline TCONS_000 & & & TCONS_000 & & & TCONS_000 & & \\
\hline 05739 & CLK2 & 0 & 68945 & SREK1 & $A F, R I$ & 35031 & VAC14 & 0 \\
\hline TCONS_000 & RUSC1- & & TCONS_000 & & & TCONS_000 & & \\
\hline 05745 & AS1 & $\mathrm{O}$ & 68982 & RAD17 & A5 & 33933 & HYDIN & A5,SE \\
\hline TCONS_000 & RUSC1- & & TCONS_000 & & & TCONS_000 & & \\
\hline 08672 & AS1 & $\mathrm{O}$ & 72292 & RAD17 & $\mathrm{RI}$ & 33953 & TXNL4B & SE \\
\hline TCONS_000 & & & TCONS_000 & MARVE & & TCONS_000 & & \\
\hline 05748 & ASH1L & A3 & 68988 & LD2 & $\mathrm{O}$ & 33955 & TXNL4B & SE \\
\hline TCONS_000 & & & TCONS_000 & MARVE & & TCONS_000 & RP11-25 & \\
\hline 08676 & GON4L & $\mathrm{AF}$ & 72295 & LD2 & $\mathrm{O}$ & 33971 & 2A24.2 & $\mathrm{O}$ \\
\hline TCONS_000 & & & TCONS_000 & & & TCONS_000 & RP11-25 & \\
\hline 05753 & GON4L & AF & 68991 & OCLN & A5,SE & 33972 & 2A24.2 & SE \\
\hline TCONS_000 & & & TCONS_000 & & & TCONS_000 & RP11-25 & \\
\hline 08678 & YY1AP1 & AF & 68992 & OCLN & A5 & 33974 & 2A24.2 & SE \\
\hline TCONS_000 & & & TCONS_000 & & & TCONS_000 & & \\
\hline 05759 & YY1AP1 & SE & 68993 & OCLN & $\mathrm{O}$ & 33989 & MLKL & $\mathrm{RI}$ \\
\hline TCONS_000 & KIAA09 & $\mathrm{A} 3, \mathrm{RI}$ & TCONS_000 & GTF2H2 & $\mathrm{AF}$ & TCONS_000 & MLKL & RI,SE \\
\hline
\end{tabular}




\begin{tabular}{|c|c|c|c|c|c|c|c|c|}
\hline 08685 & 07 & & 68994 & C & & 33990 & & \\
\hline TCONS_000 & KIAA09 & & TCONS_000 & GTF2H2 & & TCONS_000 & & \\
\hline 05770 & 07 & A3 & 72298 & C & $\mathrm{RI}$ & 33999 & LDHD & $\mathrm{O}$ \\
\hline TCONS_000 & ARHGE & & TCONS_000 & GTF2H2 & & TCONS_000 & & \\
\hline 05778 & $\mathrm{~F} 2$ & A5 & 68995 & C & $\mathrm{O}$ & 34005 & BCAR1 & $\mathrm{O}$ \\
\hline TCONS_000 & ARHGE & & TCONS_000 & RP11-98 & & TCONS_000 & & \\
\hline 08686 & $\mathrm{~F} 2$ & A5 & 69002 & $\mathrm{~J} 23.2$ & 0 & 35062 & ADAT1 & $\mathrm{O}$ \\
\hline TCONS_000 & & & TCONS_000 & & & TCONS_000 & & \\
\hline 08687 & SSR2 & AF & 69023 & SMN2 & $\mathrm{MX}, \mathrm{RI}$ & 34034 & ADAT1 & $\mathrm{O}$ \\
\hline TCONS_000 & UBQLN & & TCONS_000 & GTF2H2 & & TCONS_000 & & \\
\hline 08688 & 4 & $\mathrm{RI}$ & 69034 & B & A3,SE & 35078 & TAF1C & $\mathrm{RI}$ \\
\hline TCONS_000 & & & TCONS_000 & GTF2H2 & & TCONS_000 & & \\
\hline 05805 & ССТ3 & A3 & 69035 & B & $\mathrm{RI}$ & 34095 & TAF1C & $A 3, R I$ \\
\hline TCONS_000 & ARHGE & & TCONS_000 & GTF2H2 & & TCONS_000 & & $\mathrm{A} 5, \mathrm{MX}, \mathrm{R}$ \\
\hline 08700 & F11 & RI,SE & 69036 & B & $\mathrm{RI}$ & 34122 & MTHFSD & I,SE \\
\hline TCONS_000 & & & TCONS_000 & GTF2H2 & & TCONS_000 & & \\
\hline 05881 & DCAF8 & $\mathrm{O}$ & 72306 & $\mathrm{~B}$ & $\mathrm{RI}$ & 34158 & MVD & $\mathrm{O}$ \\
\hline TCONS_000 & & & TCONS_000 & & & TCONS_000 & & \\
\hline 05884 & DCAF8 & $\mathrm{RI}$ & 69066 & SMN1 & $\mathrm{MX}, \mathrm{RI}$ & 35100 & PIEZO1 & $\mathrm{RI}$ \\
\hline TCONS_000 & & & TCONS_000 & & & TCONS_000 & SLC22A3 & \\
\hline 05923 & F11R & $\mathrm{O}$ & 72310 & BDP1 & SE & 35109 & 1 & $\mathrm{RI}$ \\
\hline TCONS_000 & & & TCONS_000 & & & TCONS_000 & & \\
\hline 08712 & F11R & $\mathrm{O}$ & 69080 & MCCC2 & $\mathrm{RI}$ & 35115 & CHMP1A & $\mathrm{RI}$ \\
\hline TCONS_000 & & & TCONS_000 & TMEM1 & & TCONS_000 & & \\
\hline 05935 & USF1 & $\mathrm{RI}$ & 69108 & 71 & A3 & 34192 & VPS9D1 & A3 \\
\hline TCONS_000 & ARHGA & & TCONS_000 & & & TCONS_000 & & \\
\hline 05938 & P30 & $\mathrm{O}$ & 72318 & UTP15 & $\mathrm{O}$ & 34195 & FANCA & $\mathrm{RI}$ \\
\hline TCONS_000 & ARHGA & & TCONS_000 & & & TCONS_000 & & \\
\hline 05939 & P30 & $\mathrm{O}$ & 72327 & AGGF1 & $\mathrm{RI}$ & 34196 & FANCA & RI,SE \\
\hline TCONS_000 & & & TCONS_000 & $\mathrm{ZCCHC}$ & & TCONS_000 & RP11-12 & \\
\hline 08716 & DEDD & $\mathrm{O}$ & 69217 & 9 & A5,RI & 38874 & 60E13.4 & $\mathrm{O}$ \\
\hline TCONS_000 & OLFML & & TCONS_000 & & & TCONS_000 & & \\
\hline 05968 & $2 B$ & $\mathrm{O}$ & 72356 & ATG10 & $\mathrm{O}$ & 38879 & RNMTL1 & $\mathrm{O}$ \\
\hline TCONS_000 & & & TCONS_000 & & & TCONS_000 & & \\
\hline 08720 & RGS5 & $\mathrm{O}$ & 69307 & XRCC4 & $\mathrm{A} 3, \mathrm{AF}$ & 35127 & RNMTL1 & $\mathrm{O}$ \\
\hline
\end{tabular}




\begin{tabular}{|c|c|c|c|c|c|c|c|c|}
\hline \multicolumn{3}{|l|}{ TCONS_000 } & \multicolumn{3}{|l|}{ TCONS_000 } & \multicolumn{3}{|l|}{ TCONS_000 } \\
\hline $08723^{-}$ & RGS5 & $\mathrm{O}$ & $69338^{-}$ & RASA1 & A3 & 35128 & RNMTL1 & 0 \\
\hline TCONS_000 & & & TCONS_000 & & & TCONS_000 & & \\
\hline 05996 & TADA1 & $\mathrm{O}$ & 72433 & GPR98 & 0 & 35145 & RPA1 & A5 \\
\hline TCONS_000 & & & TCONS_000 & & & TCONS_000 & & \\
\hline 06026 & SELP & A3 & 69373 & FAM81B & SE & 38883 & $\mathrm{DPH} 1$ & $A 5, R I$ \\
\hline TCONS_000 & & & TCONS_000 & & & TCONS_000 & & \\
\hline 08739 & SELP & A3 & 72453 & CAST & SE & 35149 & DPH1 & A3 \\
\hline TCONS_000 & DNM3O & & TCONS_000 & & & TCONS_000 & & \\
\hline 06053 & $\mathrm{~S}$ & $\mathrm{RI}$ & 69411 & PAM & $\mathrm{O}$ & 35151 & DPH1 & A5 \\
\hline TCONS_000 & DNM3O & & TCONS_000 & & & TCONS_000 & & \\
\hline 06054 & $\mathrm{~S}$ & $\mathrm{O}$ & 72470 & PAM & $\mathrm{A} 3, \mathrm{SE}$ & 35155 & HIC1 & $\mathrm{O}$ \\
\hline TCONS_000 & DNM3O & & TCONS_000 & PPIP5K & & TCONS_000 & & \\
\hline 08746 & $S$ & A5,RI & 69414 & 2 & SE & 35158 & SGSM2 & RI,SE \\
\hline TCONS_000 & & & TCONS_000 & & & TCONS_000 & & \\
\hline 06097 & CENPL & A5,SE & 69518 & FER & $\mathrm{AF}$ & 35159 & SGSM2 & $\mathrm{RI}$ \\
\hline TCONS_000 & RP4-79 & & TCONS_000 & & & TCONS_000 & & \\
\hline 06139 & 8P15.3 & $\mathrm{O}$ & 72483 & APC & $\mathrm{O}$ & 35160 & SGSM2 & $A 5, R I$ \\
\hline TCONS_000 & & & TCONS_000 & & & TCONS_000 & & \\
\hline 06182 & RGS16 & $\mathrm{O}$ & 69566 & YTHDC2 & $\mathrm{O}$ & 38891 & SGSM2 & $\mathrm{O}$ \\
\hline TCONS_000 & NMNAT & & TCONS_000 & CSNK1 & & TCONS_000 & RAP1GA & \\
\hline 06187 & 2 & $\mathrm{O}$ & 69669 & G3 & SE & 38899 & $\mathrm{P} 2$ & $\mathrm{O}$ \\
\hline TCONS_000 & & & TCONS_000 & CSNK1 & & TCONS_000 & & \\
\hline 06198 & EDEM3 & SE & 69670 & G3 & $\mathrm{A} 3, \mathrm{SE}$ & 35194 & SPNS2 & $\mathrm{RI}$ \\
\hline TCONS_000 & & & TCONS_000 & GRAMD & & TCONS_000 & & \\
\hline 06222 & TPR & RI & 69684 & 3 & AF,SE & 38903 & ARRB2 & $\mathrm{RI}$ \\
\hline TCONS_000 & & & TCONS_000 & & & TCONS_000 & & \\
\hline 06231 & BRINP3 & $\mathrm{AF}$ & 69693 & LMNB1 & SE & 35196 & ARRB2 & RI,SE \\
\hline TCONS_000 & RP5-10 & & TCONS_000 & & & TCONS_000 & & \\
\hline 06241 & 1101.2 & $\mathrm{AL}$ & 69737 & RAD50 & $\mathrm{O}$ & 35197 & ARRB2 & RI \\
\hline TCONS_000 & & & TCONS_000 & & & TCONS_000 & & \\
\hline 06253 & UCHL5 & 0 & 69738 & RAD50 & $\mathrm{O}$ & 35198 & ARRB2 & $\mathrm{O}$ \\
\hline TCONS_000 & & & TCONS_000 & & & TCONS_000 & & \\
\hline 06255 & UCHL5 & $\mathrm{A} 3, \mathrm{AL}$ & 69766 & PHF15 & $A F$ & 35210 & MINK1 & $A 3, R I$ \\
\hline TCONS_000 & & & TCONS_000 & TXNDC1 & & TCONS_000 & & \\
\hline 06269 & ZBTB41 & SE & 69782 & 5 & 0 & 35214 & MINK1 & RI \\
\hline
\end{tabular}




\begin{tabular}{|c|c|c|c|c|c|c|c|c|}
\hline TCONS_000 & DENND & & TCONS_000 & & & TCONS_000 & & \\
\hline 06271 & $1 \mathrm{~B}$ & SE & 69808 & FAM53C & AF,SE & 38904 & RNF167 & A3 \\
\hline TCONS_000 & & & TCONS_000 & & & TCONS_000 & & \\
\hline 06341 & PTPN7 & 0 & 72613 & MATR3 & $\mathrm{O}$ & 38906 & ENO3 & A5 \\
\hline TCONS_000 & & & TCONS_000 & & & TCONS_000 & RP5-105 & \\
\hline 08844 & KLHL12 & RI,SE & 72614 & MATR3 & A3 & 35225 & $0 D 4.5$ & $\mathrm{O}$ \\
\hline TCONS_000 & & & TCONS_000 & & & TCONS_000 & & \\
\hline 06363 & CHIT1 & O & 69881 & PURA & A5 & 35227 & KIF1C & $\mathrm{O}$ \\
\hline TCONS_000 & PLEKH & & TCONS_000 & ANKHD & & TCONS_000 & & \\
\hline 06379 & A6 & A3 & 69892 & 1 & $\mathrm{RI}, \mathrm{SE}$ & 35233 & RABEP1 & A5,SE \\
\hline TCONS_000 & PIK3C2 & & TCONS_000 & ANKHD & & TCONS_000 & & \\
\hline 06387 & B & $\mathrm{RI}$ & 72628 & 1 & $\mathrm{RI}, \mathrm{SE}$ & 38909 & RABEP1 & A5 \\
\hline TCONS_000 & & & TCONS_000 & ANKHD & & TCONS_000 & & \\
\hline 06402 & LEMD1 & $A F$ & 72629 & 1 & $\mathrm{~A} 3, \mathrm{SE}$ & 38915 & XAF1 & SE \\
\hline TCONS_000 & & & TCONS_000 & ANKHD & & TCONS_000 & ALOX12 & \\
\hline $06403^{-}$ & LEMD1 & $A F$ & 72632 & 1 & $\mathrm{O}$ & 35264 & $\mathrm{P} 2$ & A5,SE \\
\hline TCONS_000 & & & TCONS_000 & & & TCONS_000 & & \\
\hline 08867 & YOD1 & A3 & 69899 & TMCO6 & O & 35278 & ACADVL & $\mathrm{RI}$ \\
\hline TCONS 000 & & & TCONS 000 & & & TCONS 000 & & \\
\hline 06463 & YOD1 & $A F$ & 72635 & WDR55 & RI & 38919 & ACADVL & $\mathrm{RI}$ \\
\hline TCONS_000 & SERTA & & TCONS_000 & & & TCONS_000 & & \\
\hline 06489 & D4-AS1 & $A F$ & 72638 & HARS2 & SE & 38920 & ACADVL & $\mathrm{RI}$ \\
\hline TCONS_000 & & & TCONS_000 & & & TCONS_000 & & \\
\hline 06493 & NEK2 & A3 & 69903 & HARS2 & $\mathrm{O}$ & 35279 & ACADVL & $\mathrm{RI}$ \\
\hline TCONS_000 & & & TCONS_000 & & & TCONS_000 & & \\
\hline 06495 & LPGAT1 & SE & 69904 & HARS2 & A3 & 35280 & ACADVL & O \\
\hline TCONS_000 & TMEM2 & & TCONS_000 & & & TCONS_000 & & \\
\hline 08897 & 06 & A3,SE & 69905 & HARS2 & RI & 35294 & ACAP1 & RI \\
\hline TCONS_000 & ANGEL & & TCONS_000 & & & TCONS_000 & & \\
\hline 06528 & 2 & A5 & 72671 & RBM27 & SE & 38923 & TNK1 & $\mathrm{O}$ \\
\hline & RP11-3 & & & & & & TNFSF12 & \\
\hline TCONS 000 & 92017. & & TCONS 000 & & & TCONS 000 & -TNFSF1 & \\
\hline 08910 & 1 & $\mathrm{O}$ & 70017 & ABLIM3 & O & 38927 & 3 & $\mathrm{O}$ \\
\hline & RP11-3 & & & & & & TNFSF12 & \\
\hline TCONS_000 & 92017. & & TCONS_000 & & & TCONS_000 & -TNFSF1 & \\
\hline 08911 & 1 & $\mathrm{O}$ & 72683 & ABLIM3 & SE & 35300 & 3 & SE \\
\hline
\end{tabular}




\begin{tabular}{|c|c|c|c|c|c|c|c|c|}
\hline \multicolumn{3}{|l|}{ TCONS_000 } & \multicolumn{3}{|l|}{ TCONS_000 } & TCONS_000 & \multicolumn{2}{|l|}{ SENP3-E } \\
\hline 06548 & BPNT1 & SE & 70018 & ABLIM3 & $\mathrm{O}$ & 35303 & IF4A1 & $\mathrm{O}$ \\
\hline TCONS_000 & & & TCONS_000 & MIR143 & & TCONS_000 & SENP3-E & \\
\hline 06577 & TLR5 & SE & 70025 & HG & SE & 38930 & IF4A1 & $\mathrm{O}$ \\
\hline TCONS_000 & & & TCONS_000 & ARHGE & & TCONS_000 & SENP3-E & \\
\hline 06580 & SUSD4 & A3,SE & 72687 & F37 & RI & 38931 & IF4A1 & $\mathrm{O}$ \\
\hline TCONS_000 & & & TCONS_000 & & & TCONS_000 & SENP3-E & \\
\hline 06585 & CAPN8 & O & 70047 & CDX1 & AF & 35305 & IF4A1 & A3 \\
\hline TCONS_000 & RP11-5 & & TCONS_000 & & & TCONS_000 & & \\
\hline 06602 & 04P24.2 & $\mathrm{O}$ & 70054 & NDST1 & AF & 35341 & DNAH2 & $\mathrm{O}$ \\
\hline TCONS_000 & RP11-5 & & TCONS_000 & & & TCONS_000 & & \\
\hline 08936 & 04P24.2 & SE & 70055 & NDST1 & AF & 35357 & CNTROB & RI \\
\hline TCONS_000 & RP11-5 & & TCONS_000 & & & TCONS_000 & ARHGEF & \\
\hline 06603 & 04P24.2 & SE & 70062 & SYNPO & AF & 38942 & 15 & RI \\
\hline TCONS_000 & & & TCONS_000 & GALNT1 & & TCONS_000 & & \\
\hline 06608 & NVL & SE & 70095 & 0 & AF,SE & 38956 & MYOCD & SE \\
\hline TCONS_000 & & & TCONS_000 & & & TCONS_000 & & \\
\hline 06611 & WDR26 & A3,SE & 70135 & CYFIP2 & $\mathrm{O}$ & 35423 & TTC19 & A3,A5 \\
\hline TCONS_000 & & & TCONS_000 & & & TCONS_000 & CCDC14 & \\
\hline 06615 & LBR & A5,SE & 70149 & TTC1 & $\mathrm{O}$ & 35466 & $4 \mathrm{~A}$ & SE \\
\hline TCONS_000 & & & TCONS_000 & & & TCONS_000 & CCDC14 & \\
\hline 06620 & ENAH & SE & 70150 & TTC1 & A5 & 35467 & $4 \mathrm{~A}$ & SE \\
\hline TCONS_000 & RP4-55 & & TCONS_000 & & & TCONS_000 & & \\
\hline 08950 & $9 A 3.7$ & $\mathrm{RI}, \mathrm{SE}$ & 70161 & CCNG1 & $\mathrm{O}$ & 38966 & MPRIP & A5,SE \\
\hline TCONS_000 & & & TCONS_000 & & & TCONS_000 & & \\
\hline 06650 & LIN9 & $\mathrm{O}$ & 72727 & WWC1 & A3 & 35470 & MPRIP & A5,SE \\
\hline TCONS_000 & MRPL5 & & TCONS_000 & & & TCONS_000 & & \\
\hline 06678 & 5 & SE & 70186 & DOCK2 & SE & 38971 & LRRC48 & SE \\
\hline TCONS_000 & MRPL5 & & TCONS_000 & & & TCONS_000 & & \\
\hline 06679 & 5 & SE & 72730 & DOCK2 & A3,SE & 35491 & LLGL1 & A3 \\
\hline TCONS_000 & & & TCONS_000 & RANBP1 & & TCONS_000 & PRPSAP & \\
\hline 06715 & TTC13 & A5 & 70190 & 7 & RI,SE & 35513 & 2 & $\mathrm{AF}$ \\
\hline TCONS_000 & C1orf13 & & TCONS_000 & & & TCONS_000 & ALDH3A & \\
\hline 06722 & 1 & RI & 70224 & CPEB4 & SE & 38982 & 2 & SE \\
\hline TCONS_000 & & & TCONS_000 & & & TCONS_000 & ALDH3A & \\
\hline 06729 & EGLN1 & SE & 70238 & $\mathrm{HRH} 2$ & AL & 38983 & 2 & SE \\
\hline
\end{tabular}




\begin{tabular}{|c|c|c|c|c|c|c|c|c|}
\hline TCONS_000 & SIPA1L & & TCONS_000 & & & TCONS_000 & & \\
\hline 06735 & 2 & SE & 70242 & SIMC1 & 0 & 35535 & SPECC1 & $\mathrm{AF}$ \\
\hline TCONS_000 & SIPA1L & & TCONS_000 & & & TCONS_000 & CCDC14 & \\
\hline 06736 & 2 & SE & 70246 & ARL10 & 0 & 35546 & $4 \mathrm{CP}$ & A5,SE \\
\hline TCONS_000 & PCNXL & & TCONS_000 & & & TCONS_000 & CCDC14 & \\
\hline 08993 & 2 & $\mathrm{O}$ & 70261 & FGFR4 & A5,RI & 35547 & $4 \mathrm{CP}$ & A5,SE \\
\hline TCONS_000 & & & TCONS_000 & & & TCONS_000 & & \\
\hline 06752 & TARBP1 & A3 & 70264 & FGFR4 & $\mathrm{O}$ & 35550 & USP32P3 & $\mathrm{O}$ \\
\hline TCONS_000 & & & TCONS_000 & & & TCONS_000 & & \\
\hline 06753 & TARBP1 & SE & 72754 & NSD1 & A5 & 38991 & WSB1 & $\mathrm{RI}$ \\
\hline TCONS_000 & & & TCONS_000 & & & TCONS_000 & & \\
\hline 08997 & TARBP1 & $\mathrm{RI}$ & 70267 & NSD1 & $\mathrm{AF}$ & 39005 & SUPT6H & $\mathrm{O}$ \\
\hline TCONS_000 & B3GAL & & TCONS_000 & & & TCONS_000 & & \\
\hline 06780 & NT2 & SE & 70279 & RGS14 & A3 & 39006 & TRAF4 & A3 \\
\hline TCONS_000 & RP11-26 & & TCONS_0007 & B4GALT & & TCONS_0003 & & \\
\hline 06811 & $1 C 10.3$ & $\mathrm{O}$ & 0295 & 7 & $\mathrm{O}$ & 9007 & ERAL1 & $\mathrm{RI}$ \\
\hline TCONS_000 & RP11-26 & & TCONS_0007 & RMND5 & & TCONS_0003 & & \\
\hline 06812 & $1 \mathrm{C} 10.3$ & A5 & 0302 & $\mathrm{~B}$ & SE & 5631 & TP53I13 & $\mathrm{O}$ \\
\hline TCONS_000 & RP11-26 & & TCONS_0007 & HNRNP & & TCONS_0003 & LRRC37 & \\
\hline 06814 & $1 \mathrm{C} 10.3$ & $\mathrm{O}$ & 2771 & $\mathrm{AB}$ & SE & 9030 & B & $\mathrm{O}$ \\
\hline TCONS_000 & HNRNP & & TCONS_0007 & ZNF354 & & TCONS_0003 & AC08480 & \\
\hline 06840 & $U$ & A5 & 2773 & B & $\mathrm{O}$ & 5741 & 9.2 & $\mathrm{O}$ \\
\hline TCONS_000 & & & TCONS_0007 & SQSTM & & TCONS_0003 & & \\
\hline 06852 & SMYD3 & $\mathrm{O}$ & 0340 & 1 & A5,SE & 5773 & TAF15 & A5 \\
\hline TCONS_000 & & & TCONS_0007 & SQSTM & & TCONS_0003 & & \\
\hline 06865 & AHCTF1 & $\mathrm{AF}$ & 0342 & 1 & A5 & 5795 & GGNBP2 & A5,SE \\
\hline TCONS_000 & & & TCONS_0007 & SQSTM & & TCONS_0003 & & \\
\hline 06881 & MIR3916 & $\mathrm{O}$ & 0344 & 1 & AF & 5815 & DUSP14 & $\mathrm{AF}$ \\
\hline TCONS_000 & & & TCONS_0007 & CTB-12 & & TCONS_0003 & TBC1D3 & \\
\hline 09037 & ZNF496 & A3,SE & 0349 & 904.1 & $\mathrm{AF}$ & 5818 & $\mathrm{~F}$ & A5,SE \\
\hline TCONS_000 & & & TCONS_0007 & LINCOO & & TCONS_0003 & & \\
\hline 06893 & ZNF692 & AF & 0357 & 847 & $\mathrm{O}$ & 9056 & socs7 & O \\
\hline TCONS_000 & & & TCONS_0007 & СTC-33 & & TCONS_0003 & & \\
\hline 06894 & ZNF692 & $A F, R I$ & 0367 & $8 \mathrm{M} 12.5$ & 0 & 5841 & LASP1 & O \\
\hline TCONS_000 & ZNF692 & A3,AF & TCONS_0007 & TRIM41 & $\mathrm{RI}$ & TCONS_0003 & STARD3 & 0 \\
\hline
\end{tabular}




\begin{tabular}{|c|c|c|c|c|c|c|c|c|}
\hline \multicolumn{3}{|l|}{09039} & \multicolumn{3}{|l|}{0369} & \multicolumn{3}{|l|}{9071} \\
\hline TCONS_000 & & & TCONS_0007 & SLC12A & & TCONS_0003 & & \\
\hline 09040 & ZNF692 & $A F, R I$ & 2799 & 7 & $\mathrm{RI}$ & 5876 & GRB7 & $\mathrm{RI}$ \\
\hline TCONS_000 & ZMYND1 & & TCONS_0007 & SLC12A & & TCONS_0003 & & \\
\hline 11744 & 1 & AF,SE & 2800 & 7 & $\mathrm{RI}$ & 5877 & GRB7 & RI \\
\hline TCONS_000 & ZMYND1 & AF,RI, & TCONS_0007 & SLC12A & & TCONS_0003 & & \\
\hline 11745 & 1 & SE & 0404 & 7 & $\mathrm{RI}$ & 9077 & MSL1 & A5 \\
\hline TCONS_000 & ZMYND1 & & TCONS_0007 & SDHAP & & TCONS_0003 & & \\
\hline 11747 & 1 & $A F$ & 2810 & 3 & $\mathrm{MX}$ & 9085 & TTC25 & $\mathrm{O}$ \\
\hline TCONS_000 & & & TCONS_0007 & SDHAP & & TCONS_0003 & ATP6VO & \\
\hline 09053 & GTPBP4 & $\mathrm{RI}$ & 0418 & 3 & $M X$ & 9092 & A1 & SE \\
\hline TCONS_000 & RP11-49 & & TCONS_0007 & RP11-4 & & TCONS_0003 & & \\
\hline 09101 & 907.7 & $\mathrm{O}$ & 0421 & 3F13.1 & SE & 5956 & NAGLU & $\mathrm{O}$ \\
\hline TCONS_000 & & & TCONS_0007 & & & TCONS_0003 & & \\
\hline 11759 & RBM17 & $A F, R I$ & 2833 & C5orf49 & A5 & 5957 & NAGLU & $\mathrm{O}$ \\
\hline TCONS_000 & & & TCONS_0007 & FASTK & & TCONS_0003 & & \\
\hline 09184 & CAMK1D & A5 & 0443 & D3 & A3 & 9093 & COASY & $\mathrm{O}$ \\
\hline TCONS_000 & & & TCONS_0007 & FASTK & & TCONS_0003 & & \\
\hline 09186 & OPTN & $\mathrm{O}$ & 0444 & D3 & A3 & 9094 & TUBG1 & RI \\
\hline TCONS_000 & & & TCONS_0007 & FASTK & & TCONS_0003 & & \\
\hline 09195 & MCM10 & $A F$ & 2834 & D3 & $A 3, R I$ & 9096 & TUBG2 & RI \\
\hline TCONS_000 & & & TCONS_0007 & & & TCONS_0003 & & \\
\hline 11787 & HSPA14 & $\mathrm{RI}$ & 2842 & CMBL & A5 & 9097 & TUBG2 & RI \\
\hline TCONS_000 & SUV39H & & TCONS_0007 & & & TCONS_0003 & & \\
\hline 09203 & 2 & A5 & 0467 & DNAH5 & $A F$ & 9099 & TUBG2 & RI \\
\hline TCONS_000 & SUV39H & & TCONS_0007 & RP11-3 & & TCONS_0003 & & \\
\hline 11790 & 2 & $\mathrm{~A} 5, \mathrm{AF}$ & 2877 & 74A4.1 & AL & 6016 & NBR2 & $\mathrm{O}$ \\
\hline TCONS_000 & & & TCONS_0007 & DROSH & & TCONS_0003 & & \\
\hline 09207 & PTER & $\mathrm{MX}$ & 2879 & A & SE & 6029 & ARL4D & $\mathrm{O}$ \\
\hline TCONS_000 & & & TCONS_0007 & DROSH & & TCONS_0003 & & \\
\hline 11796 & VIM & A5 & 0503 & A & SE & 6032 & NAGS & RI \\
\hline TCONS_000 & & & TCONS_0007 & DROSH & & TCONS_0003 & & \\
\hline 09230 & MRC1L1 & $\mathrm{O}$ & 0504 & A & SE & 9116 & G6PC3 & SE \\
\hline TCONS_000 & & & TCONS_0007 & & & TCONS_0003 & & \\
\hline 11800 & MRC1L1 & $\mathrm{O}$ & 2884 & ZFR & RI & 6035 & G6PC3 & SE \\
\hline
\end{tabular}




\begin{tabular}{|c|c|c|c|c|c|c|c|c|}
\hline TCONS 000 & & & TCONS 0007 & RP11-1 & & TCONS 0003 & & \\
\hline 11801 & MRC1L1 & $\mathrm{O}$ & 0552 & 1 & $\mathrm{O}$ & 6040 & TMUB2 & A3 \\
\hline TCONS_000 & & & TCONS_0007 & & & TCONS_0003 & & \\
\hline 11802 & MRC1L1 & 0 & 0612 & RPL37 & $\mathrm{O}$ & 6041 & TMUB2 & $\mathrm{O}$ \\
\hline TCONS_000 & & & TCONS_0007 & HMGCS & & TCONS_0003 & & \\
\hline 09255 & MLLT10 & A3 & 2936 & 1 & SE & 6052 & GRN & A5 \\
\hline TCONS_000 & & A3,A5, & TCONS_0007 & & & TCONS_0003 & & \\
\hline 09301 & PDSS1 & AF & 0680 & FGF10 & $\mathrm{O}$ & 6056 & DBF4B & $A 3, R I$ \\
\hline TCONS_000 & & & TCONS_0007 & & & TCONS_0003 & & \\
\hline 11842 & MASTL & RI & 2944 & MOCS2 & AF & 6058 & HIGD1B & A5 \\
\hline TCONS_000 & RP11-47 & & TCONS_0007 & & & TCONS_0003 & & \\
\hline 11847 & $8 \mathrm{H} 13.1$ & AL & 0726 & CCNO & $\mathrm{O}$ & 9120 & ACBD4 & $A 3, R I$ \\
\hline TCONS_000 & PTCHD3 & & TCONS_0007 & & & TCONS_0003 & & \\
\hline 09327 & P1 & $\mathrm{O}$ & 2948 & DHX29 & RI & 9131 & NSF & $\mathrm{O}$ \\
\hline TCONS_000 & PTCHD3 & & TCONS_0007 & DEPDC & & TCONS_0003 & & \\
\hline 11851 & P1 & A5 & 0768 & $1 \mathrm{~B}$ & SE & 9134 & NSF & SE \\
\hline TCONS_000 & & & TCONS_0007 & & & TCONS_0003 & & \\
\hline 11855 & MAP3K8 & A5 & 0822 & TRIM23 & $\mathrm{O}$ & 6126 & NPEPPS & A3 \\
\hline TCONS_000 & & & TCONS_0007 & CCDC1 & & TCONS_0003 & & \\
\hline 09353 & ZEB1 & A5,SE & 0833 & 25 & A5 & 6130 & NPEPPS & $\mathrm{O}$ \\
\hline TCONS_000 & & & TCONS_0007 & GUSBP & & TCONS_0003 & & \\
\hline 11857 & ZEB1 & SE & 0847 & 3 & $\mathrm{O}$ & 9143 & KPNB1 & $\mathrm{O}$ \\
\hline TCONS_000 & HSD17B & & TCONS_0007 & GUSBP & & TCONS_0003 & & \\
\hline 11872 & 7P2 & SE & 0849 & 3 & $\mathrm{O}$ & 6141 & TBKBP1 & $\mathrm{O}$ \\
\hline TCONS_000 & LINC009 & & TCONS_0007 & RP11-1 & & TCONS_0003 & & \\
\hline 11874 & 99 & $\mathrm{RI}$ & 0851 & $\begin{array}{l}\text { 319K7.1 } \\
\text { RP11-1 }\end{array}$ & $\mathrm{RI}$ & 6144 & SP2 & A5 \\
\hline TCONS_000 & LINC009 & & TCONS_0007 & $415 \mathrm{C} 14$. & & TCONS_0003 & CDK5RA & \\
\hline 09412 & 99 & $\mathrm{RI}$ & 0855 & $\begin{array}{l}4 \\
\text { RP11-1 }\end{array}$ & $\mathrm{O}$ & 6152 & P3 & $A F, R I$ \\
\hline TCONS_000 & LINC009 & & TCONS_0007 & $415 \mathrm{C} 14$. & & TCONS_0003 & CDK5RA & \\
\hline 11876 & 99 & $\mathrm{O}$ & 0856 & $\begin{array}{l}3 \\
\text { RP11-1 }\end{array}$ & $\mathrm{O}$ & 9144 & P3 & $\mathrm{RI}$ \\
\hline TCONS_000 & & & TCONS_0007 & $415 \mathrm{C} 14$. & & TCONS_0003 & & \\
\hline 09429 & BMS1 & A5 & 0857 & 4 & $\mathrm{O}$ & 6160 & NFE2L1 & AF,SE \\
\hline
\end{tabular}




\begin{tabular}{|c|c|c|c|c|c|c|c|c|}
\hline & & & & RP11-1 & & & & \\
\hline TCONS_000 & & & TCONS_0007 & $415 \mathrm{C} 14$. & & TCONS_0003 & CTD-237 & \\
\hline 09430 & BMS1 & 0 & 2974 & 3 & $\mathrm{O}$ & 6186 & 7D24.8 & SE \\
\hline TCONS_000 & & & TCONS_0007 & & & TCONS_0003 & & \\
\hline 11886 & ALOX5 & RI & 0863 & NAIP & $\mathrm{O}$ & 9154 & PDK2 & $\mathrm{RI}$ \\
\hline TCONS_000 & & & TCONS_0007 & & & TCONS_0003 & & \\
\hline 09459 & FAM21C & $A 3, R I$ & 0864 & NAIP & $\mathrm{RI}$ & 6239 & ACSF2 & RI,SE \\
\hline TCONS_000 & & & TCONS_0007 & & & TCONS_0003 & & \\
\hline 11887 & FAM21C & $A 3, R I$ & 0869 & GTF2H2 & A3 & 6240 & ACSF2 & SE \\
\hline TCONS_000 & & & TCONS_0007 & & & TCONS_0003 & & \\
\hline 11888 & FAM21C & A3 & 0870 & GTF2H2 & $\mathrm{RI}$ & 6245 & RSAD1 & $\mathrm{O}$ \\
\hline TCONS_000 & & & TCONS_0007 & & & TCONS_0003 & & \\
\hline 09472 & FAM21B & $\mathrm{O}$ & 2976 & GTF2H2 & $\mathrm{O}$ & 6246 & RSAD1 & $\mathrm{RI}$ \\
\hline TCONS_000 & & & TCONS_0007 & & & TCONS_0003 & & \\
\hline 11890 & FAM21B & $\mathrm{O}$ & 2977 & GTF2H2 & $\mathrm{O}$ & 6252 & SPATA20 & $\mathrm{RI}$ \\
\hline & & & & RP11-1 & & & & \\
\hline TCONS_000 & & & TCONS_0007 & 280N14. & & TCONS_0003 & & \\
\hline 09473 & FAM21B & SE & 2978 & 3 & RI & 6255 & ABCC3 & RI,SE \\
\hline TCONS_000 & & & TCONS_0007 & GUSBP & & TCONS_0003 & & \\
\hline 09488 & WDFY4 & 0 & 0878 & 9 & $\mathrm{O}$ & 6256 & ABCC3 & A5 \\
\hline TCONS_000 & & & TCONS_0007 & MRPS2 & & TCONS_0003 & & \\
\hline 09501 & PARGP1 & SE & 2988 & 7 & SE & 9163 & ABCC3 & $\mathrm{RI}$ \\
\hline TCONS_000 & & & TCONS_0007 & ANKRA & & TCONS_0003 & & \\
\hline 11899 & FAM21A & RI & 0896 & 2 & RI & 9164 & ABCC3 & $A 3, R I$ \\
\hline TCONS_000 & & & TCONS_0007 & ANKRA & & TCONS_0003 & & \\
\hline 09572 & SIRT1 & A5 & 0897 & 2 & A5 & 9166 & ABCC3 & A3,A5 \\
\hline TCONS_000 & HNRNP & & TCONS_0007 & ANKRA & & TCONS_0003 & & \\
\hline 09578 & $\mathrm{H} 3$ & A5 & 2991 & 2 & RI & 6270 & NME2 & SE \\
\hline TCONS_000 & & & TCONS_0007 & CTD-22 & & TCONS_0003 & & \\
\hline 11923 & CCAR1 & $\mathrm{RI}$ & 0909 & $92 \mathrm{M} 14.1$ & AL & 9181 & STXBP4 & A3 \\
\hline TCONS_000 & & & TCONS_0007 & FAM169 & & TCONS_0003 & & $A F, R I$, \\
\hline 11924 & CCAR1 & RI & 0922 & A & $\mathrm{AF}$ & 9190 & AKAP1 & SE \\
\hline TCONS_000 & & & TCONS_0007 & FAM169 & & TCONS_0003 & & \\
\hline 09599 & SRGN & $\mathrm{O}$ & 0923 & A & $\mathrm{AF}$ & 9198 & RAD51C & A5,SE \\
\hline TCONS_000 & & & TCONS_0007 & RP11-2 & & TCONS_0003 & & \\
\hline 09600 & SRGN & $\mathrm{O}$ & 0925 & $29 C 3.2$ & $\mathrm{O}$ & 9203 & CLTC & SE \\
\hline
\end{tabular}




\begin{tabular}{|c|c|c|c|c|c|c|c|c|}
\hline \multicolumn{3}{|l|}{ TCONS_000 } & \multirow{3}{*}{$\begin{array}{l}\text { TCONS_0007 } \\
3000 \\
\text { TCONS_0007 }\end{array}$} & \multicolumn{2}{|l|}{ RP11-2 } & \multicolumn{3}{|l|}{ TCONS_0003 } \\
\hline 09601 & SRGN & $\mathrm{O}$ & & $29 \mathrm{C} 3.2$ & $\mathrm{O}$ & 9209 & TLK2 & AF,SE \\
\hline TCONS_000 & & & & RP11-2 & & TCONS_0003 & & \\
\hline 09602 & SRGN & $\mathrm{O}$ & 3001 & $29 \mathrm{C} 3.2$ & $\mathrm{O}$ & 6415 & TANC2 & $\mathrm{A} 5, \mathrm{SE}$ \\
\hline TCONS_000 & & A5,RI, & TCONS_0007 & CTD-23 & & TCONS_0003 & & \\
\hline 11933 & $\mathrm{CDH} 23$ & SE & 3004 & 84B11.2 & $\mathrm{O}$ & 6416 & TANC2 & $\mathrm{A} 5, \mathrm{SE}$ \\
\hline TCONS_000 & & & TCONS_0007 & & & TCONS_0003 & & \\
\hline 09654 & CHST3 & $\mathrm{AF}$ & 0981 & MTX3 & SE & 6417 & TANC2 & $\mathrm{A} 5, \mathrm{SE}$ \\
\hline TCONS_000 & & & TCONS_0007 & TMEM1 & & TCONS_0003 & & \\
\hline 11935 & CHST3 & AF & 1042 & $61 \mathrm{~B}$ & A5,SE & 6423 & ACE & $\mathrm{RI}$ \\
\hline TCONS_000 & ANAPC1 & & TCONS_0007 & ARRDC & & TCONS_0003 & & \\
\hline 09655 & 6 & A5 & 3032 & 3 & SE & 9218 & DDX42 & $\mathrm{RI}, \mathrm{SE}$ \\
\hline TCONS_000 & ANAPC1 & & TCONS_0007 & KIAA08 & & TCONS_0003 & & \\
\hline 09656 & 6 & A5 & 1093 & 25 & $\mathrm{~A} 3, \mathrm{SE}$ & 9219 & DDX42 & SE \\
\hline TCONS_000 & & & TCONS_0007 & & & TCONS_0003 & & \\
\hline 11937 & $\mathrm{MCU}$ & $\mathrm{O}$ & 1135 & RIOK2 & $\mathrm{O}$ & 9220 & DDX42 & SE \\
\hline TCONS_000 & FAM149 & $\mathrm{A} 3, \mathrm{~A} 5$ & TCONS_0007 & & & TCONS_0003 & & \\
\hline 09673 & B1 & $\mathrm{AF}$ & 1151 & CHD1 & $\mathrm{O}$ & 6461 & CEP95 & SE \\
\hline TCONS_000 & FAM149 & & TCONS_0007 & & & TCONS_0003 & & \\
\hline 09675 & B1 & A5 & 1169 & NUDT12 & $\mathrm{RI}$ & 9229 & BPTF & $\mathrm{A} 5, \mathrm{SE}$ \\
\hline TCONS_000 & RP11-13 & & TCONS_0007 & & & TCONS_0003 & LINC006 & \\
\hline 09678 & 7L10.6 & $\mathrm{O}$ & 1170 & NUDT12 & A3 & 6511 & 74 & $\mathrm{O}$ \\
\hline TCONS_000 & & & TCONS_0007 & & & TCONS_0003 & LINC006 & \\
\hline 09692 & ZSWIM8 & $\mathrm{O}$ & 1227 & TRIM36 & $\mathrm{O}$ & 9233 & 74 & AF \\
\hline TCONS_000 & & & TCONS_0007 & CCDC1 & & TCONS_0003 & LINC006 & \\
\hline 09693 & ZSWIM8 & $\mathrm{O}$ & 3085 & 12 & SE & 9234 & 74 & AF \\
\hline TCONS_000 & & & TCONS_0007 & & & TCONS_0003 & & \\
\hline 11953 & VDAC2 & SE & 1274 & CEP120 & AF & 6567 & C17orf80 & AF \\
\hline TCONS_000 & & & TCONS_0007 & & & TCONS_0003 & RP11-30 & \\
\hline 09811 & SNCG & $\mathrm{O}$ & 1276 & ZNF608 & $\mathrm{O}$ & 6602 & 9N17.4 & $\mathrm{O}$ \\
\hline TCONS_000 & & & TCONS_0007 & & & TCONS_0003 & & \\
\hline 09815 & FAM35A & SE & 1277 & ZNF608 & SE & 6605 & CDR2L & A5 \\
\hline TCONS_000 & STAMBP & AL,RI, & TCONS_0007 & RAPGE & & TCONS_0003 & & \\
\hline 09840 & L1 & SE & 1320 & F6 & SE & 9263 & NUP85 & $\mathrm{RI}, \mathrm{SE}$ \\
\hline TCONS_000 & & & TCONS_0007 & & A5,AF, & TCONS_0003 & KIAA019 & \\
\hline 09857 & IFIT2 & $\mathrm{O}$ & 3159 & P4HA2 & $\mathrm{MX}$ & 9266 & 5 & $A 5, R I$ \\
\hline
\end{tabular}




\begin{tabular}{|c|c|c|c|c|c|c|c|c|}
\hline \multicolumn{3}{|l|}{ TCONS_000 } & \multicolumn{3}{|l|}{ TCONS_0007 } & \multicolumn{3}{|l|}{ TCONS_0003 } \\
\hline 09873 & RPP30 & $\mathrm{O}$ & 3160 & P4HA2 & $\mathrm{A} 5, \mathrm{MX}$ & 6632 & TSEN54 & $\mathrm{RI}$ \\
\hline TCONS_000 & & & TCONS_0007 & SHROO & & TCONS_0003 & & \\
\hline 09876 & RPP30 & $A L, R I$ & 3166 & M1 & $\mathrm{RI}$ & 9268 & TSEN54 & A5 \\
\hline TCONS_000 & & & TCONS_0007 & SHROO & & TCONS_0003 & & A3,RI, \\
\hline 09879 & PCGF5 & $\mathrm{AF}$ & 1356 & M1 & 0 & 6638 & MY015B & SE \\
\hline TCONS_000 & & & TCONS_0007 & & & TCONS_0003 & & \\
\hline 12042 & PCGF5 & AF,SE & 1362 & AFF4 & SE & 9277 & MYO15B & A5 \\
\hline TCONS_000 & & & TCONS_0007 & & & TCONS_0003 & & \\
\hline 09906 & CEP55 & A5 & 1414 & $\mathrm{H} 2 \mathrm{AFY}$ & A3 & 6640 & MYO15B & $\mathrm{A} 3, \mathrm{SE}$ \\
\hline TCONS_000 & SLC35G & & TCONS_0007 & & & TCONS_0003 & & A3,RI, \\
\hline 09909 & 1 & $\mathrm{O}$ & 1431 & KLHL3 & SE & 6641 & MYO15B & SE \\
\hline TCONS_000 & CYP2C1 & & TCONS_0007 & & & TCONS_0003 & TEN1-C & \\
\hline 09917 & 9 & $\mathrm{O}$ & 1454 & FAM13B & A5,SE & 6673 & DK3 & $\mathrm{RI}$ \\
\hline TCONS_000 & CYP2C1 & & TCONS_0007 & & & TCONS_0003 & TEN1-C & \\
\hline 09921 & 9 & SE & 1455 & FAM13B & A5 & 6674 & DK3 & $\mathrm{O}$ \\
\hline TCONS_000 & ZFYVE2 & & TCONS_0007 & & & TCONS_0003 & & \\
\hline 09974 & 7 & A5,SE & 3182 & FAM13B & $\mathrm{RI}$ & 6681 & SPHK1 & A5,RI \\
\hline TCONS_000 & & & TCONS_0007 & & & TCONS_0003 & & \\
\hline 10013 & LZTS2 & $A F, R I$ & 3185 & BRD8 & $\mathrm{RI}$ & 6688 & SNHG16 & $\mathrm{O}$ \\
\hline TCONS_000 & & & TCONS_0007 & & & TCONS_0003 & METTL2 & \\
\hline 12085 & SFXN3 & A5,RI & 1463 & BRD8 & A3 & 9290 & 3 & A5 \\
\hline TCONS_000 & & & TCONS_0007 & & & TCONS_0003 & METTL2 & \\
\hline 10016 & SFXN3 & $\mathrm{RI}$ & 1510 & ECSCR & A3 & 6697 & 3 & A5 \\
\hline TCONS_000 & & & TCONS_0007 & & & TCONS_0003 & & \\
\hline 10017 & SFXN3 & $\mathrm{RI}$ & 1533 & HARS & 0 & 6724 & TNRC6C & SE \\
\hline TCONS_000 & KAZALD & & TCONS 0007 & FCHSD & & TCONS_0003 & & \\
\hline 10019 & 1 & $\mathrm{RI}$ & 1568 & 1 & A3 & 6739 & AFMID & 0 \\
\hline TCONS_000 & & & TCONS_0007 & FCHSD & & TCONS_0003 & & \\
\hline 10038 & GBF1 & $\mathrm{RI}$ & 1569 & 1 & $\mathrm{RI}$ & 6747 & PGS1 & A3 \\
\hline TCONS_000 & & & TCONS_0007 & FCHSD & & TCONS_0003 & & \\
\hline 10039 & GBF1 & A5 & 1570 & 1 & $\mathrm{RI}, \mathrm{SE}$ & 6748 & PGS1 & $\mathrm{O}$ \\
\hline TCONS_000 & & & TCONS_0007 & & & TCONS_0003 & & \\
\hline 10040 & GBF1 & A5,RI & 1571 & ARAP3 & SE & 6765 & ENGASE & $\mathrm{RI}$ \\
\hline TCONS_000 & & & TCONS_0007 & & & TCONS_0003 & & \\
\hline 12088 & NFKB2 & A5,RI & 1574 & ARAP3 & RI & 9321 & ENGASE & A5 \\
\hline
\end{tabular}




\begin{tabular}{|c|c|c|c|c|c|c|c|c|}
\hline \multicolumn{3}{|l|}{ TCONS_000 } & \multicolumn{3}{|l|}{ TCONS_0007 } & \multicolumn{3}{|l|}{ TCONS_0003 } \\
\hline 12089 & NFKB2 & A5,RI & 1653 & LARS & $\mathrm{RI}$ & 9325 & GAA & $\mathrm{A} 3, \mathrm{SE}$ \\
\hline TCONS_000 & & & TCONS_0007 & CTC-25 & & TCONS_0003 & & \\
\hline 10045 & FBXL15 & $\mathrm{O}$ & 3230 & 5N20.1 & $\mathrm{O}$ & 6771 & GAA & SE \\
\hline TCONS_000 & RP11-18 & & TCONS_0007 & & & TCONS_0003 & & \\
\hline 10048 & $\mathrm{I} 14.10$ & A5 & 1733 & ZNF300 & $\mathrm{RI}$ & 6779 & RNF213 & $\mathrm{A} 3, \mathrm{SE}$ \\
\hline TCONS_000 & RP11-18 & & TCONS_0007 & & & TCONS_0003 & AC02760 & \\
\hline 10049 & $\mathrm{I} 14.10$ & A5,RI & 1740 & TNIP1 & A3 & 6804 & 1.1 & $\mathrm{O}$ \\
\hline TCONS_000 & C10orf32 & & TCONS_0007 & & & TCONS_0003 & & \\
\hline 12095 & -ASMT & A5 & 3246 & TNIP1 & A3 & 6807 & C17orf89 & $\mathrm{O}$ \\
\hline TCONS_000 & & & TCONS_0007 & & & TCONS_0003 & & \\
\hline 10079 & PDCD11 & SE & 3247 & TNIP1 & $A 3, R I$ & 9339 & HGS & $\mathrm{RI}$ \\
\hline TCONS_000 & & & TCONS_0007 & & & TCONS_0003 & & \\
\hline 10105 & ADD3 & AF,SE & 3248 & TNIP1 & A3 & 9340 & HGS & $\mathrm{O}$ \\
\hline TCONS_000 & & & TCONS_0007 & & & TCONS_0003 & & \\
\hline 10129 & PDCD4 & SE & 1752 & ANXA6 & $\mathrm{O}$ & 6819 & HGS & $\mathrm{RI}$ \\
\hline TCONS_000 & & & TCONS_0007 & & & TCONS_0003 & & \\
\hline 10159 & TCF7L2 & SE & 1763 & FAT2 & $\mathrm{O}$ & 6847 & LRRC45 & $\mathrm{RI}$ \\
\hline TCONS_000 & & & TCONS_0007 & & & TCONS_0003 & & \\
\hline 12124 & TCF7L2 & A3 & 3254 & SPARC & $\mathrm{O}$ & 6853 & GPS1 & A3 \\
\hline TCONS_000 & & & TCONS_0007 & & & TCONS_0003 & & \\
\hline 12127 & CASP7 & $\mathrm{O}$ & 3279 & SLU7 & $A F$ & 6873 & HEXDC & RI \\
\hline TCONS_000 & PLEKHS & & TCONS_0007 & & & TCONS_0003 & & \\
\hline 10175 & 1 & A5 & 1886 & LCP2 & $\mathrm{O}$ & 6883 & FOXK2 & SE \\
\hline TCONS_000 & PLEKHS & & TCONS_0007 & & & TCONS_0003 & & \\
\hline 10177 & 1 & A5 & 1908 & DUSP1 & $\mathrm{O}$ & 6894 & TBCD & RI,SE \\
\hline TCONS_000 & PLEKHS & & TCONS_0007 & & & TCONS_0003 & & \\
\hline 10178 & 1 & A5 & 1944 & RNF44 & $\mathrm{O}$ & 9358 & METRNL & O \\
\hline TCONS_000 & PLEKHS & & TCONS_0007 & & & TCONS_0003 & & \\
\hline 10179 & 1 & A5 & 1951 & HK3 & $A 3, R I$ & 6953 & MYO1C & $\mathrm{RI}$ \\
\hline TCONS_000 & & & TCONS_0007 & & & TCONS_0003 & & \\
\hline 10184 & TDRD1 & $\mathrm{O}$ & 3313 & HK3 & RI & 6954 & MYO1C & $\mathrm{O}$ \\
\hline TCONS_000 & & & TCONS_0007 & & & TCONS_0003 & & \\
\hline 12140 & PNLIP & $\mathrm{O}$ & 1967 & F12 & $\mathrm{O}$ & 6968 & SCARF1 & $\mathrm{RI}$ \\
\hline TCONS_000 & PNLIPR & $\mathrm{A} 3, \mathrm{AF}$ & TCONS_0007 & & & TCONS_0003 & & \\
\hline 10195 & P1 & $\mathrm{RI}$ & 1969 & DBN1 & RI & 6975 & PRPF8 & A3 \\
\hline
\end{tabular}




\begin{tabular}{|c|c|c|c|c|c|c|c|c|}
\hline TCONS_000 & PNLIPR & & TCONS_0007 & & & TCONS_0003 & & \\
\hline 12144 & P1 & $\mathrm{AF}$ & 1974 & PDLIM7 & A3,SE & 6987 & TLCD2 & 0 \\
\hline TCONS_000 & & & TCONS_0007 & FAM193 & & TCONS_0003 & MIR22H & \\
\hline 10216 & FAM45A & A3 & 1986 & B & SE & 6988 & G & 0 \\
\hline TCONS_000 & & & TCONS_0007 & FAM193 & & TCONS_0003 & & \\
\hline 12164 & FAM45A & $\mathrm{O}$ & 3324 & B & $M X$ & 9392 & TSR1 & $\mathrm{RI}$ \\
\hline TCONS_000 & & & TCONS_0007 & FAM193 & & TCONS_0003 & & \\
\hline 10227 & BAG3 & $\mathrm{O}$ & 3325 & B & A5,SE & 9393 & TSR1 & $\mathrm{RI}$ \\
\hline TCONS_000 & & & TCONS_0007 & FAM193 & & TCONS_0003 & & \\
\hline 12170 & WDR11 & $\mathrm{RI}$ & 1987 & B & $M X$ & 6999 & TSR1 & $\mathrm{O}$ \\
\hline TCONS_000 & & & TCONS_0007 & FAM193 & & TCONS_0003 & & \\
\hline 12174 & TACC2 & AF,SE & 1988 & B & A3 & 7000 & TSR1 & $\mathrm{O}$ \\
\hline TCONS_000 & & & TCONS_0007 & FAM193 & & TCONS_0003 & & \\
\hline 12175 & TACC2 & SE & 1989 & B & SE & 7001 & TSR1 & A5,RI \\
\hline TCONS_000 & PLEKHA & & TCONS_0007 & RP11-1 & & TCONS_0003 & METTL1 & \\
\hline 10264 & 1 & AF,SE & 3327 & 277A3.2 & $\mathrm{O}$ & 7006 & 6 & $\mathrm{O}$ \\
\hline TCONS_000 & & & TCONS_0007 & HNRNP & & TCONS_0003 & CTD-306 & \\
\hline 10281 & DMBT1 & $\mathrm{O}$ & 2032 & $\mathrm{H} 1$ & A5 & 7013 & OP21.1 & $\mathrm{O}$ \\
\hline TCONS_000 & & & TCONS_0007 & HNRNP & & TCONS_0003 & & \\
\hline 10282 & DMBT1 & $\mathrm{O}$ & 2035 & $\mathrm{H} 1$ & A5,SE & 7014 & SHPK & $\mathrm{O}$ \\
\hline TCONS_000 & & & TCONS_0007 & & & TCONS_0003 & RP11-23 & \\
\hline 10283 & DMBT1 & $\mathrm{O}$ & 2061 & MAPK9 & SE & 7016 & 5E17.6 & A3 \\
\hline TCONS_000 & & & TCONS_0007 & & & TCONS_0003 & RP11-23 & \\
\hline 10284 & DMBT1 & $\mathrm{O}$ & 3346 & GFPT2 & SE & 7017 & 5E17.6 & $\mathrm{O}$ \\
\hline TCONS_000 & & & TCONS_0007 & & & TCONS_0003 & & \\
\hline 10285 & DMBT1 & $\mathrm{O}$ & 2083 & MGAT1 & $A F, R I$ & 7022 & C17orf85 & SE \\
\hline TCONS_000 & & & TCONS_0007 & & & TCONS_0003 & & \\
\hline 10323 & ZRANB1 & $\mathrm{O}$ & 2096 & ZFP62 & $\mathrm{A} 5, \mathrm{MX}$ & 9403 & CAMKK1 & $\mathrm{O}$ \\
\hline TCONS_000 & C10orf13 & & TCONS_0007 & & & TCONS_0003 & & \\
\hline 12187 & 7 & $\mathrm{RI}, \mathrm{SE}$ & 2128 & TRIM52 & A3 & 9404 & P2RX1 & $\mathrm{RI}$ \\
\hline TCONS_000 & C10orf13 & & TCONS_0007 & & & TCONS_0003 & & \\
\hline 12188 & 7 & $\mathrm{RI}$ & 6829 & RIPK1 & $\mathrm{AF}, \mathrm{RI}$ & 9405 & P2RX1 & $A 3, R I$ \\
\hline TCONS_000 & & & TCONS_0007 & & & TCONS_0003 & & \\
\hline 10424 & LARP4B & $\mathrm{O}$ & 3412 & PRPF4B & A5 & 9406 & ATP2A3 & SE \\
\hline TCONS_000 & LINC007 & & TCONS_0007 & & & TCONS_0003 & MYBBP1 & \\
\hline 12224 & 02 & $\mathrm{O}$ & 3414 & PRPF4B & $\mathrm{O}$ & 7053 & A & $\mathrm{O}$ \\
\hline
\end{tabular}




\begin{tabular}{|c|c|c|c|c|c|c|c|c|}
\hline \multicolumn{3}{|l|}{ TCONS_000 } & \multicolumn{3}{|l|}{ TCONS_0007 } & TCONS_0003 & \multicolumn{2}{|l|}{ MYBBP1 } \\
\hline 10456 & AKR1C2 & SE & 3413 & PRPF4B & A5,SE & 7054 & A & A5,RI \\
\hline TCONS_000 & & & TCONS_0007 & RP3-40 & & TCONS_0003 & MYBBP1 & \\
\hline 10457 & AKR1C2 & A3,SE & 6833 & OB16.4 & $\mathrm{O}$ & 9415 & A & A5,RI \\
\hline TCONS_000 & RP11-33 & & TCONS_0007 & & & TCONS_0003 & & \\
\hline 10462 & 6A10.5 & $A F, R I$ & 3455 & RIOK1 & $\mathrm{RI}$ & 7056 & GGT6 & $\mathrm{O}$ \\
\hline TCONS_000 & & & TCONS_0007 & & & TCONS_0003 & & \\
\hline 10485 & SFMBT2 & $A 3, A F$ & 3456 & RIOK1 & A3 & 9417 & GGT6 & A3 \\
\hline TCONS_000 & & & TCONS_0007 & & & TCONS_0003 & & A5,RI, \\
\hline 10489 & KIN & A3 & 6865 & RIOK1 & $\mathrm{A} 3, \mathrm{RI}$ & 7076 & CHRNE & SE \\
\hline TCONS_000 & & & TCONS_0007 & & & TCONS_0003 & & $\mathrm{A} 3, \mathrm{AF}$ \\
\hline 12239 & KIN & A3 & 6914 & SIRT5 & $A F$ & 7084 & CAMTA2 & SE \\
\hline TCONS_000 & & & TCONS_0007 & & & TCONS_0003 & & \\
\hline 10500 & NUDT5 & SE & 3520 & CD83 & $\mathrm{O}$ & 9427 & DHX33 & $\mathrm{O}$ \\
\hline TCONS_000 & & & TCONS_0007 & & & TCONS_0003 & KIAA075 & \\
\hline 10515 & SEPHS1 & AF,SE & 3552 & KDM1B & A3 & 9435 & 3 & SE \\
\hline TCONS_000 & & & TCONS_0007 & & & TCONS_0003 & & \\
\hline 10517 & BEND7 & A3,A5 & 3557 & E2F3 & A5 & 9437 & DLG4 & SE \\
\hline TCONS_000 & & & TCONS_0007 & & & TCONS_0003 & & \\
\hline 10518 & BEND7 & A3 & 6932 & MRS2 & A3 & 7136 & DVL2 & A5,RI \\
\hline TCONS_000 & & $\mathrm{A} 3, \mathrm{~A} 5$ & TCONS_0007 & & & TCONS_0003 & & \\
\hline 12242 & BEND7 & $\mathrm{AL}$ & 3584 & GMNN & $\mathrm{O}$ & 7138 & PHF23 & $\mathrm{AF}$ \\
\hline TCONS_000 & & $\mathrm{A} 3, \mathrm{~A} 5$ & TCONS_0007 & & & TCONS_0003 & CTDNEP & \\
\hline 12243 & BEND7 & $\mathrm{AL}$ & 6939 & TRIM38 & RI & 7141 & 1 & $\mathrm{O}$ \\
\hline TCONS_000 & & & TCONS_0007 & & & TCONS_0003 & & \\
\hline 10521 & FRMD4A & SE & 3635 & BTN3A2 & A3,SE & 9444 & NEURL4 & 0 \\
\hline TCONS_000 & DCLRE1 & & TCONS_0007 & & & TCONS_0003 & & \\
\hline 10553 & C & MX,SE & 3640 & BTN2A2 & A5 & 9445 & NEURL4 & $\mathrm{RI}$ \\
\hline TCONS_000 & ARHGA & & TCONS_0007 & & & TCONS_0003 & C17orf61 & \\
\hline 10622 & P21 & SE & 3652 & BTN3A3 & $\mathrm{RI}, \mathrm{SE}$ & 7157 & -PLSCR3 & SE \\
\hline TCONS_000 & PRTFDC & & TCONS_0007 & & & TCONS_0003 & C17orf61 & \\
\hline 10628 & 1 & $\mathrm{AF}$ & 3655 & BTN2A1 & $\mathrm{RI}$ & 9446 & -PLSCR3 & $\mathrm{O}$ \\
\hline TCONS_000 & & & TCONS_0007 & & & TCONS_0003 & AC11318 & \\
\hline 10646 & $A B I 1$ & SE & 3708 & ZNF165 & AF & 7163 & 9.5 & $\mathrm{AF}$ \\
\hline TCONS_000 & ANKRD2 & & TCONS_0007 & & & TCONS_0003 & & \\
\hline 12326 & 6 & A5 & 3725 & PGBD1 & $\mathrm{O}$ & 7181 & LSMD1 & SE \\
\hline
\end{tabular}




\begin{tabular}{|c|c|c|c|c|c|c|c|c|}
\hline \multicolumn{3}{|l|}{ TCONS_000 } & \multicolumn{3}{|l|}{ TCONS 0007} & \multicolumn{3}{|l|}{ TCONS_0003 } \\
\hline 10669 & ACBD5 & $\mathrm{O}$ & 3726 & PGBD1 & A3 & 7182 & LSMD1 & 0 \\
\hline TCONS_000 & & & TCONS_0007 & & & TCONS_0003 & AC02533 & \\
\hline 10670 & ACBD5 & 0 & 3739 & HLA-F & A3 & 7188 & 5.1 & $A F$ \\
\hline TCONS_000 & & & TCONS_0007 & & & TCONS_0003 & & \\
\hline 10671 & ACBD5 & $\mathrm{A} 3, \mathrm{SE}$ & 3745 & HLA-V & $A F$ & 7207 & AURKB & A3 \\
\hline TCONS_000 & & & TCONS_0007 & & & TCONS_0003 & LINC003 & \\
\hline 10672 & ACBD5 & $\mathrm{O}$ & 3746 & HLA-A & 0 & 7211 & 24 & 0 \\
\hline TCONS_000 & & & TCONS_0007 & & & TCONS_0003 & & \\
\hline 10677 & MPP7 & $\mathrm{O}$ & 6971 & HLA-G & $\mathrm{O}$ & 9465 & MYH10 & SE \\
\hline TCONS_000 & WAC-AS & & TCONS_0007 & & & TCONS_0003 & & \\
\hline 10683 & 1 & $A F$ & 6972 & $\mathrm{HLA}-\mathrm{H}$ & $\mathrm{O}$ & 7252 & SCO1 & A3 \\
\hline TCONS_000 & & $\mathrm{A} 3, \mathrm{AF}$ & TCONS_0007 & & & TCONS_0003 & & \\
\hline $10689^{-}$ & SVIL & SE & 6973 & HLA-A & $\mathrm{O}$ & $9485-$ & ELAC2 & $\mathrm{RI}$ \\
\hline TCONS_000 & & & TCONS_0007 & & & TCONS_0003 & RP11-38 & \\
\hline 12338 & SVIL & AF,SE & 3749 & HLA-A & 0 & 9493 & 5D13.1 & $\mathrm{O}$ \\
\hline TCONS_000 & ARHGA & & TCONS_0007 & & & TCONS_0003 & & \\
\hline 10708 & P12 & SE & 3750 & HLA-A & A3 & 7302 & ZSWIM7 & A5 \\
\hline TCONS_000 & & & TCONS_0007 & TRIM31- & & TCONS_0003 & & \\
\hline 10753 & CUL2 & $\mathrm{O}$ & 3765 & AS1 & $\mathrm{O}$ & 7309 & NCOR1 & A3 \\
\hline TCONS_000 & ZNF37B & & TCONS_0007 & TRIM39- & & TCONS_0003 & & \\
\hline 12378 & $\mathrm{P}$ & A5 & 3769 & RPP21 & A5 & 7310 & NCOR1 & A3,SE \\
\hline TCONS_000 & & & TCONS_0007 & TRIM39- & & TCONS_0003 & & \\
\hline 10800 & ZNF33B & SE & 3770 & RPP21 & A5 & 9497 & NCOR1 & A3,SE \\
\hline TCONS_000 & & & TCONS_0007 & & & TCONS_0003 & & A3,A5, \\
\hline 10807 & HNRNPF & $A F$ & 3777 & PRR3 & A5 & 9502 & FLCN & $\mathrm{RI}$ \\
\hline TCONS_000 & & & TCONS 0007 & & & TCONS_0003 & RPL13P & \\
\hline 10819 & ZNF32 & $\mathrm{A} 5, \mathrm{AF}$ & 3786 & ATAT1 & A5,SE & 9506 & 12 & 0 \\
\hline TCONS_000 & MARCH & & TCONS_0007 & & & TCONS_0003 & & \\
\hline 10828 & 8 & 0 & 3793 & DDR1 & SE & 9511 & SREBF1 & RI,SE \\
\hline TCONS_000 & & & TCONS_0007 & & & TCONS_0003 & & \\
\hline 12388 & ZFAND4 & A5,SE & 6982 & DDR1 & SE & 7355 & FLII & $\mathrm{A} 3, \mathrm{RI}$ \\
\hline TCONS_000 & & & TCONS_0007 & & & TCONS_0003 & & \\
\hline 12390 & AGAP4 & SE & 6983 & DDR1 & 0 & 7356 & FLII & $A 3, R I$ \\
\hline TCONS_000 & RP11-17 & & TCONS_0007 & & & TCONS_0003 & & \\
\hline 10840 & 5117.2 & $\mathrm{O}$ & 3796 & VARS2 & A5,RI & 7361 & SHMT1 & SE \\
\hline
\end{tabular}




\begin{tabular}{|c|c|c|c|c|c|c|c|c|}
\hline TCONS_000 & RP11-38 & & TCONS_0007 & & & TCONS_0003 & CTD-230 & \\
\hline 10843 & L15.8 & $\mathrm{O}$ & 3797 & VARS2 & A5 & 7365 & $3 \mathrm{H} 24.2$ & 0 \\
\hline TCONS_000 & RP11-46 & & TCONS_0007 & & & TCONS_0003 & CCDC14 & \\
\hline 10853 & 3P17.1 & A5 & 3798 & VARS2 & A5,RI & 9521 & $4 \mathrm{~B}$ & $\mathrm{O}$ \\
\hline TCONS_000 & & & TCONS_0007 & & & TCONS_0003 & & \\
\hline 10856 & BMS1P5 & $\mathrm{O}$ & 6987 & VARS2 & A5,RI & 9526 & ULK2 & $\mathrm{O}$ \\
\hline TCONS_000 & & & TCONS_0007 & & & TCONS_0003 & & \\
\hline 10863 & BMS1P7 & $\mathrm{O}$ & 3800 & DPCR1 & $\mathrm{O}$ & 9547 & SPAG5 & $\mathrm{O}$ \\
\hline TCONS_000 & & & TCONS_0007 & & & TCONS_0003 & KIAA010 & \\
\hline 12409 & PARG & $\mathrm{O}$ & 3801 & DPCR1 & $\mathrm{O}$ & 9549 & 0 & $\mathrm{RI}$ \\
\hline TCONS_000 & RP11-59 & & TCONS_0007 & PRRC2 & & TCONS_0003 & KIAA010 & \\
\hline 10879 & 2B15.4 & RI,SE & 3831 & A & $\mathrm{RI}$ & 7454 & 0 & RI \\
\hline TCONS_0001 & RP11-59 & & TCONS_0007 & MSH5-S & & TCONS_0003 & & \\
\hline 0880 & 2B15.4 & $\mathrm{O}$ & 3843 & APCD1 & $\mathrm{RI}$ & 9551 & RAB34 & 0 \\
\hline TCONS_0001 & & & TCONS_0007 & & & TCONS_0003 & & \\
\hline 0919 & FAM13C & $\mathrm{O}$ & 3859 & SKIV2L & RI & 7465 & RAB34 & A3 \\
\hline TCONS_0001 & SLC16A & & TCONS_0007 & & & TCONS_0003 & & \\
\hline 2563 & 9 & A5 & 6999 & SKIV2L & SE & 7473 & TLCD1 & AF \\
\hline TCONS_0001 & & & TCONS_0007 & & & TCONS_0003 & & \\
\hline 0928 & ANK3 & SE & 7000 & SKIV2L & $\mathrm{RI}$ & 7483 & FLOT2 & $\mathrm{O}$ \\
\hline TCONS_0001 & RHOBT & & TCONS_0007 & & & TCONS_0003 & & \\
\hline 0935 & B1 & $\mathrm{O}$ & 7002 & C4A & $\mathrm{O}$ & 7484 & FLOT2 & $\mathrm{O}$ \\
\hline TCONS_0001 & & & TCONS_0007 & & & TCONS_0003 & & \\
\hline 0949 & JMJD1C & SE & 3866 & $\mathrm{C} 4 \mathrm{~A}$ & $\mathrm{RI}$ & 7485 & FLOT2 & O \\
\hline TCONS_0001 & & & TCONS_0007 & PPT2-E & A3,A5, & TCONS_0003 & CTD-237 & \\
\hline 2585 & PBLD & $\mathrm{O}$ & 3871 & GFL8 & $\mathrm{RI}$ & 7526 & 0N5.3 & SE \\
\hline TCONS_0001 & & & TCONS_0007 & HLA-DQ & & TCONS_0003 & CTD-237 & \\
\hline 2586 & PBLD & A3 & 7007 & $\mathrm{~A} 2$ & $\mathrm{O}$ & 7525 & 0N5.3 & SE \\
\hline TCONS_0001 & & & TCONS_0007 & HLA-DQ & & TCONS_0003 & & \\
\hline 0981 & RUFY2 & $\mathrm{A} 3, \mathrm{AF}$ & 3890 & $\mathrm{~A} 2$ & $\mathrm{RI}$ & 7552 & ССТ6В & AF \\
\hline TCONS_0001 & & & TCONS_0007 & & $A F, R I$, & TCONS_0003 & & \\
\hline 2588 & DNA2 & A5 & 3896 & BRD2 & SE & 7553 & ССТ6В & $\mathrm{O}$ \\
\hline TCONS_0001 & SLC25A & & TCONS_0007 & & & TCONS_0003 & & \\
\hline 0989 & 16 & $\mathrm{O}$ & 7009 & BRD2 & $\mathrm{RI}, \mathrm{SE}$ & 7561 & NLE1 & A5 \\
\hline TCONS_0001 & SLC25A & 0 & TCONS_0007 & BRD2 & $\mathrm{RI}, \mathrm{SE}$ & TCONS_0003 & SLFN11 & A5 \\
\hline
\end{tabular}




\begin{tabular}{|c|c|c|c|c|c|c|c|c|}
\hline 0990 & 16 & & 7011 & & & 7563 & & \\
\hline TCONS_0001 & & & TCONS_0007 & HSD17B & & TCONS_0003 & & \\
\hline 1016 & PCBD1 & AL & 3908 & 8 & 0 & 9583 & SLFN11 & 0 \\
\hline TCONS_0001 & & & TCONS_0007 & HSD17B & & TCONS_0003 & & $A 3, A$ \\
\hline 1030 & ASCC1 & AF,SE & 7016 & 8 & $\mathrm{O}$ & 7591 & MMP28 & 5 \\
\hline TCONS_0001 & & & TCONS_0007 & & & TCONS_0003 & & $A 3, A$ \\
\hline 2601 & TTC18 & $A F, R I$ & 3911 & RING1 & $\mathrm{O}$ & 7592 & MMP28 & 5 \\
\hline TCONS_0001 & & & TCONS_0007 & & & TCONS_0003 & & \\
\hline 2603 & TTC18 & $A F, R I$ & 3912 & RING1 & $\mathrm{O}$ & 9593 & ACACA & SE \\
\hline TCONS_0001 & & & TCONS_0007 & & & TCONS_0003 & & \\
\hline 2609 & PPP3CB & $\mathrm{A} 3, \mathrm{AF}$ & 7017 & RING1 & $\mathrm{O}$ & 7628 & DDX52 & SE \\
\hline TCONS_0001 & & & TCONS_0007 & & & TCONS_0003 & & $A 5, S$ \\
\hline 1085 & USP54 & SE & 3914 & HCG25 & A3 & 9598 & DDX52 & $\mathrm{E}$ \\
\hline TCONS_0001 & & & TCONS_0007 & B3GALT & & TCONS_0003 & RP11-115 & \\
\hline 1086 & USP54 & SE & 7018 & 4 & AL & 7637 & K3.2 & $A F$ \\
\hline TCONS_0001 & & & TCONS_0007 & & & TCONS_0003 & RP11-140 & \\
\hline 2618 & USP54 & $\mathrm{RI}, \mathrm{SE}$ & 3941 & ITPR3 & RI & 7638 & 7015.2 & $\mathrm{O}$ \\
\hline TCONS_0001 & & & TCONS_0007 & & & TCONS_0003 & AC12478 & \\
\hline 2619 & USP54 & SE & 3963 & ANKS1A & SE & 7640 & 9.1 & A3 \\
\hline TCONS_0001 & RP11-46 & & TCONS_0007 & & & TCONS_0003 & & \\
\hline 2622 & 4F9.1 & A3,A5 & 7026 & ZNF76 & RI & 9601 & PCGF2 & $\mathrm{O}$ \\
\hline TCONS_0001 & RP11-46 & & TCONS_0007 & & & TCONS_0003 & & \\
\hline 1090 & 4F9.1 & A3,A5 & 3967 & ZNF76 & A5 & 7648 & CWC25 & SE \\
\hline TCONS_0001 & RP11-57 & & TCONS_0007 & & & TCONS_0003 & & \\
\hline 1096 & 4K11.31 & A5,RI & 7028 & DEF6 & $\mathrm{RI}$ & 7667 & PLXDC1 & SE \\
\hline TCONS_0001 & CAMK2 & & TCONS_0007 & & & TCONS_0003 & & $A F, S$ \\
\hline 1099 & G & $\mathrm{RI}, \mathrm{SE}$ & 7029 & DEF6 & $\mathrm{O}$ & 7668 & PLXDC1 & $\mathrm{E}$ \\
\hline TCONS_0001 & CAMK2 & & TCONS_0007 & & & TCONS_0003 & & \\
\hline 1100 & G & SE & 7036 & CLPSL1 & AF & 7669 & PLXDC1 & AF \\
\hline TCONS_0001 & C10orf5 & & TCONS_0007 & & & TCONS_0003 & & $A 3, S$ \\
\hline 1106 & 5 & $\mathrm{O}$ & 4023 & C6orf89 & $\mathrm{O}$ & 7688 & GSDMB & $\mathrm{E}$ \\
\hline TCONS_0001 & RP11-77 & & TCONS_0007 & & & TCONS_0003 & & \\
\hline 1160 & 3D16.1 & A3,A5 & 7050 & PI16 & A5 & 7689 & GSDMB & A3 \\
\hline TCONS_0001 & RP11-77 & & TCONS_0007 & & & TCONS_0003 & & $A 3, S$ \\
\hline 1162 & 3D16.1 & A3,A5 & 4042 & CMTR1 & RI & 7690 & GSDMB & E \\
\hline
\end{tabular}




\begin{tabular}{|c|c|c|c|c|c|c|c|c|}
\hline TCONS_0001 & RP11-77 & & TCONS_0007 & & & TCONS_0003 & & \\
\hline 2643 & 3D16.1 & A3 & 4043 & CMTR1 & $\mathrm{RI}, \mathrm{SE}$ & 7700 & MED24 & A5 \\
\hline TCONS_0001 & & & TCONS_0007 & & & TCONS_0003 & & \\
\hline 2644 & SFTPD & $A F$ & 4045 & CMTR1 & A5 & 7701 & MED24 & $A 3, R I$ \\
\hline TCONS_0001 & & & TCONS_0007 & PRICKL & & TCONS_0003 & & \\
\hline 1208 & ATAD1 & $A F$ & 4077 & E4 & $\mathrm{A} 3, \mathrm{RI}$ & 7702 & MED24 & A3 \\
\hline TCONS_0001 & & & TCONS_0007 & PRICKL & & TCONS_0003 & & \\
\hline 1246 & CPEB3 & $A F$ & 4078 & E4 & $\mathrm{A} 3, \mathrm{RI}$ & 7704 & NR1D1 & $\mathrm{O}$ \\
\hline TCONS_0001 & & & TCONS_0007 & PRICKL & & TCONS_0003 & & \\
\hline 2668 & IDE & $\mathrm{MX}$ & 4079 & E4 & A3,RI & 9619 & NR1D1 & $\mathrm{O}$ \\
\hline TCONS_0001 & & & TCONS_0007 & GLTSCR & & TCONS_0003 & CTD-226 & \\
\hline 2675 & MYOF & MX,SE & 4101 & $1 \mathrm{~L}$ & SE & 7709 & 7D19.2 & $\mathrm{O}$ \\
\hline TCONS_0001 & FRA10A & & TCONS_0007 & & & TCONS_0003 & & \\
\hline 1265 & $\mathrm{C} 1$ & A5,SE & 4108 & RPL7L1 & $\mathrm{O}$ & 7724 & KRT10 & $\mathrm{O}$ \\
\hline TCONS_0001 & SORBS & & TCONS_0007 & & & TCONS_0003 & & \\
\hline 2691 & 1 & SE & 4109 & RPL7L1 & SE & 7728 & KRT23 & $\mathrm{O}$ \\
\hline TCONS_0001 & SORBS & & TCONS_0007 & & & TCONS_0003 & & \\
\hline 1292 & 1 & SE & 7068 & GNMT & $\mathrm{RI}$ & 9626 & KRT23 & A3 \\
\hline TCONS_0001 & SORBS & & TCONS_0007 & & & TCONS_0003 & & \\
\hline 1293 & 1 & SE & 4117 & GNMT & $\mathrm{O}$ & 7754 & JUP & $A F$ \\
\hline TCONS_0001 & & & TCONS_0007 & & & TCONS_0003 & & \\
\hline 2699 & TCTN3 & RI,SE & 7070 & KLHDC3 & $\mathrm{O}$ & 7761 & NT5C3B & AF \\
\hline TCONS_0001 & & & TCONS_0007 & & & TCONS_0003 & & \\
\hline 1306 & TCTN3 & SE & 7071 & KLC4 & $\mathrm{A} 3, \mathrm{SE}$ & 9634 & DNAJC7 & $A F$ \\
\hline TCONS_0001 & PIK3AP & & TCONS_0007 & & $\mathrm{A} 3, \mathrm{~A} 5$, & TCONS_0003 & & \\
\hline 1324 & 1 & $\mathrm{O}$ & 7072 & CUL9 & $\mathrm{RI}$ & 9635 & DNAJC7 & SE \\
\hline TCONS_0001 & & & TCONS_0007 & & & TCONS_0003 & & \\
\hline 2708 & MMS19 & A3 & 4141 & ABCC10 & $\mathrm{O}$ & 7778 & DHX58 & $\mathrm{RI}$ \\
\hline TCONS_0001 & & & TCONS_0007 & & & TCONS_0003 & & \\
\hline 2709 & MMS19 & $\mathrm{RI}$ & 4142 & ABCC10 & $\mathrm{O}$ & 7779 & DHX58 & $\mathrm{O}$ \\
\hline TCONS_0001 & & & TCONS_0007 & & & TCONS_0003 & PLEKHH & \\
\hline 2711 & AVPI1 & $\mathrm{O}$ & 7076 & ABCC10 & $\mathrm{O}$ & 9643 & 3 & A5,RI \\
\hline TCONS_0001 & & & TCONS_0007 & & & TCONS_0003 & LINC0067 & \\
\hline 2712 & SFRP5 & AF & 4145 & TJAP1 & $\mathrm{A} 3, \mathrm{SE}$ & 9650 & 1 & SE \\
\hline TCONS_0001 & & & TCONS_0007 & & & TCONS_0003 & LINC0067 & $M X, S$ \\
\hline 2713 & LOXL4 & RI,SE & 4146 & TJAP1 & RI,SE & 9651 & 1 & $\mathrm{E}$ \\
\hline
\end{tabular}




\begin{tabular}{|c|c|c|c|c|c|c|c|c|}
\hline TCONS_0001 & SLC25A & & TCONS_0007 & & & TCONS_0003 & LINC0067 & \\
\hline 2717 & 28 & $\mathrm{RI}$ & 7081 & VEGFA & A5 & 9652 & 1 & $\mathrm{RI}, \mathrm{SE}$ \\
\hline TCONS_0001 & RP11-48 & & TCONS_0007 & TMEM63 & & TCONS_0003 & LINC0067 & $M X, R$ \\
\hline 1366 & 3F11.7 & $\mathrm{O}$ & 4175 & B & $\mathrm{A} 5, \mathrm{RI}$ & 9654 & 1 & 1 \\
\hline TCONS_0001 & & & TCONS_0007 & TMEM63 & & TCONS_0003 & LINC0067 & \\
\hline 1370 & CoX15 & $\mathrm{O}$ & 4177 & B & AF & 9655 & 1 & $\mathrm{RI}, \mathrm{SE}$ \\
\hline TCONS_0001 & CWF19L & & TCONS_0007 & SLC25A & & TCONS_0003 & & \\
\hline 2721 & 1 & $\mathrm{O}$ & 4196 & 27 & 0 & 7857 & MPP3 & $\mathrm{RI}$ \\
\hline TCONS_0001 & & & TCONS_0007 & SLC25A & & TCONS_0003 & TMEM10 & \\
\hline 1409 & POLL & $\mathrm{A} 5, \mathrm{RI}$ & 7092 & 27 & A3 & 7865 & 1 & A5 \\
\hline TCONS_0001 & & & TCONS_0007 & & & TCONS_0003 & & \\
\hline 2726 & POLL & A5 & 4205 & CENPQ & A3 & 7872 & HDAC5 & A5 \\
\hline TCONS_0001 & & & TCONS_0007 & & & TCONS_0003 & ASB16-A & \\
\hline 2727 & POLL & A5,SE & 7095 & C6orf141 & SE & 7878 & $\mathrm{~S} 1$ & $A 3, R I$ \\
\hline TCONS_0001 & & & TCONS_0007 & & & TCONS_0003 & & \\
\hline 2731 & KCNIP2 & A3 & 4208 & C6orf141 & A3,SE & 7880 & ATXN7L3 & AF \\
\hline TCONS_0001 & & & TCONS_0007 & TRAM2- & & TCONS_0003 & AC00211 & \\
\hline 1437 & LDB1 & A5 & 4218 & AS1 & $\mathrm{O}$ & 9680 & 7.1 & A3 \\
\hline TCONS_0001 & & & TCONS_0007 & RP1-152 & & TCONS_0003 & AC00211 & \\
\hline 2734 & LDB1 & A5 & 7097 & L7.5 & A5 & 7935 & 7.1 & AF \\
\hline TCONS_0001 & & & TCONS_0007 & & & TCONS_0003 & RP13-890 & \\
\hline 1442 & PSD & A5 & 7098 & FBXO9 & $\mathrm{RI}$ & 7938 & $\mathrm{H} 12.2$ & $\mathrm{O}$ \\
\hline TCONS_0001 & CALHM & & TCONS_0007 & & & TCONS_0003 & RP13-890 & \\
\hline 1472 & 2 & A3 & 7101 & LRRC1 & 0 & 9681 & $\mathrm{H} 12.2$ & 0 \\
\hline TCONS_0001 & CALHM & & TCONS_0007 & KIAA158 & & TCONS_0003 & CTD-202 & \\
\hline 1474 & 2 & A3,A5 & 7104 & 6 & 0 & 7939 & OK17.1 & SE \\
\hline TCONS_0001 & SH3PXD & & TCONS_0007 & RP11-46 & & TCONS_0003 & CTD-202 & \\
\hline 1478 & $2 \mathrm{~A}$ & SE & 4284 & $2 \mathrm{G} 2.1$ & SE & 7940 & OK17.1 & SE \\
\hline TCONS_0001 & COL17A & & TCONS_0007 & RP11-46 & & TCONS_0003 & CTD-202 & \\
\hline 1494 & 1 & 0 & 7121 & $2 G 2.1$ & 0 & 7944 & OK17.4 & 0 \\
\hline TCONS_0001 & SORCS & & TCONS_0007 & FAM135 & & TCONS_0003 & ARHGAP & \\
\hline 2751 & 1 & A3 & 4286 & A & A3,SE & 7948 & 27 & A3 \\
\hline TCONS_0001 & XPNPE & & TCONS_0007 & & & TCONS_0003 & ARHGAP & \\
\hline 2774 & $\mathrm{P} 1$ & $\mathrm{RI}$ & 4314 & CD109 & A5 & 7949 & 27 & $\mathrm{RI}$ \\
\hline TCONS_0001 & & & TCONS_0007 & & & TCONS_0003 & LRRC37A & \\
\hline 1525 & GPAM & $\mathrm{AF}$ & 4325 & MYO6 & A5 & 7959 & $4 \mathrm{P}$ & $\mathrm{O}$ \\
\hline
\end{tabular}




\begin{tabular}{|c|c|c|c|c|c|c|c|c|}
\hline TCONS_0001 & ZDHHC & & TCONS_0007 & & & TCONS_0003 & LRRC37A & \\
\hline 2795 & 6 & RI & 4333 & MEI4 & $\mathrm{O}$ & 9691 & $4 \mathrm{P}$ & $\mathrm{AF}$ \\
\hline TCONS_0001 & C10orf1 & & TCONS_0007 & SH3BGR & & TCONS_0003 & & \\
\hline 2799 & 18 & SE & 7167 & L2 & $\mathrm{O}$ & 7989 & ARL17A & $\mathrm{O}$ \\
\hline TCONS_0001 & & $A 3, A F$ & TCONS_0007 & & & TCONS_0003 & & \\
\hline 2804 & ABLIM1 & SE & 4381 & DOPEY1 & SE & 8025 & OSBPL7 & $A 5, R I$ \\
\hline TCONS_0001 & & & TCONS_0007 & & & TCONS_0003 & & \\
\hline 1547 & ABLIM1 & $\mathrm{A} 3, \mathrm{SE}$ & 4383 & DOPEY1 & SE & 8026 & OSBPL7 & $\mathrm{RI}$ \\
\hline TCONS_0001 & & & TCONS_0007 & & & TCONS_0003 & & \\
\hline 1548 & ABLIM1 & SE & 4398 & ZNF292 & $\mathrm{O}$ & 8051 & COPZ2 & $\mathrm{O}$ \\
\hline TCONS_0001 & & & TCONS_0007 & & & TCONS_0003 & & \\
\hline 1575 & GFRA1 & AF,SE & 7222 & TSTD3 & $\mathrm{O}$ & 8052 & COPZ2 & $\mathrm{O}$ \\
\hline TCONS_0001 & & & TCONS_0007 & & & TCONS_0003 & & \\
\hline 2850 & TIAL1 & SE & 4451 & GRIK2 & $\mathrm{O}$ & 8066 & HOXB3 & A3 \\
\hline TCONS_0001 & & & TCONS_0007 & & & TCONS_0003 & & \\
\hline 1653 & FGFR2 & $\mathrm{A} 5, \mathrm{MX}$ & 4456 & AIM1 & $\mathrm{O}$ & 8067 & HOXB3 & A3 \\
\hline TCONS_0001 & & & TCONS_0007 & & & TCONS_0003 & & \\
\hline 1665 & CUZD1 & SE & 4498 & SMPD2 & RI & 8068 & HOXB3 & A3 \\
\hline TCONS_0001 & RP11-12 & & TCONS_0007 & & & TCONS_0003 & & \\
\hline 1689 & $\mathrm{~J} 10.3$ & A5,SE & 4499 & SMPD2 & RI & 8070 & HOXB6 & $\mathrm{O}$ \\
\hline TCONS_0001 & & & TCONS_0007 & & & TCONS_0003 & & \\
\hline 1695 & CTBP2 & 0 & 7244 & FIG4 & $\mathrm{O}$ & 9719 & SPOP & SE \\
\hline TCONS_0001 & & & TCONS_0007 & KIAA191 & & TCONS_0003 & & \\
\hline 1696 & CTBP2 & A3 & 4524 & 9 & $\mathrm{O}$ & 8113 & SAMD14 & SE \\
\hline TCONS_0001 & RP11-38 & & TCONS_0007 & & & TCONS_0003 & & \\
\hline 2873 & $3 C 5.4$ & SE & 4552 & FAM26F & $\mathrm{O}$ & 9726 & CHAD & $\mathrm{O}$ \\
\hline TCONS_0001 & RP11-38 & & TCONS_0007 & & & TCONS_0003 & & \\
\hline 1702 & $3 C 5.4$ & SE & 7259 & RFX6 & $\mathrm{O}$ & 8138 & SPAG9 & SE \\
\hline TCONS_0001 & & & TCONS_0007 & SMPDL3 & & TCONS_0003 & & \\
\hline 1707 & DHX32 & $\mathrm{O}$ & 4651 & A & SE & 8139 & SPAG9 & SE \\
\hline TCONS_0001 & & & TCONS_0007 & & & TCONS_0003 & & \\
\hline 1708 & DHX32 & $\mathrm{O}$ & 4669 & HINT3 & A5 & 8146 & MBTD1 & $A F$ \\
\hline TCONS_0001 & & & TCONS_0007 & & & TCONS_0003 & & \\
\hline 1713 & ADAM12 & A5 & 4728 & AKAP7 & A3 & 9735 & MBTD1 & $\mathrm{O}$ \\
\hline TCONS_0001 & & & TCONS_0007 & RP3-388 & & TCONS_0003 & & \\
\hline 1720 & CLRN3 & SE & 7512 & E23.2 & $\mathrm{O}$ & 8160 & C17orf67 & $\mathrm{O}$ \\
\hline
\end{tabular}




\begin{tabular}{|c|c|c|c|c|c|c|c|c|}
\hline TCONS_0001 & LINC009 & & TCONS_0007 & LINC002 & & TCONS_0003 & & \\
\hline 1726 & 59 & $A L$ & 7513 & 71 & $\mathrm{O}$ & 9742 & TRIM25 & A5 \\
\hline TCONS_0001 & TUBGC & & TCONS_0007 & & & TCONS_0003 & RP11-166 & \\
\hline 1736 & P2 & $A F, R I$ & 4749 & TNFAIP3 & A5 & 8168 & P13.3 & $A L$ \\
\hline TCONS_0001 & & & TCONS_0007 & & & TCONS_0003 & & \\
\hline 2904 & ATHL1 & 0 & 4750 & TNFAIP3 & A5 & 9746 & SRSF1 & 0 \\
\hline TCONS_0001 & & & TCONS_0007 & & & TCONS_0003 & & \\
\hline 2905 & ATHL1 & $\mathrm{O}$ & 4761 & ABRACL & $\mathrm{O}$ & 8184 & SRSF1 & $\mathrm{O}$ \\
\hline TCONS_0001 & & & TCONS_0007 & & & TCONS_0003 & & \\
\hline 2906 & ATHL1 & RI & 4799 & UTRN & SE & 8187 & SRSF1 & $\mathrm{O}$ \\
\hline TCONS_0001 & & & TCONS_0007 & & & TCONS_0003 & & \\
\hline 6783 & ATHL1 & 0 & 7533 & UTRN & 0 & 8188 & SRSF1 & 0 \\
\hline TCONS_0001 & & & TCONS_0007 & & & TCONS_0003 & & \\
\hline 6784 & ATHL1 & $\mathrm{O}$ & 7534 & UTRN & SE & 9751 & MKS1 & $\mathrm{RI}$ \\
\hline TCONS_0001 & & & TCONS_0007 & & & TCONS_0003 & & \\
\hline 6785 & ATHL1 & RI & 7535 & UTRN & SE & 9754 & BZRAP1 & A5 \\
\hline TCONS_0001 & & & TCONS_0007 & & & TCONS_0003 & & \\
\hline 2921 & PTDSS2 & RI,SE & 4801 & UTRN & AF & 8200 & RNF43 & $\mathrm{O}$ \\
\hline TCONS_0001 & RP11-49 & & TCONS_0007 & & & TCONS_0003 & & \\
\hline 2929 & 619.1 & $\mathrm{O}$ & 4856 & TAB2 & AF & 8204 & MTMR4 & $\mathrm{A} 5, \mathrm{RI}$ \\
\hline TCONS_0001 & RP11-49 & & TCONS_0007 & & & TCONS_0003 & & \\
\hline 2930 & 619.1 & $\mathrm{O}$ & 4914 & TIAM2 & $\mathrm{O}$ & 8206 & MTMR4 & AF \\
\hline TCONS_0001 & & & TCONS_0007 & & & TCONS_0003 & & \\
\hline 6789 & RASSF7 & $\mathrm{O}$ & 7568 & TULP4 & $\mathrm{O}$ & 9756 & MTMR4 & RI \\
\hline TCONS_0001 & & & TCONS_0007 & TMEM18 & & TCONS_0003 & & \\
\hline 6790 & RASSF7 & $\mathrm{O}$ & 4946 & 1 & A5 & 8210 & SEPT4 & $\mathrm{O}$ \\
\hline TCONS_0001 & & & TCONS_0007 & TMEM18 & & TCONS_0003 & & \\
\hline 6791 & RASSF7 & $\mathrm{O}$ & 4947 & 1 & AF & 9764 & USP32 & A5 \\
\hline TCONS_0001 & & & TCONS_0007 & & & TCONS_0003 & & \\
\hline 6792 & RASSF7 & SE & 4948 & SYTL3 & $\mathrm{RI}$ & 8258 & INTS2 & $\mathrm{O}$ \\
\hline TCONS_0001 & & & TCONS_0007 & EZR-AS & & TCONS_0003 & RP11-51L & \\
\hline 6795 & PHRF1 & $\mathrm{O}$ & 4952 & 1 & A5 & 9773 & 5.5 & RI \\
\hline TCONS_0001 & & & TCONS_0007 & & & TCONS_0003 & RP11-51L & \\
\hline 2952 & EPS8L2 & $\mathrm{O}$ & 4954 & FNDC1 & $\mathrm{O}$ & 8268 & 5.5 & $\mathrm{O}$ \\
\hline TCONS_0001 & & & TCONS_0007 & & & TCONS_0003 & & \\
\hline 2968 & PNPLA2 & 0 & 7571 & WTAP & RI & 8282 & LIMD2 & A3 \\
\hline
\end{tabular}




\begin{tabular}{|c|c|c|c|c|c|c|c|c|}
\hline \multicolumn{3}{|l|}{ TCONS_0001 } & \multicolumn{3}{|l|}{ TCONS_0007 } & \multicolumn{3}{|l|}{ TCONS_0003 } \\
\hline 6802 & PNPLA2 & $\mathrm{RI}, \mathrm{SE}$ & 4961 & MRPL18 & $\mathrm{AF}$ & 8283 & LIMD2 & A3 \\
\hline TCONS_0001 & & & TCONS_0007 & SLC22A & & TCONS_0003 & & \\
\hline 2970 & PNPLA2 & SE & 4971 & 3 & $A 3, A 5$ & 8290 & STRADA & $\mathrm{O}$ \\
\hline TCONS_0001 & & & TCONS_0007 & SLC22A & & TCONS_0003 & & \\
\hline 6803 & PNPLA2 & $\mathrm{O}$ & 4972 & 3 & A3,A5 & 8291 & STRADA & SE \\
\hline TCONS_0001 & EFCAB4 & & TCONS_0007 & & $\mathrm{A} 3, \mathrm{RI}$, & TCONS_0003 & & \\
\hline 6804 & A & SE & 7592 & MLLT4 & SE & 9780 & FTSJ3 & $\mathrm{O}$ \\
\hline TCONS_0001 & EFCAB4 & & TCONS_0007 & & & TCONS_0003 & & \\
\hline 6805 & A & A5,SE & 7593 & MLLT4 & SE & 8299 & FTSJ3 & $\mathrm{O}$ \\
\hline TCONS_0001 & EFCAB4 & & TCONS_0007 & & & TCONS_0003 & & \\
\hline 6806 & A & $A 5, R I$ & 5006 & MLLT4 & A5,SE & 9782 & FTSJ3 & $\mathrm{RI}$ \\
\hline TCONS_0001 & EFCAB4 & & TCONS_0007 & & A3,A5, & TCONS_0003 & & \\
\hline 6808 & A & $\mathrm{A} 5, \mathrm{AF}$ & 5007 & MLLT4 & SE & 9791 & DDX5 & $\mathrm{O}$ \\
\hline TCONS_0001 & EFCAB4 & & TCONS_0007 & ERMAR & & TCONS_0003 & & \\
\hline 2973 & A & AF,SE & 7601 & $\mathrm{D}$ & AF & 8331 & DDX5 & $\mathrm{O}$ \\
\hline TCONS_0001 & EFCAB4 & & TCONS_0007 & & & TCONS_0003 & hsa-mir-6 & \\
\hline 2974 & A & A5,RI & 7630 & $\mathrm{ECl} 2$ & SE & 8355 & 080 & $\mathrm{O}$ \\
\hline TCONS_0001 & EFCAB4 & & TCONS_0007 & & & TCONS_0003 & PLEKHM & \\
\hline 6809 & A & A5 & 7633 & RPP40 & $\mathrm{AL}, \mathrm{SE}$ & 9793 & $1 \mathrm{P}$ & RI \\
\hline TCONS_0001 & EFCAB4 & & TCONS_0007 & & & TCONS_0003 & PLEKHM & \\
\hline 6810 & A & A3 & 5130 & RPP40 & SE & 8358 & $1 \mathrm{P}$ & $\mathrm{RI}, \mathrm{SE}$ \\
\hline TCONS_0001 & & & TCONS_0007 & & & TCONS_0003 & LRRC37A & \\
\hline 2977 & CD151 & $\mathrm{O}$ & 5138 & F13A1 & $\mathrm{O}$ & 8369 & 3 & SE \\
\hline TCONS_0001 & & & TCONS_0007 & SLC35B & & TCONS_0003 & & \\
\hline 2978 & CD151 & $\mathrm{A} 5, \mathrm{AL}$ & 7643 & 3 & $\mathrm{O}$ & 8376 & AMZ2P1 & A5 \\
\hline TCONS_0001 & & & TCONS_0007 & SLC35B & & TCONS_0003 & & \\
\hline 6812 & CD151 & A3 & 7644 & 3 & A5,RI & 8387 & AXIN2 & $\mathrm{O}$ \\
\hline TCONS_0001 & & & TCONS_0007 & SLC35B & & TCONS_0003 & & \\
\hline 2980 & TSPAN4 & $\mathrm{AF}$ & 7645 & 3 & $\mathrm{O}$ & 8386 & AXIN2 & $\mathrm{O}$ \\
\hline TCONS_0001 & RP13-87 & & TCONS_0007 & SLC35B & & TCONS_0003 & & \\
\hline 2995 & OH17.3 & $\mathrm{O}$ & 5161 & 3 & A5 & 8408 & C17orf58 & A5 \\
\hline TCONS_0001 & & & TCONS_0007 & SLC35B & & TCONS_0003 & & \\
\hline 2997 & MUC2 & SE & 5162 & 3 & A5 & 8421 & FAM20A & $\mathrm{O}$ \\
\hline TCONS_0001 & & & TCONS_0007 & & & TCONS_0003 & & \\
\hline 2998 & MUC2 & A5,SE & 5164 & TFAP2A & $\mathrm{O}$ & 8427 & ABCA8 & SE \\
\hline
\end{tabular}




\begin{tabular}{|c|c|c|c|c|c|c|c|c|}
\hline \multicolumn{3}{|l|}{ TCONS_0001 } & \multicolumn{3}{|l|}{ TCONS_0007 } & \multicolumn{3}{|l|}{ TCONS_0003 } \\
\hline 3002 & MUC2 & $\mathrm{O}$ & 5188 & TBC1D7 & SE & 8432 & ABCA9 & RI \\
\hline TCONS_0001 & & & TCONS_0007 & & & TCONS_0003 & & \\
\hline 6818 & MUC5B & 0 & 5189 & TBC1D7 & $\mathrm{O}$ & 9808 & ABCA9 & 0 \\
\hline TCONS_0001 & & & TCONS_0007 & & & TCONS_0003 & & \\
\hline 3017 & SYT8 & RI & 5191 & TBC1D7 & SE & 9811 & ABCA6 & 0 \\
\hline TCONS_0001 & & & TCONS_0007 & AL44188 & & TCONS_0003 & AC00515 & \\
\hline 3027 & CD81 & 0 & 5198 & 3.1 & $\mathrm{RI}$ & 9833 & 2.3 & 0 \\
\hline TCONS_0001 & & & TCONS_0007 & AL44188 & & TCONS_0003 & & \\
\hline 3028 & CD81 & $\mathrm{O}$ & 5201 & 3.1 & 0 & 8475 & CD300LF & $A 3, R I$ \\
\hline TCONS_0001 & SLC22A & & TCONS_0007 & AL44188 & & TCONS_0003 & & \\
\hline 3040 & 18 & AF & 5200 & 3.1 & $\mathrm{O}$ & 9850 & HID1 & RI \\
\hline TCONS_0001 & TRIM6-T & & TCONS_0007 & AL44188 & & TCONS_0003 & & $A 3, S$ \\
\hline 6843 & RIM34 & $\mathrm{O}$ & 7650 & 3.1 & $\mathrm{O}$ & 9852 & GGA3 & E \\
\hline TCONS_0001 & & & TCONS_0007 & AL44188 & & TCONS_0003 & & \\
\hline 6845 & CCKBR & SE & 7651 & 3.1 & $\mathrm{RI}$ & 8516 & GGA3 & RI,SE \\
\hline TCONS_0001 & TMEM9 & & TCONS_0007 & & & TCONS_0003 & SLC25A1 & \\
\hline 3110 & B-AS1 & $\mathrm{O}$ & 5207 & DTNBP1 & RI,SE & 8522 & 9 & $\mathrm{~A} 5, \mathrm{RI}$ \\
\hline TCONS_0001 & & & TCONS_0007 & & & TCONS_0003 & & \\
\hline 3116 & ZNF143 & $\mathrm{O}$ & 5222 & KIF13A & $\mathrm{O}$ & 8530 & CASKIN2 & RI \\
\hline TCONS_0001 & & & TCONS_0007 & & & TCONS_0003 & & \\
\hline 3117 & ZNF143 & A3 & 7657 & KIF13A & RI,SE & 9858 & CASKIN2 & RI \\
\hline TCONS_0001 & & & TCONS_0007 & & & TCONS_0003 & & \\
\hline 6863 & WEE1 & $\mathrm{O}$ & 5239 & MBOAT1 & A3 & 8532 & RECQL5 & RI \\
\hline TCONS_0001 & & & TCONS_0007 & & & TCONS_0003 & & \\
\hline 3157 & MICAL2 & A5 & 5244 & GPLD1 & $\mathrm{O}$ & 9861 & RECQL5 & RI \\
\hline TCONS_0001 & & & TCONS_0007 & & & TCONS_0003 & & \\
\hline 6870 & MICAL2 & A5,SE & 5318 & GUSBP2 & $\mathrm{O}$ & 9862 & GALK1 & $\mathrm{A} 5, \mathrm{RI}$ \\
\hline TCONS_0001 & & & TCONS_0007 & ZNF204 & & TCONS_0003 & & \\
\hline 6877 & PARVA & AF & 5334 & $\mathrm{P}$ & $\mathrm{O}$ & 8548 & UNC13D & RI \\
\hline TCONS_0001 & & & TCONS_0007 & & & TCONS_0003 & & \\
\hline 6881 & TEAD1 & SE & 5339 & ZNF184 & A5 & 8550 & UNC13D & $\mathrm{O}$ \\
\hline TCONS_0001 & & & TCONS_0007 & ZKSCAN & & TCONS_0003 & & \\
\hline 3167 & TEAD1 & SE & 5360 & 4 & 0 & 8549 & UNC13D & $\mathrm{O}$ \\
\hline TCONS_0001 & & & TCONS_0007 & ZSCAN1 & & TCONS_0003 & & \\
\hline 3168 & TEAD1 & $M X$ & 5365 & 2 & A5 & 8551 & UNC13D & A5 \\
\hline
\end{tabular}




\begin{tabular}{|c|c|c|c|c|c|c|c|c|}
\hline \multicolumn{3}{|l|}{ TCONS_0001 } & TCONS_0007 & \multicolumn{2}{|l|}{ ZSCAN1 } & TCONS_0003 & \multicolumn{2}{|l|}{ RP11-552 } \\
\hline 3169 & TEAD1 & SE & 5366 & 2 & $\mathrm{RI}$ & 9864 & F3.12 & A3 \\
\hline TCONS_0001 & & & TCONS_0007 & ZSCAN1 & & TCONS_0003 & & \\
\hline 3176 & ARNTL & $\mathrm{A} 3, \mathrm{SE}$ & 7740 & 2 & A5 & 8566 & AcoX1 & SE \\
\hline TCONS_0001 & & & TCONS_0007 & ZSCAN2 & & TCONS_0003 & & \\
\hline 3194 & INSC & $\mathrm{O}$ & 7741 & 3 & $\mathrm{O}$ & 8567 & AcoX1 & SE \\
\hline TCONS_0001 & SPTY2D & & TCONS_0007 & & & TCONS_0003 & & \\
\hline 3247 & 1-AS1 & $\mathrm{O}$ & 7748 & GABBR1 & SE & 8568 & ACOX1 & SE \\
\hline TCONS_0001 & ZDHHC & & TCONS_0007 & & & TCONS_0003 & & $A 3, A$ \\
\hline 6905 & 13 & $\mathrm{O}$ & 5384 & ZFP57 & SE & 8587 & FOXJ1 & 5 \\
\hline TCONS_0001 & & & TCONS_0007 & ZNRD1- & & TCONS_0003 & & \\
\hline 3272 & ANO5 & SE & 5399 & AS1 & A5 & 9885 & UBE2O & $\mathrm{O}$ \\
\hline TCONS_0001 & & & TCONS_0007 & & & TCONS_0003 & & \\
\hline 3273 & ANO5 & $\mathrm{A} 3, \mathrm{SE}$ & 5402 & TRIM31 & $\mathrm{O}$ & 8598 & RHBDF2 & AF \\
\hline TCONS_0001 & & & TCONS_0007 & & & TCONS_0003 & & A5,S \\
\hline 6937 & ELP4 & A3 & 5403 & TRIM31 & $\mathrm{O}$ & 8637 & TMC6 & $\mathrm{E}$ \\
\hline TCONS_0001 & KIAA154 & & TCONS_0007 & & & TCONS_0003 & & \\
\hline 3335 & $9 \mathrm{~L}$ & A5 & 5407 & TRIM26 & $\mathrm{O}$ & 9895 & CYTH1 & AF \\
\hline TCONS_0001 & & & TCONS_0007 & & & TCONS_0003 & & \\
\hline 3357 & NAT10 & $\mathrm{O}$ & 5405 & TRIM26 & A3 & 8655 & CYTH1 & AF \\
\hline TCONS_0001 & & & TCONS_0007 & PPP1R1 & & TCONS_0003 & & \\
\hline 6945 & NAT10 & $\mathrm{O}$ & 7767 & 0 & $\mathrm{RI}$ & 9907 & AATK & $\mathrm{RI}, \mathrm{SE}$ \\
\hline TCONS_0001 & & & TCONS_0007 & & & TCONS_0003 & & \\
\hline 3391 & CD44 & A3,SE & 7772 & CCHCR1 & $\mathrm{RI}$ & 8711 & ENTHD2 & $\mathrm{O}$ \\
\hline TCONS_0001 & & & TCONS_0007 & & & TCONS_0003 & & \\
\hline 3436 & TTC17 & SE & 7775 & HLA-B & $\mathrm{O}$ & 8751 & ARL16 & SE \\
\hline TCONS_0001 & & & TCONS_0007 & & & TCONS_0003 & & \\
\hline 6959 & TTC17 & A3,SE & 5460 & HLA-C & A3 & 9919 & ARL16 & SE \\
\hline TCONS_0001 & & & TCONS_0007 & & & TCONS_0003 & & \\
\hline 6961 & TTC17 & $\mathrm{RI}, \mathrm{SE}$ & 5461 & $\begin{array}{l}\text { HLA-C } \\
\text { ATP6V1 }\end{array}$ & A3 & 8763 & $\mathrm{P} 4 \mathrm{HB}$ & $\mathrm{O}$ \\
\hline TCONS_0001 & & & TCONS_0007 & G2-DDX & & TCONS_0003 & & \\
\hline 6965 & ALKBH3 & A3,SE & 7780 & $39 \mathrm{~B}$ & $\mathrm{RI}$ & 8800 & SIRT7 & $\mathrm{O}$ \\
\hline TCONS_0001 & & & TCONS_0007 & & & TCONS_0003 & & \\
\hline 6967 & ACCS & $\mathrm{RI}$ & 5483 & BAG6 & A5,SE & 8801 & SIRT7 & $\mathrm{RI}$ \\
\hline TCONS_0001 & MAPK8I & AF,RI & TCONS_0007 & BAG6 & A5,SE & TCONS_0003 & SIRT7 & $\mathrm{O}$ \\
\hline
\end{tabular}




\begin{tabular}{|c|c|c|c|c|c|c|c|c|}
\hline 6978 & P1 & & 5484 & & & 8803 & & \\
\hline TCONS_0001 & & & TCONS_0007 & & & TCONS_0003 & & \\
\hline 3473 & DGKZ & A3 & 5485 & BAG6 & RI & 9925 & SIRT7 & $\mathrm{RI}$ \\
\hline TCONS_0001 & & & TCONS_0007 & & & TCONS_0003 & & \\
\hline 6984 & DGKZ & $\mathrm{O}$ & 5487 & GPANK & A3 & 9927 & PYCR1 & $\mathrm{O}$ \\
\hline TCONS_0001 & & & TCONS_0007 & & A3,A5, & TCONS_0003 & & \\
\hline 6993 & DDB2 & $\mathrm{RI}$ & 5498 & VWA7 & $\mathrm{RI}$ & 9931 & RFNG & $\mathrm{O}$ \\
\hline TCONS_0001 & & & TCONS_0007 & & & TCONS_0003 & & \\
\hline 3500 & DDB2 & $\mathrm{RI}$ & 5499 & VWA7 & A5 & 9932 & DUS1L & A3 \\
\hline TCONS_0001 & & & TCONS_0007 & & & TCONS_0003 & & \\
\hline 6995 & $\mathrm{NR} 1 \mathrm{H} 3$ & $\mathrm{O}$ & 5500 & VARS & $\mathrm{O}$ & 8823 & DUS1L & $\mathrm{RI}$ \\
\hline TCONS_0001 & SLC39A & & TCONS_0007 & & & TCONS_0003 & & \\
\hline 3512 & 13 & A5 & 5528 & DXO & A3 & 8824 & DUS1L & $A 3, R I$ \\
\hline TCONS_0001 & SERPIN & & TCONS_0007 & & & TCONS_0003 & & \\
\hline 7003 & G1 & $\mathrm{O}$ & 5529 & DXO & A3 & 8825 & FASN & $\mathrm{O}$ \\
\hline TCONS_0001 & FAM111 & & TCONS_0007 & & & TCONS_0003 & & \\
\hline 3570 & A & $\mathrm{A} 3, \mathrm{~A} 5$ & 5530 & DXO & A3 & 8826 & FASN & A3 \\
\hline TCONS_000 & FAM111 & & TCONS_000 & & & TCONS_000 & & \\
\hline 17012 & A & $\mathrm{A} 3, \mathrm{~A} 5$ & 77795 & DXO & A3 & 39933 & CCDC57 & $\mathrm{O}$ \\
\hline TCONS_000 & FAM111 & & TCONS_000 & & & TCONS_000 & & \\
\hline 17013 & A & A5,RI & 77798 & TNXB & $\mathrm{O}$ & 38830 & CCDC57 & $\mathrm{O}$ \\
\hline TCONS_000 & & & TCONS_000 & & & TCONS_000 & & \\
\hline 13578 & DTX4 & $\mathrm{RI}$ & 75534 & ATF6B & $\mathrm{A} 5, \mathrm{RI}$ & 39935 & CCDC57 & RI,SE \\
\hline TCONS_000 & & & TCONS_000 & & & TCONS_000 & & \\
\hline 13609 & MS4A1 & SE & 75542 & AGER & $\mathrm{O}$ & 38850 & C17orf62 & A3 \\
\hline TCONS_000 & TMEM1 & & TCONS_000 & $\mathrm{NOTCH}$ & & TCONS_000 & & \\
\hline 13621 & 09 & A3 & 75548 & 4 & A5 & 38851 & C17orf62 & A3 \\
\hline TCONS_000 & TMEM1 & & TCONS_000 & HLA-DR & & TCONS_000 & & \\
\hline 17018 & 09 & 0 & 77800 & B5 & O & 38867 & WDR45B & $\mathrm{RI}$ \\
\hline TCONS_000 & & & TCONS_000 & HLA-DR & & TCONS_000 & ROCK1P & \\
\hline 13630 & DAK & $\mathrm{O}$ & 75550 & B5 & $\mathrm{O}$ & 39953 & 1 & $\mathrm{AF}$ \\
\hline TCONS_000 & TMEM2 & & TCONS_000 & HLA-DR & & TCONS_000 & & \\
\hline 17021 & 16 & $\mathrm{~A} 3, \mathrm{~A} 5$ & 75552 & B1 & O & 39970 & SMCHD1 & A5 \\
\hline TCONS_000 & & & TCONS_000 & HLA-DQ & & TCONS_000 & & \\
\hline 13654 & MYRF & $\mathrm{A} 3, \mathrm{SE}$ & 75557 & B1 & $\mathrm{O}$ & 40990 & SMCHD1 & A5,SE \\
\hline
\end{tabular}




\begin{tabular}{|c|c|c|c|c|c|c|c|c|}
\hline $\begin{array}{l}\text { TCONS_000 } \\
13655\end{array}$ & MYRF & A3 & $\begin{array}{l}\text { TCONS_000 } \\
75565\end{array}$ & TAP2 & A3 & $\begin{array}{l}\text { TCONS_000 } \\
39997\end{array}$ & $\begin{array}{l}\text { DLGAP1- } \\
\text { AS2 }\end{array}$ & 0 \\
\hline TCONS_000 & & & TCONS_000 & & & TCONS_000 & & \\
\hline $17027^{-}$ & MYRF & A3,SE & 77805 & TAP1 & $\mathrm{O}$ & 40014 & SOGA2 & SE \\
\hline TCONS_000 & & & TCONS_000 & & & TCONS_000 & & \\
\hline 13657 & FADS2 & 0 & 75592 & $\mathrm{R} \times \mathrm{RB}$ & 0 & 41005 & RALBP1 & AF \\
\hline TCONS_000 & RP11-8 & & TCONS_000 & & & TCONS_000 & ANKRD6 & \\
\hline 17037 & $64 \mid 4.4$ & $\mathrm{AL}$ & 75593 & RXRB & RI & 41016 & 2 & AL \\
\hline TCONS_000 & & & TCONS_000 & & & TCONS_000 & ANKRD6 & \\
\hline 13674 & ROM1 & AF & 75594 & RXRB & 0 & 41017 & 2 & AL \\
\hline TCONS_000 & & & TCONS_000 & & & TCONS_000 & ANKRD6 & \\
\hline 17054 & STIP1 & $A F$ & 75595 & $\mathrm{RXRB}$ & $\mathrm{A} 3, \mathrm{RI}$ & 41018 & 2 & O \\
\hline TCONS_000 & FERMT & & TCONS_000 & & & TCONS_000 & ANKRD6 & \\
\hline 13738 & 3 & A3 & 75596 & $\mathrm{R} X \mathrm{RB}$ & A3 & 41019 & 2 & O \\
\hline TCONS_000 & & & TCONS_000 & & & TCONS_000 & ANKRD6 & \\
\hline 17058 & DNAJC4 & 0 & 77807 & $\mathrm{RXRB}$ & $A 3, R I$ & 41020 & 2 & O \\
\hline TCONS_000 & & & TCONS_000 & & & TCONS_000 & ANKRD6 & \\
\hline 17059 & DNAJC4 & $\mathrm{O}$ & 77808 & $\mathrm{RXRB}$ & A3 & 41021 & 2 & $A L, R I$ \\
\hline TCONS_000 & & & TCONS_000 & & & TCONS_000 & & \\
\hline 17060 & DNAJC4 & A3,A5 & 75602 & VPS52 & $\mathrm{RI}$ & 40093 & CEP192 & A3 \\
\hline TCONS_000 & & & TCONS_000 & & & TCONS_000 & & \\
\hline 17061 & DNAJC4 & A5 & 75603 & VPS52 & $\mathrm{RI}$ & 40100 & LDLRAD4 & $\mathrm{AF}, \mathrm{SE}$ \\
\hline TCONS_000 & & & TCONS_000 & & & TCONS_000 & ANKRD2 & \\
\hline 17062 & DNAJC4 & A3,SE & 77811 & VPS52 & $\mathrm{O}$ & 40116 & 0A5P & O \\
\hline TCONS_000 & & & TCONS_000 & & & TCONS_000 & & \\
\hline 13742 & DNAJC4 & $\mathrm{O}$ & 77813 & RGL2 & $\mathrm{RI}$ & 41075 & SNRPD1 & $\mathrm{O}$ \\
\hline TCONS_000 & & & TCONS_000 & & & TCONS_000 & & \\
\hline 13743 & DNAJC4 & $\mathrm{O}$ & 75615 & DAXX & $\mathrm{RI}$ & 41084 & RIOK3 & RI \\
\hline TCONS_000 & & & TCONS_000 & & & TCONS_000 & & \\
\hline 13747 & VEGFB & $\mathrm{O}$ & 77817 & CUTA & A3 & 41085 & RIOK3 & A5 \\
\hline TCONS_000 & & & TCONS_000 & & & TCONS_000 & & \\
\hline 17064 & VEGFB & AF & 77827 & CLPS & $\mathrm{O}$ & 40157 & LAMA3 & $\mathrm{RI}$ \\
\hline TCONS_000 & & & TCONS_000 & C6orf22 & & TCONS_000 & & \\
\hline 17066 & GPR137 & A5,RI & 75676 & 2 & $\mathrm{RI}$ & 40211 & ZNF397 & A5 \\
\hline TCONS_000 & & & TCONS_000 & & & TCONS_000 & & \\
\hline 13760 & GPR137 & A3 & 77891 & PEX6 & 0 & 40246 & PIK3C3 & SE \\
\hline
\end{tabular}




\begin{tabular}{|c|c|c|c|c|c|c|c|c|}
\hline \multicolumn{3}{|l|}{ TCONS_000 } & \multicolumn{3}{|l|}{ TCONS 000} & \multicolumn{3}{|l|}{ TCONS 000} \\
\hline 13767 & ESRRA & $\mathrm{O}$ & 77893 & PEX6 & RI & 40263 & HAUS1 & A3,SE \\
\hline TCONS_000 & CCDC8 & & TCONS_000 & & & TCONS_000 & & \\
\hline 13774 & $8 \mathrm{~B}$ & RI & 75786 & MEA1 & A5 & 41130 & KIAA1468 & RI,SE \\
\hline TCONS_000 & CCDC8 & & TCONS_000 & & & TCONS_000 & & $\mathrm{A} 3, \mathrm{MX}$, \\
\hline 13775 & $8 \mathrm{~B}$ & RI & 77894 & CUL7 & O & 41132 & KIAA1468 & SE \\
\hline TCONS_000 & CCDC8 & & TCONS_000 & & A3,A5,A & TCONS_000 & & \\
\hline 13776 & $8 \mathrm{~B}$ & $A 5, R I$ & 75789 & CUL7 & $F$ & 40347 & KIAA1468 & SE \\
\hline TCONS_000 & RPS6K & & TCONS_000 & & & TCONS_000 & & \\
\hline 13780 & A4 & $A 5, R I$ & 75790 & CUL7 & A5,SE & 40424 & CNDP2 & SE \\
\hline TCONS_000 & RPS6K & & TCONS_000 & & & TCONS_000 & & \\
\hline 17068 & A4 & $\mathrm{O}$ & 75814 & XPO5 & O & 40425 & CNDP2 & SE \\
\hline TCONS_000 & PPP2R5 & & TCONS_000 & & & TCONS_000 & & \\
\hline 13787 & B & $\mathrm{O}$ & 77906 & AARS2 & 0 & 40429 & ZNF407 & 0 \\
\hline TCONS_000 & RP11-3 & & TCONS_000 & CYP39A & & TCONS_000 & & \\
\hline 17074 & $99 \mathrm{~J} 13.3$ & A3 & 77910 & 1 & SE & 40435 & ATP9B & SE \\
\hline TCONS_000 & & & TCONS_000 & & & TCONS_000 & & \\
\hline 17075 & VPS51 & $\mathrm{O}$ & 75846 & PLA2G7 & SE & 41184 & ENOSF1 & RI,SE \\
\hline TCONS_000 & & & TCONS_000 & & & TCONS_000 & & \\
\hline 17078 & TM7SF2 & A5,RI & 75849 & GPR116 & A3 & 41188 & LPIN2 & $A F$ \\
\hline TCONS_000 & & & TCONS_000 & & & TCONS_000 & & \\
\hline 13805 & CAPN1 & AF & 75850 & GPR116 & AF,SE & 40506 & LPIN2 & AF \\
\hline TCONS_000 & $\mathrm{CDC} 42$ & & TCONS_000 & & & TCONS_000 & & \\
\hline 17087 & EP2 & AF & 75875 & MUT & A5 & 41192 & MYOM1 & SE \\
\hline TCONS_000 & AP0007 & & TCONS_000 & HMGCL & & TCONS_000 & & \\
\hline 13823 & 69.1 & AL & 75912 & L1 & $\mathrm{O}$ & 41193 & MYOM1 & A5,RI \\
\hline TCONS_000 & SSSCA & & TCONS_000 & & & TCONS_000 & & \\
\hline 13836 & 1 & $\mathrm{O}$ & 75922 & DST & SE & 41200 & EPB41L3 & $\mathrm{O}$ \\
\hline TCONS_000 & SSSCA & & TCONS_000 & & & TCONS_000 & & \\
\hline 13837 & 1 & SE & 75923 & DST & SE & 40520 & L3MBTL4 & SE \\
\hline TCONS_000 & SSSCA & & TCONS_000 & & & TCONS_000 & & \\
\hline 13838 & 1 & $\mathrm{O}$ & 77940 & DST & $\mathrm{O}$ & 40529 & PPP4R1 & AF \\
\hline TCONS_000 & SSSCA & & TCONS_000 & & & TCONS_000 & & \\
\hline 13839 & 1 & 0 & 75938 & RAB23 & A5 & 40544 & MPPE1 & SE \\
\hline TCONS_000 & EHBP1L & & TCONS_000 & LINCOO & & TCONS_000 & & \\
\hline 13841 & 1 & A5 & 77952 & 680 & RI & 40562 & SPIRE1 & SE \\
\hline
\end{tabular}




\begin{tabular}{|c|c|c|c|c|c|c|c|c|}
\hline \multicolumn{3}{|l|}{ TCONS_000 } & \multicolumn{3}{|l|}{ TCONS_000 } & TCONS_000 & \multicolumn{2}{|l|}{ RP11-773 } \\
\hline 13847 & PCNXL3 & A3 & 75970 & OOEP & O & 40572 & $\mathrm{H} 22.4$ & O \\
\hline TCONS_000 & & & TCONS_000 & & & TCONS_000 & & \\
\hline 13848 & PCNXL3 & RI & 76107 & PGM3 & O & 41228 & ABHD3 & A5,SE \\
\hline TCONS_000 & & & TCONS_000 & & & TCONS_000 & GATA6-A & \\
\hline 13866 & MUS81 & $\mathrm{RI}$ & 76120 & SNAP91 & $\mathrm{RI}, \mathrm{SE}$ & $40609^{-}$ & S1 & RI \\
\hline TCONS_000 & & & TCONS_000 & KIAA10 & & TCONS_000 & & \\
\hline 13867 & MUS81 & RI & 78048 & 09 & SE & 41248 & OSBPL1A & SE \\
\hline TCONS_000 & & & TCONS_000 & KIAA10 & & TCONS_000 & & \\
\hline 13889 & SF3B2 & A3 & 76123 & 09 & SE & 41255 & DSC2 & $\mathrm{RI}, \mathrm{SE}$ \\
\hline TCONS_000 & & & TCONS_000 & & & TCONS_000 & TRAPPC & \\
\hline 17106 & SF3B2 & A3 & 76142 & RARS2 & A5 & 41257 & 8 & A3 \\
\hline TCONS_000 & & & TCONS_000 & MMS22 & & TCONS_000 & & \\
\hline 13898 & RAB1B & 0 & 76185 & L & A5 & 40687 & NOL4 & SE \\
\hline TCONS_000 & & & TCONS_000 & & & TCONS_000 & & \\
\hline 17110 & DPP3 & 0 & 76195 & COQ3 & 0 & 40710 & TPGS2 & O \\
\hline TCONS_000 & & & TCONS_000 & & & TCONS_000 & & \\
\hline 13907 & DPP3 & O & 76274 & SESN1 & A3 & 40711 & TPGS2 & $\mathrm{AL}$ \\
\hline TCONS_000 & & & TCONS_000 & & & TCONS_000 & & \\
\hline 17112 & CCS & 0 & 78180 & MICAL1 & A5 & 41279 & EPG5 & RI \\
\hline TCONS_000 & C11orf8 & & TCONS_000 & METTL2 & & TCONS_000 & & \\
\hline 13924 & 0 & A3 & 78183 & 4 & SE & 41281 & ATP5A1 & $\mathrm{O}$ \\
\hline TCONS_000 & C11orf8 & & TCONS_000 & & & TCONS_000 & & \\
\hline 13925 & 0 & A3 & 76345 & HDAC2 & $\mathrm{AF}$ & 41290 & PIAS2 & SE \\
\hline TCONS_000 & C11orf8 & & TCONS_000 & & & TCONS_000 & & \\
\hline 13927 & 0 & A3 & $76347^{-}$ & HDAC2 & $\mathrm{O}$ & $40753^{-}$ & SMAD2 & SE \\
\hline TCONS_000 & & & TCONS_000 & & & TCONS_000 & & $A 3, A F, R$ \\
\hline $13948^{-}$ & RAD9A & O & 76379 & CEP85L & A5,SE & $40797^{-}$ & MBD1 & I,SE \\
\hline TCONS_000 & & & TCONS_000 & & & TCONS_000 & & \\
\hline 17135 & RAD9A & O & 76380 & CEP85L & A5 & 40831 & CCDC68 & $\mathrm{A} 3, \mathrm{SE}$ \\
\hline TCONS 000 & TBC1D1 & & TCONS 000 & & & TCONS 000 & & \\
\hline 13955 & $\mathrm{OC}$ & 0 & 76386 & MCM9 & SE & 41320 & NARS & RI \\
\hline TCONS_000 & RPS6K & & TCONS_000 & TBC1D3 & & TCONS_000 & & \\
\hline $13959^{-}$ & B2 & SE & 78219 & 2 & $\mathrm{~A} 3, \mathrm{SE}$ & 40875 & NARS & RI \\
\hline TCONS_000 & RPS6K & & TCONS_000 & TBC1D3 & & TCONS_000 & & \\
\hline 13960 & B2 & SE & 76396 & 2 & A3 & 40896 & PIGN & $\mathrm{O}$ \\
\hline
\end{tabular}




\begin{tabular}{|c|c|c|c|c|c|c|c|c|}
\hline TCONS_000 & RPS6K & & TCONS_000 & NCOA7- & & TCONS_000 & SERPINB & \\
\hline 13962 & B2 & SE & 76405 & AS1 & SE & 40920 & 4 & A3 \\
\hline TCONS_000 & RPS6K & A5,RI, & TCONS_000 & EPB41L & & TCONS_000 & & \\
\hline 13963 & B2 & SE & 78235 & 2 & 0 & 41359 & ZNF516 & RI \\
\hline TCONS_000 & RPS6K & & TCONS_000 & EPB41L & & TCONS_000 & & \\
\hline 17137 & B2 & A5 & 78237 & 2 & A5 & 40964 & ZNF516 & SE \\
\hline TCONS_000 & & & TCONS_000 & EPB41L & & TCONS_000 & & \\
\hline 13968 & CABP4 & A5 & 78241 & 2 & 0 & 41377 & BSG & SE \\
\hline TCONS_000 & & & TCONS_000 & & & TCONS_000 & & \\
\hline 13998 & TCIRG1 & RI,SE & 76465 & CTGF & A3 & 45052 & PTBP1 & $A 5, R I$ \\
\hline TCONS_000 & & & TCONS_000 & & & TCONS_000 & & \\
\hline 13999 & TCIRG1 & $\mathrm{RI}$ & 78247 & MOXD1 & A5 & 45056 & ARID3A & $\mathrm{AF}$ \\
\hline TCONS_000 & & & TCONS_000 & SLC18B & & TCONS_000 & & \\
\hline 14000 & TCIRG1 & $\mathrm{RI}, \mathrm{SE}$ & 78250 & 1 & $\mathrm{RI}$ & 45059 & WDR18 & O \\
\hline TCONS_000 & & & TCONS_000 & & & TCONS_000 & & \\
\hline 14001 & TCIRG1 & $\mathrm{RI}$ & 78254 & SGK1 & $\mathrm{RI}$ & 41401 & WDR18 & $\mathrm{RI}$ \\
\hline TCONS_000 & & & TCONS_000 & & & TCONS_000 & & \\
\hline 14003 & TCIRG1 & $\mathrm{RI}$ & 78260 & AHI1 & $\mathrm{O}$ & 41414 & ABCA7 & $A 3, R I$ \\
\hline TCONS_000 & & & TCONS_000 & & & TCONS_000 & & \\
\hline 17144 & LRP5 & $\mathrm{RI}$ & 78261 & AHI1 & SE & $45060^{-}$ & ABCA7 & $\mathrm{RI}$ \\
\hline TCONS_000 & & & TCONS_000 & & & TCONS_000 & & \\
\hline 14014 & GAL & $\mathrm{O}$ & 78262 & AHI1 & $\mathrm{RI}$ & 41429 & MIDN & A5,RI \\
\hline TCONS_000 & RP11-5 & & TCONS_000 & & & TCONS_000 & & \\
\hline 17146 & 54A11.9 & AF & 78263 & AHI1 & SE & 45063 & MIDN & $\mathrm{RI}$ \\
\hline TCONS_000 & & & TCONS_000 & & & TCONS_000 & & \\
\hline 14033 & ANO1 & SE & 76521 & BCLAF1 & A3,SE & 41432 & CIRBP & $A 3, A 5$ \\
\hline TCONS_000 & & & TCONS_000 & & & TCONS_000 & & \\
\hline 14034 & ANO1 & SE & 76534 & MAP7 & SE & 41442 & MUM1 & RI,SE \\
\hline TCONS_000 & & & TCONS_000 & RP11-1 & & TCONS_000 & & \\
\hline 14035 & ANO1 & SE & 78286 & $2 \mathrm{~A} 2.3$ & AL & 45068 & MUM1 & SE \\
\hline TCONS_000 & & & TCONS_000 & RP11-1 & & TCONS_000 & & \\
\hline 14036 & ANO1 & SE & 78287 & $2 \mathrm{~A} 2.3$ & 0 & 41449 & NDUFS7 & $\mathrm{O}$ \\
\hline TCONS_000 & & & TCONS_000 & RP3-46 & & TCONS_000 & & \\
\hline 17155 & PPFIA1 & A5,SE & 76586 & $0 G 2.2$ & 0 & 45069 & DAZAP1 & 0 \\
\hline TCONS_000 & & & TCONS_000 & & & TCONS_000 & & \\
\hline 17156 & PPFIA1 & A5,SE & 76599 & HIVEP2 & $A F$ & 45078 & SPPL2B & A5,RI \\
\hline
\end{tabular}




\begin{tabular}{|c|c|c|c|c|c|c|c|c|}
\hline \multicolumn{3}{|l|}{ TCONS 000} & \multicolumn{3}{|l|}{ TCONS_000 } & \multicolumn{3}{|l|}{ TCONS_000 } \\
\hline 14043 & CTTN & $A 3, R I$ & 76602 & ADAT2 & $\mathrm{O}$ & 45079 & SPPL2B & $\mathrm{A} 5, \mathrm{RI}$ \\
\hline TCONS_000 & & & TCONS_000 & & & TCONS_000 & & \\
\hline 17157 & CTTN & $\mathrm{RI}$ & 78306 & ADAT2 & O & 41509 & TLE6 & A5,RI \\
\hline TCONS_000 & NADSY & & TCONS_000 & & & TCONS_000 & & \\
\hline 17159 & $\mathrm{~N} 1$ & A5,SE & 78320 & NUP43 & A3 & 45087 & NCLN & A3 \\
\hline TCONS_000 & NADSY & & TCONS_000 & & & TCONS_000 & & \\
\hline 17160 & $\mathrm{~N} 1$ & A5 & 76645 & NUP43 & A3 & 41519 & NCLN & A3 \\
\hline TCONS_000 & & & TCONS_000 & & & TCONS_000 & & \\
\hline 17165 & INPPL1 & RI & 78321 & LRP11 & O & 45090 & FZR1 & $\mathrm{O}$ \\
\hline TCONS_000 & & & TCONS_000 & & & TCONS_000 & & \\
\hline 17167 & INPPL1 & RI,SE & 78322 & ZBTB2 & A5 & 41538 & HMG2OB & $\mathrm{O}$ \\
\hline TCONS_000 & & & TCONS_000 & & & TCONS_000 & & \\
\hline 17168 & INPPL1 & $A F, R I$ & 76663 & RMND1 & A5 & 45093 & NMRK2 & $\mathrm{O}$ \\
\hline TCONS_000 & & & TCONS_000 & & $A 3, A 5, S$ & TCONS_000 & & \\
\hline 14071 & INPPL1 & 0 & 76666 & SYNE1 & $\mathrm{E}$ & 45094 & PIAS4 & O \\
\hline TCONS_000 & & & TCONS_000 & & $\mathrm{A} 5, \mathrm{RI}, \mathrm{S}$ & TCONS_000 & MIR7-3H & \\
\hline 14072 & INPPL1 & RI & 78325 & SYNE1 & $\mathrm{E}$ & 41561 & $\mathrm{G}$ & A3 \\
\hline TCONS_000 & & & TCONS_000 & & & TCONS_000 & & \\
\hline 14073 & INPPL1 & $\mathrm{A} 3, \mathrm{RI}$ & 76753 & AGPAT4 & A3,RI & 41567 & KDM4B & SE \\
\hline TCONS_000 & ARHGE & & TCONS_000 & & & TCONS_000 & & \\
\hline 17173 & F17 & RI & 76786 & THBS2 & $\mathrm{O}$ & 45103 & SAFB & A3 \\
\hline TCONS_000 & & & TCONS_000 & & & TCONS_000 & & \\
\hline 14114 & PAAF1 & SE & 78377 & DLL1 & RI & 41586 & CAPS & $\mathrm{O}$ \\
\hline TCONS_000 & & & TCONS_000 & AC1476 & & TCONS_000 & & \\
\hline 14127 & RNF169 & O & 78391 & 51.4 & 0 & 41598 & CRB3 & O \\
\hline TCONS 000 & C11orf3 & & TCONS 000 & & & TCONS 000 & & \\
\hline 14177 & 0 & A3 & 78394 & SUN1 & O & 41599 & CRB3 & O \\
\hline TCONS 000 & & & TCONS 000 & & & TCONS 000 & & \\
\hline $14190^{-}$ & B3GNT6 & O & 78395 & SUN1 & RI & $41600^{-}$ & CRB3 & O \\
\hline TCONS_000 & & & TCONS_000 & & & TCONS_000 & CTD-220 & \\
\hline $14195^{-}$ & MYO7A & A5,SE & 78396 & SUN1 & RI,SE & 41616 & 7023.3 & O \\
\hline TCONS 000 & & & TCONS 000 & & & TCONS 000 & & \\
\hline $14214^{-}$ & PCF11 & A5 & 78404 & SUN1 & O & 41621 & MCOLN1 & RI \\
\hline TCONS_000 & & & TCONS_000 & & & TCONS_000 & & \\
\hline 14333 & FAT3 & SE & 82142 & SUN1 & RI & 45121 & PNPLA6 & $\mathrm{O}$ \\
\hline
\end{tabular}




\begin{tabular}{|c|c|c|c|c|c|c|c|c|}
\hline TCONS_000 & KIAA17 & & TCONS_000 & CYP2W & & TCONS_000 & & \\
\hline 17223 & 31 & A5 & 78405 & 1 & $\mathrm{O}$ & 41624 & PNPLA6 & SE \\
\hline TCONS_000 & KIAA17 & & TCONS_000 & & & TCONS_000 & & \\
\hline 14340 & 31 & $\mathrm{O}$ & 78420 & NUDT1 & $\mathrm{O}$ & 41628 & PNPLA6 & RI \\
\hline TCONS_000 & KIAA17 & & TCONS_000 & & & TCONS_000 & & \\
\hline 14341 & 31 & O & 78422 & NUDT1 & A5 & 41641 & C19orf59 & $\mathrm{O}$ \\
\hline TCONS_000 & C11orf5 & & TCONS_000 & & & TCONS_000 & & \\
\hline 14344 & 4 & A5 & 78424 & EIF3B & A3 & 45132 & CERS4 & SE \\
\hline TCONS_000 & & & TCONS_000 & & & TCONS_000 & & \\
\hline 14353 & HEPHL1 & RI & 78425 & EIF3B & $\mathrm{O}$ & 41713 & C19orf66 & $\mathrm{O}$ \\
\hline TCONS_000 & & & TCONS_000 & SLC29A & & TCONS_000 & PPAN-P2 & \\
\hline 14365 & PIWIL4 & $\mathrm{AF}$ & 78468 & 4 & $\mathrm{~A} 3, \mathrm{AF}$ & 41715 & RY11 & A5 \\
\hline TCONS_000 & & & TCONS_000 & & & TCONS_000 & & \\
\hline 14366 & PIWIL4 & $\mathrm{AF}$ & 82171 & ZNF853 & A3 & 41723 & ICAM4 & $\mathrm{O}$ \\
\hline TCONS_000 & & & TCONS_000 & & & TCONS_000 & & \\
\hline 14367 & PIWIL4 & AF,SE & 78523 & MIOS & A5 & 41742 & QTRT1 & A3 \\
\hline TCONS_000 & C11orf7 & & TCONS_000 & AC0071 & & TCONS_000 & & \\
\hline 14391 & 0 & $\mathrm{O}$ & 82181 & 28.1 & A5 & 41747 & DNM2 & $A L, M X$ \\
\hline TCONS_000 & C11orf7 & & TCONS_000 & & & TCONS_000 & & \\
\hline 14392 & 0 & $\mathrm{O}$ & 78537 & PHF14 & $\mathrm{O}$ & 41748 & DNM2 & $A 3, M X$ \\
\hline TCONS_000 & & & TCONS_000 & AC0191 & & TCONS_000 & & \\
\hline 17260 & ATM & $\mathrm{O}$ & 78596 & 17.1 & SE & 41749 & DNM2 & $A L, M X$ \\
\hline TCONS_000 & ZC3H12 & & TCONS_000 & & & TCONS_000 & & $\mathrm{A} 3, \mathrm{MX}$ \\
\hline 14485 & C & $A F$ & 82185 & HDAC9 & A3 & 45151 & DNM2 & $\mathrm{RI}$ \\
\hline TCONS_000 & ZC3H12 & & TCONS_000 & & & TCONS_000 & & $A L, R I, S$ \\
\hline 14486 & C & $\mathrm{AF}$ & 78606 & IL6 & $\mathrm{O}$ & 45152 & DNM2 & E \\
\hline TCONS_000 & COLCA & & TCONS_000 & & & TCONS_000 & SMARCA & \\
\hline 14492 & 2 & O & 78754 & AVL9 & $\mathrm{RI}$ & 41769 & 4 & A3,SE \\
\hline TCONS_000 & $\begin{array}{l}\text { HSPB2- } \\
\text { C11orf5 }\end{array}$ & & TCONS_000 & & & TCONS_000 & SMARCA & \\
\hline 17266 & 2 & $\mathrm{O}$ & 78755 & AVL9 & $\mathrm{O}$ & 41770 & 4 & SE \\
\hline TCONS_000 & & & TCONS_000 & & & TCONS_000 & SMARCA & \\
\hline 14545 & TTC12 & A5,RI & 78807 & SEPT7 & $M X$ & 45157 & 4 & SE \\
\hline TCONS_000 & RP11-2 & & TCONS_000 & & & TCONS_000 & & \\
\hline 17278 & 12D19.4 & $\mathrm{O}$ & 82232 & SEPT7 & $\mathrm{O}$ & 41787 & CCDC159 & $\mathrm{O}$ \\
\hline
\end{tabular}




\begin{tabular}{|c|c|c|c|c|c|c|c|c|}
\hline TCONS_000 & RP11-1 & & TCONS_000 & AC0073 & & TCONS_000 & & \\
\hline 14575 & 09L13.1 & $\mathrm{RI}$ & 82236 & 49.4 & $A F$ & 41789 & CCDC159 & A5 \\
\hline TCONS_000 & RP11-1 & & TCONS_000 & & & TCONS_000 & & \\
\hline 17283 & 09L13.1 & O & 78855 & C7orf10 & $\mathrm{O}$ & 45168 & CCDC159 & RI \\
\hline TCONS_000 & & & TCONS_000 & & & TCONS_000 & & \\
\hline 14582 & TAGLN & SE & 78873 & STK17A & O & 45169 & PRKCSH & O \\
\hline TCONS_000 & & & TCONS_000 & & & TCONS_000 & & \\
\hline 14590 & RNF214 & $A F$ & 78874 & STK17A & O & 45170 & PRKCSH & A5 \\
\hline TCONS_000 & & & TCONS_000 & & & TCONS_000 & & \\
\hline 14591 & RNF214 & $A F, R I$ & 78875 & STK17A & $\mathrm{O}$ & 41799 & PRKCSH & $\mathrm{O}$ \\
\hline TCONS_000 & & & TCONS_000 & & & TCONS_000 & & \\
\hline 17287 & CEP164 & $\mathrm{O}$ & 82257 & UBE2D4 & SE & 41800 & PRKCSH & A3 \\
\hline TCONS_000 & & & TCONS_000 & & & TCONS_000 & & \\
\hline 17288 & CEP164 & A5,SE & 82258 & UBE2D4 & SE & 45172 & PRKCSH & A3 \\
\hline TCONS_000 & & & TCONS_000 & & & TCONS_000 & & \\
\hline 17289 & CEP164 & SE & 78885 & DBNL & A3 & 41826 & ZNF439 & $\mathrm{O}$ \\
\hline TCONS_000 & & & TCONS_000 & & & TCONS_000 & & \\
\hline 17290 & CEP164 & A5 & 78886 & DBNL & A3 & 45184 & GCDH & RI \\
\hline TCONS_000 & & & TCONS_000 & & $\mathrm{A} 3, \mathrm{~A} 5, \mathrm{~A}$ & TCONS_000 & & \\
\hline 14596 & CEP164 & AF,SE & 78913 & ZMIZ2 & $\mathrm{F}, \mathrm{RI}$ & 41864 & CALR & $\mathrm{O}$ \\
\hline TCONS_000 & & & TCONS_000 & & & TCONS_000 & & \\
\hline 14597 & CEP164 & A5,SE & 78914 & ZMIZ2 & A5,AF,RI & 41878 & NACC1 & $\mathrm{O}$ \\
\hline TCONS_000 & & & TCONS_000 & & & TCONS_000 & & \\
\hline 17291 & CEP164 & $\mathrm{O}$ & 78983 & GBAS & $A F$ & 45192 & NACC1 & $\mathrm{O}$ \\
\hline TCONS_000 & & & TCONS_000 & & & TCONS_000 & & \\
\hline 14598 & CEP164 & SE & 78984 & GBAS & $A F$ & 45194 & MRI1 & RI \\
\hline TCONS_000 & RP11-7 & & TCONS_000 & & & TCONS_000 & & \\
\hline 17296 & $28 \mathrm{~F} 11.3$ & 0 & 82283 & ZNF736 & 0 & 41901 & CC2D1A & $\mathrm{O}$ \\
\hline TCONS_000 & & & TCONS_000 & & & TCONS_000 & & \\
\hline 14615 & CD3E & 0 & 79002 & ZNF736 & A3 & 45196 & CC2D1A & RI \\
\hline TCONS_000 & & & TCONS_000 & & & TCONS_000 & & \\
\hline 14621 & UBE4A & $\mathrm{RI}$ & 79012 & ZNF107 & O & 45197 & CC2D1A & A5 \\
\hline TCONS_000 & & & TCONS_000 & & & TCONS_000 & & \\
\hline 14630 & KMT2A & A5,SE & 79028 & ССТ6Р3 & SE & 41904 & DCAF15 & $\mathrm{RI}$ \\
\hline TCONS_000 & TMEM2 & & TCONS_000 & & & TCONS_000 & & \\
\hline 14638 & 5 & $\mathrm{AL}$ & 79046 & ССТ6Р1 & A5 & 41946 & CYP4F12 & RI \\
\hline
\end{tabular}




\begin{tabular}{|c|c|c|c|c|c|c|c|c|}
\hline \multicolumn{3}{|l|}{ TCONS_000 } & TCONS_000 & \multicolumn{2}{|l|}{ STAG3L } & \multicolumn{3}{|l|}{ TCONS_000 } \\
\hline 14678 & VPS11 & RI & 79083 & 4 & A3 & 41947 & CYP4F12 & A5,RI \\
\hline TCONS_000 & & & TCONS_000 & SBDSP & & TCONS_000 & & \\
\hline 17309 & VPS11 & A5,RI & 79104 & 1 & 0 & 41948 & CYP4F12 & A5,RI \\
\hline TCONS_000 & & & TCONS_000 & SBDSP & & TCONS_000 & & \\
\hline 14685 & $\mathrm{C} 2 \mathrm{CD} 2 \mathrm{~L}$ & A3 & 79105 & 1 & 0 & 41981 & C19orf44 & $\mathrm{O}$ \\
\hline TCONS_000 & & & TCONS_000 & POM12 & & TCONS_000 & & \\
\hline 14689 & PDZD3 & $\mathrm{RI}, \mathrm{SE}$ & 79110 & 1 & A3 & 41989 & SIN3B & A5 \\
\hline TCONS_000 & CTD-25 & & TCONS_000 & POM12 & & TCONS_000 & & \\
\hline 14695 & 23D13.2 & $\mathrm{O}$ & 79111 & 1 & $\mathrm{O}$ & 41990 & SIN3B & $\mathrm{O}$ \\
\hline TCONS_000 & ARHGE & & TCONS_000 & POM12 & AL,RI,S & TCONS_000 & & \\
\hline 14704 & F12 & SE & 79112 & 1 & $\mathrm{E}$ & 45214 & MYO9B & $\mathrm{O}$ \\
\hline TCONS_000 & & & TCONS_000 & & & TCONS_000 & & \\
\hline 17318 & TBCEL & $\mathrm{O}$ & 79123 & NCF1B & A5,RI & 41995 & MYO9B & $\mathrm{RI}$ \\
\hline TCONS_000 & & & TCONS_000 & LINCOO & & TCONS_000 & & \\
\hline 17376 & VWA5A & $\mathrm{O}$ & 79134 & 035 & A5 & 41996 & MYO9B & A5 \\
\hline TCONS_000 & & & TCONS_000 & LINCOO & & TCONS_000 & & \\
\hline 14759 & VWA5A & $\mathrm{O}$ & 79135 & 035 & $\mathrm{O}$ & 41997 & MYO9B & $\mathrm{AF}$ \\
\hline TCONS_000 & & & TCONS_000 & & $A 3, A 5, R I$ & TCONS_000 & & \\
\hline 14761 & TBRG1 & $\mathrm{O}$ & 82318 & ELN & ,SE & 45215 & MYO9B & $A 3, R I$ \\
\hline TCONS_000 & & & TCONS_000 & & $A 3, A 5, R I$ & TCONS_000 & & \\
\hline 17377 & TBRG1 & O & 79160 & ELN & ,SE & 42000 & MYO9B & A3,SE \\
\hline TCONS_000 & & & TCONS_000 & & $A 3, A 5, S$ & TCONS_000 & & \\
\hline 14773 & ROBO3 & $\mathrm{O}$ & 79161 & ELN & $\mathrm{E}$ & 42009 & OCEL1 & SE \\
\hline TCONS_000 & SLC37A & & TCONS 000 & & $A 3, A 5, R I$ & TCONS_000 & & \\
\hline 14775 & 2 & A5,RI & 82322 & ELN & ,SE & 45218 & GTPBP3 & A3 \\
\hline TCONS_000 & RP11-7 & & TCONS_000 & GTF2IR & & TCONS_000 & & \\
\hline 14797 & 02B10.2 & 0 & 82329 & D1 & 0 & 42066 & ARRDC2 & 0 \\
\hline TCONS_000 & & & TCONS_000 & PMS2P & & TCONS_000 & & \\
\hline 14843 & ACAD8 & $\mathrm{RI}$ & 82332 & 5 & 0 & 42076 & PIK3R2 & $\mathrm{RI}$ \\
\hline TCONS_000 & & & TCONS_000 & GTF2IR & & TCONS_000 & & \\
\hline 17399 & ACAD8 & A3,SE & 79194 & D2B & SE & 42077 & PIK3R2 & $\mathrm{RI}$ \\
\hline TCONS_000 & & & TCONS_000 & NSUN5 & & TCONS_000 & & \\
\hline 17401 & GLB1L2 & SE & 79205 & $\mathrm{P} 1$ & RI & 42094 & KXD1 & $\mathrm{O}$ \\
\hline TCONS_000 & LINC01 & & TCONS_000 & NSUN5 & & TCONS_000 & & \\
\hline 14848 & 001 & $\mathrm{O}$ & 79206 & P1 & A5 & 42095 & KXD1 & SE \\
\hline
\end{tabular}




\begin{tabular}{|c|c|c|c|c|c|c|c|c|}
\hline TCONS_000 & LINC01 & & TCONS_000 & NSUN5 & & TCONS_000 & & \\
\hline 14849 & 001 & $\mathrm{O}$ & 79207 & $\mathrm{P} 1$ & A5,RI & 42097 & UBA52 & 0 \\
\hline TCONS_000 & LINC01 & & TCONS_000 & & & TCONS_000 & & \\
\hline 14850 & 001 & 0 & 79223 & HSPB1 & 0 & 42098 & UBA52 & SE \\
\hline TCONS_000 & & & TCONS_000 & & & TCONS_000 & & \\
\hline 17402 & BET1L & $\mathrm{O}$ & 79230 & DTX2 & SE & 42119 & UPF1 & $\mathrm{AF}$ \\
\hline TCONS_000 & & & TCONS_000 & RP5-11 & & TCONS_000 & & \\
\hline 14855 & SIRT3 & $\mathrm{O}$ & 79263 & 8517.1 & 0 & 45238 & UPF1 & $\mathrm{AF}$ \\
\hline TCONS_000 & & & TCONS_000 & & & TCONS_000 & & \\
\hline 17410 & ANO9 & A3 & 79293 & DMTF1 & A3,A5 & 42122 & DDX49 & $\mathrm{O}$ \\
\hline TCONS_000 & & & TCONS_000 & & & TCONS_000 & & \\
\hline 14864 & ANO9 & A5,RI & 79316 & STEAP2 & $\mathrm{O}$ & 45239 & DDX49 & $\mathrm{RI}$ \\
\hline TCONS_000 & & & TCONS_000 & & & TCONS_000 & & \\
\hline 14865 & ANO9 & $\mathrm{RI}$ & 82367 & C7orf63 & $\mathrm{O}$ & 45244 & RFXANK & A3 \\
\hline TCONS_000 & & & TCONS_000 & & & TCONS_000 & & \\
\hline 17418 & HRAS & SE & 79346 & AKAP9 & SE & 45245 & RFXANK & A3 \\
\hline TCONS_000 & C11orf3 & & TCONS_000 & & & TCONS_000 & & \\
\hline 14882 & 5 & $\mathrm{RI}$ & 82371 & AKAP9 & A5,SE & 42141 & GATAD2A & $\mathrm{O}$ \\
\hline TCONS_000 & & & TCONS_000 & & & TCONS_000 & & \\
\hline 17422 & IRF7 & RI,SE & 82372 & AKAP9 & SE & 42146 & GATAD2A & $\mathrm{O}$ \\
\hline TCONS_000 & & & TCONS_000 & & & TCONS_000 & & \\
\hline 14886 & IRF7 & $\mathrm{RI}$ & 79347 & AKAP9 & A5,SE & 45251 & ZNF101 & $\mathrm{O}$ \\
\hline TCONS_000 & & & TCONS_000 & & & TCONS_000 & & \\
\hline 14887 & IRF7 & $\mathrm{RI}$ & 79354 & GATAD1 & $\mathrm{O}$ & 45269 & ZNF714 & SE \\
\hline TCONS_000 & & & TCONS_000 & AC0063 & & TCONS_000 & & \\
\hline 14888 & IRF7 & $\mathrm{RI}$ & 79374 & 78.2 & $\mathrm{O}$ & 45272 & ZNF738 & AL \\
\hline TCONS_000 & & & TCONS_000 & & & TCONS_000 & & \\
\hline 14889 & IRF7 & 0 & 82380 & PEG10 & A5 & 42216 & ZNF738 & AL \\
\hline TCONS_000 & & & TCONS_000 & PPP1R9 & & TCONS_000 & & \\
\hline 14895 & CDHR5 & A3 & 82381 & $A$ & SE & 45306 & ZNF507 & SE \\
\hline TCONS_000 & & & TCONS_000 & PPP1R9 & & TCONS_000 & & $\mathrm{A} 3, \mathrm{~A} 5, \mathrm{~S}$ \\
\hline 14896 & CDHR5 & $\mathrm{RI}$ & 82382 & $A$ & A5,SE & 42281 & DPY19L3 & E \\
\hline TCONS_000 & & & TCONS_000 & PPP1R9 & & TCONS_000 & & \\
\hline 14901 & SCT & $\mathrm{O}$ & 82383 & A & SE & 45312 & LSM14A & RI,SE \\
\hline TCONS_000 & & & TCONS_000 & & & TCONS_000 & & \\
\hline 14903 & DEAF1 & AF & 82399 & TRRAP & $A F$ & 45318 & ZNF302 & SE \\
\hline
\end{tabular}




\begin{tabular}{|c|c|c|c|c|c|c|c|c|}
\hline \multicolumn{3}{|l|}{ TCONS_000 } & \multicolumn{3}{|l|}{ TCONS_000 } & \multicolumn{2}{|l|}{ TCONS_000 } & \multirow{2}{*}{$\begin{array}{l}A 3, A 5, S \\
E\end{array}$} \\
\hline 14904 & DEAF1 & $\mathrm{O}$ & 82406 & CPSF4 & A3 & 42338 & ZNF181 & \\
\hline TCONS_000 & & & TCONS_000 & & & TCONS_000 & GRAMD1 & \\
\hline 14909 & PDDC1 & A3 & 82407 & CPSF4 & 0 & 42347 & A & 0 \\
\hline TCONS_000 & & & TCONS_000 & ZKSCA & & TCONS_000 & & \\
\hline 14916 & PIDD & A3,A5 & 79449 & N5 & 0 & 42353 & HPN & 0 \\
\hline TCONS_000 & & & TCONS_000 & & & TCONS_000 & & \\
\hline 17425 & PIDD & A3 & 82409 & ZNF655 & SE & 45332 & HPN & A3 \\
\hline TCONS_000 & & & TCONS_000 & ZKSCA & A5,RI,S & TCONS_000 & & \\
\hline 14925 & MUC6 & $\mathrm{MX}, \mathrm{RI}$ & 82416 & N1 & $\mathrm{E}$ & 45333 & HPN & $\mathrm{O}$ \\
\hline TCONS_000 & & & TCONS_000 & ZSCAN & & TCONS_000 & CTD-252 & \\
\hline 14928 & MUC6 & $\mathrm{O}$ & 79481 & 21 & O & 45338 & $7 \mid 21.4$ & $\mathrm{RI}$ \\
\hline TCONS_000 & & & TCONS_000 & ZSCAN & & TCONS_000 & & \\
\hline 14931 & MUC6 & $\mathrm{RI}$ & 79482 & 21 & A3 & 42385 & CD22 & A3 \\
\hline TCONS_000 & & & TCONS_000 & & & TCONS_000 & & \\
\hline 14932 & MUC6 & $\mathrm{RI}$ & 79488 & AP4M1 & O & 45344 & ETV2 & O \\
\hline TCONS_000 & & & TCONS_000 & & & TCONS_000 & & \\
\hline 14926 & MUC6 & $\mathrm{RI}$ & 79489 & AP4M1 & SE & 45345 & KMT2B & $\mathrm{RI}$ \\
\hline TCONS_000 & & & TCONS_000 & & & TCONS_000 & & \\
\hline 14927 & MUC6 & $\mathrm{RI}$ & 79490 & AP4M1 & A5,RI & 42407 & KMT2B & 0 \\
\hline TCONS_000 & & & TCONS_000 & LAMTO & & TCONS_000 & AC00239 & \\
\hline 14929 & MUC6 & $\mathrm{RI}$ & 82422 & $\mathrm{R} 4$ & 0 & 42408 & 8.9 & SE \\
\hline TCONS_000 & & & TCONS_000 & & & TCONS_000 & AC00239 & \\
\hline 14930 & MUC6 & $\mathrm{O}$ & 82425 & PILRB & $A 3, R I$ & 45346 & 8.9 & SE \\
\hline TCONS_000 & & & TCONS_000 & & & TCONS_000 & AC00239 & \\
\hline 14933 & MUC6 & $A 3, R I$ & 82427 & PILRB & $\mathrm{RI}$ & 42412 & 8.9 & RI \\
\hline TCONS_000 & & & TCONS_000 & & & TCONS_000 & & \\
\hline 14987 & NAP1L4 & AF,SE & 79509 & PILRB & $\mathrm{A} 3, \mathrm{RI}$ & 42413 & C19orf55 & A3 \\
\hline TCONS_000 & & & TCONS_000 & & & TCONS_000 & ARHGAP & \\
\hline 14988 & NAP1L4 & AF & 79526 & GNB2 & A5 & 42414 & 33 & A3 \\
\hline TCONS_000 & & & TCONS_000 & & & TCONS_000 & & \\
\hline 17448 & NAP1L4 & AF & 82431 & EPO & 0 & 45348 & KIRREL2 & 0 \\
\hline TCONS_000 & & & TCONS_000 & SLC12A & & TCONS_000 & & \\
\hline 14989 & NAP1L4 & SE & 79533 & 9 & RI & 45349 & KIRREL2 & SE \\
\hline TCONS_000 & & A3,RI, & TCONS_000 & & & TCONS_000 & & \\
\hline 15001 & CARS & SE & 79536 & SRRT & A3 & 45351 & KIRREL2 & RI \\
\hline
\end{tabular}




\begin{tabular}{|c|c|c|c|c|c|c|c|c|}
\hline $\begin{array}{l}\text { TCONS_000 } \\
17449\end{array}$ & CARS & $\begin{array}{l}\text { A3,RI, } \\
\text { SE }\end{array}$ & $\begin{array}{l}\text { TCONS_000 } \\
79537\end{array}$ & SRRT & A5 & $\begin{array}{l}\text { TCONS_000 } \\
42415\end{array}$ & APLP1 & A3 \\
\hline TCONS_000 & & & TCONS_000 & & $A 3, R I, S$ & TCONS_000 & & \\
\hline 15039 & TRIM5 & A3 & 82437 & SRRT & E & 42426 & CAPNS1 & A3 \\
\hline TCONS_000 & & A5,RI, & TCONS_000 & & & TCONS_000 & CTD-316 & \\
\hline 17464 & TRIM3 & SE & 79548 & TRIM56 & $\mathrm{O}$ & 42455 & 2L10.1 & $\mathrm{RI}$ \\
\hline TCONS_000 & & & TCONS_000 & SERPIN & & TCONS_000 & & \\
\hline 15070 & TPP1 & O & 79555 & E1 & $\mathrm{O}$ & 45375 & SPINT2 & $\mathrm{O}$ \\
\hline TCONS_000 & & & TCONS_000 & PRKRIP & & TCONS_000 & & \\
\hline 15104 & CYB5R2 & AF,SE & 82452 & 1 & A3 & 42523 & FAM98C & A3 \\
\hline TCONS_000 & & & TCONS_000 & FAM185 & & TCONS_000 & & \\
\hline 17493 & RIC3 & $\mathrm{A} 3, \mathrm{RI}$ & 79582 & A & SE & 45376 & FAM98C & $\mathrm{O}$ \\
\hline TCONS_000 & & & TCONS_000 & & & TCONS_000 & & \\
\hline 17494 & RIC3 & $\mathrm{A} 3, \mathrm{RI}$ & 82463 & РMPCB & SE & 42524 & FAM98C & $\mathrm{O}$ \\
\hline TCONS_000 & & $A 3, R I$, & TCONS_000 & & & TCONS_000 & & \\
\hline 17495 & RIC3 & SE & 82465 & KMT2E & SE & 42556 & SAMD4B & $\mathrm{O}$ \\
\hline TCONS_000 & & & TCONS_000 & & & TCONS_000 & PLEKHG & \\
\hline 17515 & MRVI1 & $\mathrm{O}$ & 82466 & KMT2E & RI,SE & 42567 & 2 & A3 \\
\hline TCONS_000 & & & TCONS_000 & & A5,RI,S & TCONS_000 & PLEKHG & \\
\hline 15156 & MRVI1 & $\mathrm{O}$ & 79613 & KMT2E & $\mathrm{E}$ & 42568 & 2 & A3 \\
\hline TCONS_000 & & & TCONS_000 & & & TCONS_000 & & \\
\hline 15157 & MRVI1 & $\mathrm{O}$ & 79644 & DUS4L & $\mathrm{O}$ & 42579 & TIMM50 & $\mathrm{O}$ \\
\hline TCONS_000 & & & TCONS_000 & & & TCONS_000 & & \\
\hline 15161 & EIF4G2 & $\mathrm{O}$ & 79742 & ZNF277 & A5 & 42595 & PLD3 & A3 \\
\hline TCONS_000 & & & TCONS_000 & & & TCONS_000 & & \\
\hline 17518 & ZBED5 & A5 & 79746 & IFRD1 & $\mathrm{O}$ & 42596 & PLD3 & $\mathrm{O}$ \\
\hline TCONS_000 & & & TCONS_000 & & & TCONS_000 & & \\
\hline 17520 & DKK3 & AF & 79761 & TES & A3,SE & 42597 & PLD3 & A3 \\
\hline TCONS_000 & & & TCONS_000 & & & TCONS_000 & & \\
\hline 15202 & COPB1 & A5 & 79800 & CFTR & A5 & 45390 & PLD3 & A3 \\
\hline TCONS_000 & PLEKH & & TCONS_000 & & & TCONS_000 & & \\
\hline 17534 & A7 & A3,A5 & 82515 & CFTR & A5,SE & 45391 & PLD3 & $A 3, A 5$ \\
\hline TCONS_000 & PIK3C2 & & TCONS_000 & & & TCONS_000 & & \\
\hline 15234 & A & $\mathrm{O}$ & 79814 & CPED1 & $\mathrm{O}$ & 45392 & PLD3 & A3 \\
\hline TCONS_000 & & & TCONS_000 & & & TCONS_000 & & \\
\hline 15239 & ABCC8 & $\mathrm{O}$ & 82520 & CPED1 & SE & 42606 & LTBP4 & RI,SE \\
\hline
\end{tabular}




\begin{tabular}{|c|c|c|c|c|c|c|c|c|}
\hline $\begin{array}{l}\text { TCONS_000 } \\
17539\end{array}$ & $A B C C 8$ & $\mathrm{RI}$ & $\begin{array}{l}\text { TCONS_000 } \\
79822\end{array}$ & $\begin{array}{l}\text { FEZF1- } \\
\text { AS1 }\end{array}$ & A5 & $\begin{array}{l}\text { TCONS_000 } \\
42608\end{array}$ & LTBP4 & $\mathrm{RI}$ \\
\hline TCONS_000 & & & TCONS_000 & RP11-27 & & TCONS_000 & & \\
\hline 15241 & $A B C C 8$ & $\mathrm{RI}$ & 79852 & 4B21.1 & SE & 42609 & LTBP4 & $\mathrm{A} 5, \mathrm{RI}$ \\
\hline TCONS_000 & & & TCONS_000 & RP11-27 & & TCONS_000 & & \\
\hline 15253 & SAAL1 & $\mathrm{RI}$ & 79853 & 4B21.1 & $\mathrm{O}$ & 45397 & SNRPA & $\mathrm{RI}$ \\
\hline TCONS_000 & & & TCONS_000 & RP11-27 & & TCONS_000 & MIA-RA & \\
\hline 15335 & MPPED2 & AF,SE & 79855 & 4B21.1 & A5,SE & 42620 & B4B & $\mathrm{O}$ \\
\hline TCONS_000 & & & TCONS_000 & RP11-27 & & TCONS_000 & & \\
\hline 15358 & FBXO3 & A3 & 82530 & 4B21.1 & SE & 45401 & $A X L$ & $\mathrm{RI}$ \\
\hline TCONS_000 & & & TCONS_000 & RP11-27 & & TCONS_000 & ARHGE & \\
\hline 15367 & LMO2 & A5 & 79857 & 4B21.1 & SE & 42665 & $\mathrm{~F} 1$ & $\mathrm{~A} 3, \mathrm{~A} 5$ \\
\hline TCONS_000 & CTD-258 & & TCONS_000 & RP11-27 & & TCONS_000 & & \\
\hline 15412 & $9 \mathrm{M} 5.4$ & SE & 82532 & 4B21.1 & $A F, R I$ & 42674 & MEGF8 & SE \\
\hline TCONS_000 & & & TCONS_000 & & & TCONS_000 & & \\
\hline 15414 & AMBRA1 & AF & 79883 & FLNC & $\mathrm{RI}$ & 42684 & ZNF283 & SE \\
\hline TCONS_000 & & & TCONS_000 & KLHDC1 & & TCONS_000 & & \\
\hline 15425 & CKAP5 & A3 & 79907 & 0 & SE & 42695 & ZNF223 & A5 \\
\hline TCONS_000 & ARFGAP & & TCONS_000 & & & TCONS_000 & & \\
\hline 15429 & 2 & SE & 82552 & MEST & $\mathrm{RI}$ & 42698 & ZNF224 & A5 \\
\hline TCONS_000 & ARFGAP & & TCONS_000 & & & TCONS_000 & & \\
\hline 15431 & 2 & A5 & 82567 & NUP205 & $\mathrm{RI}$ & 42723 & BCL3 & $\mathrm{O}$ \\
\hline TCONS_000 & & & TCONS_000 & & & TCONS_000 & & \\
\hline 17599 & CELF1 & $\mathrm{O}$ & 82576 & RAB19 & $\mathrm{O}$ & 42732 & BCAM & $\mathrm{RI}$ \\
\hline TCONS_000 & & & TCONS_000 & PRSS3P & & TCONS_000 & & \\
\hline 15454 & CELF1 & A3,SE & 80096 & 1 & 0 & 42751 & APOC4 & $\mathrm{O}$ \\
\hline TCONS_000 & & & TCONS_000 & & & TCONS_000 & & \\
\hline 15473 & FNBP4 & $A 3, R I$ & 82620 & TRBC2 & $\mathrm{O}$ & 45447 & CLASRP & A5,RI \\
\hline TCONS_000 & & & TCONS_000 & & & TCONS_000 & & \\
\hline 15476 & FNBP4 & A5 & 80106 & GSTK1 & SE & 42791 & VASP & $\mathrm{O}$ \\
\hline TCONS_000 & & & TCONS_000 & & & TCONS_000 & & \\
\hline 15496 & SSRP1 & $\mathrm{O}$ & 80107 & GSTK1 & A3,SE & 42790 & VASP & SE \\
\hline TCONS_000 & & & TCONS_000 & TMEM1 & & TCONS_000 & & \\
\hline 15497 & SSRP1 & 0 & 80108 & 39 & SE & 42795 & GIPR & A3 \\
\hline TCONS_000 & AP00125 & $\mathrm{O}$ & TCONS_000 & $Z Y X$ & 0 & TCONS_000 & GIPR & SE \\
\hline
\end{tabular}




\begin{tabular}{|c|c|c|c|c|c|c|c|c|}
\hline 15526 & 8.4 & & 82625 & & & 42796 & & \\
\hline TCONS_000 & RP11-10 & & TCONS_000 & & & TCONS_000 & & \\
\hline 15530 & 36E20.9 & SE & 80118 & $Z Y X$ & $\mathrm{O}$ & 42807 & CCDC61 & A3 \\
\hline TCONS_000 & & & TCONS_000 & FAM115 & & TCONS_000 & & \\
\hline 15546 & MS4A6A & A5 & 80123 & B & SE & 42808 & CCDC61 & A3 \\
\hline TCONS_000 & & & TCONS_000 & & & TCONS_000 & & \\
\hline 15547 & MS4A6A & A5 & 80146 & ZNF212 & A5 & 42811 & IGFL2 & AF \\
\hline TCONS_000 & & & TCONS_000 & & & TCONS_000 & & \\
\hline 15548 & MS4A6A & A5 & 82635 & ZNF783 & A5,SE & 42819 & CALM3 & $\mathrm{O}$ \\
\hline TCONS_000 & SLC15A & & TCONS_000 & & & TCONS_000 & ARHGA & \\
\hline 15555 & 3 & $\mathrm{O}$ & 82640 & REPIN1 & $\mathrm{O}$ & 42832 & P35 & $\mathrm{O}$ \\
\hline TCONS_000 & & & TCONS_000 & TMEM1 & & TCONS_000 & & \\
\hline 15585 & CPSF7 & A5,RI & 82644 & $76 \mathrm{~A}$ & A5 & 42838 & CCDC9 & $\mathrm{O}$ \\
\hline TCONS_000 & & & TCONS_000 & & & TCONS_000 & GLTSCR & \\
\hline 15586 & CPSF7 & $\mathrm{A} 5, \mathrm{RI}$ & 82646 & SLC4A2 & A5 & 42852 & 2 & $\mathrm{O}$ \\
\hline TCONS_000 & & $\mathrm{A} 5, \mathrm{AF}$ & TCONS_000 & & & TCONS_000 & & \\
\hline 17634 & CPSF7 &, $\mathrm{RI}$ & 82647 & SLC4A2 & A5 & 42882 & GRIN2D & $\mathrm{O}$ \\
\hline TCONS_000 & & & TCONS_000 & & & TCONS_000 & & \\
\hline 15626 & MIR3654 & A3 & 80201 & AGAP3 & $\mathrm{O}$ & 45473 & CYTH2 & A3 \\
\hline TCONS_000 & & & TCONS_000 & & & TCONS_000 & & \\
\hline 15629 & EML3 & $\mathrm{O}$ & 82651 & AGAP3 & $\mathrm{O}$ & 45474 & CYTH2 & A3 \\
\hline & HNRNP & & & & & & & \\
\hline TCONS_000 & UL2-BS & & TCONS_000 & & & TCONS_000 & & \\
\hline 15656 & CL2 & SE & 80210 & NUB1 & A5 & 42911 & RUVBL2 & AF \\
\hline TCONS_000 & & & TCONS_000 & WDR86- & & TCONS_000 & SNRNP7 & \\
\hline 15668 & NXF1 & A3,RI & 80213 & AS1 & A5 & 42925 & 0 & $\mathrm{~A} 3, \mathrm{RI}$ \\
\hline TCONS_000 & & & TCONS_000 & GALNT1 & & TCONS_000 & & \\
\hline 17656 & NXF1 & $\mathrm{RI}$ & 80219 & 1 & $\mathrm{O}$ & 45484 & CD37 & $\mathrm{O}$ \\
\hline TCONS_000 & & & TCONS_000 & PAXIP1- & & TCONS_000 & & \\
\hline 17657 & WDR74 & A5,RI & 80273 & AS2 & $A 3, R I$ & 45485 & CD37 & $\mathrm{O}$ \\
\hline TCONS_000 & & & TCONS_000 & AC0212 & & TCONS_000 & & \\
\hline 17658 & WDR74 & A5 & 80289 & 18.2 & $A F$ & 42980 & SCAF1 & AF \\
\hline TCONS_000 & & & TCONS_000 & & & TCONS_000 & & \\
\hline 15679 & WDR74 & A5 & 80295 & NOM1 & $\mathrm{RI}$ & 42985 & PRMT1 & $\mathrm{O}$ \\
\hline TCONS_000 & & & TCONS_000 & & & TCONS_000 & & \\
\hline 15685 & SNHG1 & $\mathrm{RI}$ & 82739 & DNAJB6 & $\mathrm{O}$ & 42994 & MED25 & $A L, R I$ \\
\hline
\end{tabular}




\begin{tabular}{|c|c|c|c|c|c|c|c|c|}
\hline \multicolumn{3}{|l|}{ TCONS_000 } & \multicolumn{3}{|l|}{ TCONS 000} & \multicolumn{3}{|l|}{ TCONS_000 } \\
\hline 15686 & SNHG1 & $\mathrm{O}$ & 80332 & PDGFA & SE & 45498 & MED25 & AL \\
\hline TCONS_000 & & & TCONS_000 & & & TCONS_000 & & $A 3, A F$, \\
\hline 15687 & SNHG1 & A3 & 80345 & CoX19 & SE & 42996 & PTOV1 & $\mathrm{RI}$ \\
\hline TCONS_000 & HRASLS & & TCONS_000 & MICALL & & TCONS_000 & & \\
\hline 17661 & 5 & SE & 80360 & 2 & $\mathrm{~A} 3, \mathrm{RI}$ & 45500 & PTOV1 & $A 3, R I$ \\
\hline TCONS_000 & & & TCONS_000 & & & TCONS_000 & & \\
\hline 17668 & C11orf95 & $\mathrm{O}$ & 80364 & INTS1 & A3,A5 & 42998 & PTOV1 & A3 \\
\hline TCONS_000 & MACRO & & TCONS_000 & TMEM1 & & TCONS_000 & TBC1D1 & \\
\hline 17669 & D1 & A3 & 82760 & $84 \mathrm{~A}$ & $\mathrm{RI}$ & 43003 & 7 & A5 \\
\hline TCONS_000 & MACRO & & TCONS_000 & & & TCONS_000 & TBC1D1 & \\
\hline 17670 & D1 & $\mathrm{RI}$ & 82767 & TNRC18 & $\mathrm{O}$ & 45502 & 7 & A5 \\
\hline TCONS_000 & MACRO & & TCONS_000 & & & TCONS_000 & TBC1D1 & \\
\hline 15706 & D1 & $\mathrm{RI}$ & 80398 & TNRC18 & AF,SE & 45503 & 7 & $\mathrm{RI}$ \\
\hline TCONS_000 & PPP1R1 & & TCONS_000 & & & TCONS_000 & & \\
\hline 15719 & $4 \mathrm{~B}$ & $\mathrm{O}$ & 80399 & TNRC18 & O & 43008 & ZNF473 & O \\
\hline TCONS_000 & TRMT11 & & TCONS_000 & & & TCONS_000 & & \\
\hline 15724 & 2 & O & 80420 & PMS2 & RI & 43011 & MYH14 & AF,SE \\
\hline TCONS 000 & TRMT11 & & TCONS 000 & RP5-115 & & TCONS 000 & & \\
\hline 15725 & 2 & $\mathrm{O}$ & 82779 & 904.1 & $\mathrm{O}$ & 43014 & POLD1 & O \\
\hline TCONS_000 & CDC42B & & TCONS_000 & & & TCONS_000 & & \\
\hline 17680 & $P G$ & $\mathrm{O}$ & 80459 & ICA1 & AF,RI,SE & 43015 & POLD1 & O \\
\hline TCONS_000 & & & TCONS_000 & & & TCONS_000 & & \\
\hline 17682 & ATG2A & RI & 82780 & ICA1 & SE & 43016 & EMC10 & A5,SE \\
\hline TCONS_000 & & & TCONS_000 & & $A 3, A F, R I$ & TCONS_000 & & \\
\hline 17683 & ATG2A & A3 & 82781 & ICA1 & ,SE & 45509 & EMC10 & A5 \\
\hline TCONS_000 & & & TCONS 000 & & & TCONS_000 & CEACA & \\
\hline 17688 & SYVN1 & $A F, R I$ & 82808 & AGR2 & A5 & 43027 & M18 & RI \\
\hline TCONS_000 & SLC25A & & TCONS_000 & AC0191 & & TCONS_000 & & \\
\hline 17692 & 45 & $\mathrm{AF}$ & 80515 & 17.2 & $A 3, R I$ & 43036 & FPR2 & RI \\
\hline TCONS_000 & & & TCONS_000 & AC0191 & & TCONS_000 & & \\
\hline 17694 & LTBP3 & A5 & 80516 & 17.2 & 0 & 43043 & ZNF613 & 0 \\
\hline TCONS_000 & AP00136 & & TCONS_000 & & & TCONS_000 & & \\
\hline 15796 & 2.1 & 0 & 80535 & MACC1 & A3,SE & 43050 & ZNF766 & 0 \\
\hline TCONS_000 & & & TCONS_000 & & & TCONS_000 & & \\
\hline 17699 & RELA & RI & 80537 & MACC1 & SE & 45526 & ZNF578 & SE \\
\hline
\end{tabular}




\begin{tabular}{|c|c|c|c|c|c|c|c|c|}
\hline \multicolumn{3}{|l|}{ TCONS_000 } & TCONS_000 & \multicolumn{2}{|l|}{ CTA-293 } & TCONS_000 & \multicolumn{2}{|l|}{ CTD-224 } \\
\hline 15798 & RELA & A3 & 82813 & F17.1 & $\mathrm{O}$ & 43075 & 5F17.3 & SE \\
\hline TCONS_000 & & & TCONS_000 & & & TCONS_000 & & \\
\hline 17700 & RELA & $\mathrm{A} 3, \mathrm{RI}$ & 80546 & CDCA7L & A3,SE & 43083 & ZNF761 & 0 \\
\hline TCONS_000 & SLC29A & & TCONS_000 & & $A 3, R I, S$ & TCONS_000 & & \\
\hline 15860 & 2 & $\mathrm{~A} 3, \mathrm{RI}$ & 82814 & CDCA7L & $\mathrm{E}$ & 45549 & TTYH1 & SE \\
\hline TCONS_000 & CTD-307 & & TCONS_000 & & $A 3, R I, S$ & TCONS_000 & & \\
\hline 17709 & 407.5 & $\mathrm{RI}$ & 82823 & TRA2A & E & 43128 & LENG8 & $\mathrm{O}$ \\
\hline TCONS_000 & CTD-307 & & TCONS_000 & & & TCONS_000 & & \\
\hline 15867 & 407.5 & $\mathrm{O}$ & 80639 & HOXA6 & O & 43126 & LENG8 & A5 \\
\hline TCONS_000 & & & TCONS_000 & AC0072 & & TCONS_000 & & \\
\hline 15874 & RBM4B & $\mathrm{O}$ & 80656 & 55.8 & $\mathrm{O}$ & 43133 & LILRB4 & A3 \\
\hline TCONS_000 & CORO1 & & TCONS_000 & DPY19L & & TCONS_000 & & \\
\hline 15913 & B & SE & 82858 & 1P1 & $\mathrm{RI}, \mathrm{SE}$ & 43134 & LILRB4 & A3,SE \\
\hline TCONS_000 & CORO1 & & TCONS_000 & & & TCONS_000 & CTC-550 & \\
\hline 15914 & B & SE & 80704 & RP9P & A5 & 43143 & B14.7 & A3 \\
\hline TCONS_000 & TMEM13 & & TCONS_000 & DPY19L & & TCONS_000 & & \\
\hline 17712 & 4 & A3 & 80719 & 1 & $A F$ & 43145 & EPS8L1 & $\mathrm{O}$ \\
\hline TCONS_000 & PITPNM & & TCONS_000 & & & TCONS_000 & & \\
\hline 15921 & 1 & RI & 80802 & COA1 & $M X$ & 43146 & EPS8L1 & RI,SE \\
\hline TCONS_000 & & & TCONS_000 & POLR2J & & TCONS_000 & & \\
\hline 17714 & ACY3 & $\mathrm{O}$ & 80823 & 4 & SE & 43167 & SSC5D & 0 \\
\hline TCONS_000 & SUV420 & & TCONS_000 & & & TCONS_000 & CCDC10 & \\
\hline 15953 & $\mathrm{H} 1$ & AF,SE & 80825 & PGAM2 & $\mathrm{O}$ & 43172 & 6 & $\mathrm{O}$ \\
\hline TCONS_000 & & & TCONS_000 & & & TCONS_000 & & \\
\hline 15960 & C11orf24 & A5 & 82899 & POLD2 & A5,RI & 43173 & ZNF581 & $\mathrm{O}$ \\
\hline TCONS_000 & RP11-84 & & TCONS_000 & & & TCONS_000 & & \\
\hline 16000 & $9 \mathrm{H} 4.2$ & SE & 80832 & POLD2 & 0 & 45558 & U2AF2 & $\mathrm{O}$ \\
\hline TCONS_000 & & & TCONS_000 & & & TCONS_000 & & A3,A5, \\
\hline 16028 & ARAP1 & $\mathrm{O}$ & 80859 & MYO1G & $\mathrm{RI}$ & 45560 & EPN1 & SE \\
\hline TCONS_000 & STARD1 & & TCONS_000 & & & TCONS_000 & & \\
\hline 16029 & 0 & $\mathrm{O}$ & 80866 & TBRG4 & A5 & 45571 & ZNF264 & $\mathrm{O}$ \\
\hline TCONS_000 & & & TCONS_000 & SEPT7P & & TCONS_000 & & \\
\hline 16040 & FCHSD2 & $\mathrm{RI}, \mathrm{SE}$ & 80871 & 2 & SE & 43236 & ZNF776 & $\mathrm{O}$ \\
\hline TCONS_000 & RP11-16 & & TCONS_000 & SEPT7P & $A 3, R I, S$ & TCONS_000 & AC0106 & \\
\hline 16064 & $7 \mathrm{~N} 4.2$ & $\mathrm{O}$ & 82918 & 2 & $E$ & 43256 & 42.1 & A5 \\
\hline
\end{tabular}




\begin{tabular}{|c|c|c|c|c|c|c|c|c|}
\hline TCONS_000 & CTD-254 & & TCONS_000 & & & TCONS_000 & CTD-261 & \\
\hline 16114 & 7H18.1 & $\mathrm{O}$ & 82923 & IGFBP3 & $\mathrm{O}$ & 45594 & $9 J 13.3$ & $\mathrm{O}$ \\
\hline TCONS_000 & CTD-254 & & TCONS_000 & & & TCONS_000 & & \\
\hline 16116 & 7H18.1 & AF & 80892 & TNS3 & $A F$ & 45595 & RPS5 & $\mathrm{O}$ \\
\hline TCONS_000 & & & TCONS_000 & & & TCONS_000 & & \\
\hline 16119 & PAK1 & AF,SE & 80897 & HUS1 & $\mathrm{O}$ & 43285 & ZNF446 & $A L$ \\
\hline TCONS_000 & & & TCONS_000 & & & TCONS_000 & & \\
\hline 16135 & RSF1 & A5 & 80912 & DDC & SE & 43286 & TRIM28 & $\mathrm{O}$ \\
\hline TCONS_000 & & & TCONS_000 & & & TCONS_000 & WASH5 & \\
\hline 17764 & INTS4 & RI,SE & 80916 & GRB10 & $\mathrm{O}$ & 45605 & $\mathrm{P}$ & $\mathrm{O}$ \\
\hline TCONS_000 & & & TCONS_000 & & & TCONS_000 & AC0922 & \\
\hline 17773 & NARS2 & A5 & 80917 & GRB10 & O & 45606 & 99.8 & $\mathrm{O}$ \\
\hline TCONS_000 & & & TCONS_000 & & & TCONS_000 & & \\
\hline 16159 & TENM4 & SE & 82936 & COBL & A3,SE & 45609 & MIER2 & $A F$ \\
\hline TCONS_000 & & & TCONS_000 & & & TCONS_000 & & \\
\hline 17780 & CREBZF & $\mathrm{O}$ & 82937 & COBL & A3,SE & 45611 & $\mathrm{SHC} 2$ & RI \\
\hline TCONS_000 & & & TCONS_000 & & & TCONS_000 & TMEM25 & \\
\hline 17784 & SYTL2 & A3,SE & 82938 & COBL & SE & 43326 & 9 & $A 3, R I$ \\
\hline TCONS_000 & & & TCONS_000 & & & TCONS_000 & TMEM25 & \\
\hline 17785 & SYTL2 & RI,SE & 80926 & COBL & SE & 45619 & 9 & RI \\
\hline TCONS_000 & & & TCONS_000 & & & TCONS_000 & ADAMT & \\
\hline 16224 & ME3 & SE & 80941 & FKBP9L & $\mathrm{O}$ & 43344 & SL5 & A3 \\
\hline TCONS_000 & & & TCONS_000 & & & TCONS_000 & & \\
\hline 16225 & ME3 & $\mathrm{O}$ & 82953 & ZNF680 & $\mathrm{O}$ & 43352 & TCF3 & $\mathrm{O}$ \\
\hline TCONS_000 & & & TCONS_000 & RP11-79 & & TCONS_000 & & \\
\hline 16226 & ME3 & SE & 80959 & $7 \mathrm{H} 7.5$ & $\mathrm{O}$ & 43353 & TCF3 & SE \\
\hline TCONS_000 & & & TCONS_000 & RP11-79 & & TCONS_000 & & \\
\hline 17794 & FZD4 & $A L$ & 82955 & $7 \mathrm{H} 7.5$ & $\mathrm{O}$ & 45628 & TCF3 & SE \\
\hline TCONS_000 & & & TCONS_000 & & & TCONS_000 & & \\
\hline 16298 & TAF1D & $\mathrm{O}$ & 80964 & ZNF117 & $\mathrm{O}$ & 43364 & BTBD2 & $\mathrm{O}$ \\
\hline TCONS_000 & & & TCONS_000 & & & TCONS_000 & & \\
\hline 17828 & TAF1D & A3 & 82961 & ZNF117 & $A F$ & 43370 & MKNK2 & A3 \\
\hline TCONS_000 & & & TCONS_000 & & & TCONS_000 & & \\
\hline 17831 & TAF1D & $A 3, R I$ & 82973 & GUSB & RI & 43375 & MOB3A & $\mathrm{AF}$ \\
\hline TCONS_000 & & & TCONS_000 & & & TCONS_000 & & \\
\hline 17835 & FAM76B & O & 82974 & GUSB & A3 & 43380 & AP3D1 & A3 \\
\hline
\end{tabular}




\begin{tabular}{|c|c|c|c|c|c|c|c|c|}
\hline \multirow{2}{*}{$\begin{array}{l}\text { TCONS_000 } \\
16321\end{array}$} & \multirow[b]{2}{*}{ FAM76B } & \multirow[b]{2}{*}{ AF,SE } & \multicolumn{3}{|l|}{ TCONS_000 } & \multicolumn{3}{|l|}{ TCONS_000 } \\
\hline & & & 82975 & GUSB & RI & 45645 & TLE2 & $A 5, R I$ \\
\hline TCONS_000 & & & TCONS_000 & & & TCONS_000 & & \\
\hline 16325 & MTMR2 & SE & 80979 & GUSB & RI & 45647 & TLE2 & $\mathrm{RI}$ \\
\hline TCONS_000 & & & TCONS_000 & GS1-124 & & TCONS_000 & AC0052 & \\
\hline 17839 & MTMR2 & $\mathrm{O}$ & 82983 & K5.2 & $\mathrm{O}$ & 43416 & 62.3 & A3 \\
\hline TCONS_000 & & & TCONS_000 & GS1-124 & & TCONS_000 & AC0052 & \\
\hline 16333 & CCDC82 & RI,SE & 82984 & K5.2 & $\mathrm{O}$ & 43417 & 62.2 & $\mathrm{O}$ \\
\hline TCONS_000 & & & TCONS_000 & GS1-124 & & TCONS_000 & & \\
\hline 17842 & CCDC82 & SE & 82985 & K5.2 & SE & 43434 & DAPK3 & A5 \\
\hline TCONS_000 & & & TCONS_000 & GS1-124 & & TCONS_000 & & \\
\hline 17843 & PGR & $\mathrm{O}$ & 82986 & K5.2 & SE & 45666 & PLIN4 & RI \\
\hline TCONS_000 & & & TCONS_000 & & & TCONS_000 & & \\
\hline 16357 & MMP3 & RI & 81002 & PMS2P4 & A3 & 45671 & PLIN4 & A3 \\
\hline TCONS_000 & & & TCONS_000 & NSUN5 & & TCONS_000 & & \\
\hline 16418 & CASP1 & $\mathrm{O}$ & 81023 & P2 & $\mathrm{O}$ & 45673 & PLIN5 & O \\
\hline TCONS_000 & MSANT & & TCONS_000 & NSUN5 & & TCONS_000 & & \\
\hline 16426 & D4 & A5 & 81024 & P2 & RI & 45676 & PLIN5 & RI \\
\hline TCONS_000 & & & TCONS_000 & NSUN5 & & TCONS_000 & & \\
\hline 17867 & C11orf65 & AF & 81026 & P2 & RI & 43479 & PLIN3 & $\mathrm{O}$ \\
\hline TCONS_000 & & & TCONS_000 & NSUN5 & & TCONS_000 & & \\
\hline 17887 & USP28 & A3,SE & 81027 & P2 & $\mathrm{RI}, \mathrm{SE}$ & 45683 & PTPRS & $\mathrm{AF}, \mathrm{SE}$ \\
\hline TCONS_000 & & & TCONS_000 & NSUN5 & & TCONS_000 & & \\
\hline 17888 & USP28 & AF & 83001 & P2 & $\mathrm{RI}$ & 45684 & SAFB2 & $\mathrm{O}$ \\
\hline TCONS_000 & & & TCONS_000 & NSUN5 & & TCONS_000 & & \\
\hline 16520 & USP28 & AF & 83002 & P2 & $\mathrm{O}$ & 45687 & SAFB2 & $\mathrm{O}$ \\
\hline TCONS_000 & & & TCONS_000 & NSUN5 & & TCONS_000 & & \\
\hline 17894 & PCSK7 & O & 83003 & P2 & RI & 45688 & SAFB2 & $\mathrm{O}$ \\
\hline TCONS_000 & & & TCONS_000 & STAG3L & & TCONS_000 & & \\
\hline 17897 & BACE1 & AF & 83005 & 3 & $\mathrm{O}$ & 43539 & KHSRP & A5 \\
\hline TCONS_000 & & & TCONS_000 & STAG3L & & TCONS_000 & & \\
\hline 16576 & CD3D & $\mathrm{O}$ & 81036 & 3 & $\mathrm{O}$ & 43540 & KHSRP & RI \\
\hline TCONS_000 & & & TCONS_000 & & & TCONS_000 & & \\
\hline 17921 & TREH & $\mathrm{O}$ & 83006 & NSUN5 & A3 & 43538 & KHSRP & $\mathrm{O}$ \\
\hline TCONS_000 & & & TCONS_000 & & & TCONS_000 & & \\
\hline 16587 & DDX6 & AF & 83010 & MLXIPL & A3,RI & 45696 & KHSRP & A5 \\
\hline
\end{tabular}




\begin{tabular}{|c|c|c|c|c|c|c|c|c|}
\hline \multicolumn{3}{|l|}{ TCONS_000 } & \multicolumn{3}{|l|}{ TCONS_000 } & TCONS_000 & \multicolumn{2}{|l|}{ SLC25A } \\
\hline 16615 & HYOU1 & $\mathrm{AF}$ & 81061 & MLXIPL & $\mathrm{O}$ & 43543 & 23 & SE \\
\hline TCONS_000 & & & TCONS_000 & & & TCONS_000 & SLC25A & \\
\hline 16616 & HYOU1 & $\mathrm{O}$ & 81065 & STX1A & RI & 43544 & 23 & A3,SE \\
\hline TCONS_000 & & & TCONS_000 & & & TCONS_000 & DENND & \\
\hline 16617 & HYOU1 & RI & 81066 & STX1A & $A 3, R I$ & 45700 & $1 \mathrm{C}$ & $\mathrm{O}$ \\
\hline TCONS_000 & & & TCONS_000 & & & TCONS_000 & CTD-312 & \\
\hline 16629 & MCAM & 0 & 83013 & ABHD11 & $\mathrm{O}$ & 43558 & $8 \mathrm{G} 10.6$ & $\mathrm{O}$ \\
\hline TCONS_000 & & & TCONS_000 & & & TCONS_000 & & \\
\hline 16630 & MCAM & A3 & 83014 & ABHD11 & $\mathrm{O}$ & 45706 & SH2D3A & RI \\
\hline TCONS_000 & & & TCONS_000 & & & TCONS_000 & & \\
\hline 16631 & MCAM & SE & 81101 & PMS2P2 & SE & 43561 & SH2D3A & A3,SE \\
\hline TCONS_000 & RP11-16 & & TCONS_000 & & & TCONS_000 & & \\
\hline 17929 & 6D19.1 & $\mathrm{O}$ & 81102 & PMS2P3 & A3 & 43562 & SH2D3A & A3 \\
\hline TCONS_000 & & & TCONS_000 & & & TCONS_000 & & \\
\hline 17953 & VSIG2 & $\mathrm{O}$ & 81105 & PMS2P2 & SE & 43565 & EMR4P & RI \\
\hline TCONS_000 & & & TCONS_000 & & & TCONS_000 & СТВ-133 & \\
\hline 16683 & ESAM & A5 & 81106 & PMS2P2 & SE & 43570 & G6.2 & RI \\
\hline TCONS_000 & & & TCONS_000 & & & TCONS_000 & СТВ-133 & \\
\hline 16684 & ESAM & A5 & 81108 & PMS2P2 & SE & 43571 & G6.2 & A5 \\
\hline TCONS_000 & MSANT & & TCONS_000 & POM121 & & TCONS_000 & & \\
\hline 17956 & D2 & A3 & 81110 & C & SE & 45708 & XAB2 & $\mathrm{O}$ \\
\hline TCONS_000 & & & TCONS_000 & & & TCONS_000 & & \\
\hline 16705 & PUS3 & SE & 81121 & PMS2P3 & A3 & 43576 & CD209 & RI \\
\hline TCONS_000 & & & TCONS_000 & & & TCONS_000 & & \\
\hline 16706 & PUS3 & $\mathrm{O}$ & 83022 & PMS2P3 & A3 & 45712 & TIMM44 & RI \\
\hline TCONS_000 & & & TCONS_000 & & & TCONS_000 & & \\
\hline 16709 & CDON & A5,AF & 81126 & CCL26 & $A F$ & 43582 & NDUFA7 & SE \\
\hline TCONS_000 & ARHGA & & TCONS_000 & TMEM1 & & TCONS_000 & & \\
\hline 17969 & P32 & $\mathrm{O}$ & 81131 & $20 \mathrm{~A}$ & SE & 45726 & ZNF414 & $\mathrm{O}$ \\
\hline TCONS_000 & & & TCONS_000 & POMZP & & TCONS_000 & & \\
\hline 17972 & NFRKB & A3 & 81148 & 3 & SE & 43593 & MYO1F & RI \\
\hline TCONS_000 & & & TCONS_000 & & & TCONS_000 & & \\
\hline 16756 & ZBTB44 & $\mathrm{O}$ & 83037 & GSAP & RI & 45733 & ZNF558 & A5,SE \\
\hline TCONS_000 & & & TCONS_000 & & & TCONS_000 & & \\
\hline 16757 & ZBTB44 & A3 & 81183 & HGF & $\mathrm{O}$ & 43611 & ZNF266 & SE \\
\hline
\end{tabular}




\begin{tabular}{|c|c|c|c|c|c|c|c|c|}
\hline \multicolumn{3}{|l|}{ TCONS_000 } & TCONS_000 & \multicolumn{2}{|l|}{ CACNA } & \multicolumn{3}{|l|}{ TCONS_000 } \\
\hline 16758 & ZBTB44 & $\mathrm{RI}$ & 81190 & 2D1 & SE & 45738 & ZNF426 & 0 \\
\hline TCONS_000 & & & TCONS_000 & CACNA & & TCONS_000 & & \\
\hline 16765 & SNX19 & A5,SE & 81191 & 2D1 & A3,SE & 45753 & RAVER1 & $\mathrm{O}$ \\
\hline TCONS_000 & & & TCONS_000 & & & TCONS_000 & & \\
\hline 16776 & NCAPD3 & $\mathrm{O}$ & 81196 & PCLO & SE & 43676 & RAVER1 & 0 \\
\hline TCONS_000 & & & TCONS_000 & SEMA3 & & TCONS_000 & & \\
\hline 16777 & NCAPD3 & SE & 83045 & $\mathrm{D}$ & O & 45755 & ICAM3 & $\mathrm{RI}$ \\
\hline TCONS_000 & & & TCONS_000 & TMEM2 & & TCONS_000 & & \\
\hline 16780 & THYN1 & SE & 81207 & 43 & A5 & 43681 & TYK2 & $\mathrm{RI}$ \\
\hline TCONS_000 & B4GALN & & TCONS_000 & & & TCONS_000 & & $A 3, R I$, \\
\hline 17989 & T3 & A3 & 81218 & ABCB1 & $\mathrm{RI}, \mathrm{SE}$ & 43682 & TYK2 & SE \\
\hline TCONS_000 & & & TCONS_000 & SLC25A & & TCONS_000 & & \\
\hline 17992 & WNK1 & $\mathrm{O}$ & 81219 & 40 & SE & 45758 & TYK2 & $\mathrm{RI}$ \\
\hline TCONS_000 & & & TCONS_000 & & & TCONS_000 & & \\
\hline 21945 & WNK1 & $\mathrm{O}$ & 81234 & STEAP4 & SE & 43684 & TYK2 & $\mathrm{RI}$ \\
\hline TCONS_000 & ADIPOR & & TCONS 000 & & & TCONS_000 & CDKN2 & \\
\hline 18009 & 2 & A5 & 83064 & PEX1 & RI & 43699 & $\mathrm{D}$ & $\mathrm{O}$ \\
\hline TCONS_000 & & & TCONS_000 & & & TCONS_000 & & \\
\hline 18018 & FKBP4 & $\mathrm{O}$ & 83065 & PEX1 & SE & 43719 & KANK2 & A3,A5 \\
\hline TCONS_000 & & & TCONS_000 & & & TCONS_000 & & \\
\hline 18019 & FKBP4 & A5 & 83075 & PON2 & A3,RI & 43720 & DOCK6 & SE \\
\hline TCONS_000 & & & TCONS_000 & & & TCONS_000 & & \\
\hline 18020 & FKBP4 & SE & 81322 & PDK4 & $\mathrm{O}$ & 45767 & KANK2 & A3,SE \\
\hline TCONS_000 & & & TCONS_000 & & & TCONS_000 & & \\
\hline 18046 & NDUFA9 & $\mathrm{O}$ & 83080 & ASNS & SE & 43722 & DOCK6 & SE \\
\hline TCONS_000 & & & TCONS_000 & AC0049 & & TCONS_000 & & \\
\hline 18047 & NDUFA9 & $\mathrm{RI}$ & 81356 & 67.7 & 0 & 43729 & RGL3 & 0 \\
\hline TCONS_000 & & & TCONS_000 & AC0049 & & TCONS_000 & & $\mathrm{A} 3, \mathrm{AL}$, \\
\hline 18053 & CD9 & A3,SE & 81358 & 67.7 & 0 & 45776 & RGL3 & SE \\
\hline TCONS_000 & PLEKHG & & TCONS_000 & & & TCONS_000 & & \\
\hline 18061 & 6 & $\mathrm{AF}$ & 81361 & TECPR1 & A5,RI & 45782 & RGL3 & SE \\
\hline TCONS_000 & PLEKHG & & TCONS_000 & SMURF & & TCONS_000 & & \\
\hline 18062 & 6 & $\mathrm{AF}$ & 81372 & 1 & A5,SE & 43731 & ZNF653 & $\mathrm{O}$ \\
\hline TCONS_000 & PLEKHG & & TCONS_000 & & & TCONS_000 & & \\
\hline 18065 & 6 & RI & 81376 & KPNA7 & SE & 45787 & ECSIT & A3 \\
\hline
\end{tabular}




\begin{tabular}{|c|c|c|c|c|c|c|c|c|}
\hline \multicolumn{3}{|l|}{ TCONS_000 } & TCONS_000 & ATP5J2- & & TCONS_000 & & \\
\hline 22014 & LTBR & A3 & 81384 & PTCD1 & 0 & 45793 & MAN2B1 & 0 \\
\hline TCONS_000 & & & TCONS_000 & & & TCONS_000 & & \\
\hline 18077 & TAPBPL & A5,RI & 83097 & CYP3A5 & RI,SE & 43774 & MAN2B1 & 0 \\
\hline TCONS_000 & & & TCONS_000 & & & TCONS_000 & & \\
\hline 18079 & TAPBPL & A5 & 81399 & CYP3A5 & RI,SE & 43782 & FBXW9 & A3 \\
\hline TCONS_000 & & & TCONS_000 & & & TCONS_000 & & \\
\hline 22015 & TAPBPL & A5,RI & 81400 & CYP3A5 & RI,SE & 45797 & FBXW9 & A3 \\
\hline TCONS_000 & & & TCONS_000 & & & TCONS_000 & & \\
\hline 22017 & NCAPD2 & A3 & 83110 & MCM7 & $A F, R I$ & 45798 & TNPO2 & $\mathrm{A} 3, \mathrm{~A} 5$ \\
\hline TCONS_000 & & & TCONS_000 & & & TCONS_000 & & \\
\hline 18101 & LAG3 & $\mathrm{O}$ & 81430 & C7orf43 & $\mathrm{RI}$ & 45799 & TNPO2 & A3 \\
\hline TCONS_000 & & & TCONS_000 & & & TCONS_000 & & \\
\hline 22023 & CD4 & $\mathrm{O}$ & 81431 & C7orf43 & A3 & 45802 & HOOK2 & $\mathrm{O}$ \\
\hline TCONS_000 & LEPREL & & TCONS_000 & & & TCONS_000 & & \\
\hline 18103 & 2 & A3,SE & 81437 & PMS2P1 & SE & 45810 & PALM3 & $\mathrm{O}$ \\
\hline TCONS_000 & & & TCONS_000 & & & TCONS_000 & & \\
\hline 18120 & ATN1 & $\mathrm{O}$ & 81450 & $\mathrm{LRCH} 4$ & $\mathrm{O}$ & 43838 & SAMD1 & $\mathrm{O}$ \\
\hline TCONS_000 & & & TCONS_000 & & & TCONS_000 & & \\
\hline 22033 & PEX5 & $\mathrm{O}$ & 81451 & $\mathrm{LRCH} 4$ & $\mathrm{RI}$ & 43844 & LPHN1 & $A 3, R I$ \\
\hline TCONS_000 & & & TCONS_000 & & & TCONS_000 & & \\
\hline 22034 & PEX5 & SE & 81452 & $\mathrm{LRCH} 4$ & $\mathrm{O}$ & 45812 & DDX39A & RI,SE \\
\hline TCONS_000 & & & TCONS_000 & & & TCONS_000 & & \\
\hline 22036 & NECAP1 & 0 & 83115 & $\mathrm{LRCH} 4$ & $\mathrm{RI}$ & 43857 & GIPC1 & AF \\
\hline TCONS_000 & ALG1L1 & & TCONS_000 & & & TCONS_000 & & \\
\hline 22040 & $\mathrm{OP}$ & 0 & 81455 & GIGYF1 & $\mathrm{RI}$ & 43864 & DNAJB1 & SE \\
\hline TCONS_000 & & & TCONS_000 & & & TCONS_000 & & \\
\hline 22052 & RIMKLB & AF & 83121 & GIGYF1 & 0 & 43865 & DNAJB1 & $\mathrm{AF}, \mathrm{SE}$ \\
\hline TCONS_000 & & & TCONS_000 & & & TCONS_000 & & \\
\hline 18182 & PHC1 & $A F, R I$ & 81457 & EPHB4 & $\mathrm{RI}$ & 43866 & DNAJB1 & $\mathrm{AF}, \mathrm{SE}$ \\
\hline TCONS_000 & & & TCONS_000 & & & TCONS_000 & & \\
\hline 22053 & PHC1 & $A F, R I$ & 81462 & $\mathrm{ACHE}$ & A3 & 43879 & ILVBL & AF \\
\hline TCONS_000 & PIK3C2 & & TCONS_000 & & & TCONS_000 & & \\
\hline 18350 & G & SE & 83124 & FIS1 & SE & 43888 & BRD4 & AF \\
\hline TCONS_000 & PIK3C2 & & TCONS_000 & & & TCONS_000 & & \\
\hline 22109 & G & AF,SE & 81541 & NAMPT & $\mathrm{O}$ & 43889 & AKAP8 & SE \\
\hline
\end{tabular}




\begin{tabular}{|c|c|c|c|c|c|c|c|c|}
\hline TCONS_000 & PLEKHA & & TCONS_000 & & & TCONS_000 & & \\
\hline 22112 & 5 & A5,SE & 81540 & NAMPT & 0 & 43890 & AKAP8 & RI \\
\hline TCONS_000 & SLCO1B & & TCONS_000 & & & TCONS_000 & & \\
\hline 18378 & 3 & $\mathrm{O}$ & 81556 & LAMB1 & $\mathrm{RI}$ & 43891 & AKAP8 & $\mathrm{RI}$ \\
\hline TCONS_000 & & & TCONS_000 & & & TCONS_000 & & \\
\hline 18418 & RASSF8 & AL & 81565 & NRCAM & $\mathrm{AL}, \mathrm{SE}$ & 43899 & AKAP8L & RI,SE \\
\hline TCONS_000 & & & TCONS_000 & & & TCONS_000 & & \\
\hline 18419 & RASSF8 & AL & 83147 & NRCAM & $\mathrm{AL}, \mathrm{SE}$ & 43900 & AKAP8L & $\mathrm{RI}$ \\
\hline TCONS_000 & & & TCONS_000 & & & TCONS_000 & & \\
\hline 18444 & ARNTL2 & $\mathrm{O}$ & 81586 & IMMP2L & O & 43902 & AKAP8L & $A 3, R I$ \\
\hline TCONS_000 & & & TCONS_000 & TSPAN1 & & TCONS_000 & CYP4F1 & \\
\hline 22152 & PPFIBP1 & SE & 81625 & 2 & A5 & 43912 & 1 & RI \\
\hline TCONS_000 & & & TCONS_000 & & & TCONS_000 & EPS15L & \\
\hline 18462 & CCDC91 & SE & 81645 & CADPS2 & SE & 43917 & 1 & $\mathrm{O}$ \\
\hline TCONS_000 & & & TCONS_000 & & & TCONS_000 & & \\
\hline 22159 & CCDC91 & $\mathrm{O}$ & 81660 & POT1 & A3,SE & 45833 & USHBP1 & SE \\
\hline TCONS_000 & & & TCONS_000 & & & TCONS_000 & & \\
\hline 18480 & DDX11 & A3 & 81661 & РОT1 & A3 & 43942 & ANO8 & A3 \\
\hline TCONS_000 & & & TCONS_000 & & & TCONS_000 & & \\
\hline 22164 & DDX11 & A5,SE & 83193 & IMPDH1 & $\mathrm{O}$ & 43943 & ANO8 & A3 \\
\hline TCONS_000 & & & TCONS_000 & & & TCONS_000 & & \\
\hline 18539 & PPHLN1 & SE & 81688 & IMPDH1 & $\mathrm{RI}$ & 43956 & JAK3 & RI \\
\hline TCONS_000 & & & TCONS_000 & RP11-30 & & TCONS_000 & & \\
\hline 18564 & ANO6 & $\mathrm{O}$ & 81694 & 9L24.2 & $\mathrm{O}$ & 45836 & JAK3 & $\mathrm{O}$ \\
\hline TCONS_000 & & & TCONS_000 & MKLN1- & & TCONS_000 & & \\
\hline 22225 & PFKM & RI,SE & 81733 & AS1 & SE & 43972 & LRRC25 & SE \\
\hline TCONS_000 & RP11-57 & & TCONS_000 & & & TCONS_000 & & \\
\hline 22229 & 9D7.4 & $\mathrm{O}$ & 81771 & WDR91 & RI & 45838 & ISYNA1 & RI \\
\hline TCONS_000 & & & TCONS_000 & SLC37A & & TCONS_000 & & \\
\hline 18631 & CACNB3 & A3 & 83235 & 3 & $\mathrm{O}$ & 45839 & ISYNA1 & 0 \\
\hline TCONS_000 & SMARC & & TCONS_000 & & & TCONS_000 & & \\
\hline 22238 & D1 & $\mathrm{RI}$ & 83284 & TRPV6 & $\mathrm{RI}$ & 43980 & ELL & RI,SE \\
\hline TCONS_000 & & & TCONS_000 & & & TCONS_000 & & \\
\hline 18677 & GPD1 & $\mathrm{O}$ & 83285 & TRPV6 & $A 3, R I$ & 43986 & FKBP8 & $\mathrm{O}$ \\
\hline TCONS_000 & & & TCONS_000 & & & TCONS_000 & HOMER & \\
\hline 18751 & DAZAP2 & $\mathrm{O}$ & 83286 & TRPV6 & A3,SE & 44002 & 3 & $\mathrm{O}$ \\
\hline
\end{tabular}




\begin{tabular}{|c|c|c|c|c|c|c|c|c|}
\hline \multicolumn{3}{|l|}{ TCONS_000 } & \multicolumn{3}{|l|}{ TCONS_000 } & \multicolumn{3}{|l|}{ TCONS_000 } \\
\hline $22255^{-}$ & ACVRL1 & O & $81870^{-}$ & EPHA1 & $\mathrm{RI}$ & $45845^{-}$ & SUGP2 & RI \\
\hline TCONS_000 & & & TCONS_000 & & & TCONS_000 & & \\
\hline 18764 & GRASP & 0 & 81871 & EPHA1 & $\mathrm{RI}$ & 45847 & SUGP2 & RI \\
\hline TCONS_000 & & & TCONS_000 & & & TCONS_000 & & AF,MX, \\
\hline 18775 & NR4A1 & $\mathrm{RI}$ & 81872 & EPHA1 & $\mathrm{RI}$ & 44004 & SUGP2 & $\mathrm{RI}$ \\
\hline TCONS_000 & & & TCONS_000 & & & TCONS_000 & & \\
\hline 18788 & KRT7 & $\mathrm{O}$ & 83288 & EPHA1 & $\mathrm{RI}$ & 44009 & SUGP2 & $A F, R I$ \\
\hline & & & & & & & MEF2BN & \\
\hline TCONS_000 & & & TCONS_000 & & & TCONS_000 & B-MEF2 & \\
\hline 22262 & TENC1 & $A F, R I$ & 83289 & EPHA1 & $\mathrm{O}$ & 44012 & B & $\mathrm{O}$ \\
\hline TCONS_000 & & & TCONS_000 & FAM115 & & TCONS_000 & & \\
\hline 18811 & TENC1 & $A F, R I$ & 83291 & A & A5 & 45853 & SUGP1 & RI \\
\hline TCONS_000 & & & TCONS_000 & FAM115 & & TCONS_000 & & \\
\hline 22263 & ZNF740 & $\mathrm{O}$ & 81879 & A & A5 & 45854 & LPAR2 & A3,SE \\
\hline TCONS_000 & & & TCONS_000 & FAM115 & & TCONS_000 & & \\
\hline 22268 & AMHR2 & A5 & 81880 & A & A5 & 44027 & GMIP & $\mathrm{O}$ \\
\hline TCONS_000 & & & TCONS_000 & & & TCONS_000 & & \\
\hline 22269 & AMHR2 & SE & 81907 & PDIA4 & 0 & 44028 & GMIP & A3 \\
\hline TCONS_000 & & & TCONS_000 & & & TCONS_000 & & \\
\hline 18840 & PCBP2 & 0 & 81915 & ZNF777 & AF & 44029 & GMIP & RI,SE \\
\hline TCONS_000 & & & TCONS_000 & & & TCONS_000 & & \\
\hline 22274 & COPZ1 & $\mathrm{O}$ & 81920 & ZNF767 & SE & 44030 & GMIP & 0 \\
\hline TCONS_000 & TMEM19 & & TCONS_000 & RP11-72 & & TCONS_000 & & A5,RI, \\
\hline 18901 & $8 B$ & SE & 83306 & 8K20.1 & AF & 44031 & GMIP & SE \\
\hline TCONS_000 & TMEM19 & & TCONS_000 & & & TCONS_000 & & \\
\hline 18902 & $8 \mathrm{~B}$ & $M X$ & 82037 & ATG9B & 0 & 45856 & GMIP & 0 \\
\hline TCONS_000 & TMEM19 & & TCONS_000 & SMARC & & TCONS_000 & ATP13A & A3,A5, \\
\hline 18903 & $8 \mathrm{~B}$ & $\mathrm{O}$ & 83360 & D3 & SE & 44034 & 1 & $\mathrm{RI}$ \\
\hline TCONS_000 & TMEM19 & & TCONS_000 & SMARC & & TCONS_000 & ATP13A & \\
\hline 22281 & $8 \mathrm{~B}$ & A3 & 83361 & D3 & SE & 44035 & 1 & $\mathrm{~A} 3, \mathrm{RI}$ \\
\hline TCONS_000 & TMEM19 & & TCONS_000 & & & TCONS_000 & ATP13A & \\
\hline 22282 & $8 \mathrm{~B}$ & RI,SE & 82055 & WDR86 & $\mathrm{O}$ & 45857 & 1 & A3 \\
\hline TCONS_000 & TMEM19 & & TCONS_000 & & & TCONS_000 & & \\
\hline 18906 & $8 B$ & $\mathrm{O}$ & 82084 & КМT2C & A5 & 44067 & ZNF100 & 0 \\
\hline TCONS_000 & DGKA & $A F, R I$ & TCONS_000 & КMT2C & A5 & TCONS_000 & ZNF98 & $\mathrm{O}$ \\
\hline
\end{tabular}




\begin{tabular}{|c|c|c|c|c|c|c|c|c|}
\hline \multicolumn{3}{|l|}{18910} & \multicolumn{3}{|l|}{82085} & \multicolumn{3}{|l|}{45899} \\
\hline TCONS_000 & & & TCONS_000 & & & TCONS_000 & & \\
\hline 18909 & DGKA & $A F, R I$ & 83384 & LMBR1 & SE & 45906 & ZNF675 & O \\
\hline TCONS_000 & & & TCONS_000 & & & TCONS_000 & & \\
\hline 18929 & ERBB3 & RI & 83386 & LMBR1 & SE & 44097 & ZNF681 & $\mathrm{O}$ \\
\hline TCONS_000 & & & TCONS_000 & ARHGE & & TCONS_000 & LINC006 & \\
\hline 22285 & ERBB3 & $\mathrm{O}$ & 83421 & F10 & A3,SE & 44104 & 62 & AL \\
\hline TCONS_000 & & & TCONS_000 & ARHGE & & TCONS_000 & ANKRD2 & \\
\hline 18941 & ESYT1 & A3 & 83422 & F10 & A3,SE & 44119 & 7 & RI,SE \\
\hline TCONS_000 & & & TCONS_000 & & & TCONS_000 & SCGB1B & \\
\hline 22286 & ESYT1 & A3 & 83497 & FAM85A & $\mathrm{O}$ & 45918 & $2 \mathrm{P}$ & A3 \\
\hline TCONS_000 & & & TCONS_000 & & & TCONS_000 & & \\
\hline 22287 & ESYT1 & $\mathrm{O}$ & 83553 & PCM1 & SE & 45934 & DMKN & A5 \\
\hline TCONS_000 & & & TCONS_000 & & & TCONS_000 & & \\
\hline 22288 & MYL6B & A3 & 83554 & PCM1 & SE & 45939 & ATP4A & $\mathrm{O}$ \\
\hline TCONS_000 & & & TCONS_000 & & $\mathrm{A} 5, \mathrm{RI}, \mathrm{S}$ & TCONS_000 & AD0006 & \\
\hline 22289 & MYL6B & A3 & 83555 & PCM1 & E & 45942 & 71.6 & A3 \\
\hline TCONS_000 & & & TCONS_000 & & & TCONS_000 & AD0006 & \\
\hline 22290 & MYL6B & $\mathrm{O}$ & 86329 & PCM1 & A3,SE & 45943 & 71.6 & A3 \\
\hline TCONS_000 & & & TCONS_000 & & & TCONS_000 & & \\
\hline 22291 & MYL6B & O & 86334 & SH2D4A & SE & 44196 & ZNF260 & O \\
\hline TCONS_000 & & & TCONS_000 & & & TCONS_000 & & \\
\hline 22295 & NABP2 & $\mathrm{O}$ & 83580 & NPM2 & $\mathrm{O}$ & 44202 & ZNF461 & A5 \\
\hline TCONS_000 & SLC39A & & TCONS_000 & & & TCONS_000 & & \\
\hline 22296 & 5 & $\mathrm{RI}$ & 86341 & DMTN & AF,SE & 44211 & ZNF829 & A5 \\
\hline TCONS_000 & SLC39A & & TCONS_000 & & & TCONS_000 & & \\
\hline 22297 & 5 & RI & 86342 & DMTN & SE & 44248 & CAPN12 & $\mathrm{RI}$ \\
\hline TCONS_000 & HSD17 & & TCONS_000 & & & TCONS_000 & & \\
\hline 18982 & B6 & A3 & 83581 & DMTN & AF & 44249 & CAPN12 & $\mathrm{RI}$ \\
\hline TCONS_000 & & & TCONS_000 & FAM160 & & TCONS_000 & & \\
\hline 19007 & MARS & O & 83585 & B2 & A5 & 44250 & CAPN12 & $\mathrm{O}$ \\
\hline TCONS_000 & & & TCONS_000 & FAM160 & & TCONS_000 & & \\
\hline 19008 & MBD6 & $\mathrm{A} 3, \mathrm{RI}$ & 83586 & B2 & A5,RI & 45964 & CAPN12 & $\mathrm{O}$ \\
\hline TCONS_000 & ARHGE & & TCONS_000 & & & TCONS_000 & & \\
\hline 22306 & F25 & SE & 83593 & BMP1 & RI,SE & 44260 & LGALS4 & SE \\
\hline
\end{tabular}




\begin{tabular}{|c|c|c|c|c|c|c|c|c|}
\hline TCONS_000 & ARHGE & & TCONS_000 & & & TCONS_000 & & \\
\hline 19019 & $\mathrm{~F} 25$ & A3,SE & 83627 & CHMP7 & $\mathrm{O}$ & 44269 & $\mathrm{ECH} 1$ & SE \\
\hline TCONS_000 & ARHGE & & TCONS_000 & & & TCONS_000 & & \\
\hline 19020 & $\mathrm{~F} 25$ & $\mathrm{O}$ & 83628 & CHMP7 & $\mathrm{O}$ & 44281 & RINL & $\mathrm{O}$ \\
\hline TCONS_000 & & & TCONS_000 & & & TCONS_000 & СТC-360 & \\
\hline 19022 & OS9 & $\mathrm{O}$ & 83651 & DOCK5 & RI & 45967 & G5.8 & RI \\
\hline TCONS_000 & & & TCONS_000 & & & TCONS_000 & & \\
\hline 19023 & OS9 & SE & 86371 & PTK2B & $\mathrm{O}$ & 45969 & PAF1 & $\mathrm{O}$ \\
\hline TCONS_000 & & $A 3, A 5, S$ & TCONS_000 & & & TCONS_000 & & \\
\hline 19024 & OS9 & $\mathrm{E}$ & 83691 & ESCO2 & $A F$ & 44295 & PAF1 & $\mathrm{O}$ \\
\hline TCONS_000 & & & TCONS_000 & RP11-11 & & TCONS_000 & & \\
\hline 22308 & OS9 & A3 & 83751 & N9.4 & A5 & 44323 & FCGBP & $\mathrm{O}$ \\
\hline TCONS_000 & MARCH & & TCONS_000 & & & TCONS_000 & & \\
\hline 19038 & 9 & RI & 83767 & GPR124 & $\mathrm{O}$ & 44324 & FCGBP & A3 \\
\hline TCONS_000 & METTL2 & & TCONS_000 & & & TCONS_000 & & \\
\hline 19040 & $1 \mathrm{~B}$ & RI & 86450 & TACC1 & $\mathrm{O}$ & 45972 & FCGBP & $\mathrm{O}$ \\
\hline TCONS_000 & RP11-1 & & TCONS_000 & PLEKHA & & TCONS_000 & & \\
\hline 19051 & $50 C 16.1$ & $\mathrm{O}$ & 83815 & 2 & SE & 44353 & ADCK4 & $\mathrm{O}$ \\
\hline TCONS_000 & & & TCONS_000 & PLEKHA & & TCONS_000 & & \\
\hline 22326 & LEMD3 & RI & 83817 & 2 & A5 & 45988 & ADCK4 & $A 5, R I$ \\
\hline TCONS_000 & & & TCONS_000 & & & TCONS_000 & & \\
\hline 19196 & NUP107 & RI & 86461 & GOLGA7 & $A F$ & 44361 & TGFB1 & $A L$ \\
\hline TCONS_000 & & & TCONS_000 & & & TCONS_000 & & \\
\hline 22339 & NUP107 & RI & 83853 & POLB & SE & 45990 & TGFB1 & $\mathrm{O}$ \\
\hline TCONS_000 & & & TCONS_000 & & & TCONS_000 & & \\
\hline 22340 & NUP107 & $\mathrm{RI}$ & 86469 & HGSNAT & $\mathrm{O}$ & 44370 & B3GNT8 & $\mathrm{O}$ \\
\hline TCONS_000 & & & TCONS_000 & & & TCONS_000 & AC01152 & \\
\hline 19213 & MDM2 & $\mathrm{O}$ & 83967 & UBXN2B & SE & 44377 & 6.1 & A5 \\
\hline TCONS_000 & & & TCONS_000 & & & TCONS_000 & & \\
\hline 19225 & LYZ & $\mathrm{O}$ & 84034 & CSPP1 & A5,SE & 44396 & DEDD2 & AF,SE \\
\hline TCONS_000 & & & TCONS_000 & & & TCONS_000 & & \\
\hline 22359 & TRHDE & $\mathrm{O}$ & 84042 & SULF1 & RI,SE & 44415 & CNFN & $\mathrm{O}$ \\
\hline TCONS_000 & ZDHHC & & TCONS_000 & & & TCONS_000 & & \\
\hline 19291 & 17 & A3,SE & 84057 & XKR9 & A5,SE & 45999 & LIPE & $A F$ \\
\hline TCONS_000 & & & TCONS_000 & & & TCONS_000 & & \\
\hline 19294 & NAV3 & $\mathrm{O}$ & 84127 & RDH10 & $\mathrm{O}$ & 44431 & PHLDB3 & A3 \\
\hline
\end{tabular}




\begin{tabular}{|c|c|c|c|c|c|c|c|c|}
\hline \multicolumn{3}{|l|}{ TCONS_000 } & \multicolumn{3}{|l|}{ TCONS 000} & \multicolumn{3}{|l|}{ TCONS_000 } \\
\hline 19309 & NAV3 & SE & 84128 & RDH10 & 0 & 44470 & ZNF45 & A5 \\
\hline TCONS_000 & RP11-8 & & TCONS_000 & & & TCONS_000 & AC00612 & \\
\hline 22377 & $4 \mathrm{G} 21.1$ & SE & 84151 & HNF4G & $A F$ & 44504 & 6.4 & 0 \\
\hline TCONS_000 & METTL2 & & TCONS_000 & & & TCONS_000 & PPP1R13 & \\
\hline 19317 & 5 & 0 & 86520 & HNF4G & 0 & 46016 & $\mathrm{~L}$ & $A F, R I$ \\
\hline TCONS_000 & & & TCONS_000 & $\mathrm{ZC} 2 \mathrm{HC} 1$ & & TCONS_000 & & \\
\hline 19368 & socs2 & AF & 84165 & A & $\mathrm{O}$ & 44520 & EML2 & 0 \\
\hline TCONS_000 & & & TCONS_000 & & & TCONS_000 & & \\
\hline 19438 & APAF1 & $\mathrm{O}$ & 86548 & LRRCC1 & A3,SE & 44524 & EML2 & A3 \\
\hline TCONS_000 & & & TCONS_000 & & & TCONS_000 & & \\
\hline 19447 & SCYL2 & A5 & 86549 & LRRCC1 & A3,SE & 46023 & SIX5 & $\mathrm{O}$ \\
\hline TCONS_000 & & & TCONS_000 & & & TCONS_000 & & \\
\hline 19454 & GAS2L3 & SE & 84183 & LRRCC1 & SE & 46026 & DMPK & $\mathrm{RI}, \mathrm{SE}$ \\
\hline TCONS_000 & MYBPC & & TCONS_000 & & & TCONS_000 & & $A 3, R I, S$ \\
\hline 19463 & 1 & $\mathrm{RI}, \mathrm{SE}$ & 84184 & LRRCC1 & SE & 46027 & DMPK & $\mathrm{E}$ \\
\hline TCONS_000 & MYBPC & & TCONS_000 & & & TCONS_000 & & \\
\hline 19464 & 1 & SE & 84185 & LRRCC1 & A3,SE & 44536 & DMPK & SE \\
\hline TCONS_000 & MYBPC & & TCONS_000 & & & TCONS_000 & & \\
\hline 19467 & 1 & RI,SE & 86556 & CPNE3 & SE & 44537 & DMPK & SE \\
\hline TCONS_000 & MYBPC & & TCONS_000 & & & TCONS_000 & & \\
\hline 19471 & 1 & SE & 86572 & TMEM67 & A3 & 44538 & DMPK & 0 \\
\hline TCONS_000 & & & TCONS_000 & & & TCONS_000 & & \\
\hline 22417 & TDG & RI,SE & 84251 & ESRP1 & A5 & 46033 & SYMPK & A3 \\
\hline TCONS_000 & RP11-1 & & TCONS 000 & & $\mathrm{~A} 3, \mathrm{~A} 5, \mathrm{~S}$ & TCONS_000 & & \\
\hline 19550 & 14F10.3 & 0 & 86582 & INTS8 & E & 44546 & MYPOP & 0 \\
\hline TCONS_000 & TCP11L & & TCONS_000 & & & TCONS_000 & AC00626 & \\
\hline 19555 & 2 & A5 & 84259 & INTS8 & A5,SE & 44548 & 2.5 & $\mathrm{O}$ \\
\hline TCONS_000 & & & TCONS_000 & & & TCONS_000 & & \\
\hline 22430 & ACACB & A5 & 84289 & MATN2 & 0 & 44561 & PTGIR & 0 \\
\hline TCONS_000 & & & TCONS_000 & & & TCONS_000 & & \\
\hline 19597 & MVK & A5 & 86606 & CTHRC1 & $A F$ & 44562 & PTGIR & 0 \\
\hline TCONS_000 & ANKRD & & TCONS_000 & & & TCONS_000 & & \\
\hline 19604 & $13 \mathrm{~A}$ & A3 & 84358 & RIMS2 & $\mathrm{MX}, \mathrm{SE}$ & 44569 & PRKD2 & A3 \\
\hline TCONS_000 & & & TCONS_000 & HAS2-AS & & TCONS_000 & & \\
\hline 19624 & TCTN1 & $\mathrm{O}$ & 84454 & 1 & A5,SE & 44574 & STRN4 & $\mathrm{O}$ \\
\hline
\end{tabular}




\begin{tabular}{|c|c|c|c|c|c|c|c|c|}
\hline TCONS_000 & TRAFD & & TCONS_000 & & & TCONS_000 & & \\
\hline 22460 & 1 & A5,RI & 84483 & FER1L6 & 0 & 44588 & $\mathrm{ZC} 3 \mathrm{H} 4$ & 0 \\
\hline TCONS_000 & TRAFD & & TCONS_000 & & & TCONS_000 & & \\
\hline 22461 & 1 & A5,SE & 84484 & FER1L6 & $A F$ & 46041 & $\mathrm{ZC} 3 \mathrm{H} 4$ & $A F$ \\
\hline TCONS_000 & & & TCONS_000 & & & TCONS_000 & & \\
\hline 19653 & OAS1 & 0 & 84485 & FER1L6 & $A F$ & 44600 & KPTN & 0 \\
\hline TCONS_000 & & & TCONS_000 & & & TCONS_000 & & \\
\hline 22463 & DTX1 & $\mathrm{O}$ & 84486 & FER1L6 & $A 3, A F$ & 44602 & NAPA & $\mathrm{RI}$ \\
\hline TCONS_000 & & & TCONS_000 & KHDRBS & & TCONS_000 & & \\
\hline 19661 & DTX1 & $\mathrm{RI}$ & 86698 & 3 & $\mathrm{O}$ & 44614 & LIG1 & A5 \\
\hline TCONS_000 & & & TCONS_000 & KHDRBS & & TCONS_000 & & \\
\hline 19665 & TPCN1 & $\mathrm{RI}$ & 84601 & 3 & $\mathrm{O}$ & 44639 & DBP & $\mathrm{O}$ \\
\hline TCONS_000 & & & TCONS_000 & & & TCONS_000 & & \\
\hline 19676 & SDSL & $\mathrm{RI}, \mathrm{SE}$ & 86706 & LY6E & SE & 46051 & CA11 & SE \\
\hline TCONS_000 & & & TCONS_000 & & & TCONS_000 & & \\
\hline 22470 & SDSL & SE & 86710 & GSDMD & A3 & 46054 & FUT1 & $\mathrm{RI}$ \\
\hline TCONS_000 & PRKAB & & TCONS_000 & & & TCONS_000 & & \\
\hline 22478 & 1 & $\mathrm{RI}$ & 84656 & GSDMD & $\mathrm{RI}$ & 46055 & FUT1 & A5,RI \\
\hline TCONS 000 & PXN-AS & & TCONS 000 & & & TCONS 000 & PLEKHA & \\
\hline 22479 & 1 & $\mathrm{O}$ & 84665 & ZNF707 & A5,SE & 44656 & 4 & RI,SE \\
\hline TCONS_000 & & & TCONS_000 & & & TCONS_000 & PLEKHA & \\
\hline 19726 & RNF10 & SE & 84667 & MAPK15 & 0 & 46057 & 4 & SE \\
\hline TCONS_000 & TMEM1 & & TCONS_000 & & & TCONS_000 & & \\
\hline 19758 & $20 B$ & A5 & 86720 & $\mathrm{MROH} 1$ & SE & 46059 & LHB & $\mathrm{O}$ \\
\hline TCONS_000 & TMEM1 & & TCONS 000 & & & TCONS_000 & & \\
\hline 22493 & $20 B$ & SE & 86721 & $\mathrm{MROH} 1$ & $\mathrm{RI}, \mathrm{SE}$ & 44663 & CGB & $\mathrm{O}$ \\
\hline TCONS_000 & & & TCONS_000 & CTD-323 & & TCONS_000 & & \\
\hline 19784 & KNTC1 & A3 & 86723 & $2 \mathrm{M} 19.2$ & $\mathrm{RI}$ & 46061 & TEAD2 & $A F$ \\
\hline TCONS_000 & & & TCONS_000 & & & TCONS_000 & & \\
\hline 22497 & HIP1R & $\mathrm{RI}$ & 86725 & HSF1 & RI & 46062 & TEAD2 & AF,SE \\
\hline TCONS_000 & & & TCONS_000 & & $\mathrm{A} 3, \mathrm{~A} 5, \mathrm{R}$ & TCONS_000 & & \\
\hline 19790 & HIP1R & $\mathrm{RI}$ & 84697 & HSF1 & I,SE & 44679 & IRF3 & A5 \\
\hline TCONS_000 & & & TCONS_000 & & & TCONS_000 & & \\
\hline 19791 & HIP1R & RI & 86729 & KIFC2 & RI & 46068 & IRF3 & A5,RI \\
\hline TCONS_000 & & & TCONS_000 & & & TCONS_000 & PTOV1-A & \\
\hline 19794 & HIP1R & $\mathrm{O}$ & 86730 & KIFC2 & $\mathrm{O}$ & 44689 & S1 & A3 \\
\hline
\end{tabular}




\begin{tabular}{|c|c|c|c|c|c|c|c|c|}
\hline \multicolumn{3}{|l|}{ TCONS_000 } & \multicolumn{3}{|l|}{ TCONS 000} & TCONS_000 & AC01876 & $A 3, A F, R$ \\
\hline 19795 & HIP1R & 0 & 86731 & KIFC2 & 0 & 44691 & 6.5 & 1 \\
\hline TCONS_000 & OGFOD & & TCONS_000 & & & TCONS_000 & AC01876 & \\
\hline 22500 & 2 & A5,RI & 84708 & KIFC2 & $\mathrm{RI}$ & 44692 & 6.5 & AF,SE \\
\hline TCONS_000 & C12orf6 & & TCONS_000 & & & TCONS_000 & & \\
\hline 19810 & 5 & A5,AF & 84709 & KIFC2 & 0 & 46071 & PNKP & $\mathrm{A} 3, \mathrm{RI}$ \\
\hline TCONS_000 & & & TCONS_000 & PPP1R16 & & TCONS_000 & & \\
\hline 22502 & SETD8 & A5 & 84711 & A & $\mathrm{O}$ & 46073 & AKT1S1 & A5 \\
\hline TCONS_000 & & & TCONS_000 & PPP1R16 & & TCONS_000 & & \\
\hline 22503 & SETD8 & $\mathrm{O}$ & 86732 & $A$ & $\mathrm{RI}$ & 46076 & VRK3 & $\mathrm{RI}$ \\
\hline TCONS_000 & SNRNP & & TCONS_000 & PPP1R16 & & TCONS_000 & & \\
\hline 19818 & 35 & $\mathrm{O}$ & 84713 & A & $\mathrm{O}$ & 46081 & C19orf48 & $\mathrm{O}$ \\
\hline TCONS_000 & & & TCONS_000 & PPP1R16 & & TCONS_000 & & \\
\hline 22507 & DDX55 & $\mathrm{A} 3, \mathrm{RI}$ & 84714 & $A$ & $\mathrm{O}$ & 44762 & ETFB & O \\
\hline TCONS_000 & & & TCONS_000 & & & TCONS_000 & SIGLEC1 & \\
\hline 19903 & ULK1 & $\mathrm{RI}$ & 86733 & GPT & $\mathrm{RI}$ & 44771 & 0 & $\mathrm{O}$ \\
\hline TCONS_000 & & & TCONS_000 & RP11-43 & & TCONS_000 & & \\
\hline 22529 & ULK1 & $\mathrm{RI}$ & $84747^{-}$ & $9 \mathrm{C} 15.4$ & $\mathrm{O}$ & 44784 & ZNF577 & $\mathrm{O}$ \\
\hline TCONS_000 & & & TCONS_000 & & & TCONS_000 & & \\
\hline 19907 & PUS1 & $\mathrm{RI}$ & $86805^{-}$ & LONRF1 & $\mathrm{O}$ & $46090^{-}$ & ZNF577 & $\mathrm{O}$ \\
\hline TCONS_000 & & $\mathrm{MX}, \mathrm{RI}$ & TCONS_000 & & & TCONS_000 & & \\
\hline 19914 & FBRSL1 & SE & 84838 & LONRF1 & A3 & 46096 & ZNF841 & 0 \\
\hline TCONS_000 & & $\mathrm{A} 5, \mathrm{AF}$ & TCONS_000 & & & TCONS_000 & & \\
\hline 22543 & PXMP2 & SE & 84863 & FGF20 & A5 & 44796 & ZNF841 & $\mathrm{O}$ \\
\hline TCONS_000 & & & TCONS_000 & & & TCONS_000 & CTD-301 & \\
\hline 19930 & ZNF26 & $M X$ & 84870 & MTUS1 & AF & 44811 & 8017.3 & $A 3, A 5$ \\
\hline TCONS_000 & RP11-2 & & TCONS_000 & & & TCONS_000 & & \\
\hline 20001 & 64F23.3 & AF & $86810^{-}$ & MTUS1 & AF,SE & 44816 & ZNF83 & 0 \\
\hline TCONS_000 & & & TCONS_000 & & & TCONS_000 & & \\
\hline 20006 & VWF & $\mathrm{O}$ & 84874 & FGL1 & RI & 44849 & ZNF888 & SE \\
\hline TCONS_000 & SCNN1 & & TCONS_000 & CSGALN & & TCONS_000 & & \\
\hline 20022 & A & SE & 84889 & АCT1 & AF,SE & 44867 & ZNF415 & SE \\
\hline TCONS_000 & CD27-A & & TCONS_000 & & & TCONS_000 & & \\
\hline 20029 & $\mathrm{~S} 1$ & 0 & 84930 & LOXL2 & $\mathrm{O}$ & 46124 & TFPT & $\mathrm{O}$ \\
\hline TCONS_000 & & & TCONS_000 & & & TCONS_000 & & \\
\hline 22598 & CHD4 & A3 & 84936 & ENTPD4 & A3 & 44889 & MBOAT7 & RI \\
\hline
\end{tabular}




\begin{tabular}{|c|c|c|c|c|c|c|c|c|}
\hline \multicolumn{3}{|l|}{ TCONS_000 } & TCONS_000 & \multicolumn{2}{|l|}{ RP11-62 } & \multicolumn{3}{|l|}{ TCONS_000 } \\
\hline $20043^{-}$ & CHD4 & A3 & $84948^{-}$ & 4C23.1 & 0 & $44894^{-}$ & LILRB3 & $\mathrm{RI}$ \\
\hline TCONS_000 & & & TCONS_000 & & & TCONS_000 & & \\
\hline 22602 & CHD4 & A3 & 84978 & PBK & A5 & 46130 & LILRB2 & 0 \\
\hline TCONS_000 & & & TCONS_000 & & $A 3, A 5, S$ & TCONS_000 & & \\
\hline 20056 & ZNF384 & $\mathrm{RI}, \mathrm{SE}$ & 85081 & FGFR1 & $\mathrm{E}$ & 46131 & $\mathrm{RDH} 13$ & $\mathrm{~A} 5, \mathrm{SE}$ \\
\hline TCONS_000 & & & TCONS_000 & & & TCONS_000 & PPP1R12 & \\
\hline 20065 & CDCA3 & $\mathrm{O}$ & 85115 & SLC20A2 & $A F$ & 46133 & $\mathrm{C}$ & $\mathrm{A} 3, \mathrm{RI}$ \\
\hline TCONS_000 & & & TCONS_000 & & & TCONS_000 & & \\
\hline 20066 & SPSB2 & $\mathrm{O}$ & 86909 & ASPH & AF,SE & 44926 & TNNT1 & A3 \\
\hline TCONS_000 & & & TCONS_000 & & $A 3, A F, S$ & TCONS_000 & & \\
\hline 20067 & SPSB2 & A3 & 86910 & ASPH & E & 44931 & PTPRH & A3 \\
\hline TCONS_000 & & & TCONS_000 & ARFGEF & & TCONS_000 & & \\
\hline 20071 & PHB2 & $\mathrm{RI}$ & 85278 & 1 & $\mathrm{O}$ & 44936 & PPP6R1 & O \\
\hline TCONS_000 & & & TCONS_000 & & & TCONS_000 & & \\
\hline 20080 & LPCAT3 & $\mathrm{RI}$ & 85291 & NCOA2 & A5,SE & 44938 & PPP6R1 & $\mathrm{AF}$ \\
\hline TCONS_000 & & & TCONS_000 & & & TCONS_000 & TMEM15 & \\
\hline 20085 & C1R & $\mathrm{RI}$ & $86950^{-}$ & NCOA2 & SE & 44945 & $\mathrm{OB}$ & $\mathrm{O}$ \\
\hline TCONS_000 & & & TCONS_000 & & & TCONS_000 & & \\
\hline $20088^{-}$ & C1R & $\mathrm{RI}$ & 86962 & TPD52 & AF,SE & 46141 & ZNF667 & SE \\
\hline TCONS_000 & & & TCONS_000 & & & TCONS_000 & & \\
\hline 20098 & RBP5 & $\mathrm{O}$ & 85374 & TPD52 & SE & 45007 & C19orf18 & 0 \\
\hline TCONS_000 & CD163L & & TCONS 000 & & & TCONS_000 & ZSCAN1 & \\
\hline 20102 & 1 & 0 & 85385 & ZNF704 & A5 & 45011 & 8 & A5 \\
\hline TCONS_000 & SLC2A1 & & TCONS 000 & & & TCONS_000 & & \\
\hline 22611 & 4 & $\mathrm{RI}, \mathrm{SE}$ & 86977 & ZFAND1 & AF,SE & 46189 & RSAD2 & $\mathrm{O}$ \\
\hline TCONS_000 & & & TCONS_000 & & & TCONS_000 & & \\
\hline 22612 & SLC2A3 & $\mathrm{RI}$ & 86992 & NBN & AF,SE & 51596 & ID2 & SE \\
\hline TCONS_000 & & & TCONS_000 & & & TCONS_000 & & \\
\hline 20113 & SLC2A3 & O & 85573 & CALB1 & $\mathrm{AF}$ & 46279 & TRIB2 & 0 \\
\hline TCONS_000 & FAM86F & & TCONS_000 & & & TCONS_000 & & \\
\hline 22614 & $\mathrm{P}$ & A3,A5 & 85574 & CALB1 & $\mathrm{AF}$ & 46280 & TRIB2 & 0 \\
\hline TCONS_000 & DDX12 & & TCONS_000 & & & TCONS_000 & & \\
\hline 20154 & $\mathrm{P}$ & A5,RI & 86999 & GEM & $\mathrm{O}$ & 51638 & FAM84A & $\mathrm{O}$ \\
\hline TCONS_000 & CLEC2 & & TCONS_000 & KIAA142 & & TCONS_000 & & \\
\hline 20163 & B & $\mathrm{O}$ & 87001 & 9 & $\mathrm{O}$ & 46288 & GEN1 & $\mathrm{O}$ \\
\hline
\end{tabular}




\begin{tabular}{|c|c|c|c|c|c|c|c|c|}
\hline TCONS_000 & CLEC7 & & TCONS_000 & & & TCONS_000 & & \\
\hline $20171^{-}$ & A & A3 & 87002 & C8orf37 & $\mathrm{O}$ & $51671^{-}$ & NCOA1 & A3 \\
\hline TCONS_000 & CLEC7 & & TCONS_000 & & & TCONS_000 & & \\
\hline 20173 & A & A3 & 87006 & NIPAL2 & $\mathrm{RI}, \mathrm{SE}$ & 46385 & SLC35F6 & 0 \\
\hline & RP11-2 & & & & & & & \\
\hline TCONS_000 & 77P12.1 & & TCONS_000 & & & TCONS_000 & TMEM21 & \\
\hline 22622 & 0 & $\mathrm{O}$ & 87007 & NIPAL2 & $\mathrm{O}$ & 51683 & 4 & A3 \\
\hline TCONS_000 & & & TCONS_000 & & & TCONS_000 & & \\
\hline 20196 & STYK1 & SE & 87020 & PABPC1 & $\mathrm{O}$ & 46404 & CAD & $\mathrm{RI}$ \\
\hline TCONS_000 & & & TCONS_000 & & & TCONS_000 & & \\
\hline 22625 & YBX3 & SE & 85706 & YWHAZ & $\mathrm{O}$ & 51685 & CAD & $\mathrm{O}$ \\
\hline TCONS_000 & MANSC & & TCONS_000 & & & TCONS_000 & & \\
\hline 20239 & 1 & $\mathrm{RI}$ & 85707 & YWHAZ & $\mathrm{O}$ & 46411 & NRBP1 & O \\
\hline TCONS_000 & HIST4H & & TCONS_000 & & & TCONS_000 & & \\
\hline 22642 & 4 & A3 & 85747 & UBR5 & $A 3, R I$ & 51687 & NRBP1 & $\mathrm{RI}$ \\
\hline TCONS_000 & HIST4H & & TCONS_000 & & & TCONS_000 & KRTCAP & \\
\hline 22643 & 4 & A3 & 85812 & SYBU & $\mathrm{RI}$ & 46412 & 3 & $A L$ \\
\hline TCONS_000 & HIST4H & & TCONS_000 & & & TCONS_000 & KRTCAP & \\
\hline 22644 & 4 & A3 & 85849 & EXT1 & $\mathrm{O}$ & 46413 & 3 & SE \\
\hline TCONS_000 & HIST4H & & TCONS_000 & & & TCONS_000 & KRTCAP & \\
\hline 22645 & 4 & $A L$ & 85850 & EXT1 & $\mathrm{O}$ & 51690 & 3 & $\mathrm{O}$ \\
\hline TCONS_000 & & & TCONS_000 & & A5,AF,S & TCONS_000 & & \\
\hline 20274 & MGP & SE & 85879 & ENPP2 & E & 51691 & ZNF512 & SE \\
\hline TCONS_000 & & & TCONS_000 & & & TCONS_000 & & \\
\hline 20317 & RECQL & O & 87057 & TAF2 & $\mathrm{RI}$ & 46428 & BRE & $M X$ \\
\hline TCONS_000 & & & TCONS_000 & & & TCONS_000 & & \\
\hline 20318 & RECQL & A5 & 85885 & TAF2 & $\mathrm{RI}$ & 46497 & BIRC6 & $A 3, A 5$ \\
\hline TCONS_000 & & & TCONS_000 & & & TCONS_000 & & \\
\hline 22656 & RECQL & 0 & 85936 & TATDN1 & A5,SE & 46505 & LTBP1 & A3 \\
\hline TCONS_000 & & & TCONS_000 & LINC008 & & TCONS_000 & AC00739 & \\
\hline 22657 & KCNJ8 & $\mathrm{O}$ & 85955 & 61 & $\mathrm{O}$ & 46528 & 0.5 & $\mathrm{AL}$ \\
\hline TCONS_000 & & & TCONS_000 & & & TCONS_000 & NDUFAF & \\
\hline 20324 & $A B C C 9$ & $\mathrm{O}$ & 85966 & CASC8 & $\mathrm{O}$ & 51730 & 7 & $\mathrm{RI}$ \\
\hline TCONS_000 & & & TCONS_000 & & & TCONS_000 & NDUFAF & \\
\hline 20325 & $A B C C 9$ & $\mathrm{O}$ & 85990 & ASAP1 & SE & 46533 & 7 & $\mathrm{RI}$ \\
\hline TCONS_000 & KRAS & A5,SE & TCONS_000 & LRRC6 & A3 & TCONS_000 & RMDN2 & SE \\
\hline
\end{tabular}




\begin{tabular}{|c|c|c|c|c|c|c|c|c|}
\hline \multicolumn{3}{|l|}{20361} & \multicolumn{3}{|l|}{87079} & \multicolumn{3}{|l|}{46544} \\
\hline TCONS_000 & RASSF & & TCONS_000 & & & TCONS_000 & & \\
\hline 20365 & 8-AS1 & $\mathrm{RI}$ & 86009 & TMEM71 & A3 & 51735 & PKDCC & $\mathrm{RI}$ \\
\hline TCONS_000 & & & TCONS_000 & & & TCONS_000 & AC01088 & \\
\hline 20379 & ASUN & RI & $86070^{-}$ & PTK2 & $A 5, A F$ & 46593 & 3.5 & $\mathrm{O}$ \\
\hline & RP11-1 & & & & & & & \\
\hline TCONS_000 & $060 J 15$. & & TCONS_000 & & & TCONS_000 & & \\
\hline 20393 & 4 & $A L$ & 86071 & PTK2 & $A 5, A F$ & 46627 & RHOQ & 0 \\
\hline TCONS_000 & & & TCONS_000 & & & TCONS_000 & & \\
\hline 20394 & PTHLH & $\mathrm{O}$ & 86073 & PTK2 & A5,SE & 46628 & RHOQ & $\mathrm{O}$ \\
\hline TCONS_000 & CAPRIN & $A 3, R I, S$ & TCONS_000 & & & TCONS_000 & & \\
\hline 22689 & 2 & E & 86074 & PTK2 & A5,SE & 46629 & $\mathrm{RHOQ}$ & SE \\
\hline TCONS_000 & CAPRIN & & TCONS_000 & & & TCONS_000 & & \\
\hline 20409 & 2 & $\mathrm{RI}, \mathrm{SE}$ & 86076 & PTK2 & $\mathrm{A} 5, \mathrm{MX}$ & 46630 & RHOQ & SE \\
\hline TCONS_000 & CAPRIN & & TCONS_000 & & & TCONS_000 & & \\
\hline 20410 & 2 & $\mathrm{RI}, \mathrm{SE}$ & 86082 & SLC45A4 & O & 51749 & $\mathrm{RHOQ}$ & O \\
\hline TCONS_000 & CAPRIN & & TCONS_000 & & & TCONS_000 & & \\
\hline 20411 & 2 & $\mathrm{RI}, \mathrm{SE}$ & 86092 & LYNX1 & SE & 46659 & FOXN2 & SE \\
\hline TCONS_000 & CAPRIN & $\mathrm{A} 3, \mathrm{RI}, \mathrm{S}$ & TCONS_000 & & & TCONS_000 & & \\
\hline 20412 & 2 & E & 86097 & LY6H & SE & 46682 & SPTBN1 & O \\
\hline TCONS_000 & DENND & & TCONS_000 & & & TCONS_000 & & \\
\hline 20439 & $5 \mathrm{~B}$ & $\mathrm{O}$ & 86107 & MROH6 & $\mathrm{A} 3, \mathrm{RI}$ & 51773 & RPS27A & A5 \\
\hline TCONS_000 & & & TCONS_000 & & & TCONS_000 & KIAA184 & \\
\hline 20454 & YARS2 & $\mathrm{O}$ & 86112 & NAPRT1 & $\mathrm{RI}$ & 46729 & 1 & O \\
\hline TCONS_000 & & & TCONS_000 & & & TCONS_000 & & \\
\hline 20466 & KIF21A & SE & 86140 & SCRIB & A5,SE & 46733 & AHSA2 & SE \\
\hline TCONS_000 & & & TCONS_000 & & & TCONS_000 & & \\
\hline 22696 & KIF21A & $\mathrm{RI}, \mathrm{SE}$ & 86141 & SCRIB & A5,SE & 46734 & AHSA2 & SE \\
\hline TCONS_000 & & & TCONS_000 & & & TCONS_000 & RP11-35 & \\
\hline 20495 & TWF1 & A3 & 87112 & SCRIB & SE & 51795 & 5B11.2 & 0 \\
\hline TCONS_000 & SLC38A & & TCONS_000 & & & TCONS_000 & & $A 3, A 5, A$ \\
\hline 22704 & 1 & SE & 87113 & PUF60 & A3 & 51810 & EHBP1 & F,SE \\
\hline TCONS_000 & SLC38A & & TCONS_000 & & & TCONS_000 & & \\
\hline 20518 & 1 & SE & 87115 & PUF60 & $\mathrm{O}$ & 46745 & EHBP1 & AF,SE \\
\hline TCONS_000 & SLC38A & & TCONS_000 & SHARPI & & TCONS_000 & & \\
\hline 20536 & 4 & 0 & 87125 & $\mathrm{~N}$ & $\mathrm{O}$ & 51812 & EHBP1 & AF,SE \\
\hline
\end{tabular}




\begin{tabular}{|c|c|c|c|c|c|c|c|c|}
\hline TCONS_000 & RAPGE & & TCONS_000 & & & TCONS_000 & & \\
\hline 20566 & F3 & $\mathrm{RI}$ & 86177 & KM-PA-2 & $\mathrm{O}$ & 51816 & AFTPH & A3,SE \\
\hline TCONS_000 & & & TCONS_000 & & & TCONS_000 & & \\
\hline 20612 & ADCY6 & O & 86179 & BOP1 & $\mathrm{O}$ & 46769 & AFTPH & A3,SE \\
\hline TCONS_000 & & & TCONS_000 & & & TCONS_000 & & \\
\hline 20614 & ADCY6 & $\mathrm{RI}$ & 87127 & DGAT1 & $\mathrm{RI}$ & 51819 & CEP68 & A5,RI \\
\hline TCONS_000 & & & TCONS_000 & & & TCONS_000 & & \\
\hline 20616 & DDX23 & RI & 86182 & FBXL6 & $\mathrm{O}$ & 46778 & CEP68 & A5,RI \\
\hline TCONS_000 & & & TCONS_000 & & & TCONS_000 & & \\
\hline 20630 & KMT2D & $\mathrm{O}$ & 86183 & CPSF1 & $\mathrm{RI}$ & 51850 & NAGK & $\mathrm{RI}$ \\
\hline TCONS_000 & LMBR1 & & TCONS_000 & & & TCONS_000 & & \\
\hline 22729 & L & $\mathrm{O}$ & 87129 & CPSF1 & $\mathrm{RI}$ & 46840 & ZNF638 & A3 \\
\hline TCONS_000 & LMBR1 & & TCONS_000 & & & TCONS_000 & & \\
\hline 22730 & L & A3 & 86194 & CYHR1 & A5 & 46841 & ZNF638 & SE \\
\hline TCONS_000 & LMBR1 & & TCONS_000 & ARHGAP & & TCONS_000 & & \\
\hline 20637 & L & RI,SE & 86202 & 39 & $\mathrm{O}$ & 51861 & SMYD5 & RI \\
\hline TCONS_000 & LMBR1 & & TCONS_000 & & & TCONS_000 & & \\
\hline 20638 & L & $\mathrm{RI}$ & 86204 & ZNF251 & $\mathrm{O}$ & 46862 & STAMBP & $\mathrm{O}$ \\
\hline TCONS_000 & LMBR1 & & TCONS_000 & & & TCONS_000 & & \\
\hline 20639 & L & $\mathrm{RI}$ & 87142 & DOCK8 & A5 & 51871 & STAMBP & $\mathrm{O}$ \\
\hline TCONS_000 & LMBR1 & $A 3, R I, S$ & TCONS_000 & & & TCONS_000 & & \\
\hline 20640 & L & E & 87144 & DOCK8 & $\mathrm{O}$ & 46870 & DGUOK & $\mathrm{O}$ \\
\hline TCONS_000 & & & TCONS_000 & & & TCONS_000 & & \\
\hline 20660 & FMNL3 & A3,SE & 89987 & KANK1 & $\mathrm{O}$ & 46875 & TET3 & $\mathrm{O}$ \\
\hline TCONS_000 & NCKAP & & TCONS_000 & KIAA143 & & TCONS_000 & & \\
\hline 20668 & $5 \mathrm{~L}$ & O & 90016 & 2 & $\mathrm{RI}$ & 51877 & INO80B & A5 \\
\hline TCONS_000 & RP11-4 & & TCONS_000 & KIAA143 & & TCONS_000 & & \\
\hline 20672 & $69 \mathrm{H} 8.6$ & AF & 87197 & 2 & A5 & 46887 & INO80B & A5 \\
\hline TCONS_000 & CSRNP & & TCONS_000 & & & TCONS_000 & & \\
\hline 22746 & 2 & AF & 87200 & IL33 & O & 46888 & INO80B & A5 \\
\hline TCONS_000 & GALNT & & TCONS_000 & & & TCONS_000 & & \\
\hline 20726 & 6 & AF,SE & 87207 & UHRF2 & A5,SE & 46889 & INO80B & A5 \\
\hline TCONS_000 & GALNT & & TCONS_000 & RP11-62 & & TCONS_000 & & \\
\hline 20727 & 6 & $\mathrm{O}$ & 87254 & F24.2 & $\mathrm{O}$ & 46890 & INO80B & A3,A5 \\
\hline TCONS_000 & & & TCONS_000 & & & TCONS_000 & & \\
\hline 20738 & KRT81 & 0 & 87273 & FOCAD & $\mathrm{O}$ & 46891 & INO80B & RI \\
\hline
\end{tabular}




\begin{tabular}{|c|c|c|c|c|c|c|c|c|}
\hline \multicolumn{3}{|l|}{ TCONS_000 } & \multicolumn{3}{|l|}{ TCONS_000 } & \multicolumn{3}{|l|}{ TCONS_000 } \\
\hline 22757 & CSAD & $\mathrm{O}$ & 87344 & TEK & A5 & 46892 & INO80B & A3 \\
\hline TCONS_000 & & & TCONS_000 & & & TCONS_000 & & \\
\hline 22758 & CSAD & $\mathrm{A} 3, \mathrm{SE}$ & 87358 & SPINK4 & $\mathrm{O}$ & 46894 & TTC31 & $A 5, R I$ \\
\hline TCONS_000 & & & TCONS_000 & ANKRD1 & & TCONS_000 & & \\
\hline 20776 & CSAD & $\mathrm{RI}$ & 87365 & $8 B$ & A3 & 46895 & TTC31 & A5 \\
\hline TCONS_000 & & & TCONS_000 & & & TCONS_000 & & \\
\hline 20777 & CSAD & SE & 87370 & PRSS3 & $\mathrm{A} 3, \mathrm{SE}$ & 46896 & TTC31 & A3 \\
\hline TCONS_000 & & & TCONS_000 & & & TCONS_000 & & \\
\hline 20778 & CSAD & A5,SE & 90077 & NUDT2 & $\mathrm{O}$ & 51885 & DOK1 & A3 \\
\hline TCONS_000 & & & TCONS_000 & & & TCONS_000 & & \\
\hline 20782 & ITGB7 & $\mathrm{O}$ & 87382 & IL11RA & $\mathrm{O}$ & 46944 & MRPL19 & AL \\
\hline TCONS_000 & & & TCONS_000 & RP11-19 & & TCONS_000 & & \\
\hline 20783 & ITGB7 & $\mathrm{O}$ & 87384 & 5F19.9 & SE & 46952 & REG3G & A5 \\
\hline TCONS_000 & & & TCONS_000 & RP11-19 & & TCONS_000 & & \\
\hline 22762 & ITGB7 & $\mathrm{RI}$ & 87385 & 5F19.9 & A3 & 46953 & REG3G & $\mathrm{O}$ \\
\hline TCONS_000 & & & TCONS_000 & & & TCONS_000 & & \\
\hline 20784 & RARG & $\mathrm{O}$ & 87400 & TESK1 & $\mathrm{O}$ & 46962 & TMSB10 & $\mathrm{O}$ \\
\hline TCONS_000 & & & TCONS_000 & & & TCONS_000 & & \\
\hline 20788 & AAAS & $\mathrm{O}$ & 87401 & TESK1 & $\mathrm{O}$ & 46973 & TCF7L1 & $\mathrm{O}$ \\
\hline TCONS_000 & & & TCONS_000 & CCDC10 & & TCONS_000 & & \\
\hline 20796 & ATF7 & $\mathrm{A} 5, \mathrm{AF}$ & 87405 & 7 & A3 & 46974 & TCF7L1 & $\mathrm{O}$ \\
\hline TCONS_000 & CALCO & & TCONS_000 & & & TCONS_000 & & \\
\hline 20804 & $\mathrm{CO} 1$ & $\mathrm{~A} 3, \mathrm{RI}$ & 87410 & RGP1 & $\mathrm{RI}$ & 51893 & ELMOD3 & SE \\
\hline TCONS_000 & & & TCONS_000 & & & TCONS_000 & & \\
\hline 20819 & SMUG1 & $\mathrm{O}$ & 90086 & $\mathrm{ZCCHC} 7$ & A5 & 46985 & MAT2A & 0 \\
\hline TCONS_000 & PHC1P & & TCONS 000 & TRMT10 & A3,A5,R & TCONS 000 & & \\
\hline 22774 & 1 & AF & 90097 & B & I & 51895 & MAT2A & $\mathrm{RI}$ \\
\hline TCONS_000 & & & TCONS_000 & & & TCONS_000 & & \\
\hline 22775 & ITGA7 & SE & 87464 & DCAF10 & SE & 46997 & USP39 & $A F$ \\
\hline TCONS_000 & & & TCONS_000 & ANKRD2 & & TCONS_000 & & \\
\hline 20844 & ITGA7 & 0 & 87489 & OA2 & 0 & 47001 & USP39 & A5 \\
\hline TCONS_000 & RP11-7 & & TCONS_000 & RP11-26 & & TCONS_000 & & \\
\hline 20863 & 6217.5 & 0 & 90124 & $2 \mathrm{H} 14.4$ & $A L$ & 51898 & PTCD3 & $\mathrm{RI}$ \\
\hline TCONS_000 & RP11-7 & & TCONS_000 & RP11-87 & & TCONS_000 & & \\
\hline 20864 & 6217.5 & 0 & 87570 & H9.2 & $\mathrm{O}$ & 47017 & KDM3A & 0 \\
\hline
\end{tabular}




\begin{tabular}{|c|c|c|c|c|c|c|c|c|}
\hline \multicolumn{3}{|l|}{ TCONS_000 } & TCONS_000 & \multicolumn{2}{|l|}{ RP11-87 } & \multicolumn{3}{|l|}{ TCONS_000 } \\
\hline 22779 & MMP19 & SE & 87572 & H9.2 & 0 & 51901 & KDM3A & SE \\
\hline TCONS_000 & & & TCONS_000 & RP11-87 & & TCONS_000 & & \\
\hline 22780 & MMP19 & $\mathrm{O}$ & 90130 & H9.2 & $\mathrm{O}$ & 51902 & KDM3A & $\mathrm{RI}$ \\
\hline TCONS_000 & & & TCONS_000 & RP11-87 & & TCONS_000 & AC08389 & \\
\hline 22781 & MMP19 & $\mathrm{RI}$ & 87573 & H9.2 & 0 & 51905 & 9.3 & $\mathrm{O}$ \\
\hline TCONS_000 & & & TCONS_000 & & & TCONS_000 & ANKRD3 & \\
\hline 20867 & MMP19 & $\mathrm{O}$ & 90137 & CBWD3 & SE & 47047 & 6BP2 & 0 \\
\hline TCONS_000 & & & TCONS_000 & & & TCONS_000 & & \\
\hline 20868 & MMP19 & $\mathrm{RI}$ & 87609 & PIP5K1B & SE & 47094 & PROM2 & A3 \\
\hline TCONS_000 & & & TCONS_000 & & & TCONS_000 & & \\
\hline 20869 & MMP19 & SE & 87626 & TJP2 & $\mathrm{O}$ & 51913 & FAHD2A & SE \\
\hline TCONS_000 & & & TCONS_000 & & & TCONS_000 & FAHD2C & \\
\hline 20871 & MMP19 & $\mathrm{RI}$ & 87627 & TJP2 & $\mathrm{O}$ & 47107 & $\mathrm{P}$ & $\mathrm{RI}$ \\
\hline TCONS_000 & ANKRD & & TCONS_000 & & & TCONS_000 & FAHD2C & \\
\hline 20898 & 52 & $\mathrm{O}$ & 87636 & SMC5 & SE & 51917 & $\mathrm{P}$ & $\mathrm{RI}$ \\
\hline TCONS_000 & & $\mathrm{A} 5, \mathrm{AF}$ & TCONS_000 & & & TCONS_000 & & \\
\hline 22788 & PAN2 & $\mathrm{RI}$ & $87637^{-}$ & SMC5 & $\mathrm{RI}$ & 51919 & CIAO1 & $\mathrm{RI}$ \\
\hline TCONS_000 & & $\mathrm{A} 3, \mathrm{AF}$ & TCONS_000 & & & TCONS_000 & & \\
\hline 20910 & PAN2 & $\mathrm{RI}$ & 87679 & PCSK5 & SE & 51921 & CNNM3 & SE \\
\hline TCONS_000 & & A3,A5,A & TCONS_000 & & & TCONS_000 & ANKRD3 & \\
\hline 20911 & PAN2 & $\mathrm{F}, \mathrm{RI}$ & 87712 & VPS13A & A3 & 47126 & 6 & A5,SE \\
\hline TCONS_000 & & A3,A5,A & TCONS_000 & RP11-43 & & TCONS_000 & ANKRD3 & A3,A5,R \\
\hline 20912 & PAN2 & $\mathrm{F}, \mathrm{RI}$ & 87739 & 9K3.1 & 0 & 51923 & 6 & I,SE \\
\hline TCONS_000 & & & TCONS_000 & & & TCONS_000 & ANKRD3 & \\
\hline 20913 & PAN2 & $A F, R I$ & 90198 & NTRK2 & 0 & 51927 & 6 & A5 \\
\hline TCONS_000 & & $\mathrm{A} 3, \mathrm{~A} 5, \mathrm{~A}$ & TCONS_000 & & & TCONS_000 & & \\
\hline 20914 & PAN2 & $\mathrm{F}, \mathrm{RI}$ & 87746 & NTRK2 & SE & 47141 & ZAP70 & $\mathrm{RI}$ \\
\hline TCONS_000 & & $\mathrm{A} 5, \mathrm{AF}$ & TCONS_000 & RP11-21 & & TCONS_000 & & \\
\hline 22789 & PAN2 & $\mathrm{RI}$ & 87748 & $3 G 2.3$ & $\mathrm{O}$ & 51930 & UNC50 & 0 \\
\hline TCONS_000 & & & TCONS_000 & & & TCONS_000 & & \\
\hline 22790 & PAN2 & $A F, R I$ & 87757 & NAA35 & A5 & 47149 & UNC50 & AF \\
\hline TCONS_000 & & $\mathrm{A} 5, \mathrm{AF}$ & TCONS_000 & & & TCONS_000 & & \\
\hline 22792 & PAN2 & $\mathrm{RI}$ & 90243 & CTSL & A5 & 47173 & NPAS2 & A3 \\
\hline TCONS_000 & & & TCONS_000 & & & TCONS_000 & & \\
\hline 22794 & STAT2 & RI & 90246 & C9orf47 & $\mathrm{A} 5, \mathrm{AL}$ & 47189 & MAP4K4 & A3,SE \\
\hline
\end{tabular}




\begin{tabular}{|c|c|c|c|c|c|c|c|c|}
\hline \multicolumn{3}{|l|}{ TCONS_000 } & TCONS_000 & \multicolumn{2}{|l|}{ SECISBP } & \multicolumn{3}{|l|}{ TCONS_000 } \\
\hline 20917 & STAT2 & $\mathrm{RI}$ & 87784 & 2 & A3 & 47200 & IL1R2 & A5 \\
\hline TCONS_000 & & & TCONS_000 & & & TCONS_000 & & \\
\hline 20947 & PRIM1 & $\mathrm{O}$ & 87790 & SYK & A5,SE & 47202 & IL1R2 & A3,A5 \\
\hline TCONS_000 & ARHGA & & TCONS_000 & & & TCONS_000 & & \\
\hline 20974 & P9 & A5,RI & 90257 & WNK2 & SE & 47219 & SLC9A4 & SE \\
\hline TCONS_000 & ARHGA & & TCONS_000 & & & TCONS_000 & & \\
\hline 20975 & P9 & A5 & 90259 & WNK2 & SE & 47230 & C2orf49 & $\mathrm{RI}$ \\
\hline TCONS_000 & OSBPL & & TCONS_000 & & & TCONS_000 & & \\
\hline 21190 & 8 & $\mathrm{O}$ & 87818 & PHF2 & A3 & 47245 & SULT1C2 & $\mathrm{RI}$ \\
\hline TCONS_000 & & & TCONS_000 & & & TCONS_000 & & \\
\hline 22873 & PoC1B & SE & 87819 & PHF2 & $\mathrm{A} 3, \mathrm{RI}$ & 47246 & SULT1C2 & $\mathrm{O}$ \\
\hline TCONS_000 & & & TCONS_000 & & & TCONS_000 & & \\
\hline 21274 & ATP2B1 & $\mathrm{AF}$ & 90267 & PHF2 & $\mathrm{RI}$ & 47274 & RANBP2 & O \\
\hline TCONS_000 & & & TCONS_000 & & & TCONS_000 & & \\
\hline 21277 & EPYC & $\mathrm{O}$ & 87834 & C9orf3 & O & 47286 & BCL2L11 & AF,SE \\
\hline TCONS_000 & & & TCONS_000 & ERCC6L & & TCONS_000 & & \\
\hline 22885 & EEA1 & SE & $87850^{-}$ & 2 & AF,SE & 51987 & SLC20A1 & $\mathrm{O}$ \\
\hline TCONS_000 & & & TCONS_000 & RP11-53 & & TCONS_000 & & \\
\hline 21307 & UBE2N & $\mathrm{O}$ & $90280^{-}$ & $5 \mathrm{M} 15.2$ & $\mathrm{O}$ & 51989 & PSD4 & $\mathrm{A} 3, \mathrm{AF}$ \\
\hline TCONS_000 & & & TCONS_000 & & & TCONS_000 & & \\
\hline 21366 & $\mathrm{NR} 2 \mathrm{C} 1$ & $\mathrm{RI}$ & 90285 & TMOD1 & A3 & 51990 & PSD4 & $A F$ \\
\hline TCONS_000 & & & TCONS_000 & & & TCONS_000 & & $A 3, A F, R$ \\
\hline 22898 & NR2C1 & RI,SE & 87874 & TGFBR1 & AF & 47347 & PSD4 & 1 \\
\hline TCONS_000 & & & TCONS_000 & & & TCONS 000 & & \\
\hline 21378 & NTN4 & A5 & 87880 & TGFBR1 & 0 & 47348 & PSD4 & $A F, R I$ \\
\hline TCONS_000 & & & TCONS_000 & & & TCONS 000 & & \\
\hline 21435 & GLT8D2 & 0 & 87898 & INVS & SE & 47367 & CBWD2 & $\mathrm{RI}, \mathrm{SE}$ \\
\hline TCONS_000 & & & TCONS_000 & & & TCONS_000 & RP11-39 & \\
\hline 21438 & NFYB & AF,SE & 90298 & FSD1L & SE & 51995 & 5L14.5 & $\mathrm{AF}$ \\
\hline TCONS_000 & SLC41A & & TCONS_000 & & & TCONS_000 & & \\
\hline 21445 & 2 & $\mathrm{O}$ & 87963 & FAM206A & 0 & 47373 & WASH2P & A5 \\
\hline TCONS_000 & SLC41A & & TCONS_000 & & & TCONS_000 & AC01098 & \\
\hline 21446 & 2 & $\mathrm{O}$ & 90323 & HSDL2 & SE & 52003 & 2.1 & $A F$ \\
\hline TCONS_000 & & & TCONS_000 & & & TCONS_000 & AC01327 & \\
\hline 21480 & SART3 & RI & 88032 & SLC31A2 & SE & 52012 & 5.2 & SE \\
\hline
\end{tabular}




\begin{tabular}{|c|c|c|c|c|c|c|c|c|}
\hline \multicolumn{3}{|l|}{ TCONS_000 } & \multicolumn{3}{|l|}{ TCONS_000 } & \multicolumn{3}{|l|}{ TCONS_000 } \\
\hline 22941 & SART3 & RI & 90324 & SLC31A2 & A5,SE & 47516 & MYO7B & SE \\
\hline TCONS_000 & & & TCONS_000 & & & TCONS_000 & & \\
\hline 21508 & KCTD10 & A3 & 88042 & RGS3 & A5 & 47519 & MYO7B & RI,SE \\
\hline TCONS_000 & & & TCONS_000 & & & TCONS_000 & & \\
\hline 21550 & VPS29 & SE & 88046 & ZNF618 & SE & 47524 & UGGT1 & A5 \\
\hline TCONS_000 & & A5,AF, & TCONS_000 & PSMD5- & & TCONS_000 & & \\
\hline 21573 & ATXN2 & SE & 88083 & AS1 & SE & 47536 & IMP4 & $\mathrm{O}$ \\
\hline TCONS_000 & & & TCONS_000 & & & TCONS_000 & & \\
\hline 21574 & $\begin{array}{l}\text { ATXN2 } \\
\text { MAPKA }\end{array}$ & AF,SE & 88087 & CNTRL & SE & 52065 & PTPN18 & $\mathrm{RI}$ \\
\hline TCONS_000 & PK5-AS & & TCONS_000 & & & TCONS_000 & ARHGEF & \\
\hline 22959 & $\begin{array}{l}1 \\
\text { MAPKA }\end{array}$ & O & 88092 & GSN & SE & 47553 & 4 & 0 \\
\hline TCONS_000 & PK5-AS & & TCONS_000 & & $\mathrm{A} 3, \mathrm{~A} 5, \mathrm{~A}$ & TCONS_000 & CCDC74 & \\
\hline 21582 & 1 & SE & 88107 & DAB2IP & $\mathrm{F}$ & 47574 & $A$ & 0 \\
\hline TCONS_000 & HECTD & & TCONS_000 & RABGAP & & TCONS_000 & & \\
\hline 22966 & 4 & $\mathrm{RI}$ & 90344 & 1 & A5,SE & 47594 & CCNT2 & A5,SE \\
\hline TCONS_000 & HECTD & & TCONS_000 & & & TCONS_000 & RAB3GA & \\
\hline 21606 & 4 & A5 & 88134 & NEK6 & $\mathrm{O}$ & 52087 & $\mathrm{P} 1$ & $\mathrm{RI}$ \\
\hline TCONS_000 & & & TCONS_000 & & & TCONS_000 & RAB3GA & \\
\hline 22969 & DDX54 & $A 3, R I$ & 88146 & GAPVD1 & A5,SE & 52088 & $\mathrm{P} 1$ & O \\
\hline TCONS_000 & & & TCONS_000 & & & TCONS_000 & RAB3GA & \\
\hline 21624 & SLC8B1 & $\mathrm{O}$ & 88169 & ZBTB34 & SE & 47603 & $\mathrm{P} 1$ & O \\
\hline TCONS_000 & & & TCONS_000 & RALGPS & & TCONS_000 & RAB3GA & \\
\hline 21628 & SDS & $\mathrm{O}$ & 88173 & 1 & A5 & 52089 & $\mathrm{P} 1$ & O \\
\hline TCONS_000 & & & TCONS_000 & RALGPS & & TCONS_000 & RAB3GA & \\
\hline 21629 & SDS & O & 88176 & 1 & AF & 52090 & $\mathrm{P} 1$ & SE \\
\hline TCONS_000 & & & TCONS_000 & & & TCONS_000 & & \\
\hline 21658 & KSR2 & 0 & 88179 & GARNL3 & AF & 52092 & R3HDM1 & SE \\
\hline TCONS_000 & & & TCONS_000 & & & TCONS_000 & & \\
\hline 22983 & TAOK3 & AF & 88181 & SLC2A8 & $\mathrm{RI}$ & 52093 & UBXN4 & RI \\
\hline TCONS_000 & & & TCONS_000 & & & TCONS_000 & & \\
\hline 21672 & CIT & A3,SE & 88184 & ZNF79 & 0 & 52096 & SPOPL & A3 \\
\hline TCONS_000 & GCN1L & & TCONS_000 & & & TCONS_000 & & \\
\hline 22985 & 1 & RI & 88202 & FPGS & $\mathrm{O}$ & 47624 & SPOPL & A3,SE \\
\hline
\end{tabular}




\begin{tabular}{|c|c|c|c|c|c|c|c|c|}
\hline TCONS_000 & GCN1L & & TCONS_000 & & & TCONS_000 & & \\
\hline 22986 & 1 & 0 & 90366 & LCN2 & SE & 47659 & MBD5 & A5 \\
\hline TCONS_000 & GCN1L & & TCONS_000 & & & TCONS_000 & & \\
\hline 22987 & 1 & RI & 90378 & SPTAN1 & SE & 47672 & LYPD6B & 0 \\
\hline TCONS_000 & GCN1L & & TCONS_000 & & $A 3, R I, S$ & TCONS_000 & & \\
\hline 22988 & 1 & $\mathrm{RI}$ & 90379 & SPTAN1 & E & 47683 & FMNL2 & RI,SE \\
\hline TCONS_000 & & & TCONS_000 & & & TCONS_000 & & \\
\hline 21704 & PXN & SE & 88260 & SPTAN1 & SE & 52109 & FMNL2 & SE \\
\hline TCONS_000 & & & TCONS_000 & & & TCONS_000 & & \\
\hline 21705 & PXN & SE & 88261 & SPTAN1 & $\mathrm{RI}, \mathrm{SE}$ & 47716 & MARCH7 & $\mathrm{O}$ \\
\hline TCONS_000 & & & TCONS_000 & & & TCONS_000 & & \\
\hline 21707 & PXN & $\mathrm{O}$ & 88262 & SET & $\mathrm{O}$ & 52161 & ERICH2 & $\mathrm{O}$ \\
\hline TCONS_000 & & & TCONS_000 & & & TCONS_000 & AC00740 & \\
\hline 22990 & PXN & SE & 90382 & TBC1D13 & SE & 47780 & 5.6 & O \\
\hline TCONS_000 & & & TCONS_000 & & & TCONS_000 & & \\
\hline 22991 & PXN & SE & 88281 & FAM73B & A5,SE & 47781 & ERICH2 & O \\
\hline TCONS_000 & HNF1A- & & TCONS_000 & & & TCONS_000 & & \\
\hline 22999 & AS1 & $\mathrm{O}$ & 90384 & FAM73B & $\mathrm{O}$ & 47790 & DCAF17 & SE \\
\hline TCONS 000 & C12orf4 & & TCONS 000 & LINC009 & & TCONS 000 & & \\
\hline 21753 & 3 & SE & 88303 & 63 & A3 & 47897 & AGPS & A5 \\
\hline TCONS_000 & & & TCONS_000 & RP11-49 & & TCONS_000 & & \\
\hline 21768 & KDM2B & SE & 88308 & 2E3.2 & $\mathrm{RI}$ & 52179 & RBM45 & $\mathrm{RI}$ \\
\hline TCONS_000 & RP11-5 & & TCONS 000 & RP11-49 & & TCONS 000 & & \\
\hline 21781 & $12 \mathrm{M} 8.5$ & SE & 88309 & 2E3.2 & $\mathrm{RI}, \mathrm{SE}$ & 52215 & ANKAR & SE \\
\hline TCONS_000 & & & TCONS 000 & & & TCONS 000 & AC09338 & \\
\hline 21790 & CLIP1 & AF,SE & 88351 & NUP214 & A3 & 48069 & 8.3 & SE \\
\hline TCONS_000 & $\mathrm{ZCCHC}$ & & TCONS_000 & & & TCONS_000 & & \\
\hline 23021 & 8 & RI & 88352 & NUP214 & A3 & 52222 & NAB1 & A5 \\
\hline TCONS_000 & & & TCONS_000 & & & TCONS_000 & & \\
\hline 21801 & RSRC2 & $A 3, R I$ & 88355 & PRRC2B & A3 & 52243 & NIF3L1 & 0 \\
\hline TCONS_000 & & & TCONS_000 & & & TCONS_000 & AC00503 & \\
\hline 21800 & RSRC2 & SE & 90411 & PRRC2B & A3,SE & 48178 & 7.3 & 0 \\
\hline TCONS_000 & PITPNM & & TCONS_000 & & & TCONS_000 & & \\
\hline 21818 & 2 & 0 & 88359 & POMT1 & A5,RI & 48202 & CASP8 & SE \\
\hline TCONS_000 & PITPNM & & TCONS_000 & & & TCONS_000 & & \\
\hline 23028 & 2 & 0 & 90415 & C9orf9 & $A 3, A F$ & 48211 & CASP8 & SE \\
\hline
\end{tabular}




\begin{tabular}{|c|c|c|c|c|c|c|c|c|}
\hline \multicolumn{3}{|l|}{ TCONS_000 } & \multicolumn{3}{|l|}{ TCONS 000} & \multicolumn{3}{|l|}{ TCONS_000 } \\
\hline $21837^{-}$ & RILPL2 & SE & $88387^{-}$ & SURF2 & A5 & $52259^{-}$ & NBEAL1 & SE \\
\hline TCONS_000 & & & TCONS_000 & & & TCONS_000 & & \\
\hline 23034 & EIF2B1 & $\mathrm{O}$ & 88388 & SURF2 & RI & 48255 & $A B I 2$ & SE \\
\hline TCONS_000 & CCDC9 & & TCONS_000 & ADAMTS & & TCONS_000 & & \\
\hline 21845 & 2 & 0 & 88395 & $\mathrm{~L} 2$ & A3 & 52266 & ZDBF2 & $\mathrm{AF}, \mathrm{SE}$ \\
\hline TCONS_000 & & & TCONS_000 & & & TCONS_000 & & \\
\hline 21855 & NCOR2 & $\mathrm{A} 3, \mathrm{SE}$ & 90420 & WDR5 & $\mathrm{RI}$ & 52268 & ZDBF2 & AF,SE \\
\hline TCONS_000 & & & TCONS_000 & & & TCONS_000 & AC00787 & \\
\hline 21875 & UBC & $\mathrm{O}$ & 90421 & WDR5 & $\mathrm{AF}$ & 48319 & 9.7 & $\mathrm{O}$ \\
\hline TCONS_000 & & & TCONS_000 & & & TCONS_000 & & \\
\hline 23051 & POLE & $\mathrm{O}$ & 88411 & PPP1R26 & $\mathrm{AF}$ & 52285 & CREB1 & SE \\
\hline TCONS_000 & & & TCONS_000 & & & TCONS_000 & AC07976 & \\
\hline 21917 & POLE & $\mathrm{A} 3, \mathrm{RI}$ & 90430 & PMPCA & $\mathrm{O}$ & 48325 & 7.4 & $\mathrm{O}$ \\
\hline TCONS_000 & GOLGA & & TCONS_000 & & $A F, R I, S$ & TCONS_000 & & \\
\hline 21924 & 3 & $\mathrm{~A} 5, \mathrm{AF}$ & 90431 & EGFL7 & E & 52287 & PIKFYVE & $\mathrm{RI}, \mathrm{SE}$ \\
\hline TCONS_000 & GOLGA & & TCONS_000 & & & TCONS_000 & & \\
\hline 21926 & 3 & A5 & 88425 & EGFL7 & $\mathrm{RI}$ & 52289 & MAP2 & 0 \\
\hline TCONS 000 & GOLGA & & TCONS 000 & KIAA198 & & TCONS 000 & AC00703 & \\
\hline 23053 & 3 & $\mathrm{O}$ & 90435 & 4 & A3 & 48358 & 8.7 & $\mathrm{O}$ \\
\hline TCONS_000 & & & TCONS_000 & & & TCONS_000 & AC00703 & \\
\hline 21932 & CHFR & $\mathrm{O}$ & 88432 & RABL6 & SE & 48359 & 8.7 & $\mathrm{O}$ \\
\hline TCONS_000 & & & TCONS_000 & & & TCONS_000 & & \\
\hline 21933 & CHFR & SE & 90438 & MAMDC4 & $\mathrm{RI}, \mathrm{SE}$ & 48361 & CPS1 & SE \\
\hline TCONS_000 & & & TCONS_000 & & & TCONS_000 & & \\
\hline 21935 & CHFR & $\mathrm{RI}$ & 90439 & MAMDC4 & $\mathrm{RI}$ & 48362 & CPS1 & 0 \\
\hline TCONS_000 & & $A F, R I, S$ & TCONS_000 & & & TCONS_000 & & \\
\hline 23074 & ZMYM2 & $\mathrm{E}$ & 90440 & MAMDC4 & $\mathrm{RI}$ & 48364 & CPS1 & $\mathrm{O}$ \\
\hline TCONS_000 & & & TCONS_000 & & & TCONS_000 & & \\
\hline 24328 & ZMYM2 & $A F, R I$ & 88435 & PHPT1 & AF,SE & 52294 & CPS1 & $\mathrm{RI}$ \\
\hline TCONS_000 & & & TCONS_000 & & & TCONS_000 & & \\
\hline 23082 & IFT88 & RI,SE & 88436 & PHPT1 & SE & 48366 & CPS1 & $A F$ \\
\hline TCONS_000 & & & TCONS_000 & & & TCONS_000 & & \\
\hline 23086 & IL17D & AF & 88447 & C9orf142 & A5,RI & 48426 & SLC11A1 & $\mathrm{RI}$ \\
\hline TCONS_000 & MIPEPP & A5,AL, & TCONS_000 & & & TCONS_000 & & \\
\hline 23093 & 3 & $\mathrm{RI}$ & 88446 & C9orf142 & $\mathrm{O}$ & 48428 & SLC11A1 & RI \\
\hline
\end{tabular}




\begin{tabular}{|c|c|c|c|c|c|c|c|c|}
\hline \multirow{2}{*}{$\begin{array}{l}\text { TCONS_000 } \\
24331\end{array}$} & \multicolumn{2}{|l|}{ MIPEPP } & \multicolumn{3}{|l|}{ TCONS_000 } & \multicolumn{3}{|l|}{ TCONS_000 } \\
\hline & 3 & A5 & 90446 & C9orf142 & 0 & 48440 & VIL1 & $\mathrm{RI}$ \\
\hline TCONS_000 & & & TCONS_000 & & & TCONS_000 & & \\
\hline 23169 & USPL1 & SE & 88452 & UAP1L1 & $\mathrm{RI}$ & 48448 & BCS1L & A5,RI \\
\hline TCONS_000 & & & TCONS_000 & & & TCONS_000 & & $A F, R I, S$ \\
\hline 23179 & FRY & 0 & 90447 & UAP1L1 & 0 & 48456 & STK36 & $\mathrm{E}$ \\
\hline TCONS_000 & & & TCONS_000 & & & TCONS_000 & & \\
\hline 24403 & NAA16 & SE & 88476 & NELFB & $\mathrm{O}$ & 52313 & TTLL4 & $\mathrm{RI}$ \\
\hline TCONS_000 & & & TCONS_000 & & & TCONS_000 & & \\
\hline 24404 & NAA16 & SE & 88482 & NOXA1 & $A 3, R I$ & 48476 & ANKZF1 & $\mathrm{RI}$ \\
\hline TCONS_000 & & & TCONS_000 & & & TCONS_000 & & \\
\hline 24405 & NAA16 & A5,RI & 88484 & NOXA1 & $A 3, R I$ & 52320 & ANKZF1 & $\mathrm{O}$ \\
\hline TCONS_000 & & & TCONS_000 & & & TCONS_000 & & \\
\hline 23235 & NAA16 & $\mathrm{RI}, \mathrm{SE}$ & 90452 & NOXA1 & A3 & 52321 & ANKZF1 & $\mathrm{RI}$ \\
\hline TCONS_000 & & & TCONS_000 & & & TCONS_000 & & \\
\hline 23238 & RGCC & $\mathrm{O}$ & $90453^{-}$ & NOXA1 & $\mathrm{RI}$ & 52322 & ANKZF1 & $\mathrm{RI}$ \\
\hline TCONS_000 & & & TCONS_000 & & & TCONS_000 & & \\
\hline 24414 & AKAP11 & SE & $90454^{-}$ & ARRDC1 & $\mathrm{O}$ & 52324 & DNAJB2 & $\mathrm{RI}$ \\
\hline TCONS_000 & & & TCONS_000 & & & TCONS_000 & & \\
\hline 23246 & AKAP11 & AF,SE & $88490^{-}$ & EHMT1 & A3 & 52325 & DES & $\mathrm{O}$ \\
\hline TCONS_000 & & & TCONS_000 & & & TCONS_000 & & \\
\hline 24415 & AKAP11 & SE & 88493 & FAM157B & $\mathrm{O}$ & 52329 & GMPPA & $\mathrm{RI}$ \\
\hline TCONS_000 & TPT1-A & & TCONS_000 & & & TCONS 000 & TMEM19 & $A 3, R I, S$ \\
\hline 23279 & S1 & $\mathrm{A} 3, \mathrm{SE}$ & 88516 & RFX3 & SE & 52330 & 8 & $\mathrm{E}$ \\
\hline TCONS_000 & & & TCONS_000 & & & TCONS_000 & & \\
\hline 23334 & TRIM13 & SE & 88540 & RLN2 & 0 & 48497 & STK11IP & $\mathrm{RI}$ \\
\hline TCONS_000 & RNASE & & TCONS_000 & & & TCONS 000 & & \\
\hline 23349 & $\mathrm{H} 2 \mathrm{~B}$ & A5 & 88542 & PLGRKT & $\mathrm{AF}$ & 48498 & STK11IP & 0 \\
\hline TCONS_000 & RNASE & & TCONS_000 & & & TCONS_000 & & \\
\hline 24444 & $\mathrm{H} 2 \mathrm{~B}$ & A5 & 90492 & ERMP1 & $\mathrm{O}$ & 52332 & STK11IP & $\mathrm{RI}$ \\
\hline TCONS_000 & PCDH1 & & TCONS_000 & & & TCONS_000 & & \\
\hline 23378 & 7 & $\mathrm{O}$ & 88577 & MPDZ & SE & 48503 & SGPP2 & $A F$ \\
\hline TCONS_000 & & & TCONS_000 & RP11-53 & & TCONS_000 & & \\
\hline 23381 & TDRD3 & A3,A5 & 88582 & 6018.2 & $\mathrm{O}$ & 52334 & COL4A3 & AF,SE \\
\hline TCONS_000 & & & TCONS_000 & & & TCONS_000 & & \\
\hline 24460 & TDRD3 & A3 & 90511 & PSIP1 & A3 & 48572 & ITM2C & $\mathrm{O}$ \\
\hline
\end{tabular}




\begin{tabular}{|c|c|c|c|c|c|c|c|c|}
\hline \multicolumn{3}{|l|}{ TCONS_000 } & \multicolumn{3}{|l|}{ TCONS_000 } & \multicolumn{3}{|l|}{ TCONS_000 } \\
\hline 23398 & BORA & O & 90512 & PSIP1 & $\mathrm{RI}$ & 48631 & GIGYF2 & MX,SE \\
\hline TCONS_000 & RP11-2 & & TCONS_000 & & & TCONS_000 & & \\
\hline 23412 & $9 G 8.3$ & RI & 90515 & KLHL9 & 0 & 52352 & GIGYF2 & SE \\
\hline TCONS_000 & & & TCONS_000 & & & TCONS_000 & & \\
\hline 23427 & CLN5 & 0 & 88727 & APTX & $\mathrm{AF}$ & 48656 & DGKD & SE \\
\hline TCONS_000 & & & TCONS_000 & RP11-13 & & TCONS_000 & & \\
\hline 23428 & SCEL & 0 & 88766 & 3022.6 & $\mathrm{AL}$ & 52364 & ACKR3 & $\mathrm{O}$ \\
\hline TCONS_000 & & & TCONS_000 & & & TCONS_000 & & \\
\hline 23500 & CLYBL & $\mathrm{O}$ & 90569 & UBAP2 & $\mathrm{RI}$ & 48681 & ACKR3 & $\mathrm{O}$ \\
\hline TCONS_000 & & & TCONS_000 & & & TCONS_000 & & \\
\hline 23501 & CLYBL & O & 88813 & FANCG & A3 & 48682 & ACKR3 & $\mathrm{O}$ \\
\hline TCONS_000 & & & TCONS_000 & & & TCONS_000 & & \\
\hline 23505 & PCCA & $\mathrm{O}$ & 88814 & FANCG & $\mathrm{RI}$ & 52365 & ACKR3 & $\mathrm{O}$ \\
\hline TCONS_000 & BIVM-E & & TCONS_000 & & & TCONS_000 & & \\
\hline 24503 & RCC5 & A5 & 88815 & FANCG & $\mathrm{O}$ & 48739 & CAPN10 & $\mathrm{RI}$ \\
\hline TCONS_000 & BIVM-E & & TCONS_000 & & & TCONS_000 & & \\
\hline 23519 & RCC5 & A5 & 88820 & FAM214B & RI & 48740 & CAPN10 & $\mathrm{O}$ \\
\hline TCONS_000 & & & TCONS_000 & & & TCONS_000 & & \\
\hline 23541 & COL4A2 & $\mathrm{RI}$ & 88821 & FAM214B & RI & 48744 & GPR35 & $\mathrm{A} 3, \mathrm{AL}$ \\
\hline TCONS_000 & & & TCONS_000 & & & TCONS_000 & AC01129 & \\
\hline 23547 & CARKD & $\mathrm{A} 3, \mathrm{AF}$ & 88832 & CD72 & RI & 52405 & 8.2 & A5 \\
\hline TCONS_000 & & & TCONS_000 & & & TCONS_000 & AC01129 & \\
\hline 24512 & CARKD & $A F$ & 90589 & GBA2 & $\mathrm{O}$ & 52406 & 8.2 & $\mathrm{O}$ \\
\hline TCONS_000 & ARHGE & & TCONS_000 & & & TCONS_000 & AC01129 & \\
\hline 23558 & $\mathrm{~F} 7$ & $\mathrm{RI}, \mathrm{SE}$ & 88853 & GBA2 & RI & 52407 & 8.2 & $\mathrm{O}$ \\
\hline TCONS_000 & & & TCONS_000 & & & TCONS_000 & & \\
\hline 23578 & MCF2L & $\mathrm{RI}$ & 88854 & GBA2 & $\mathrm{RI}$ & 52412 & AQP12A & SE \\
\hline TCONS_000 & & & TCONS_000 & ANKRD1 & & TCONS_000 & & \\
\hline 24523 & MCF2L & A5 & 88894 & $8 \mathrm{~A}$ & $\mathrm{O}$ & 52413 & AQP12A & SE \\
\hline TCONS_000 & TMEM2 & & TCONS_000 & RP11-29 & & TCONS_000 & & \\
\hline 23601 & $55 B$ & 0 & 88901 & 2B8.1 & 0 & 48750 & SNED1 & 0 \\
\hline TCONS_000 & & & TCONS_000 & BMS1P1 & & TCONS_000 & & \\
\hline 24538 & CDC16 & RI & 88983 & 0 & SE & 48761 & ANO7 & RI \\
\hline TCONS_000 & CDC16 & A3,RI & TCONS_000 & BMS1P1 & SE & TCONS_000 & SEPT2 & SE \\
\hline
\end{tabular}




\begin{tabular}{|c|c|c|c|c|c|c|c|c|}
\hline 24539 & & & 88984 & 0 & & 48764 & & \\
\hline TCONS_000 & & & TCONS_000 & BMS1P1 & & TCONS_000 & & \\
\hline 24540 & CDC16 & $\mathrm{RI}$ & 90629 & 0 & $\mathrm{O}$ & 48767 & FARP2 & A5 \\
\hline TCONS_000 & & & TCONS_000 & RP11-76 & & TCONS_000 & & \\
\hline 23612 & UPF3A & RI & 88999 & $4 \mathrm{~K} 9.4$ & RI & 52422 & BOK & $\mathrm{O}$ \\
\hline TCONS_000 & & & TCONS_000 & & & TCONS_000 & & \\
\hline 23613 & UPF3A & A5 & 89130 & ZFAND5 & $\mathrm{O}$ & 52423 & BOK & $\mathrm{O}$ \\
\hline TCONS_000 & & & TCONS_000 & & & TCONS_000 & AC13352 & \\
\hline 23617 & UPF3A & RI,SE & 90690 & C9orf41 & A5 & 48787 & 8.2 & $\mathrm{O}$ \\
\hline TCONS_000 & & & TCONS_000 & & & TCONS_000 & & A3,A5, \\
\hline 23620 & CHAMP1 & A3 & 89149 & NMRK1 & A3 & 52433 & D2HGDH & $\mathrm{RI}$ \\
\hline TCONS_000 & & & TCONS_000 & & & TCONS_000 & & \\
\hline 23621 & CHAMP1 & A3 & 89151 & NMRK1 & $\mathrm{O}$ & 48792 & D2HGDH & A3,RI \\
\hline TCONS_000 & & & TCONS_000 & & & TCONS_000 & & \\
\hline 23637 & GJB6 & $\mathrm{O}$ & 89152 & NMRK1 & A5 & 48812 & FAM150B & A3 \\
\hline TCONS_000 & & & TCONS_000 & & & TCONS_000 & & \\
\hline 23638 & GJB6 & SE & 90695 & PRUNE2 & A3,SE & 48813 & FAM150B & A3 \\
\hline TCONS_000 & & & TCONS_000 & & & TCONS_000 & & \\
\hline 23639 & GJB6 & AF,SE & 89163 & PRUNE2 & A3 & 52442 & FAM150B & $\mathrm{A} 3, \mathrm{SE}$ \\
\hline TCONS_000 & & & TCONS_000 & & & TCONS_000 & & $\mathrm{A} 3, \mathrm{AF}$ \\
\hline 23647 & XPO4 & SE & 89165 & PRUNE2 & A3 & 52443 & FAM150B & $\mathrm{RI}$ \\
\hline TCONS_000 & & & TCONS_000 & & & TCONS_000 & & \\
\hline 24546 & LATS2 & RI & 89170 & PRUNE2 & A5 & 52444 & FAM150B & $\mathrm{A} 3, \mathrm{AF}$ \\
\hline TCONS_000 & & & TCONS_000 & & & TCONS_000 & & \\
\hline 23665 & CENPJ & A3 & 90702 & TLE1 & RI & 52445 & FAM150B & $\mathrm{O}$ \\
\hline TCONS_000 & & & TCONS_000 & & & TCONS_000 & KIDINS2 & \\
\hline 24551 & RNF6 & $A F$ & 90707 & TLE1 & $\mathrm{O}$ & 48875 & 20 & A3,SE \\
\hline TCONS_000 & & & TCONS_000 & & & TCONS_000 & & \\
\hline 23690 & MTIF3 & SE & 90744 & GKAP1 & SE & 52476 & ROCK2 & $\mathrm{AF}$ \\
\hline TCONS_000 & & & TCONS_000 & & & TCONS_000 & & \\
\hline 23692 & MTIF3 & SE & 90746 & KIF27 & $\mathrm{RI}, \mathrm{SE}$ & 52487 & NBAS & SE \\
\hline TCONS_000 & & & TCONS_000 & & & TCONS_000 & & \\
\hline 24561 & MTIF3 & SE & 89262 & SEMA4D & AF,SE & 49055 & SF3B14 & $\mathrm{O}$ \\
\hline TCONS_000 & & & TCONS_000 & & & TCONS_000 & & \\
\hline 24563 & MTIF3 & SE & 89263 & SEMA4D & $\mathrm{AF}, \mathrm{RI}$ & 52508 & TP53I3 & $A 3, R I$ \\
\hline
\end{tabular}




\begin{tabular}{|c|c|c|c|c|c|c|c|c|}
\hline \multicolumn{3}{|l|}{ TCONS_000 } & TCONS_000 & \multicolumn{2}{|l|}{ RP11-36 } & \multicolumn{3}{|l|}{ TCONS_000 } \\
\hline 23700 & LNX2 & A5 & 89268 & 7F23.1 & $\mathrm{O}$ & 49064 & ITSN2 & A5,SE \\
\hline TCONS_000 & SLC46A & & TCONS_000 & & & TCONS_000 & & \\
\hline 23708 & 3 & $\mathrm{O}$ & 89293 & NOL8 & A5 & 49065 & ITSN2 & SE \\
\hline TCONS_000 & & & TCONS_000 & & & TCONS_000 & & \\
\hline 24578 & FRY-AS1 & $\mathrm{O}$ & 89294 & NOL8 & SE & 49070 & ADCY3 & $\mathrm{O}$ \\
\hline TCONS_000 & STARD1 & & TCONS_000 & & & TCONS_000 & & \\
\hline 23755 & 3 & AF & 89305 & ECM2 & A3 & 52510 & ADCY3 & $\mathrm{O}$ \\
\hline TCONS_000 & SUPT20 & & TCONS_000 & & & TCONS_000 & & A5,RI, \\
\hline 23778 & $\mathrm{H}$ & A3 & 89306 & ECM2 & A3 & 52516 & DNMT3A & SE \\
\hline TCONS_000 & SUPT20 & A3, RI, & TCONS_000 & & & TCONS_000 & & \\
\hline 24593 & $\mathrm{H}$ & SE & 90781 & ECM2 & $\mathrm{O}$ & 52519 & DTNB & SE \\
\hline TCONS_000 & LINC010 & & TCONS_000 & & & TCONS_000 & & \\
\hline 23785 & 48 & $\mathrm{RI}$ & 90782 & ECM2 & A3 & 49080 & DTNB & RI,SE \\
\hline TCONS_000 & FREM2- & & TCONS_000 & & & TCONS_000 & & \\
\hline 24622 & AS1 & $\mathrm{O}$ & 89360 & FBP1 & A3 & 49108 & SLC5A6 & AF,SE \\
\hline TCONS_000 & & & TCONS_000 & & & TCONS_000 & & \\
\hline 24638 & ELF1 & $\mathrm{AF}$ & 90790 & FBP1 & SE & 52533 & SLC5A6 & SE \\
\hline TCONS_000 & & & TCONS_000 & RP11-43 & & TCONS_000 & & \\
\hline 24640 & MTRF1 & $\mathrm{O}$ & 89367 & 505.2 & $\mathrm{AL}$ & 49110 & MPV17 & $\mathrm{O}$ \\
\hline TCONS_000 & & & TCONS_000 & & & TCONS_000 & & \\
\hline 24641 & MTRF1 & O & 89387 & AAED1 & SE & 52536 & MPV17 & A3 \\
\hline TCONS_000 & & & TCONS_000 & & & TCONS_000 & & \\
\hline 24645 & MTRF1 & A5,AF & 90816 & HIATL2 & $\mathrm{O}$ & 49113 & GTF3C2 & O \\
\hline TCONS_000 & & & TCONS_000 & & & TCONS_000 & & \\
\hline 24650 & VWA8 & $\mathrm{RI}$ & 89399 & HIATL2 & O & 52541 & EIF2B4 & RI \\
\hline TCONS_000 & CCDC12 & & TCONS_000 & RP11-49 & & TCONS_000 & & \\
\hline 23885 & 2 & $\mathrm{O}$ & 89403 & 8P14.3 & $\mathrm{O}$ & 49121 & ZNF513 & RI \\
\hline TCONS_000 & & & TCONS_000 & & & TCONS_000 & & \\
\hline 23920 & ZC3H13 & A3 & 90818 & TSTD2 & $\mathrm{O}$ & 49131 & IFT172 & RI,SE \\
\hline TCONS_000 & & & TCONS_000 & & & TCONS_000 & & \\
\hline 23922 & ZC3H13 & $\mathrm{O}$ & 89408 & XPA & A5,SE & 52543 & IFT172 & $\mathrm{O}$ \\
\hline TCONS_000 & & & TCONS_000 & & & TCONS_000 & & \\
\hline 23929 & LCP1 & $\mathrm{O}$ & 89430 & TBC1D2 & A3 & 49134 & IFT172 & RI \\
\hline TCONS_000 & & & TCONS_000 & & & TCONS_000 & TRMT61 & \\
\hline 23927 & LCP1 & $\mathrm{O}$ & 90833 & ANKS6 & A3 & 49161 & $\mathrm{~B}$ & $\mathrm{O}$ \\
\hline
\end{tabular}




\begin{tabular}{|c|c|c|c|c|c|c|c|c|}
\hline \multicolumn{3}{|l|}{ TCONS_000 } & \multicolumn{3}{|l|}{ TCONS_000 } & \multicolumn{3}{|l|}{ TCONS_000 } \\
\hline 23945 & SUCLA2 & SE & 90849 & TEX10 & RI & 49185 & MEMO1 & O \\
\hline TCONS_000 & & & TCONS_000 & RP11-19 & & TCONS_000 & & \\
\hline 24003 & INTS6 & 0 & 89466 & 6118.4 & $\mathrm{RI}$ & 49215 & STRN & $\mathrm{O}$ \\
\hline TCONS_000 & & & TCONS_000 & & & TCONS_000 & HEATR5 & \\
\hline 24021 & NEK3 & $\mathrm{O}$ & 89469 & KLF4 & $\mathrm{RI}$ & 52554 & B & RI \\
\hline TCONS_000 & & & TCONS_000 & & & TCONS_000 & & \\
\hline 24685 & NEK3 & $\mathrm{RI}$ & 89474 & IKBKAP & $\mathrm{RI}$ & 49221 & EIF2AK2 & A3 \\
\hline TCONS_000 & RP11-17 & & TCONS_000 & TMEM24 & & TCONS_000 & & \\
\hline 24715 & 3B14.5 & $\mathrm{O}$ & 89480 & 5 & SE & 49224 & CEBPZ & $\mathrm{RI}$ \\
\hline TCONS_000 & & & TCONS_000 & KIAA036 & & TCONS_000 & & \\
\hline 24723 & MYCBP2 & A5,SE & 89512 & 8 & $\mathrm{RI}$ & 49228 & PRKD3 & $A F$ \\
\hline TCONS_000 & & & TCONS_000 & KIAA036 & & TCONS_000 & AC00922 & \\
\hline 24092 & MYCBP2 & A5 & 89513 & 8 & $\mathrm{O}$ & 49240 & 9.5 & $\mathrm{O}$ \\
\hline TCONS_000 & & & TCONS_000 & KIAA036 & & TCONS_000 & & \\
\hline 24724 & MYCBP2 & A5,SE & 89509 & 8 & $\mathrm{O}$ & 52587 & FTOP1 & $\mathrm{O}$ \\
\hline TCONS_000 & & & TCONS_000 & KIAA036 & & TCONS_000 & AC01673 & \\
\hline 24093 & MYCBP2 & A5,SE & 89510 & 8 & $\mathrm{O}$ & 49350 & 5.1 & $\mathrm{O}$ \\
\hline TCONS_000 & & & TCONS_000 & & A5,RI, & TCONS_000 & & \\
\hline 24095 & MYCBP2 & A5 & 90887 & KIF12 & SE & 49363 & THADA & A5 \\
\hline TCONS_000 & & & TCONS_000 & & & TCONS_000 & & \\
\hline 24102 & RBM26 & SE & 89581 & TNC & SE & 52593 & PREPL & AF \\
\hline TCONS_000 & SLC15A & & TCONS_000 & & & TCONS_000 & & \\
\hline 24766 & 1 & RI & 89582 & TNC & $\mathrm{O}$ & 52598 & PIGF & A3,SE \\
\hline TCONS_000 & & & TCONS_000 & & & TCONS_000 & & \\
\hline 24194 & GGACT & SE & 89583 & TNC & SE & 49535 & EFEMP1 & SE \\
\hline TCONS_000 & & & TCONS_000 & & & TCONS_000 & AC01130 & \\
\hline 24215 & ARGLU1 & $A F$ & 90901 & FBXW2 & A5 & 52683 & 6.2 & AF \\
\hline TCONS_000 & & & TCONS_000 & & & TCONS_000 & AC01130 & \\
\hline 24223 & LIG4 & 0 & 89619 & C5 & $\mathrm{O}$ & 52684 & 6.2 & AF,SE \\
\hline TCONS_000 & & & TCONS_000 & & & TCONS_000 & & \\
\hline 24224 & LIG4 & $\mathrm{O}$ & 89621 & C5 & O & 49554 & FANCL & A5 \\
\hline TCONS_000 & & & TCONS_000 & & & TCONS_000 & & \\
\hline 24774 & LIG4 & $\mathrm{O}$ & 89652 & ZBTB26 & A5 & 52737 & XPO1 & A5 \\
\hline TCONS_000 & MCF2L- & & TCONS_000 & & & TCONS_000 & & \\
\hline 24299 & AS1 & A3 & 90920 & STRBP & $\mathrm{O}$ & 52738 & XPO1 & AF \\
\hline
\end{tabular}




\begin{tabular}{|c|c|c|c|c|c|c|c|c|}
\hline TCONS_000 & & & TCONS_000 & & & TCONS_000 & AC00807 & \\
\hline 24309 & GRTP1 & $\mathrm{O}$ & 89672 & GOLGA1 & $\mathrm{O}$ & 52761 & 4.3 & $\mathrm{O}$ \\
\hline TCONS_000 & DCUN1D & & TCONS_000 & & & TCONS_000 & & \\
\hline 24313 & 2 & $\mathrm{O}$ & 89704 & TOR2A & $\mathrm{O}$ & 52774 & SPRED2 & $\mathrm{O}$ \\
\hline TCONS_000 & DCUN1D & & TCONS_000 & & & TCONS_000 & & \\
\hline 24314 & 2 & SE & 89736 & NAIF1 & 0 & 49693 & FBXO48 & A3 \\
\hline TCONS_000 & & & TCONS_000 & & $A F, R I$, & TCONS_000 & & \\
\hline 24320 & RASA3 & RI & 90939 & PTGES2 & $\mathrm{SE}$ & 49706 & AAK1 & $\mathrm{O}$ \\
\hline TCONS_000 & AL58974 & & TCONS_000 & & & TCONS_000 & & \\
\hline 27362 & 3.1 & AL,SE & 90940 & PTGES2 & $\mathrm{RI}, \mathrm{SE}$ & 52802 & AAK1 & 0 \\
\hline TCONS_000 & AL58974 & & TCONS_000 & & & TCONS_000 & & \\
\hline 24818 & 3.1 & AL & 90942 & ClZ1 & $\mathrm{RI}, \mathrm{SE}$ & 49727 & TIA1 & A5,SE \\
\hline TCONS_000 & AL58974 & $\mathrm{A} 3, \mathrm{AL}$ & TCONS_000 & & & TCONS_000 & & \\
\hline 24819 & 3.1 & SE & 89749 & GOLGA2 & SE & 49750 & FAM136A & A5 \\
\hline TCONS_000 & & & TCONS_000 & & & TCONS_000 & & \\
\hline 24829 & PARP2 & A5,RI & 89768 & ZER1 & A5 & 49767 & MCEE & 0 \\
\hline TCONS_000 & & & TCONS_000 & SH3GLB & & TCONS_000 & & \\
\hline 27364 & PARP2 & O & 90958 & 2 & RI,SE & 49776 & SFXN5 & O \\
\hline TCONS_000 & & & TCONS_000 & & & TCONS_000 & & \\
\hline 27365 & PARP2 & SE & 89791 & PTGES & SE & 52816 & SFXN5 & O \\
\hline TCONS_000 & METTL1 & & TCONS_000 & & & TCONS_000 & & \\
\hline 24861 & 7 & $\mathrm{RI}$ & 89831 & DDX31 & $\mathrm{RI}$ & 49814 & RTKN & RI \\
\hline TCONS_000 & METTL1 & & TCONS_000 & & & TCONS_000 & & \\
\hline 27367 & 7 & $A 3, R I$ & 89849 & $A B O$ & $\mathrm{O}$ & 52823 & RTKN & $\mathrm{RI}$ \\
\hline TCONS_000 & METTL1 & & TCONS_000 & & & TCONS_000 & & \\
\hline 27368 & 7 & $A 3, R I$ & 89850 & $\mathrm{ABO}$ & $\mathrm{O}$ & 52824 & RTKN & $\mathrm{RI}$ \\
\hline TCONS_000 & ARHGEF & & TCONS_000 & & & TCONS_000 & & \\
\hline 24865 & 40 & $A F, R I$ & 89864 & REXO4 & A3 & 49833 & DQX1 & $\mathrm{O}$ \\
\hline TCONS_000 & ARHGEF & & TCONS_000 & SDCCAG & & TCONS_000 & & \\
\hline 24867 & 40 & $\mathrm{O}$ & 89892 & 3 & $\mathrm{O}$ & 49840 & LOXL3 & $\mathrm{RI}$ \\
\hline TCONS_000 & ARHGEF & & TCONS_000 & SDCCAG & & TCONS_000 & & \\
\hline 27369 & 40 & O & 89893 & 3 & $\mathrm{RI}$ & 52839 & REG1P & O \\
\hline TCONS_000 & TRAV12- & & TCONS_000 & SDCCAG & & TCONS_000 & & \\
\hline 24888 & 3 & O & 89894 & 3 & A5 & 52840 & REG1P & A3 \\
\hline TCONS_000 & & & TCONS_000 & SDCCAG & & TCONS_000 & & \\
\hline 24898 & TRDC & 0 & 90988 & 3 & SE & 52841 & REG1P & A3,A5 \\
\hline
\end{tabular}




\begin{tabular}{|c|c|c|c|c|c|c|c|c|}
\hline \multicolumn{3}{|l|}{ TCONS_000 } & TCONS_000 & \multicolumn{2}{|l|}{ SDCCAG } & \multicolumn{3}{|l|}{ TCONS 000} \\
\hline 24899 & TRDC & $\mathrm{O}$ & 90989 & 3 & SE & 49867 & REG1P & RI \\
\hline TCONS_000 & & & TCONS_000 & & & TCONS_000 & & \\
\hline 24900 & TRAC & $\mathrm{O}$ & 89899 & INPP5E & $\mathrm{RI}$ & 49894 & CAPG & AF \\
\hline TCONS_000 & & & TCONS_000 & & & TCONS_000 & TMEM15 & \\
\hline 24902 & TRAC & $\mathrm{O}$ & 89900 & SEC16A & SE & 52846 & $O A$ & $\mathrm{AF}, \mathrm{SE}$ \\
\hline TCONS_000 & & & TCONS_000 & & & TCONS_000 & TMEM15 & \\
\hline 27376 & TRAC & $\mathrm{O}$ & 89917 & SNHG7 & $\mathrm{O}$ & 49907 & $O A$ & SE \\
\hline TCONS_000 & & & TCONS_000 & & & TCONS_000 & TMEM15 & \\
\hline 27381 & MMP14 & $\mathrm{O}$ & 89923 & FBXW5 & $\mathrm{O}$ & 49908 & $O A$ & A5 \\
\hline TCONS_000 & RP11-66 & & TCONS_000 & & & TCONS_000 & & \\
\hline 24949 & N24.3 & $\mathrm{O}$ & 89924 & FBXW5 & $\mathrm{RI}$ & 49915 & ST3GAL5 & SE \\
\hline TCONS_000 & & & TCONS_000 & & & TCONS_000 & & \\
\hline 24959 & PCK2 & $\mathrm{A} 3, \mathrm{AF}$ & 89939 & ENTPD2 & $\mathrm{RI}$ & 52860 & CD8A & $\mathrm{RI}$ \\
\hline TCONS_000 & & & TCONS_000 & & & TCONS_000 & AC09657 & \\
\hline 27394 & PCK2 & A3,A5 & 90998 & DPP7 & $\mathrm{RI}$ & 49954 & 9.7 & $\mathrm{O}$ \\
\hline TCONS_000 & & & TCONS_000 & & & TCONS_000 & AC09657 & \\
\hline 27395 & DCAF11 & $\mathrm{RI}$ & $91003^{-}$ & ANAPC2 & $\mathrm{RI}$ & 49955 & 9.7 & $\mathrm{O}$ \\
\hline TCONS_000 & & & TCONS_000 & & & TCONS_000 & AC09657 & \\
\hline 27396 & DCAF11 & O & $91011^{-}$ & PNPLA7 & $\mathrm{O}$ & 49956 & 9.13 & O \\
\hline TCONS_000 & & & TCONS_000 & & & TCONS_000 & & \\
\hline 27397 & DCAF11 & O & 89970 & DPH7 & SE & 52874 & IGKV1-6 & $\mathrm{O}$ \\
\hline TCONS_000 & & & TCONS_000 & & & TCONS_000 & & \\
\hline 27398 & DCAF11 & $\mathrm{O}$ & 89971 & DPH7 & RI,SE & 52895 & MRPS5 & $\mathrm{O}$ \\
\hline TCONS_000 & & & TCONS_000 & & & TCONS_000 & ANKRD3 & \\
\hline 27399 & DCAF11 & A5 & 91012 & $\mathrm{DPH} 7$ & SE & $50010^{-}$ & $6 C$ & SE \\
\hline TCONS_000 & & & TCONS_000 & ZMYND1 & & TCONS_000 & ANKRD3 & \\
\hline 27400 & DCAF11 & $\mathrm{O}$ & 89973 & 9 & AF & 52903 & $6 C$ & SE \\
\hline TCONS_000 & & & TCONS_000 & ZMYND1 & & TCONS_000 & & \\
\hline 27401 & RNF31 & $\mathrm{RI}$ & 91013 & 9 & $\mathrm{O}$ & 52906 & GPAT2 & $\mathrm{O}$ \\
\hline TCONS_000 & & & TCONS_000 & & & TCONS_000 & & \\
\hline 25002 & NFATC4 & $\mathrm{RI}$ & 91049 & STS & 0 & 50022 & DUSP2 & O \\
\hline TCONS_000 & & & TCONS_000 & & & TCONS_000 & & \\
\hline 25003 & NFATC4 & $\mathrm{O}$ & 91050 & STS & O & 52907 & DUSP2 & O \\
\hline TCONS_000 & & & TCONS_000 & & & TCONS_000 & SNRNP2 & \\
\hline 27412 & NFATC4 & RI & 91097 & OFD1 & SE & 50032 & 00 & RI \\
\hline
\end{tabular}




\begin{tabular}{|c|c|c|c|c|c|c|c|c|}
\hline \multicolumn{3}{|l|}{ TCONS_000 } & \multicolumn{3}{|l|}{ TCONS 000} & \multicolumn{3}{|l|}{ TCONS_000 } \\
\hline 25013 & KHNYN & A5 & 91098 & OFD1 & SE & 50035 & NEURL3 & SE \\
\hline TCONS_000 & & & TCONS_000 & & & TCONS_000 & ANKRD2 & \\
\hline 25076 & BRMS1L & $\mathrm{RI}, \mathrm{SE}$ & 93387 & OFD1 & $\mathrm{RI}, \mathrm{SE}$ & 52930 & 3 & 0 \\
\hline TCONS_000 & & & TCONS_000 & & & TCONS_000 & & \\
\hline 25086 & SSTR1 & $\mathrm{O}$ & 91118 & TXLNG & 0 & 50053 & SEMA4C & $\mathrm{AF}$ \\
\hline TCONS_000 & & & TCONS_000 & & & TCONS_000 & & \\
\hline 25185 & PRPF39 & A3 & 93399 & REPS2 & $\mathrm{O}$ & 52931 & FAHD2B & $\mathrm{RI}$ \\
\hline TCONS_000 & & & TCONS_000 & & & TCONS_000 & AC15954 & \\
\hline 25186 & PRPF39 & $\mathrm{A} 3, \mathrm{RI}$ & 91122 & REPS2 & A3 & 50059 & 0.1 & A5 \\
\hline TCONS_000 & & & TCONS_000 & & & TCONS_000 & AC15954 & \\
\hline 27493 & PRPF39 & $\mathrm{A} 3, \mathrm{RI}$ & 91137 & CDKL5 & $\mathrm{O}$ & 50060 & 0.1 & SE \\
\hline TCONS_000 & & & TCONS_000 & & & TCONS_000 & AC15954 & \\
\hline 27494 & PRPF39 & $\mathrm{A} 3, \mathrm{RI}$ & 93411 & SAT1 & $\mathrm{O}$ & 50061 & 0.1 & A3 \\
\hline TCONS_000 & & & TCONS_000 & & & TCONS_000 & ANKRD3 & \\
\hline 25194 & LRR1 & A5,SE & 93412 & ZFX & SE & 52934 & $6 \mathrm{~B}$ & AL,SE \\
\hline TCONS_000 & & & TCONS_000 & & & TCONS_000 & & \\
\hline 25203 & KLHDC2 & $\mathrm{AF}$ & 93413 & $Z F X$ & $\mathrm{O}$ & 52938 & ACTR1B & $\mathrm{RI}$ \\
\hline TCONS_000 & & & TCONS_000 & & & TCONS_000 & & \\
\hline 25279 & SAMD4A & AF,SE & 93414 & $Z F X$ & SE & 50071 & ACTR1B & $\mathrm{RI}$ \\
\hline TCONS_000 & & & TCONS_000 & & & TCONS_000 & & \\
\hline 27529 & SAMD4A & $\mathrm{AF}$ & 91215 & MID1IP1 & A3 & 52953 & RNF149 & SE \\
\hline TCONS_000 & & & TCONS_000 & & & TCONS_000 & & \\
\hline 25307 & KTN1 & SE & 91226 & USP9X & A3,A5 & 52954 & RNF149 & A3 \\
\hline TCONS_000 & & & TCONS_000 & & & TCONS_000 & & \\
\hline 25306 & KTN1 & SE & 91247 & KDM6A & A5,SE & 52963 & RGPD3 & 0 \\
\hline TCONS_000 & KIAA058 & & TCONS 000 & & & TCONS_000 & & \\
\hline 25358 & 6 & SE & 91248 & KDM6A & $\mathrm{RI}$ & 50197 & ANAPC1 & $\mathrm{RI}$ \\
\hline TCONS_000 & KIAA058 & & TCONS_000 & & & TCONS_000 & & \\
\hline 25359 & 6 & SE & 91272 & RGN & SE & 50220 & IL1A & $\mathrm{O}$ \\
\hline TCONS_000 & & & TCONS_000 & & & TCONS_000 & & \\
\hline 25394 & MNAT1 & $\mathrm{O}$ & 91277 & RBM10 & A5 & 50223 & IL1B & 0 \\
\hline TCONS_000 & & & TCONS_000 & & & TCONS_000 & & \\
\hline 25395 & MNAT1 & A3 & 91293 & ARAF & RI & 50224 & IL1B & $\mathrm{O}$ \\
\hline TCONS_000 & & & TCONS_000 & & & TCONS_000 & & \\
\hline 25417 & HIF1A & RI & 91294 & ARAF & RI & 52993 & SCTR & RI,SE \\
\hline
\end{tabular}




\begin{tabular}{|c|c|c|c|c|c|c|c|c|}
\hline TCONS_000 & LINC006 & & TCONS_000 & & & TCONS_000 & & \\
\hline 25431 & 43 & A5 & 93441 & FTSJ1 & $\mathrm{A} 3, \mathrm{SE}$ & 50328 & CLASP1 & SE \\
\hline TCONS_000 & & & TCONS_000 & & & TCONS_000 & & \\
\hline 27596 & SYNE2 & A5 & 93442 & FTSJ1 & $\mathrm{RI}, \mathrm{SE}$ & 50329 & CLASP1 & SE \\
\hline TCONS_000 & & & TCONS_000 & & & TCONS_000 & & \\
\hline 27597 & SYNE2 & A5 & 93443 & FTSJ1 & $\mathrm{RI}, \mathrm{SE}$ & 52999 & ERCC3 & A5,RI \\
\hline TCONS_000 & & & TCONS_000 & & & TCONS_000 & & \\
\hline 25452 & ZBTB1 & SE & 93444 & FTSJ1 & $\mathrm{RI}, \mathrm{SE}$ & 53000 & ERCC3 & A5,RI \\
\hline TCONS_000 & PPP1R3 & & TCONS_000 & & & TCONS_000 & & \\
\hline 25458 & 6 & $\mathrm{O}$ & 91307 & FTSJ1 & $\mathrm{RI}, \mathrm{SE}$ & 53002 & ERCC3 & A5,RI \\
\hline TCONS_000 & PPP1R3 & & TCONS_000 & & & TCONS_000 & & \\
\hline 27599 & 6 & SE & 91310 & PORCN & A3 & 50369 & SAP130 & $\mathrm{AF}$ \\
\hline TCONS_000 & & & TCONS_000 & & & TCONS_000 & & \\
\hline 25472 & GPHN & A5,SE & 91311 & PORCN & $\mathrm{O}$ & 50378 & SMPD4 & RI,SE \\
\hline TCONS_000 & PLEKHH & & TCONS_000 & & & TCONS_000 & & \\
\hline 25486 & 1 & O & 91312 & PORCN & A3,SE & 53019 & MZT2A & O \\
\hline TCONS_000 & & & TCONS_000 & & & TCONS_000 & & \\
\hline 25488 & ARG2 & $\mathrm{RI}$ & 93445 & PORCN & $\mathrm{O}$ & 50456 & GTDC1 & $\mathrm{O}$ \\
\hline TCONS_000 & & & TCONS_000 & & & TCONS_000 & & \\
\hline 27626 & EXD2 & SE & 93446 & PORCN & $\mathrm{O}$ & 50459 & GTDC1 & $\mathrm{O}$ \\
\hline TCONS_000 & GALNT1 & & TCONS_000 & & & TCONS_000 & & \\
\hline 27628 & 6 & $\mathrm{O}$ & 91336 & WAS & $\mathrm{O}$ & 53046 & ZEB2 & $\mathrm{O}$ \\
\hline TCONS_000 & & & TCONS_000 & & & TCONS_000 & & \\
\hline 27631 & SRSF5 & A5 & 91340 & HDAC6 & A5,RI & 50485 & NEB & SE \\
\hline TCONS_000 & & & TCONS_000 & & & TCONS_000 & & \\
\hline 25550 & SIPA1L1 & SE & 91341 & HDAC6 & A5,RI & 50499 & CACNB4 & AF,SE \\
\hline TCONS_000 & & & TCONS_000 & & A3,A5, & TCONS_000 & PRPF40 & A3,A5, \\
\hline 27642 & SIPA1L1 & SE & 91342 & HDAC6 & $\mathrm{RI}$ & 53054 & A & SE \\
\hline TCONS_000 & & & TCONS_000 & & & TCONS_000 & PRPF40 & \\
\hline 25566 & DCAF4 & A5,RI & 93453 & HDAC6 & A5,RI & 53056 & A & A3,SE \\
\hline TCONS_000 & & & TCONS_000 & & & TCONS_000 & PRPF40 & \\
\hline 27646 & RBM25 & $\mathrm{A} 3, \mathrm{SE}$ & 93454 & HDAC6 & RI & 50505 & A & $\mathrm{O}$ \\
\hline TCONS_000 & & & TCONS_000 & & & TCONS_000 & PRPF40 & \\
\hline 25592 & PAPLN & $\mathrm{O}$ & 93455 & HDAC6 & A5,RI & 50506 & A & A5,SE \\
\hline TCONS_000 & & & TCONS_000 & & & TCONS_000 & & \\
\hline 25597 & АСОT2 & $\mathrm{O}$ & 91344 & HDAC6 & RI & 50542 & NR4A2 & RI \\
\hline
\end{tabular}




\begin{tabular}{|c|c|c|c|c|c|c|c|c|}
\hline TCONS_000 & RP5-102 & A5,AF, & TCONS_000 & & & TCONS_000 & & \\
\hline 25613 & 1120.4 & SE & 93456 & PQBP1 & A5,RI & 50543 & NR4A2 & $\mathrm{RI}$ \\
\hline TCONS_000 & RP5-102 & & TCONS_000 & & & TCONS_000 & & \\
\hline 25614 & 1120.4 & A5,SE & 91375 & MAGED1 & $\mathrm{RI}$ & 50544 & NR4A2 & $\mathrm{O}$ \\
\hline TCONS_000 & & & TCONS_000 & & & TCONS_000 & & \\
\hline 25619 & COQ6 & $\mathrm{O}$ & 93464 & TSPYL2 & A3 & 50600 & BAZ2B & A5,SE \\
\hline TCONS_000 & $\mathrm{CCDC} 17$ & & TCONS_000 & & & TCONS_000 & LY75-CD & \\
\hline 25622 & 6 & SE & 91381 & TSPYL2 & A3 & 53087 & 302 & SE \\
\hline TCONS_000 & & & TCONS_000 & & & TCONS_000 & & \\
\hline 25647 & EIF2B2 & O & 91382 & TSPYL2 & $\mathrm{RI}$ & 50616 & ITGB6 & O \\
\hline TCONS_000 & & & TCONS_000 & & & TCONS_000 & & \\
\hline 27662 & EIF2B2 & $\mathrm{O}$ & 93468 & MAGED2 & $A F, R I$ & 50653 & FAP & 0 \\
\hline TCONS_000 & & & TCONS_000 & & & TCONS_000 & & \\
\hline 25671 & TTLL5 & A5 & 93469 & TRO & A5 & 50654 & FAP & 0 \\
\hline TCONS_000 & & & TCONS_000 & & & TCONS_000 & & \\
\hline 25672 & TTLL5 & RI,SE & 93473 & RRAGB & A3,SE & 53102 & GRB14 & $\mathrm{RI}$ \\
\hline TCONS_000 & & & TCONS_000 & & & TCONS_000 & & \\
\hline 25673 & TTLL5 & $\mathrm{RI}, \mathrm{SE}$ & 93508 & HEPH & AF & 50668 & COBLL1 & AF,SE \\
\hline TCONS_000 & & & TCONS_000 & & & TCONS_000 & & \\
\hline 27666 & TTLL5 & SE & 93509 & STARD8 & RI & 50680 & TTC21B & 0 \\
\hline TCONS_000 & & & TCONS_000 & & & TCONS_000 & & \\
\hline 27687 & FLRT2 & A5 & 91613 & KIF4A & $\mathrm{O}$ & 50684 & SCN9A & SE \\
\hline TCONS_000 & & & TCONS_000 & & & TCONS_000 & FASTKD & \\
\hline 25733 & SPATA7 & SE & 93512 & MED12 & O & 53121 & 1 & $\mathrm{O}$ \\
\hline TCONS_000 & & & TCONS_000 & & & TCONS_000 & & \\
\hline 25790 & CPSF2 & A5 & 91630 & NONO & $\mathrm{RI}$ & 50701 & METTL5 & A3 \\
\hline TCONS_000 & & & TCONS_000 & & A3,RI, & TCONS_000 & AC09381 & \\
\hline 25807 & CHGA & $\mathrm{O}$ & 93517 & TAF1 & SE & 53128 & 8.1 & $\mathrm{RI}$ \\
\hline TCONS_000 & & & TCONS_000 & & & TCONS_000 & & \\
\hline 25808 & CHGA & 0 & 91645 & OGT & RI & 53147 & TTN & SE \\
\hline TCONS_000 & RP11-37 & & TCONS_000 & & & TCONS_000 & & \\
\hline 25815 & 1E8.4 & $\mathrm{O}$ & 91646 & OGT & SE & 50849 & PDE1A & $\mathrm{O}$ \\
\hline TCONS_000 & DICER1- & & TCONS_000 & & & TCONS_000 & & \\
\hline 27732 & AS1 & $\mathrm{O}$ & 91698 & ATP7A & SE & 50927 & TFPI & SE \\
\hline TCONS_000 & & & TCONS_000 & & & TCONS_000 & & \\
\hline 27733 & GLRX5 & A5 & 93601 & TNMD & $\mathrm{O}$ & 50928 & TFPI & SE \\
\hline
\end{tabular}




\begin{tabular}{|c|c|c|c|c|c|c|c|c|}
\hline \multicolumn{3}{|l|}{ TCONS_000 } & \multicolumn{3}{|l|}{ TCONS_000 } & TCONS_000 & \multicolumn{2}{|l|}{ OSGEPL } \\
\hline 25891 & CCNK & $\mathrm{O}$ & 91753 & CENPI & A5,SE & 50960 & 1 & SE \\
\hline TCONS_000 & & & TCONS_000 & & & TCONS_000 & & \\
\hline 25894 & CCNK & $\mathrm{RI}$ & 91774 & ARMCX4 & A3,SE & 53249 & DNAH7 & SE \\
\hline TCONS_000 & & & TCONS_000 & RP4-769 & & TCONS_000 & & \\
\hline 25908 & YY1 & $\mathrm{O}$ & 91782 & N13.6 & SE & 51019 & HECW2 & 0 \\
\hline TCONS_000 & & & TCONS_000 & LINC006 & & TCONS_000 & ANKRD4 & \\
\hline 27756 & DLK1 & $\mathrm{O}$ & 91791 & 30 & A5,SE & 53259 & 4 & $\mathrm{O}$ \\
\hline TCONS_000 & RP11-79 & & TCONS_000 & LINC006 & & TCONS_000 & ANKRD4 & \\
\hline 25924 & $6 \mathrm{G} 6.2$ & $\mathrm{O}$ & 91792 & 30 & A5,SE & 51032 & 4 & A3 \\
\hline TCONS_000 & PPP2R5 & & TCONS_000 & & & TCONS_000 & & \\
\hline 25925 & C & $\mathrm{MX}$ & 91847 & NRK & $\mathrm{A} 3, \mathrm{SE}$ & 51040 & SF3B1 & $\mathrm{RI}$ \\
\hline TCONS_000 & & & TCONS_000 & & & TCONS_000 & & \\
\hline 25978 & AMN & $\mathrm{RI}$ & 93618 & MUM1L1 & A5,SE & 51080 & CLK1 & $A F, R I$ \\
\hline TCONS_000 & & & TCONS_000 & & & TCONS_000 & & \\
\hline 27775 & TNFAIP2 & A5 & 91852 & CXorf57 & $\mathrm{RI}$ & 51081 & CLK1 & $A F, R I$ \\
\hline TCONS_000 & & & TCONS_000 & TBC1D8 & & TCONS_000 & & \\
\hline 27776 & TNFAIP2 & A5 & 93621 & B & A5 & 51082 & CLK1 & $\mathrm{AF}$ \\
\hline TCONS_000 & & & TCONS_000 & TBC1D8 & & TCONS_000 & & \\
\hline 25985 & TNFAIP2 & O & 91856 & $\mathrm{~B}$ & $\mathrm{O}$ & 51085 & PPIL3 & $\mathrm{AF}, \mathrm{SE}$ \\
\hline TCONS_000 & & & TCONS_000 & & & TCONS_000 & & \\
\hline 25986 & TNFAIP2 & O & 91862 & MID2 & $\mathrm{A} 5, \mathrm{AF}$ & 53285 & ORC2 & $\mathrm{RI}$ \\
\hline TCONS_000 & & & TCONS_000 & & & TCONS_000 & & \\
\hline 25987 & TNFAIP2 & A5 & 93633 & ALG13 & $\mathrm{O}$ & 51168 & GPR1 & $\mathrm{O}$ \\
\hline TCONS_000 & & & TCONS_000 & & & TCONS_000 & & \\
\hline 25988 & TNFAIP2 & A5 & 91963 & MCTS1 & AF & 51169 & KLF7 & $\mathrm{A} 5, \mathrm{AF}$ \\
\hline TCONS_000 & & & TCONS_000 & & & TCONS_000 & METTL21 & \\
\hline 27778 & TNFAIP2 & SE & 92055 & OCRL & 0 & 51177 & A & $\mathrm{AF}$ \\
\hline TCONS_000 & & & TCONS_000 & SLC25A1 & & TCONS_000 & METTL21 & \\
\hline 25998 & MARK3 & $\mathrm{RI}, \mathrm{SE}$ & 92066 & 4 & AF,SE & 51178 & $A$ & O \\
\hline TCONS_000 & & & TCONS_000 & SLC25A1 & & TCONS_000 & & \\
\hline 26000 & MARK3 & A3,SE & 92067 & 4 & A5,SE & 53327 & KANSL1L & $\mathrm{RI}$ \\
\hline TCONS_000 & & A3,RI, & TCONS_000 & SLC25A1 & & TCONS_000 & & \\
\hline 26001 & MARK3 & SE & 92068 & 4 & AF,SE & 53339 & FN1 & $A 3, R I$ \\
\hline TCONS_000 & & & TCONS_000 & SLC25A1 & & TCONS_000 & & \\
\hline 27804 & ZBTB42 & A3 & 93682 & 4 & AF,SE & 51230 & FN1 & $\mathrm{A} 3, \mathrm{SE}$ \\
\hline
\end{tabular}




\begin{tabular}{|c|c|c|c|c|c|c|c|c|}
\hline TCONS_000 & CEP170 & & TCONS_000 & & & TCONS_000 & & \\
\hline 26052 & $\mathrm{~B}$ & A3 & 92075 & MST4 & SE & 51263 & TMBIM1 & AF \\
\hline TCONS_000 & RP11-44 & & TCONS_000 & & & TCONS_000 & & \\
\hline 26067 & N21.1 & 0 & 92088 & HPRT1 & AF & 53354 & ATG9A & RI,SE \\
\hline TCONS_000 & & & TCONS_000 & & & TCONS_000 & & \\
\hline 27813 & MTA1 & $\mathrm{RI}, \mathrm{SE}$ & 92109 & DDX26B & SE & 51301 & ATG9A & 0 \\
\hline TCONS_000 & & & TCONS_000 & & & TCONS_000 & & \\
\hline 26134 & OSGEP & A5,RI & 92108 & DDX26B & SE & 53355 & GLB1L & $\mathrm{O}$ \\
\hline TCONS_000 & TMEM55 & & TCONS_000 & & & TCONS_000 & & \\
\hline 26140 & B & A5 & 92115 & SLC9A6 & A5 & 51307 & GLB1L & $\mathrm{RI}$ \\
\hline TCONS_000 & & & TCONS_000 & & & TCONS_000 & & \\
\hline 26201 & CHD8 & $\mathrm{O}$ & 93694 & HTATSF1 & $\mathrm{O}$ & 53358 & CHPF & $\mathrm{RI}$ \\
\hline TCONS_000 & & & TCONS_000 & & & TCONS_000 & & \\
\hline 26210 & METTL3 & $\mathrm{RI}$ & 92174 & ZNF185 & A3,SE & 53360 & OBSL1 & SE \\
\hline TCONS_000 & & & TCONS_000 & & & TCONS_000 & & \\
\hline 27839 & ACIN1 & A3 & 92175 & ZNF185 & SE & 53361 & OBSL1 & $\mathrm{O}$ \\
\hline TCONS_000 & SLC22A & & TCONS_000 & & & TCONS_000 & & \\
\hline 26271 & 17 & O & 92207 & RPL10 & $\mathrm{O}$ & 51327 & EPHA4 & A5 \\
\hline TCONS_000 & & & TCONS_000 & & & TCONS_000 & & \\
\hline 27848 & MYH7 & $\mathrm{O}$ & 93708 & TAZ & $\mathrm{RI}, \mathrm{SE}$ & 51329 & EPHA4 & $\mathrm{O}$ \\
\hline TCONS_000 & & & TCONS_000 & & & TCONS_000 & & \\
\hline 26272 & AP1G2 & $\mathrm{O}$ & 92231 & GDI1 & $\mathrm{RI}$ & 51339 & SCG2 & SE \\
\hline TCONS_000 & & & TCONS_000 & & & TCONS_000 & & \\
\hline 27849 & AP1G2 & $\mathrm{O}$ & 92239 & PLXNA3 & O & 53365 & AP1S3 & $\mathrm{AF}, \mathrm{SE}$ \\
\hline TCONS_000 & & & TCONS_000 & & & TCONS_000 & & \\
\hline 27850 & AP1G2 & SE & 92240 & PLXNA3 & $A 3, R I$ & 51386 & DNER & O \\
\hline TCONS_000 & & & TCONS_000 & & & TCONS_000 & & \\
\hline 26276 & AP1G2 & $\mathrm{AF}$ & 93713 & FUNDC2 & $A F$ & 51422 & ECEL1 & 0 \\
\hline TCONS_000 & DHRS4- & & TCONS_000 & & & TCONS_000 & & \\
\hline 26279 & AS1 & $\mathrm{O}$ & 92270 & ARSD & $\mathrm{O}$ & 53400 & COL6A3 & $\mathrm{O}$ \\
\hline TCONS_000 & DHRS4- & & TCONS_000 & & & TCONS_000 & & \\
\hline 26280 & AS1 & $\mathrm{AF}$ & 92279 & ARSE & AF,SE & 53401 & COL6A3 & O \\
\hline TCONS_000 & DHRS4- & & TCONS_000 & & & TCONS_000 & & \\
\hline 26281 & AS1 & $\mathrm{O}$ & 92283 & PRKX & A3 & 53402 & COL6A3 & SE \\
\hline TCONS_000 & DHRS4- & & TCONS_000 & RP11-70 & & TCONS_000 & & \\
\hline 26282 & AS1 & AF & 92290 & 6015.1 & $\mathrm{O}$ & 53403 & COL6A3 & SE \\
\hline
\end{tabular}




\begin{tabular}{|c|c|c|c|c|c|c|c|c|}
\hline \multicolumn{3}{|l|}{ TCONS_000 } & \multicolumn{3}{|l|}{ TCONS_000 } & \multicolumn{3}{|l|}{ TCONS_000 } \\
\hline 26285 & EMC9 & A3 & 92319 & GPR143 & $A F$ & 51452 & COL6A3 & SE \\
\hline TCONS_000 & RP11-46 & & TCONS_000 & ARHGAP & & TCONS_000 & & \\
\hline 27853 & 8E2.2 & 0 & 92327 & 6 & AL,SE & 51453 & COL6A3 & RI \\
\hline TCONS_000 & RP11-46 & & TCONS_000 & TRAPPC & & TCONS_000 & & \\
\hline 27854 & 8E2.2 & SE & 92332 & 2 & 0 & 51454 & COL6A3 & $\mathrm{O}$ \\
\hline TCONS_000 & RABGG & & TCONS_000 & & & TCONS_000 & & \\
\hline 26315 & $\mathrm{TA}$ & $\mathrm{RI}$ & 92346 & GEMIN8 & A5 & 51460 & RAB17 & $\mathrm{O}$ \\
\hline TCONS_000 & & & TCONS_000 & & & TCONS_000 & & \\
\hline 26324 & CIDEB & SE & 93759 & ACE2 & $\mathrm{O}$ & 51466 & ILKAP & A5 \\
\hline TCONS_000 & & & TCONS_000 & & & TCONS_000 & & \\
\hline 26325 & ADCY4 & $\mathrm{RI}$ & 92390 & RAI2 & $\mathrm{O}$ & 53408 & ILKAP & $\mathrm{O}$ \\
\hline TCONS_000 & & & TCONS_000 & & & TCONS_000 & & \\
\hline 27861 & ADCY4 & $\mathrm{RI}$ & 92393 & PHKA2 & $\mathrm{O}$ & 53409 & ILKAP & $\mathrm{RI}$ \\
\hline TCONS_000 & & & TCONS_000 & & & TCONS_000 & & \\
\hline 26326 & RIPK3 & $\mathrm{O}$ & 92394 & PHKA2 & RI & 51465 & ILKAP & RI \\
\hline TCONS_000 & SDR39U & & TCONS_000 & & & TCONS_000 & & \\
\hline 27862 & 1 & $\mathrm{RI}$ & 93763 & PHKA2 & $\mathrm{RI}$ & 51472 & HES6 & A3 \\
\hline TCONS_000 & SDR39U & & TCONS_000 & & & TCONS_000 & & \\
\hline 27863 & 1 & $\mathrm{AF}$ & 92398 & GPR64 & $\mathrm{A} 5, \mathrm{AF}$ & 51482 & HDAC4 & $\mathrm{AF}$ \\
\hline TCONS_000 & SDR39U & & TCONS_000 & & & TCONS_000 & & \\
\hline 26332 & 1 & $\mathrm{O}$ & 92423 & KLHL15 & $\mathrm{O}$ & 51481 & HDAC4 & $\mathrm{A} 3, \mathrm{AF}$ \\
\hline TCONS_000 & SDR39U & & TCONS_000 & & & TCONS_000 & & \\
\hline 26333 & 1 & $\mathrm{O}$ & 92430 & TAB3 & $\mathrm{O}$ & 51493 & ANKMY1 & O \\
\hline TCONS_000 & & & TCONS_000 & & & TCONS_000 & & \\
\hline 26341 & GZMB & $\mathrm{O}$ & 92487 & CASK & $\mathrm{A} 3, \mathrm{SE}$ & 53427 & AQP12B & 0 \\
\hline TCONS_000 & PPP2R3 & & TCONS_000 & & $A 3, A 5$ & TCONS_000 & & \\
\hline 26416 & C & $\mathrm{O}$ & 92488 & CASK & SE & 53429 & AQP12B & $\mathrm{RI}$ \\
\hline TCONS_000 & PPP2R3 & & TCONS_000 & & & TCONS_000 & & \\
\hline 26417 & C & $\mathrm{RI}$ & 92499 & MAOB & $\mathrm{RI}$ & 53430 & AQP12B & SE \\
\hline TCONS_000 & PPP2R3 & & TCONS_000 & & & TCONS_000 & & \\
\hline 26419 & $\mathrm{C}$ & $\mathrm{RI}$ & 92503 & EFHC2 & RI & 53439 & KIF1A & SE \\
\hline TCONS_000 & RALGAP & & TCONS_000 & RP6-99M & & TCONS_000 & & \\
\hline 27888 & $\mathrm{~A} 1$ & A5,SE & 92509 & 1.2 & AF & 53440 & KIF1A & RI,SE \\
\hline TCONS_000 & & & TCONS_000 & & & TCONS_000 & MTERFD & \\
\hline 26452 & SEC23A & 0 & 92522 & SLC9A7 & $\mathrm{O}$ & 51502 & 2 & RI \\
\hline
\end{tabular}




\begin{tabular}{|c|c|c|c|c|c|c|c|c|}
\hline \multirow{2}{*}{$\begin{array}{l}\text { TCONS_000 } \\
26478\end{array}$} & \multicolumn{2}{|l|}{ MIS18B } & \multicolumn{3}{|l|}{ TCONS_000 } & \multicolumn{3}{|l|}{ TCONS_000 } \\
\hline & P1 & SE & 92523 & SLC9A7 & O & 53443 & PASK & O \\
\hline TCONS_000 & & & TCONS_000 & & & TCONS_000 & & \\
\hline 26502 & NEMF & $\mathrm{RI}, \mathrm{SE}$ & 92529 & ZNF41 & AF & 53444 & HDLBP & AF \\
\hline TCONS_000 & & & TCONS_000 & & & TCONS_000 & & \\
\hline 26521 & CDKL1 & $\mathrm{O}$ & 92546 & SLC38A5 & $\mathrm{O}$ & 53445 & HDLBP & $\mathrm{O}$ \\
\hline TCONS_000 & & & TCONS_000 & & & TCONS_000 & & \\
\hline 26522 & CDKL1 & AL & 93818 & PCSK1N & AF & 53446 & HDLBP & AF \\
\hline TCONS_000 & & & TCONS_000 & & & TCONS_000 & & \\
\hline 26523 & MAP4K5 & A5 & 92552 & TIMM17B & SE & 53447 & HDLBP & $A 3, A F$ \\
\hline TCONS_000 & & & TCONS_000 & & & TCONS_000 & & \\
\hline 26525 & MAP4K5 & $\mathrm{O}$ & 93823 & GRIPAP1 & $\mathrm{RI}, \mathrm{SE}$ & 55018 & NRSN2 & RI \\
\hline TCONS_000 & & & TCONS_000 & & & TCONS_000 & & \\
\hline 27945 & NID2 & $\mathrm{RI}, \mathrm{SE}$ & 93834 & IQSEC2 & SE & 53480 & SIRPA & A5 \\
\hline TCONS_000 & GNPNAT & & TCONS_000 & & & TCONS_000 & & \\
\hline 26547 & 1 & SE & 93835 & IQSEC2 & RI & 53481 & STK35 & $\mathrm{O}$ \\
\hline TCONS_000 & & & TCONS_000 & & & TCONS_000 & & \\
\hline 27958 & $\mathrm{GCH} 1$ & O & 93840 & HUWE1 & $\mathrm{O}$ & 55028 & NOP56 & $\mathrm{RI}$ \\
\hline TCONS_000 & & & TCONS_000 & & & TCONS_000 & & \\
\hline 26607 & WDHD1 & A3 & 92630 & HUWE1 & A5 & 55029 & NOP56 & A3 \\
\hline TCONS_000 & LINC005 & & TCONS_000 & & & TCONS_000 & & \\
\hline 26615 & 20 & $\mathrm{AL}, \mathrm{SE}$ & 92635 & HUWE1 & A5 & 53484 & NOP56 & A5 \\
\hline TCONS_000 & C14orf10 & & TCONS_000 & & & TCONS_000 & & \\
\hline 27965 & 5 & $\mathrm{RI}, \mathrm{SE}$ & 92649 & FAM104B & O & 53485 & NOP56 & $A 3, R I$ \\
\hline TCONS_000 & & & TCONS_000 & RP11-35 & & TCONS_000 & & \\
\hline 27970 & TIMM9 & 0 & 93870 & $7 C 3.3$ & SE & 53486 & EBF4 & $\mathrm{RI}$ \\
\hline TCONS_000 & RP11-90 & & TCONS_000 & RP11-35 & & TCONS_000 & & \\
\hline 26678 & 2B17.1 & 0 & 92688 & 7C3.3 & A3,SE & 55030 & EBF4 & $\mathrm{RI}$ \\
\hline TCONS_000 & & & TCONS_000 & ARHGEF & & TCONS_000 & & \\
\hline 26688 & WDR89 & SE & 93872 & 9 & $\mathrm{O}$ & 53541 & MCM8 & $A 5, R I$ \\
\hline TCONS_000 & & & TCONS_000 & & & TCONS_000 & & \\
\hline 26699 & ZBTB25 & $\mathrm{AL}$ & 93881 & AMER1 & O & 53543 & MCM8 & A5 \\
\hline TCONS_000 & & & TCONS_000 & & & TCONS_000 & & \\
\hline 26702 & ZBTB25 & $\mathrm{O}$ & 93897 & LAS1L & $\mathrm{RI}, \mathrm{SE}$ & 53558 & PLCB4 & SE \\
\hline TCONS_000 & & & TCONS_000 & & & TCONS_000 & & \\
\hline 26705 & ZBTB25 & AF & 93899 & TEX11 & $\mathrm{O}$ & 55054 & PLCB4 & SE \\
\hline
\end{tabular}




\begin{tabular}{|c|c|c|c|c|c|c|c|c|}
\hline TCONS_000 & ATP6V1 & & TCONS_000 & & $\mathrm{A} 5, \mathrm{AF}$ & TCONS_000 & & \\
\hline 26726 & $\mathrm{D}$ & A5 & 92761 & ZMYM3 & $\mathrm{RI}$ & 53582 & ISM1 & $\mathrm{AF}$ \\
\hline TCONS_000 & & & TCONS_000 & & & TCONS_000 & CSRP2B & \\
\hline 27986 & RDH11 & $\mathrm{O}$ & 92762 & ZMYM3 & $A F, R I$ & 53605 & $\mathrm{P}$ & A3 \\
\hline TCONS_000 & ZFYVE2 & & TCONS_000 & & & TCONS_000 & CSRP2B & \\
\hline 27987 & 6 & $\mathrm{RI}$ & 93902 & RPS4X & $\mathrm{O}$ & 55076 & $\mathrm{P}$ & $\mathrm{O}$ \\
\hline TCONS_000 & & & TCONS_000 & & & TCONS_000 & & \\
\hline 26828 & NUMB & SE & 92777 & HDAC8 & A3 & 53614 & ZNF133 & $\mathrm{A} 3, \mathrm{SE}$ \\
\hline TCONS_000 & & & TCONS_000 & & & TCONS_000 & & \\
\hline 26829 & NUMB & SE & 93907 & FTX & $\mathrm{O}$ & 53615 & ZNF133 & A3 \\
\hline TCONS_000 & ELMSAN & & TCONS_000 & & & TCONS_000 & & \\
\hline 28011 & 1 & $\mathrm{AF}$ & 92814 & ABCB7 & A3 & 55079 & ZNF133 & $\mathrm{RI}$ \\
\hline TCONS_000 & & & TCONS_000 & & & TCONS_000 & & \\
\hline 28013 & ABCD4 & SE & 92833 & TAF9B & $\mathrm{O}$ & 55082 & SEC23B & A5 \\
\hline TCONS_000 & & & TCONS_000 & & & TCONS_000 & & \\
\hline 26888 & NEK9 & $\mathrm{AF}$ & 92836 & TAF9B & $\mathrm{O}$ & 53639 & RIN2 & O \\
\hline TCONS_000 & & & TCONS_000 & & & TCONS_000 & & \\
\hline 28027 & VIPAS39 & RI,SE & 92856 & BRWD3 & $\mathrm{RI}$ & 55085 & RIN2 & $\mathrm{O}$ \\
\hline TCONS_000 & & & TCONS_000 & & & TCONS_000 & & \\
\hline 26933 & DIO2 & $\mathrm{O}$ & 92860 & HMGN5 & SE & 53653 & PLK1S1 & SE \\
\hline TCONS_000 & & & TCONS_000 & & & TCONS_000 & & \\
\hline 28031 & STON2 & $A 3, A F$ & 92909 & GLA & RI,SE & 53670 & SYNDIG1 & SE \\
\hline TCONS_000 & RP11-35 & & TCONS_000 & MORF4L & & TCONS_000 & & \\
\hline 28034 & 3P15.1 & $A L$ & 93986 & 2 & A3 & 53673 & ENTPD6 & $\mathrm{O}$ \\
\hline TCONS_000 & CCDC88 & & TCONS_000 & & & TCONS_000 & & \\
\hline 26987 & C & SE & 93007 & ACSL4 & $\mathrm{O}$ & 53674 & ENTPD6 & $A 3, R I$ \\
\hline TCONS_000 & CCDC88 & & TCONS_000 & & & TCONS_000 & & \\
\hline 26988 & C & RI,SE & 93008 & ACSL4 & $\mathrm{O}$ & 55095 & ENTPD6 & A5,RI \\
\hline TCONS_000 & & & TCONS_000 & & & TCONS_000 & & \\
\hline 28054 & SMEK1 & A5 & 93010 & ACSL4 & $\mathrm{O}$ & 55096 & ENTPD6 & A3,RI \\
\hline TCONS_000 & & & TCONS_000 & & & TCONS_000 & & \\
\hline 27102 & SYNE3 & A3 & 93997 & CHRDL1 & A3 & 55097 & PYGB & $\mathrm{O}$ \\
\hline TCONS_000 & & & TCONS_000 & & & TCONS_000 & RP4-694 & \\
\hline 27103 & SYNE3 & $\mathrm{O}$ & 93022 & AMOT & $\mathrm{O}$ & 53688 & B14.5 & $\mathrm{O}$ \\
\hline TCONS_000 & & & TCONS_000 & & & TCONS_000 & CTD-251 & \\
\hline 27132 & DEGS2 & $\mathrm{O}$ & 93024 & IL13RA2 & $\mathrm{O}$ & 53702 & 4C3.1 & $A F, A L$ \\
\hline
\end{tabular}




\begin{tabular}{|c|c|c|c|c|c|c|c|c|}
\hline \multicolumn{3}{|l|}{ TCONS_000 } & \multicolumn{3}{|l|}{ TCONS_000 } & \multicolumn{3}{|l|}{ TCONS_000 } \\
\hline 27190 & MOK & $\mathrm{O}$ & 93025 & IL13RA2 & A3 & 53707 & FRG1B & AL,SE \\
\hline TCONS_000 & & & TCONS_000 & & & TCONS_000 & & \\
\hline 27191 & MOK & SE & 93026 & IL13RA2 & O & 53709 & FRG1B & AL,SE \\
\hline TCONS_000 & & & TCONS_000 & RP11-76 & & TCONS_000 & & \\
\hline 28103 & MOK & A3 & 93033 & 1E20.1 & O & 53710 & FRG1B & AL,SE \\
\hline TCONS_000 & CDC42B & & TCONS_000 & & & TCONS_000 & & \\
\hline 27204 & PB & SE & 93037 & KLHL13 & SE & 55101 & FRG1B & SE \\
\hline TCONS_000 & & & TCONS_000 & & & TCONS_000 & & \\
\hline 27211 & CKB & $\mathrm{O}$ & 94001 & CXorf56 & A5,RI & 55102 & FRG1B & AL,SE \\
\hline TCONS_000 & PPP1R1 & & TCONS_000 & & & TCONS_000 & & \\
\hline 28111 & $3 B$ & $\mathrm{O}$ & 94016 & THOC2 & A3 & 55103 & FRG1B & AL,SE \\
\hline TCONS_000 & PPP1R1 & & TCONS_000 & SMARCA & & TCONS_000 & & \\
\hline 28112 & $3 B$ & $\mathrm{RI}$ & 93132 & 1 & $\mathrm{O}$ & 53733 & TM9SF4 & A5 \\
\hline TCONS_000 & & & TCONS_000 & SMARCA & & TCONS_000 & & \\
\hline 27244 & AKT1 & $\mathrm{O}$ & 93133 & 1 & SE & 53757 & MAPRE1 & O \\
\hline & & & & RP11-45 & & & & \\
\hline TCONS_000 & & & TCONS_000 & 3F18_B. & & TCONS_000 & TP53INP & \\
\hline 27245 & AKT1 & RI & 93147 & 1 & A5 & 55125 & 2 & $\mathrm{O}$ \\
\hline & & & & RP11-45 & & & & \\
\hline TCONS_000 & & & TCONS_000 & 3F18_B. & & TCONS_000 & & A3,RI, \\
\hline 27246 & AKT1 & $\mathrm{O}$ & 94046 & 1 & $\mathrm{RI}$ & 53791 & ACSS2 & SE \\
\hline TCONS_000 & & & TCONS_000 & & & TCONS_000 & & \\
\hline 27247 & AKT1 & A3 & 94047 & RAP2C & A3 & 53793 & PROCR & 0 \\
\hline TCONS_000 & & & TCONS_000 & & & TCONS_000 & & \\
\hline 28117 & AKT1 & A3 & 93150 & MBNL3 & $\mathrm{O}$ & 55129 & PROCR & $\mathrm{O}$ \\
\hline TCONS_000 & & & TCONS_000 & & & TCONS_000 & & \\
\hline 28118 & AKT1 & $\mathrm{O}$ & 93151 & MBNL3 & SE & 55132 & ERGIC3 & A3,SE \\
\hline TCONS_000 & & & TCONS_000 & & & TCONS_000 & & \\
\hline 28121 & AHNAK2 & $A F$ & 93153 & MBNL3 & SE & 53805 & SPAG4 & O \\
\hline TCONS_000 & & & TCONS_000 & & & TCONS_000 & & \\
\hline 27260 & CDCA4 & $A F$ & 93165 & FAM122B & SE & 53806 & SPAG4 & O \\
\hline TCONS_000 & & & TCONS_000 & & & TCONS_000 & & \\
\hline 27281 & IGHA2 & $\mathrm{O}$ & 93168 & FAM122B & SE & 53807 & SPAG4 & $\mathrm{O}$ \\
\hline TCONS_000 & & & TCONS_000 & & & TCONS_000 & & \\
\hline 28129 & IGHA2 & $\mathrm{O}$ & 93202 & RBMX & $\mathrm{O}$ & 53808 & SPAG4 & $\mathrm{O}$ \\
\hline
\end{tabular}




\begin{tabular}{|c|c|c|c|c|c|c|c|c|}
\hline \multicolumn{3}{|l|}{ TCONS_000 } & \multicolumn{3}{|l|}{ TCONS_000 } & \multicolumn{3}{|l|}{ TCONS_000 } \\
\hline 27283 & IGHG1 & $\mathrm{O}$ & 93203 & RBMX & O & 55139 & EPB41L1 & A3,SE \\
\hline TCONS_000 & & & TCONS_000 & & & TCONS_000 & TGIF2-C & \\
\hline 27284 & IGHG4 & O & 93204 & RBMX & $\mathrm{O}$ & 53829 & 20orf24 & AF \\
\hline TCONS_000 & & & TCONS_000 & & & TCONS_000 & & \\
\hline 27285 & IGHG1 & O & 93212 & ATP11C & AF & 55144 & SRC & A5 \\
\hline TCONS_000 & & & TCONS_000 & & & TCONS_000 & & \\
\hline 27286 & IGHG3 & O & 93239 & CXorf40B & A5 & 53859 & NNAT & O \\
\hline TCONS_000 & & & TCONS_000 & & A3,A5, & TCONS_000 & RALGAP & \\
\hline 27287 & IGHG4 & $\mathrm{O}$ & 94066 & GABRE & SE & 53872 & B & A3 \\
\hline TCONS_000 & & & TCONS_000 & & & TCONS_000 & & \\
\hline 27288 & IGHG1 & $\mathrm{O}$ & 93248 & GABRE & A5,SE & 53880 & ACTR5 & A3 \\
\hline TCONS_000 & & & TCONS_000 & & & TCONS_000 & & \\
\hline 27289 & IGHG1 & $\mathrm{O}$ & 93252 & GABRE & $\mathrm{A} 3, \mathrm{SE}$ & 53901 & PLCG1 & A3,A5 \\
\hline TCONS_000 & & & TCONS_000 & & & TCONS_000 & & \\
\hline 28130 & IGHG1 & $\mathrm{O}$ & 94067 & TREX2 & $\mathrm{O}$ & 55155 & PLCG1 & $\mathrm{O}$ \\
\hline TCONS_000 & & & TCONS_000 & & & TCONS_000 & & \\
\hline 28131 & IGHG2 & $\mathrm{O}$ & 94068 & TREX2 & A3,SE & 55156 & PLCG1 & RI \\
\hline TCONS_000 & & & TCONS_000 & ARHGAP & & TCONS_000 & & \\
\hline 28132 & IGHG2 & $\mathrm{O}$ & 93278 & 4 & $\mathrm{O}$ & 53902 & LPIN3 & $\mathrm{O}$ \\
\hline TCONS_000 & & & TCONS_000 & & & TCONS_000 & & \\
\hline 28133 & IGHG2 & $\mathrm{O}$ & 94074 & HCFC1 & $A 3, R I$ & 53903 & LPIN3 & $A 3, R I$ \\
\hline TCONS_000 & & & TCONS_000 & & & TCONS_000 & & \\
\hline 27292 & IGHG2 & $\mathrm{O}$ & 93289 & IRAK1 & RI & 53904 & LPIN3 & $A 5, R I$ \\
\hline TCONS_000 & & & TCONS_000 & & & TCONS_000 & & \\
\hline 28134 & IGHG1 & O & 94077 & FAM3A & $\mathrm{O}$ & 55160 & LPIN3 & RI \\
\hline TCONS_000 & & & TCONS_000 & & & TCONS_000 & & \\
\hline 27293 & IGHG3 & O & 94078 & FAM3A & RI & 53913 & L3MBTL1 & O \\
\hline TCONS_000 & & & TCONS_000 & & & TCONS_000 & OSER1-A & \\
\hline 28135 & IGHG2 & O & 94079 & FAM3A & $\mathrm{O}$ & 53928 & $\mathrm{~S} 1$ & O \\
\hline TCONS_000 & & & TCONS_000 & & & TCONS_000 & OSER1-A & \\
\hline 28136 & IGHG1 & O & 93332 & MTCP1 & $\mathrm{O}$ & 55165 & $\mathrm{~S} 1$ & AF,SE \\
\hline TCONS_000 & & & TCONS_000 & & & TCONS_000 & & \\
\hline 28137 & IGHGI & $\mathrm{O}$ & 94088 & ZFY & A5 & 55166 & TTPAL & $\mathrm{O}$ \\
\hline TCONS_000 & & & TCONS_000 & & & TCONS_000 & PABPC1 & \\
\hline 27294 & IGHG2 & $\mathrm{O}$ & 94108 & USP9Y & SE & 53953 & $\mathrm{~L}$ & A3 \\
\hline
\end{tabular}




\begin{tabular}{|c|c|c|c|c|c|c|c|c|}
\hline \multicolumn{3}{|l|}{ TCONS_000 } & \multicolumn{3}{|l|}{ TCONS 000} & \multicolumn{3}{|l|}{ TCONS_000 } \\
\hline 27295 & IGHG2 & $\mathrm{O}$ & 94218 & USP9Y & SE & 55170 & RBPJL & RI \\
\hline TCONS_000 & & & TCONS_000 & & & TCONS_000 & & \\
\hline 28138 & IGHG1 & 0 & 94219 & USP9Y & $\mathrm{RI}, \mathrm{SE}$ & 54013 & PCIF1 & $\mathrm{RI}$ \\
\hline TCONS_000 & & & TCONS_000 & & & TCONS_000 & & \\
\hline 27297 & IGHG1 & $\mathrm{O}$ & 94121 & NLGN4Y & 0 & 55182 & PCIF1 & $\mathrm{RI}$ \\
\hline TCONS_000 & & & TCONS_000 & & & TCONS_000 & & \\
\hline 27298 & IGHA1 & $\mathrm{O}$ & 94173 & KDM5D & A3,SE & 54020 & SLC2A10 & AF \\
\hline TCONS_000 & & & TCONS_000 & & & TCONS_000 & & \\
\hline 57528 & LIF & 0 & 58022 & SLC2A11 & $\mathrm{A} 5, \mathrm{RI}$ & 55185 & NCOA3 & $\mathrm{RI}$ \\
\hline TCONS_000 & & & TCONS_000 & & & TCONS_000 & & \\
\hline 58296 & DUSP18 & AL & 58027 & DDTL & A5 & 54093 & TSHZ2 & A5 \\
\hline TCONS_000 & & & TCONS_000 & & & TCONS_000 & & \\
\hline 58303 & PIK3IP1 & $\mathrm{RI}$ & 56755 & CABIN1 & RI & 55196 & TSHZ2 & A5 \\
\hline TCONS_000 & EIF4ENI & & TCONS_000 & KIAA167 & & TCONS_000 & & \\
\hline 57578 & $\mathrm{~F} 1$ & A3 & 56772 & 1 & SE & 54105 & CSTF1 & A5 \\
\hline TCONS_000 & & & TCONS_000 & & & TCONS_000 & & \\
\hline 57584 & PISD & $\mathrm{RI}$ & 58048 & SRRD & 0 & 54117 & TFAP2C & $\mathrm{RI}$ \\
\hline TCONS_000 & & & TCONS_000 & & & TCONS_000 & & \\
\hline 58306 & PRR14L & SE & 58065 & HSCB & A5 & 54118 & TFAP2C & $\mathrm{O}$ \\
\hline TCONS_000 & & & TCONS_000 & & & TCONS_000 & STX16-N & \\
\hline $57594^{-}$ & PRR14L & A5 & $56829^{-}$ & EWSR1 & $\mathrm{RI}, \mathrm{SE}$ & $55204^{-}$ & PEPL1 & A5,SE \\
\hline TCONS_000 & & & TCONS_000 & & $\mathrm{A} 3, \mathrm{RI}$, & TCONS_000 & & \\
\hline 57595 & PRR14L & A5 & 56831 & EWSR1 & SE & 55212 & GNAS & 0 \\
\hline TCONS_000 & & & TCONS_000 & & & TCONS_000 & & \\
\hline $57620^{-}$ & RBFOX2 & SE & $56869^{-}$ & SLC35E4 & 0 & $54159^{-}$ & GNAS & O \\
\hline TCONS_000 & & & TCONS_000 & & & TCONS_000 & & \\
\hline 57663 & IFT27 & A3 & $58081^{-}$ & TUG1 & A3 & $54160^{-}$ & GNAS & 0 \\
\hline TCONS_000 & & & TCONS_000 & & & TCONS_000 & & \\
\hline $58331^{-}$ & LGALS2 & 0 & $56885^{-}$ & SMTN & 0 & $54162^{-}$ & GNAS & 0 \\
\hline TCONS 000 & & & TCONS 000 & & & TCONS 000 & & \\
\hline $57684^{-}$ & LGALS2 & 0 & 56888 & RNF185 & A5,SE & $54168^{-}$ & NELFCD & RI \\
\hline TCONS_000 & BAIAP2L & & TCONS_000 & & & TCONS_000 & & \\
\hline $57690^{-}$ & 2 & $\mathrm{RI}$ & $56892^{-}$ & LIMK2 & A3 & 54169 & NELFCD & $A 5, R I$ \\
\hline TCONS 000 & BAIAP2L & $\mathrm{O}$ & TCONS 000 & HMGXB4 & SE & TCONS_000 & NELFCD & $A 5, R I$ \\
\hline
\end{tabular}




\begin{tabular}{|c|c|c|c|c|c|c|c|c|}
\hline 57691 & 2 & & 56923 & & & 55217 & & \\
\hline TCONS_000 & & & TCONS_000 & & & TCONS_000 & & \\
\hline 58335 & PLA2G6 & A5,SE & 56975 & CYTH4 & $\mathrm{RI}$ & 55218 & NELFCD & A5 \\
\hline TCONS_000 & & & TCONS_000 & & & TCONS_000 & & \\
\hline 58336 & PLA2G6 & A3 & 56983 & GGA1 & RI & 54191 & LSM14B & $\mathrm{O}$ \\
\hline TCONS_000 & & & TCONS_000 & & & TCONS_000 & & \\
\hline 58344 & SUN2 & A5 & 56999 & GCAT & $\mathrm{O}$ & 55219 & LSM14B & RI \\
\hline TCONS_000 & & & TCONS_000 & & & TCONS_000 & & \\
\hline 57730 & CBX7 & A3 & 57015 & PICK1 & A5,SE & 54198 & MTG2 & $\mathrm{O}$ \\
\hline TCONS_000 & TNFRSF & & TCONS_000 & & & TCONS_000 & & \\
\hline 57810 & $13 C$ & $\mathrm{O}$ & 58120 & CBY1 & SE & 54222 & MRGBP & RI \\
\hline TCONS_000 & & & TCONS_000 & APOBEC & & TCONS_000 & & \\
\hline 58365 & NAGA & $\mathrm{RI}$ & 58124 & $3 D$ & $\mathrm{O}$ & 54223 & OGFR & O \\
\hline TCONS_000 & CYP2D7 & & TCONS_000 & & & TCONS_000 & & \\
\hline 57821 & $\mathrm{P} 1$ & RI & 57075 & TNRC6B & $M X$ & 54225 & OGFR & A3 \\
\hline TCONS_000 & & & TCONS_000 & & & TCONS_000 & & \\
\hline 58368 & TCF20 & $\mathrm{O}$ & 58143 & FAM109B & $\mathrm{O}$ & 54235 & SLC17A9 & A5 \\
\hline TCONS_000 & & & TCONS_000 & & & TCONS_000 & ARFGAP & \\
\hline 58372 & A4GALT & $\mathrm{O}$ & 57121 & FAM109B & $\mathrm{O}$ & 54240 & 1 & RI \\
\hline & & & & & & & RTEL1-T & \\
\hline TCONS_000 & KIAA164 & & TCONS_000 & GOLGA2 & & TCONS_000 & NFRSF6 & \\
\hline 57876 & 4 & AF & 57132 & P4 & O & 54252 & B & $\mathrm{O}$ \\
\hline & & & & & & & RTEL1-T & \\
\hline TCONS_000 & & & TCONS_000 & & & TCONS_000 & NFRSF6 & \\
\hline 55384 & PREX1 & $\mathrm{O}$ & 57147 & PARVG & A3 & 54253 & B & RI \\
\hline & & & & & & & RTEL1-T & \\
\hline TCONS_000 & & & TCONS_000 & & & TCONS_000 & NFRSF6 & \\
\hline 54871 & SALL4 & $\mathrm{O}$ & 57157 & FAM118A & A3 & 55231 & B & $\mathrm{RI}$ \\
\hline TCONS_000 & & & TCONS_000 & & & TCONS_000 & RP4-583 & \\
\hline 54886 & ZNF217 & $\mathrm{O}$ & 57158 & FAM118A & $\mathrm{O}$ & 54256 & P15.15 & $A 3, R I$ \\
\hline TCONS_000 & & & TCONS_000 & & & TCONS_000 & RP4-583 & \\
\hline 55396 & ZNF217 & AF,SE & 58174 & TTC38 & RI & 54257 & P15.15 & RI \\
\hline TCONS_000 & & & TCONS_000 & & & TCONS_000 & RP4-583 & \\
\hline 55397 & ZNF217 & AF & 58175 & TTC38 & A5,SE & 54258 & P15.15 & O \\
\hline TCONS_000 & CYP24A & & TCONS_000 & & & TCONS_000 & RP4-583 & \\
\hline 54896 & 1 & A3 & 58178 & TRMU & O & 54259 & P15.15 & A5 \\
\hline
\end{tabular}




\begin{tabular}{|c|c|c|c|c|c|c|c|c|}
\hline \multicolumn{3}{|l|}{ TCONS_000 } & \multicolumn{3}{|l|}{ TCONS_000 } & TCONS_000 & \multicolumn{2}{|l|}{ RP4-583 } \\
\hline 54900 & AURKA & A5 & 58180 & TRMU & SE & 54260 & P15.15 & A3 \\
\hline TCONS_000 & & & TCONS_000 & & & TCONS_000 & SLC2A4 & \\
\hline 54901 & AURKA & A5 & 57202 & GRAMD4 & $A F$ & 54261 & $\mathrm{RG}$ & 0 \\
\hline TCONS_000 & PPP4R1 & & TCONS_000 & & & TCONS_000 & & \\
\hline 54922 & $\mathrm{~L}$ & A5,RI & 58182 & GRAMD4 & AF & 54277 & PCMTD2 & A5 \\
\hline TCONS_000 & & & TCONS_000 & & & TCONS_000 & & \\
\hline 55403 & LAMA5 & $\mathrm{RI}$ & 58199 & TRABD & A5,RI & 54283 & C20orf96 & $\mathrm{RI}$ \\
\hline TCONS_000 & & & TCONS_000 & & & TCONS_000 & & \\
\hline 55404 & LAMA5 & $\mathrm{RI}$ & 57235 & TRABD & A5,RI & 55239 & C20orf96 & $\mathrm{RI}$ \\
\hline TCONS_000 & & & TCONS_000 & & & TCONS_000 & & \\
\hline 54970 & TCFL5 & $\mathrm{AF}$ & 57236 & TRABD & A5 & 54363 & LZTS3 & A5,RI \\
\hline TCONS_000 & & & TCONS_000 & & & TCONS_000 & & \\
\hline $54973^{-}$ & DIDO1 & $A F, R I$ & $57240^{-}$ & TRABD & $A F, R I$ & 54364 & LZTS3 & $\mathrm{RI}$ \\
\hline TCONS_000 & & & TCONS_000 & & & TCONS_000 & & \\
\hline 54974 & DIDO1 & $\mathrm{RI}$ & 58201 & SELO & A5 & 55265 & ADAM33 & $\mathrm{O}$ \\
\hline TCONS_000 & & & TCONS_000 & & & TCONS_000 & & \\
\hline 54981 & YTHDF1 & $\mathrm{O}$ & 57247 & SELO & A5,RI & 54379 & ADAM33 & $A 3, R I$ \\
\hline TCONS_000 & & & TCONS_000 & & & TCONS_000 & & \\
\hline 55410 & YTHDF1 & O & 57248 & SELO & $\mathrm{O}$ & 54380 & SIGLEC1 & $\mathrm{RI}$ \\
\hline TCONS_000 & & & TCONS_000 & & & TCONS_000 & & \\
\hline 54987 & PTK6 & $\mathrm{RI}$ & 58202 & SELO & $\mathrm{O}$ & 54381 & SIGLEC1 & $\mathrm{RI}$ \\
\hline TCONS_000 & & & TCONS_000 & & & TCONS_000 & & \\
\hline 54990 & HELZ2 & $\mathrm{O}$ & 57253 & PPP6R2 & $A 3, R I$ & 55266 & SIGLEC1 & RI \\
\hline TCONS_000 & & & TCONS_000 & & & TCONS_000 & & \\
\hline 54998 & ARFRP1 & $\mathrm{O}$ & 58204 & PPP6R2 & A3 & 54395 & RASSF2 & A5 \\
\hline TCONS_000 & & & TCONS_000 & & & TCONS_000 & & \\
\hline 54999 & ARFRP1 & $A F$ & 57259 & NCAPH2 & $\mathrm{A} 3, \mathrm{RI}$ & 55275 & GPCPD1 & SE \\
\hline TCONS_000 & & & TCONS_000 & AC00205 & & TCONS_000 & & \\
\hline 55412 & ZBTB46 & $\mathrm{O}$ & 58206 & 5.4 & A5,AL & 54440 & ESF1 & A5 \\
\hline TCONS_000 & MIR155 & & TCONS_000 & AP00052 & & TCONS_000 & & \\
\hline 55489 & $\mathrm{HG}$ & $\mathrm{O}$ & 58208 & 5.9 & A3 & 54443 & FLRT3 & A5 \\
\hline & & & & ANKRD6 & & & & \\
\hline TCONS_000 & & & TCONS_000 & 2P1-PAR & & TCONS_000 & & \\
\hline 56203 & USP16 & A3 & 58209 & P4P3 & SE & 54450 & RRBP1 & RI,SE \\
\hline TCONS_000 & SON & A3,SE & TCONS_000 & CECR5 & $A F$ & TCONS_000 & RRBP1 & A5,SE \\
\hline
\end{tabular}




\begin{tabular}{|c|c|c|c|c|c|c|c|c|}
\hline 55548 & & & 57294 & & & 54449 & & \\
\hline TCONS_000 & & & TCONS_000 & & & TCONS_000 & & \\
\hline 55581 & DOPEY2 & $A F$ & 57312 & DGCR2 & SE & 55285 & RRBP1 & RI,SE \\
\hline TCONS_000 & & & TCONS 000 & & & TCONS_000 & & \\
\hline 56219 & TTC3 & $\mathrm{O}$ & 58229 & UFD1L & $A F$ & 54480 & NKX2-2 & $\mathrm{O}$ \\
\hline TCONS_000 & & & TCONS_000 & & & TCONS_000 & LINC002 & \\
\hline 55594 & TTC3 & AF & 57343 & TRMT2A & 0 & 54482 & 61 & A3 \\
\hline TCONS_000 & & & TCONS_000 & & & TCONS_000 & & \\
\hline 55595 & TTC3 & SE & 58234 & TRMT2A & $\mathrm{RI}$ & 55297 & FOXA2 & A5 \\
\hline TCONS_000 & & & TCONS_000 & & & TCONS_000 & & \\
\hline 56226 & KCNJ15 & $\mathrm{O}$ & 58235 & TRMT2A & $\mathrm{RI}$ & 54490 & CD93 & $\mathrm{O}$ \\
\hline TCONS_000 & & & TCONS_000 & XXbac-B & & TCONS_000 & C20orf11 & \\
\hline 55653 & MX2 & SE & 57345 & 444P24.8 & 0 & 54551 & 2 & $\mathrm{O}$ \\
\hline TCONS_000 & & & TCONS_000 & & & TCONS_000 & CDK5RA & \\
\hline 55761 & ADARB1 & AF,SE & 57351 & PI4KAP1 & RI & 55316 & $\mathrm{P} 1$ & $\mathrm{RI}$ \\
\hline TCONS_000 & & & TCONS_000 & & & TCONS_000 & & \\
\hline 55778 & YBEY & A5,SE & 58246 & PI4KAP2 & A3,A5 & 54569 & NECAB3 & $\mathrm{RI}$ \\
\hline TCONS_000 & & & TCONS_000 & & & TCONS_000 & & \\
\hline 55784 & PCNT & SE & 57371 & YDJC & SE & 54572 & E2F1 & O \\
\hline TCONS_000 & & & TCONS_000 & & & TCONS_000 & & \\
\hline 56288 & PRMT2 & $\mathrm{RI}, \mathrm{SE}$ & 57389 & TOP3B & A5 & 55320 & NCOA6 & 0 \\
\hline TCONS_000 & AF12793 & & TCONS_000 & GUSBP1 & & TCONS_000 & & \\
\hline 56327 & 6.3 & $\mathrm{O}$ & 57412 & 1 & A5 & 54588 & GGT7 & $\mathrm{RI}$ \\
\hline TCONS_000 & & & TCONS_000 & GUSBP1 & & TCONS_000 & & \\
\hline 55836 & BTG3 & A5,SE & 57415 & 1 & $\mathrm{O}$ & 55322 & GGT7 & $\mathrm{RI}$ \\
\hline TCONS_000 & & & TCONS_000 & GUSBP1 & & TCONS_000 & & \\
\hline 56344 & ATP5J & $\mathrm{O}$ & 58252 & 1 & A5 & 55323 & GGT7 & $A 3, R I$ \\
\hline TCONS_000 & ADAMTS & & TCONS_000 & GUSBP1 & & TCONS_000 & & \\
\hline $55877^{-}$ & 5 & $\mathrm{O}$ & $58253^{-}$ & 1 & SE & 54591 & GSS & $\mathrm{RI}$ \\
\hline TCONS_000 & AL03561 & & TCONS_000 & GUSBP1 & & TCONS_000 & TRPC4A & \\
\hline $56425^{-}$ & 0.2 & 0 & $58254^{-}$ & 1 & $\mathrm{O}$ & $54592^{-}$ & $\mathrm{P}$ & O \\
\hline TCONS_000 & RWDD2 & & TCONS_000 & AP00034 & & TCONS_000 & TRPC4A & \\
\hline 56469 & $\mathrm{~B}$ & $\mathrm{RI}$ & 57424 & 9.1 & RI & 55324 & $\mathrm{P}$ & A5 \\
\hline TCONS_000 & & & TCONS_000 & & & TCONS_000 & & \\
\hline $55971^{-}$ & PAXBP1 & A5 & 57432 & GSTT2B & RI & $54615^{-}$ & FER1L4 & RI,SE \\
\hline
\end{tabular}




\begin{tabular}{|c|c|c|c|c|c|c|c|c|}
\hline TCONS_000 & TMEM50 & & TCONS_000 & & & TCONS_000 & & A5,RI, \\
\hline 56488 & B & SE & 57447 & GUCD1 & $\mathrm{O}$ & 54617 & FER1L4 & SE \\
\hline TCONS_000 & & & TCONS_000 & & & TCONS_000 & & \\
\hline 56492 & GART & $A F, R I$ & 58265 & FAM211B & $A F, R I$ & 54637 & NFS1 & A5 \\
\hline TCONS_000 & DONSO & & TCONS_000 & & & TCONS_000 & & \\
\hline 55993 & $\mathrm{~N}$ & $\mathrm{O}$ & 57455 & LRP5L & A3,RI & 55336 & NDRG3 & AF,SE \\
\hline TCONS_000 & & & TCONS_000 & & & TCONS_000 & & \\
\hline 56017 & RUNX1 & $\mathrm{O}$ & 58274 & TTC28 & SE & 55344 & TGM2 & $\mathrm{O}$ \\
\hline TCONS_000 & & & TCONS_000 & & & TCONS_000 & & \\
\hline 56025 & HLCS & AF,SE & 57498 & RHBDD3 & $\mathrm{O}$ & 54682 & TGM2 & $\mathrm{O}$ \\
\hline TCONS_000 & & & TCONS_000 & & & TCONS_000 & & \\
\hline 56506 & DSCR3 & $\mathrm{RI}$ & 57499 & RHBDD3 & A3,RI & 54683 & TGM2 & $\mathrm{O}$ \\
\hline TCONS_000 & & & TCONS_000 & & & TCONS_000 & & \\
\hline 56071 & PRDM15 & SE & 57500 & RHBDD3 & $\mathrm{RI}$ & 55345 & SNHG17 & SE \\
\hline TCONS_000 & & & TCONS_000 & & & TCONS_000 & & \\
\hline 56530 & WDR4 & A5 & 57502 & AP1B1 & RI,SE & 55352 & OSER1 & $\mathrm{O}$ \\
\hline TCONS_000 & AP00163 & & TCONS_000 & & & TCONS_000 & & \\
\hline 56108 & 1.9 & $\mathrm{O}$ & 57516 & ZMAT5 & O & 55357 & MATN4 & 0 \\
\hline TCONS_000 & & & TCONS_000 & & & TCONS_000 & & \\
\hline 56550 & C21orf2 & $\mathrm{O}$ & 57520 & ASCC2 & RI & 55377 & ZMYND8 & A3 \\
\hline TCONS_000 & & & TCONS_000 & & & TCONS_000 & & \\
\hline 56159 & ITGB2 & $\mathrm{O}$ & 57522 & ASCC2 & A5 & 55382 & SULF2 & A5 \\
\hline TCONS_000 & & & TCONS_000 & & & TCONS_000 & & \\
\hline 56160 & ITGB2 & AF & 56668 & LZTR1 & SE & 57999 & RANBP1 & A5,SE \\
\hline TCONS_000 & & & TCONS_000 & & & TCONS_000 & & \\
\hline 56161 & ITGB2 & A3 & 56669 & LZTR1 & $\mathrm{RI}$ & 56640 & ZDHHC8 & $\mathrm{RI}$ \\
\hline TCONS_000 & & & TCONS_000 & & & TCONS_000 & & \\
\hline 56165 & POFUT2 & A5 & 56671 & $\mathrm{HIC2}$ & SE & 56656 & MED15 & O \\
\hline TCONS_000 & МСМЗА & & TCONS_000 & BMS1P2 & & TCONS_000 & & \\
\hline 56565 & $\mathrm{P}$ & RI & 58009 & 0 & A3,A5 & 56667 & LZTR1 & $\mathrm{RI}$ \\
\hline TCONS_000 & & & TCONS_000 & BMS1P2 & & TCONS_000 & & \\
\hline 57982 & CECR2 & AF,SE & 58010 & 0 & A5,RI & 57991 & DGCR5 & SE \\
\hline TCONS_000 & & & TCONS_000 & & & TCONS_000 & & \\
\hline 57989 & DGCR5 & $\mathrm{O}$ & $56700^{-}$ & IGLV1-36 & $\mathrm{O}$ & 56609 & SEPT5 & $\mathrm{O}$ \\
\hline TCONS_000 & DGCR5 & SE & TCONS_000 & IGLL5 & $\mathrm{O}$ & TCONS_000 & MMP11 & $\mathrm{O}$ \\
\hline
\end{tabular}


57990

56713

56733

TCONS_000

56731

RGL4

A3 